\title{
ANÁLISE PROBABILÍSTICA DO COMPORTAMENTO AO LONGO DO TEMPO DE ELEMENTOS PARCIALMENTE PRÉ-MOLDADOS COM ÊNFASE EM FLECHAS DE LAJES COM ARMAÇÃO TRELIÇADA
}

\section{Andrei José Merlin}

Tese apresentada à Escola de Engenharia de São Carlos da Universidade de São Paulo, como parte dos requisitos para obtenção do título de Doutor em Engenharia de Estruturas.

ORIENTADOR: Mounir Khalil El Debs 
Ficha catalográfica preparada pela Seção de Tratamento da Informação do Serviço de Biblioteca - EESC/USP

M565a

Merlin, Andrei José

Análise probabilística do comportamento ao longo do tempo de elementos parcialmente pré-moldados com ênfase em flechas de lajes com armação treliçada / Andrei José Merlin. -- São Carlos, 2006.

Tese (Doutorado) -- Escola de Engenharia de São Carlos-Universidade de São Paulo, 2006.

Área: Engenharia de Estruturas.

Orientador: Prof. Dr. Mounir Khalil El Debs.

1. Análise probabilística. 2. Comportamento ao longo do tempo. 3. Elementos parcialmente pré-moldados. 4. Laje pré-moldada. 5. Flecha diferida. I. Título. 
À minha esposa Fabiana e Ao meu filho Gabriel 


\section{AGRADECIMENTOS}

A Deus que me deu coragem e sabedoria para enfrentar todos os obstáculos da minha vida.

Ao professor Mounir Khalil El Debs pela dedicação, compressão e orientação prestadas na elaboração deste trabalho.

A minha família que sempre me incentivou e compreendeu os momentos em que estive ausente.

Ao professor Antonio R. Marí, do Departamento de Engenharia da Universidade Politécnica da Catalunha, por disponibilizar o acesso e utilização do programa computacional CONSNOU, utilizado na análise numérica.

Aos professores João Bento de Hanai e Paulo de Mattos Pimenta pelas sugestões dadas ao trabalho no Exame de Qualificação.

A todos os colegas do Departamento de Estruturas, em especial, Rodrigo Delalibera, Fernando Menezes, Ricardo Carrazedo, Jorge Góes e Gustavo Tristão pelo convívio e amizade desde o curso de mestrado.

Aos professores e funcionários do Departamento de Estruturas da EESC/USP pela colaboração.

Ao Conselho Nacional de Desenvolvimento Científico e Tecnológico CNPq, pela bolsa de estudo concedida.

A todos que, direta ou indiretamente, contribuíram para a elaboração deste trabalho. 


\section{SUMÁRIO}

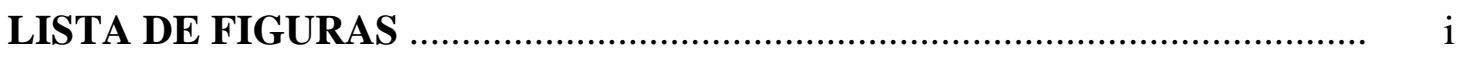

LISTA DE TABELAS .................................................................... vii

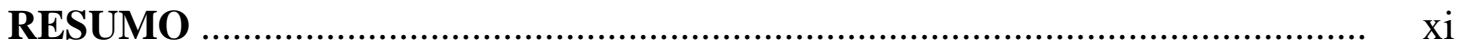

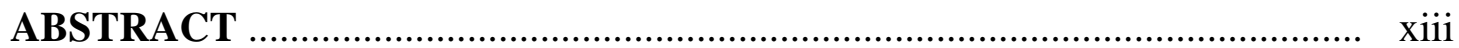

\section{CAPÍTULO 1: INTRODUÇÃO}

1.1 Considerações iniciais ..................................................................... 1

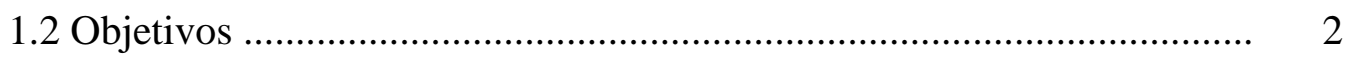

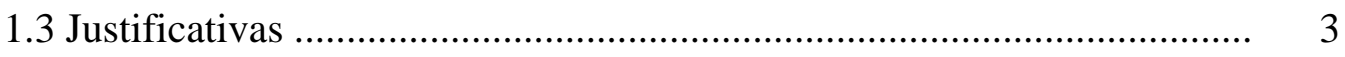

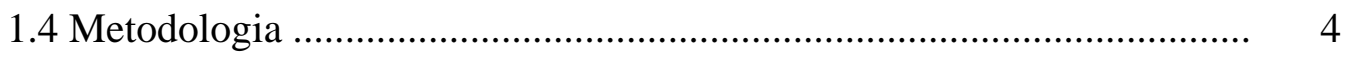

1.5 Apresentação do trabalho ....................................................................... 4

\section{CAPÍTULO 2: COMPORTAMENTO REOLÓGICO DO CONCRETO}

2.1 Considerações iniciais ......................................................................... 7

2.2 Modelos reológicos ....................................................................... 14

2.2.1 Elementos fundamentais dos modelos reológicos............................ 15

2.2.2 Modelos reológicos básicos ....................................................... 16

2.2.2.1 Modelo de Maxwell ................................................................. 16

2.2.2.2 Modelo de Kelvin ................................................................... 17

2.2.2.3 Modelo de Boltzmann .......................................................... 18

2.2.2.4 Modelo de Burger ................................................................ 19

2.3 Modelos para a previsão da fluência e retração ...................................... 21

2.3.1 Definições .............................................................................. 21

2.3.1.1 Deformação total e deformação por fluência ........................... 21

2.3.1.2 Coeficiente de fluência ........................................................... 21

2.3.1.3 Fluência específica .............................................................. 22

2.3.1.4 Função fluência ................................................................... 22

2.3.2 Modelo CEB-90 (1991) ................................................................ 23 
2.3.2.1 Fluência ........................................................................ 23

2.3.2.2 Retração ....................................................................... 26

2.3.3 Modelo ACI-209 (1992) ............................................................. 28

2.3.3.1 Fluência .................................................................................. 28

2.3.3.2 Retração .............................................................................. $\quad 30$

2.3.4 Modelo NBR 6118 (2003) …........................................................ 32

2.3.4.1 Fluência ....................................................................... 32

2.3.4.2 Retração .......................................................................... 36

2.3.5 Comparação entre os modelos ................................................. 37

2.4 Métodos de análise da fluência ............................................................ 42

2.4.1 Formulação integral ..................................................................... 43

2.4.1.1 Método incremental ou método passo a passo ........................ 43

2.4.1.2 Método do Módulo Efetivo (EM method) ............................... 45

2.4.1.3 Método da Tensão Média ........................................................ 46

2.4.1.4 Método do Módulo Efetivo Ajustado (AAEM method) ............ 47

2.4.2 Formulação diferencial .................................................................. 48

2.4.2.1 Método de Dischinger ou método da razão de fluência (Rate of creep method) ................................................................... 49

2.4.2.2 Método da razão da deformação lenta irreversível (Rate of flow method) ............................................................................. 52

2.4.2.3 Método de Dischinger melhorado (Improved Dischinger method) ................................................................................... 54

2.4.3 Método dos núcleos degenerados ................................................. 55

\section{CAPÍTULO 3: ANÁLISE NUMÉRICA}

3.1 Considerações iniciais ....................................................................... 57

3.2 Propriedades dos materiais .................................................................. 59

3.3 Comportamento diferido do concreto ................................................ 62

3.4 Elemento finito ....................................................................................... 63

3.5 Efeito da protensão ....................................................................... 66

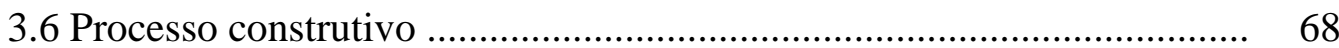

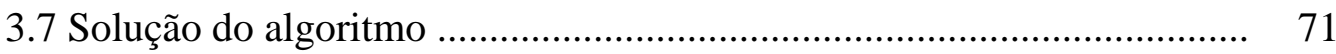

3.8 Avaliação do modelo ............................................................................. 73 
3.8.1 Ensaios de curta duração de lajes contínuas .................................. 73

3.8.2 Ensaios de longa duração de lajes ................................................ 80

3.8.3 Ensaios de longa duração de vigas reforçadas á flexão ................. 86

\section{CAPÍTULO 4: ANÁLISE PROBABILÍSTICA}

4.1 Considerações iniciais ....................................................................... 97

4.2 Conceitos básicos e definições .......................................................... 100

4.3 Simulação de Monte Carlo ................................................................... 109

4.3.1 Parâmetros do sistema e suas propriedades estatísticas ................ 111

4.3.2 Amostragem por Hipercubo Latino ............................................. 114

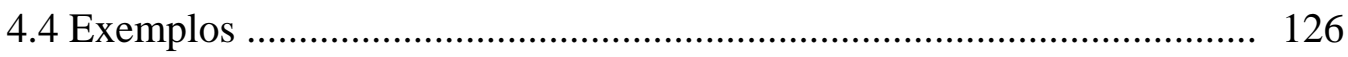

4.4.1 Exemplo 1: Viga reforçada à flexão ............................................. 126

4.4.2 Exemplo 2: Viga reforçada à flexão com continuidade estrutural posterior

\section{CAPÍTULO 5: ANÁLISE DAS FLECHAS DIFERIDAS EM LAJES PRÉ- MOLDADAS}

5.1 Considerações iniciais ....................................................................... 139

5.1.1 Cálculo da flecha .................................................................... 143

5.1.1.1 Cálculo da flecha imediata ................................................. 144

5.1.1.2 Cálculo da flecha diferida no tempo .................................... 146

5.1.2 Combinações de ações ................................................................. 148

5.1.3 Deslocamentos limites ................................................................ 150

5.2 Análise preliminar ............................................................................ 153

5.2.1 Características das lajes ............................................................. 153

5.2.2 Processo construtivo da laje pré-moldada ................................... 155

5.2.3 Parâmetros adotados ................................................................ 156

5.2.4 Descrição das modelagens numéricas ............................................ 158

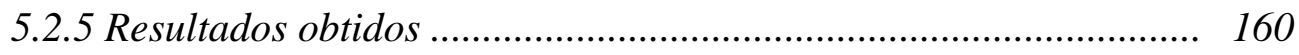

5.3 Análise determinística ....................................................................... 166

5.3.1 Coeficiente multiplicador básico ............................................... 166 
5.3.2 Influência da umidade relativa e temperatura no coeficiente multiplicador 174

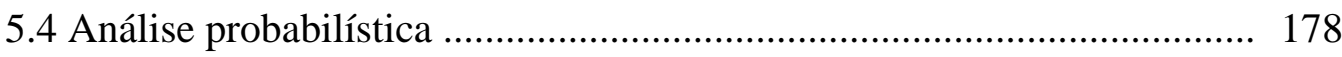

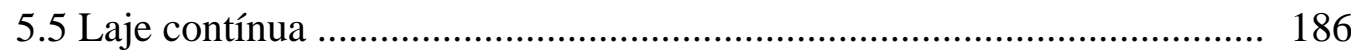

5.6 Exemplos de cálculo ........................................................................ 189

5.6.1 Laje com vão pequeno ............................................................... 189

5.6.2 Laje com vão médio .................................................................. 191

5.6.3 Laje com vão grande ................................................................... 193

5.7 Análise dos resultados e comentários ................................................. 195

CAPÍTULO 6: CONSIDERAÇÕES FINAIS E CONCLUSÕES ................. 199

REFERÊNCIAS BIBLIOGRÁFICAS ............................................ 205

APÊNDICE A - Resultados obtidos para a determinação do coeficiente multiplicador básico

APÊNDICE B - Resultados obtidos para a determinação do coeficiente $\alpha_{U, T}$ 


\section{LISTA DE FIGURAS}

FIGURA 2.1 Tipos de água associados ao silicato de cálcio hidratado [MEHTA \& MONTEIRO (1994)]

FIGURA 2.2 Retração e fluência com o tempo [adaptado de LEONHARDT \& MÖNNING (1978)]

FIGURA 2.3 (a) Modelo de Maxwell, (b) Modelo de Kelvin, (c) Modelo de Boltzmann, (d) Modelo de Burger .................................. 16

FIGURA 2.4 Regime viscoelástico de Maxwell ...................................... 17

FIGURA 2.5 Regime viscoelástico de Kelvin ........................................ 18

FIGURA 2.6 Regime viscoelástico de Boltzmann .................................... 19

FIGURA 2.7 Regime viscoelástico de Burger .......................................... 20

FIGURA 2.8 Curvas de função fluência ...................................................... 23

FIGURA $2.9 \quad$ Variação de $\beta_{\mathrm{f}}(\mathrm{t})$.............................................................. 35

FIGURA 2.10 Variação de $\beta_{\mathrm{s}}(\mathrm{t})$............................................................. 37

FIGURA 2.11 Influência da idade de aplicação da carga no coeficiente de fluência último; $\mathrm{U}=60 \%$ e $\mathrm{A}_{\mathrm{C}} / \mathrm{u}_{\mathrm{ar}}=250 \mathrm{~mm}$...................... 38

FIGURA 2.12 Influência da umidade relativa no coeficiente de fluência último; $\mathrm{A}_{\mathrm{c}} / \mathrm{u}_{\mathrm{ar}}=250 \mathrm{~mm}$ 38

FIGURA 2.13 Influência das dimensões da peça no coeficiente de fluência último; $\mathrm{U}=60 \%$

FIGURA 2.14 Comparação dos modelos de fluência com resultados de ensaios para a idade de carregamento de sete dias [HASPARYK et al. (2005)]

FIGURA 2.15 Comparação dos modelos de fluência com resultados de ensaios para a idade de carregamento de 28 dias [HASPARYK et al. (2005)]

FIGURA 2.16 Influência da umidade relativa na deformação por retração última; $\mathrm{A}_{\mathrm{c}} / \mathrm{u}_{\mathrm{ar}}=250 \mathrm{~mm}$ 
FIGURA 2.17 Influência das dimensões da peça na deformação por retração última; $\mathrm{U}=60 \%$

FIGURA 2.18 Evolução da deformação por retração com o tempo; U = $60 \%$ e $\mathrm{A}_{\mathrm{c}} / \mathrm{u}_{\mathrm{ar}}=250 \mathrm{~mm}$

FIGURA 2.19 Definição dos intervalos para o método incremental [adaptado CEB (1984)] (a) Tensões no decorrer do tempo; (b) Curvas de funções fluência; (c) Função fluência $\mathrm{x}$ variação de tensão

FIGURA 2.20 Método do módulo efetivo [adaptado CEB (1984)] .............. 45

FIGURA 2.21 Método da tensão média [adaptado CEB (1984)] ................. 47

FIGURA 2.22 Método do módulo efetivo ajustado [adaptado CEB (1984)] 48

FIGURA 2.23 Curvas de função fluência segundo o método da razão de fluência

FIGURA 2.24 Relação entre deformação e tempo para uma carga unitária aplicada entre $\mathrm{t}$ e $\mathrm{t}_{\mathrm{o}}$ segundo o método da razão de fluência [adaptado DILGER (1982b)]

FIGURA 2.25 Relação entre deformação e tempo para uma carga unitária aplicada entre $\mathrm{t}$ e $\mathrm{t}_{\mathrm{o}}$ segundo o método da deformação lenta irreversível [adaptado DILGER (1982b)] ..................... 53

FIGURA 2.26 Modelo generalizado de Kelvin ............................................ 56

FIGURA $3.1 \quad$ Elemento finito ................................................................. 60

FIGURA 3.2 Diagrama tensão x deformação uniaxial do concreto ............ 61

FIGURA 3.3 Diagrama tensão x deformação uniaxial do aço da armadura passiva

FIGURA 3.4 Diagrama tensão x deformação uniaxial do aço de protensão 62

FIGURA 3.5 Elemento finito com armadura de protensão ......................... 64

FIGURA 3.6 Deformação de um segmento de cabo de protensão .............. 67

FIGURA 3.7 Relaxação com deformação variável ................................... 68

FIGURA 3.8 Estrutura construída seqüencialmente ................................ 70

FIGURA $3.9 \quad$ Fluxograma simplificado ................................................. 71

FIGURA 3.10 Características geométricas (dimensões em cm) ................... 74 
FIGURA 3.11 Detalhes da vigota, nervura transversal e viga de apoio (dimensões em cm) ....................................................... 74

FIGURA 3.12 Sistema de aplicação do carregamento (dimensões em cm) .. 75

FIGURA 3.13 Deslocamentos experimentais - M15 ................................ 77

FIGURA 3.14 Deslocamentos experimentais - M40 .................................. 77

FIGURA 3.15 Deslocamentos experimentais - Mac ................................ 78

FIGURA 3.16 Discretização longitudinal (dimensões em cm) .................... 78

FIGURA 3.17 Discretização da seção transversal (dimensões em cm) ........ 78

FIGURA 3.18 Comparação entre os deslocamentos experimentais e da análise numérica - M15 .................................................. 79

FIGURA 3.19 Comparação entre os deslocamentos experimentais e da análise numérica - M40 ................................................. 80

FIGURA 3.20 Comparação entre os deslocamentos experimentais e da análise numérica - Mac .................................................... 80

FIGURA 3.21 Características geométricas (dimensões em cm) .................. 81

FIGURA 3.22 Valores máximos e mínimos da umidade ambiente ............. 82

FIGURA 3.23 Valores máximos e mínimos da temperatura ambiente ......... 82

FIGURA 3.24 Flechas obtidas durante o ensaio ........................................ 83

FIGURA 3.25 Discretização longitudinal (dimensões em cm) ................... 84

FIGURA 3.26 Discretização da seção transversal (dimensões em cm) ........ 84

FIGURA 3.27 Evolução da flecha (laje L1) ............................................... 85

FIGURA 3.28 Evolução da flecha (laje L2) ................................................ 85

FIGURA 3.29 Evolução da flecha (laje L3) ............................................... 86

FIGURA 3.30 Características geométricas (dimensões em cm) ................... 87

FIGURA 3.31 Sistema de aplicação do carregamento (dimensões em cm) .. 88

FIGURA 3.32 Evolução da força vertical ................................................. 89

FIGURA 3.33 Valores da umidade ambiente durante o ensaio .................... 90

FIGURA 3.34 Valores da temperatura ambiente durante o ensaio ............. 90

FIGURA 3.35 Flechas obtidas durante o ensaio ......................................... 92

FIGURA 3.36 Discretização longitudinal (dimensões em cm) .................... 92

FIGURA 3.37 Discretização da seção transversal (dimensões em cm) ........ 93

FIGURA 3.38 Evolução da força vertical utilizada na análise numérica ...... 93 
FIGURA 3.39 Evolução da flecha (viga V1) ............................................... 94

FIGURA 3.40 Evolução da flecha (viga V2) ............................................. 95

FIGURA 4.1 Diagrama de Euler ou Venn ............................................. 100

FIGURA 4.2 Mapeamento de eventos através da variável aleatória $X$ [adaptado ANG \& TANG (1975)] ....................................... 101

FIGURA 4.3 Distribuições de probabilidade [adaptado ANG \& TANG

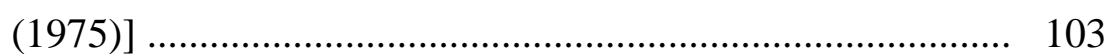

FIGURA 4.4 Função de densidade de probabilidade da distribuição normal padronizada ........................................................ 105

FIGURA 4.5 Função de probabilidade conjunta ....................................... 106

FIGURA 4.6 Coeficiente de correlação [ANG \& TANG (1975)] .............. 109

FIGURA 4.7 Modelagem das incertezas ................................................ 110

FIGURA 4.8 Divisão do domínio da variável estatística em intervalos de igual probabilidade ......................................................... 114

FIGURA 4.9 Divisão do domínio da variável estatística em 16 intervalos 116

FIGURA 4.10 Gráficos de probabilidade normal para a flecha ................... 120

FIGURA 4.11 Teste de Kolmogorov-Smirnov [adaptado ANG \& TANG (1975)] f.................................................................. 121

FIGURA 4.12 Teste de Kolmogorov-Smirnov para a flecha ....................... 129

FIGURA 4.13 Limites de confiança para a flecha ..................................... 130

FIGURA 4.14 Coeficiente de regressão padronizado para a flecha da viga aos 40 e 103 dias ................................................................ 130

FIGURA 4.15 Coeficiente de correlação parcial para a flecha da viga aos 40 e 103 dias ............................................................... 131

FIGURA 4.16 Etapas construtivas da viga ................................................ 131

FIGURA 4.17 Teste de Kolmogorov-Smirnov para a flecha ....................... 134

FIGURA 4.18 Limites de confiança para a flecha ....................................... 134

FIGURA 4.19 Teste de Kolmogorov-Smirnov para o momento fletor no

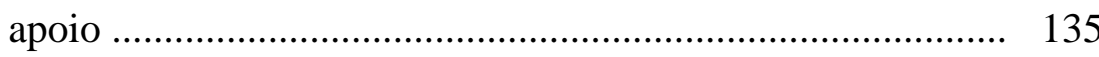

FIGURA 4.20 Limites de confiança para o momento fletor no apoio .......... 135

FIGURA 4.21 Coeficiente de regressão padronizado para a flecha da viga aos 103 dias 
FIGURA 4.22 Coeficiente de correlação parcial para a flecha da viga aos 103 dias

FIGURA 4.23 Coeficiente de regressão padronizado para o momento fletor no apoio aos 103 dias

FIGURA 4.24 Coeficiente de correlação parcial para o momento fletor no apoio aos 103 dias

FIGURA 5.1 Laje formada por nervuras pré-moldadas [EL DEBS (2000)] 140

FIGURA 5.2 Seção transversal da vigota treliçada e perspectiva da armação treliçada

FIGURA 5.3 Valores do coeficiente $\beta$ 144

FIGURA 5.4 Seção transversal das lajes (dimensões em $\mathrm{cm}$ ) . 154

FIGURA 5.5 Vigota (dimensões em cm) 154

FIGURA 5.6 Processo construtivo da laje pré-moldada 156

FIGURA 5.7 Discretização da seção transversal das lajes (dimensões em $\mathrm{cm})$ 158

FIGURA 5.8 Discretização longitudinal das lajes de 200 e $250 \mathrm{~cm}$ 159

FIGURA 5.9 Variação do coeficiente multiplicador para a situação 1 ..... 164

FIGURA 5.10 Variação do coeficiente multiplicador para a situação 2 ..... 164

FIGURA 5.11 Variação do coeficiente multiplicador para a situação 1 . 165

FIGURA 5.12 Variação do coeficiente multiplicador para a situação 2 ....... 165

FIGURA 5.13 Coeficiente multiplicador ................................................. 170

FIGURA 5.14 Regressão linear dos resultados ........................................ 171

FIGURA 5.15 Resíduo da regressão ...................................................... 171

FIGURA 5.16 Coeficiente multiplicador para a laje LT12 ......................... 172

FIGURA 5.17 Coeficiente multiplicador para a laje LT16 ......................... 172

FIGURA 5.18 Coeficiente multiplicador para a laje LT20 ......................... 173

FIGURA 5.19 Coeficiente multiplicador para a laje LT25 ........................ 173

FIGURA 5.20 Coeficiente multiplicador para a laje LT30 ........................ 174

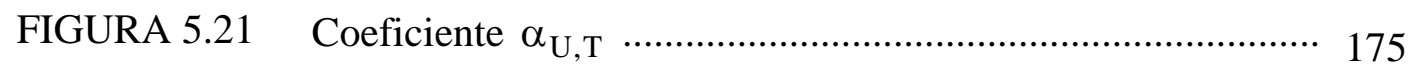

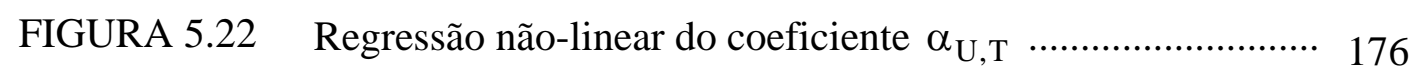

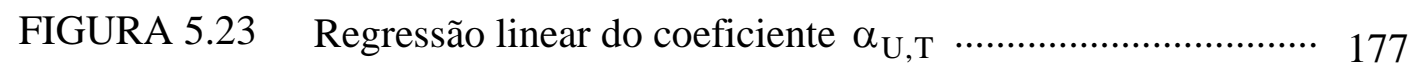


FIGURA 5.24 Distribuição uniforme no quadrado unitário .......................... 180

FIGURA 5.25 Distribuição dos pares de resistências ................................. 180

FIGURA 5.26 Coeficiente de regressão padronizado para o coeficiente

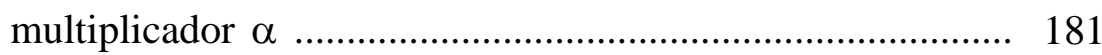

FIGURA 5.27 Coeficiente de correlação parcial para o coeficiente multiplicador $\alpha$

FIGURA 5.28 Gráficos de probabilidade normal para o coeficiente multiplicador

FIGURA 5.29 Regressão do coeficiente $\varphi_{\mathrm{U}, \mathrm{T}}$ com 95\% probabilidade ...... 184

FIGURA 5.30 Regressão do coeficiente $\varphi_{\mathrm{U}, \mathrm{T}}$ com 90\% probabilidade …… 184

FIGURA 5.31 Regressão do coeficiente $\varphi_{\mathrm{U}, \mathrm{T}}$ com 85\% probabilidade …… 184

FIGURA 5.32 Relação entre os coeficientes multiplicadores (contínua e biapoiada) - condição 1

FIGURA 5.33 Relação entre os coeficientes multiplicadores (contínua e biapoiada) - condição 2

FIGURA 5.34 Relação entre os coeficientes multiplicadores (contínua e biapoiada) - condição 3

FIGURA 5.35 Seção transversal da laje com vão pequeno (dimensões em $\mathrm{cm})$

FIGURA 5.36 Seção transversal da laje com vão médio (dimensões em $\mathrm{cm})$

FIGURA 5.37 Seção transversal da laje com vão grande (dimensões em $\mathrm{cm})$ 


\section{LISTA DE TABELAS}

TABELA 2.1 Coeficiente de espessura média ......................................... 29

TABELA 2.2 Coeficiente de idade para a retração ..................................... 31

TABELA 2.3 Coeficiente de espessura média .............................................. 31

TABELA 2.4 Valores da fluência e da retração em função da velocidade de endurecimento do cimento ................................................ 33

TABELA 2.5 Valores numéricos usuais para a determinação da fluência e da retração

TABELA 3.1 Armadura de flexão dos modelos ........................................ 75

TABELA 3.2 Características mecânicas do concreto .................................. 76

TABELA 3.3 Características da armadura negativa .................................. 76

TABELA 3.4 Características das lajes ......................................................... 81

TABELA 3.5 Características mecânicas do concreto .................................. 83

TABELA 3.6 Disposição da armadura passiva ........................................ 87

TABELA $3.7 \quad$ Etapas do ensaio .............................................................. 89

TABELA 3.8 Características mecânicas do concreto ................................. 91

TABELA 3.9 Características mecânicas da armadura passiva .................... 91

TABELA 3.10 Características mecânicas da armadura ativa ......................... 91

TABELA 4.1 Valores críticos $D_{N}^{\alpha}$ no Teste de Kolmogorov-Smirnov [ANG \& TANG (1975)] ................................................ 122

TABELA 4.2 Permutações geradas aleatoriamente dos inteiros 1, 2,..., 16127

TABELA 4.3 Valores dos parâmetros no centróide dos intervalos .............. 128

TABELA 4.4 Grupo de valores dos parâmetros de entrada gerados aleatoriamente ............................................................ 128

TABELA 4.5 Permutações geradas aleatoriamente dos inteiros 1, 2,..., 16132

TABELA 4.6 Grupo de valores dos parâmetros de entrada gerados aleatoriamente 
TABELA 5.1 Coeficiente dependente do instante de aplicação da carga [EF-96 (1997)] ................................................................. 148

TABELA 5.2 Valores de $\psi_{1}$ e $\psi_{2}$, segundo NBR 6118 (2003) ..................... 150

TABELA 5.3 Limites para deslocamentos segundo NBR 6118 (2003) ....... 151

TABELA 5.4 Valor do coeficiente C definido pela EF-96 (1997) ............... 152

TABELA 5.5 Característica da treliça eletrosoldada (valores em mm) ....... 155

TABELA 5.6 Situações consideradas para cada tipo de laje ......................... 157

TABELA 5.7 Variações consideradas para os parâmetros ............................ 157

TABELA 5.8 Variações consideradas para os vãos das lajes ........................ 158

TABELA 5.9 Pontos de escoramento das lajes (dimensões em cm) ............ 159

TABELA 5.10 Resultados obtidos para a situação 1 da laje LT12 ................. 160

TABELA 5.11 Resultados obtidos para a situação 1 da laje LT16 ................. 160

TABELA 5.12 Resultados obtidos para a situação 1 da laje LT20 …………. 160

TABELA 5.13 Resultados obtidos para a situação 1 da laje LT25 ………..... 161

TABELA 5.14 Resultados obtidos para a situação 1 da laje LT30 ................. 161

TABELA 5.15 Resultados obtidos para a situação 2 da laje LT12 ................. 161

TABELA 5.16 Resultados obtidos para a situação 2 da laje LT16 ………..... 162

TABELA 5.17 Resultados obtidos para a situação 2 da laje LT20 ................. 162

TABELA 5.18 Resultados obtidos para a situação 2 da laje LT25 ................. 162

TABELA 5.19 Resultados obtidos para a situação 2 da laje LT30 ................. 163

TABELA 5.20 Variação do coeficiente multiplicador em porcentagem ........ 163

TABELA 5.21 Casos analisados para a laje LT12 ……………………….... 167

TABELA 5.22 Casos analisados para a laje LT16 ……………………….... 167

TABELA 5.23 Casos analisados para a laje LT20 ……………………........ 168

TABELA 5.24 Casos analisados para a laje LT25 ………………………..... 168

TABELA 5.25 Casos analisados para a laje LT30 …………………………. 169

TABELA 5.26 Casos analisados para a determinação de $\alpha_{\mathrm{U}, \mathrm{T}}$ …………..... 175

TABELA 5.27 Casos analisados para a determinação de $\alpha_{\mathrm{U}, \mathrm{T}}$ (análise probabilística) ..................................................................... 178

TABELA 5.28 Propriedades estatísticas das variáveis aleatórias .................... 179

TABELA 5.29 Casos analisados para o caso de lajes contínuas ..................... 186 
TABELA 5.30 Parâmetros considerados para a laje com vão pequeno

TABELA 5.31 Resultados obtidos para a laje com vão pequeno (análise determinística)

TABELA 5.32 Resultados obtidos para a laje com vão pequeno (análise probabilística)

TABELA 5.33 Parâmetros considerados para a laje com vão médio 192

TABELA 5.34 Resultados obtidos para a laje com vão médio (análise determinística)

TABELA 5.35 Resultados obtidos para a laje com vão médio (análise probabilística)

TABELA 5.36 Coeficientes obtidos para os exemplos realizados 197 


\section{RESUMO}

MERLIN, A. J. (2006). Análise probabilística do comportamento ao longo do tempo de elementos parcialmente pré-moldados com ênfase em flechas de lajes com armação treliçada. São Carlos, 2006. 212p + apêndice. Tese (Doutorado) - Escola de Engenharia de São Carlos, Universidade de São Paulo.

O objetivo principal deste trabalho é apresentar um modelo de análise probabilística do comportamento ao longo do tempo de estruturas de concreto. Para isso, é realizada a análise probabilística em conjunto com análise numérica. A análise numérica é realizada através de um programa computacional, baseado no método dos elementos finitos, que considera o comportamento não-linear e dependente do tempo dos materiais, assim como o processo evolutivo da construção. Para determinar o efeito das incertezas dos parâmetros é realizada uma análise probabilística, utilizando o método de amostragem por hipercubo latino.

O modelo apresentado pode ser aplicado para a análise probabilística do comportamento ao longo do tempo das estruturas de concreto em geral. No entanto, foi aplicado na análise das flechas diferidas de lajes pré-moldadas formadas por vigotas com armação treliçada. Com esta análise, pôde-se propor um coeficiente multiplicador das flechas imediatas para a avaliação das flechas diferidas no tempo.

O coeficiente multiplicador obtido para as lajes pré-moldadas formadas por vigotas com armação treliçada pode alcançar valores muito superiores ao fator $\alpha_{\mathrm{f}}$ recomendado pela NBR 6118 (2003) para o caso de vigas de concreto armado.

Palavras-chaves: Análise probabilística, comportamento ao longo do tempo, elementos parcialmente pré-moldados, laje pré-moldada, flecha diferida. 


\section{ABSTRACT}

MERLIN, A. J. (2006). Probabilistic analysis of the long-term behavior of partially precast elements, with emphasis on deflections of slabs with lattice reinforcement. São Carlos, 2006. 212p + appendix. Thesis (Ph.D.) - Escola de Engenharia de São Carlos, Universidade de São Paulo.

The goal of this research is to present a probabilistic analysis model of the long-term behavior of concrete structures. For that, the probabilistic analysis is carried out together with numerical analysis. The numerical analysis is carried out using a software based on the finite element method that takes into account the nonlinear and time dependent behavior of the materials, as well as the evolutionary construction process. A probabilistic analysis is carried out in order to determine the effects of the uncertainties of the parameters, using latin hypercube sampling method.

The presented model can be applied in the probabilistic analysis of the long-term behavior of concrete structures in general. However, it was applied in the analysis of the long-term deflections of precast slabs made by joist with lattice reinforcement. By this analysis, a multiplier coefficient of immediate deflections to evaluate long-term deflections could be proposed.

The multiplier coefficient obtained for precast slabs made by joist with lattice reinforcement can reach values much higher than the factor $\alpha_{\mathrm{f}}$ recommended by NBR 6118 (2003) for the case of reinforced concrete beams.

Keywords: Probabilistic analysis, long-term behavior, partially precast elements, precast slab, long-term deflection. 


\section{INTRODUÇÃO}

\subsection{Considerações iniciais}

Nos dias de hoje pode-se observar um alto nível de refinamento empregado na análise estrutural, sendo cada vez mais comum a utilização de modelos que consideram a não linearidade física dos materiais, fissuração, fluência e retração do concreto, comportamento elasto-plástico da armadura, relaxação da armadura de protensão, além da influência do processo construtivo no comportamento da estrutura.

Esta evolução nos processos de análise se deve ao grande desenvolvimento computacional ocorrido nas últimas décadas, principalmente o aumento de capacidade de processamento dos microcomputadores de uso pessoal (PC). Este fato permitiu realizar, de forma eficiente, a análise dos mais complexos problemas de engenharia.

Apesar de todo esse avanço, a análise estrutural ainda é normalmente realizada considerando os parâmetros de entrada do problema com base em valores determinísticos, não considerando a variabilidade estatística dos parâmetros, ou através de métodos semi-probabilísticos, considerando valores para determinados parâmetros com pequena probabilidade de serem ultrapassados (valores característicos). No entanto, como alertam BAZANT \& BAWEJA (1995a), a variabilidade estatística dos parâmetros deveria ser considerada a fim de minimizar o risco de ocorrência de efeitos significativos para a segurança estrutural.

Assim, devido às incertezas causadas pela variabilidade estatística dos parâmetros de entrada, a análise estrutural deveria ser realizada considerando tais 
parâmetros como variáveis aleatórias que possuem um determinado valor médio, uma certa medida de dispersão (desvio padrão) e uma distribuição de probabilidade. E assim, a resposta da estrutura (deslocamento, reação de apoio, tensão no concreto, por exemplo) também seria uma variável aleatória, que pode ser caracterizada por um valor esperado, desvio padrão e uma distribuição de probabilidade. E a partir da análise da distribuição de probabilidade da resposta, as estruturas seriam projetadas para que certos efeitos extremos, tal como deslocamento máximo ou tensão máxima, tivessem pequena probabilidade especificada de serem ultrapassados.

A partir do exposto acima, o que se pretende com esse trabalho é realizar a análise ao longo do tempo, considerando a variabilidade estatística dos parâmetros de entrada, de elementos estruturais pré-moldados que recebem um concreto moldado no local para completar a seção transversal, ou seja, elementos parcialmente pré-moldados. O modelo apresentado não se aplica somente às estruturas de concreto pré-moldado, mas para a análise dos deslocamentos e esforços ao longo do tempo das estruturas de concreto em geral.

Neste trabalho, o modelo apresentado foi empregado para a análise das flechas de lajes nervuradas formadas por vigotas pré-moldadas com armação treliçada.

\subsection{Objetivos}

O objetivo geral deste trabalho é apresentar um modelo para análise do comportamento ao longo do tempo de estruturas de concreto, considerando os parâmetros do problema como variáveis aleatórias, ou seja, mediante análise probabilística.

Os objetivos específicos são:

- Apresentar um modelo para análise probabilística dos deslocamentos e esforços ao longo do tempo de elementos estruturais parcialmente prémoldados; 
- Estudar os efeitos das incertezas estatísticas dos modelos de fluência e retração do concreto nas flechas diferidas de lajes formadas por vigotas pré-moldadas com armação treliçada;

- Fornecer indicações de projeto para lajes formadas por vigotas treliçadas, através da proposta de um coeficiente multiplicador das flechas imediatas para avaliação das flechas diferidas.

\subsection{Justificativas}

Os avanços da tecnologia dos materiais e das técnicas de análise estrutural proporcionaram uma redução das seções transversais das vigas e das espessuras das lajes. Com isso, embora se tenha obtido uma maior eficiência desses elementos, os pavimentos vêm se tornando cada vez mais flexíveis, e os problemas de deslocamentos excessivos, mais comuns. A necessidade de se efetuar uma avaliação consistente dos deslocamentos passou, então, a ser fundamental para o bom desempenho das estruturas em serviço.

Quando se trata de pavimentos constituídos por lajes pré-moldadas, a questão é ainda mais preocupante, pois este tipo de laje apresenta deformações ainda maiores quando comparada com as lajes maciças. E isto se torna ainda mais crítico quando se considera as deformações ao longo do tempo devidas aos efeitos reológicos do concreto.

Estes aspectos já justificam a importância e relevância de um trabalho de pesquisa desenvolvido para analisar as deformações em lajes pré-moldadas, no entanto, vale ressaltar ainda que não se conhece o efeito da variabilidade estatística dos modelos de fluência e retração do concreto no comportamento de lajes prémoldadas formadas por vigotas com armação treliçada. Na realidade, as incertezas estatísticas não são consideradas na análise das estruturas de concreto em geral. 


\subsection{Metodologia}

A análise estrutural é realizada utilizando o programa computacional denominado CONSNOU desenvolvido em linguagem FORTRAN pelo Professor Antonio R. Marí do Departamento de Engenharia da Universidade Politécnica da Catalunha, situada em Barcelona - Espanha. Este programa computacional, baseado no método dos elementos finitos, divide a seção transversal dos elementos em número discreto de filamentos de concreto e aço e a integração das áreas dos filamentos é feita considerando o comportamento não-linear e dependente do tempo dos materiais, assim como o processo evolutivo da construção.

Para determinar o efeito da variabilidade estatística dos parâmetros é realizada uma análise probabilística, utilizando o método de simulações de Monte Carlo. Inicialmente, gera-se um grupo de valores (amostragem) das variáveis aleatórias de acordo com suas correspondentes distribuição de probabilidade, utilizando o método de amostragem por hipercubo latino sugerido por McKAY et al. (1979). Então, aplica-se a análise estrutural para cada uma das amostras geradas. Cada análise, feita desta forma, chama-se de uma simulação. Após a realização de $N$ simulações, tem-se à disposição um conjunto de dados representando uma resposta da estrutura (deslocamento, reação de apoio, tensão no concreto), que também pode ser tratado como uma variável aleatória, da qual se conhece uma amostra de $N$ componentes. Mediante uma análise estatística desta amostra, tornase possível caracterizar os principais momentos e o tipo de distribuição de probabilidade desta variável aleatória. Assim, pode-se determinar como a dispersão dos parâmetros da estrutura influencia a variação da resposta.

\subsection{Apresentação do trabalho}

Esta tese está dividida em seis capítulos, cujo conteúdo é apresentado sucintamente a seguir:

O capítulo 1 apresenta a introdução do trabalho, objetivos, justificativas e metodologia empregada. 
O capítulo 2 descreve sobre o comportamento reológico do concreto, apresentando ainda os modelos para a previsão da fluência e retração, contidos no CEB-90 (1991), ACI-209 (1992) e NBR 6118 (2003), além dos métodos de análise da fluência.

No capítulo 3, são apresentadas as bases do programa computacional CONSNOU, fundamentado no método dos elementos finitos, que foi empregado na análise numérica. Ainda neste capítulo, é feita uma avaliação do programa computacional através da simulação de modelos reais analisados em laboratório.

O capítulo 4 detalha o modelo empregado na análise probabilística. O modelo probabilístico é baseado no método de simulação de Monte Carlo, utilizando amostragem por hipercubo latino.

No capítulo 5, são apresentadas as lajes formadas por elementos prémoldados com armação treliçada. Neste capítulo, encontra-se ainda a análise probabilística das flechas diferidas deste tipo de laje. Com esta análise, pôde-se propor um coeficiente multiplicador das flechas imediatas para a avaliação das flechas diferidas no tempo.

Por fim, no capítulo 6, apresentam-se as conclusões obtidas com o trabalho, algumas considerações finais e sugestões para pesquisas futuras. 


\section{COMPORTAMENTO REOLÓGICO DO CONCRETO}

\subsection{Considerações iniciais}

Quando uma carga é aplicada em uma peça de concreto, ocorre uma deformação instantânea seguida de uma deformação com o tempo. Esse aumento da deformação com o tempo sob a ação de cargas permanentes é chamado de fluência. Como esse aumento de deformação pode ser várias vezes maior do que a deformação no momento do carregamento, a fluência tem considerável importância no comportamento das estruturas [NEVILLE (1997)]. No entanto, conjuntamente com o comportamento viscoelástico do concreto acontece o fenômeno de retração por secagem. Assim, para definir fluência, deve-se considerar duas peças de concreto idênticas sujeitas às mesmas condições ambientais, sendo uma peça carregada e a outra sem carga. A diferença de deformação dessas duas peças define a deformação instantânea mais a deformação por fluência.

As causas dessas variações de deformações estão na microestrutura da matriz de argamassa.

A matriz de argamassa é a pasta de cimento endurecida que envolve e aglutina os agregados. A água contida na pasta de cimento apresenta-se de várias formas, sendo que a classificação da água em diversos tipos está baseada no grau de dificuldade ou facilidade com a qual ela pode ser removida. MEHTA \& MONTEIRO (1994) classificam a água existente na pasta nos seguintes estados: 
a) Água capilar: está é a água presente nos vazios maiores que $5 \mathrm{~nm}$. Pode ser descrita como o volume de água que está livre da influência das forças de atração exercidas pela superfície sólida. $\mathrm{Na}$ realidade, do ponto de vista do comportamento da pasta, é aconselhável dividir a água capilar em duas categorias: a água em vazios grandes, de diâmetro maior que $50 \mathrm{~nm}$, a qual pode ser considerada como água livre, uma vez que a sua remoção não causa qualquer variação de volume e a água retirada por tensão capilar em capilares pequenos (5 a $50 \mathrm{~nm}$ ), cuja remoção pode causar a retração do sistema.

b) Água adsorvida: é a água que está próxima à superfície do sólido, isto é, sob a influência de forças de atração, as moléculas estão fisicamente adsorvidas na superfície dos sólidos na pasta. Desde que as energias de ligação de moléculas individuais de água diminuem com a distância em relação à superfície do sólido, uma porção da água adsorvida pode ser perdida por secagem, resultando na retração da pasta.

c) Água interlamelar: esta é a água associada à estrutura do silicato de cálcio hidratado (C-S-H). A água interlamelar é perdida somente por secagem forte. A estrutura do C-S-H retrai consideravelmente quando a água interlamelar é perdida.

d) Água quimicamente combinada: é a água integrante da estrutura de vários produtos hidratados do cimento. Está água não é perdida na secagem. Os diferentes tipos de água associados ao C-S-H estão ilustrados na figura 2.1.

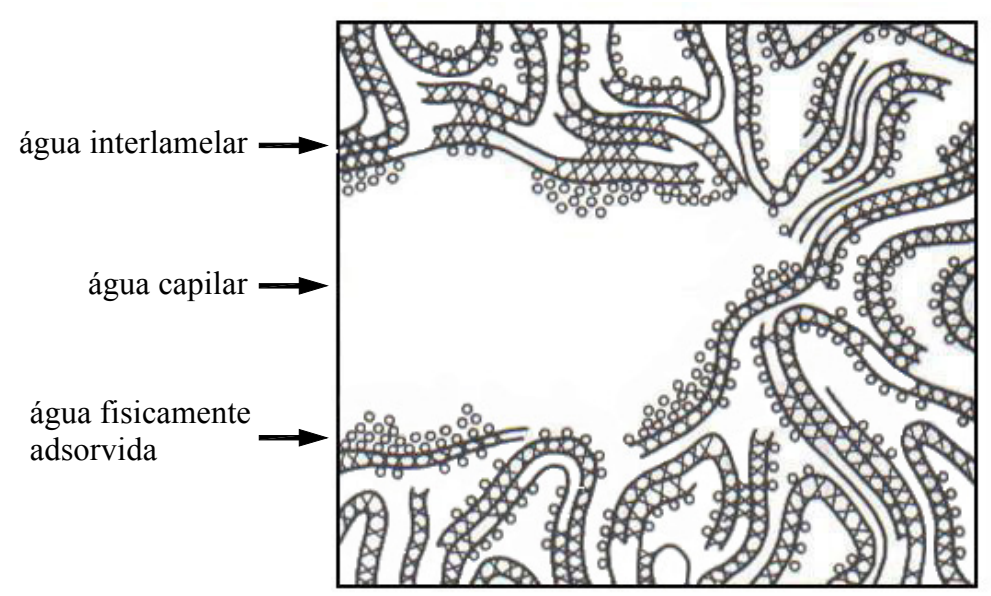

FIGURA 2.1 - Tipos de água associados ao silicato de cálcio hidratado

[MEHTA \& MONTEIRO (1994)] 
Portanto, o fenômeno da retração por secagem está associado à contração da massa da pasta, por ocasião da evaporação da água não fixada quimicamente da pasta de cimento. Isso ocorre nas peças de concreto, independentemente do estado de tensões existente, dependendo principalmente dos seguintes fatores:

\section{a) Características dos agregados:}

A retração no concreto ocorre devido às modificações de volume da pasta de cimento; entretanto, as restrições existentes a essas mudanças de volume alteram o valor das deformações [HASPARYK et al. (2005)]. Segundo NEVILLE (1997), a maior influência é exercida pelo agregado, que restringe a quantidade de retração que poderia efetivamente ocorrer.

A granulometria, por si mesma, não tem influência sobre a magnitude da retração, mas agregados maiores permitem misturas mais pobres, resultando, portanto, menor retração [NEVILLE (1997)]. De modo semelhante, para uma mesma resistência, um concreto com trabalhabilidade baixa contém maior teor de agregado do que outro com trabalhabilidade alta, com agregado do mesmo tamanho, e, em conseqüência, o primeiro terá menor retração.

Com relação ao efeito de contenção da retração exercido pelo agregado, as propriedades elásticas do agregado determinam o grau de contenção e, como exemplificado por NEVILLE (1997), agregado de aço resulta uma retração um terço menor do que os agregados comuns.

\section{b) Teor de cimento e relação água/cimento:}

A influência do consumo de cimento e água no concreto sobre a retração não é direta, pois, à medida que se aumenta a pasta, há um decréscimo na quantidade de agregado, fazendo com que haja um aumento na retração [MEHTA \& MONTEIRO (1994)].

O uso de aditivos plastificantes e superplastificantes, em concretos com a mesma composição, faz com que as deformações por retração sejam maiores. Entretanto, com a redução da relação água/cimento conseguida com o uso desses aditivos, o efeito é contrário, pois, para uma mesma resistência desejada, será necessário menos água e, conseqüentemente, haverá menor deformação. 


\section{c) Espessura da peça de concreto:}

Para que a água no interior do concreto possa migrar para a superfície de um determinado elemento, a espessura da peça influencia a retração aumentando ou diminuindo o caminho a ser percorrido pela água. Quanto menor a distância percorrida, menor será a dificuldade de migração da água e maior a velocidade de retração [HASPARYK et al. (2005)].

\section{d) Umidade relativa do ambiente:}

A umidade relativa do ambiente que circunda o concreto tem muita influência sobre a retração, segundo NEVILLE (1997). Espera-se que um aumento na umidade atmosférica torne mais lenta a taxa relativa do fluxo de umidade do interior para as superfícies externas do concreto [MEHTA \& MONTEIRO (1994)].

Peças de concreto seladas, ou seja, peças que não haja troca de umidade com o meio ambiente apresentam uma pequena retração denominada de retração autógena, causada pela redução da umidade relativa no interior dos poros em decorrência da evolução da reação de hidratação do cimento. A retração autógena tem valor pequeno para concretos convencionais, sendo mais significativa para concretos de alto desempenho, como destacado por REIS (2003).

$\mathrm{Na}$ fluência de peças de concreto submetidas a tensões permanentes, a água não fixada quimicamente, existente nos microporos da pasta de cimento, é comprimida nos capilares e eliminada, provocando uma contração da pasta.

MEHTA \& MONTEIRO (1994) destacam a distinção entre dois tipos de fluência, a fluência básica e a fluência por secagem, sendo a fluência total a soma dessas duas. A fluência básica representa a deformação que o concreto, em condições de elevada umidade $(\sim 100 \%)$, sofre sob carga constante. Já a fluência por secagem ocorre quando o concreto perde umidade para o ambiente e está submetido simultaneamente a um carregamento no tempo. Entretanto, é prática comum ignorar a distinção entre as fluências básica e por secagem, e fluência é simplesmente considerada como a deformação sob carga além da soma da deformação elástica e da deformação livre por secagem. 
Vários são os fatores que interferem na fluência, estando muitas vezes inter-relacionados e ocorrendo simultaneamente, podendo ser dividido em: características dos materiais e tipo de concreto, níveis de resistência, fatores temporais, condições ambientais, dimensões e geometria da peça entre outros.

\section{a) Características dos materiais e tipo de concreto:}

Em função de o concreto ser um material compósito constituído por diferentes materiais com características distintas, cada um desses materiais influenciará de maior ou menor forma na fluência. Dentre os principais fatores que afetam a fluência podem ser destacados: teor da pasta de cimento, relação água/cimento, proporção entre os materiais na dosagem, características do cimento e agregados e o grau de compactação.

Uma vez constatado que o que sofre fluência é a pasta de cimento hidratada, o agregado terá a função apenas de contê-la [HASPARYK et al. (2005)]. Assim, similarmente à retração, a fluência é função do volume de pasta e aumenta à medida que o volume de pasta aumenta [MEHTA \& MONTEIRO (1994)].

A relação água/cimento também afeta a fluência. Para concretos com um determinado consumo de cimento, o aumento da relação água/cimento pode ocasionar um maior volume de vazios permeáveis, aumentando a fluência [MEHTA \& MONTEIRO (1994)].

Entre as várias características do agregado, o seu teor empregado é o que mais afeta a fluência, quando comparado com a sua granulometria, dimensão máxima e forma do grão, desde que o adensamento do concreto seja pleno [NEVILLE (1997)]. Quando maior o volume de agregado empregado menor será a fluência. Ainda de acordo com NEVILLE (1997), certas propriedades do agregado podem alterar a fluência do concreto, sendo seu módulo de elasticidade o mais importante desses fatores, pois quanto maior o módulo de elasticidade, maior o efeito de contenção oferecido pelo agregado à fluência da pasta. Adicionalmente, a porosidade do agregado também afeta a fluência em função de conferir um módulo de elasticidade mais baixo ao agregado.

Segundo NEVILLE (1997), o tipo de cimento também interfere no valor da fluência, na medida em que influencia a resistência do concreto no momento de aplicação da carga. 
HASPARYK et al. (2005) destacam que diferentes tipos de concreto refletem em grandes variações no valor da fluência, verificando que um concreto de alto desempenho (CAD) apresenta menor fluência quando comparado com concreto convencional.

b) Níveis de resistência e tensão aplicada:

A resistência afeta de forma considerável a fluência [MEHTA \& MONTEIRO (1994)]. De acordo com NEVILLE (1997), dentro um grande intervalo, a fluência é inversamente proporcional à resistência do concreto no momento da aplicação da carga. Já a tensão aplicada possui uma proporcionalidade direta com a fluência, exceção feita para peças carregadas a idades muito pequenas [NEVILLE (1997)]. Não existe um limite inferior da proporcionalidade porque o concreto é passível de fluência mesmo sob tensões muito pequenas. O limite superior de proporcionalidade é alcançado quando surgem no concreto microfissuras; isso ocorre a uma tensão expressa como fração da resistência, ficando usualmente entre 0,4 e 0,6 .

\section{c) Fatores temporais:}

A idade na qual o concreto é submetido a um carregamento constante pode afetar o resultado da fluência. Quanto mais jovem o concreto é submetido a um carregamento, maior será a sua fluência total em função de sua menor maturidade [HASPARYK et al. (2005)].

\section{d) Condições ambientais:}

Segundo NEVILLE (1997), a umidade relativa do ambiente que envolve o concreto é um dos fatores mais importantes que atuam sobre a fluência. Quanto menor a umidade do ambiente, mais favorável se tornará o processo de secagem do concreto, refletindo maior fluência [MEHTA \& MONTEIRO (1994)].

Já a temperatura a qual o concreto é exposto pode ter dois efeitos opostos sobre a fluência, de acordo com MEHTA \& MONTEIRO (1994). Se uma peça de concreto é exposta a uma temperatura maior do que a normal como parte do processo de cura, antes de ser carregada, a resistência aumentará e a deformação por fluência será menor do que aquela de um concreto correspondente armazenado a uma temperatura mais baixa. No entanto, a exposição à alta temperatura, durante o período em que está carregada, pode aumentar a fluência. 


\section{e) Dimensões e geometria da peça:}

Quanto maior a dimensão da peça, maior a dificuldade de migração de água do seu interior para o exterior em virtude do maior caminho a percorrer, e conseqüentemente menor será a fluência. Desta forma, no caso de concretos selados, a dimensão não afeta a fluência [NEVILLE (1997)].

No que diz respeito à geometria da peça, admite-se que a fluência é função da sua relação volume e área superficial. A influência da forma tem menor importância que da dimensão da peça [NEVILLE (1997)].

A deformação por fluência diminui com o passar do tempo, atingindo uma paralisação após um longo período de tempo e, para o caso de descarregamento, a deformação por fluência é parcialmente reversível, ou seja, após uma recuperação elástica ocorre uma recuperação posterior da deformação com o tempo, como mostrado na figura 2.2.
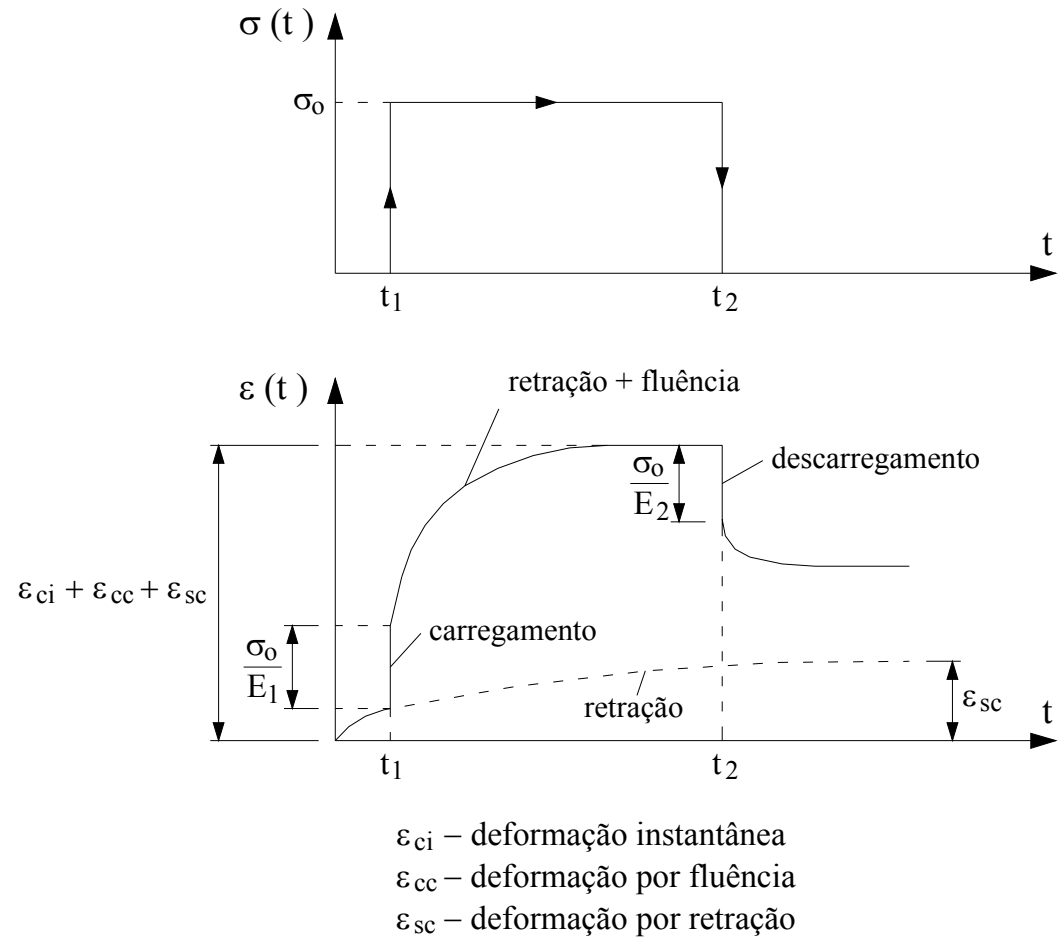

FIGURA 2.2 - Retração e fluência com o tempo [adaptado de LEONHARDT \& MÖNNING (1978)] 
Portanto, em uma peça de concreto submetida a uma compressão uniaxial, a deformação total $\varepsilon_{\mathrm{c}}(\mathrm{t})$ na idade $\mathrm{t}$ pode ser expressa por:

$$
\begin{aligned}
& \varepsilon_{\mathrm{c}}(\mathrm{t})=\varepsilon_{\mathrm{ci}}(\mathrm{t})+\varepsilon_{\mathrm{cc}}(\mathrm{t})+\varepsilon_{\mathrm{sc}}(\mathrm{t})+\varepsilon_{\mathrm{T}}(\mathrm{t})=\varepsilon_{\mathrm{c \sigma}}(\mathrm{t})+\varepsilon_{\mathrm{cn}}(\mathrm{t}) \\
& \text { onde: } \\
& \varepsilon_{\mathrm{ci}}(\mathrm{t}) \quad \text { - deformação instantânea; } \\
& \varepsilon_{\mathrm{cc}}(\mathrm{t}) \quad \text { - deformação devido à fluência; } \\
& \varepsilon_{\mathrm{sc}}(\mathrm{t}) \quad \text { - deformação devido à retração; } \\
& \varepsilon_{\mathrm{T}}(\mathrm{t}) \quad \text { - deformação devido à variação térmica; } \\
& \varepsilon_{\mathrm{c \sigma}}(\mathrm{t}) \quad \text { - deformação dependente de tensão (instantânea e fluência); } \\
& \varepsilon_{\mathrm{cn}}(\mathrm{t}) \quad \text { - deformação independente de tensões (retração e variação } \\
& \text { térmica). }
\end{aligned}
$$

\subsection{Modelos reológicos}

A reologia consiste no estudo da relação entre tensões e deformações por meio de modelos de representação que consideram o comportamento elástico, viscoso e plástico dos materiais.

Diversas tentativas já foram realizadas para simular o comportamento das deformações do concreto ao longo do tempo através de modelos reológicos constituídos de elementos representando deformações específicas de cada componente ou fase do concreto [NEVILLE (1997)]. Essa aproximação é em grande parte empírica e seu sucesso depende da habilidade em atribuir a cada parte da deformação do concreto um determinado elemento do modelo. Em outras tentativas, elementos reológicos são combinados simplesmente para se aproximarem de ensaios reais de deformação sem considerar seu significado físico, sendo apenas um método de ajuste de equações.

A seguir são apresentados os elementos fundamentais que formam os modelos reológicos assim como a combinação entre esses elementos para formar modelos mais complexos. 


\subsubsection{Elementos fundamentais dos modelos reológicos}

O comportamento reológico do concreto, ou seja, a sua capacidade de deformação ao longo do tempo pode ser estimado pela criação de modelos reológicos baseados em dois elementos fundamentais com propriedades reológicas ideais: uma mola e um amortecedor. Para a mola, a relação entre tensão e deformação é dada pela lei de Hooke, ou seja, elasticidade linear perfeita:

$$
\sigma(\mathrm{t})=\mathrm{E} . \varepsilon(\mathrm{t})
$$

onde:

E - módulo de elasticidade.

A lei de Hooke estabelece que as tensões são diretamente proporcionais às deformações, variando linearmente com o módulo de elasticidade E. A resposta da mola à tensão é imediata; em conseqüência, quando uma tensão, $\sigma_{0}$, é mantida constante, a deformação será $\sigma_{0} / \mathrm{E}$, constante ao longo do tempo.

$\mathrm{O}$ amortecedor pode ser visualizado como um macaco que desloca um fluido viscoso em um cilindro com fundo vazado. Usando a lei de Newton, ou seja, viscosidade linear perfeita:

$$
\dot{\varepsilon}(\mathrm{t})=\frac{\sigma(\mathrm{t})}{\eta}
$$

onde:

$\dot{\varepsilon}=\frac{\mathrm{d} \varepsilon}{\mathrm{dt}} \quad-$ taxa de deformação;

$\eta \quad-$ coeficiente de viscosidade.

A lei de Newton estabelece que a taxa de deformação é proporcional à tensão, variando linearmente de acordo com o coeficiente de viscosidade $\eta$. Assim, quando uma tensão, $\sigma_{0}$, é mantida constante, o amortecedor irá deformar continuamente a uma taxa constante. 


\subsubsection{Modelos reológicos básicos}

Formulações complexas do comportamento viscoelástico dos materiais podem ser obtidas pela associação dos elementos fundamentais (mola e amortecedor), resultando em modelos compostos ou conjugados. Esta associação é feita com os elementos fundamentais arranjados em série ou em paralelo.

Os modelos compostos mais típicos são os modelos de Maxwell, Kelvin, Boltzmann e Burger, conforme figura 2.3.

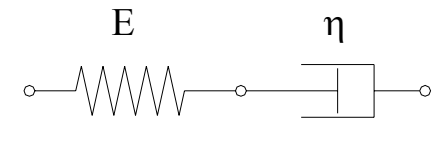

(a)

$\mathrm{E}_{2}$

$\mathrm{E}_{1}$

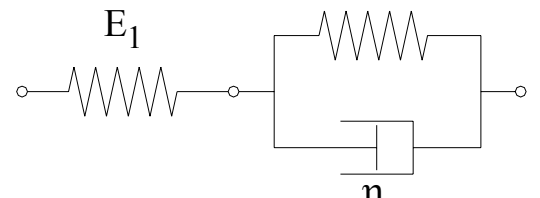

(c)
$\mathrm{E}$

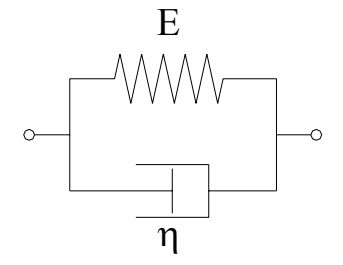

(b)

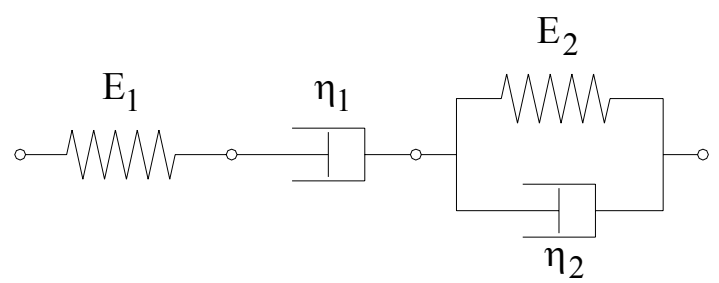

(d)

(b) Modelo de Kelvin

FIGURA 2.3 - (a) Modelo de Maxwell

(d) Modelo de Burger

\subsubsection{Modelo de Maxwell}

O modelo de Maxwell compreende uma mola e um amortecedor conectados em série, como mostra a figura 2.3 (a). As seguintes equações se aplicam a esse modelo:

$$
\begin{array}{lll}
\sigma_{E}(t)=\sigma_{\eta}(t)=\sigma(t) & \text { equação de equilíbrio } & 2.4 \\
\varepsilon(t)=\varepsilon_{E}(t)+\varepsilon_{\eta}(t) & \text { equação de compatibilidade } & 2.5 \\
\sigma_{E}(t)=E \cdot \varepsilon_{E}(t) & \text { equação constitutiva (mola) } & 2.6 \\
\sigma_{\eta}(t)=\eta \cdot \dot{\varepsilon}_{\eta}(t) & \text { equação constitutiva (amortecedor) } & 2.7
\end{array}
$$


Das equações anteriores, obtém-se a seguinte equação diferencial:

$$
\dot{\varepsilon}(\mathrm{t})=\frac{\dot{\sigma}(\mathrm{t})}{\mathrm{E}}+\frac{\sigma(\mathrm{t})}{\eta}
$$

Da integração da equação diferencial do modelo e considerando tensão constante $\sigma(\mathrm{t})=\sigma_{\mathrm{o}}$, obtém-se:

$$
\varepsilon(\mathrm{t})=\frac{\sigma_{\mathrm{o}}}{\mathrm{E}}+\frac{\sigma_{\mathrm{o}}}{\eta} \cdot \mathrm{t}
$$

O modelo de Maxwell, conforme figura 2.4, prevê o aumento da deformação sem limites e em uma situação de descarregamento no tempo $t_{1}$, a deformação elástica $\sigma_{0} / \mathrm{E}$ é recuperada instantaneamente, enquanto a deformação permanente $\left(\sigma_{0} / \eta\right) \cdot t_{1}$ permanece no amortecedor.
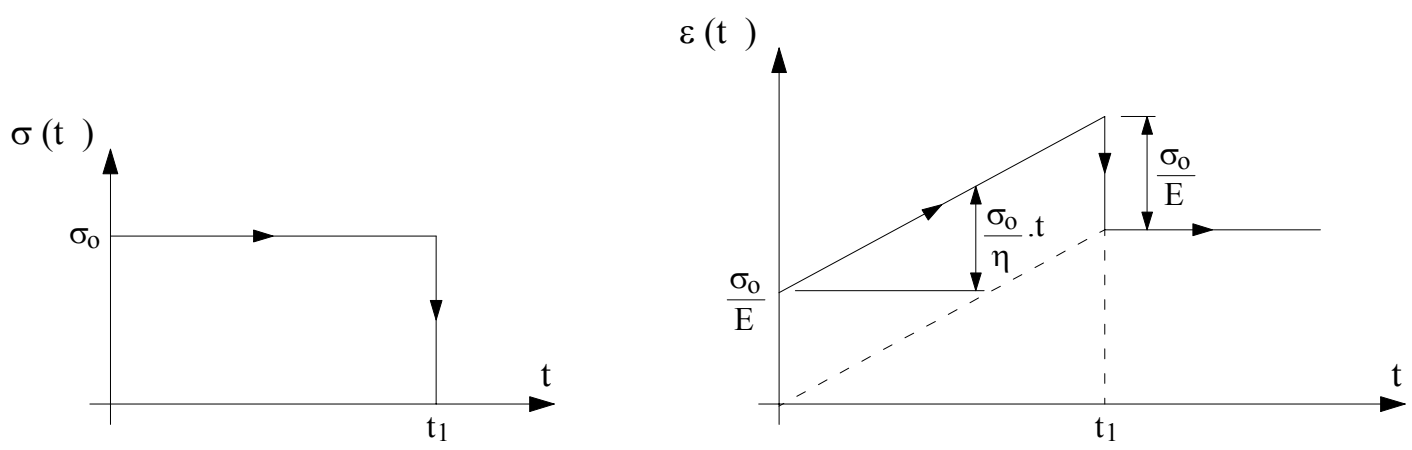

FIGURA 2.4 - Regime viscoelástico de Maxwell

\subsubsection{Modelo de Kelvin}

O modelo de Kelvin combina uma mola e um amortecedor em paralelo, como mostra a figura 2.3 (b). As seguintes equações se aplicam a esse modelo:

$$
\begin{array}{ll}
\sigma(t)=\sigma_{E}(t)+\sigma_{\eta}(t) & \text { equação de equilíbrio } \\
\varepsilon_{E}(t)=\varepsilon_{\eta}(t)=\varepsilon(t) & \text { equação de compatibilidade } \\
\sigma_{E}(t)=E \cdot \varepsilon_{E}(t) & \text { equação constitutiva (mola) } \\
\sigma_{\eta}(t)=\eta \cdot \dot{\varepsilon}_{\eta}(t) & \text { equação constitutiva (amortecedor) }
\end{array}
$$


Resultando na equação diferencial:

$$
\sigma(\mathrm{t})=\mathrm{E} . \varepsilon(\mathrm{t})+\eta \cdot \dot{\varepsilon}(\mathrm{t})
$$

Da integração da equação diferencial do modelo e considerando tensão constante $\sigma(\mathrm{t})=\sigma_{\mathrm{o}}$, obtém-se:

$$
\varepsilon(\mathrm{t})=\frac{\sigma_{\mathrm{o}}}{\mathrm{E}} \cdot\left(1-\mathrm{e}^{-\mathrm{E} \cdot \mathrm{t} / \eta}\right)
$$

Pelo modelo de Kelvin, conforme figura 2.5, a deformação aumenta a uma taxa decrescente e tem um valor assintótico de $\sigma_{\mathrm{o}} / \mathrm{E}$. Na fase de carregamento, o amortecedor armazena toda a energia e a transfere para a mola com o decorrer do tempo e em uma posterior fase de descarregamento, as deformações são totalmente reversíveis ao longo do tempo.
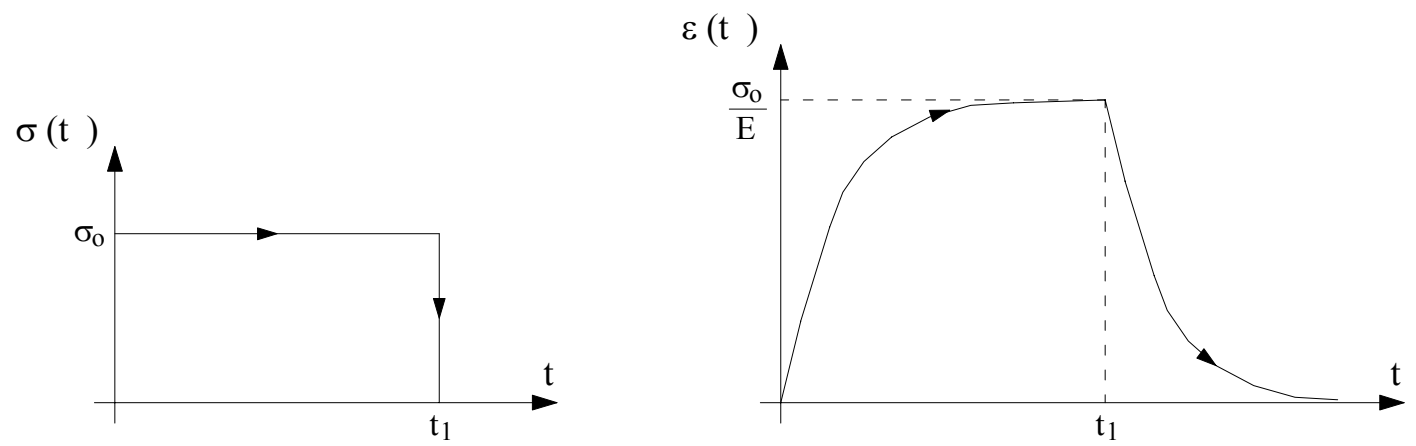

FIGURA 2.5 - Regime viscoelástico de Kelvin

\subsubsection{Modelo de Boltzmann}

No modelo de Boltzmann, também conhecido por modelo de três parâmetros, uma mola é conectada em série com um elemento de Kelvin, como mostra a figura 2.3 (c). Assumindo $\varepsilon_{1}$ e $\varepsilon_{2}$ a deformação da mola e do elemento de Kelvin, respectivamente, aplicam-se as seguintes equações:

$$
\begin{array}{ll}
\sigma_{1}(\mathrm{t})=\sigma_{2}(\mathrm{t})=\sigma(\mathrm{t}) & \text { equação de equilíbrio } \\
\varepsilon(\mathrm{t})=\varepsilon_{1}(\mathrm{t})+\varepsilon_{2}(\mathrm{t}) & \text { equação de compatibilidade } \\
\sigma_{1}(\mathrm{t})=\mathrm{E}_{1} \cdot \varepsilon_{1}(\mathrm{t}) & \text { equação constitutiva (mola) } \\
\sigma_{2}(\mathrm{t})=\mathrm{E}_{2} \cdot \varepsilon_{2}(\mathrm{t})+\eta \cdot \dot{\varepsilon}_{2}(\mathrm{t}) & \text { equação constitutiva (Kelvin) }
\end{array}
$$


Resultando na equação diferencial:

$$
\eta \cdot \mathrm{E}_{1} \cdot \dot{\varepsilon}(\mathrm{t})+\mathrm{E}_{1} \cdot \mathrm{E}_{2} \cdot \varepsilon(\mathrm{t})=\eta \cdot \dot{\sigma}(\mathrm{t})+\left(\mathrm{E}_{1}+\mathrm{E}_{2}\right) \cdot \sigma(\mathrm{t})
$$

Da integração da equação diferencial do modelo e considerando tensão constante $\sigma(\mathrm{t})=\sigma_{\mathrm{o}}$, obtém-se:

$$
\varepsilon(t)=\sigma_{o} \cdot\left[\frac{E_{1}+E_{2}}{E_{1} \cdot E_{2}}-\frac{1}{E_{2}} \cdot e^{-E_{2} \cdot t / \eta}\right]
$$

Pelo modelo de Boltzmann, conforme figura 2.6, a deformação é proporcional a $\sigma_{\mathrm{o}}$, mudando de $\sigma_{\mathrm{o}} / \mathrm{E}_{1}$ no tempo $\mathrm{t}=0$ para $\sigma_{0} \cdot\left[\left(E_{1}+E_{2}\right) /\left(E_{1} \cdot E_{2}\right)\right]$ no tempo $t=\infty$. Em uma situação de descarregamento, a deformação elástica é recuperada instantaneamente, enquanto que a deformação viscoelástica é recuperada ao longo do tempo.

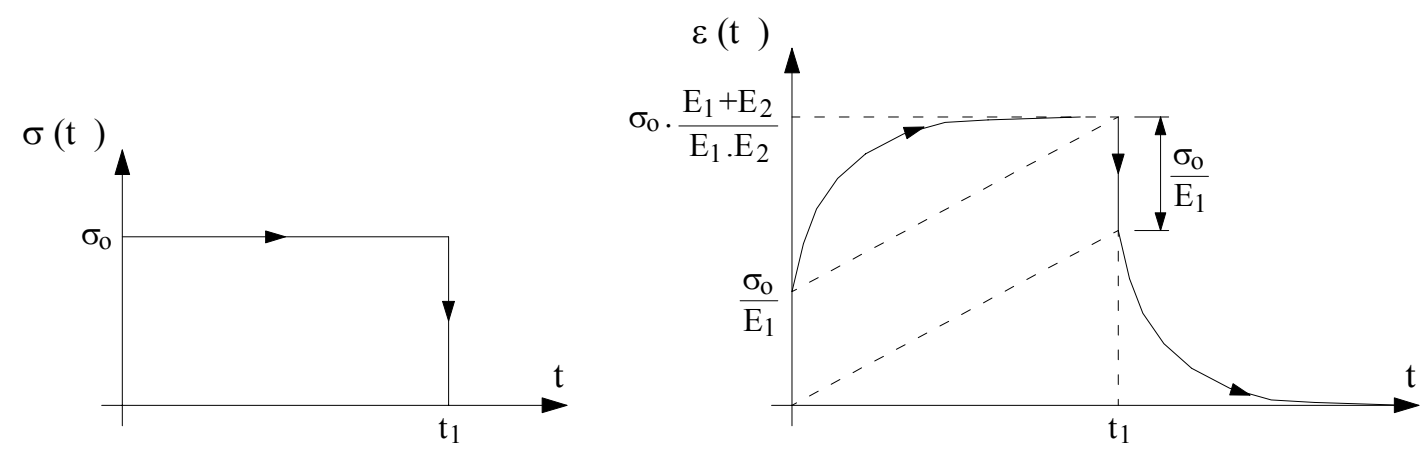

FIGURA 2.6 - Regime viscoelástico de Boltzmann

\subsubsection{Modelo de Burger}

No modelo de Burger, um elemento de Maxwell combina com um elemento de Kelvin em série, como mostra a figura 2.3 (d). Assumindo $\varepsilon_{1}$ e $\varepsilon_{2}$ a deformação do elemento de Maxwell e do elemento de Kelvin, respectivamente, aplicam-se as seguintes equações:

$$
\begin{array}{ll}
\sigma_{1}(\mathrm{t})=\sigma_{2}(\mathrm{t})=\sigma(\mathrm{t}) & \text { equação de equilíbrio } \\
\varepsilon(\mathrm{t})=\varepsilon_{1}(\mathrm{t})+\varepsilon_{2}(\mathrm{t}) & \text { equação de compatibilidade }
\end{array}
$$




$$
\left.\begin{array}{l}
\sigma_{1}(\mathrm{t})=\mathrm{E}_{1} \cdot \varepsilon_{\mathrm{E}_{1}}(\mathrm{t}) \\
\sigma_{1}(\mathrm{t})=\eta_{1} \cdot \dot{\varepsilon}_{\eta_{1}}(\mathrm{t})
\end{array}\right\} \text { equação constitutiva (Maxwell) }
$$

Da integração da equação diferencial do modelo e considerando tensão constante $\sigma(\mathrm{t})=\sigma_{\mathrm{o}}$, obtém-se:

$$
\varepsilon(\mathrm{t})=\frac{\sigma_{\mathrm{o}}}{\mathrm{E}_{1}}+\frac{\sigma_{\mathrm{o}}}{\eta_{1}} \cdot \mathrm{t}+\frac{\sigma_{\mathrm{o}}}{\mathrm{E}_{2}} \cdot\left[1-\mathrm{e}^{-\mathrm{E}_{2} \cdot \mathrm{t} / \eta_{2}}\right]
$$

Pelo modelo de Burger, conforme figura 2.7, em uma situação de descarregamento, a deformação elástica é recuperada instantaneamente, enquanto que a deformação viscoelástica é recuperada ao longo do tempo e a deformação viscosa permanece no sistema.
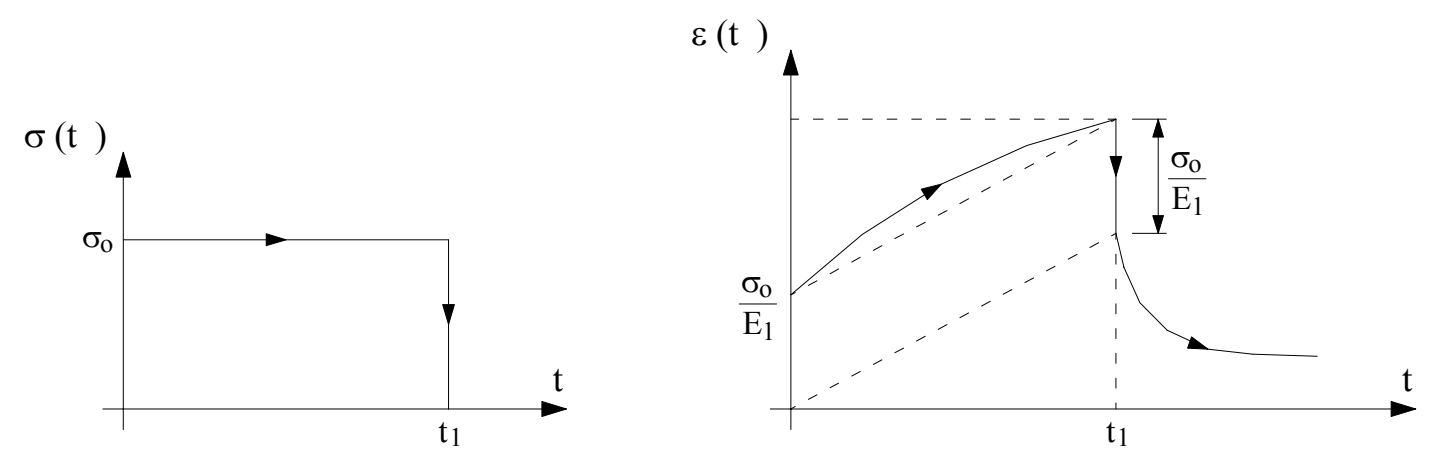

FIGURA 2.7 - Regime viscoelástico de Burger

Como alertado por NEVILLE (1997), os modelos reológicos não fazem nada mais que expressar as funções de deformação de uma forma alternativa, mas úteis para visualizar os efeitos da fluência e especialmente a superposição das deformações. Freqüentemente, modelos reológicos são ajustados a resultados experimentais pela inclusão de parâmetros empíricos de forma que, na realidade, são os dados reais que darão origem ao modelo e não vice e versa. 


\subsection{Modelos para a previsão da fluência e retração}

Quando não são disponíveis dados experimentais, é necessário lançar mão de um modelo para a previsão da fluência e retração, que usualmente represente o consenso comum. Neste contexto, apresentam-se a seguir as recomendações para a previsão da fluência e retração contidas no CEB-90 (1991), ACI-209 (1992) e NBR 6118 (2003). Os modelos de fluência de tais normas são baseados em coeficientes de fluência, que são funções das propriedades do concreto, condições ambientais e propriedades geométricas da peça. Enquanto que para a retração, baseiam-se na umidade relativa, nas dimensões e composição da peça de concreto.

\subsubsection{Definições}

\subsubsection{Deformação total e deformação por fluência}

A deformação total na idade $\mathrm{t}$, causada por uma tensão constante $\sigma\left(\mathrm{t}_{\mathrm{o}}\right)$, atuante desde a idade $\mathrm{t}_{\mathrm{o}}$, será:

$$
\varepsilon_{\mathrm{c}}\left(\mathrm{t}, \mathrm{t}_{\mathrm{o}}\right)=\frac{\sigma\left(\mathrm{t}_{\mathrm{o}}\right)}{\mathrm{E}_{\mathrm{c}}\left(\mathrm{t}_{\mathrm{o}}\right)}+\varepsilon_{\mathrm{cc}}\left(\mathrm{t}, \mathrm{t}_{\mathrm{o}}\right)
$$

onde:

$$
\begin{aligned}
& \frac{\sigma\left(t_{o}\right)}{E_{c}\left(t_{o}\right)} \quad \text { deformação instantânea no concreto, na idade } t_{o} \text {; } \\
& \varepsilon_{\mathrm{cc}}\left(\mathrm{t}, \mathrm{t}_{\mathrm{o}}\right) \text { - deformação por fluência no concreto, na idade } \mathrm{t} \text {; } \\
& \mathrm{E}_{\mathrm{c}}\left(\mathrm{t}_{\mathrm{o}}\right) \text { - módulo de deformação longitudinal do concreto na idade } \\
& t_{0} \text {. }
\end{aligned}
$$

\subsubsection{Coeficiente de fluência}

Há duas definições para o coeficiente de fluência:

a) relação entre a deformação por fluência no tempo $t$ e a deformação inicial no tempo $t_{o}$ (modelo do ACI).

$$
\varphi_{\mathrm{o}}\left(\mathrm{t}, \mathrm{t}_{\mathrm{o}}\right)=\frac{\varepsilon_{\mathrm{cc}}\left(\mathrm{t}, \mathrm{t}_{\mathrm{o}}\right)}{\sigma\left(\mathrm{t}_{\mathrm{o}}\right) / \mathrm{E}_{\mathrm{c}}\left(\mathrm{t}_{\mathrm{o}}\right)}
$$


b) relação entre a deformação por fluência no tempo $t$ e a deformação inicial para tensões aplicadas aos 28 dias (modelo do CEB e NBR 6118).

$$
\varphi_{28}\left(\mathrm{t}, \mathrm{t}_{\mathrm{o}}\right)=\frac{\varepsilon_{\mathrm{cc}}\left(\mathrm{t}, \mathrm{t}_{\mathrm{o}}\right)}{\sigma\left(\mathrm{t}_{\mathrm{o}}\right) / \mathrm{E}_{28}}
$$

onde $\mathrm{E}_{28}$ é o módulo de deformação inicial para a idade de 28 dias.

\subsubsection{Fluência específica}

A fluência específica é a razão entre o coeficiente de fluência e o módulo de deformação do concreto. Representa-se por:

$$
\begin{array}{ll}
\mathrm{C}\left(\mathrm{t}, \mathrm{t}_{\mathrm{o}}\right)=\frac{\varphi_{\mathrm{o}}\left(\mathrm{t}, \mathrm{t}_{\mathrm{o}}\right)}{\mathrm{E}_{\mathrm{c}}\left(\mathrm{t}_{\mathrm{o}}\right)} & \text { para o ACI } \\
\mathrm{C}\left(\mathrm{t}, \mathrm{t}_{\mathrm{o}}\right)=\frac{\varphi_{28}\left(\mathrm{t}, \mathrm{t}_{\mathrm{o}}\right)}{\mathrm{E}_{\mathrm{c} 28}} & \text { para CEB e NBR } 6118
\end{array}
$$

\subsubsection{Função fluência}

A função fluência representa a deformação total na idade $t$, para uma tensão unitária atuante desde a idade $\mathrm{t}_{\mathrm{o}}$. Assim,

$$
\Phi\left(\mathrm{t}, \mathrm{t}_{\mathrm{o}}\right)=\frac{1}{\mathrm{E}_{\mathrm{c}}\left(\mathrm{t}_{\mathrm{o}}\right)}+\mathrm{C}\left(\mathrm{t}, \mathrm{t}_{\mathrm{o}}\right)
$$

E com isso, tem-se:

$$
\begin{array}{ll}
\Phi\left(\mathrm{t}, \mathrm{t}_{\mathrm{o}}\right)=\frac{1}{\mathrm{E}_{\mathrm{c}}\left(\mathrm{t}_{\mathrm{o}}\right)}+\frac{\varphi_{\mathrm{o}}\left(\mathrm{t}, \mathrm{t}_{\mathrm{o}}\right)}{\mathrm{E}_{\mathrm{c}}\left(\mathrm{t}_{\mathrm{o}}\right)} & \text { para o ACI } \\
\Phi\left(\mathrm{t}, \mathrm{t}_{\mathrm{o}}\right)=\frac{1}{\mathrm{E}_{\mathrm{c}}\left(\mathrm{t}_{\mathrm{o}}\right)}+\frac{\varphi_{28}\left(\mathrm{t}, \mathrm{t}_{\mathrm{o}}\right)}{\mathrm{E}_{\mathrm{c} 28}} & \text { para CEB e NBR } 6118
\end{array}
$$

A figura 2.8 apresenta curvas esquemáticas típicas de função fluência para início de carregamento em diversas idades. 


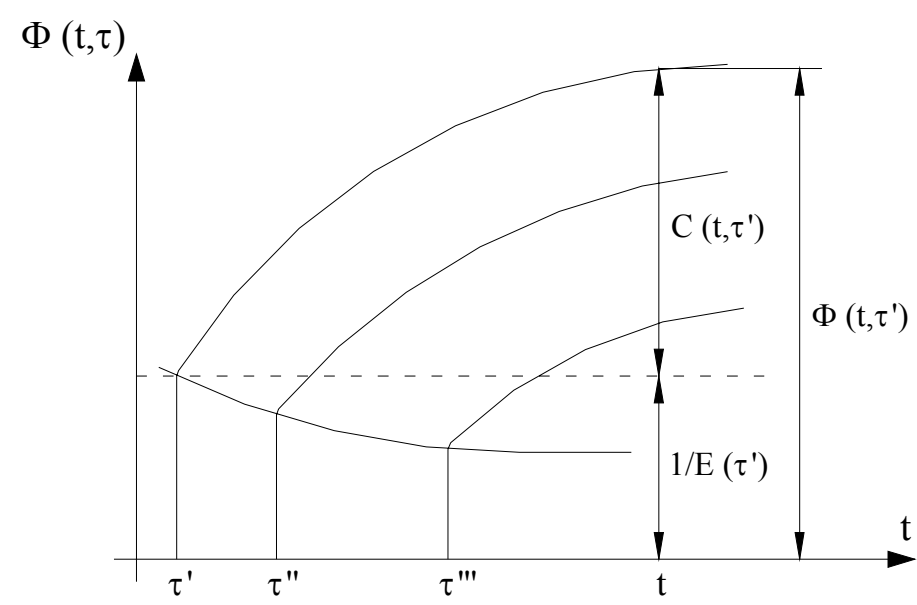

FIGURA 2.8 - Curvas de função fluência

\subsubsection{Modelo CEB-90 (1991)}

\subsubsection{Fluência}

Segundo CEB-90 (1991), o coeficiente de fluência $\varphi\left(t, t_{0}\right)$ é dado por:

$\varphi\left(\mathrm{t}, \mathrm{t}_{\mathrm{o}}\right)=\varphi_{\mathrm{o}} \cdot \beta_{\mathrm{c}}\left(\mathrm{t}-\mathrm{t}_{\mathrm{o}}\right)$

onde:

$\varphi_{\mathrm{o}} \quad$ - coeficiente de fluência básico conforme expressão 2.36;

$\beta_{\mathrm{c}}$ - coeficiente que descreve o desenvolvimento da fluência com o tempo, após o carregamento, de acordo com a equação 2.41 ;

t $\quad$ - idade do concreto, em dias;

$\mathrm{t}_{\mathrm{o}} \quad$ - idade do concreto ao ser carregado, em dias.

O coeficiente de fluência básico pode ser estimado por:

$\varphi_{\mathrm{o}}=\varphi_{\mathrm{U}} \cdot \beta\left(\mathrm{f}_{\mathrm{cm}}\right) \cdot \beta\left(\mathrm{t}_{\mathrm{o}}\right)$

com:

$$
\begin{aligned}
& \varphi_{\mathrm{U}}=1+\frac{1-\mathrm{U} / \mathrm{U}_{\mathrm{o}}}{0,46 \cdot\left(\mathrm{h}_{\mathrm{fic}} / \mathrm{h}_{\mathrm{o}}\right)^{1 / 3}} \\
& \beta\left(\mathrm{f}_{\mathrm{cm}}\right)=\frac{5,3}{\left(\mathrm{f}_{\mathrm{cm}} / \mathrm{f}_{\mathrm{cmo}}\right)^{0,5}} \\
& \beta\left(\mathrm{t}_{\mathrm{o}}\right)=\frac{1}{0,1+\left(\mathrm{t}_{\mathrm{o}} / \mathrm{t}_{1}\right)^{0,2}}
\end{aligned}
$$


onde:

$\mathrm{h}_{\mathrm{fic}}=\frac{2 \cdot \mathrm{A}_{\mathrm{c}}}{\mathrm{u}_{\mathrm{ar}}} \quad$ (espessura fictícia do elemento, em $\left.\mathrm{mm}\right)$

$\mathrm{A}_{\mathrm{c}} \quad$ - área da seção transversal do elemento;

$\mathrm{u}_{\mathrm{ar}} \quad$ - perímetro do elemento em contato com o ar;

$\mathrm{f}_{\mathrm{cm}}$ - resistência média à compressão, aos 28 dias, em MPa;

$\mathrm{f}_{\mathrm{cmo}}=10 \mathrm{MPa}$;

U - umidade relativa do ambiente, em \%;

$\mathrm{U}_{\mathrm{o}}=100 \%$;

$\mathrm{h}_{\mathrm{o}}=100 \mathrm{~mm}$

$\mathrm{t}_{1}=1$ dia.

O desenvolvimento da fluência com o tempo é dado por:

$\beta_{\mathrm{c}}\left(\mathrm{t}-\mathrm{t}_{\mathrm{o}}\right)=\left[\frac{\left(\mathrm{t}-\mathrm{t}_{\mathrm{o}}\right) / \mathrm{t}_{1}}{\beta_{\mathrm{H}}+\left(\mathrm{t}-\mathrm{t}_{\mathrm{o}}\right) / \mathrm{t}_{1}}\right]^{0,3}$

com:

$\beta_{\mathrm{H}}=150 .\left\{1+\left(1,2 \cdot \frac{\mathrm{U}}{\mathrm{U}_{\mathrm{o}}}\right)^{18}\right\} \cdot \frac{\mathrm{h}_{\text {fic }}}{\mathrm{h}_{\mathrm{o}}}+250 \leq 1500$

\section{- Efeito do tipo de cimento}

O efeito do tipo de cimento no coeficiente de fluência pode ser levado em conta como uma modificação da idade no ato do carregamento, $\mathrm{t}_{\mathrm{o}}$, de acordo com a equação:

$$
\mathrm{t}_{\mathrm{o}}=\mathrm{t}_{\mathrm{o}, \mathrm{T}} \cdot\left[\frac{9}{2+\left(\mathrm{t}_{\mathrm{o}, \mathrm{T}} / \mathrm{t}_{1, \mathrm{~T}}\right)^{1 / 2}}+1\right]^{\alpha} \geq 0,5 \operatorname{dias}
$$

onde:

$\mathrm{t}_{\mathrm{o}, \mathrm{T}}$ - idade do concreto ajustada à temperatura, de acordo com a equação 2.44;

$\mathrm{t}_{1, \mathrm{~T}}=1$ dia; 
a - coeficiente que depende do tipo de cimento, assumindo os seguintes valores:

-1 - para cimento de endurecimento lento;

0 - para cimento de endurecimento normal ou rápido;

1 - para cimento de endurecimento rápido e de alta resistência.

- Efeito de temperaturas altas ou baixas, antes e durante o carregamento

O efeito de temperaturas elevadas ou reduzidas na maturidade do concreto pode ser considerado, calculando uma idade ajustada no ato do carregamento pela expressão:

$\mathrm{t}_{\mathrm{o}, \mathrm{T}}=\sum_{\mathrm{i}=1}^{\mathrm{n}} \Delta \mathrm{t}_{\mathrm{i}} \cdot \mathrm{e}^{-\left[\frac{4000}{273+\mathrm{T}\left(\Delta \mathrm{t}_{\mathrm{i}}\right) / \mathrm{T}_{\mathrm{o}}}-13,65\right]}$

onde:

$\mathrm{t}_{\mathrm{o}, \mathrm{T}} \quad$ - idade do concreto ajustada à temperatura, em dias;

$\mathrm{T}\left(\Delta \mathrm{t}_{\mathrm{i}}\right)$ - temperatura em ${ }^{\circ} \mathrm{C}$, durante o período $\Delta \mathrm{t}_{\mathrm{i}}$;

$\Delta \mathrm{t}_{\mathrm{i}} \quad-$ número de dias que se verifica a temperatura $\mathrm{T}$;

$\mathrm{T}_{\mathrm{o}}=1^{\circ} \mathrm{C}$.

As equações 2.45 a 2.48 descrevem o efeito da temperatura, quando o elemento estiver sob carregamento, para valores de temperatura diferentes de $20^{\circ} \mathrm{C}$.

O efeito da temperatura sobre o desenvolvimento da fluência é considerado, substituindo-se o parâmetro $\beta_{\mathrm{H}}$ da equação 2.41 por $\beta_{\mathrm{H}, \mathrm{T}}$, que é dado por:

$$
\beta_{\mathrm{H}, \mathrm{T}}=\beta_{\mathrm{H}} \cdot \beta_{\mathrm{T}}
$$

com:

$\beta_{\mathrm{T}}=\mathrm{e}^{\left[\frac{1500}{273+\left(\mathrm{T} / \mathrm{T}_{\mathrm{o}}\right)}-5,12\right]}$ 
O efeito da temperatura no coeficiente $\varphi_{0}$ é considerado, substituindo-se $\varphi_{\mathrm{U}}$ da equação 2.36 por $\varphi_{\mathrm{U}, \mathrm{T}}$, que é calculado pela expressão:

$$
\varphi_{\mathrm{U}, \mathrm{T}}=\varphi_{\mathrm{T}}+\left(\varphi_{\mathrm{U}}-1\right) \cdot \varphi_{\mathrm{T}}^{1,2}
$$

com:

$$
\varphi_{\mathrm{T}}=\mathrm{e}^{\left[0,015 \cdot\left(\mathrm{T} / \mathrm{T}_{0}-20\right)\right]}
$$

Se a temperatura variar enquanto a peça está sob carga, a fluência pode ser estimada pela seguinte expressão:

$$
\varphi\left(\mathrm{t}, \mathrm{t}_{\mathrm{o}}, \mathrm{T}\right)=\varphi_{\mathrm{o}} \cdot \beta_{\mathrm{c}}\left(\mathrm{t}-\mathrm{t}_{\mathrm{o}}\right)+\Delta \varphi_{\mathrm{T}, \mathrm{var}}
$$

com:

$$
\Delta \varphi_{\mathrm{T}, \operatorname{var}}=0,0004 .\left(\mathrm{T} / \mathrm{T}_{\mathrm{o}}-20\right)^{2}
$$

\section{- Efeito de altas tensões}

Para níveis de tensão variando de $0,4 . \mathrm{f}_{\mathrm{cm}}\left(\mathrm{t}_{\mathrm{o}}\right)<\left|\sigma_{\mathrm{c}}\right|<0,6 . \mathrm{f}_{\mathrm{cm}}\left(\mathrm{t}_{\mathrm{o}}\right)$, a fluência cresce não linearmente e pode ser considerada pela seguinte expressão:

$$
\begin{aligned}
& \varphi_{\mathrm{o}, \mathrm{k}}=\varphi_{\mathrm{o}} \cdot \mathrm{e}^{\left[1,5 \cdot\left(\mathrm{k}_{\mathrm{o}}-0,4\right)\right]} \quad \text { para } 0,4<\mathrm{k}_{\mathrm{o}} \leq 0,6 \quad 2.51 \mathrm{a} \\
& \varphi_{\mathrm{o}, \mathrm{k}}=\varphi_{\mathrm{o}} \quad \text { para } \mathrm{k}_{\mathrm{o}} \leq 0,4 \\
& \text { onde: } \\
& \varphi_{\mathrm{o}, \mathrm{k}} \text { - coeficiente de fluência básico, não linear, que substitui } \varphi_{\mathrm{o}} \text { na } \\
& \mathrm{k}_{\mathrm{o}} \quad \text { - relação tensão normal / resistência }\left|\sigma_{\mathrm{c}}\right| / \mathrm{f}_{\mathrm{cm}}
\end{aligned}
$$

\subsubsection{Retração}

A deformação específica por retração ou expansão, ocorrida em um intervalo de tempo $\left(\mathrm{t}-\mathrm{t}_{\mathrm{o}}\right)$, é dada por:

$$
\varepsilon_{\mathrm{cs}}\left(\mathrm{t}, \mathrm{t}_{\mathrm{o}}\right)=\varepsilon_{\mathrm{cso}} \cdot\left[\beta_{\mathrm{s}}\left(\mathrm{t}-\mathrm{t}_{\mathrm{o}}\right)\right]
$$

onde:

$\varepsilon_{\text {cso }} \quad$ - coeficiente de retração básica, de acordo com a expressão 2.53;

$\beta_{\mathrm{s}}-$ coeficiente que representa o desenvolvimento da retração no decorrer do tempo, calculado através da equação 2.57 ; 
t $\quad$ - idade do concreto, em dias;

$\mathrm{t}_{\mathrm{o}} \quad$ - idade do concreto, em dias, no instante em que o efeito da retração ou expansão começa a ser considerado.

O coeficiente de retração básica pode ser obtido pela expressão:

$\varepsilon_{\mathrm{cso}}=\varepsilon_{\mathrm{c}}\left(\mathrm{f}_{\mathrm{cm}}\right) \cdot \beta_{\mathrm{U}}$

com:

$\varepsilon_{\mathrm{c}}\left(\mathrm{f}_{\mathrm{cm}}\right)=\left[160+10 \cdot \beta_{\mathrm{sc}} \cdot\left(9-\mathrm{f}_{\mathrm{cm}} / \mathrm{f}_{\mathrm{cmo}}\right)\right] \cdot 10^{-6}$

onde:

$\beta_{\mathrm{sc}}-$ coeficiente que depende do tipo de cimento, assumindo os seguintes valores:

4 - para cimento de endurecimento lento;

5 - para cimento de endurecimento normal ou rápido;

8 - para cimento de endurecimento rápido e de alta resistência.

E,

$\beta_{\mathrm{U}}=-1,55 . \beta_{\mathrm{sU}} \quad$ para $40 \% \leq \mathrm{U}<99 \%$

$\beta_{U}=+0,25 \quad$ para $U \geq 99 \%$

onde:

$\beta_{\mathrm{sU}}=1-\left(\frac{\mathrm{U}}{\mathrm{U}_{\mathrm{o}}}\right)^{3}$

O desenvolvimento da retração com o tempo é dado por:

$\beta_{\mathrm{s}}\left(\mathrm{t}-\mathrm{t}_{\mathrm{o}}\right)=\left[\frac{\left(\mathrm{t}-\mathrm{t}_{\mathrm{o}}\right) / \mathrm{t}_{1}}{350 .\left(\mathrm{h}_{\mathrm{fic}} / \mathrm{h}_{\mathrm{o}}\right)^{2}+\left(\mathrm{t}-\mathrm{t}_{\mathrm{o}}\right) / \mathrm{t}_{1}}\right]^{0,5}$

onde $\mathrm{h}_{\text {fic }}$ é definido na equação 2.40 .

As equações 2.58 a 2.60 descrevem o efeito da temperatura do concreto na secagem para valores diferentes de $20^{\circ} \mathrm{C}$.

O efeito da temperatura sobre o coeficiente $\beta_{\mathrm{s}}$ é considerado, substituindo-se o produto 350. $\left(\mathrm{h}_{\mathrm{fic}} / \mathrm{h}_{\mathrm{o}}\right)^{2}$ da equação 2.57 por $\alpha_{\mathrm{s}, \mathrm{T}}$, que é dado por: 


$$
\alpha_{\mathrm{s}, \mathrm{T}}=350 \cdot\left(\frac{\mathrm{h}_{\mathrm{fic}}}{\mathrm{h}_{\mathrm{o}}}\right)^{2} \cdot \mathrm{e}^{\left[-0,06 \cdot\left(\mathrm{T} / \mathrm{T}_{\mathrm{o}}-20\right)\right]}
$$

O efeito da temperatura sobre o coeficiente de retração básica é considerado, substituindo-se $\beta_{\mathrm{U}}$ da equação 2.53 por $\beta_{\mathrm{U}, \mathrm{T}}$, que é calculado pela expressão:

$\beta_{\mathrm{U}, \mathrm{T}}=\beta_{\mathrm{U}} \cdot \beta_{\mathrm{sT}}$

com:

$$
\beta_{\mathrm{sT}}=1+\left[\frac{8}{103-100 .\left(\mathrm{U} / \mathrm{U}_{\mathrm{o}}\right)}\right] \cdot\left[\frac{\left(\mathrm{T} / \mathrm{T}_{\mathrm{o}}\right)-20}{40}\right]
$$

\subsubsection{Modelo ACI-209 (1992)}

\subsubsection{Fluência}

Segundo ACI-209 (1992), o coeficiente de fluência é expresso por uma função produto:

$\varphi_{\mathrm{o}}\left(\mathrm{t}, \mathrm{t}_{\mathrm{o}}\right)=\varphi_{\infty}\left(\mathrm{t}_{\mathrm{o}}\right) \cdot \frac{\left(\mathrm{t}-\mathrm{t}_{\mathrm{o}}\right)^{0,6}}{10+\left(\mathrm{t}-\mathrm{t}_{\mathrm{o}}\right)^{0,6}}$

com:

$\varphi_{\infty}\left(\mathrm{t}_{\mathrm{o}}\right)=2,35 \cdot \gamma_{\mathrm{t}}^{\mathrm{c}} \cdot \gamma_{\mathrm{U}}^{\mathrm{c}} \cdot \gamma_{\mathrm{d}}^{\mathrm{c}} \cdot \gamma_{\mathrm{S}}^{\mathrm{c}} \cdot \gamma_{\mathrm{F}}^{\mathrm{c}} \cdot \gamma_{\mathrm{A}}^{\mathrm{c}}$

onde : $\gamma_{\mathrm{t}}^{\mathrm{c}}, \gamma_{\mathrm{U}}^{\mathrm{c}}, \gamma_{\mathrm{d}}^{\mathrm{c}}, \gamma_{\mathrm{S}}^{\mathrm{c}}, \gamma_{\mathrm{F}}^{\mathrm{c}}, \gamma_{\mathrm{A}}^{\mathrm{c}}$ são fatores de correção para o cálculo da fluência.

O coeficiente $\gamma_{\mathrm{t}}^{\mathrm{c}}$, que considera idade de carregamento diferente de sete dias para cura úmida e diferente de três dias para cura a vapor, é calculado pelas seguintes expressões:

$$
\begin{array}{lll}
\gamma_{\mathrm{t}}^{\mathrm{c}}=1,25 \cdot \mathrm{t}_{\mathrm{o}}-0,118 & \text { para concreto com cura úmida } & 2.63 \mathrm{a} \\
\gamma_{\mathrm{t}}^{\mathrm{c}}=1,13 \cdot \mathrm{t}_{\mathrm{o}}{ }^{-0,094} & \text { para concreto com cura a vapor } & 2.63 \mathrm{~b}
\end{array}
$$


O coeficiente de umidade $\gamma_{U}^{c}$ é calculado pela expressão:

$$
\gamma_{\mathrm{U}}^{\mathrm{c}}=1,27-0,0067 . \mathrm{U} \quad \text { para } \mathrm{U} \geq 40 \%
$$

Dois métodos são recomendados para a determinação do coeficiente de espessura da peça $\gamma_{\mathrm{d}}^{\mathrm{c}}$ :

a) Espessura média d

A espessura média é calculada por $\mathrm{d}=4 . \mathrm{v} / \mathrm{s}$, sendo " $\mathrm{v}$ " o volume da peça e "s" a superfície, em mm.

Se a espessura média for menor que $150 \mathrm{~mm}$, o coeficiente de espessura $\gamma_{d}^{c}$ é fornecido pela tabela 2.1 .

TABELA 2.1 - Coeficiente de espessura média

\begin{tabular}{|c|c|c|c|c|c|}
\hline $\begin{array}{c}\text { Espessura média } \\
(\mathbf{m m})\end{array}$ & 50 & 75 & 100 & 125 & 150 \\
\hline$\gamma_{\mathbf{d}}^{\mathbf{c}}$ & 1,30 & 1,17 & 1,11 & 1,04 & 1,00 \\
\hline
\end{tabular}

Se a espessura média ficar entre 150 e $380 \mathrm{~mm}$, usam-se as expressões:

$\gamma_{\mathrm{d}}^{\mathrm{c}}=1,14-0,00092 . \mathrm{d} \quad$ para $\mathrm{t}-\mathrm{t}_{\mathrm{o}} \leq 1$ ano

$\gamma_{\mathrm{d}}^{\mathrm{c}}=1,10-0,00067 . \mathrm{d} \quad$ para $\mathrm{t}-\mathrm{t}_{\mathrm{o}}>1$ ano

b) Relação volume / superfície (quando d > $380 \mathrm{~mm}$ )

$\gamma_{\mathrm{d}}^{\mathrm{c}}=2 / 3 \cdot\left[1+1,13 . \mathrm{e}^{(-0,0213 . \mathrm{v} / \mathrm{s})} \mid\right.$

sendo $\mathrm{v} / \mathrm{s}$ em mm.

Os coeficientes que dependem da composição do concreto são:

- coeficiente que considera a consistência da mistura $\left(\gamma_{S}^{\mathrm{c}}\right)$ :

$\gamma_{\mathrm{S}}^{\mathrm{c}}=0,82+0,00264 . \mathrm{S}$

sendo S o valor do SLUMP do concreto fresco em $\mathrm{mm}$. 
- coeficiente que considera a influência do agregado miúdo $\left(\gamma_{\mathrm{F}}^{\mathrm{c}}\right)$ :

$\gamma_{\mathrm{F}}^{\mathrm{c}}=0,88+0,0024 . \mathrm{F}$

sendo $\mathrm{F}$ a relação em massa de agregado miúdo / agregado total, em \%.

- coeficiente que considera o conteúdo de ar incorporado no volume $\operatorname{concreto}\left(\gamma_{\mathrm{A}}^{\mathrm{c}}\right)$ :

$\gamma_{\mathrm{A}}^{\mathrm{c}}=0,46+0,09 . \mathrm{A} \geq 1$

sendo A o índice de vazios, em \%, no volume de concreto.

\subsubsection{Retração}

A deformação específica do concreto, por retração, depende do tipo de cura e é calculada através da expressão:

- para cura úmida:

$\varepsilon_{\mathrm{cs}}\left(\mathrm{t}, \mathrm{t}_{\mathrm{o}}\right)=\frac{\mathrm{t}-\mathrm{t}_{\mathrm{o}}}{35+\left(\mathrm{t}-\mathrm{t}_{\mathrm{o}}\right)} \cdot \varepsilon_{\mathrm{cs} \infty}$

- para cura a vapor:

$\varepsilon_{\mathrm{cs}}\left(\mathrm{t}, \mathrm{t}_{\mathrm{o}}\right)=\frac{\mathrm{t}-\mathrm{t}_{\mathrm{o}}}{55+\left(\mathrm{t}-\mathrm{t}_{\mathrm{o}}\right)} \cdot \varepsilon_{\mathrm{cs} \infty}$

com:

$\varepsilon_{\mathrm{cs} \infty}=780.10^{-6} \cdot \gamma_{\mathrm{t}}^{\mathrm{s}} \cdot \gamma_{\mathrm{U}}^{\mathrm{s}} \cdot \gamma_{\mathrm{d}}^{\mathrm{s}} \cdot \gamma_{\mathrm{S}}^{\mathrm{s}} \cdot \gamma_{\mathrm{B}}^{\mathrm{s}} \cdot \gamma_{\mathrm{F}}^{\mathrm{s}} \cdot \gamma_{\mathrm{A}}^{\mathrm{s}}$

onde : $\gamma_{\mathrm{t}}^{\mathrm{s}}, \gamma_{\mathrm{U}}^{\mathrm{s}}, \gamma_{\mathrm{d}}^{\mathrm{s}}, \gamma_{\mathrm{S}}^{\mathrm{s}}, \gamma_{\mathrm{B}}^{\mathrm{s}}, \gamma_{\mathrm{F}}^{\mathrm{s}}, \gamma_{\mathrm{A}}^{\mathrm{s}}$ são fatores de correção para o cálculo da retração.

$\mathrm{O}$ coeficiente $\gamma_{\mathrm{t}}^{\mathrm{s}}$, que considera o período de cura úmida diferente de sete dias, é fornecido na tabela 2.2. 
TABELA 2.2 - Coeficiente de idade para a retração

\begin{tabular}{|c|c|c|c|c|c|c|}
\hline $\begin{array}{c}\text { Período de cura } \\
\text { úmida (dias) }\end{array}$ & 1 & 3 & 7 & 14 & 28 & 90 \\
\hline$\gamma_{\mathbf{t}}^{\mathbf{s}}$ & 1,2 & 1,1 & 1,0 & 0,93 & 0,86 & 0,75 \\
\hline
\end{tabular}

O coeficiente de umidade $\gamma_{\mathrm{U}}^{\mathrm{s}}$ é calculado pelas expressões:

$$
\begin{array}{lc}
\gamma_{U}^{\mathrm{s}}=1,40-0,010 . \mathrm{U} & \text { para } 40 \% \leq \mathrm{U} \leq 80 \% \\
\gamma_{\mathrm{U}}^{\mathrm{s}}=3,00-0,030 . \mathrm{U} & \text { para } 80 \%<\mathrm{U} \leq 100 \%
\end{array}
$$

Dois métodos são recomendados para estimar o coeficiente de espessura da peça $\gamma_{\mathrm{d}}^{\mathrm{s}}$ :

a) Espessura média $d$

Se a espessura média for menor que $150 \mathrm{~mm}$, o coeficiente de espessura $\gamma_{\mathrm{d}}^{\mathrm{s}}$ é fornecido pela tabela 2.3.

TABELA 2.3 - Coeficiente de espessura média

\begin{tabular}{|c|c|c|c|c|c|}
\hline $\begin{array}{c}\text { Espessura média } \\
(\mathbf{m m})\end{array}$ & 50 & 75 & 100 & 125 & 150 \\
\hline$\gamma_{\mathbf{d}}^{\mathbf{S}}$ & 1,35 & 1,25 & 1,17 & 1,08 & 1,00 \\
\hline
\end{tabular}

Se a espessura média ficar entre 150 e $380 \mathrm{~mm}$, usam-se as expressões:

$\gamma_{d}^{\mathrm{s}}=1,23-0,0015 . \mathrm{d} \quad$ para $\mathrm{t}-\mathrm{t}_{\mathrm{o}} \leq 1$ ano

$\gamma_{\mathrm{d}}^{\mathrm{s}}=1,17-0,00114 . \mathrm{d} \quad$ para $\mathrm{t}-\mathrm{t}_{\mathrm{o}}>1$ ano

b) Relação volume / superfície (quando d > $380 \mathrm{~mm}$ )

$\gamma_{\mathrm{d}}^{\mathrm{s}}=1,2 . \mathrm{e}^{(-0,00472 . \mathrm{v} / \mathrm{s})}$

sendo $\mathrm{v} / \mathrm{s}$ em mm. 
Os coeficientes que dependem da composição do concreto são: $\gamma_{\mathrm{S}}^{\mathrm{S}}, \gamma_{\mathrm{B}}^{\mathrm{S}}$, $\gamma_{\mathrm{F}}^{\mathrm{s}}$ e $\gamma_{\mathrm{A}}^{\mathrm{s}}$

$\gamma_{S}^{\mathrm{s}}=0,89+0,00161 . S$

$\gamma_{\mathrm{B}}^{\mathrm{s}}=0,75+0,00061 . \mathrm{B}$

$\gamma_{\mathrm{F}}^{\mathrm{s}}=0,30+0,014 . \mathrm{F} \quad$ para $\mathrm{F} \leq 50$

$\gamma_{\mathrm{F}}^{\mathrm{s}}=0,90+0,002 . \mathrm{F} \quad$ para $\mathrm{F}>50$

$\gamma_{\mathrm{A}}^{\mathrm{s}}=0,95+0,008 . \mathrm{A}$

onde:

$\mathrm{S}$ - valor do SLUMP do concreto fresco, em mm;

B - massa de cimento no volume de concreto $\left(\mathrm{kg} / \mathrm{m}^{3}\right)$;

F - relação em massa de agregado miúdo / agregado total, em \%;

A - índice de vazios, em \%, no volume de concreto.

\subsubsection{Modelo NBR 6118 (2003)}

\subsubsection{Fluência}

Segundo NBR 6118 (2003), o coeficiente de fluência $\varphi\left(t, t_{0}\right)$, válido também para a tração, é dado por:

$\varphi\left(\mathrm{t}, \mathrm{t}_{\mathrm{o}}\right)=\varphi_{\mathrm{a}}+\varphi_{\mathrm{f} \infty} \cdot\left[\beta_{\mathrm{f}}(\mathrm{t})-\beta_{\mathrm{f}}\left(\mathrm{t}_{\mathrm{o}}\right)\right]+\varphi_{\mathrm{d} \infty} \cdot \beta_{\mathrm{d}}$

onde:

$\mathrm{t} \quad$ - idade fictícia do concreto no instante considerado, em dias;

$\mathrm{t}_{\mathrm{o}} \quad$ - idade fictícia do concreto ao ser feito o carregamento, em dias;

$\varphi_{\mathrm{a}} \quad$ - coeficiente de deformação rápida;

$\varphi_{\mathrm{f} \infty} \quad$ - valor final do coeficiente de deformação lenta irreversível;

$\varphi_{\mathrm{d} \infty} \quad$ - valor final do coeficiente de deformação lenta reversível, que é considerado igual a 0,4 ;

$\beta_{\mathrm{f}} \quad-$ coeficiente relativo à deformação lenta irreversível, função da idade do concreto (ver figura 2.9);

$\beta_{\mathrm{d}} \quad-$ coeficiente relativo à deformação lenta reversível, função do tempo $\left(\mathrm{t}-\mathrm{t}_{\mathrm{o}}\right)$ decorrido após o carregamento. 
A idade fictícia, em dias, quando o endurecimento se faz à temperatura ambiente de $20^{\circ} \mathrm{C}$ e, nos demais casos, quando não houver cura a vapor, a idade a considerar é a idade fictícia dada por:

$$
\mathrm{t}=\alpha \cdot \sum_{\mathrm{i}} \frac{\mathrm{T}_{\mathrm{i}}+10}{30} \cdot \Delta \mathrm{t}_{\mathrm{ef}, \mathrm{i}}
$$

onde:

$\alpha \quad-$ coeficiente dependente da velocidade de endurecimento do cimento; na falta de dados experimentais permite-se o emprego dos valores constantes da tabela 2.4;

$\mathrm{T}_{\mathrm{i}} \quad$ - temperatura média diária do ambiente, em graus Celsius;

$\Delta \mathrm{T}_{\mathrm{ef}, \mathrm{i}}$ - período, em dias, durante o qual a temperatura média diária do ambiente, $\mathrm{T}_{\mathrm{i}}$, pode ser admitida constante.

TABELA 2.4 - Valores da fluência e da retração em função da velocidade

de endurecimento do cimento

\begin{tabular}{|l|c|c|}
\hline \multicolumn{1}{|c|}{ Cimento Portland (CP) } & \multicolumn{2}{|c|}{$\alpha$} \\
\cline { 2 - 3 } & Fluência & Retração \\
\hline De endurecimento lento (CP III e CP IV, todas as classes de resistência) & 1 & \\
\hline De endurecimento normal (CP I e CP II, todas as classes de resistência) & 2 \\
\hline De endurecimento rápido (CP V - ARI) & 3 \\
\hline onde: & \\
CP I e CP I-S - cimento Portland comum; & \\
CP II-E, CP II-F e CP II-Z - cimento Portland composto; & \\
CP III - cimento Portland de alto forno; \\
CP IV - cimento Portland pozolânico; \\
CP V - ARI - cimento Portland de alta resistência inicial; \\
RS - cimento Portland resistente a sulfatos (propriedade específica de alguns dos tipos de cimento citados). \\
\hline
\end{tabular}

O coeficiente de deformação rápida é calculado pela expressão:

$\varphi_{\mathrm{a}}=0,8 .\left[1-\frac{\mathrm{f}_{\mathrm{c}}\left(\mathrm{t}_{\mathrm{o}}\right)}{\mathrm{f}_{\mathrm{c}}\left(\mathrm{t}_{\infty}\right)}\right]$

onde $\mathrm{f}_{\mathrm{c}}\left(\mathrm{t}_{\mathrm{o}}\right) / \mathrm{f}_{\mathrm{c}}\left(\mathrm{t}_{\infty}\right)$ é a função do crescimento da resistência do concreto com a idade.

O coeficiente $\beta_{\mathrm{d}}$ relativo à deformação lenta reversível é expresso por:

$\beta_{d}=\frac{t-t_{o}+20}{t-t_{o}+70}$ 
O valor final do coeficiente de deformação lenta irreversível é dado por:

$\varphi_{\mathrm{foo}}=\varphi_{1 \mathrm{c}} \cdot \varphi_{2 \mathrm{c}}$

onde:

$\varphi_{1 \mathrm{c}} \quad$ - coeficiente dependente da umidade relativa do ambiente $\mathrm{U}$, em $\%$, e da consistência do concreto dada pela tabela 2.5 ;

$\varphi_{2 c}-$ coeficiente dependente da espessura fictícia $h_{\text {fic }}$ da peça.

O coeficiente $\varphi_{2 c}$ relativo à deformação lenta irreversível é dado por:

$\varphi_{2 \mathrm{c}}=\frac{42+\mathrm{h}_{\mathrm{fic}}}{20+\mathrm{h}_{\mathrm{fic}}}$

onde $\mathrm{h}_{\text {fic }}$ é a espessura fictícia da peça, em centímetros.

Define-se como espessura fictícia o seguinte valor:

$\mathrm{h}_{\text {fic }}=\gamma \cdot \frac{2 \cdot \mathrm{A}_{\mathrm{c}}}{\mathrm{u}_{\mathrm{ar}}}$

onde:

$\gamma \quad$ - coeficiente dependente da umidade relativa do ambiente (ver tabela 2.5);

$\mathrm{A}_{\mathrm{c}} \quad$ - área da seção transversal da peça;

$\mathrm{u}_{\mathrm{ar}}$ - parte do perímetro externo da seção transversal da peça em contato com o ar.

TABELA 2.5 - Valores numéricos usuais para a determinação da fluência e da retração

\begin{tabular}{|c|c|c|c|c|c|c|c|c|}
\hline \multirow{3}{*}{ Ambiente } & \multirow{3}{*}{$\begin{array}{l}\mathrm{U} \\
\%\end{array}$} & \multicolumn{3}{|c|}{$\begin{array}{l}\text { Fluência } \\
\varphi_{1 \mathrm{c}}\end{array}$} & \multicolumn{3}{|c|}{$\begin{array}{l}\text { Retração } \\
10^{4} \cdot \varepsilon_{1 \mathrm{~s}}\end{array}$} & \multirow{3}{*}{$\gamma$} \\
\hline & & \multicolumn{6}{|c|}{$\begin{array}{l}\text { Abatimento de acordo com a NBR NM } 67 \\
\mathrm{~cm}\end{array}$} & \\
\hline & & $0-4$ & $5-9$ & $10-15$ & $0-4$ & $5-9$ & $10-15$ & \\
\hline $\mathrm{Na}$ água & - & 0,6 & 0,8 & 1,0 & $+1,0$ & $+1,0$ & $+1,0$ & 30,0 \\
\hline $\begin{array}{l}\text { Em ambiente muito úmido } \\
\text { imediatamente acima da } \\
\text { água }\end{array}$ & 90 & 1,0 & 1,3 & 1,6 & $-1,0$ & $-1,3$ & $-1,6$ & 5,0 \\
\hline Ao ar livre, em geral & 70 & 1,5 & 2,0 & 2,5 & $-2,5$ & $-3,2$ & $-4,0$ & 1,5 \\
\hline Em ambiente seco & 40 & 2,3 & 3,0 & 3,8 & $-4,0$ & $-5,2$ & $-6,5$ & 1,0 \\
\hline
\end{tabular}


$\mathrm{O}$ coeficiente $\beta_{\mathrm{f}}$ relativo à deformação lenta irreversível pode ser calculado através da seguinte expressão:

$$
\beta_{\mathrm{f}}=\frac{\mathrm{t}^{2}+\mathrm{A} \cdot \mathrm{t}+\mathrm{B}}{\mathrm{t}^{2}+\mathrm{C} \cdot \mathrm{t}+\mathrm{D}}
$$

onde:

$$
\begin{aligned}
& \mathrm{A}=42 \cdot \mathrm{h}^{3}-350 \cdot \mathrm{h}^{2}+588 \cdot \mathrm{h}+113 ; \\
& \mathrm{B}=768 \cdot \mathrm{h}^{3}-3060 \cdot \mathrm{h}^{2}+3234 \cdot \mathrm{h}-23 ; \\
& \mathrm{C}=-200 \cdot \mathrm{h}^{3}+13 \cdot \mathrm{h}^{2}+10990 \cdot \mathrm{h}+183 ; \\
& \mathrm{D}=7579 \cdot \mathrm{h}^{3}-31916 \cdot \mathrm{h}^{2}+35343 \cdot \mathrm{h}+1931
\end{aligned}
$$

$\mathrm{h}$ - espessura fictícia, em metros; para valores de $\mathrm{h}$ fora do intervalo $(0,05 \leq \mathrm{h} \leq 1,6)$, adotam-se os extremos correspondentes;

$\mathrm{t} \quad$ - tempo, em dias $(\mathrm{t} \geq 3)$.

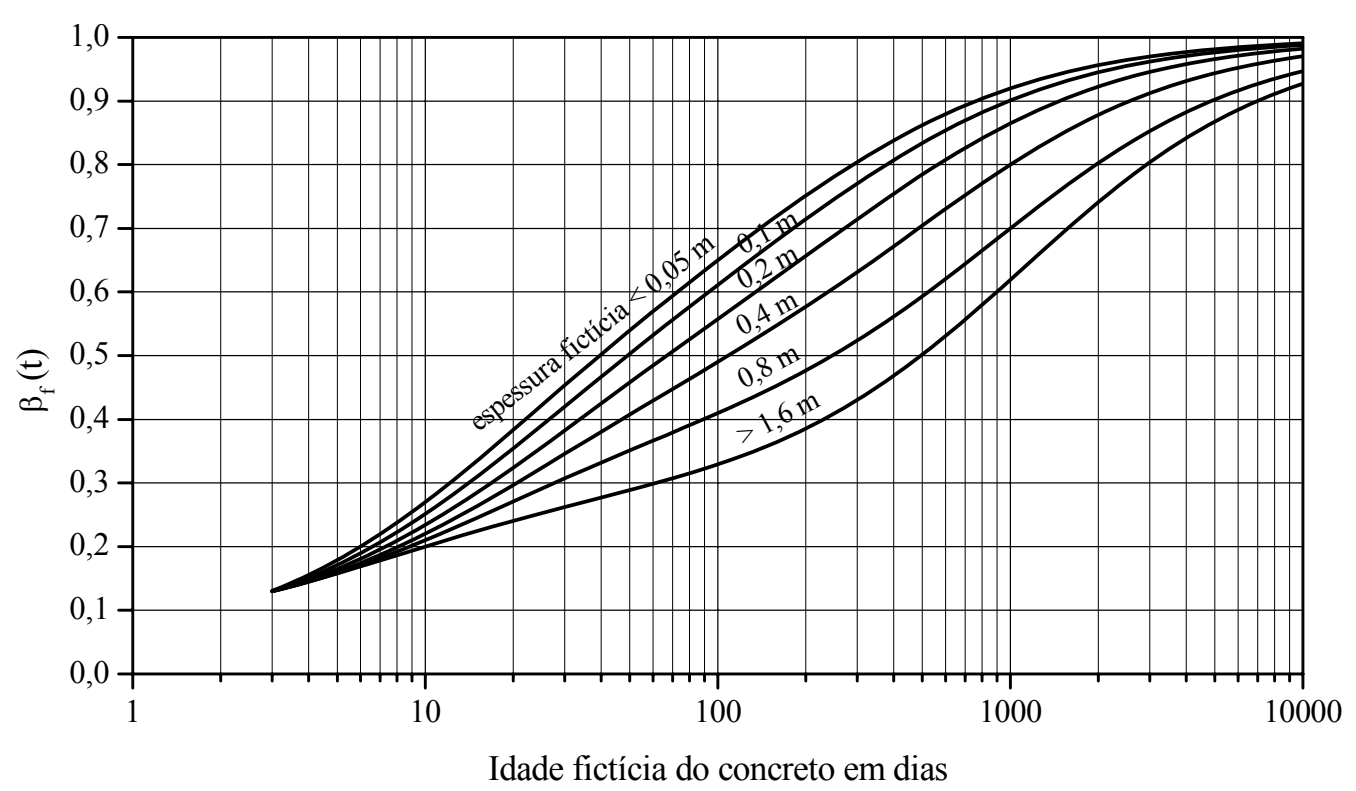

FIGURA 2.9 - Variação de $\beta_{\mathrm{f}}(\mathrm{t})$ 


\subsubsection{Retração}

A deformação por retração, entre os instantes $t_{0}$ e $t$, é dada por:

$\varepsilon_{\mathrm{cs}}\left(\mathrm{t}, \mathrm{t}_{\mathrm{o}}\right)=\varepsilon_{\mathrm{cs} \infty} \cdot\left[\beta_{\mathrm{s}}(\mathrm{t}) \cdot \beta_{\mathrm{s}}\left(\mathrm{t}_{\mathrm{o}}\right)\right]$

onde:

$\mathrm{t}$ - idade fictícia do concreto no instante considerado, em dias;

$\mathrm{t}_{\mathrm{o}} \quad-$ idade fictícia do concreto no instante em que o efeito da retração na peça começa a ser considerado, em dias;

$\varepsilon_{\mathrm{cs} \infty} \quad-$ valor final da retração;

$\beta_{\mathrm{s}}(\mathrm{t})$ - coeficiente relativo à retração, no instante $\mathrm{t}$ ou $\mathrm{t}_{\mathrm{o}}$ (ver $\beta_{\mathrm{S}}\left(\mathrm{t}_{\mathrm{o}}\right) \quad$ figura 2.10).

O valor final da retração é dado por:

$\varepsilon_{\mathrm{cs} \infty}=\varepsilon_{1 \mathrm{~s}} \cdot \varepsilon_{2 \mathrm{~s}}$

onde:

$\varepsilon_{1 \mathrm{~s}} \quad$ - coeficiente dependente da umidade relativa do ambiente e da consistência do concreto (ver tabela 2.5);

$\varepsilon_{2 s} \quad$ - coeficiente dependente da espessura fictícia da peça.

O coeficiente $\varepsilon_{2 s}$ relativo à retração é dado por:

$\varepsilon_{2 \mathrm{~s}}=\frac{33+2 \cdot \mathrm{h}_{\mathrm{fic}}}{20,8+3 \cdot \mathrm{h}_{\mathrm{fic}}}$

O coeficiente $\beta_{\mathrm{s}}$ relativo à retração é dado por:

$\beta_{\mathrm{s}}=\frac{\left(\frac{\mathrm{t}}{100}\right)^{3}+\mathrm{A} \cdot\left(\frac{\mathrm{t}}{100}\right)^{2}+\mathrm{B} \cdot\left(\frac{\mathrm{t}}{100}\right)}{\left(\frac{\mathrm{t}}{100}\right)^{3}+\mathrm{C} \cdot\left(\frac{\mathrm{t}}{100}\right)^{2}+\mathrm{D} \cdot\left(\frac{\mathrm{t}}{100}\right)+\mathrm{E}}$

onde:

$\mathrm{A}=40$;

$B=116 \cdot h^{3}-282 \cdot h^{2}+220 \cdot h-4,8 ;$

$C=2,5 \cdot h^{3}-8,8 \cdot h+40,7$;

$\mathrm{D}=-75 \cdot \mathrm{h}^{3}+585 \cdot \mathrm{h}^{2}+496 \cdot \mathrm{h}-6,8$ 
$E=-1639 \cdot h^{4}+88 \cdot h^{3}+584 \cdot h^{2}-39 \cdot h+0,8$

$\mathrm{h}$ - espessura fictícia, em metros; para valores de $\mathrm{h}$ fora do intervalo $(0,05 \leq \mathrm{h} \leq 1,6)$, adotam-se os extremos correspondentes;

$\mathrm{t} \quad$ - tempo, em dias $(\mathrm{t} \geq 3)$.

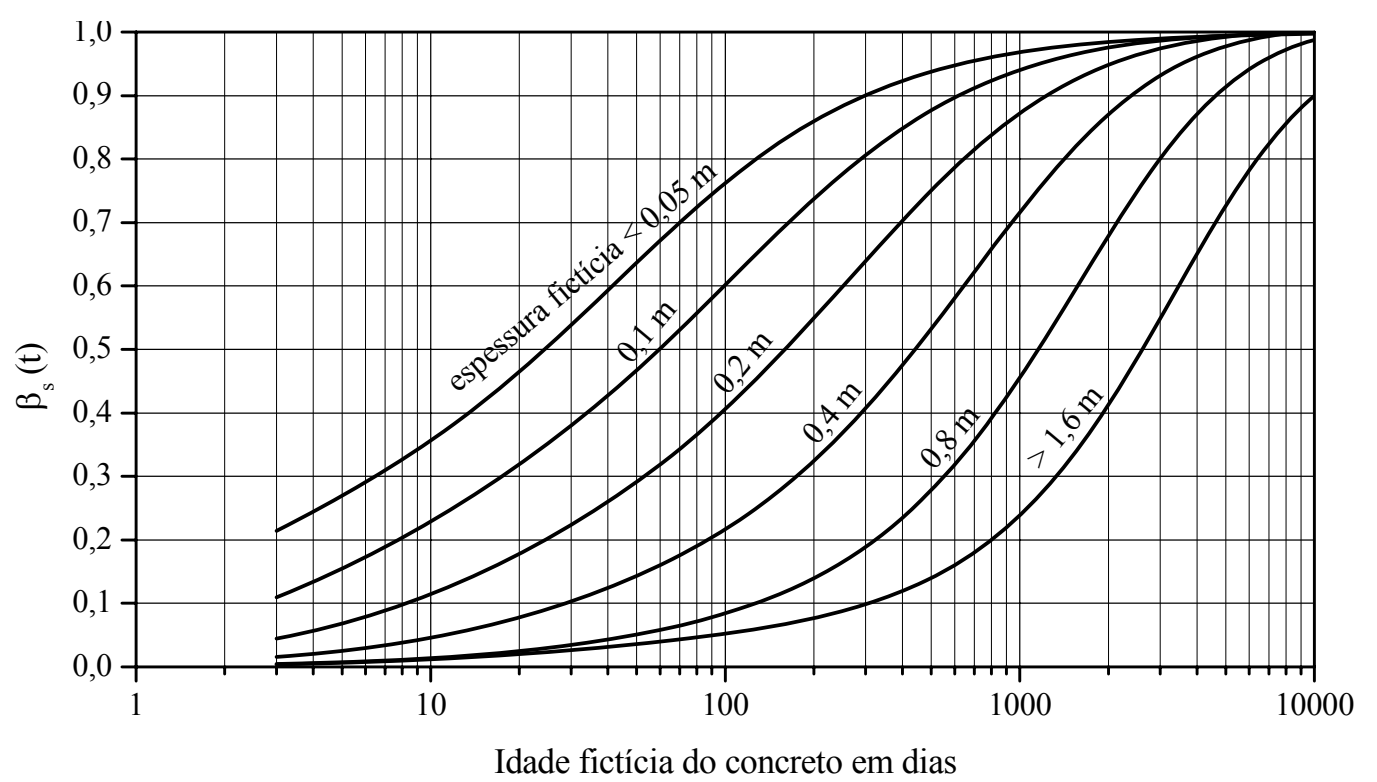

FIGURA 2.10 - Variação de $\beta_{\mathrm{s}}(\mathrm{t})$

\subsubsection{Comparação entre os modelos}

Vale ressaltar que os modelos para a previsão da fluência e retração do concreto são baseados no ajuste de dados experimentais, sendo, portanto, pelo menos em parte empíricos. No entanto, por mais complexa que seja a formulação matemática empregada, o modelo desenvolvido apresentará certas incertezas e condições restritas de uso, e conseqüentemente, se um modelo tiver excelente concordância com determinados dados de ensaio, não significa que este modelo vai satisfazer todos os eventuais ensaios realizados no futuro [NEVILLE et al. (1983)]. Portanto, qualquer modelo desenvolvido tem que ter precisão suficiente, contudo, é necessário considerar na análise estrutural as incertezas envolvidas neste modelo, para se obter estruturas de concreto mais racionais [TSUBAKI (1993)].

A seguir, comparações entre os modelos de fluência são apresentadas nas figuras $2.11,2.12$ e 2.13, averiguando, respectivamente, a influência da idade de 
aplicação da carga, umidade relativa e dimensões da peça no coeficiente de fluência último $\varphi\left(\infty, t_{\mathrm{o}}\right)$. Pelas figuras, pode-se observar que houve diferenças significativas entre os modelos, principalmente, para concretos carregados a pequenas idades, ambientes secos e elementos com seção transversal reduzida, ficando os modelos do CEB-90 (1991) e da NBR 6118 (2003) mais próximos entre si.

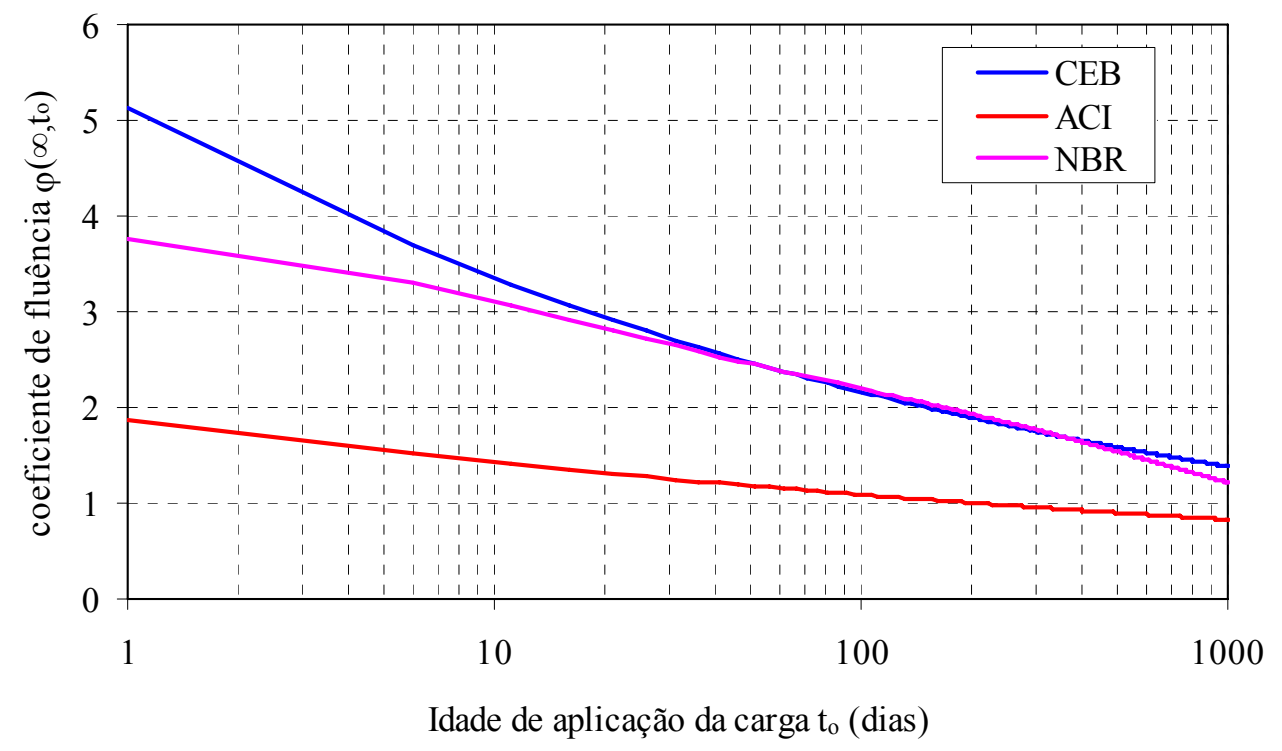

FIGURA 2.11 - Influência da idade de aplicação da carga no coeficiente de fluência último; $\mathrm{U}=60 \%$ e $\mathrm{A}_{\mathrm{c}} / \mathrm{u}_{\mathrm{ar}}=250 \mathrm{~mm}$

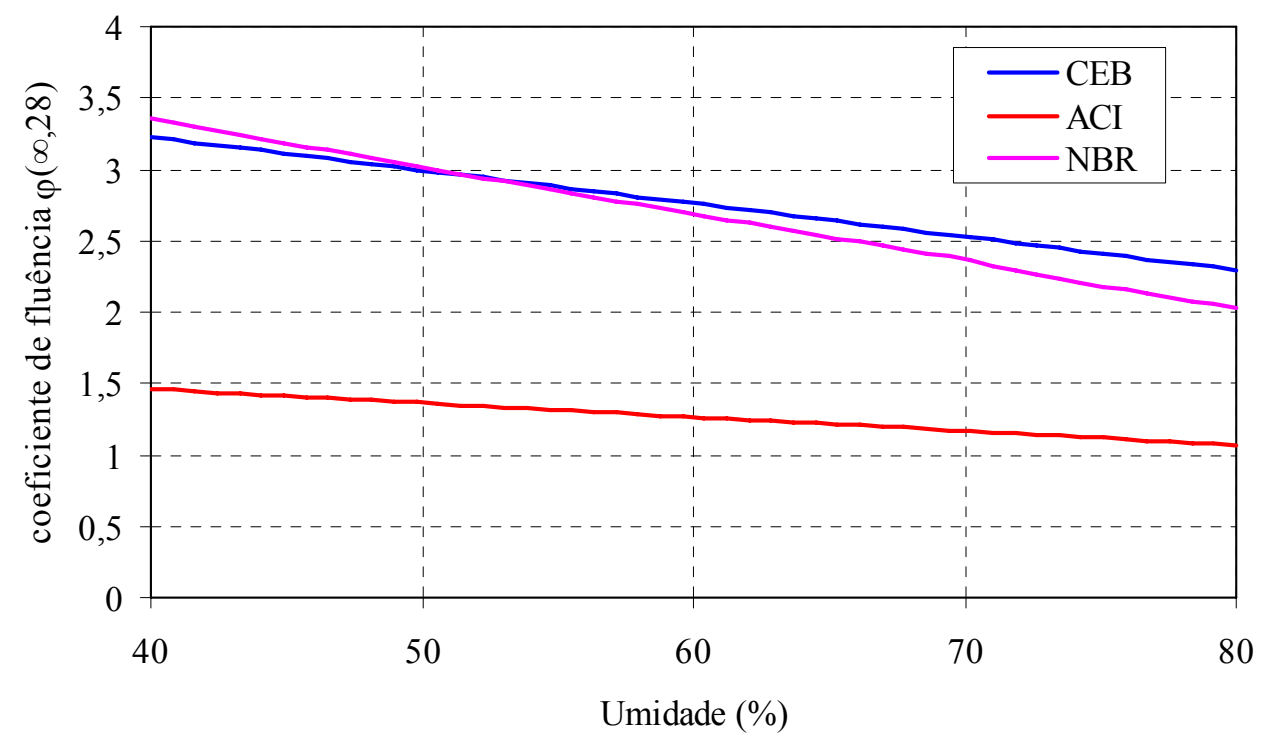

FIGURA 2.12 - Influência da umidade relativa no coeficiente de fluência último; $A_{c} / u_{a r}=250 \mathrm{~mm}$ 


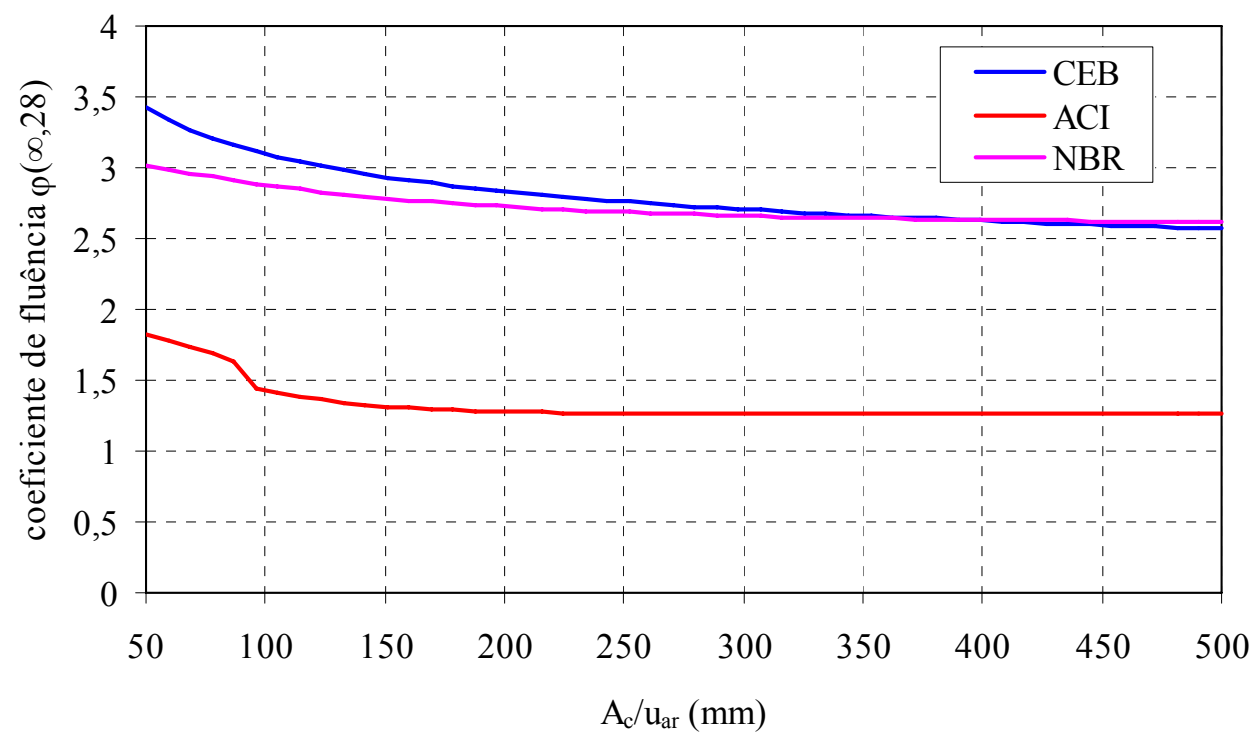

FIGURA 2.13 - Influência das dimensões da peça no coeficiente de fluência último; $\mathrm{U}=60 \%$

Para fins de exemplificação dos três modelos de fluência, é feita a comparação dos modelos com resultados de ensaios. Foi utilizado na comparação, conforme figuras 2.14 e 2.15, resultado de ensaios realizados por HASPARYK et al. (2005) no Laboratório de Concreto de Furnas Centrais Elétricas S.A., baseados em um concreto convencional, com $496 \mathrm{~kg} / \mathrm{m}^{3}$ de cimento, agregado do tipo litológico quartzo-micaxisto e relação a/c igual a 0,43 .

Para os exemplos em questão, os modelos de fluência do ACI-209 (1992) e da NBR 6118 (2003) superestimaram os resultados do ensaio para as duas idades de carregamento avaliadas. O modelo do CEB-90 (1991) apresentou comportamento subestimado para a idade de carregamento de sete dias, tendendo a aproximar-se dos resultados de ensaio para idades mais avançadas. Já para a idade de 28 dias, o modelo do CEB-90 (1991) superestima o resultado da fluência como os outros, porém mais próximo dos valores de ensaio.

Como foi visto, houve discrepâncias entre os modelos para a previsão da fluência contidos nas normas. Mas vale alertar que cada norma tem seus procedimentos e considerações e isso pode conduzir a resultados mais concordantes quando se determina as deformações da estrutura como um todo e não apenas do coeficiente de fluência isoladamente. 


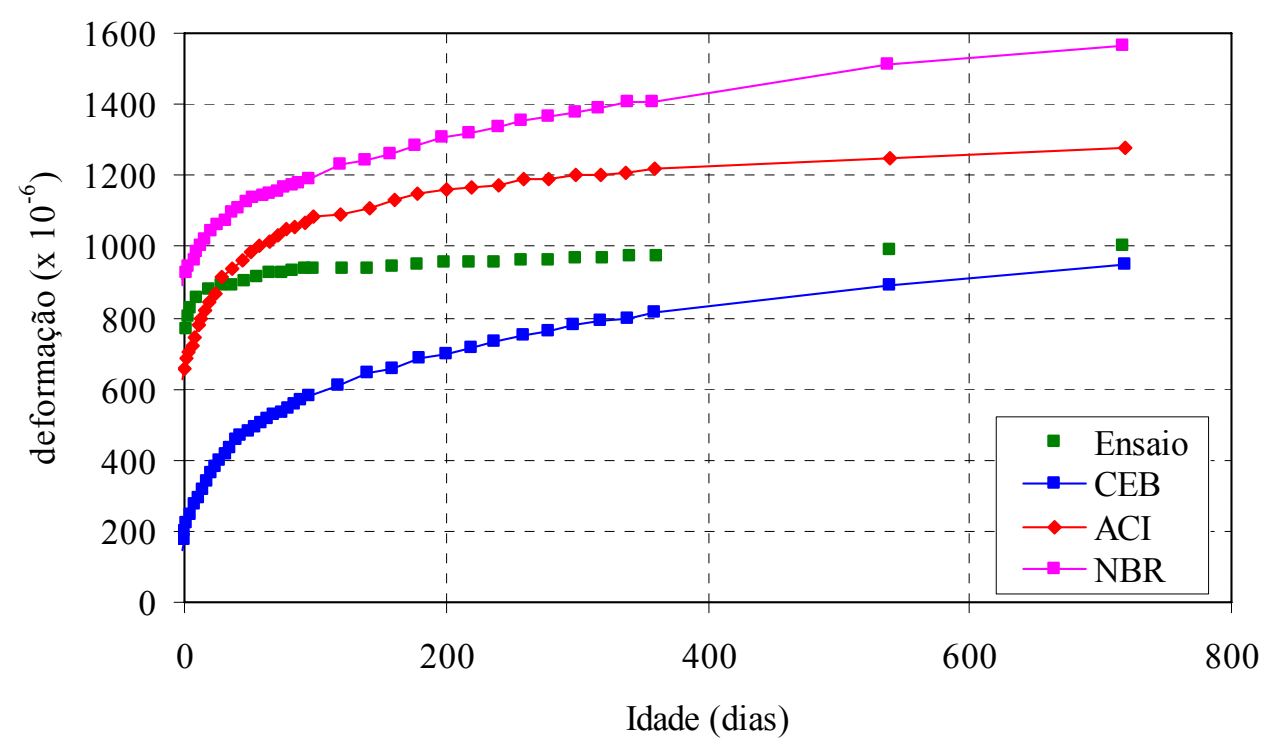

FIGURA 2.14 - Comparação dos modelos de fluência com resultados de ensaios para a idade de carregamento de sete dias [HASPARYK et al. (2005)]

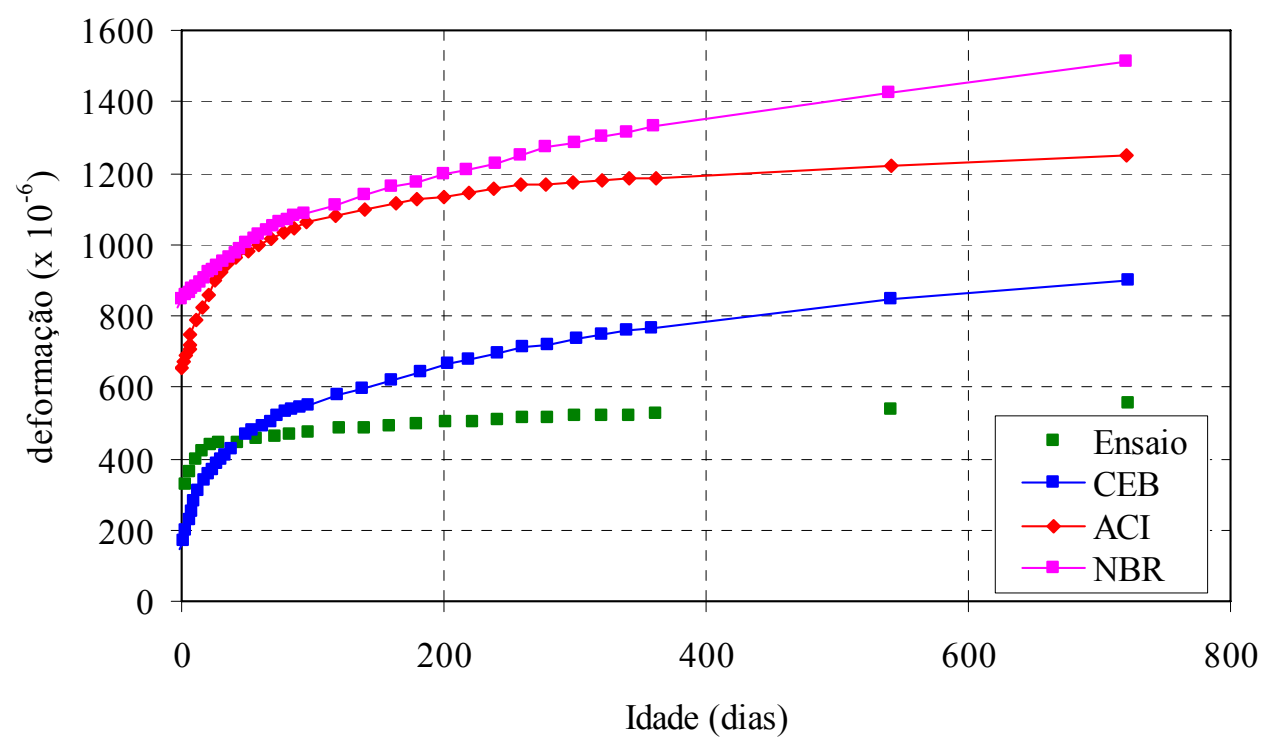

FIGURA 2.15 - Comparação dos modelos de fluência com resultados de ensaios para a idade de carregamento de 28 dias [HASPARYK et al. (2005)]

Apresentam-se nas figuras 2.16 e 2.17 comparações entre os modelos de retração, avaliando, respectivamente, a influência da umidade relativa e dimensões da peça no valor da deformação por retração última, com a consideração do início do efeito da retração aos três dias $\varepsilon(\infty, 3)$. Assim como para a fluência, houve diferenças 
significativas entre os modelos de retração, principalmente, para ambientes secos e elementos com seção transversal elevada.

Os valores da retração última no modelo do CEB-90 (1991) são praticamente constantes com a variação de $\mathrm{A}_{\mathrm{c}} / \mathrm{u}_{\mathrm{ar}}$, conforme mostra a figura 2.17, porque tal valor entra na equação de desenvolvimento da retração com o tempo, $\beta_{\mathrm{s}}\left(\mathrm{t}-\mathrm{t}_{\mathrm{o}}\right)$, e quando $\mathrm{t} \rightarrow \infty, \beta_{\mathrm{s}} \rightarrow 1$ qualquer que seja o valor de $\mathrm{A}_{\mathrm{c}} / \mathrm{u}_{\mathrm{ar}}$.

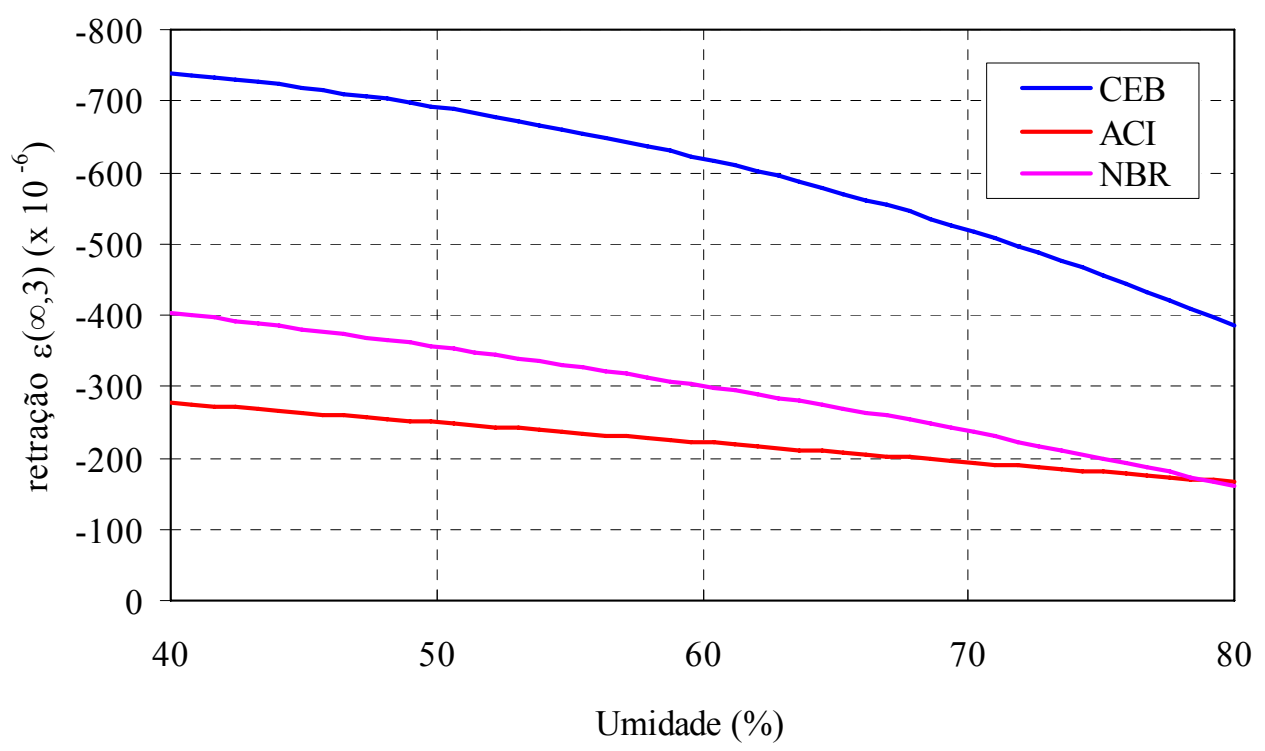

FIGURA 2.16 - Influência da umidade relativa na deformação por retração última; $\mathrm{A}_{\mathrm{c}} / \mathrm{u}_{\mathrm{ar}}=250 \mathrm{~mm}$

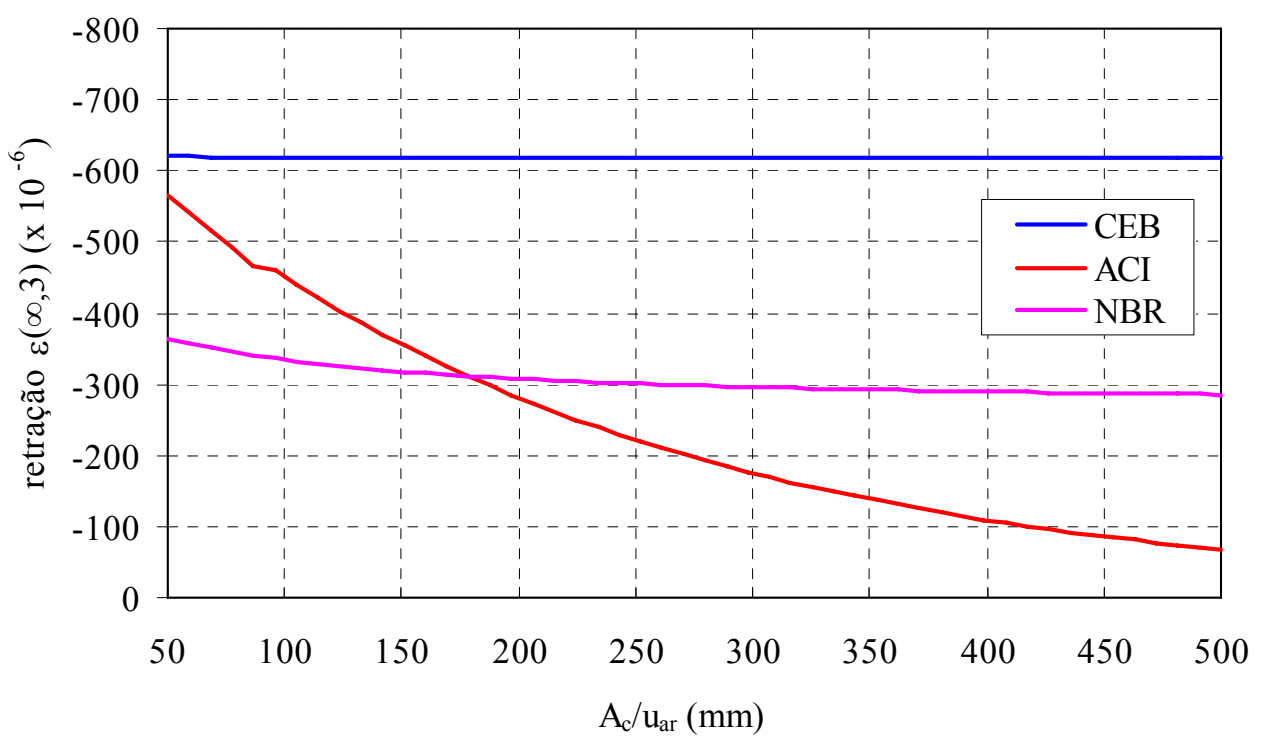

FIGURA 2.17 - Influência das dimensões da peça na deformação por retração última; $U=60 \%$ 
Na figura 2.18, apresenta-se a evolução da retração com o tempo para os três modelos de retração. Pela figura, nota-se que os modelos do CEB-90 (1991) e da NBR 6118 (2003) ficaram mais próximos entre si, no entanto, a partir de 2000 dias a diferença entre os modelos começa a crescer. Próximo de 10000 dias, os valores da retração para os modelos do ACI-209 (1992) e da NBR 6118 (2003) começam a se manter constantes, enquanto o modelo do CEB-90 (1990) continua aumentando.

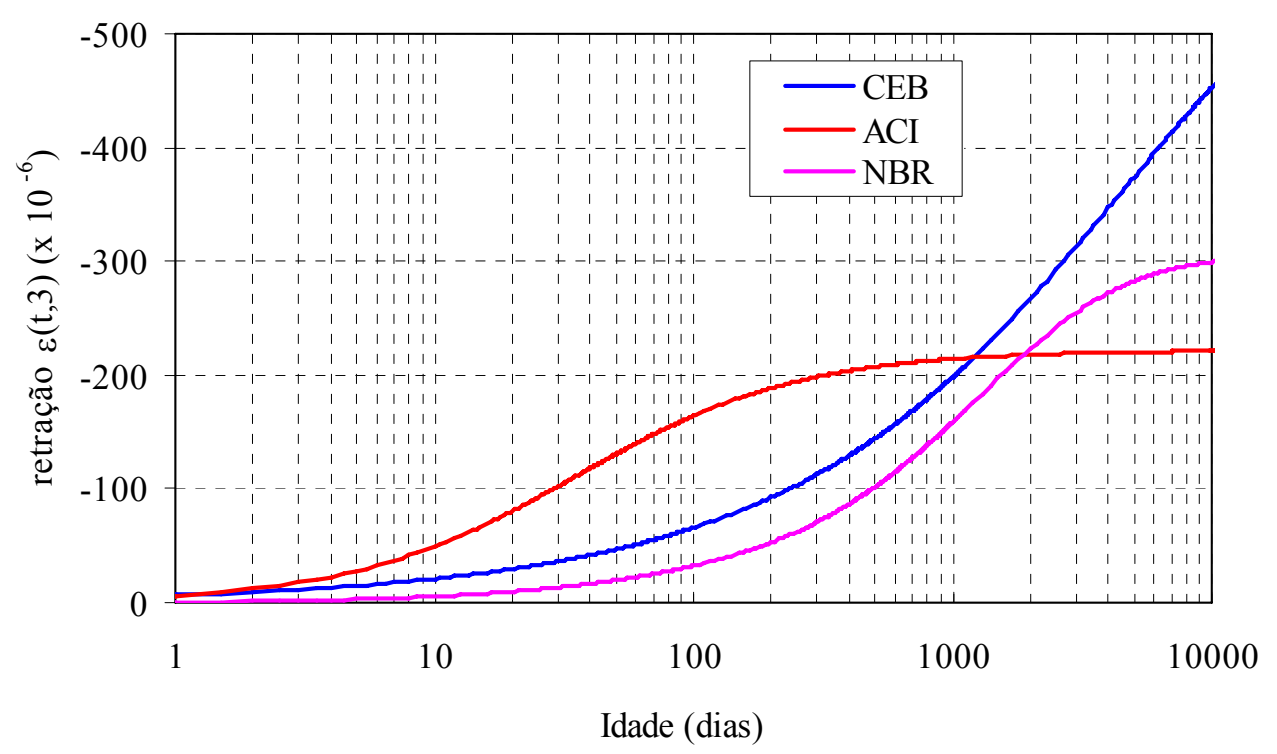

FIGURA 2.18 - Evolução da deformação por retração com o tempo; $\mathrm{U}=60 \%$ e $\mathrm{A}_{\mathrm{c}} / \mathrm{u}_{\mathrm{ar}}=250 \mathrm{~mm}$

\subsection{Métodos de análise da fluência}

Para se estimar a deformação em um dado tempo em peças de concreto em que a carga não é mantida constante é necessário empregar métodos de análise que considerem todo o histórico de tensões. A característica comum em todos os métodos de análise da fluência é que todos são baseados na hipótese de que a fluência varia linearmente com a tensão e, conseqüentemente, obedecem ao princípio da superposição dos efeitos. Pelo princípio da superposição, postulado por McHENRY ${ }^{1}$ apud MEHTA \& MONTEIRO (1994), admite-se que as deformações

\footnotetext{
${ }^{1}$ McHENRY, D. (1943). A new aspect of creep in concrete and its application to design. Proc. ASTM., v.43, p.1069-86. apud MEHTA, P.K.; MONTEIRO, P.J.M. (1994). Concreto: estrutura, propriedades e materiais. São Paulo, Pini.
} 
produzidas no concreto em um tempo $\mathrm{t}$ qualquer, por um acréscimo de tensão em um tempo $t_{0}$ qualquer, são independentes dos efeitos de qualquer tensão aplicada tanto antes quanto depois de $\mathrm{t}_{\mathrm{o}}$.

Portanto, pelo princípio da superposição a resposta para uma soma de duas histórias de tensões é a soma das respostas obtidas para cada uma delas separadamente. Conseqüentemente, a deformação devido a um histórico de tensão $\sigma(\mathrm{t})$ pode ser obtida considerando o histórico como uma soma de incrementos $\mathrm{d} \sigma(\tau)$ aplicados em tempos $\tau \in(0, t)$ e somando as correspondentes deformações, dadas por $\mathrm{d} \sigma(\tau) \Phi(\mathrm{t}, \tau)$. Com isso chega-se na integral de superposição ou integral de Stieltjes, dada por:

$$
\varepsilon_{\sigma}(\mathrm{t})=\int_{0}^{\mathrm{t}} \Phi(\mathrm{t}, \tau) \mathrm{d} \sigma(\tau)
$$

Vale ressaltar, entretanto, que o princípio da superposição só é válido sob as seguintes condições:

a) O nível de tensões estiver dentro das condições de serviço. O CEB-90 (1991) estabelece o limite em 0,4. $f_{\mathrm{cm}}\left(\mathrm{t}_{\mathrm{o}}\right)$, enquanto que o ACI-209 (1992) entre 0,4 e 0,5.f , já a NBR 6118 (2003) em 0,5.f.

b) Somente para acréscimo de tensões. Quando as tensões decrescem, o princípio da superposição pode ser aplicado desde que o decréscimo de tensão seja pequeno;

c) Quando a peça não sofrer mudanças significativas no teor de umidade;

d) Quando não houver aumentos exagerados de tensões logo após o carregamento inicial.

\subsubsection{Formulação integral}

\subsubsection{Método incremental ou método passo a passo}

O Método incremental consiste em resolver a integral de Stieltjes dividindo o tempo total de análise em pequenos intervalos discretos $t_{1}, t_{2}, \ldots, t_{i}, \ldots$, 
$\mathrm{t}_{\mathrm{k}}$ e tomando-se os sub-intervalos $\Delta \mathrm{t}_{\mathrm{i}}=\mathrm{t}_{\mathrm{i}}-\mathrm{t}_{\mathrm{i}-1}$, como indicado na figura 2.19. Assim, a integral de Stieltjes, representada pela área do diagrama da figura 2.19 (c), pode ser resolvida de maneira aproximada utilizando a forma retangular ou a forma trapezoidal.

$$
\begin{array}{ll}
\varepsilon_{\sigma}\left(\mathrm{t}_{\mathrm{k}}\right)=\sum_{\mathrm{i}=1}^{\mathrm{k}} \Phi\left(\mathrm{t}_{\mathrm{k}}, \mathrm{t}_{\mathrm{i}}\right) \cdot \Delta \sigma_{\mathrm{i}} & \text { aprox. retangular } \\
\varepsilon_{\sigma}\left(\mathrm{t}_{\mathrm{k}}\right)=\sum_{\mathrm{i}=1}^{\mathrm{k}} \frac{\Phi\left(\mathrm{t}_{\mathrm{k}}, \mathrm{t}_{\mathrm{i}}\right)+\Phi\left(\mathrm{t}_{\mathrm{k}}, \mathrm{t}_{\mathrm{i}-1}\right)}{2} \cdot \Delta \sigma_{\mathrm{i}} & \text { aprox. trapezoidal }
\end{array}
$$

Segundo DILGER (1982b), se for tomado um intervalo de tempo muito grande, pode-se utilizar a regra de Simpson para se obter um resultado mais preciso.

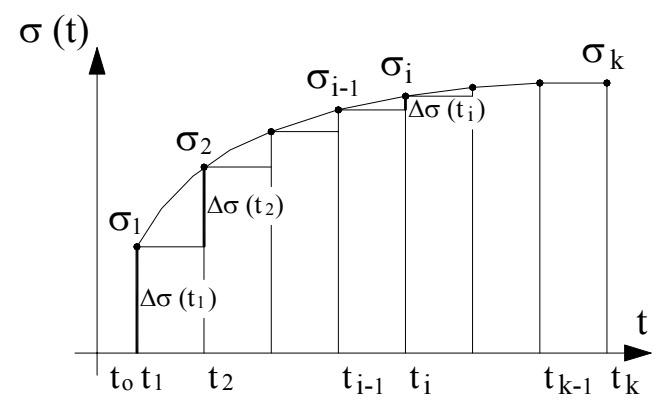

(a)

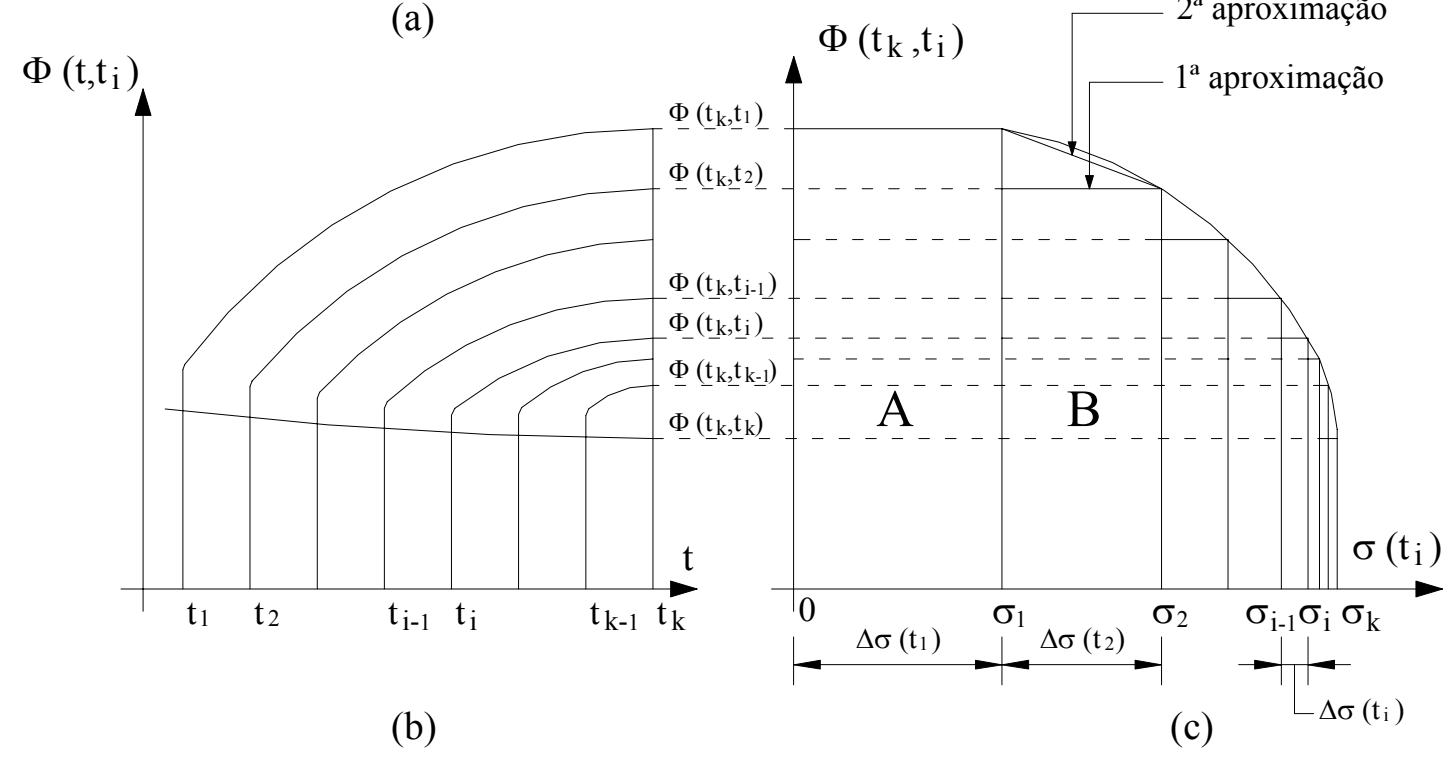

FIGURA 2.19 - Definição dos intervalos para o método incremental [adaptado CEB (1984)]

(a) Tensões no decorrer do tempo; (b) Curvas de funções fluência;

(c) Função fluência x variação de tensão 


\subsubsection{Método do Módulo Efetivo (EM method)}

O Método do Módulo Efetivo proposto em 1927 por $\mathrm{FABER}^{2}$ apud BAZANT (1982) constitui numa aproximação menos refinada para o cálculo da integral de Stieltjes e consiste na aplicação da regra retangular em um único intervalo de tempo $\mathrm{t}-\mathrm{t}_{0}$.

$$
\varepsilon_{\sigma}(\mathrm{t})=\sigma\left(\mathrm{t}_{\mathrm{o}}\right) \cdot \Phi\left(\mathrm{t}, \mathrm{t}_{\mathrm{o}}\right)+\int_{\mathrm{t}_{\mathrm{o}}}^{\mathrm{t}} \Phi(\mathrm{t}, \tau) \mathrm{d} \sigma(\tau)
$$

Porém,

$$
\int_{\mathrm{t}_{\mathrm{o}}}^{\mathrm{t}} \Phi(\mathrm{t}, \tau) \mathrm{d} \sigma(\tau)=\left[\sigma(\mathrm{t})-\sigma\left(\mathrm{t}_{\mathrm{o}}\right)\right] \Phi\left(\mathrm{t}, \mathrm{t}_{\mathrm{o}}\right)
$$

E assim, como ilustrado na figura 2.20.

$$
\varepsilon_{\sigma}(\mathrm{t})=\sigma(\mathrm{t}) \cdot \Phi\left(\mathrm{t}, \mathrm{t}_{\mathrm{o}}\right)
$$

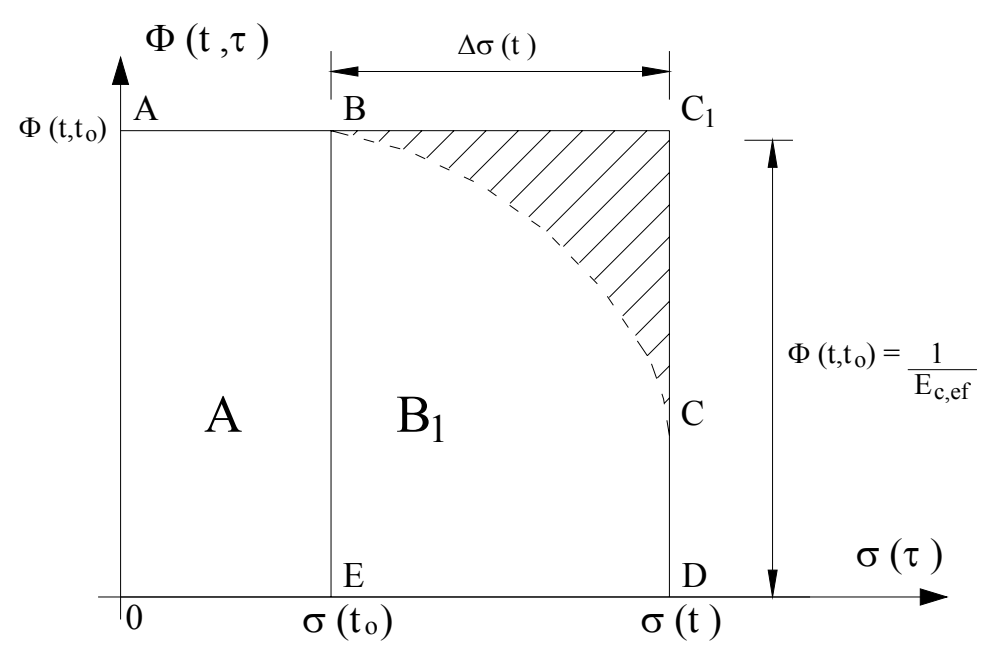

FIGURA 2.20 - Método do módulo efetivo [adaptado CEB (1984)]

${ }^{2}$ FABER, H. (1927). Plastic yield, shrinkage and other problems of concrete and their effect on design, Minutes Proc. Inst. Civ. Eng., v.225, p.27-76. apud BAZANT, Z.P. (1982). Mathematical models for creep and shrinkage of concrete. In: BAZANT, Z.P.; WITTMANN, F.H., eds. Creep and shrinkage in concrete structures. New York, John Wiley \& Sons. Cap. 7, p.163-256. 
Introduzindo a função fluência $\Phi\left(\mathrm{t}, \mathrm{t}_{\mathrm{o}}\right)$, tem-se:

$\varepsilon_{\sigma}(t)=\sigma(t) \cdot\left[\frac{1}{E_{c}\left(t_{o}\right)}+\frac{\varphi_{28}\left(t, t_{o}\right)}{E_{c 28}}\right]$

Tomando-se: $\left[\frac{1}{\mathrm{E}_{\mathrm{c}}\left(\mathrm{t}_{\mathrm{o}}\right)}+\frac{\varphi_{28}\left(\mathrm{t}, \mathrm{t}_{\mathrm{o}}\right)}{\mathrm{E}_{\mathrm{c} 28}}\right]=\Phi\left(\mathrm{t}, \mathrm{t}_{\mathrm{o}}\right)=\frac{1}{\mathrm{E}_{\mathrm{c}, \mathrm{ef}}}$, tem-se:

$$
\varepsilon_{\sigma}(\mathrm{t})=\frac{\sigma(\mathrm{t})}{\mathrm{E}_{\mathrm{c}, \mathrm{ef}}}
$$

Quando se considera o módulo de elasticidade constante com o tempo, por razões de simplificação, tem-se:

$$
\mathrm{E}_{\mathrm{c}, \mathrm{ef}}=\frac{\mathrm{E}_{\mathrm{c}}\left(\mathrm{t}_{\mathrm{o}}\right)}{1+\varphi_{28}\left(\mathrm{t}, \mathrm{t}_{\mathrm{o}}\right)}
$$

Segundo o método do módulo efetivo, a deformação por fluência na idade $\mathrm{t}$ depende exclusivamente do valor da tensão instantânea, sendo que o histórico de tensões não é considerado. Portanto, este método apresenta resultados satisfatórios somente quando a tensão no concreto não varia significativamente e quando a influência da idade do concreto não for expressiva, caso dos concretos de idade avançada. Em situações de tensões decrescentes, as deformações por fluência são subestimadas e sob tensões crescentes, são superestimadas.

\subsubsection{Método da Tensão Média}

O Método da Tensão Média trata-se de uma melhor aproximação para o cálculo da integral de Stieltjes e consiste na aplicação da regra trapezoidal em um único intervalo de tempo $\mathrm{t}-\mathrm{t}_{0}$, como mostra a figura 2.21 .

$$
\varepsilon_{\sigma}(\mathrm{t})=\sigma\left(\mathrm{t}_{\mathrm{o}}\right) \cdot \Phi\left(\mathrm{t}, \mathrm{t}_{\mathrm{o}}\right)+\Delta \sigma\left(\mathrm{t}, \mathrm{t}_{\mathrm{o}}\right) \cdot \frac{\Phi(\mathrm{t}, \mathrm{t})+\Phi\left(\mathrm{t}, \mathrm{t}_{\mathrm{o}}\right)}{2}
$$




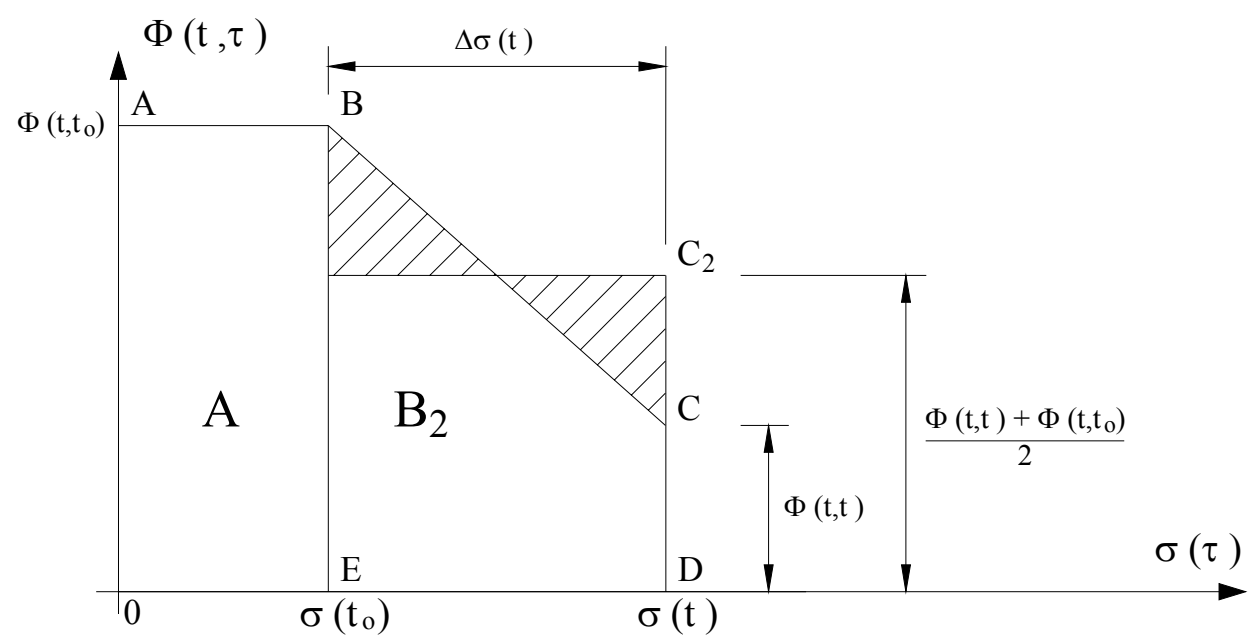

FIGURA 2.21 - Método da tensão média [adaptado CEB (1984)]

\subsubsection{Método do Módulo Efetivo Ajustado (AAEM method)}

O método do módulo efetivo ajustado, também conhecido por método de Trost-Bazant, foi desenvolvido em 1967 por TROST ${ }^{3}$ apud DILGER (1982b) e melhorado posteriormente por BAZANT (1972). Este método consiste em aplicar uma fórmula de enquadramento mais refinada para substituir o cálculo da integral de superposição através de um fator de correção.

$$
\int_{\mathrm{t}_{\mathrm{o}}}^{\mathrm{t}} \Phi(\mathrm{t}, \tau) \mathrm{d} \sigma(\tau)=\left[\sigma(\mathrm{t})-\sigma\left(\mathrm{t}_{\mathrm{o}}\right)\right] \cdot \mu\left(\mathrm{t}, \mathrm{t}_{\mathrm{o}}\right) \cdot \Phi\left(\mathrm{t}, \mathrm{t}_{\mathrm{o}}\right)
$$

O coeficiente $\mu\left(t, t_{0}\right)$ é um fator de redução conveniente a ser aplicado na deformação $\Delta \sigma(\mathrm{t}) \cdot \Phi\left(\mathrm{t}, \mathrm{t}_{\mathrm{o}}\right)$. Este fator é introduzido através de um multiplicador $\chi\left(\mathrm{t}, \mathrm{t}_{\mathrm{o}}\right)$ conhecido como coeficiente de envelhecimento, como apresentado na figura 2.22. Assim, a integral de superposição torna-se:

$$
\int_{\mathrm{t}_{\mathrm{o}}}^{\mathrm{t}} \Phi(\mathrm{t}, \tau) \mathrm{d} \sigma(\tau)=\left[\sigma(\mathrm{t})-\sigma\left(\mathrm{t}_{\mathrm{o}}\right)\right] \cdot\left[\frac{1}{\mathrm{E}_{\mathrm{c}}\left(\mathrm{t}_{\mathrm{o}}\right)}+\chi\left(\mathrm{t}, \mathrm{t}_{\mathrm{o}}\right) \cdot \frac{\varphi_{28}\left(\mathrm{t}, \mathrm{t}_{\mathrm{o}}\right)}{\mathrm{E}_{\mathrm{c} 28}}\right]
$$

\footnotetext{
${ }^{3}$ TROST, H. (1967). Auswirkungen des Superpositionsprinzips auf Kriech und Relaxations probleme bei Beton und Spannbeton. Beton. Stahlbeton., v.62, n.10, p.230-8; n.11, p.261-9. apud DILGER, W.H. (1982b). Methods of structural creep analysis. In: BAZANT, Z.P.; WITTMANN, F.H., eds. Creep and shrinkage in concrete structures. New York, John Wiley \& Sons. Cap. 9, p.305-340.
} 
E a expressão geral torna-se:

$$
\begin{aligned}
& \varepsilon_{\sigma}(t)=\sigma\left(t_{o}\right) \cdot\left[\frac{1}{E_{c}\left(t_{o}\right)}+\frac{\varphi_{28}\left(t, t_{o}\right)}{E_{c 28}}\right]+ \\
& +\left[\sigma(\mathrm{t})-\sigma\left(\mathrm{t}_{\mathrm{o}}\right)\right] \cdot\left[\frac{1}{\mathrm{E}_{\mathrm{c}}\left(\mathrm{t}_{\mathrm{o}}\right)}+\chi\left(\mathrm{t}, \mathrm{t}_{\mathrm{o}}\right) \cdot \frac{\varphi_{28}\left(\mathrm{t}, \mathrm{t}_{\mathrm{o}}\right)}{\mathrm{E}_{\mathrm{c} 28}}\right] \\
& \rfloor_{\Phi\left(t, t_{0}\right)}^{\Delta} \Phi(\mathrm{t}, \tau) \quad H_{\mathrm{B}} \Delta \sigma(\mathrm{t})
\end{aligned}
$$

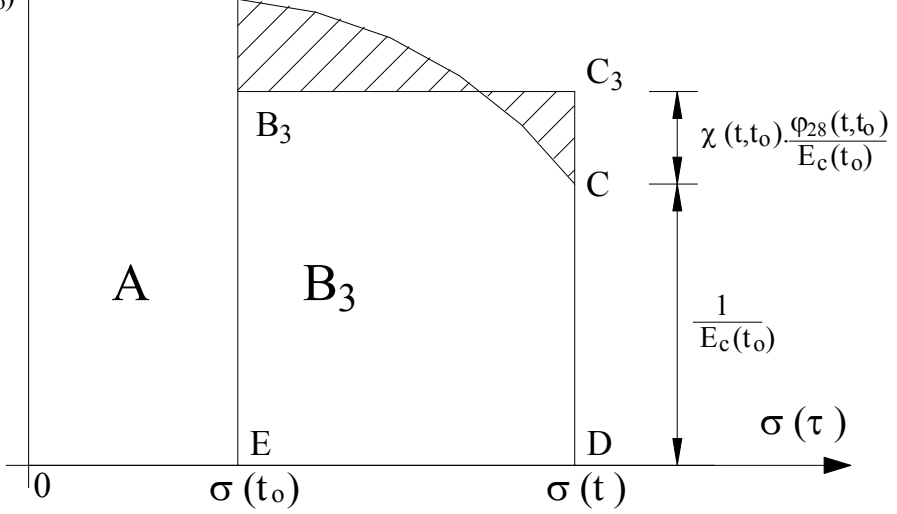

FIGURA 2.22 - Método do módulo efetivo ajustado [adaptado CEB (1984)]

Os valores de $\chi\left(\mathrm{t}, \mathrm{t}_{\mathrm{o}}\right)$ são sempre positivos e menores que 1 , exceto nos casos de concretos velhos, com cargas de longa duração onde $\chi\left(t, t_{0}\right)=1$.

O coeficiente $\chi\left(t, t_{0}\right)$ pode ser definido para qualquer função fluência, contudo, para a análise prática é necessário estabelecer os valores de $\chi$ para diferentes idades de carregamento, diferentes tempos de duração do carregamento e diferentes dimensões da peça.

\subsubsection{Formulação diferencial}

Nesses métodos, a equação integral de superposição é transformada em equações diferenciais ordinárias, através do uso de uma forma convenientemente simplificada para a função fluência. Tal simplificação da função fluência corresponde a uma representação parcial das propriedades dos materiais. 


\subsubsection{Método de Dischinger ou método da razão de fluência (Rate of creep method)}

As bases do método de Dischinger, também chamado de método da razão de fluência, foram estabelecidas em 1930 por GLANVILLE ${ }^{4}$ apud DILGER (1982b). Posteriormente, em 1932, WHITNEY ${ }^{5}$ apud DILGER (1982b) desenvolveu as formulações matemáticas para o método, sendo que, em 1937, DISCHINGER ${ }^{6}$ apud DILGER (1982b) aplicou suas formulações para a resolução de problemas estruturais mais complexos.

O método de Dischinger é baseado na hipótese de que a velocidade de desenvolvimento (razão ou taxa) de fluência é independente da idade de aplicação do carregamento, ou seja, as curvas de fluência são paralelas para todas as idades de aplicação da carga, sendo obtidas por translação paralela ao eixo vertical, conforme a figura 2.23 .

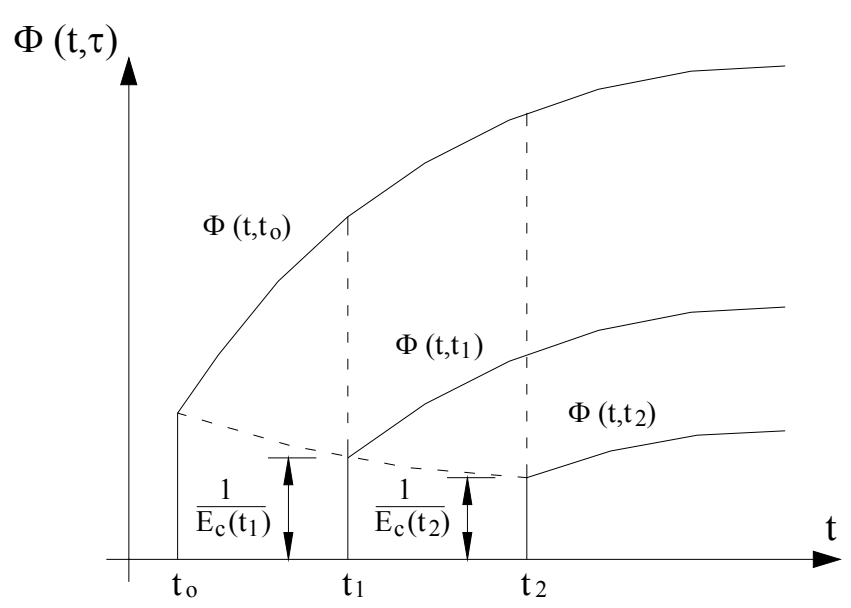

FIGURA 2.23 - Curvas de função fluência segundo o método da razão de fluência

\footnotetext{
${ }^{4}$ GLANVILLE, W.H. (1930). Studies in reinforced concrete, III - creep or flow of concrete under load. Building Research Tech. Pap., n.12. apud DILGER, W.H. (1982b). Methods of structural creep analysis. In: BAZANT, Z.P.; WITTMANN, F.H., eds. Creep and shrinkage in concrete structures. New York, John Wiley \& Sons. Cap. 9, p.305-340.

${ }^{5}$ WHITNEY, C.S. (1932). Plain and reinforced concrete arches. Journal of American Concrete Institute, v.28, p.479-519. apud DILGER, W.H. (1982b). Methods of structural creep analysis. In: BAZANT, Z.P.; WITTMANN, F.H., eds. Creep and shrinkage in concrete structures. New York, John Wiley \& Sons. Cap. 9, p.305-340.

${ }^{6}$ DISCHINGER, F. (1937). Untersuchungen über die Knicksicherheit, die elastische Verformung und das Kriechen des Betons bei Bogenbrücken. Der Bauingenieur, v.18, n.33/34, p.487-520; n.35/36, p.539-52; n.39/40, p.595-621. apud DILGER, W.H. (1982b). Methods of structural creep analysis. In: BAZANT, Z.P.; WITTMANN, F.H., eds. Creep and shrinkage in concrete structures. New York, John Wiley \& Sons. Cap. 9, p.305-340.
} 
Para o instante $t_{0}$ de aplicação da carga, a função fluência assume a seguinte forma:

$$
\Phi\left(\mathrm{t}, \mathrm{t}_{\mathrm{o}}\right)=\frac{1}{\mathrm{E}_{\mathrm{c}}\left(\mathrm{t}_{\mathrm{o}}\right)}+\mathrm{C}\left(\mathrm{t}, \mathrm{t}_{\mathrm{o}}\right)=\frac{1}{\mathrm{E}_{\mathrm{c}}\left(\mathrm{t}_{\mathrm{o}}\right)} \cdot\left[1+\varphi\left(\mathrm{t}, \mathrm{t}_{\mathrm{o}}\right)\right]
$$

Considerando agora um caso em que a carga é aplicada em um instante $t_{1}>t_{0}$, tem-se:

$$
\Phi\left(\mathrm{t}, \mathrm{t}_{1}\right)=\frac{1}{\mathrm{E}_{\mathrm{c}}\left(\mathrm{t}_{1}\right)}+\frac{1}{\mathrm{E}_{\mathrm{c}}\left(\mathrm{t}_{\mathrm{o}}\right)} \cdot\left[\varphi\left(\mathrm{t}, \mathrm{t}_{\mathrm{o}}\right)-\varphi\left(\mathrm{t}_{1}, \mathrm{t}_{\mathrm{o}}\right)\right]
$$

Aplicando estas equações para o cálculo da deformação total no instante $\mathrm{t}$ devido uma tensão $\sigma_{\mathrm{o}}$ entre $\mathrm{t}_{\mathrm{o}}$ e $\mathrm{t}_{1}$ (ver figura 2.24), tem-se:

$$
\varepsilon(\mathrm{t})=\sigma_{\mathrm{o}} \cdot\left[\Phi\left(\mathrm{t}, \mathrm{t}_{\mathrm{o}}\right)-\Phi\left(\mathrm{t}, \mathrm{t}_{1}\right)\right]
$$

Ou ainda,

$$
\varepsilon(t)=\sigma_{o} \cdot\left[\frac{1}{E_{c}\left(t_{o}\right)}-\frac{1}{E_{c}\left(t_{1}\right)}+\frac{1}{E_{c}\left(t_{o}\right)} \cdot \varphi\left(t_{1}, t_{o}\right)\right]
$$

Fazendo-se $\mathrm{E}_{\mathrm{c}}\left(\mathrm{t}_{1}\right)=\mathrm{E}_{\mathrm{c}}\left(\mathrm{t}_{\mathrm{o}}\right)$, a deformação no instante $\mathrm{t}>\mathrm{t}_{1}$ será:

$$
\varepsilon(t)=\frac{\sigma_{o}}{E_{c}\left(t_{o}\right)} \cdot \varphi\left(t_{1}, t_{o}\right)
$$

Um ponto importante a ser observado é que a deformação após a remoção do carregamento permanece constante (figura 2.24), o que significa que a recuperação por fluência observada em experimentos após a remoção de carga não é representada de maneira adequada por esse método. 

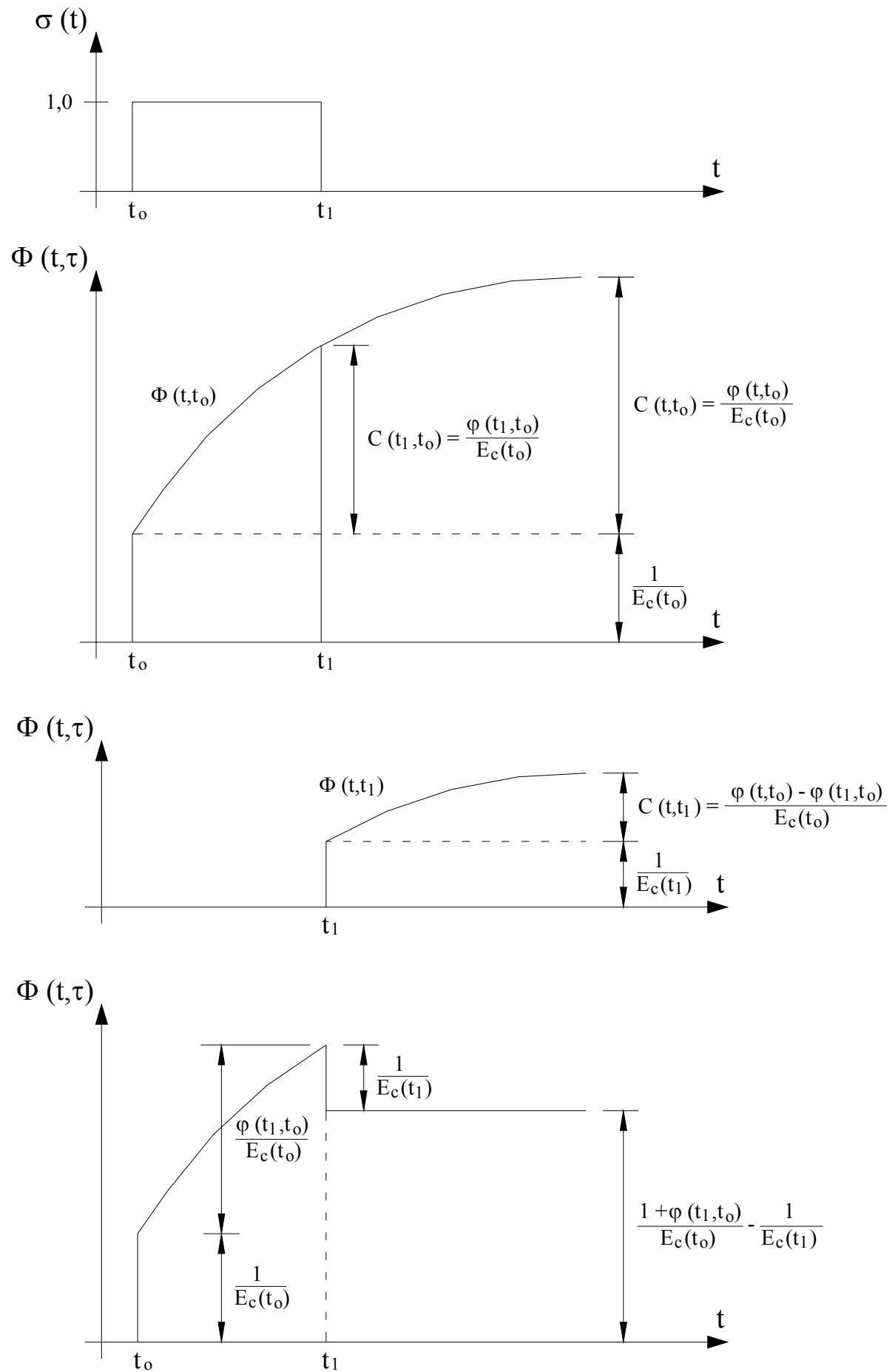

FIGURA 2.24 - Relação entre deformação e tempo para uma carga unitária aplicada entre $t$ e $t_{o}$ segundo o método da razão de fluência [adaptado DILGER (1982b)] 
O método da razão de fluência conduz a seguinte equação diferencial:

$$
\frac{d \varepsilon}{d t}=\frac{\sigma(t)}{E_{c}\left(t_{o}\right)} \cdot \frac{d \varphi}{d t}+\frac{1}{E_{c}(t)} \cdot \frac{d \sigma}{d t}+\frac{d \varepsilon_{s c}}{d t}
$$

A suposição de que as curvas de fluência são paralelas implica que a fluência decresce rapidamente com o acréscimo da idade de aplicação do carregamento, tornando-se nula quando o concreto for carregado em idade muito avançada. Isto faz com a haja, no caso de tensões decrescentes, uma superestimativa da deformação por fluência. Mas como destacado por BAZANT (1988), o método da razão de fluência apresenta bons resultados para cargas aplicadas em concretos novos, em contraste com o método do módulo efetivo cuja aplicação é adequada para concretos de idades avançadas.

\subsubsection{Método da razão da deformação lenta irreversível (Rate of flow method)}

A fim de suprir as deficiências apresentadas pelo método de Dischinger, em 1965, ENGLAND \& ILLSTON ${ }^{7}$ apud DILGER (1982b) propuseram representar a função fluência como a soma de três componentes: a deformação elástica $\left(\varepsilon_{\mathrm{el}}\right)$, a deformação lenta reversível $\left(\varepsilon_{\mathrm{d}}\right)$, deformação lenta irreversível $\left(\varepsilon_{\mathrm{f}}\right)$. Os autores concluíram através de experimentos que a deformação lenta reversível independe da idade de aplicação do carregamento e atinge o seu valor final muito antes da fluência lenta irreversível. A fluência lenta irreversível representa o componente irreversível da fluência total, e é considerada da mesma forma que o método da razão de fluência considera a deformação por fluência total, ou seja, a razão da fluência lenta irreversível é a mesma em qualquer idade.

Utilizando a função fluência com a carga inicial aplicada na idade $t_{o}$, tem-se:

$$
\Phi\left(\mathrm{t}, \mathrm{t}_{\mathrm{o}}\right)=\frac{1}{\mathrm{E}_{\mathrm{c}}\left(\mathrm{t}_{\mathrm{o}}\right)}+\mathrm{C}_{\mathrm{d}}\left(\mathrm{t}-\mathrm{t}_{\mathrm{o}}\right)+\mathrm{C}_{\mathrm{f}}(\mathrm{t})-\mathrm{C}_{\mathrm{f}}\left(\mathrm{t}_{\mathrm{o}}\right)
$$

\footnotetext{
${ }^{7}$ ENGLAND, G.L.; ILLSTON, J.M. (1965). Methods of computing stress in concrete from a history of measured strain. Civil Engineering, London. apud DILGER, W.H. (1982b). Methods of structural creep analysis. In: BAZANT, Z.P.; WITTMANN, F.H., eds. Creep and shrinkage in concrete structures. New York, John Wiley \& Sons. Cap. 9, p.305-340.
} 


$$
\Phi\left(\mathrm{t}, \mathrm{t}_{\mathrm{o}}\right)=\frac{1}{\mathrm{E}_{\mathrm{c}}\left(\mathrm{t}_{\mathrm{o}}\right)}+\frac{\varphi_{\mathrm{d}}\left(\mathrm{t}-\mathrm{t}_{\mathrm{o}}\right)}{\mathrm{E}_{\mathrm{c}}\left(\mathrm{t}_{\mathrm{o}}\right)}+\frac{\varphi_{\mathrm{f}}(\mathrm{t})-\varphi_{\mathrm{f}}\left(\mathrm{t}_{\mathrm{o}}\right)}{\mathrm{E}_{\mathrm{c}}\left(\mathrm{t}_{\mathrm{o}}\right)}
$$

E para cargas subseqüentes aplicadas em um instante $t^{\prime}>t_{0}$, tem-se:

$$
\Phi\left(\mathrm{t}, \mathrm{t}^{\prime}\right)=\frac{1}{E_{\mathrm{c}}\left(\mathrm{t}^{\prime}\right)}+\frac{\varphi_{\mathrm{d}}\left(\mathrm{t}-\mathrm{t}^{\prime}\right)}{\mathrm{E}_{\mathrm{c}}\left(\mathrm{t}^{\prime}\right)}+\frac{\varphi_{\mathrm{f}}(\mathrm{t})-\varphi_{\mathrm{f}}\left(\mathrm{t}^{\prime}\right)}{\mathrm{E}_{\mathrm{c}}\left(\mathrm{t}_{0}\right)}
$$

Para uma tensão unitária aplicada na idade $t_{0}$ e removida na idade $t_{1}$, como mostrada na figura 2.25 , a deformação no instante $\mathrm{t}$ será:

$$
\varepsilon(\mathrm{t})=\left[\Phi\left(\mathrm{t}, \mathrm{t}_{\mathrm{o}}\right)-\Phi\left(\mathrm{t}, \mathrm{t}_{1}\right)\right]
$$

$$
\begin{aligned}
\varepsilon(t)= & \frac{1}{E_{c}\left(t_{o}\right)}+\frac{1}{E_{c}\left(t_{o}\right)} \cdot \varphi_{d}\left(t-t_{o}\right)+\frac{1}{E_{c}\left(t_{o}\right)} \cdot\left[\varphi_{f}\left(t_{1}\right)-\varphi_{f}\left(t_{o}\right)\right]- \\
& -\frac{1}{E_{c}\left(t_{1}\right)}-\frac{1}{E_{c}\left(t_{1}\right)} \cdot \varphi_{d}\left(t-t_{1}\right)
\end{aligned}
$$
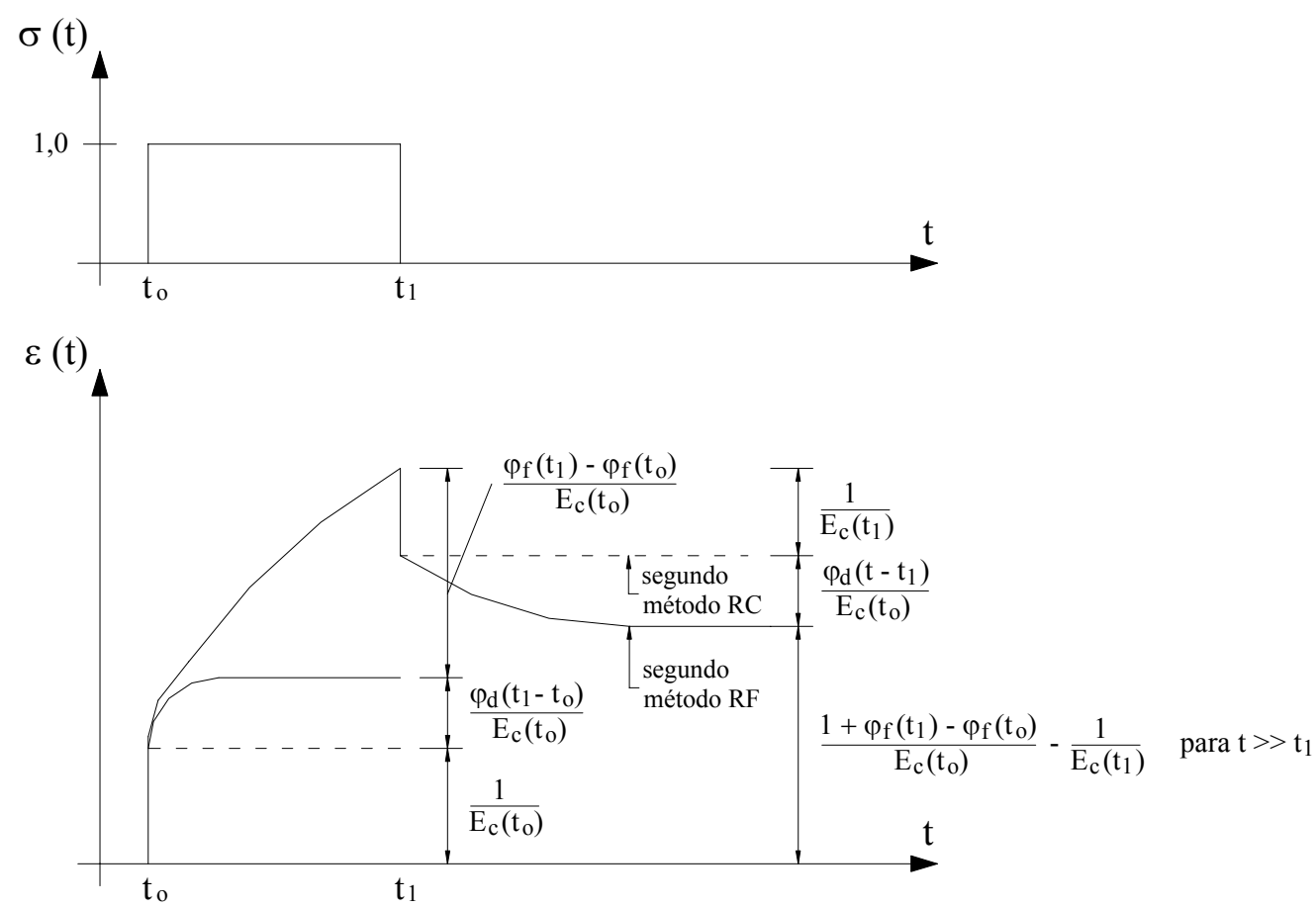

FIGURA 2.25 - Relação entre deformação e tempo para uma carga unitária aplicada entre $t_{\text {e }} t_{0}$ segundo o método da deformação lenta irreversível [adaptado DILGER (1982b)] 
Para um tempo $\mathrm{t} \gg \mathrm{t}_{1}$, observa-se a completa recuperação do componente da deformação lenta reversível. Assim, a deformação por fluência deve ser expressa da seguinte forma:

$$
\varepsilon(t)=\frac{1+\varphi_{\mathrm{f}}\left(\mathrm{t}_{1}\right)-\varphi_{\mathrm{f}}\left(\mathrm{t}_{\mathrm{o}}\right)}{\mathrm{E}_{\mathrm{c}}\left(\mathrm{t}_{\mathrm{o}}\right)}-\frac{1}{\mathrm{E}_{\mathrm{c}}\left(\mathrm{t}_{1}\right)}
$$

\subsubsection{Método de Dischinger melhorado (Improved Dischinger method)}

Para possibilitar um tratamento analítico mais simples, em 1970, NIELSEN ${ }^{8}$ apud DILGER (1982b) propôs adicionar a parcela de deformação lenta reversível à parcela de deformação elástica instantânea, e tratar a parcela de deformação lenta irreversível da mesma maneira como o método da razão de fluência considera a deformação por fluência total. Com estas considerações, tem-se que, para uma carga inicial aplicada na idade $t_{0}$, a função fluência pode ser expressa da seguinte forma:

$$
\Phi\left(\mathrm{t}, \mathrm{t}_{\mathrm{o}}\right)=\frac{1}{\mathrm{E}_{\mathrm{d}}}+\frac{\varphi_{\mathrm{f}}(\mathrm{t})-\varphi_{\mathrm{f}}\left(\mathrm{t}_{\mathrm{o}}\right)}{\mathrm{E}_{\mathrm{c}}\left(\mathrm{t}_{\mathrm{o}}\right)}
$$

onde:

$$
\frac{1}{E_{d}}=\frac{1}{E_{c}\left(t_{o}\right)}+\frac{\varphi_{d}}{E_{c}\left(t_{o}\right)}
$$

Para cargas subseqüentes aplicadas em um instante $t^{\prime}>t_{o}$, tem-se:

$$
\Phi\left(\mathrm{t}, \mathrm{t}^{\prime}\right)=\frac{1}{\mathrm{E}_{\mathrm{d}}}+\frac{\varphi_{\mathrm{f}}(\mathrm{t})-\varphi_{\mathrm{f}}\left(\mathrm{t}^{\prime}\right)}{\mathrm{E}_{\mathrm{c}}\left(\mathrm{t}_{\mathrm{o}}\right)}
$$

com

$$
\frac{1}{E_{d}}=\frac{1}{E_{c}\left(t^{\prime}\right)}+\frac{\varphi_{d}}{E_{c}\left(t_{o}\right)}
$$

O método melhorado de Dischinger constitui um método composto pelo método do módulo efetivo e pelo método da razão de fluência. A vantagem do

\footnotetext{
${ }^{8}$ NIELSEN, L.F. (1970). Kriechen und Relaxation des Betons. Beton. Stahlbeton., v.65, p.272-5. apud DILGER, W.H. (1982b). Methods of structural creep analysis. In: BAZANT, Z.P.; WITTMANN, F.H., eds. Creep and shrinkage in concrete structures. New York, John Wiley \& Sons. Cap. 9, p.305-340.
} 
método melhorado de Dischinger, como salientado por DILGER (1982b), está na simplicidade do tratamento analítico e dos bons resultados obtidos para os casos práticos, em que o tempo de aplicação de carga excede de três meses. Contudo, em concreto de idade avançada, a fluência é subestimada como no caso do método da razão de fluência.

A equação diferencial pelo método melhorado de Dischinger será:

$$
\frac{d \varepsilon}{d t}=\frac{\sigma(t)}{E_{c}\left(t_{o}\right)} \frac{d \varphi_{f}}{d t}+\frac{1+\varphi_{d}}{E_{c}(t)} \frac{d \sigma}{d t}+\frac{d \varepsilon_{s c}}{d t}
$$

\subsubsection{Método dos núcleos degenerados}

Como já foi visto, a integral de Stieltjes pode ser resolvida dividindo o tempo total de análise em passos de tempo $\Delta \mathrm{t}$. E assim, a integral de Stieltjes pode ser aproximada por uma soma finita envolvendo acréscimos incrementais de tensão sobre os passos de tempo. No entanto, este método exige o armazenamento de todo o histórico de tensão. Isso pode ser contornado aproximando a função fluência $\Phi(\mathrm{t}, \tau)$ por uma série de exponenciais reais conhecida por série de Dirichlet ou série de Prony, dada por:

$$
\Phi(\mathrm{t}, \tau)=\frac{1}{\mathrm{E}(\tau)}+\sum_{\mathrm{i}=1}^{\mathrm{n}} \frac{1}{\mathrm{E}_{\mathrm{i}}(\tau)} \cdot\left[1-\mathrm{e}^{\frac{-(\mathrm{t}-\tau)}{\tau_{\mathrm{i}}}}\right]
$$

em que $\tau_{\mathrm{i}}$ são coeficientes chamados de tempos de estabilização e $\mathrm{E}_{\mathrm{i}}(\tau)$ são os coeficientes dependentes de $\tau$ e que têm a dimensão do módulo de elasticidade. Estes coeficientes podem ser determinados ajustando a série de Dirichlet aos valores experimentais ou fórmulas empíricas, como aquelas recomendadas por normas, através do método dos mínimos quadrados. 
BAZANT \& WU (1973) mostra que a série de Dirichlet representa a solução do seguinte sistema de equações diferenciais:

$$
\begin{array}{ll}
\dot{\varepsilon}=\dot{\sigma} / E+\sum_{i=1}^{n} \dot{\varepsilon}_{i} & \\
\dot{\varepsilon}_{i}=\sigma_{i} / \eta_{i} & i=1,2, \ldots, n \\
\dot{\sigma}=\dot{\sigma}_{i}+E_{i} \cdot \dot{\varepsilon}_{i} & i=1,2, \ldots, n
\end{array}
$$

Este sistema de equações que corresponde ao modelo reológico mostrado na figura 2.26, com variáveis $\mathrm{E}, \mathrm{E}_{\mathrm{i}}$ e $\eta_{\mathrm{i}}$, é conhecido como modelo generalizado de Kelvin.

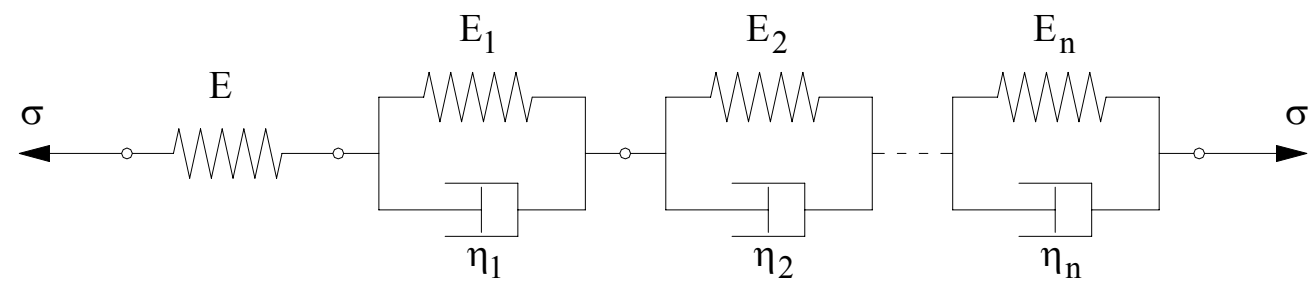

FIGURA 2.26 - Modelo generalizado de Kelvin

Quando a função fluência, representada pela série de Dirichlet, é introduzida na integral de Stieltjes, o integrando se degenera em um produto de uma função de $\tau$ e uma função de $\mathrm{t}$. A função resultante não envolve a variável de integração e pode ser extraída da integral, restando apenas uma integração de funções que são independentes de $\mathrm{t}$. Portanto, para cada novo passo de tempo, é necessário somente considerar a mudança no valor da integral do último passo de tempo ao invés de todo o histórico de tensão, como é exigido no caso geral. 


\section{ANÁLISE NUMÉRICA}

\subsection{Considerações iniciais}

A análise de estruturas de concreto é um problema consideravelmente complexo devido às dificuldades causadas por muitos fatores, podendo citar entre eles, a consideração do comportamento conjunto de dois ou mais materiais com propriedades distintas, os efeitos da história de carregamento aplicado, não linearidade da resposta devido à fissuração e a influência dos efeitos diferidos provocados pela fluência e retração do concreto e a relaxação do aço de protensão. Além disso, maiores dificuldades são adicionadas se for considerado a influência do processo construtivo, tais como, a mudança das características resistentes da seção, incorporação de novas partes à estrutura, ou ainda, variação nas condições de contorno devido, por exemplo, aos processos de cimbramento e descimbramento.

A consideração desses fatores terá especial importância na determinação dos deslocamentos, distribuição de tensões e fissuração das distintas partes da estrutura, além de influenciar na evolução das tensões e deformações ao longo do tempo.

Devido ao comportamento característico dos materiais constituintes das estruturas de concreto (fluência, retração, relaxação, fissuração), pode haver significativas redistribuições de tensões, variações nas reações de apoio e dos esforços internos no caso de estruturas hiperestáticas, sendo que a importância desses fenômenos é mais destacável no caso de construções realizadas por etapas.

Muitos métodos, baseado na seção transformada, foram propostos para levar em consideração os efeitos dependentes do tempo em seções compostas não 
fissuradas, como aqueles desenvolvidos por DILGER (1982a), GHALI \& FAVRE (1986), GILBERT (1989) e NEVILLE et al. (1983). Além disso, empreendeu-se muito esforço na análise ao longo do tempo de seções fissuradas, podendo citar os trabalhos desenvolvidos por BRADFORD \& GILBERT (1992), GHALI \& FAVRE (1986), RAO et al. (1994) e SMERDA \& KRISTEK (1988).

Foram desenvolvidos ainda muitos modelos analíticos para a previsão da resposta não linear e dependente do tempo de estruturas de concreto, tais como CRUZ et al. (1998), JENDELE \& PHILLIPS (1992), JURKIEWIEZ et al. (1999), KANG \& SCORDELIS (1980), KWAK \& SEO (2000) e MARÍ (2000), baseados no método dos elementos finitos com aproximação do elemento de viga em camadas ou filamentos.

Já os modelos desenvolvidos por CAROL \& MURCIA (1989), DEZI \& TARANTINO (1993), GILBERT \& BRADFORD (1995) e TORRES (2001), baseiam-se na extensão dos métodos matriciais, não necessitando a discretização em elementos de menor dimensão nem o emprego de funções de forma, reduzindo o grau de liberdade do problema e obtendo-se sistemas com menor número de equações. No entanto, deve-se efetuar a integração ao longo do elemento, necessitando de regras numéricas adequadas.

Os efeitos do processo construtivo no esquema estrutural foram incluídos nos modelos desenvolvidos por GHALI \& ELBADRY (1989), TRADOS et al. (1979), VAN ZYL \& SCORDELIS (1979), SHUSHKEWICH (1986), HERKENHOFF (1994), DEZI \& TARANTINO (1991) e CRUZ et al. (1998).

Para o desenvolvimento deste trabalho, a análise estrutural é realizada utilizando o programa computacional denominado CONSNOU desenvolvido em linguagem FORTRAN pelo Professor Antonio R. Marí do Departamento de Engenharia da Universidade Politécnica da Catalunha, situada em Barcelona Espanha. Este programa computacional, baseado no método dos elementos finitos, divide a seção transversal dos elementos em número discreto de filamentos de concreto e aço e a integração das áreas dos filamentos é feita considerando o comportamento não-linear e dependente do tempo dos materiais, assim como o processo evolutivo da construção. 
A seguir, são apresentadas as bases do programa computacional CONSNOU, assim como uma avaliação do mesmo através da simulação de estruturas reais analisadas em laboratório.

\subsection{Propriedades dos materiais}

A fim de incorporar propriedades de materiais variados dentro da estrutura, o elemento é dividido em um número discreto de filamentos de concreto e aço, como mostrado na figura 3.1, assumindo que cada um dos filamentos apresente um estado uniaxial de tensão. Assume-se ainda que as seções planas permanecem planas e são desprezadas as deformações por cisalhamento. A deformação total em um determinado tempo e ponto da estrutura $\varepsilon(\mathrm{t})$, é obtida diretamente pela soma das parcelas da deformação mecânica $\varepsilon^{\mathrm{m}}(\mathrm{t})$ e deformação não mecânica $\varepsilon^{\mathrm{nm}}(\mathrm{t})$. Ou seja,

$$
\begin{aligned}
& \varepsilon(\mathrm{t})=\varepsilon^{\mathrm{m}}(\mathrm{t})+\varepsilon^{\mathrm{nm}}(\mathrm{t}) \\
& \varepsilon^{\mathrm{nm}}(\mathrm{t})=\varepsilon_{\mathrm{CC}}(\mathrm{t})+\varepsilon_{\mathrm{CS}}(\mathrm{t})+\varepsilon_{\mathrm{T}}(\mathrm{t}) \\
& \text { onde: } \\
& \varepsilon_{\mathrm{CC}}(\mathrm{t}) \text { - deformação devido à fluência do concreto; } \\
& \varepsilon_{\mathrm{CS}}(\mathrm{t}) \text { - deformação devido à retração do concreto; } \\
& \varepsilon_{\mathrm{T}}(\mathrm{t}) \text { - deformação devido à variação térmica. }
\end{aligned}
$$

A contribuição do concreto tracionado entre fissuras (tension stiffening) é introduzida no modelo através da equação constitutiva do concreto na tração. Quando a deformação mecânica de um filamento de concreto atinge a deformação correspondente à sua resistência à tração, ocorre a fissuração. Então, a tensão não se anula imediatamente, mas diminui gradualmente enquanto a deformação aumenta, como mostrada na figura 3.2, de acordo com a curva proposta por CARREIRA \& CHU (1986) que é dada por: 
$\sigma_{\mathrm{t}}(\varepsilon)=\mathrm{ft}_{\mathrm{t}} \cdot\left[\frac{\beta \cdot\left(\frac{\varepsilon}{\varepsilon_{\mathrm{t}}}\right)}{\beta-1+\left(\frac{\varepsilon}{\varepsilon_{\mathrm{t}}}\right)^{\beta}}\right]$

onde:

$\mathrm{f}_{\mathrm{t}} \quad$ - resistência do concreto à tração;

$\varepsilon_{\mathrm{t}}-$ deformação correspondente à tensão $\mathrm{f}_{\mathrm{t}}$;

$\beta$ - parâmetro que depende da forma do diagrama tensão $\mathrm{x}$ deformação.

Existe um grande número de trabalhos que fizeram a consideração da contribuição do concreto tracionado entre fissuras através da modificação do diagrama constitutivo do concreto tracionado, podendo citar entre eles, ALWIS et al. (1994), BAZANT \& OH (1984), CERVENKA (1985), HSU \& ZHANG (1996), HU \& SCHNOBRICH (1990), LEIBENGOOD et al. (1986), MASSICOTTE et al. (1990), OWEN et al. (1983), RAJASHEKHAR \& ELLINGWOOD (1995), SATHURAPPAN et al. (1992), SUN et al. (1993) e TORRES (2001).

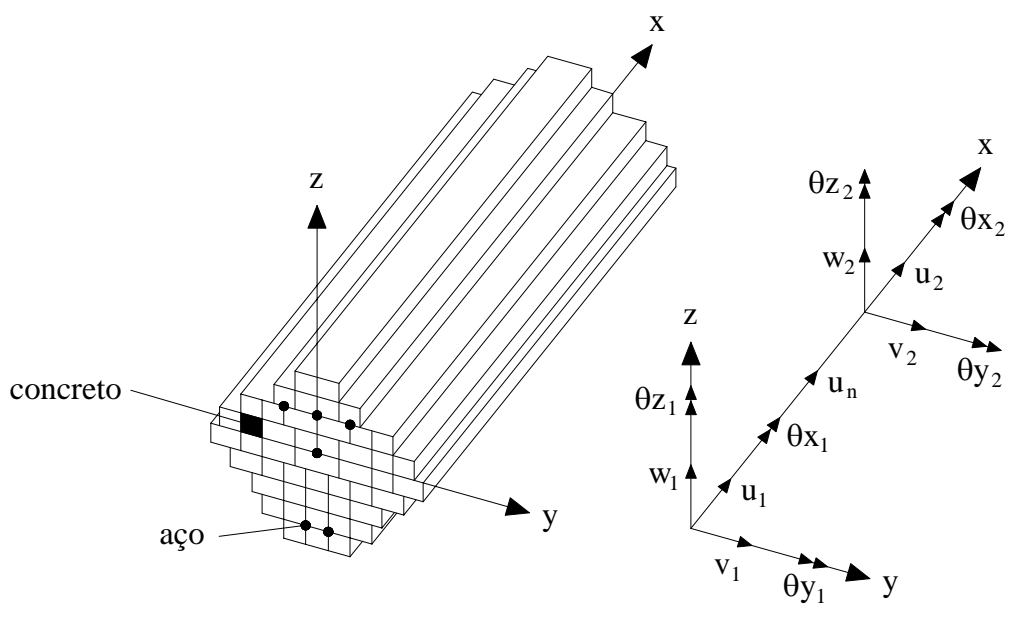

FIGURA 3.1 - Elemento finito 


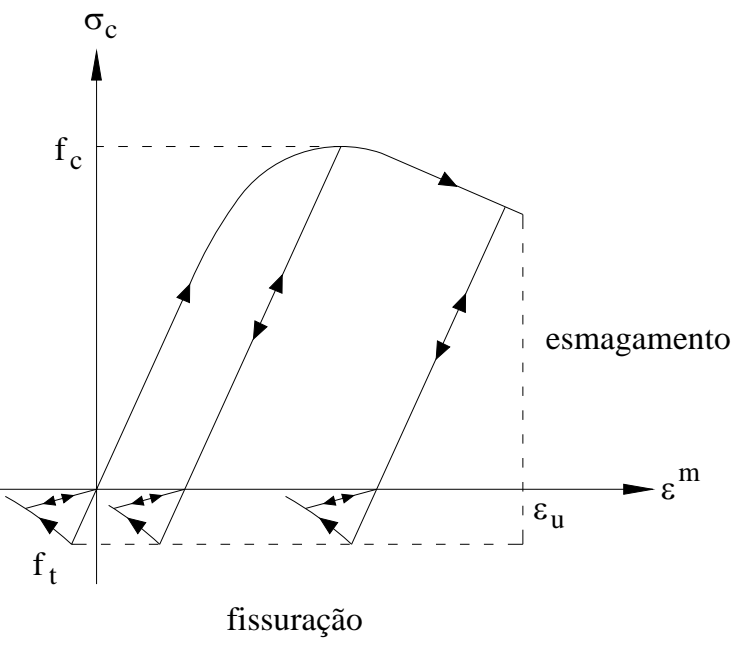

FIGURA 3.2 - Diagrama tensão x deformação uniaxial do concreto

Para o aço da armadura passiva, assume-se uma relação tensão $\mathrm{x}$ deformação bilinear, conforme figura 3.3. Enquanto que para o aço de protensão é usada uma curva tensão x deformação multilinear, como mostrado na figura 3.4.

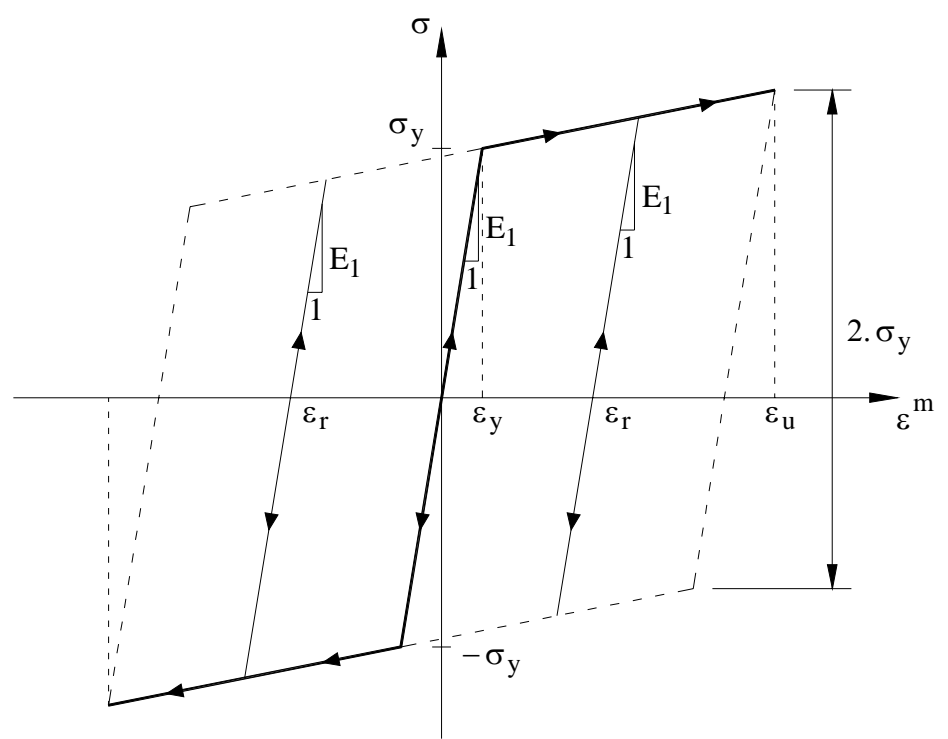

FIGURA 3.3 - Diagrama tensão x deformação uniaxial do aço da armadura passiva 


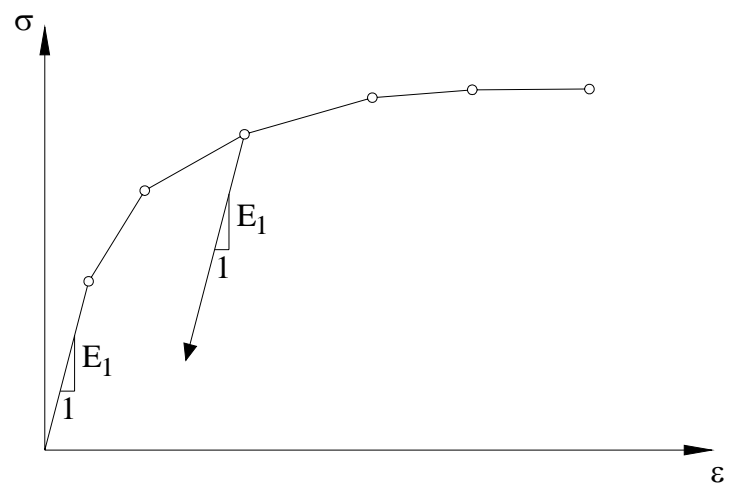

FIGURA 3.4 - Diagrama tensão x deformação uniaxial do aço de protensão

\subsection{Comportamento diferido do concreto}

A deformação por fluência do concreto $\varepsilon_{\mathrm{cc}}(\mathrm{t})$ é avaliada através da solução da integral de superposição dada por:

$$
\begin{aligned}
& \varepsilon_{\mathrm{CC}}(\mathrm{t})=\int_{0}^{\mathrm{t}} \mathrm{C}(\mathrm{t}, \tau) \mathrm{d} \sigma(\tau) \\
& \text { onde } \mathrm{C}(\mathrm{t}, \tau) \text { é a fluência específica, dependente da idade } \tau \text { em que } \\
& \text { começou agir a tensão } \sigma(\tau) \text {. }
\end{aligned}
$$

Como já foi visto, a análise da fluência pode ser feita dividindo o intervalo de tempo total em intervalos de tempo $\Delta \mathrm{t}$, separados por passos de tempo. Com isso, a integral anterior pode ser aproximada por uma soma finita envolvendo acréscimos incrementais de tensão sobre os passos de tempo. A forma adotada para a fluência específica é a série de Dirichlet, dada por:

$$
C(t, \tau)=\sum_{i=1}^{m} a_{i}(\tau) \cdot\left[1-e^{-\lambda_{i} \cdot(t-\tau)}\right]
$$

em que os coeficientes $\mathrm{m}, \lambda_{\mathrm{i}}$ e $\mathrm{a}_{\mathrm{i}}(\tau)$ são obtidos mediante um ajuste, pelo método dos mínimos quadrados, aos valores experimentais ou fórmulas empíricas, como aquelas recomendadas por normas. 
Foram utilizados três termos da série de Dirichlet, ou seja, $\mathrm{m}=3$ e adotou-se $\lambda_{\mathrm{i}}=10^{-\mathrm{i}}$. Além disso, a curva utilizada para o ajuste da série de Dirichlet foi obtida através das recomendações do CEB-90 (1991).

Substituindo a fluência específica, representada pela série de Dirichlet, na equação 3.4 e assumindo variação linear de tensão $\sigma(t)$ e dos valores $\mathrm{a}_{\mathrm{i}}(\mathrm{t})$ dentro de cada passo de tempo $\Delta \mathrm{t}_{\mathrm{n}}=\mathrm{t}_{\mathrm{n}}-\mathrm{t}_{\mathrm{n}-1}$, obtém-se a seguinte relação recursiva para o valor do incremento de deformação por fluência $\Delta \varepsilon_{\mathrm{cc}}\left(\mathrm{t}_{\mathrm{n}}\right)$, no intervalo $\Delta \mathrm{t}_{\mathrm{n}}$ :

$$
\begin{aligned}
& \Delta \varepsilon_{\mathrm{CC}}\left(\mathrm{t}_{\mathrm{n}}\right)=\sum_{\mathrm{i}=1}^{\mathrm{m}} \mathrm{A}_{\mathrm{i}, \mathrm{n}} \cdot\left(1-\mathrm{e}^{-\lambda_{\mathrm{i}} \cdot \Delta \mathrm{t}_{\mathrm{n}}}\right)+\Delta \sigma_{\mathrm{n}} \cdot \Psi_{1} \\
& \Psi_{1}=\sum_{\mathrm{i}=1}^{\mathrm{m}} \mathrm{a}_{\mathrm{i}}\left(\mathrm{t}_{\mathrm{n}-1}\right) \cdot \mathrm{B}_{\mathrm{i}}+\mathrm{b}_{\mathrm{i}}\left(\mathrm{t}_{\mathrm{n}}\right) \cdot\left(\frac{\lambda_{\mathrm{i}} \cdot \Delta \mathrm{t}_{\mathrm{n}}}{2}-\mathrm{B}_{\mathrm{i}}\right) \\
& \mathrm{B}_{\mathrm{i}}=1-\frac{\lambda_{\mathrm{i}}-\mathrm{e}^{-\lambda_{\mathrm{i}} \cdot \Delta \mathrm{t}_{\mathrm{n}}}}{\lambda_{\mathrm{i}} \cdot \Delta \mathrm{t}_{\mathrm{n}}} ; \mathrm{b}_{\mathrm{i}}\left(\mathrm{t}_{\mathrm{n}}\right)=\frac{\mathrm{a}_{\mathrm{i}}\left(\mathrm{t}_{\mathrm{n}}\right)-\mathrm{a}_{\mathrm{i}}\left(\mathrm{t}_{\mathrm{n}-1}\right)}{\lambda_{\mathrm{i}} \cdot \Delta \mathrm{t}_{\mathrm{n}}} \\
& \mathrm{A}_{\mathrm{i}}\left(\mathrm{t}_{\mathrm{n}}\right)=\mathrm{A}_{\mathrm{i}}\left(\mathrm{t}_{\mathrm{n}-1}\right) \cdot \mathrm{e}^{-\lambda_{\mathrm{i}} \cdot \Delta \mathrm{t}_{\mathrm{n}}}+\left[\mathrm{a}_{\mathrm{i}}\left(\mathrm{t}_{\mathrm{n}-1}\right) \cdot\left(1-\mathrm{B}_{\mathrm{i}}\right)+\mathrm{b}_{\mathrm{i}}\left(\mathrm{t}_{\mathrm{n}-1}\right) \cdot \mathrm{B}_{\mathrm{i}}\right] \cdot \Delta \mathrm{t}_{\mathrm{n}} \\
& \mathrm{A}_{\mathrm{i}}\left(\mathrm{t}_{\mathrm{o}}\right)=0
\end{aligned}
$$

Como o incremento de deformação por fluência $\Delta \varepsilon_{\mathrm{cc}}\left(\mathrm{t}_{\mathrm{n}}\right)$ para o intervalo $\Delta \mathrm{t}_{\mathrm{n}}$ depende da mudança da tensão $\Delta \sigma_{\mathrm{n}}$, na equação 3.6 esta relação deve ser avaliada iterativamente em cada passo de tempo. Este fato, contudo, não introduz uma modificação substancial no esquema de solução, já que iterações são necessárias para resolver o problema não linear. A relação recursiva das equações 3.6 a 3.10 evita o armazenamento de todo o histórico de tensão, sendo necessário armazenar apenas a tensão e uma variável interna do último passo de tempo, como já foi ressaltado no capítulo anterior.

\subsection{Elemento finito}

A análise da estrutura é realizada utilizando elementos de finitos unidos entre si. Cada elemento tem um comprimento e uma seção transversal prismática de 
forma arbitrária, composta por um certo número de filamentos de concreto e aço, como mostrado na figura 3.1. Cada filamento é geometricamente definido por sua área e posição em relação ao eixo local da seção. Cada filamento pode ser constituído de diferentes tipos de concreto ou aço, podendo, com isso, estudar os efeitos de distribuições arbitrárias de deformações por retração ou térmicas. Para cada elemento finito, considera-se a armadura passiva constante ao longo do elemento e paralelo ao seu eixo longitudinal.

Existe a possibilidade ainda de considerar a atuação de um número discreto de cabos protendidos na estrutura, cada um tendo um perfil e área da seção transversal constante ao longo do seu comprimento. Cada cabo de protensão é composto por um número discreto de segmentos retilíneos, sendo que a localização dos dois pontos extremos de um segmento é definida pelas excentricidades locais $e_{y}$ e $e_{z}$ em cada extremo, como mostrado na figura 3.5.

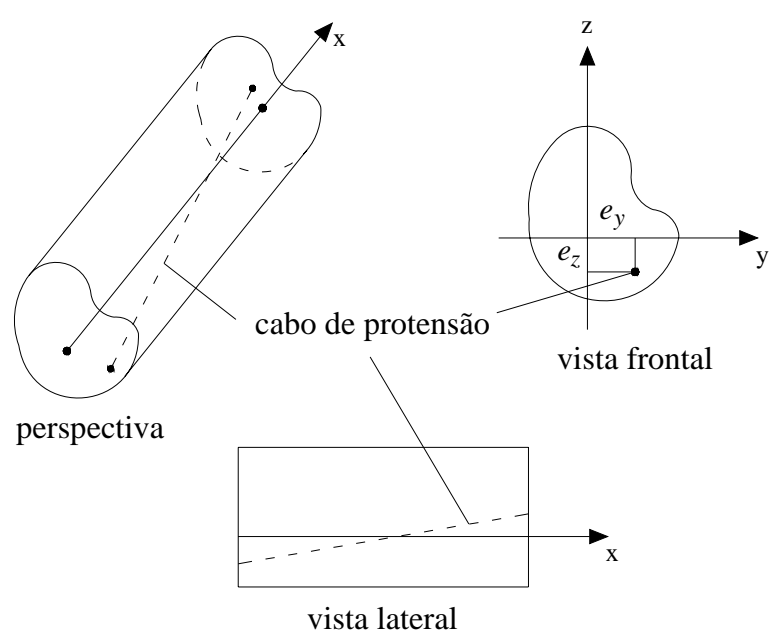

FIGURA 3.5 - Elemento finito com armadura de protensão

O elemento finito utilizado possui seis graus de liberdade, três deslocamentos e três rotações, associados a cada nó extremo, e um deslocamento axial associado a um nó interno localizado na metade do comprimento do elemento. O campo de deslocamentos considerado para o elemento é de polinômios cúbicos para os deslocamentos transversais e rotações na extremidade do elemento, funções lineares para os deslocamentos axiais e rotações na extremidade do elemento e 
quadrática para o grau de liberdade axial intermediário. Estas funções de forma levam a uma solução exata nos deslocamentos e deformações para o caso de vigas prismática, com seção transversal constante, carregadas nos nós extremos. E para o caso da análise de vigas de seção variável, deveria ser usados polinômios de maior grau. Contudo, vigas de seção variável poderiam ser analisadas com uma aproximação razoável utilizando as funções de forma descritas anteriormente se fossem divididas em um número suficiente de pequenos elementos prismáticos com seções transversais diferentes.

A deformação axial $\varepsilon_{X}$ para qualquer ponto dentro do elemento pode ser obtida assumindo a hipótese cinemática de Euler - Navier - Bernoulli de que seções transversais planas e ortogonais ao eixo antes da deformação permanecem planas, indeformadas e normais ao eixo após a deformação. A matriz de rigidez elástica do elemento é obtida pela seguinte expressão:

$$
\mathrm{K}_{\mathrm{e}}=\int_{\mathrm{V}} \mathrm{B}^{\mathrm{T}} \cdot \mathrm{E} \cdot \mathrm{B} \mathrm{dV}
$$

onde

E - módulo tangente do material;

B - matriz que relaciona deformações aos deslocamentos nodais.

O vetor de cargas internas devido às tensões nos filamentos de concreto e aço, pode ser avaliado por:

$$
\mathrm{R}^{\text {int }}=\int_{\mathrm{V}} \mathrm{B}^{\mathrm{T}} \cdot \sigma \mathrm{dV}+\int_{\mathrm{L}} \mathrm{B}_{\theta} \cdot \mathrm{T}_{\mathrm{x}} \mathrm{dx}
$$

onde

$\mathrm{T}_{\mathrm{X}} \quad$ - momento torsor da viga;

$\mathrm{B}_{\theta}$ - componente da matriz $\mathrm{B}$ associado ao grau de liberdade a torção.

O vetor de cargas equivalentes devido à deformação não mecânica $\varepsilon^{\mathrm{nm}}$ é calculado pela seguinte equação:

$$
\mathrm{R}^{\mathrm{nm}}=\int_{\mathrm{V}} \mathrm{B}^{\mathrm{T}} \cdot \mathrm{E} \cdot \varepsilon^{\mathrm{nm}} \mathrm{dV}
$$


As propriedades dos materiais do concreto e aço para qualquer tempo ou nível de carga dependem da relação tensão x deformação não-linear, fissuração e esmagamento do concreto e escoamento da armadura. A matriz de rigidez do elemento e as forças internas para qualquer tempo são avaliadas pela integração sobre o volume do elemento considerando a contribuição de cada filamento de concreto ou aço na seção transversal e cada segmento de aço de protensão dentro do elemento. A integração numérica é realizada utilizando quadratura gaussiana com dois pontos de Gauss.

\subsection{Efeito da protensão}

O efeito da protensão é introduzido na análise da estrutura como um vetor de cargas equivalentes obtido pelo equilíbrio das forças nos cabos.

Pode-se determinar o incremento de deformação $\Delta \varepsilon_{\mathrm{p}}$ de um segmento de aço de protensão aderido ao concreto para qualquer estágio de análise, dividindo o incremento de comprimento do segmento pelo seu comprimento original. O valor do incremento de comprimento é obtido dos deslocamentos e rotações de ambas as extremidades do elemento, como mostrado na figura 3.6. E assim, a deformação $\varepsilon_{\mathrm{p}}$ para qualquer estágio é obtida da soma de $\Delta \varepsilon_{\mathrm{p}}$ com a deformação total do estágio anterior. A tensão $\sigma_{\mathrm{p}}$ correspondente à deformação $\varepsilon_{\mathrm{p}}$ é obtida através da relação tensão x deformação do aço de protensão. A tensão para qualquer estágio é então computada subtraindo a tensão de relaxação da tensão obtida no estágio anterior. 


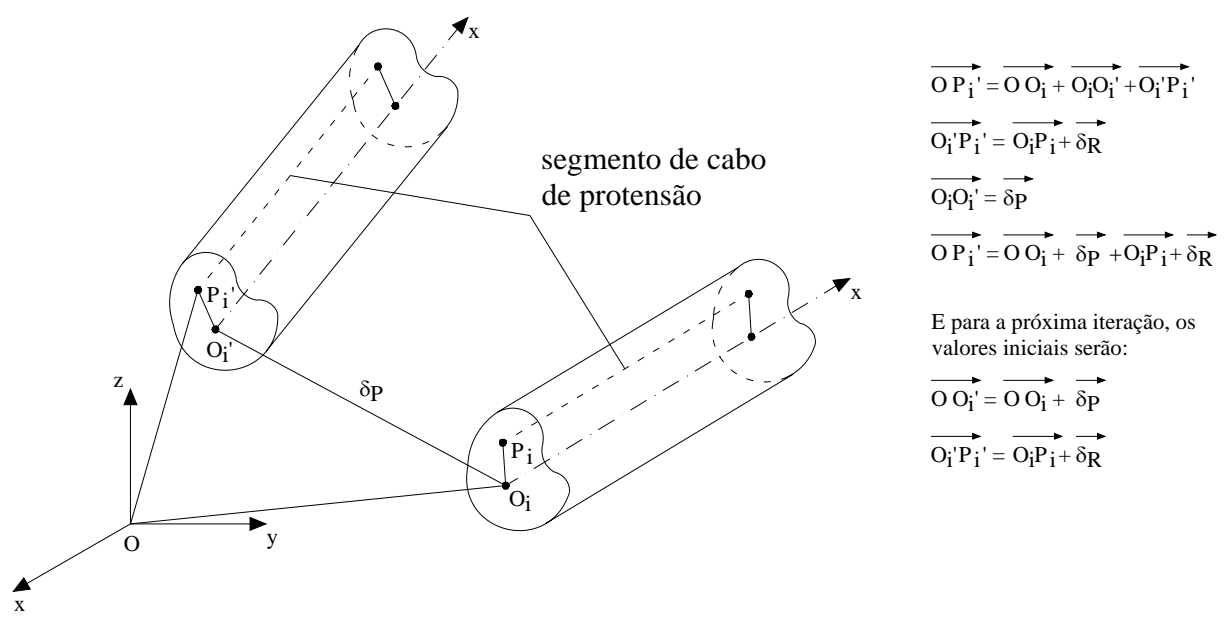

FIGURA 3.6 - Deformação de um segmento de cabo de protensão

As variações de tensão no aço de protensão produzidas pela relaxação são levadas em conta em conjunto com o resto das deformações produzidas nos passos de carga ou de tempo por compatibilidade com o concreto desta fibra mediante o método da tensão fictícia inicial. Quando no começo de um intervalo de tempo, ocorre a mudança na tensão no cabo, devido a outras causas que não a relaxação, define-se uma tensão fictícia inicial de modo que esta tensão inicial produziria, no instante atual, a tensão conhecida se fosse considerada uma curva de relaxação pura. E então, a relaxação da tensão durante o intervalo de tempo atual é calculada usando a curva de relaxação pura através da seguinte equação desenvolvida por MAGURA et al. (1964), baseada em dados experimentais.

$$
\frac{\sigma_{\mathrm{p}}}{\sigma_{\mathrm{pi}}}=1-\frac{\log _{10} \mathrm{t}}{10} \cdot\left(\frac{\sigma_{\mathrm{pi}}}{\sigma_{\mathrm{py}}}-0,55\right), \frac{\sigma_{\mathrm{pi}}}{\sigma_{\mathrm{py}}} \geq 0,55
$$

onde

$\sigma_{\mathrm{pi}} \quad$ - tensão fictícia inicial: aquela com que se deve iniciar o cabo para que sua tensão no tempo t seja $\sigma_{p}$;

$\sigma_{\mathrm{p}} \quad$ - tensão atual no cabo de protensão: é a diferença entre a tensão inicial e as perdas (por relaxação e por deformações elásticas);

$\sigma_{\text {py }}$ - tensão máxima no aço de protensão.

Portanto, como mostrado na figura 3.7, sendo $\sigma_{\mathrm{pi}}$ a tensão inicial aplicada no instante $t_{i}$, no instante $t_{1}$ a tensão terá variado como conseqüência da 
relaxação $\left(\Delta \sigma_{\text {pr1 }}\right)$ e das demais deformações. Mediante a equação 3.14, pode-se calcular a tensão fictícia inicial $\sigma_{\mathrm{pi}, 1}$ que se fosse aplicado em $\mathrm{t}_{\mathrm{i}}$ teria conduzido a $\sigma_{\mathrm{p} 1}$ no instante $\mathrm{t}_{1}$. Usando $\sigma_{\mathrm{pi}, 1}$ pode-se determinar a perda por relaxação no período de tempo entre $t_{1}$ e $t_{2}$. E assim por diante pode-se aplicar esta seqüência a qualquer intervalo de tempo em um método passo a passo.

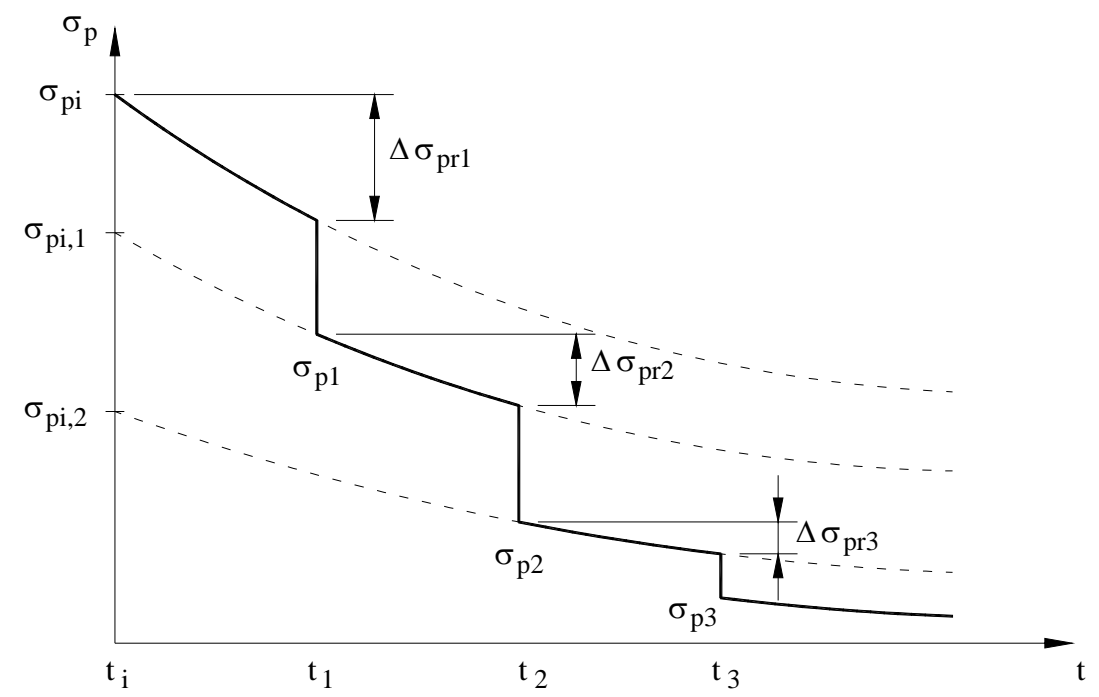

FIGURA 3.7 - Relaxação com deformação variável

\subsection{Processo construtivo}

As estruturas de engenharia são construídas seqüencialmente, ou seja, durante o período de construção, a geometria e o peso da estrutura se modificam com a adição de uma nova parte. Simultaneamente, as restrições dos deslocamentos podem modificar, devido à mudança na natureza, número ou localização dos apoios. Esta evolução da rigidez, esquema estático e peso da estrutura conduzem a mudanças repentinas na distribuição de tensões e deslocamentos instantâneos. Se o comportamento dos materiais constituintes for dependente do tempo, estas mudanças podem causar significativa redistribuição dos esforços internos e deslocamentos diferidos durante a vida útil da estrutura. Como conseqüência, as condições de segurança e utilização podem ser afetadas devido à fissuração inesperada ou deslocamento excessivo, por exemplo. 
A fim de considerar as mudanças estruturais que possa ocorrer durante o processo construtivo e ao longo de toda a vida útil das estruturas, a estrutura é analisada em estágios. Para cada estágio ou fase construtiva, pode-se considerar as mudanças na geometria longitudinal e transversal da estrutura pela adição ou remoção de elementos ou filamentos. Os cabos podem sofrer protensão, desprotensão ou serem removidos a qualquer instante. E os apoios externos ou as uniões entre elementos também podem ser modificados a qualquer momento.

Cada filamento da seção transversal de um dado elemento pode ser constituído de diferentes tipos de concreto, sendo especificado o instante de moldagem ou demolição, para cada tipo de concreto, no início do processamento. Similarmente, para cada filamento de aço, é especificado o instante em que começa atuar na estrutura ou o instante de sua remoção. Quando um filamento de concreto ou aço começa atuar no elemento, sua rigidez é incluída na rigidez do elemento; quando esse filamento é removido, sua rigidez e sua contribuição no vetor de cargas internas não são mais levadas em conta na análise. Neste caso, aparecerá um vetor de cargas desequilibradas no próximo passo de tempo, isto é automaticamente introduzido no procedimento iterativo até o equilíbrio ser obtido.

Variações nas condições de contorno também são reconhecidas pelo modelo, permitindo reproduzir os processos de cimbramento, descimbramento, execução de novos apoios e eliminação dos existentes. Não havendo nenhum problema especial quando um novo apoio é introduzido devido ao procedimento incremental; contudo, a liberação de uma restrição é realizada pela introdução, sobre o novo sistema estrutural, de uma força de igual valor e sentido oposto à reação do apoio removido. Nesses casos, também aparecerão cargas desequilibradas, fazendo com que a análise iterativa restabeleça o equilíbrio na estrutura.

A ligação interna entre elementos pode ser mudada no decorrer do processo construtivo. Ao restringir um grau de liberdade, o problema é solucionado pela adequada consideração da matriz de rigidez do elemento e funções de forma. No caso da liberação da ligação exige também a introdução de forças na extremidade do elemento correspondente ao grau de liberdade liberado, como cargas desequilibradas.

Para cada cabo de protensão, o instante em que ocorre a protensão, reprotensão ou desprotensão também é especificado no começo do processamento, 
sendo que as variações na força nos cabos são introduzidas como forças externas na correspondente fase construtiva.

E assim, o programa computacional pode ser utilizado para a análise de estruturas construídas seqüencialmente, ou seja, estruturas formadas por elementos que são ligados entre si, podendo recebem uma nova camada de concreto para completar a seção transversal, com apoios provisórios ou não, como ilustrado na figura 3.8.

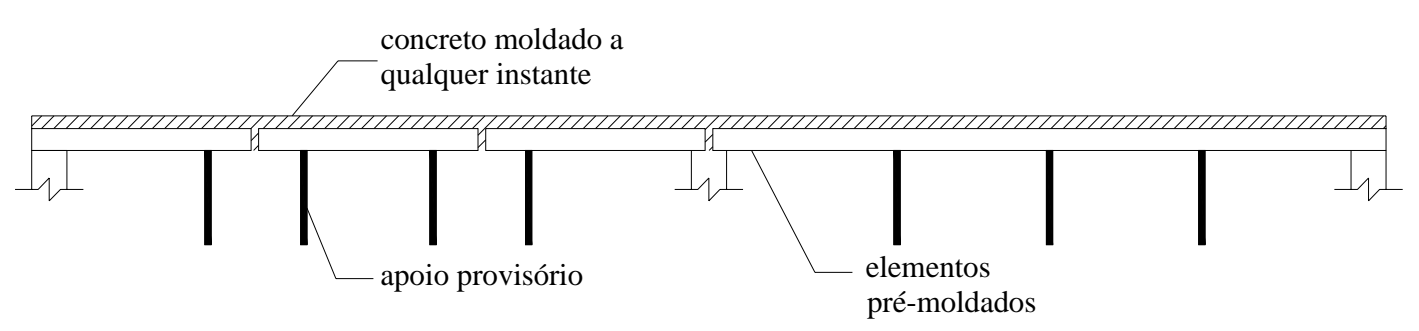

FIGURA 3.8 - Estrutura construída seqüencialmente

O esquema geral do programa computacional é apresentado esquematicamente na figura 3.9, em que os dados de entrada gerais (1) incluem geometria da estrutura, discretização, condições de contorno, propriedades dos materiais, armadura passiva, perfil da armadura de protensão, fases construtivas, condições ambientais, critério de convergência e informações de controle dos dados de saída. Os dados de entrada de cada fase construtiva (2) incluem variações da geometria, condições de contorno, carregamento, protensão, além dos intervalos de tempo entre as fases construtivas e os passos de carga. 


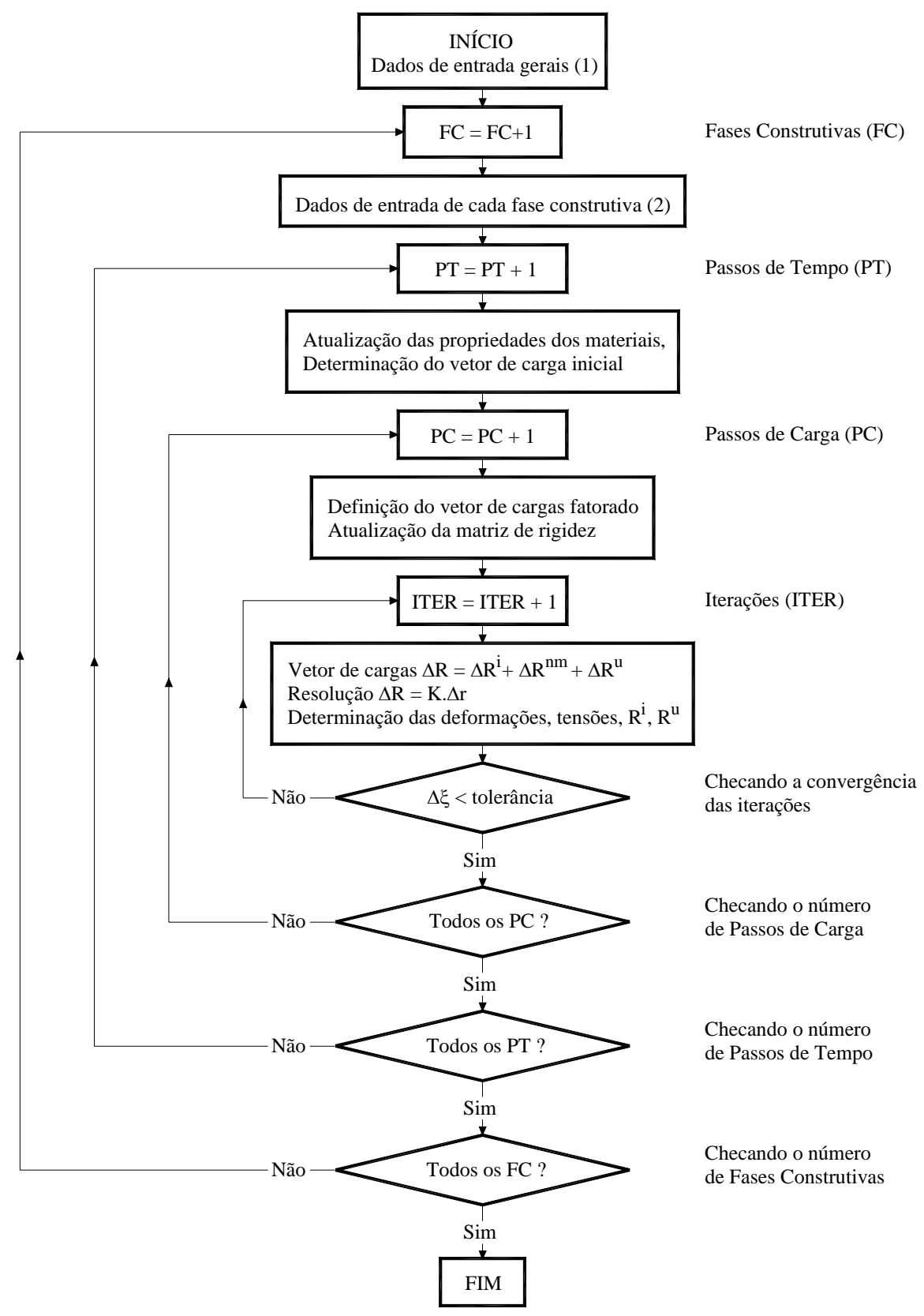

FIGURA 3.9 - Fluxograma simplificado

\subsection{Solução do algoritmo}

A fim de incorporar a não linearidade e o efeito dependente do tempo da estrutura de concreto, o domínio do tempo é dividido em intervalos e os incrementos de deslocamentos e deformações obtidos da integração de cada passo é adicionado aos valores obtidos anteriormente, percorrendo, assim, todo o domínio do tempo. 
Define-se um número de fases construtivas ao longo do domínio do tempo, sendo cada fase uma situação da estrutura em que pode variar sua geometria, carregamento ou condição de contorno. Para cada fase construtiva, deve-se definir a protensão atuante, cargas externas, distribuições de temperatura, curvas tensão $\mathrm{x}$ deformação, propriedades dos materiais ao longo do tempo e esquema estrutural.

O tempo transcorrido de uma fase construtiva para outra é subdividido em intervalos de tempo, separados por passos de tempo. As propriedades dos materiais, matriz de rigidez e vetor de cargas são atualizados para cada passo de tempo. Durante o intervalo de tempo $t_{n-1}$ a $t_{n}$ são avaliados os incrementos de deformações não mecânicas $\Delta \varepsilon^{\mathrm{nm}}$ ocorridos devido à fluência e retração do concreto e mudanças térmicas. E então, os incrementos de cargas equivalentes $\Delta \mathrm{R}^{\mathrm{nm}}$ para o tempo $\mathrm{t}_{\mathrm{n}}$ são calculados de seus respectivos incrementos de deformações não mecânicas $\Delta \varepsilon^{\mathrm{nm}}$. E assim, para um tempo $\mathrm{t}_{\mathrm{n}}$, o incremento de carga $\Delta \mathrm{R}_{\mathrm{n}}$ a ser aplicado na estrutura é obtido adicionando o incremento de carga externa $\Delta \mathrm{R}_{\mathrm{n}}^{\mathrm{e}}$ e cargas desequilibradas $\mathrm{R}_{\mathrm{n}-1}^{\mathrm{u}}$ do tempo $\mathrm{t}_{\mathrm{n}-1}$ aos incrementos de cargas equivalentes $\Delta \mathrm{R}^{\mathrm{nm}}$ devido às deformações não mecânicas.

$$
\Delta \mathrm{R}_{\mathrm{n}}=\Delta \mathrm{R}_{\mathrm{n}}^{\mathrm{e}}+\Delta \mathrm{R}_{\mathrm{n}}^{\mathrm{nm}}+\mathrm{R}_{\mathrm{n}-1}^{\mathrm{u}}
$$

A carga total obtida para cada passo de tempo é dividida em incrementos de carga. Para cada passo de carga, emprega-se o método dos elementos finitos, resultando em equações de equilíbrio não lineares. Um procedimento iterativo é usado para a resolução das equações de equilíbrio, obtendo-se os incrementos de deslocamentos globais para cada iteração. No começo de cada iteração, são conhecidos todos os deslocamentos nodais, deformações totais, deformações totais não mecânicas e tensões em todos os pontos da estrutura.

Os incrementos de deformação para qualquer filamento de concreto ou aço são obtidos transformando inicialmente o incremento de deslocamentos globais para coordenadas locais do elemento e então, por meio das relações deformaçãodeslocamento, obtém-se os incrementos de deformação. As deformações totais são obtidas adicionando o incremento de deformação ao valor da deformação total 
anterior. A deformação mecânica é calculada subtraindo-se a deformação não mecânica da deformação total e a tensão é obtida pela curva tensão x deformação não linear. O vetor de cargas internas é obtido pela equação 3.12, e o vetor de cargas desequilibradas é obtido subtraindo-o do vetor de cargas externas total.

\subsection{Avaliação do modelo}

Para se avaliar o modelo empregado pelo programa computacional CONSNOU, fez-se o confronto do mesmo com os seguintes resultados de ensaios realizados em laboratório:

- ensaios de curta duração de lajes contínuas formadas por vigotas prémoldadas com armação treliçada realizados por MAGALHÃES (2001) no Laboratório de Estruturas da EESC-USP;

- ensaios de longa duração de lajes formadas por vigotas pré-moldadas com armação treliçada realizados por ROGGE (2001) no Laboratório de Materiais e Sistemas Estruturais do Departamento de Engenharia Civil da UFSCar;

- ensaios de longa duração de vigas reforçadas à flexão no bordo comprimido realizados por REIS (2003) no Laboratório de Estruturas da EESC-USP.

\subsubsection{Ensaios de curta duração de lajes contínuas}

\section{a) Descrição do ensaio}

MAGALHÃES (2001) realizou ensaios de curta duração de três faixas de lajes contínuas constituídas por vigotas pré-moldadas com armação treliçada, elementos de enchimento em poliestireno expandido (EPS) e concreto moldado no local. Os ensaios tiveram o objetivo de analisar a redistribuição dos momentos fletores e para isso cada faixa de laje foi dimensionada considerando-se análise elástico-linear com rigidez constante, supondo redistribuição do momento fletor negativo no apoio de 15\% (modelo M15), 40\% (modelo M40) e um modelo dimensionado com tramos isolados com armadura construtiva para controle de fissuração no apoio intermediário (modelo Mac). 
As características geométricas das lajes podem ser vistas na figura 3.10. Enquanto que os detalhes da vigota, da nervura transversal e da viga de apoio estão mostrados na figura 3.11. E na tabela 3.1 estão apresentadas as armaduras de flexão dispostas em cada modelo.

armadura construtiva

armadura negativa

armadura construtiva

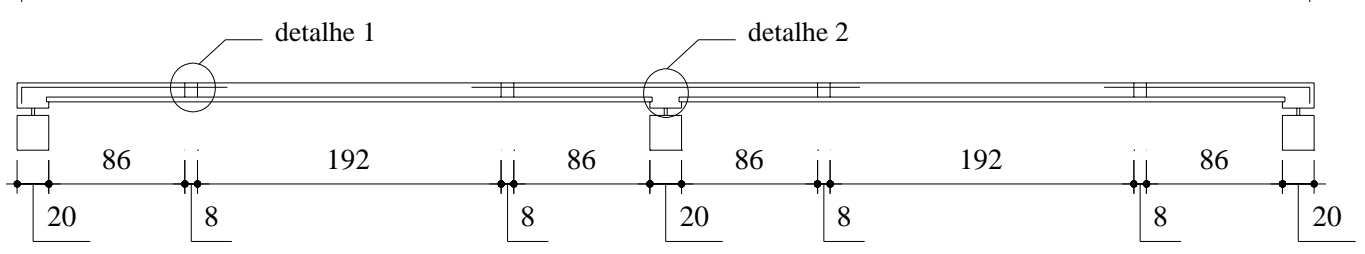

vista longitudinal

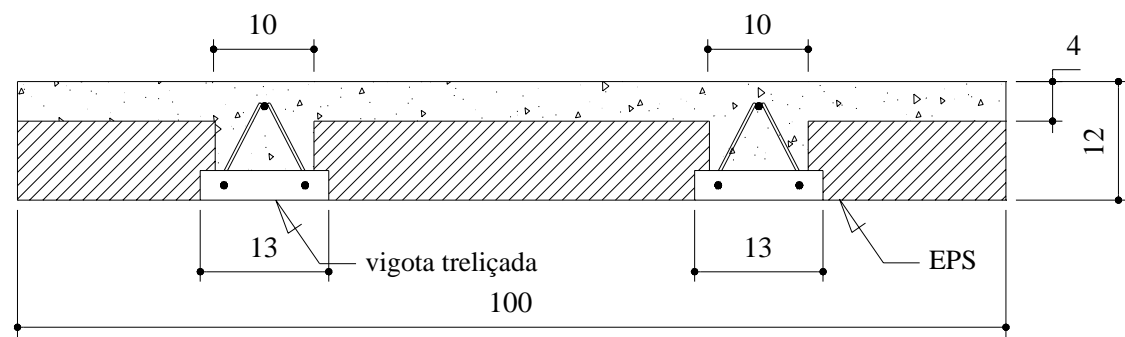

seção transversal

FIGURA 3.10 - Características geométricas (dimensões em cm)

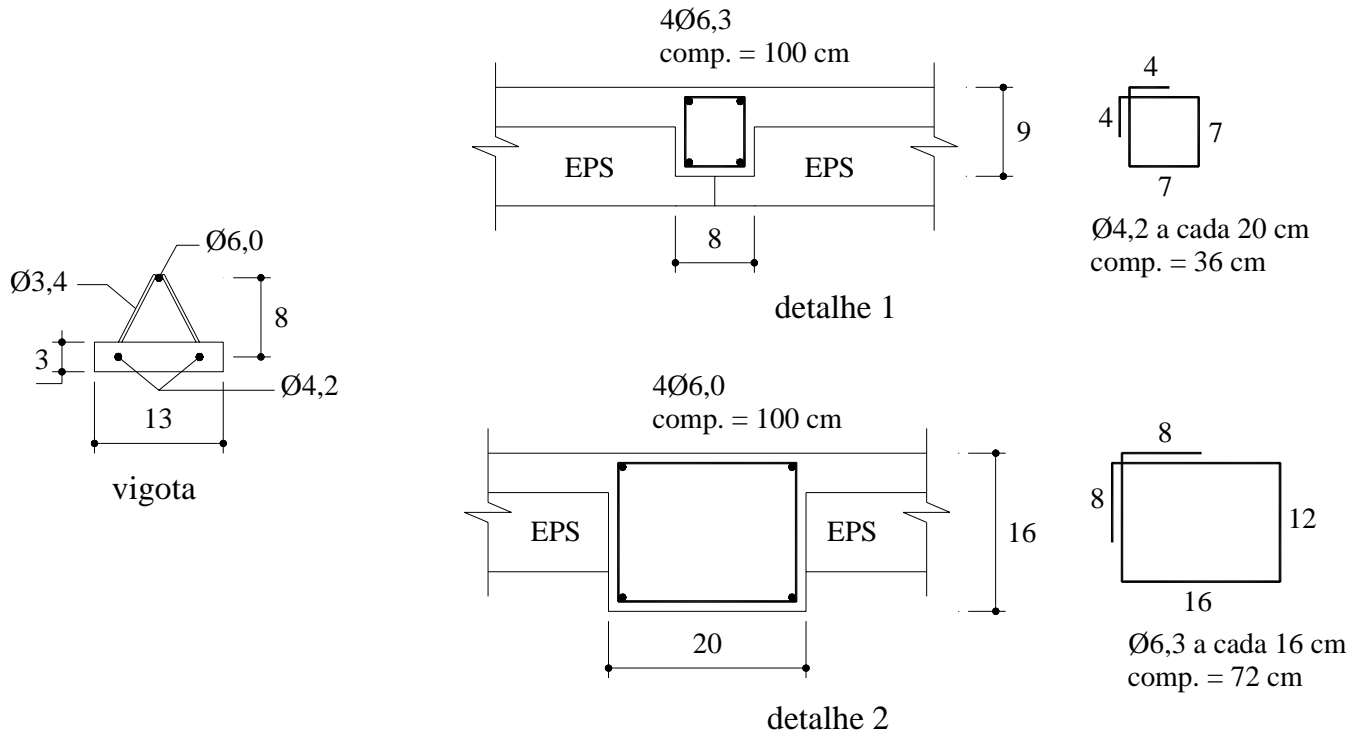

FIGURA 3.11 - Detalhes da vigota, nervura transversal e viga de apoio (dimensões em cm) 
TABELA 3.1 - Armadura de flexão dos modelos

\begin{tabular}{ccc}
\hline Modelo & $\begin{array}{c}\text { Armadura } \\
\text { negativa }\end{array}$ & $\begin{array}{c}\text { Armadura } \\
\text { adicional }\end{array}$ \\
\hline M15 & $8 \phi 6,0$ & $2 \phi 4,2+1 \phi 3,4$ \\
M40 & $5 \phi 6,0$ & $2 \phi 5,0+1 \phi 4,2$ \\
Mac & $6 \phi 4,2$ & $3 \phi 6,0$ \\
\hline
\end{tabular}

O carregamento foi aplicado através de uma estrutura de reação composta basicamente por dois pórticos metálicos e a laje de reação, como mostrado na figura 3.12 .

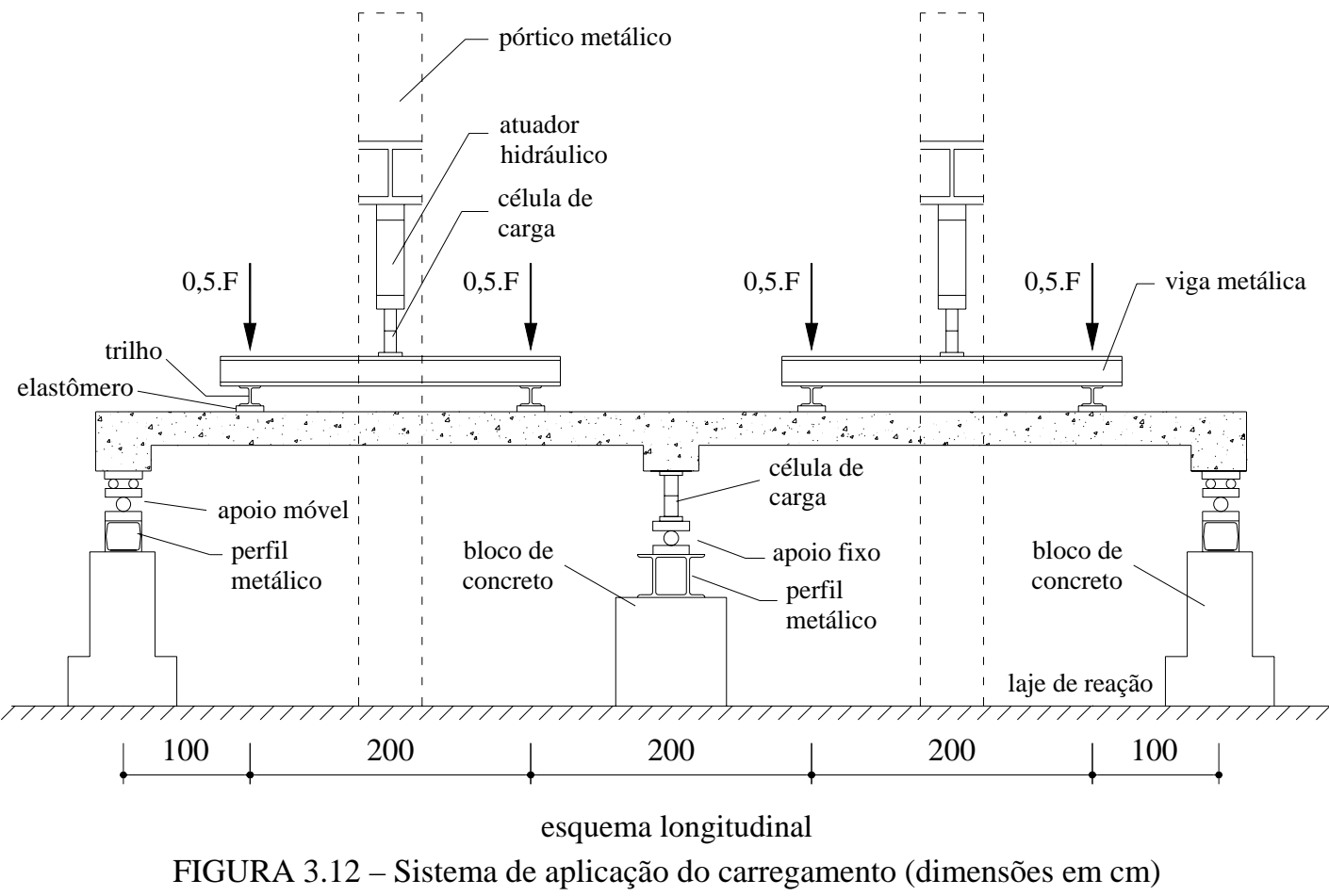

As características mecânicas do concreto foram obtidas a partir de 6 corpos de prova para o concreto pré-moldado da vigota e 18 corpos de prova para o concreto da capa estrutural moldada no local. Dos 6 corpos de prova do concreto prémoldado, 3 foram ensaiados à compressão axial e 3 foram ensaiados à tração a partir do ensaio à compressão diametral. Para o concreto moldado no local, 12 corpos de prova foram ensaiados a compressão axial, entretanto, foram aproveitados os resultados dos ensaios de 10 corpos de prova. Ainda tiveram 4 corpos de prova ensaiados à tração e 2 corpos de prova ensaiados à compressão axial para se obter o módulo de elasticidade longitudinal do concreto. 
Na tabela 3.2 estão apresentados os resultados dos ensaios em corpos de prova dos concretos moldado no local e pré-moldado.

Por conveniência do cronograma de ensaio, todos as faixas de lajes foram concretadas no mesmo dia e ensaiadas com 14, 15 e 16 dias.

TABELA 3.2 - Características mecânicas do concreto

\begin{tabular}{cccccc}
\hline Tipo & $\begin{array}{c}\text { Idade } \\
\text { (dias) }\end{array}$ & $\begin{array}{c}\mathbf{f}_{\mathbf{c m}} \\
(\mathbf{M P a})\end{array}$ & $\begin{array}{c}\mathbf{f}_{\mathbf{c t m}} \\
\mathbf{( M P a )}\end{array}$ & $\begin{array}{c}\mathbf{E}_{\mathbf{c}} \\
(\mathbf{G P a})\end{array}$ & $\begin{array}{c}\mathbf{E}_{\mathbf{c s}} \\
(\mathbf{G P a})\end{array}$ \\
\hline pré-moldado & 54 & 38,9 & 2,8 & - & - \\
moldado no local & 15 & 21,4 & 2,0 & 25,7 & 24,5 \\
\hline
\end{tabular}

Na tabela 3.3 são apresentadas as propriedades das barras utilizadas como armaduras negativas nas faixas de lajes, com diâmetros nominais de 4,2 mm e $6,0 \mathrm{~mm}$.

TABELA 3.3 - Características da armadura negativa

\begin{tabular}{cccccc}
\hline $\begin{array}{c}\phi_{\text {nominal }} \\
(\mathbf{m m})\end{array}$ & $\begin{array}{c}\mathbf{A}_{\mathbf{s}} \\
\left(\mathbf{c m}^{\mathbf{2}}\right)\end{array}$ & $\begin{array}{c}\mathbf{E}_{\mathbf{s}} \\
(\mathbf{G P a})\end{array}$ & $\begin{array}{c}\mathbf{f}_{\mathbf{y}} \\
(\mathbf{M P a})\end{array}$ & $\begin{array}{c}\boldsymbol{\varepsilon}_{\mathbf{y}} \\
(\mathbf{\% o})\end{array}$ & $\begin{array}{c}\mathbf{f}_{\mathbf{u}} \\
(\mathbf{M P a})\end{array}$ \\
\hline 4,2 & 0,139 & 229 & 730 & 5,22 & 813 \\
6,0 & 0,283 & 224 & 660 & 4,95 & 726 \\
\hline
\end{tabular}

Os deslocamentos obtidos no decorrer do ensaio das seções a 1 m do eixo do apoio externo, seção do meio do vão e seção a $1 \mathrm{~m}$ do eixo do apoio interno para as faixas de lajes M15, M40 e Mac estão apresentadas, respectivamente, nas figuras 3.13, 3.14 e 3.15 .

Pelas figuras, pode-se notar que os deslocamentos para as três lajes ficaram próximos entre si. Por exemplo, para a força de $15 \mathrm{kN}$ o deslocamento no meio do vão foi de $16,0 \mathrm{~mm}, 15,9 \mathrm{~mm}$ e $13,2 \mathrm{~mm}$, respectivamente, para as lajes M15, M40 e Mac. Isso ocorreu porque, embora houvesse menor taxa de armadura no apoio da laje com maior redistribuição de momento fletor, esta apresentava maior taxa de armadura no vão. 


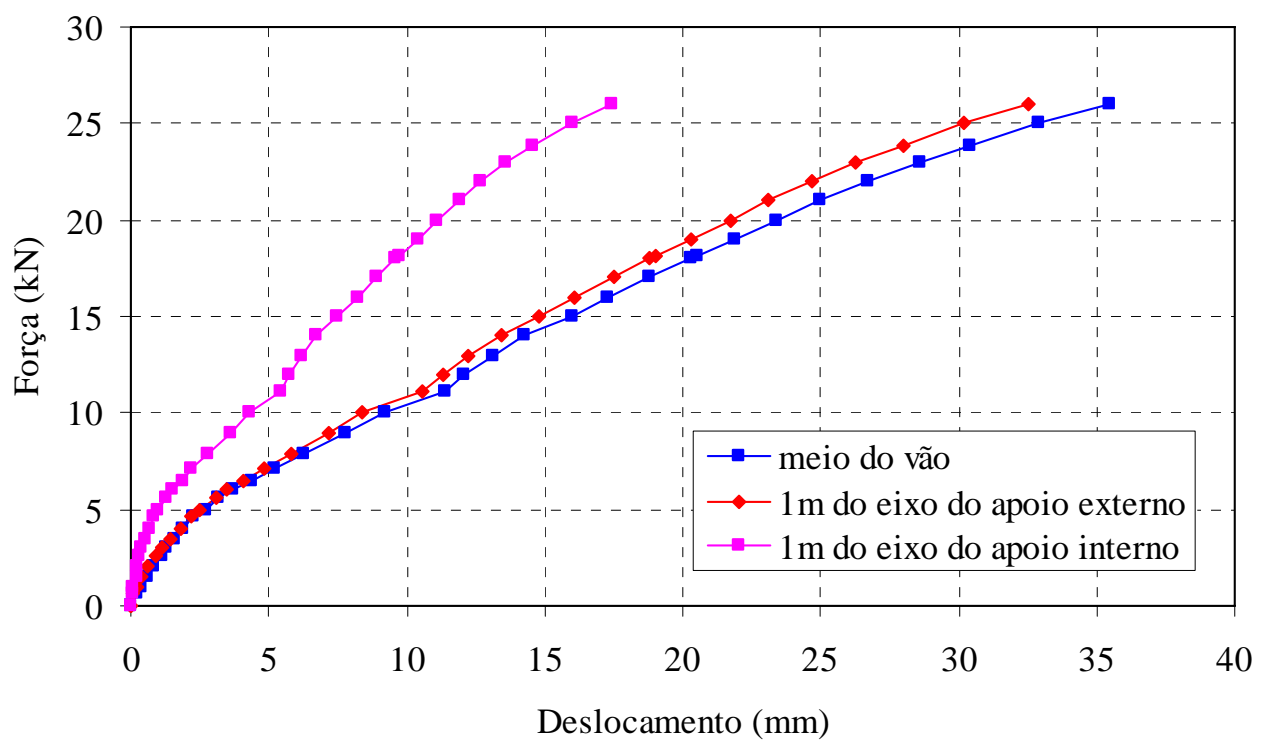

FIGURA 3.13 - Deslocamentos experimentais - M15

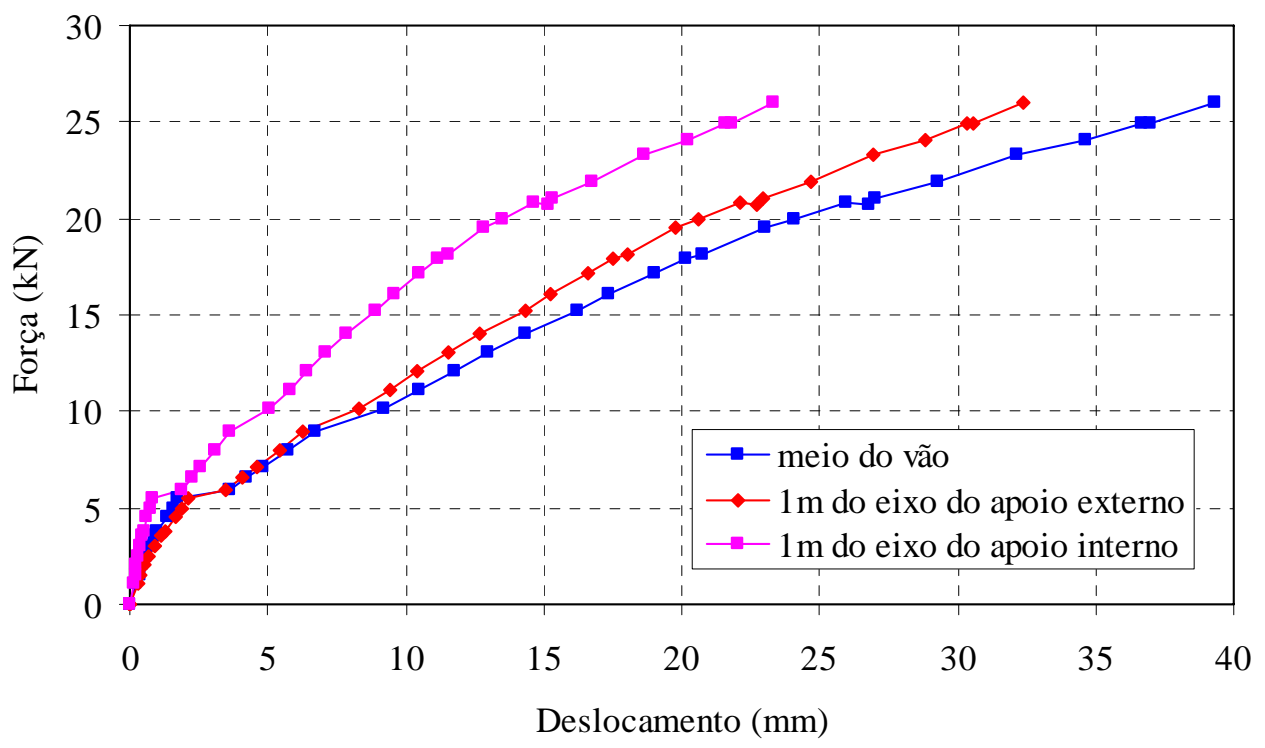

FIGURA 3.14 - Deslocamentos experimentais - M40 


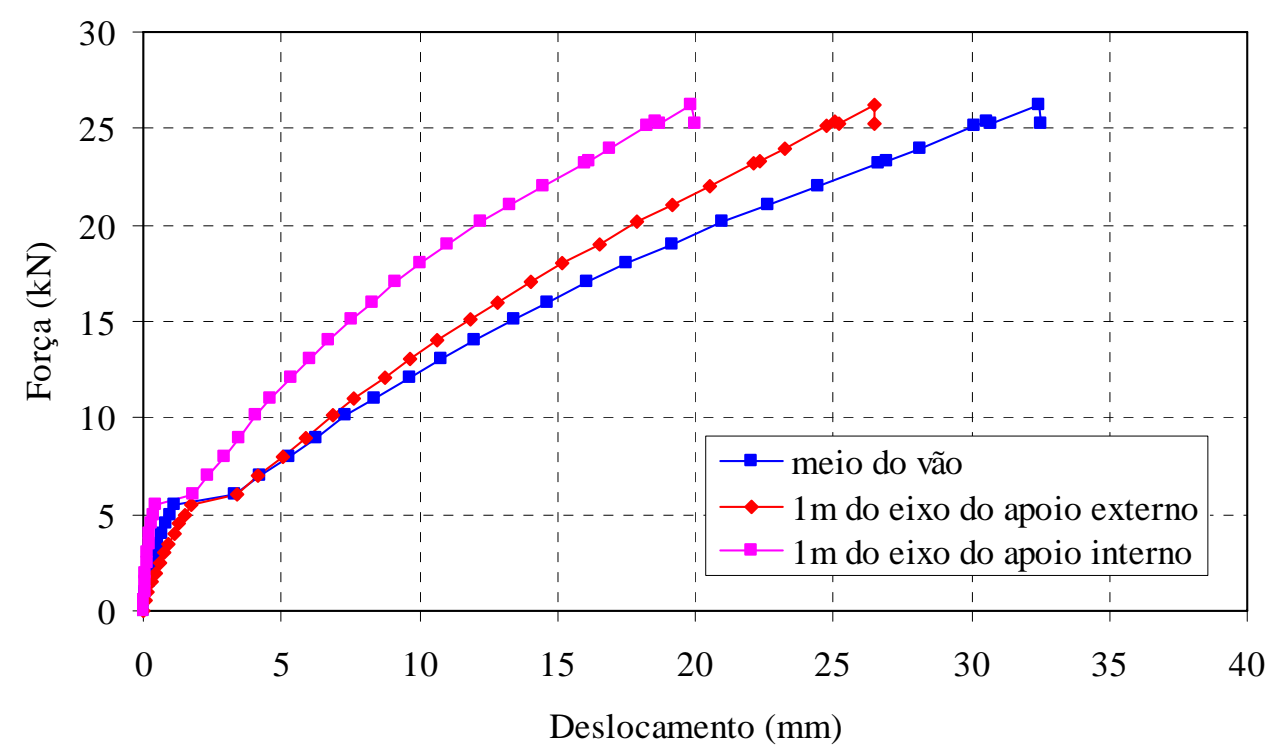

FIGURA 3.15 - Deslocamentos experimentais - Mac

\section{b) Análise numérica}

A análise numérica das faixas de lajes foi realizada tomando-se partido da simetria em relação ao apoio central, como mostrada na figura 3.16. Por esta figura, pode-se verificar a discretização das faixas de lajes, sendo divididas em 40 elementos de 10 cm cada um. Já a seção transversal foi subdividida em 24 camadas de $0,5 \mathrm{~cm}$, como pode ser vista na figura 3.17 .

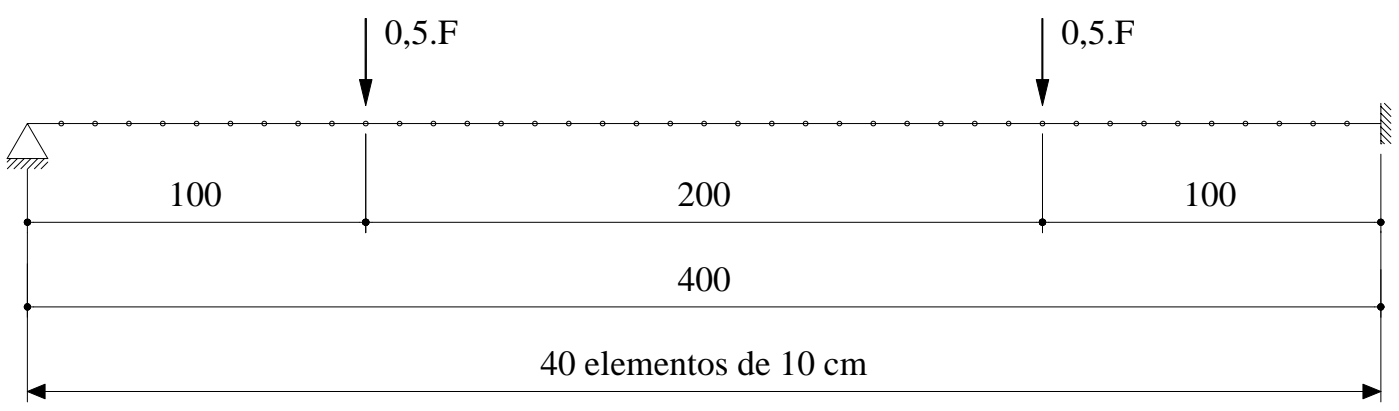

FIGURA 3.16 - Discretização longitudinal (dimensões em cm)

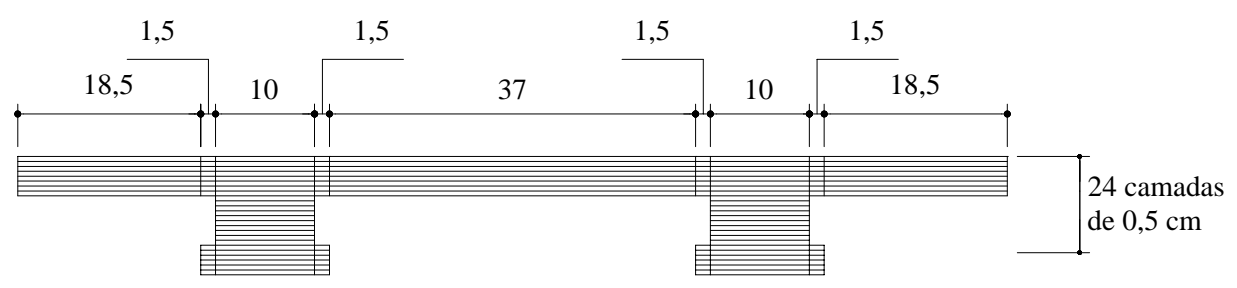

FIGURA 3.17 - Discretização da seção transversal (dimensões em cm) 


\section{c) Comparação entre os resultados}

As comparações entre os deslocamentos experimentais e os obtidos da análise numérica estão apresentadas nas figuras 3.18, 3.19 e 3.20, respectivamente, para os modelos M15, M40 e Mac. Pelas figuras, pode-se verificar que os deslocamentos obtidos da análise numérica ficaram bem próximos dos valores dos deslocamentos experimentais. As seções localizadas a $1 \mathrm{~m}$ do eixo do apoio interno foram as que tiveram melhor concordância entre os resultados numéricos e experimentais, no entanto, mesmo para as outras seções houve boa aproximação, existindo uma mesma tendência dos deslocamentos numéricos e experimentais.

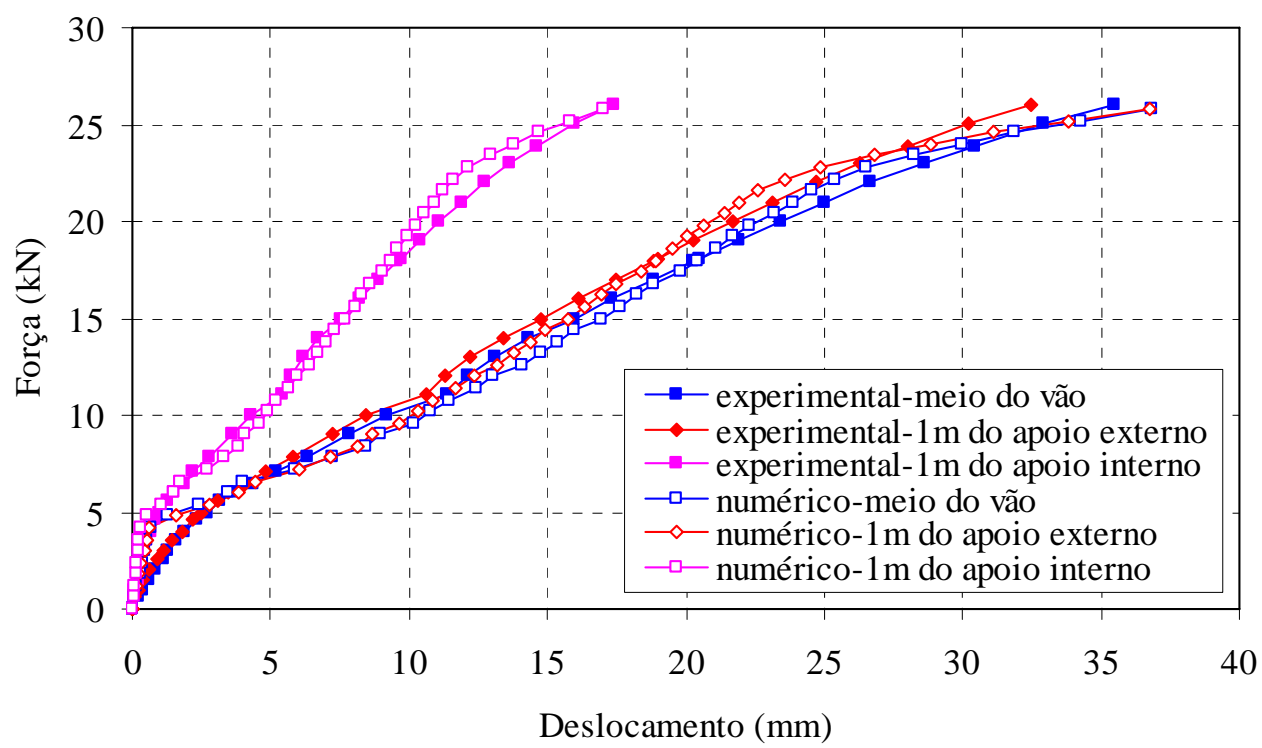

FIGURA 3.18 - Comparação entre os deslocamentos experimentais e da análise numérica - M15 


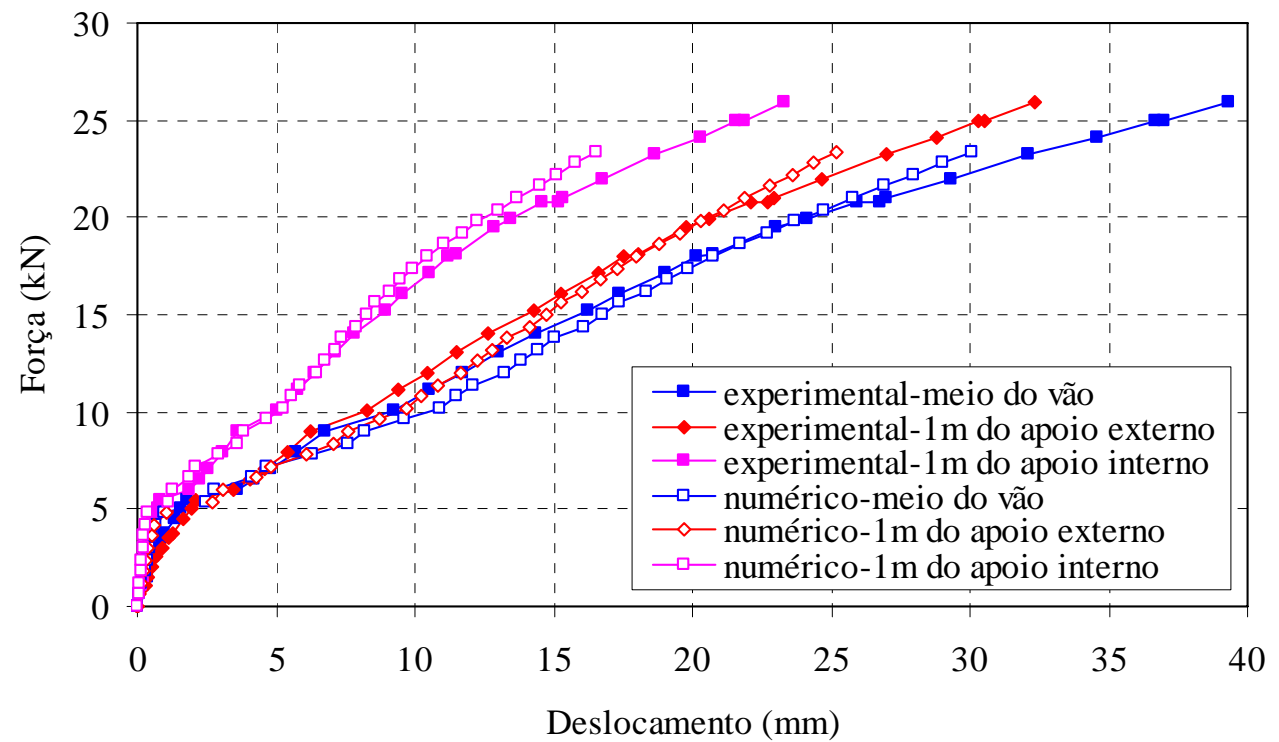

FIGURA 3.19 - Comparação entre os deslocamentos experimentais e da análise numérica - M40

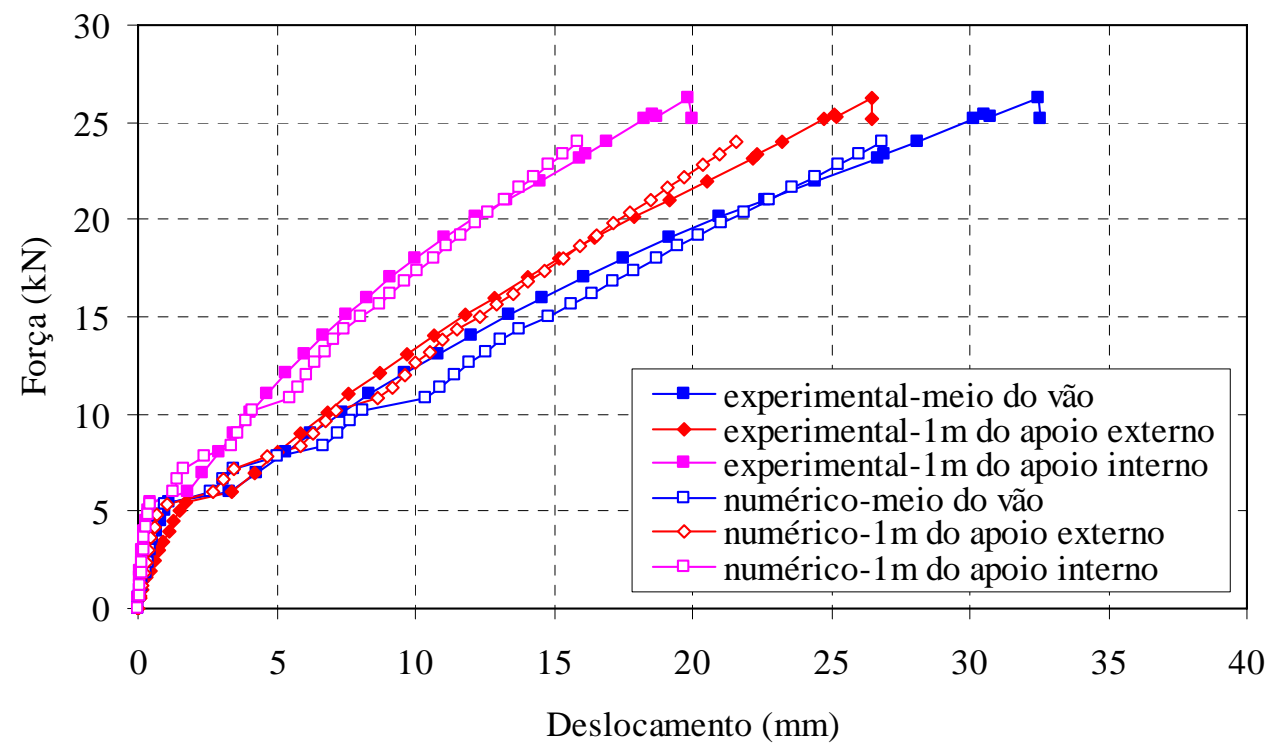

FIGURA 3.20 - Comparação entre os deslocamentos experimentais e da análise numérica - Mac

\subsubsection{Ensaios de longa duração de lajes}

\section{a) Descrição do ensaio}

Os ensaios realizados por ROGGE (2001) tiveram por objetivo avaliar a deformação ao longo do tempo de lajes executadas com vigotas pré-moldadas do tipo armação treliçada. Foi realizada a análise de três lajes simplesmente apoiadas que serão identificadas aqui por L1, L2 e L3 que possuíam as mesmas dimensões e taxas 
de armadura, diferenciando-se em relação à data de retirada do escoramento e a data de aplicação do carregamento. Durante todo o ensaio, as lajes estiveram armazenadas em um galpão coberto e embora não tenha havido o controle da umidade e temperatura ambiente, esses parâmetros foram monitorados continuamente.

Apresentam-se na figura 3.21 as características geométricas das lajes ensaiadas. Enquanto que na tabela 3.4 são especificadas as características das lajes com relação à armadura passiva utilizada e as particularidades de cada uma com relação ao carregamento aplicado.

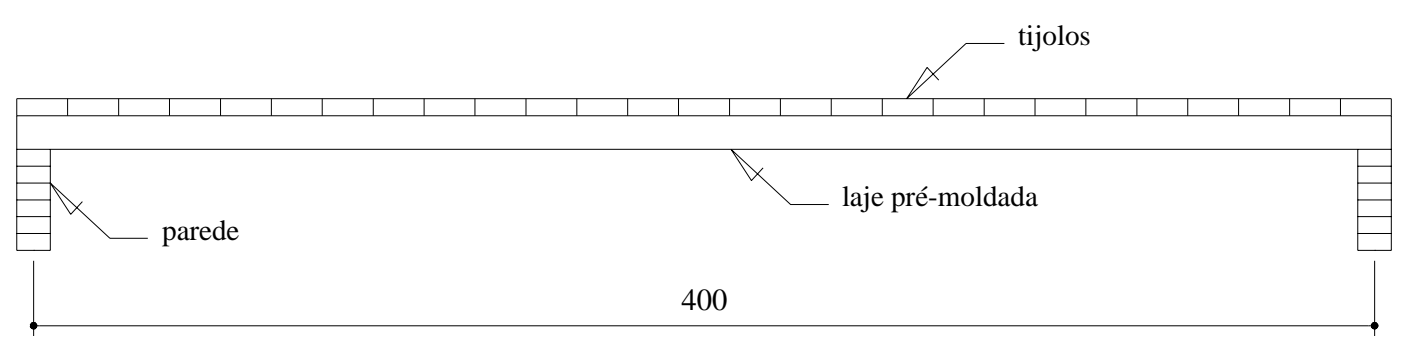

vista longitudinal

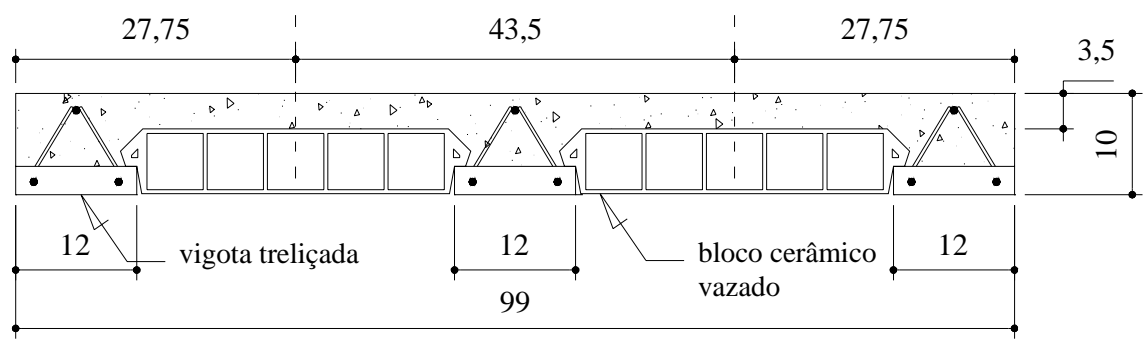

seção transversal

FIGURA 3.21 - Características geométricas (dimensões em cm)

TABELA 3.4 - Características das lajes

\begin{tabular}{cccccc}
\hline Laje & $\begin{array}{c}\text { Área de aço } \\
\text { por nervura } \\
\left(\mathbf{( m}^{2}\right)\end{array}$ & $\begin{array}{c}\text { Área de aço } \\
\text { total } \\
\left.\mathbf{( c m}^{2}\right)\end{array}$ & $\begin{array}{c}\text { Altura útil } \\
\mathbf{( c m )}\end{array}$ & $\begin{array}{c}\text { Retirada do } \\
\text { escoramento } \\
\text { (dias) }\end{array}$ & $\begin{array}{c}\text { Carregamento } \\
\text { (dias) }\end{array}$ \\
\hline L1 & 1,04 & 3,12 & 8,5 & 8 & 35 \\
L2 & 1,04 & 3,12 & 8,5 & 8 & 42 \\
L3 & 1,04 & 3,12 & 8,5 & 28 & 42 \\
\hline
\end{tabular}

Pela figura 3.21 observa-se a presença de tijolos sobre a laje. Este foi o meio empregado para a aplicação de um carregamento distribuído nas lajes. Foram 
dispostos sobre a laje 182 tijolos de 1,55 daN cada, totalizando um carregamento distribuído de $0,705 \mathrm{kN} / \mathrm{m}$ aplicados em cada laje no dia especificado na tabela 3.4.

Pelas figuras 3.22 e 3.23 pode-se verificar, respectivamente, a variação da umidade e temperatura ambiente no decorrer do ensaio.

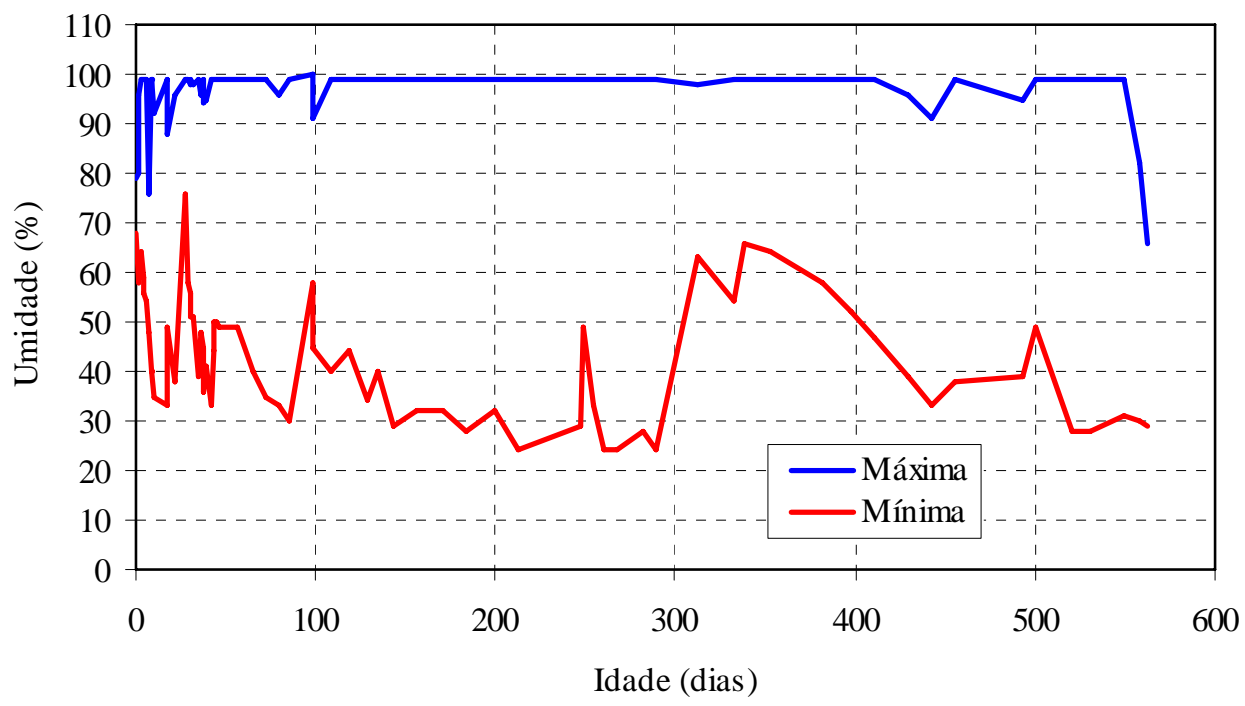

FIGURA 3.22 - Valores máximos e mínimos da umidade ambiente

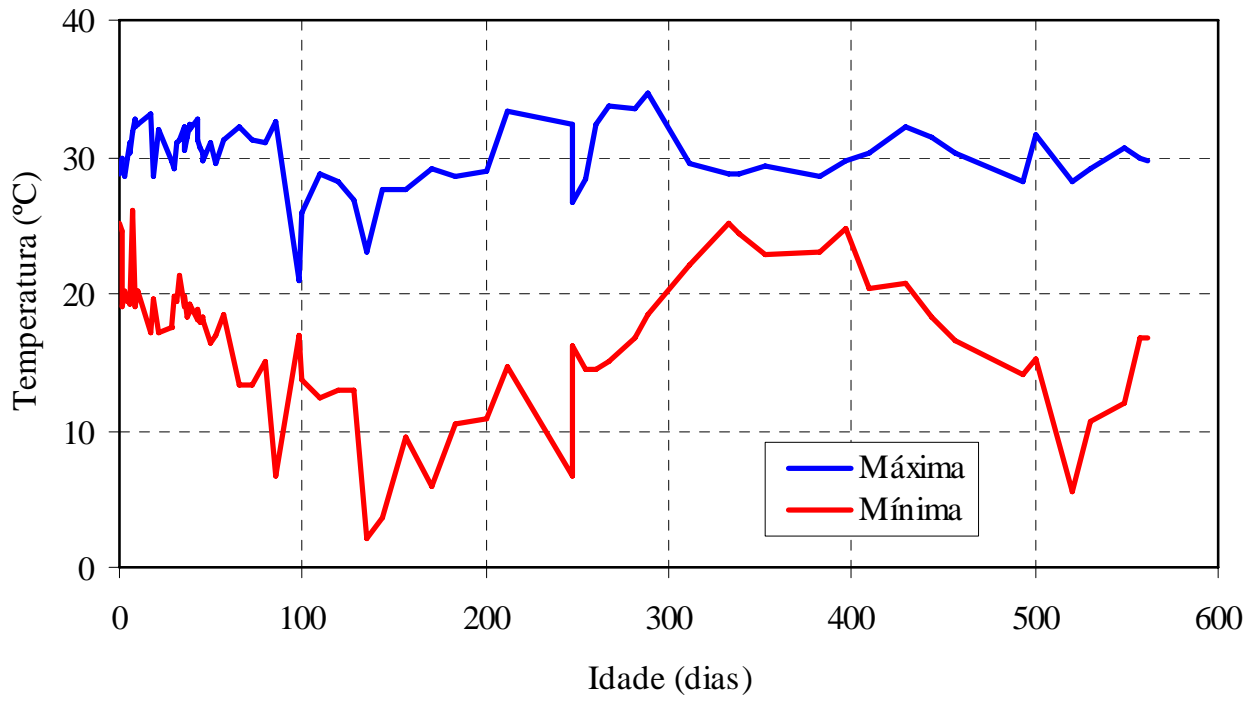

FIGURA 3.23 - Valores máximos e mínimos da temperatura ambiente

As características mecânicas do concreto foram obtidas a partir de seis corpos de prova moldados no dia da concretagem, sendo que dois foram ensaiados aos 7 dias e os outros quatro foram ensaiados aos 28 dias. Os valores obtidos dos 
ensaios à compressão e à tração estão apresentados na tabela 3.5. O aço utilizado nas nervuras foi do tipo CA-60, no entanto, não foi realizado ensaios para a determinação das propriedades mecânicas da armadura.

TABELA 3.5 - Características mecânicas do concreto

\begin{tabular}{ccc}
\hline $\begin{array}{c}\text { Idade } \\
\text { (dias) }\end{array}$ & $\begin{array}{c}\mathbf{f}_{\mathbf{c j}} \\
(\mathbf{M P a})\end{array}$ & $\begin{array}{c}\mathbf{f}_{\mathbf{t j}} \\
\mathbf{( M P a )}\end{array}$ \\
\hline 7 & 20,55 & 0,41 \\
\hline \multirow{2}{*}{28} & 24,45 & 1,79 \\
& 26,10 & 1,65 \\
\hline
\end{tabular}

Apresenta-se na figura 3.24 a evolução da flecha das lajes L1, L2 e L3 obtida no decorrer do ensaio.

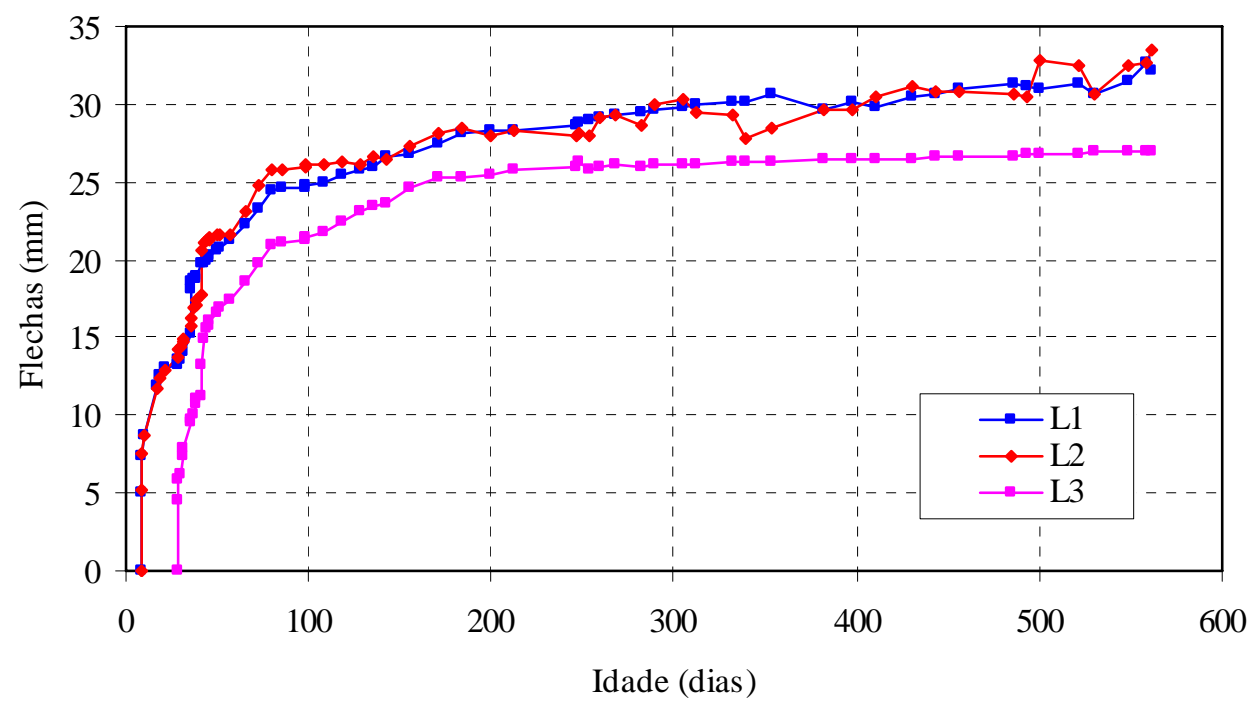

FIGURA 3.24 - Flechas obtidas durante o ensaio

\section{b) Análise numérica}

A análise numérica foi realizada dividindo a viga em 40 elementos de 10 cm cada um. Pela figura 3.25 pode-se observar o esquema de carregamento aplicado e a discretização longitudinal da viga. Já a figura 3.26 apresenta a discretização empregada para seção transversal. 


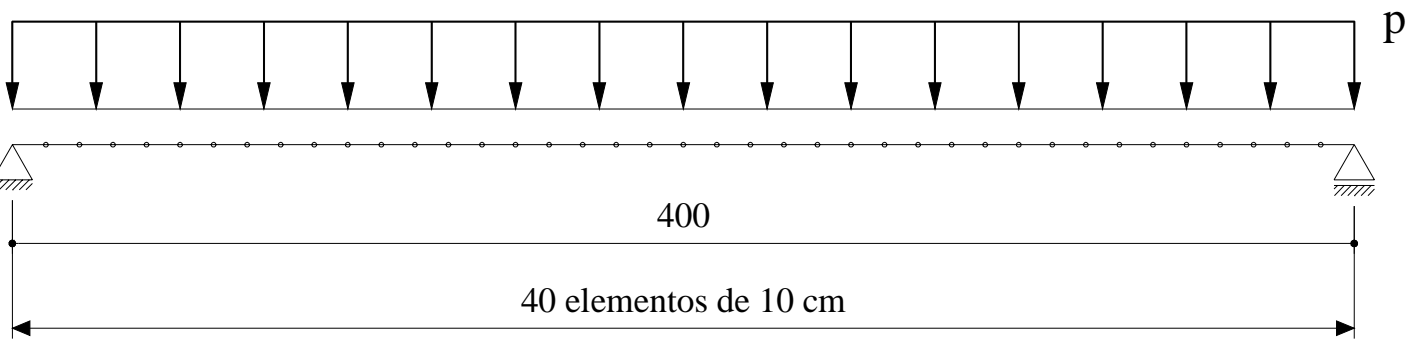

FIGURA 3.25 - Discretização longitudinal (dimensões em cm)

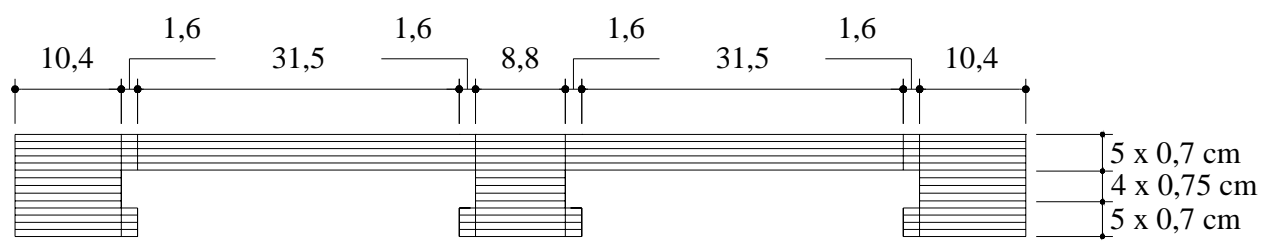

FIGURA 3.26 - Discretização da seção transversal (dimensões em cm)

Foram consideradas na análise numérica condições ambientais constantes durante todo o ensaio. Para todas as lajes foi considerado o valor da temperatura ambiente de $25^{\circ} \mathrm{C}$ e umidade ambiente de $60 \%$.

O valor da resistência média à compressão do concreto, aos 28 dias, considerado na análise numérica das lajes foi de $25 \mathrm{MPa}$.

\section{c) Comparação entre os resultados}

As flechas obtidas no ensaio e as obtidas da análise numérica das lajes L1, L2 e L3 estão apresentadas nas figuras 3.27, 3.28 e 3.29, respectivamente. Pelas figuras pode-se observar que houve uma concordância muito boa entre os resultados experimentais e da análise numérica, ou seja, a análise numérica conseguiu descrever o comportamento ao longo do tempo para esse tipo de laje.

Para estes casos, o ajuste entre os resultados experimentais e da análise numérica foram surpreendentemente bons, no entanto, é aceitável uma certa discordância entre os resultados devido à própria incerteza do modelo de fluência considerado na análise numérica. 


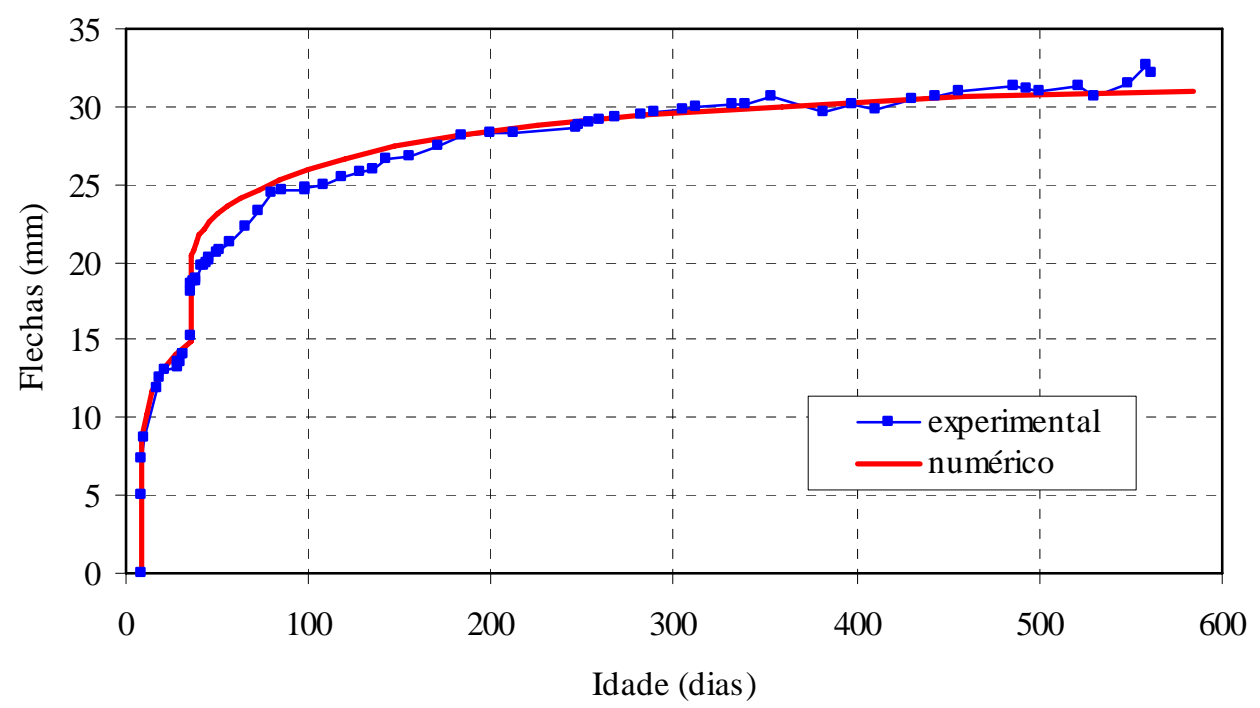

FIGURA 3.27 - Evolução da flecha (laje L1)

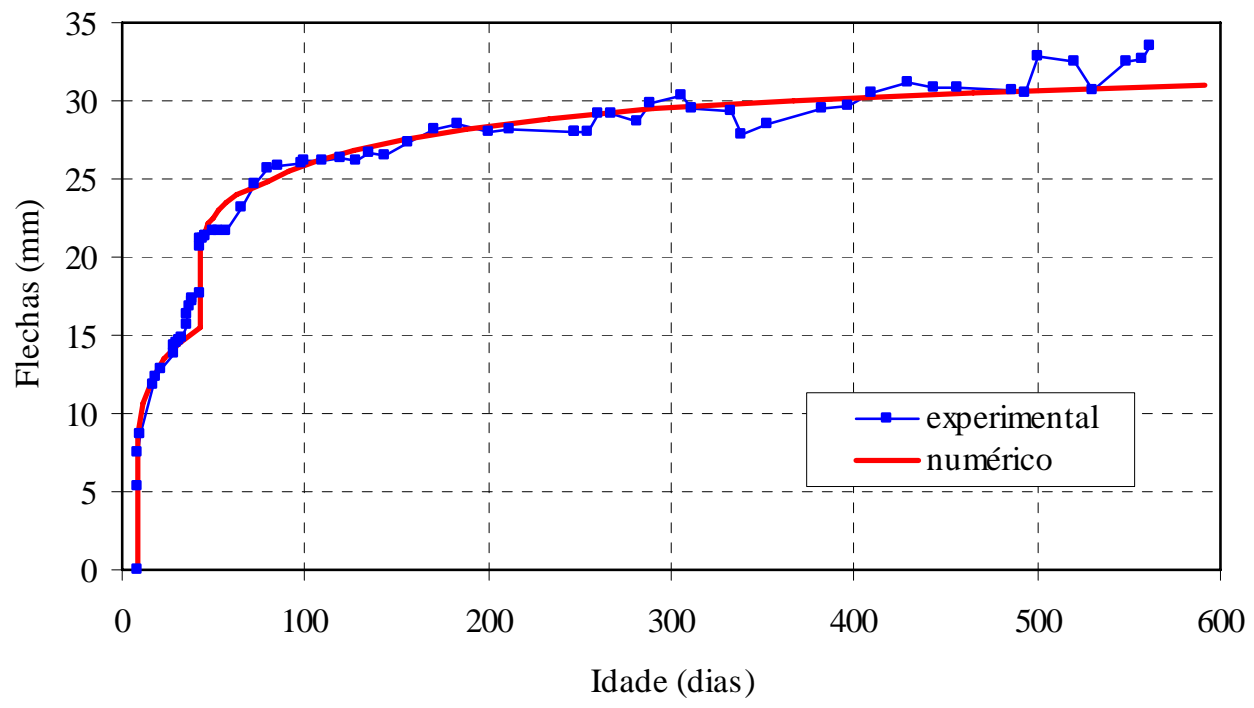

FIGURA 3.28 - Evolução da flecha (laje L2) 


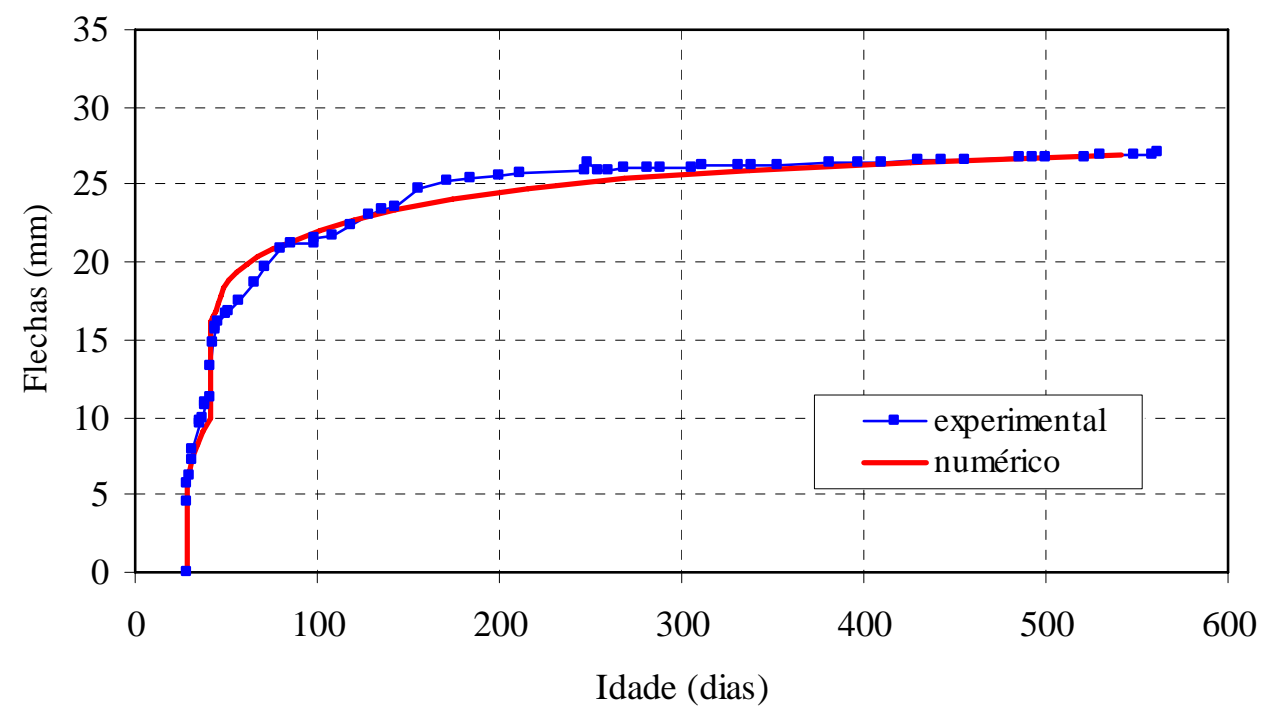

FIGURA 3.29 - Evolução da flecha (laje L3)

\subsubsection{Ensaios de longa duração de vigas reforçadas à flexão}

\section{a) Descrição do ensaio}

Os ensaios realizados por REIS (2003) tiveram como objetivo a avaliação da eficiência de técnicas de reforço em vigas. Foram utilizados, neste trabalho, os ensaios referentes às vigas reforçadas à flexão no bordo comprimido (vigas denominadas VFC).

Foram ensaiadas três vigas do tipo VFC, de mesmas dimensões e taxas de armadura, sendo que as vigas VFC-1 e VFC-3 foram submetidas inicialmente a um carregamento de longa duração, sendo armazenadas em uma câmara climatizada, com temperatura de $32{ }^{\circ} \mathrm{C} \pm 2{ }^{\circ} \mathrm{C}$ e umidade de $38 \% \pm 4 \%$, e posteriormente submetidas a um carregamento monotônico de curta duração responsável pela ruptura das mesmas. Já a viga VFC-2 não foi submetida a nenhum carregamento inicial, nem mesmo o peso próprio, sendo apenas submetida a um carregamento monotônico de curta duração responsável por sua ruptura. A fase referente ao ensaio de longa duração das vigas VCF-1 e VCF-3, que serão denominadas a partir de agora de V1 e V2, respectivamente, foi a fase de interesse para este trabalho.

As dimensões das vigas estão apresentadas na figura 3.30. Por esta figura pode-se notar a presença de dois blocos de concreto nas extremidades das vigas que serviram para ancorar o cabo de protensão responsável por gerar o carregamento de 
longa duração nas peças. A disposição empregada para armadura passiva esta especificada na tabela 3.6.

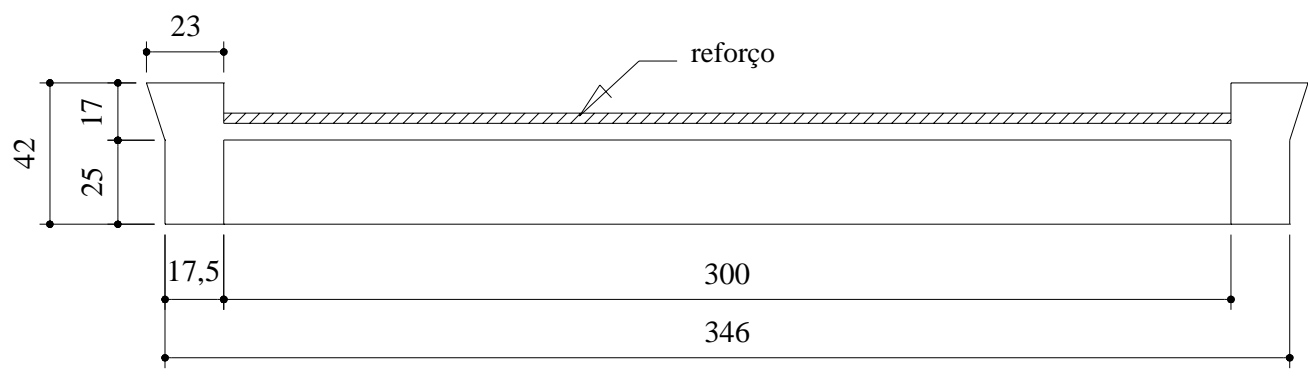

vista longitudinal

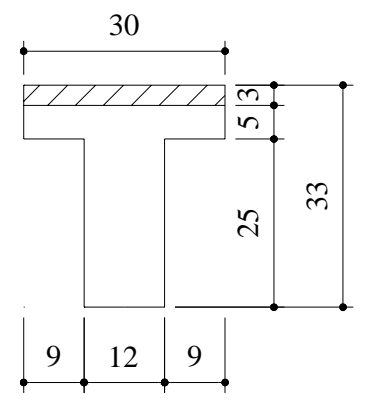

seção transversal

FIGURA 3.30 - Características geométricas (dimensões em cm)

TABELA 3.6 - Disposição da armadura passiva

\begin{tabular}{|c|c|c|c|c|}
\hline Características & Valores & \multirow{7}{*}{$\mathrm{A}_{\mathrm{sw}}$} & \multirow{7}{*}{$\mathrm{d}_{1}$} & \multirow{7}{*}{$\mathrm{d}_{2}$} \\
\hline$A_{s 1}\left(\mathrm{~cm}^{2}\right)$ & $6,3(2 \phi 20 \mathrm{~mm})$ & & & \\
\hline$A_{s 2}\left(\mathrm{~cm}^{2}\right)$ & $6,3(2 \phi 20 \mathrm{~mm})$ & & & \\
\hline$A_{s}^{\prime}\left(\mathrm{cm}^{2}\right)$ & $1,26(4 \phi 6,3 \mathrm{~mm})$ & & & \\
\hline $\mathrm{d}_{1}(\mathrm{~cm})$ & 25,5 & & & \\
\hline $\mathrm{d}_{2}(\mathrm{~cm})$ & 29,5 & & & \\
\hline d' (cm) & 5,45 & & & \\
\hline $\mathrm{A}_{\mathrm{sw}}\left(\mathrm{cm}^{2} / \mathrm{m}\right)$ & $8,0(\phi 10 \mathrm{~mm} \mathrm{c} / 10 \mathrm{~cm})$ & & & \\
\hline Cobrimento (cm) & 1,5 & & & \\
\hline
\end{tabular}

O carregamento foi aplicado através de um sistema constituído por uma cordoalha engraxada não aderente passando externamente à viga que se ancorava em blocos de concreto moldados em suas extremidades. Para produzir o carregamento necessário, foi adotada uma configuração poligonal para o cabo de protensão, que saiu da extremidade da viga com uma inclinação de $18^{\circ}$ e foi desviado na seção 
transversal situada a $125 \mathrm{~cm}$ dos apoios por meio de dispositivos metálicos, como esquematizado na figura 3.31. Pela figura pode-se notar ainda que este sistema de aplicação do carregamento origina na viga além de forças verticais nos pontos dos dispositivos metálicos, mas forças horizontais (longitudinais) excêntricas acarretando esforços de flexo-compressão na viga.
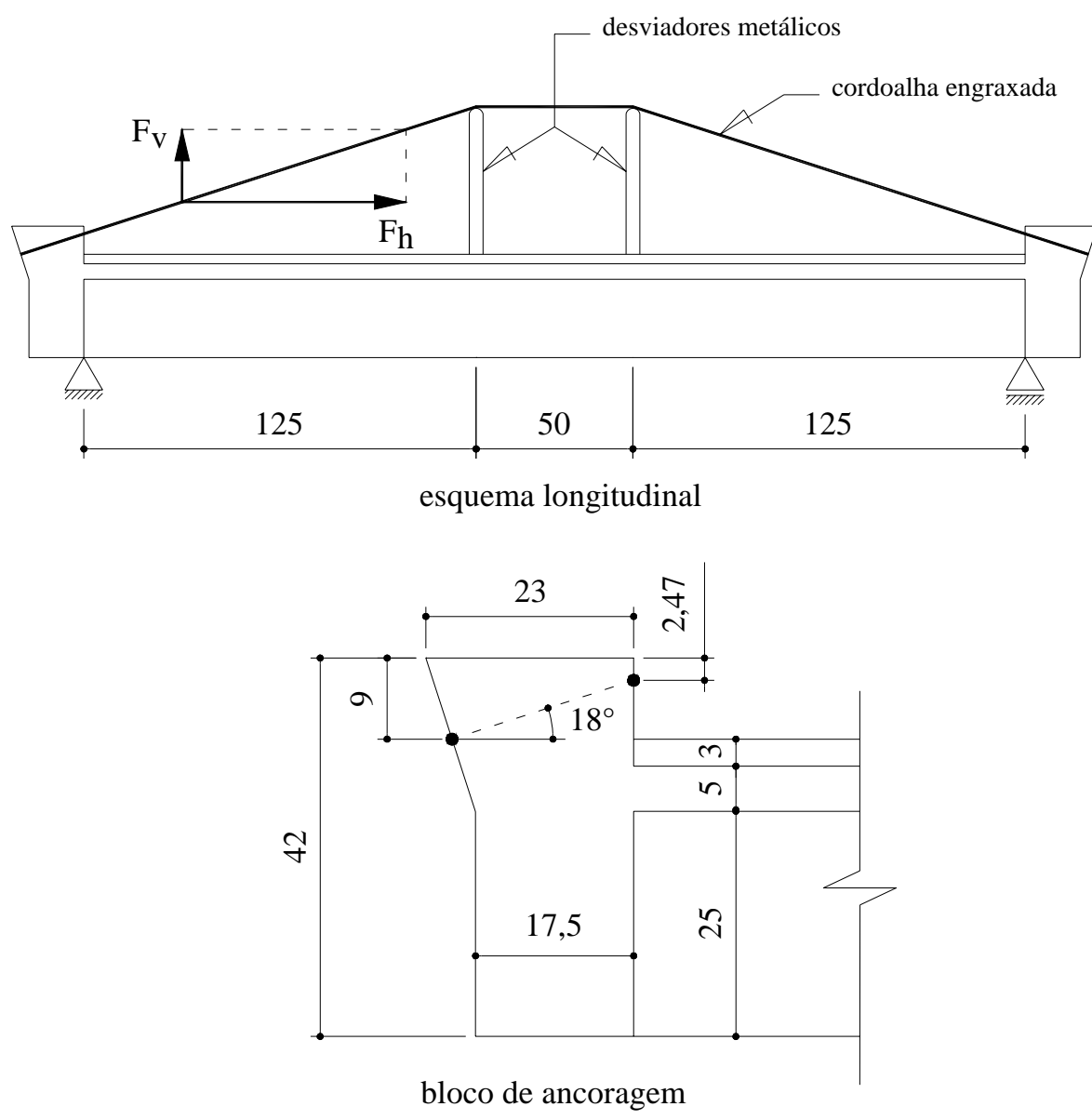

FIGURA 3.31 - Sistema de aplicação do carregamento (dimensões em cm)

O sistema empregado não consegue manter constante o carregamento aplicado devido aos efeitos de relaxação do cabo de protensão e do aumento da flecha com o tempo. Por esta razão, houve um acompanhamento constante da variação da força no cabo e da flecha na viga. Na figura 3.32 apresenta o valor da força vertical aplicado na viga durante todo o período do ensaio. 


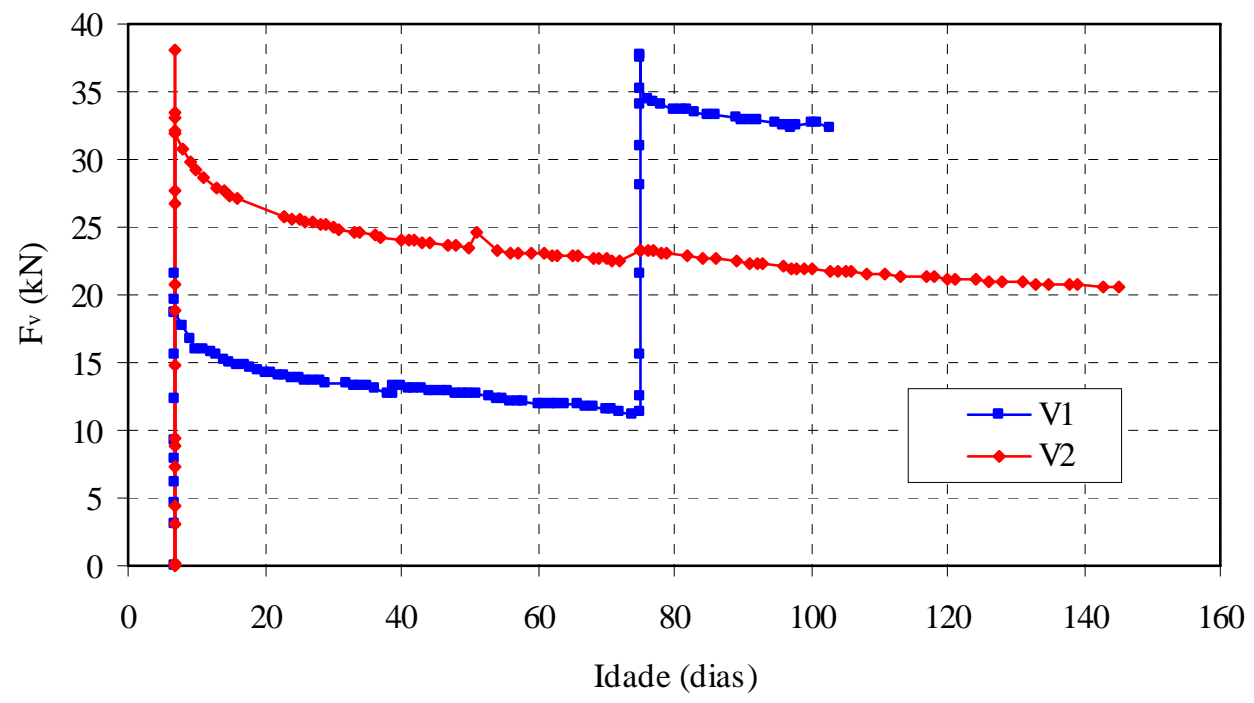

FIGURA 3.32 - Evolução da força vertical

Portanto, como observado na figura 3.32, as vigas ensaiadas se diferenciavam em relação ao valor e ao período de tempo em que o carregamento permaneceu atuante e as particularidades de cada uma delas estão apresentadas na tabela 3.7.

TABELA 3.7 - Etapas do ensaio

\begin{tabular}{|c|c|c|}
\hline Etapas & $\begin{array}{l}\text { Idade } \\
\text { (dias) }\end{array}$ & $\begin{array}{c}\text { Intervalo de tempo } \\
\text { entre cada etapa } \\
\text { (dias) }\end{array}$ \\
\hline \multicolumn{3}{|c|}{ V1 } \\
\hline Moldagem & 0 & 0 \\
\hline Protensão $n^{0} 1$ & 7 & 7 \\
\hline Reforço no bordo comprimido & 40 & 33 \\
\hline Protensão $\mathrm{n}^{\circ} 2$ & 75 & 35 \\
\hline Final do ensaio de longa duração & 104 & 29 \\
\hline \multicolumn{3}{|l|}{ ( } \\
\hline Moldagem & 0 & 0 \\
\hline Protensão $\mathrm{n}^{\circ} 1$ & 7 & 7 \\
\hline Reforço no bordo comprimido & 75 & 68 \\
\hline Final do ensaio de longa duração & 145 & 70 \\
\hline
\end{tabular}

Na viga V1, após 7 dias da moldagem do substrato, foi aplicado um carregamento através da protensão da cordoalha engraxada que originou forças verticais de 19,6 kN (Protensão n 1). Após 68 dias da aplicação deste carregamento, com a viga já reforçada, aumentou-se o carregamento (Protensão n ${ }^{\circ} 2$ ) para 35,1kN. 
Já na viga V2 foi aplicado apenas um carregamento (Protensão $\mathrm{n}^{0} 1$ ) de $32 \mathrm{kN}$ aos 7 dias após a moldagem do substrato e antes da execução do reforço.

Mesmo tendo-se ajustado a câmara climatizada na temperatura de $32{ }^{\circ} \mathrm{C}$ $\pm 2{ }^{\circ} \mathrm{C}$ e umidade de $38 \% \pm 4 \%$, nem sempre estes valores forma satisfeitos. Nas figuras 3.33 e 3.34 pode-se observar as variações ambientais durante todo o período em que os modelos permaneceram armazenados na câmara climatizada.

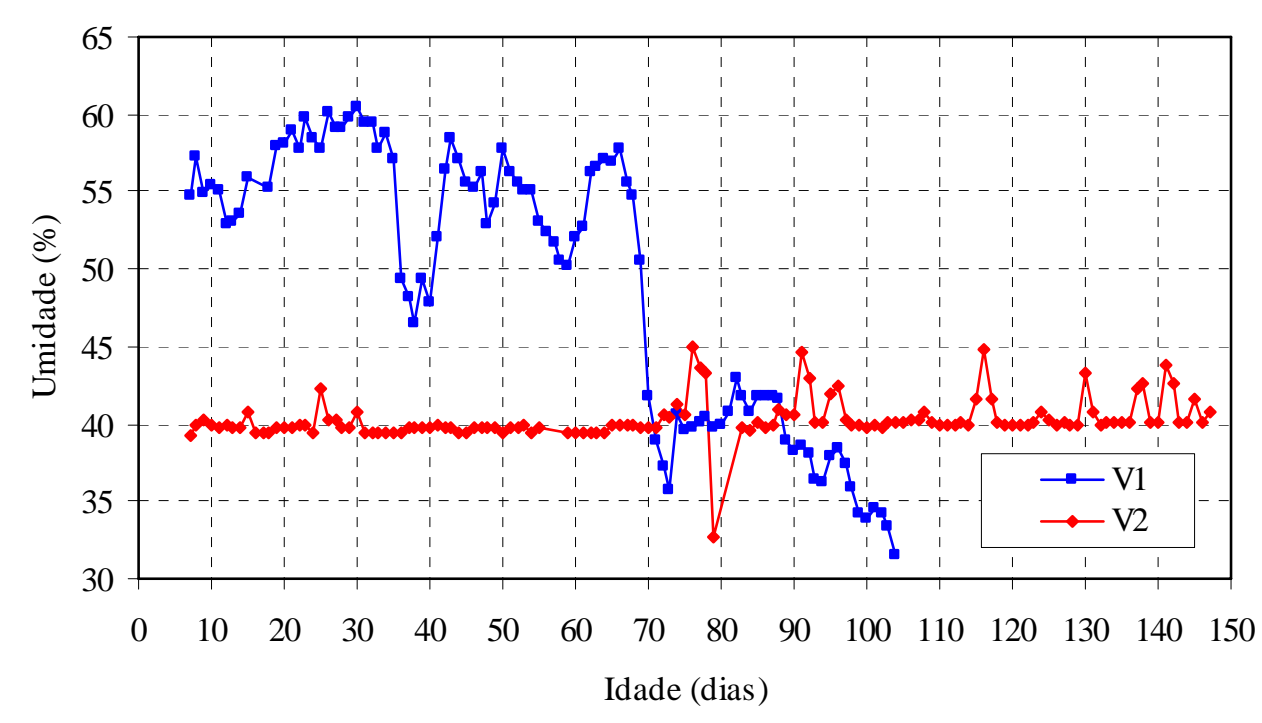

FIGURA 3.33 - Valores da umidade ambiente durante o ensaio

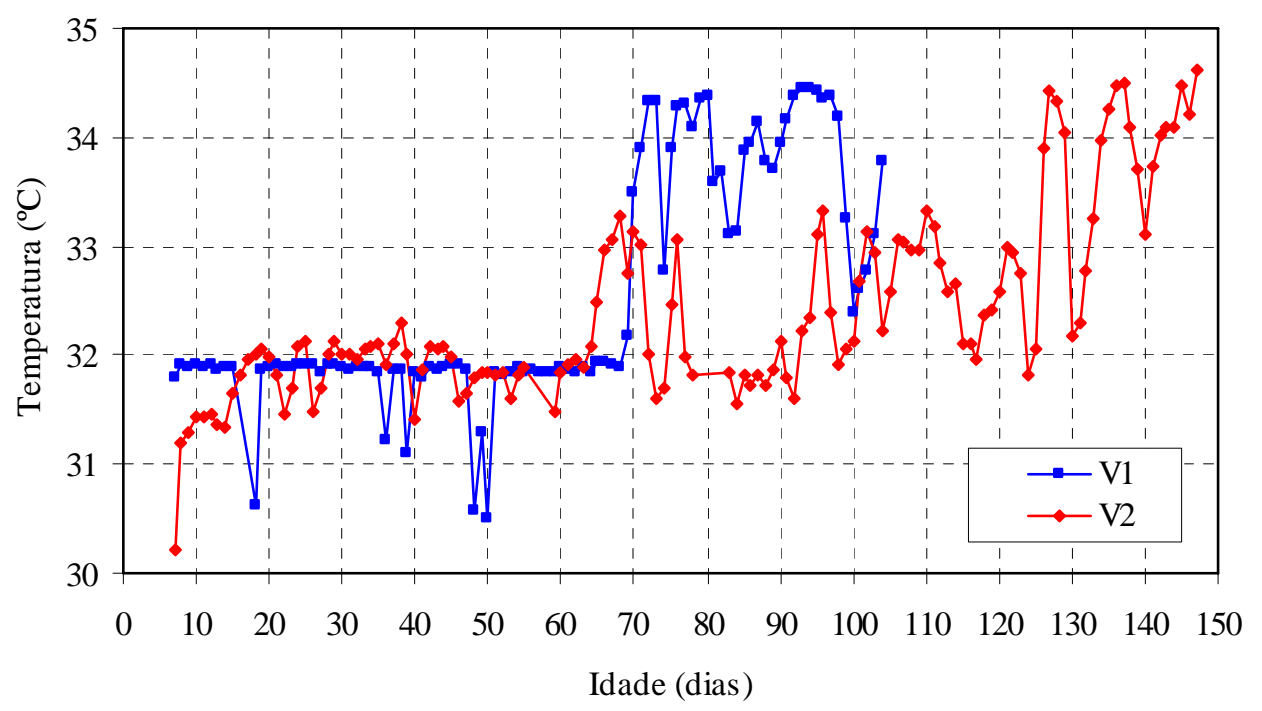

FIGURA 3.34 - Valores da temperatura ambiente durante o ensaio 
As características mecânicas do concreto do substrato e do reforço estão apresentadas na tabela 3.8. Já a armadura passiva utilizada nas vigas apresentou as propriedades mecânicas descritas na tabela 3.9.

A armadura de protensão utilizada para aplicar o carregamento, constituía-se de uma cordoalha de 7 fios tipo CP 190-RB (não aderente) com bitola de $12,7 \mathrm{~mm}$, que segundo o fabricante apresenta as características apresentadas na tabela 3.10.

TABELA 3.8 - Características mecânicas do concreto

\begin{tabular}{|c|c|c|c|c|c|c|c|}
\hline \multirow[b]{2}{*}{ Etapas do ensaio } & \multirow{2}{*}{$\begin{array}{l}\text { Idade } \\
\text { (dias) }\end{array}$} & \multicolumn{3}{|c|}{ Substrato } & \multicolumn{3}{|c|}{ Reforço } \\
\hline & & $\begin{array}{c}\mathbf{f}_{\mathrm{cj}} \\
(\mathrm{MPa})\end{array}$ & $\begin{array}{c}\mathbf{f}_{\mathrm{tj}} \\
(\mathbf{M P a})\end{array}$ & $\begin{array}{c}\mathrm{E}_{\mathrm{co}} \\
(\mathrm{MPa})\end{array}$ & $\begin{array}{c}\mathbf{f}_{\mathrm{cj}} \\
(\mathbf{M P a})\end{array}$ & $\begin{array}{c}\mathbf{f}_{\mathrm{tj}} \\
(\mathbf{M P a})\end{array}$ & $\begin{array}{c}\mathrm{E}_{\mathrm{co}} \\
(\mathrm{MPa})\end{array}$ \\
\hline \multicolumn{8}{|c|}{ V1 } \\
\hline Concretagem do substrato & 0 & - & - & - & - & - & - \\
\hline Protensão $n^{\circ} 1$ & 7 & 14,61 & 1,90 & - & - & - & - \\
\hline Concretagem do reforço & 40 & 21,51 & 2,73 & 24378 & - & - & - \\
\hline Protensão $n^{\circ} 2$ & 75 & 22,06 & 2,37 & 26000 & 66,24 & 5,07 & 34952 \\
\hline Final & 104 & 25,79 & 2,69 & 26403 & 71,55 & 5,46 & 35718 \\
\hline \multicolumn{8}{|c|}{ V2 } \\
\hline Concretagem do substrato & 0 & - & - & - & - & - & - \\
\hline Protensão $n^{\circ} 1$ & 7 & 16,19 & 1,81 & 26704 & - & - & - \\
\hline Concretagem do reforço & 75 & 29,90 & 2,85 & 31328 & - & - & - \\
\hline Final & 145 & 32,59 & 3,49 & 31772 & 90,33 & 6,03 & 34138 \\
\hline
\end{tabular}

TABELA 3.9 - Características mecânicas da armadura passiva

\begin{tabular}{|c|c|c|c|c|}
\hline$\phi(\mathbf{m m})$ & Tipo de armadura & $\mathbf{f}_{\mathbf{y}}(\mathbf{M P a})$ & $\mathbf{f}_{\mathrm{u}}(\mathrm{MPa})$ & $\varepsilon_{\mathrm{y}}(\%)$ \\
\hline \multicolumn{5}{|c|}{ V1 } \\
\hline 6,3 & CA-60 - $A_{s}^{\prime}$ & 605 & 844 & 2,95 \\
\hline 10 & $C A-50-A_{s w}$ & 521 & 833 & 2,54 \\
\hline 20 & $C A-50-A_{s 1}$ e $A_{s 2}$ & 561 & 682 & 2,74 \\
\hline \multicolumn{5}{|c|}{ V2 } \\
\hline 6,3 & CA-60 - $\mathrm{A}_{\mathrm{s}}^{\prime}$ & 633 & 824 & 3,09 \\
\hline 10 & $\mathrm{CA}-50-\mathrm{A}_{\mathrm{sw}}$ & 564 & 653 & 2,75 \\
\hline 20 & $C A-50-A_{s 1}$ e $A_{s 2}$ & 525 & 637 & 2,56 \\
\hline * módulo de & ticidade das armadul & i consid & igual a : & $0 \mathrm{MPa}$ \\
\hline
\end{tabular}

TABELA 3.10 - Características mecânicas da armadura ativa

\begin{tabular}{cccccc}
\hline$\phi(\mathbf{m m})$ & $\mathbf{A}_{\mathbf{s}}\left(\mathbf{c m}^{2}\right)$ & $\mathbf{E}_{\mathbf{p s}}(\mathbf{M P a})$ & $\mathbf{f}_{\mathrm{py}}(\mathbf{M P a})$ & $\boldsymbol{\varepsilon}_{\mathrm{py}}(\%)$ & $\mathbf{f}_{\mathrm{pu}}(\mathbf{M P a})$ \\
\hline 12,7 & 0,999 & 208000 & 1820 & 8,8 & 2000 \\
\hline
\end{tabular}


Apresenta-se na figura 3.35 o desenvolvimento da flecha no decorrer do ensaio das vigas V1 e V2.

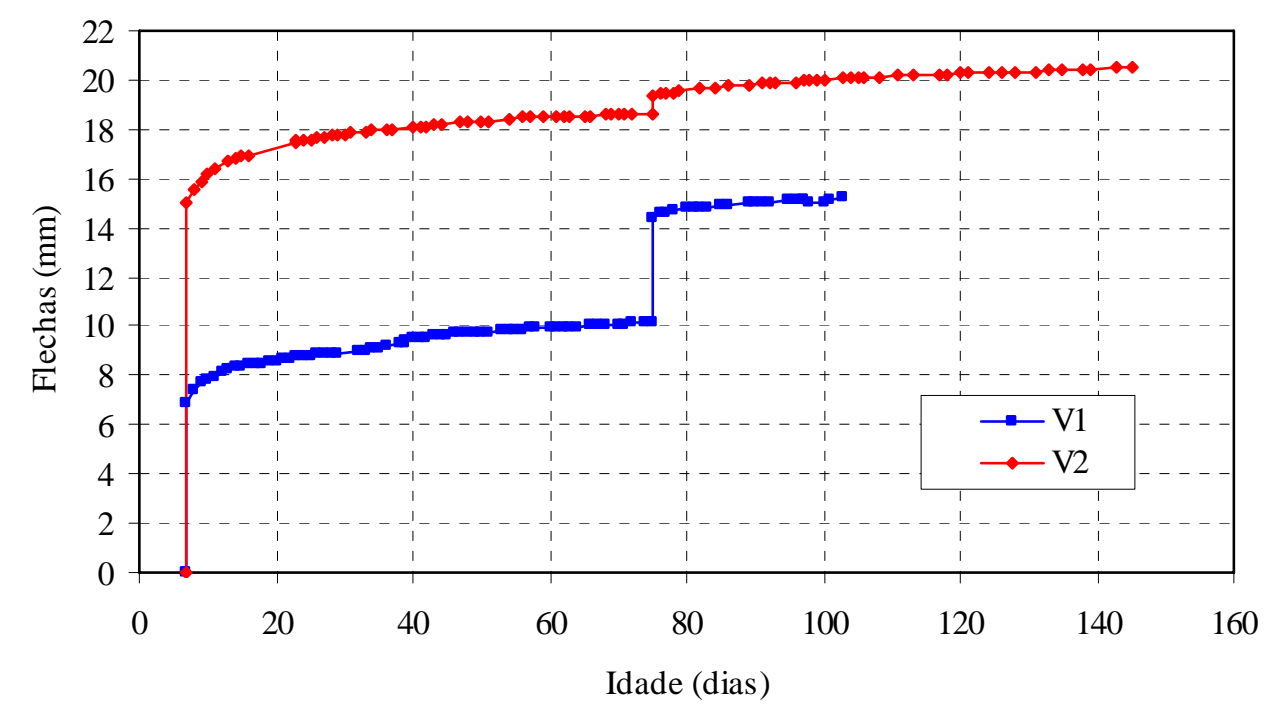

FIGURA 3.35 - Flechas obtidas durante o ensaio

\section{b) Análise numérica}

A análise numérica foi realizada dividindo a viga em 60 elementos de 5 cm cada um. Pela figura 3.36 pode-se observar o esquema de carregamento aplicado e a discretização longitudinal da viga. Já a seção transversal foi subdividida em 49 filamentos de concreto e três filamentos de aço, como pode ser visto na figura 3.37.

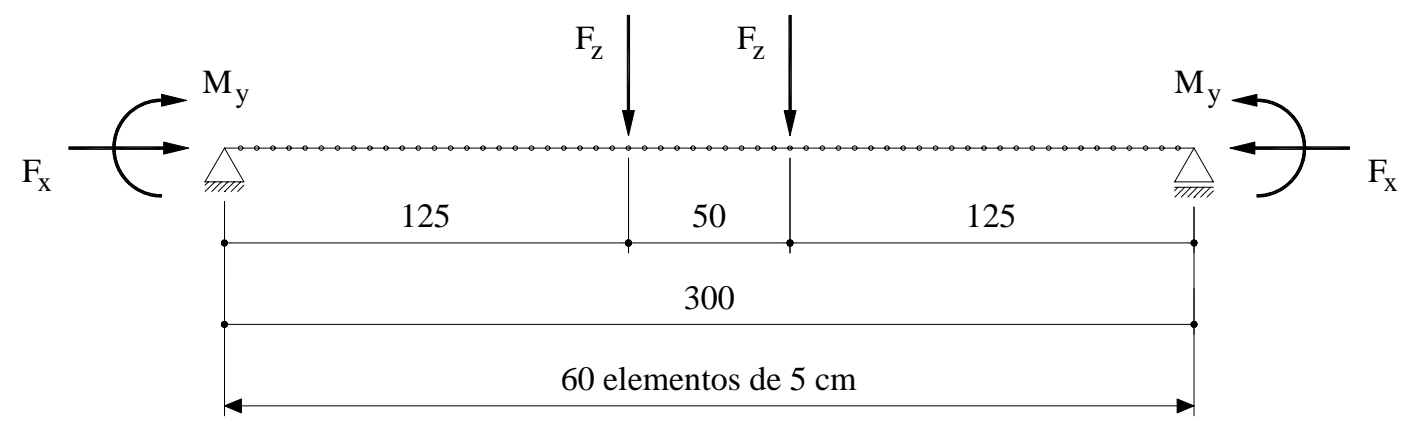

FIGURA 3.36 - Discretização longitudinal (dimensões em cm) 


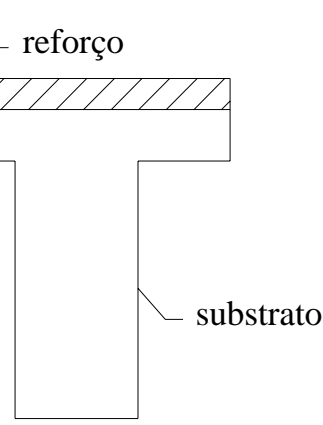

tipos de concreto

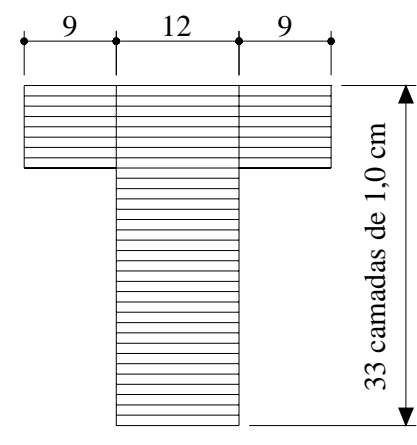

filamentos de concreto

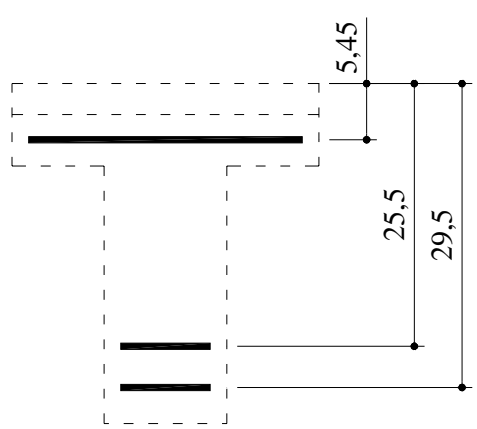

filamentos de aço

FIGURA 3.37 - Discretização da seção transversal (dimensões em cm)

Como já mencionado, houve a diminuição do carregamento aplicado durante o período do ensaio devido aos efeitos de relaxação do cabo de protensão e do aumento da curvatura da viga por fluência. Isso foi levado em consideração na análise numérica através da redução do carregamento em determinados passos de tempos de forma que se aproximasse aos valores obtidos no ensaio. E assim, o carregamento considerado na análise numérica não apresentou uma redução contínua ao longo do tempo conforme observado no ensaio, mas pequenas perdas localizadas como mostrado na figura 3.38 .

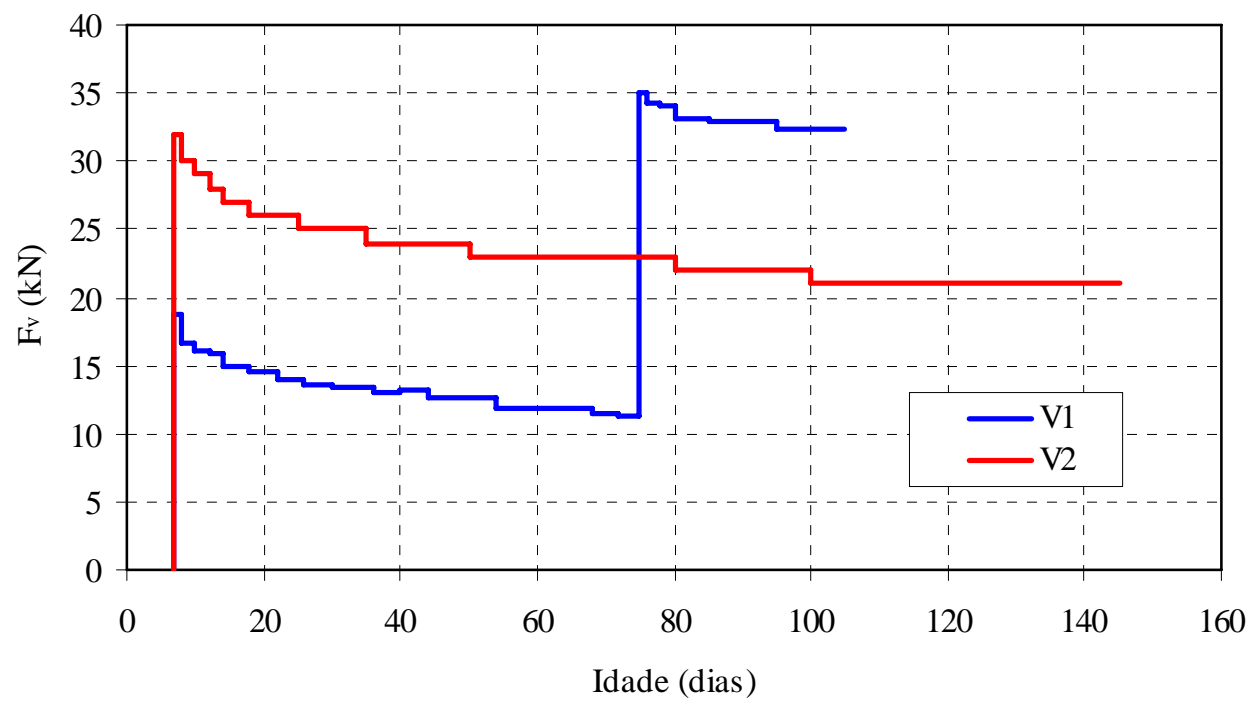

FIGURA 3.38 - Evolução da força vertical utilizada na análise numérica 
Foram consideradas na análise numérica condições ambientais constantes durante todo o ensaio. $\mathrm{O}$ valor da temperatura ambiente considerada foi de $32{ }^{\circ} \mathrm{C}$ e umidade ambiente de 50\% e 40\%, respectivamente, para as vigas V1 e V2.

O valor da resistência média à compressão do concreto, aos 28 dias, considerado na análise numérica da viga V1 foi de $20 \mathrm{MPa}$ para o concreto do substrato e 55 MPa para o concreto do reforço. Já para a viga V2, considerou-se 25 MPa para o concreto do substrato e $80 \mathrm{MPa}$ para o concreto do reforço.

\section{c) Comparação entre os resultados}

Mostra-se nas figuras 3.39 e 3.40 as flechas obtidas no ensaio e as obtidas da análise numérica das vigas V1 e V2, respectivamente. Nota-se pelas figuras que a análise numérica empregada foi capaz de descrever com grande eficiência a evolução da flecha das vigas.

Para a viga V1 a análise numérica apresentou uma concordância muito boa com os resultados experimentais até 75 dias após o início do ensaio, quando houve o aumento do carregamento aplicado (Protensão $n^{0} 2$ ). Mas mesmo após este instante, a diferença entre os valores experimentais e da análise numérica foram pequenos, tendo uma diferença máxima de 4,65\% aos 75 dias e diminuindo em seguida, como se pode notar pela figura 3.39 .

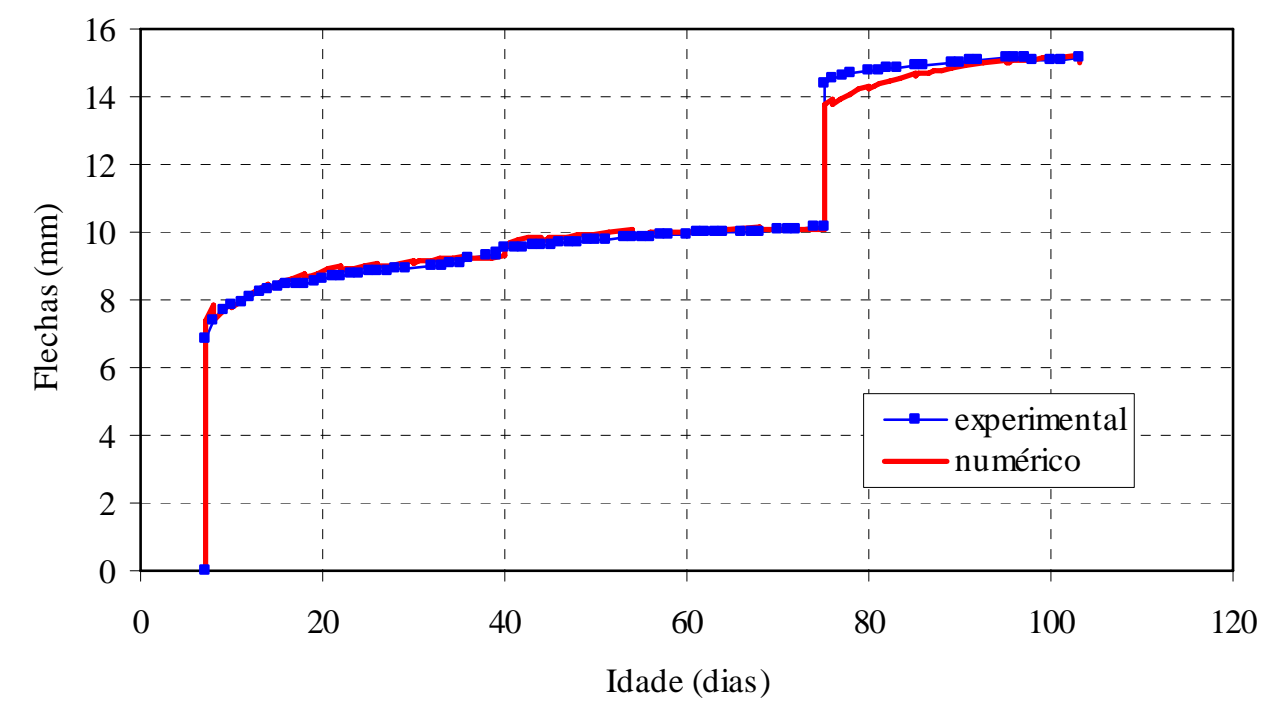

FIGURA 3.39 - Evolução da flecha (viga V1) 
Já a viga V2 a diferença máxima entre os resultados experimentais e da análise numérica foi de 5,66 \% aos 145 dias, no fim do ensaio, conforme figura 3.40. No entanto, vale ressaltar que houve aos 75 dias, dia da concretagem do reforço da viga V2, um salto na flecha da viga de $0,648 \mathrm{~mm}$. A princípio este salto se deve ao peso próprio do reforço, mas como se pode observar pela figura 3.39, a concretagem do reforço da viga V1 foi realizada aos 40 dias, com um concreto mais jovem, e mesmo assim não houve um salto na flecha dessa magnitude. Portanto, pode-se considerar que a diferença entre os resultados experimentais e da análise numérica possa ser ainda menor.

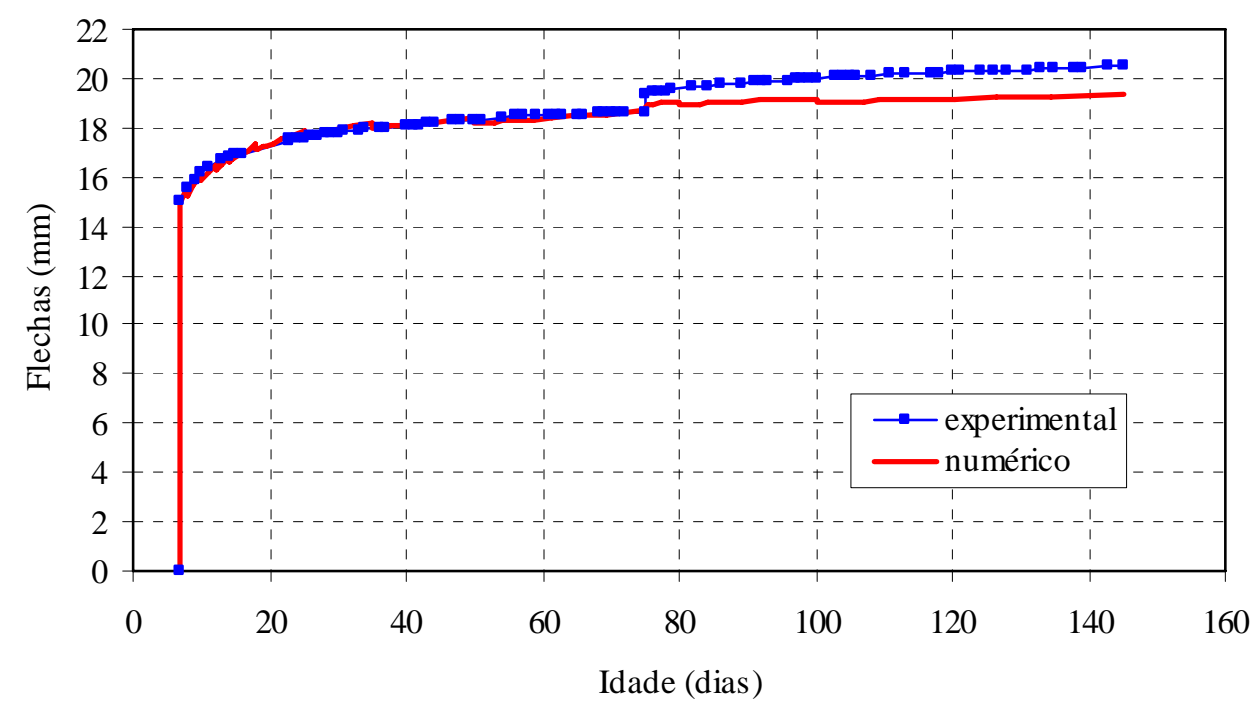

FIGURA 3.40 - Evolução da flecha (viga V2) 


\section{ANÁLISE PROBABILÍSTICA}

\subsection{Considerações iniciais}

Uma boa estimativa da fluência e retração do concreto é de crucial importância para assegurar a funcionalidade das estruturas de concreto ao longo do tempo. Previsões errôneas destes fenômenos contribuem para ocorrência de deformações excessivas e fissuração, afetando a longevidade das estruturas de concreto. E ainda, como alertado por BAZANT \& BAWEJA (1995b), erros na previsão da fluência e retração do concreto geralmente são maiores que aqueles causados por simplificações no método de análise estrutural, ou seja, para o caso de estruturas sensíveis à fluência, faz pouco sentido utilizar análise em elementos finitos ou qualquer outra aproximação computacional sofisticada se não for introduzido um modelo realista para a fluência e retração do concreto.

Por esta razão, além das disposições contidas em normas para a previsão da fluência e retração do concreto, pode-se encontrar muitos trabalhos de pesquisa que desenvolveram modelos ajustando-os a dados experimentais contidos na literatura, como por exemplo, BAZANT \& BAWEJA (1995b), BAZANT \& CHERN (1982) e BAZANT \& PANULA (1980). Tais modelos, denominados de modelos determinísticos, são importantes para previsão do comportamento médio, no entanto, ainda falta uma estimativa da variabilidade estatística esperada, que somente pode ser obtida através de uma análise probabilística.

BAZANT (1988) afirma ainda que as formulações determinísticas dos modelos de fluência do concreto alcançaram um limite de refinamento que tentativas adicionais de desenvolvimento teriam pouco sentido se não for considerada a 
aleatoriedade do fenômeno da fluência. Ao invés de tentar desenvolver modelos determinísticos mais sofisticados para a fluência, melhor seria formular modelos que levassem em consideração as incertezas na descrição do fenômeno, qualquer que seja a fonte dessas incertezas.

Quando se compara as flechas de estruturas de concreto reais causadas pela fluência e retração do concreto com modelos determinísticos, como nos trabalhos realizados por ESPION \& HALLEUX (1990) e RUSSEL et al. (1982), observa-se uma variabilidade estatística dos resultados causados pelas incertezas inerentes aos fenômenos de fluência e retração do concreto.

Portanto, devido à essa variabilidade estatística dos fenômenos relacionados com o comportamento do concreto, as estruturas deveriam ser projetadas para que certos efeitos extremos, tal como deslocamento máximo ou tensão máxima, tivessem pequena probabilidade especificada de serem ultrapassados, ao invés de se determinar os efeitos médios, como é normalmente realizado atualmente. Ou seja, a fim de assegurar a segurança das estruturas de concreto, além do valor médio, deve-se considerar a variabilidade dos fatores envolvidos no problema.

A variabilidade dos fenômenos de fluência e retração do concreto é causada por vários fatores. Como fatores externos, pode-se destacar a mudança das condições ambientais, tais como temperatura e umidade, sendo o efeito desses fatores, em geral, preponderante sobre os demais [BAZANT (1988)]. Por outro lado, os fatores internos são a variabilidade da qualidade e a composição da mistura dos materiais usados no concreto e a variabilidade devida ao mecanismo interno de fluência e retração. Portanto, conforme BAZANT (1988), a variabilidade estatística pode ser atribuída aos seguintes fatores de incertezas:

\section{a) Fatores internos de incerteza}

1) Natureza estocástica do mecanismo físico da fluência e retração;

2) Propriedades dos materiais, tais como, a resistência à compressão e módulo de elasticidade. 


\section{b) Fatores externos de incertezas}

3) Condições ambientais, isto é, a fluência e retração do concreto são significativamente influenciadas pelas mudanças sazonais ou diárias do tempo;

4) Cargas externas (a estrutura pode estar sujeita às cargas altamente variáveis, tais como neve e cargas acidentais);

5) Técnica de medição.

\section{c) Fatores de incerteza devido à formulação ou modelagem}

6) Escolha das fórmulas para prever a fluência e retração;

7) Escolha dos métodos analíticos utilizados.

O fator (1) é devido ao efeito randômico da microestrutura do concreto. Diferente de outras fontes, a variabilidade devida ao fator (1) é inerente ao concreto e não pode ser eliminada. O fator (2) pode ser eliminado somente sob condições controladas, tais como as condições de laboratório. Em condições reais de construção, seria muito difícil eliminar a variabilidade na composição da mistura e a qualidade dos materiais. O fator (3) afeta as condições de secagem do concreto e a taxa de fluência e retração, além de causar tensões por retração. As propriedades dos materiais também são afetadas pelas mudanças ambientais. O fator (4) pode fazer com que o estado de tensão seja maior ou menor que o nível de tensão de projeto, levando-se a uma deformação por fluência maior ou menor que a esperada. Além disso, a variação do nível de tensão pode causar variação das propriedades dos materiais. Já o fator (5), refere-se somente aos dados de medida, e não no concreto em si. Portanto, esta variação não deveria ser incluída em um modelo de previsão da fluência e retração. Quando são feitas observações de campo para atualizar o modelo probabilístico, e portanto, diminuir as variações na previsão, então esse fator deveria ser explicitamente incluído no modelo. A eliminação do fator (6) pode ser a meta final para os pesquisadores no campo da fluência e retração do concreto. As fórmulas para fluência e retração usadas nas normas devem ser de tal forma que a previsão possa ser obtida com um mínimo de erro. Para o fator (7), é importante conhecer os erros causados pela escolha de um método particular de análise. 
E assim, a partir do exposto acima, o objetivo deste capítulo é apresentar um modelo para análise probabilística de estruturas de concreto sujeitas aos fenômenos de fluência e retração.

\subsection{Conceitos básicos e definições}

Da teoria de probabilidade, o grupo de todos os êxitos ou resultados possíveis em um problema probabilístico é denominado espaço amostral $S$, e cada uma das possibilidades individuais é um ponto amostral. Um evento é então definido como um subgrupo do espaço amostral, como os designados $E_{1}$ ou $E_{2}$ na figura 4.1, denominada diagrama de Euler ou Venn.

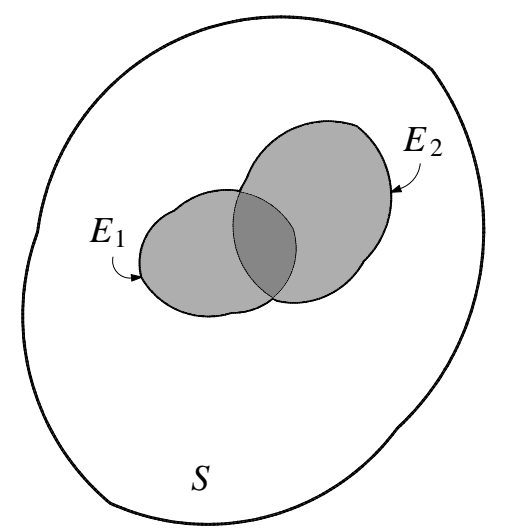

FIGURA 4.1 - Diagrama de Euler ou Venn

O evento $E_{1}+E_{2}$ é um conjunto de pontos que estão tanto em $E_{1}$ como em $E_{2}$ ou em ambos, enquanto que $E_{1} E_{2}$ é o conjunto de pontos comuns a $E_{1}$ e $E_{2}$. Então, a probabilidade de um evento, tal como $E_{1}$, é a soma de todas as possibilidades associadas a todos os pontos contidos no conjunto $E_{1}$. Semelhantemente, a probabilidade de $E_{1}+E_{2}$, é a soma das probabilidades associadas a todos os pontos contidos no conjunto $E_{1}+E_{2}$. Se $E_{1}$ e $E_{2}$ não têm pontos comuns, isto é, se os eventos são mutuamente exclusivos, então:

$$
P\left(E_{1}+E_{2}\right)=P\left(E_{1}\right)+P\left(E_{2}\right)
$$


Se eles têm pontos comuns, então:

$$
P\left(E_{1}+E_{2}\right)=P\left(E_{1}\right)+P\left(E_{2}\right)-P\left(E_{1} E_{2}\right)
$$

$\mathrm{O}$ conjunto $E_{1}+E_{2}$, representado freqüentemente por $E_{1} \cup E_{2}$, é denominado união dos dois conjuntos. $\mathrm{O}$ conjunto $E_{1} E_{2}$, representado freqüentemente por $E_{1} \cap E_{2}$, é denominado intercessão dos dois conjuntos.

Cada resultado possível ou evento pode ser identificado através do valor de uma função, tal função é denominada variável aleatória, que é usualmente designada por uma letra maiúscula. Portanto, uma variável aleatória pode ser considerada uma função que associa um número real a cada resultado possível de um fenômeno aleatório (evento), ou seja, atribui um valor numérico para cada elemento de um determinado espaço amostral, conforme figura 4.2. Assim, como exemplificado por REAL (2000), a resistência à compressão de um corpo de prova cilíndrico de concreto $\left(f_{C}\right)$ pode ser considerada como uma variável aleatória, pois ela atribui um valor numérico a um evento aleatório distinto, que é a tensão para a qual acontece a ruptura de um certo corpo de prova de concreto.

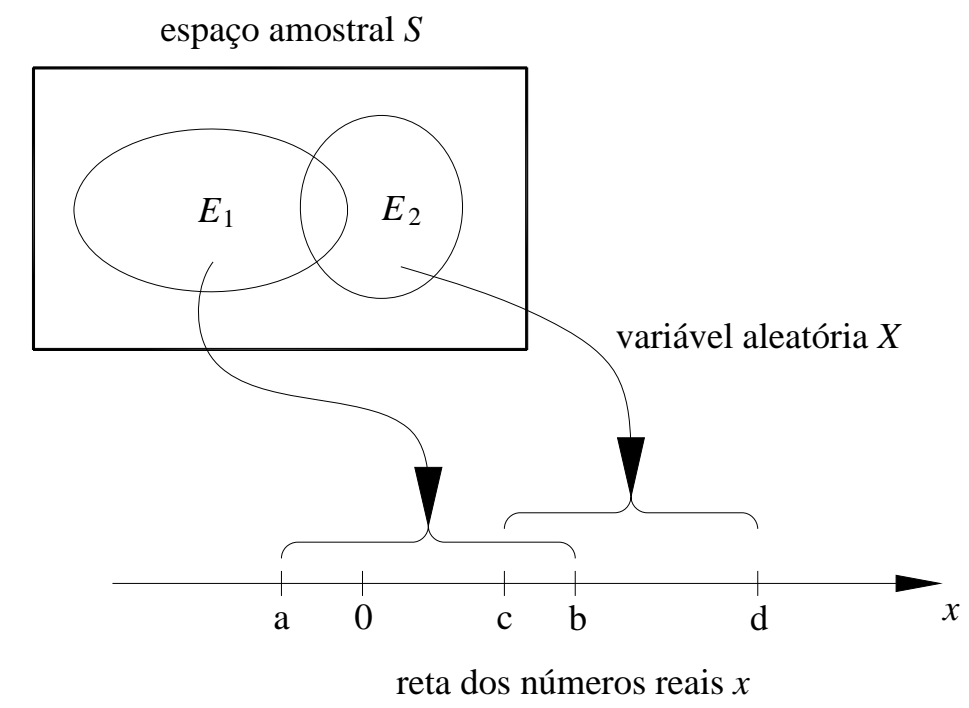

FIGURA 4.2 - Mapeamento de eventos através da variável aleatória $X$ [adaptado ANG \& TANG (1975)] 
AUGUSTI et al. (1984) salientam que o termo variável aleatória somente deve ser utilizado quando não há variação no tempo e processo aleatório ou processo estocástico se houver variação com o tempo (ou com algum outro parâmetro independente).

A interpretação de uma variável aleatória como uma função pode ser freqüentemente evitada, já que os cálculos probabilísticos podem ser realizados em termos de densidade de probabilidade, como destacado por GARDNER (1986).

Como o valor de uma variável aleatória representa um evento, ela pode assumir somente um valor numérico associado a uma probabilidade de ocorrência deste evento. A lei que descreve a medida de probabilidade associada a cada um dos valores possíveis de uma variável aleatória é chamada de distribuição de probabilidade.

A distribuição de probabilidade de uma variável aleatória $X$ pode ser descrita através de sua função de distribuição de probabilidade acumulada (FDPA), dada por:

$$
F_{X}(x)=P(X \leq x) \quad \text { para todos valores de } x
$$

Uma variável aleatória $X$ é dita discreta se somente certos valores discretos de $x$ têm probabilidades positivas. E, $X$ é uma variável aleatória contínua se são definidas medidas de probabilidade para qualquer valor de $x$, como mostrado na figura 4.3.

Para uma variável aleatória discreta $X$, sua distribuição de probabilidade pode também ser descrita em termos de uma função de massa de probabilidade (FMP), que é simplesmente uma função expressando $P(X=x)$ para todos os valores possíveis de $x$. Portanto, se $X$ for uma variável aleatória discreta com FMP, $p_{X}\left(x_{i}\right)=P\left(X=x_{i}\right)$, sua função de distribuição será:

$$
F_{X}(x)=P(X \leq x)=\sum_{\text {todos } x_{i} \leq x} P\left(X=x_{i}\right)=\sum_{\text {todos } x_{i} \leq x} p_{X}\left(x_{i}\right)
$$

Contudo, se $X$ for contínua, as probabilidades somente poderão estar associadas a intervalos definidos sobre a reta dos números reais, conseqüentemente, para um valor específico de $X$, tal como $X=x$, somente pode ser definida a 
densidade de probabilidade. Portanto, para uma variável aleatória contínua a lei de probabilidade também pode ser descrita em termos de uma função de densidade de probabilidade (FDP), e se $f_{X}(x)$ é a FDP de $X$, a probabilidade de $X$ no intervalo (a,b] é:

$$
P(a<X \leq b)=\int_{a}^{b} f_{X}(x) \cdot d x
$$

Conseqüentemente, é possível definir a função de distribuição de probabilidade acumulada da variável aleatória $X$ na forma:

$$
F_{X}(x)=P(X \leq x)=\int_{-\infty}^{x} f_{X}(\xi) \cdot d \xi
$$

E portanto, se $F_{X}(x)$ possuir primeira derivada, então, tem-se:

$$
f_{X}(x)=\frac{d F_{X}(x)}{d x}
$$

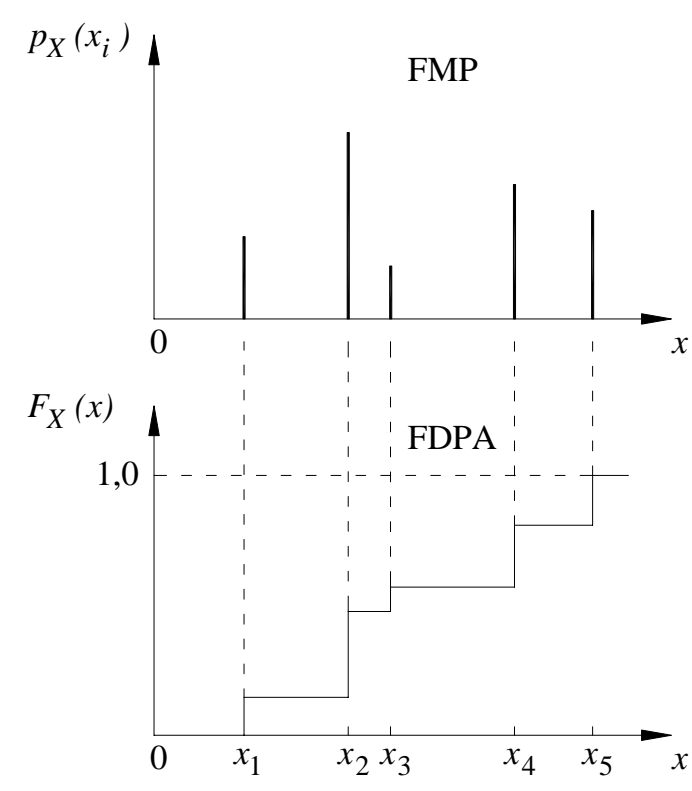

Discreta

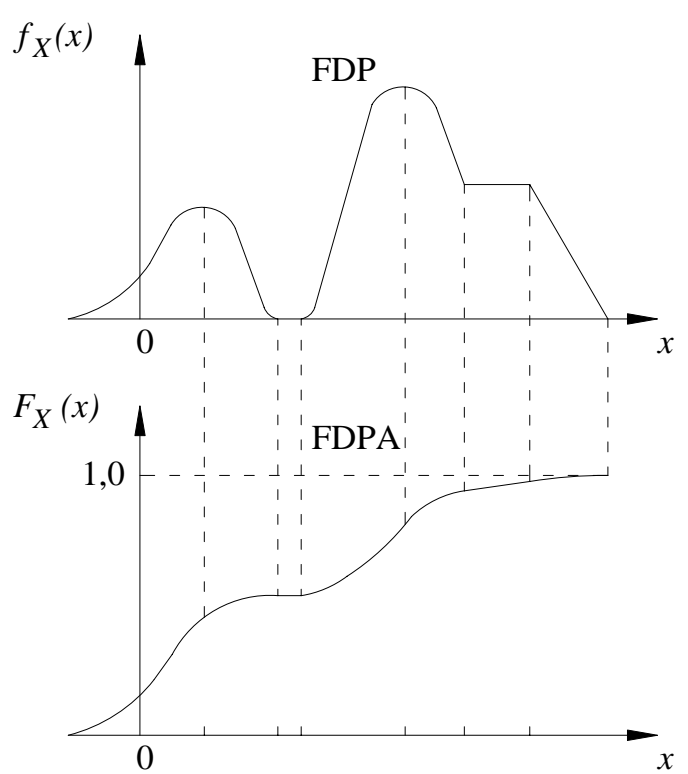

Contínua FIGURA 4.3 - Distribuições de probabilidade [adaptado ANG \& TANG (1975)]

Qualquer função escolhida para representar a função de distribuição de probabilidade de uma variável aleatória $X$, deve satisfazer os axiomas da definição 
de probabilidade, ANG \& TANG (1975). Portanto, a função $F_{X}(x)$ deve possuir as seguintes propriedades:
a) $F_{X}(x=-\infty)=0 ; F_{X}(x=+\infty)=1$;
b) $F_{X}(x) \geq 0$, e não ser decrescente com $x$;
c) ser contínua com $\mathrm{x}$.

As características probabilísticas de uma variável aleatória podem ser descrita em termos de certos parâmetros; os principais parâmetros de uma variável aleatória são o valor central e uma medida de dispersão de seus valores.

O valor central de uma variável aleatória $X$ é conhecido como média ou valor esperado de $X$, sendo denotado por $E(X)$, é definido pelas seguintes expressões:

$$
\begin{array}{ll}
E(X)=\sum_{\operatorname{todos} x_{i}} x_{i} \cdot p_{X}\left(x_{i}\right) & \text { se } X \text { for discreta } \\
E(X)=\int_{-\infty}^{\infty} x \cdot f_{X}(x) \cdot d x & \text { se } X \text { for contínua }
\end{array}
$$

Enquanto que a variância $\operatorname{Var}(X)$ é uma medida de dispersão ou variabilidade, sendo definida por:

$$
\begin{aligned}
& \operatorname{Var}(X)=\sum_{\operatorname{todos} x_{i}}\left(x_{i}-\mu_{X}\right)^{2} \cdot p_{X}\left(x_{i}\right) \quad \text { se } X \text { for discreta } \\
& \operatorname{Var}(X)=\int_{-\infty}^{\infty}\left(x-\mu_{X}\right)^{2} \cdot f_{X}(x) \cdot d x \quad \text { se } X \text { for contínua } \\
& \text { em que } \mu_{X} \equiv E(X) .
\end{aligned}
$$

Dimensionalmente, uma medida de dispersão mais conveniente é a raiz quadrada da variância, ou desvio padrão $\sigma$, isto é:

$$
\sigma_{X}=\sqrt{\operatorname{Var}(X)}
$$

É difícil dizer, somente com base na variância ou desvio padrão, se a dispersão é grande ou pequena; por isso, seria mais útil uma medida de dispersão 
relativa ao valor central . Em outras palavras, se a dispersão é significativamente grande ou pequena com relação ao valor central. Por esta razão, o coeficiente de variação $(V)$, é freqüentemente uma medida de dispersão adimensional conveniente, conforme a seguinte equação:

$$
V_{X}=\frac{\sigma_{X}}{\mu_{X}}
$$

A função de distribuição de probabilidade mais conhecida e mais amplamente empregada é a distribuição normal, também conhecida por distribuição gaussiana, que é definida pela sua função de densidade de probabilidade na forma:

$$
f_{X}(x)=\frac{1}{\sigma_{X} \cdot \sqrt{2 \cdot \pi}} \cdot \exp \left[-\frac{1}{2} \cdot\left(\frac{x-\mu_{X}}{\sigma_{X}}\right)^{2}\right] \quad-\infty<x<\infty
$$

onde $\mu_{X}$ e $\sigma_{X}$ são os parâmetros da distribuição, sendo também a média e o desvio padrão da variável aleatória $X$.

A distribuição gaussiana com parâmetros $\mu_{X}=0$ e $\sigma_{X}=1$, conforme figura 4.4, é conhecida como distribuição normal padronizada e pode ser obtida através da transformação:

$$
s=\frac{x-\mu_{X}}{\sigma_{X}}
$$

Resultando na seguinte função de densidade de probabilidade:

$$
f_{S}(s)=\frac{1}{\sqrt{2 \cdot \pi}} \cdot \exp \left[-\frac{1}{2} \cdot s^{2}\right] \quad-\infty<s<\infty
$$

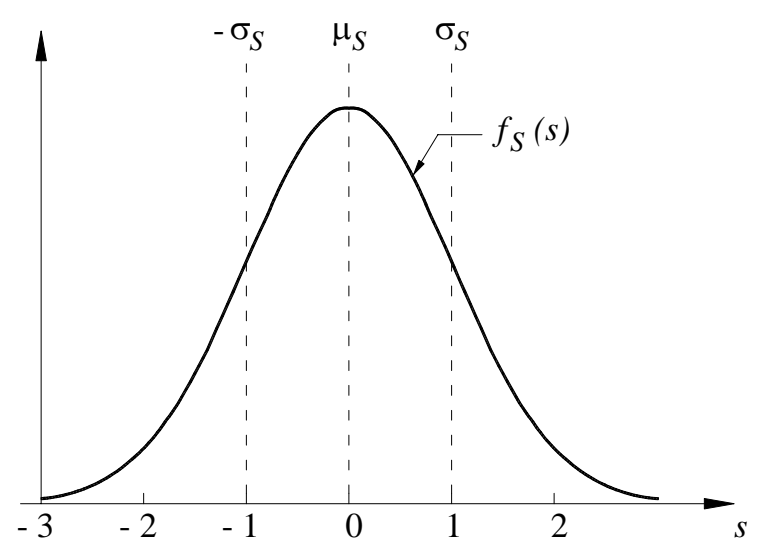

FIGURA 4.4 - Função de densidade de probabilidade da distribuição normal padronizada 
O conceito de uma variável aleatória e sua distribuição de probabilidade pode ser estendida a duas ou mais variáveis aleatórias. A fim de identificar numericamente eventos que são resultados de dois ou mais processos físicos, os eventos em um espaço amostral pode ser mapeado em duas (ou mais) dimensões do espaço real (figura 4.5); implicitamente isto exige duas ou mais variáveis aleatórias.

Como os valores de $X$ e $Y$ representam eventos, há probabilidades associadas com qualquer par de valores $x$ e $y$; as probabilidades de todos os possíveis pares de $x$ e $y$ podem ser descritas com a função de probabilidade conjunta das variáveis aleatórias $X$ e $Y$, definida como:

$F_{X, Y}(x, y)=P(X \leq x, Y \leq y)$

que é a probabilidade acumulada da ocorrência conjunta dos eventos identificados por $X \leq x$ e $Y \leq y$.

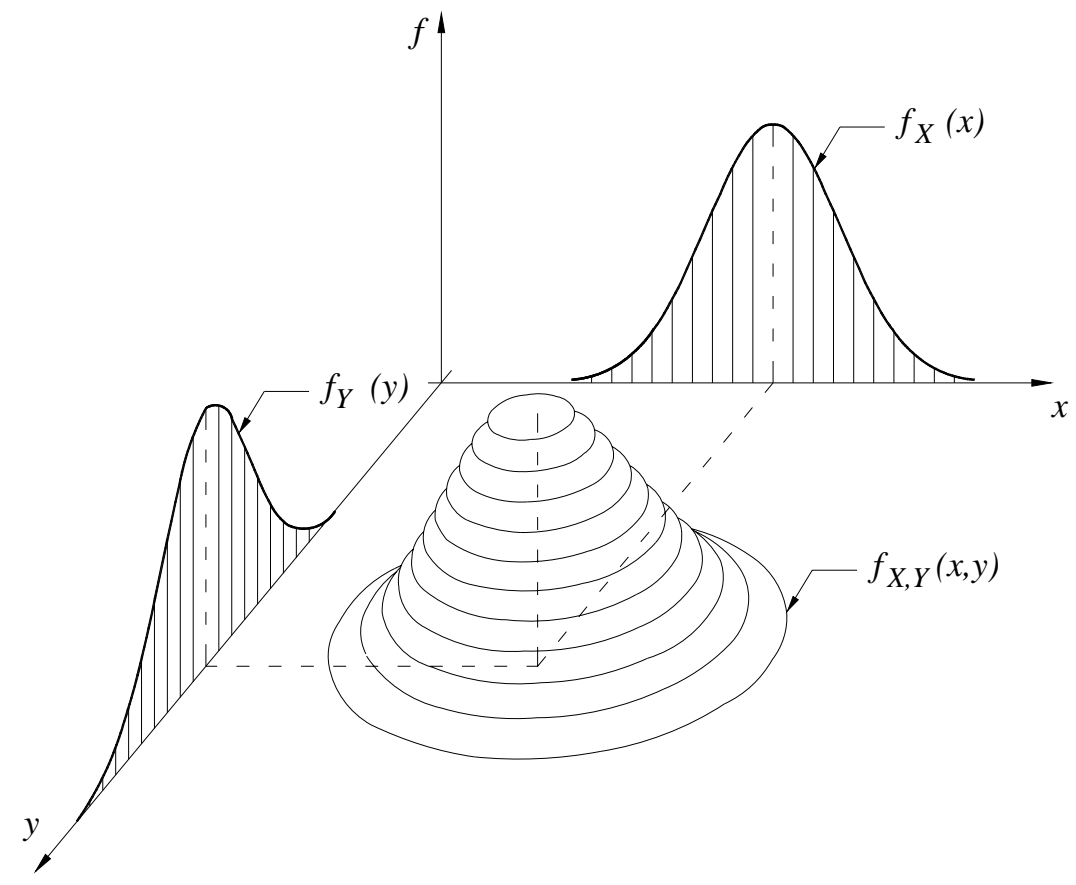

FIGURA 4.5 - Função de probabilidade conjunta

Se as variáveis aleatórias forem discretas, a distribuição de probabilidade também pode ser descrita com a função de massa de probabilidade conjunta (FMP), que é simplesmente:

$$
p_{X, Y}(x, y)=P(X=x, Y=y)
$$


Então a função de distribuição, torna-se:

$$
F_{X, Y}(x, y)=\sum_{\left(x_{i} \leq x, y_{i} \leq y\right)} p_{X, Y}\left(x_{i}, y_{i}\right)
$$

que é simplesmente a soma das probabilidades associadas com todos os pares de pontos $\left(x_{i}, y_{i}\right)$ no subconjunto $\left\{x_{i} \leq x, y_{i} \leq y\right\}$.

Se as variáveis aleatórias $X$ e $Y$ forem contínuas, a distribuição de probabilidade pode também ser descrita com a função de densidade de probabilidade (FDP), que pode ser definida como:

$$
f_{X, Y}(x, y)=P(x<X \leq x+d x, y<Y \leq y+d y)
$$

Então,

$$
F_{X, Y}(x, y)=\int_{-\infty}^{x} \int_{-\infty}^{y} f_{X, Y}(u, v) d v d u
$$

E também,

$$
P(a<X \leq b, c<Y \leq d)=\int_{a}^{b} \int_{c}^{d} f_{X, Y}(u, v) d v d u
$$

O momento de $2^{\mathrm{a}}$. Ordem conjunto de $X$ e $Y$ é dado por:

$$
E(X Y)=\int_{-\infty}^{\infty} \int_{-\infty}^{\infty} x y f_{X, Y}(x, y) d x d y
$$

E se $X$ e $Y$ forem estatisticamente independentes, a equação anterior tornará:

$$
E(X Y)=\int_{-\infty}^{\infty} x f_{X}(x) d x \int_{-\infty}^{\infty} y f_{Y}(y) d y=E(X) E(Y)
$$

Já o momento de $2^{\mathrm{a}}$. Ordem com relação às médias $\mu_{X}$ e $\mu_{Y}$ é denominada a covariância de $X$ e $Y$. Isto é:

$$
\operatorname{Cov}(X, Y)=E\left[\left(X-\mu_{X}\right)\left(Y-\mu_{Y}\right)\right]=E(X Y)-E(X) E(Y)
$$


E considerando a equação 4.22, $\operatorname{Cov}(X, Y)=0$ se $X$ e $Y$ forem estatisticamente independentes.

Portanto, a $\operatorname{Cov}(X, Y)$ é uma medida do grau de inter-relação (linear) entre as variáveis $X$ e $Y$. Para este propósito, contudo, é preferível utilizar a covariância normalizada ou coeficiente de correlação, que é definido como:

$$
\rho=\frac{\operatorname{Cov}(X, Y)}{\sigma_{X} \sigma_{Y}}
$$

Os valores de $\rho$ variam entre -1 e +1 . Quando $\rho= \pm 1,0, X$ e $Y$ são linearmente relacionados como mostrado na figura 4.6-a e 4.6-b, e quando $\rho=0$, os valores de $X$ e $Y$ podem aparecerem como na figura 4.6-c. Para valores intermediários de $\rho$, os valores de $X$ e $Y$ apareceriam como na figura 4.6-d. Contudo, pode-se observar pelas figuras 4.6-e e 4.6-f que quando a relação entre $X$ e $Y$ for não linear, $\rho=0$ até mesmo quando houver uma perfeita relação funcional entre as variáveis.

Portanto, a magnitude do coeficiente de correlação $\rho$ (entre 0 e 1) é uma medida do grau de inter-relação linear entre duas variáveis.

É importante salientar que $\rho$ é uma medida do grau de relação (linear) entre duas variáveis. Isto não implica necessariamente em uma relação causa-efeito entre as variáveis. Duas variáveis $X$ e $Y$ podem dependerem de uma outra variável (ou variáveis), causando uma forte correlação entre os valores de $X$ e $Y$, mas os valores de uma variável pode não ter efeito direto nos valores da outra. 


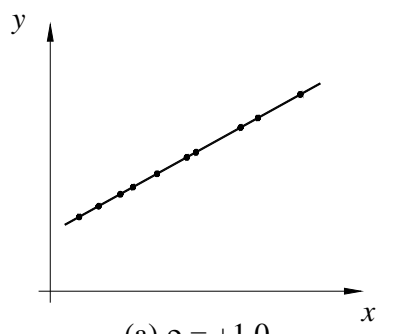

(a) $\rho=+1,0$

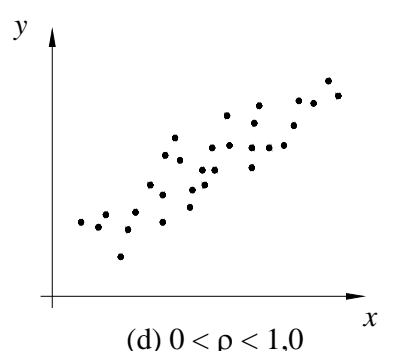

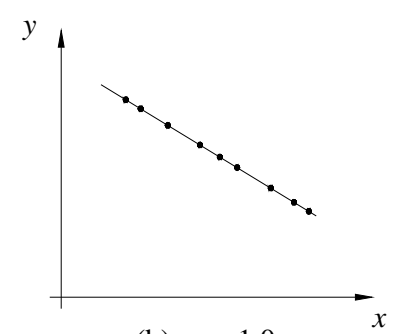

(b) $\rho=-1,0$

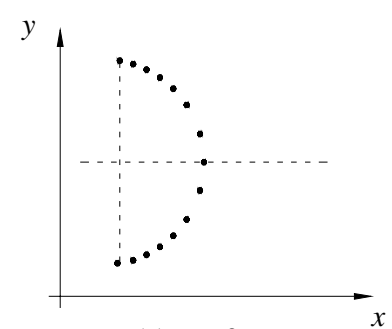

(e) $\rho=0$
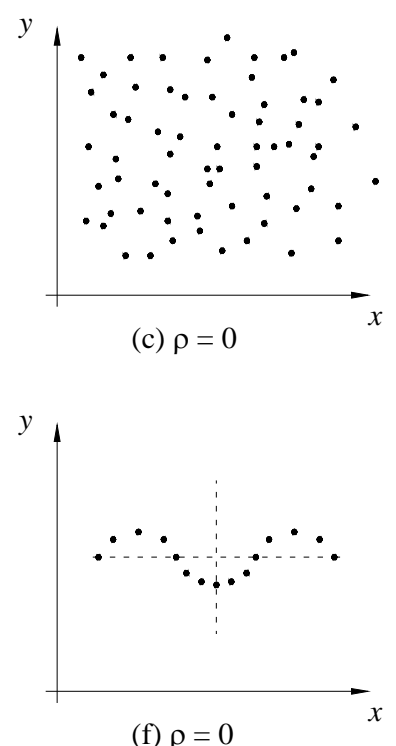

FIGURA 4.6 - Coeficiente de correlação [ANG \& TANG (1975)]

\subsection{Simulação de Monte Carlo}

Modelos matemáticos são criados para simular problemas reais, e assim sendo, para qualquer seleção de dados de entrada $X_{i}=\left(X_{1}, \ldots, X_{n}\right)$, um dado de saída $Y=h\left(X_{i}\right)$ é produzido pela aplicação do modelo matemático. Se o modelo for exato, a resposta $Y$ se assemelhará ao resultado obtido em um experimento sob as condições $X_{i}$. No entanto, os modelos matemáticos, geralmente, não são exatos, além disso, a modelagem do problema real é complexa, necessitando-se de simplificações. A dificuldade pode aumentar quando os parâmetros do sistema não são constantes, variando de alguma maneira dos valores nominais, como o que acontece com os parâmetros relacionados ao concreto. Com isso, a modelagem do problema deve ser feita considerando os valores de entrada como variáveis aleatórias. E com isso, obtém-se do estudo uma distribuição de probabilidade para o dado de saída $Y(t)$, como mostrado na figura 4.7, e a informação desejada é obtida da análise dessa distribuição. 


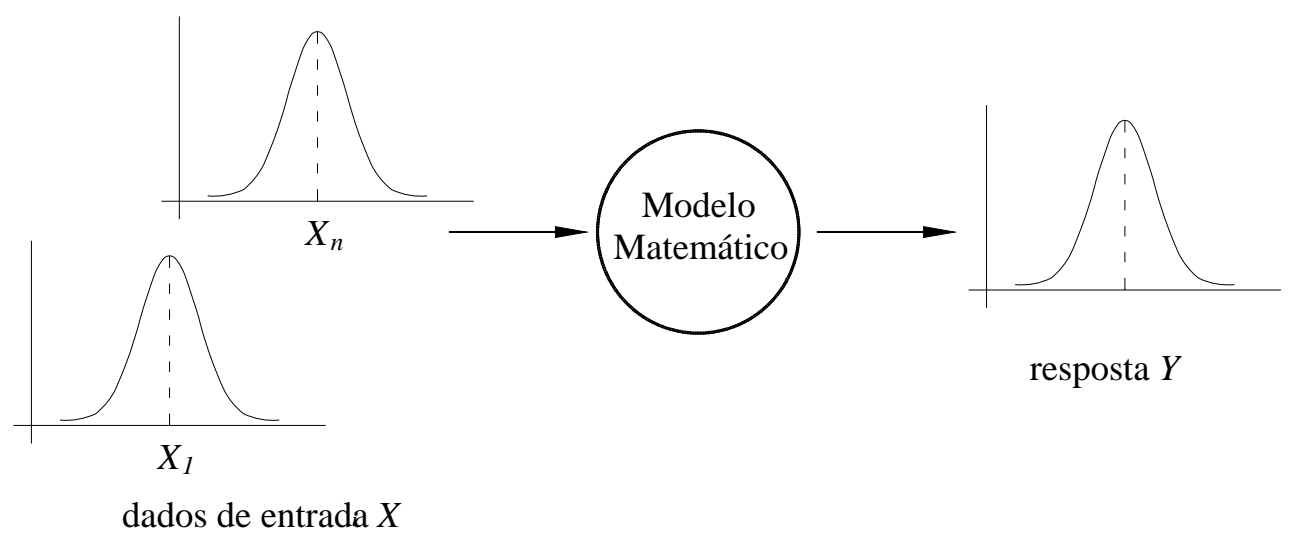

FIGURA 4.7 - Modelagem das incertezas

Portanto, se forem especificado os parâmetros $X_{1}, \ldots, X_{n}$, pode-se determinar a resposta $Y\left(X_{i}, t\right)$ para um determinado tempo $t$ pelo processamento do modelo através da análise determinística usual da estrutura. O método mais simples para a determinação da distribuição de $Y\left(X_{i}, t\right)$ é a simulação através do método Monte Carlo ou simulação de Monte Carlo, baseado na amostragem aleatória simples dos parâmetros de entrada $X_{i}$ de acordo com suas distribuições de probabilidade. Para cada amostra gerada aleatoriamente $X_{i}^{k}(k=1,2, \ldots, N)$, é determinada a resposta $Y^{k}$ e a distribuição de $Y$ pode ser construída assumindo que cada $Y^{k}$ tem a mesma probabilidade. Portanto, a simulação de Monte Carlo é simplesmente um processo de repetição de geração de soluções para um determinado problema, sendo que cada solução é determinada a partir de um particular grupo de valores das variáveis aleatórias geradas de acordo com suas correspondentes distribuição de probabilidade.

A simulação de Monte Carlo teve sua origem como extensão do Método de Monte Carlo. Este método foi proposto por Von Neumann e Ulam para a solução de problemas matemáticos cujo tratamento analítico não se mostrava viável. Isto se deu durante a Segunda Guerra Mundial, ao longo das pesquisas no Laboratório de Los Alamos, que resultaram na construção da primeira bomba atômica. A aplicação original do Método de Monte Carlo voltava-se à resolução de integrais múltiplas, no entanto, logo se verificou que ele poderia ser aplicado na solução de diversos outros problemas matemáticos complexos. 
Passado o momento de euforia inicial, as principais deficiências do novo método foram mais bem reconhecidas, notavelmente o grande trabalho computacional envolvido e a baixa precisão dos seus resultados, lembrando-se que nesta época, final da década de 40, os computadores começavam a tornar-se realidade, mas ainda com um desempenho bastante baixo.

Sendo restritos os recursos computacionais, as atenções se voltaram para a obtenção de resultados mais precisos, mas sem que se aumentassem, proporcionalmente, os tempos de processamento envolvidos. Este esforço resultou no desenvolvimento das técnicas de redução de variância, muitas delas objetivando um controle parcial do processo de amostragem.

No início da década de 50, com o advento dos primeiros computadores, a idéia do Método de Monte Carlo foi estendida para a solução de problemas probabilísticos de caráter mais geral, como é o caso das filas de espera. Viu-se, com isso, que poderíamos simular um processo e estimar seus principais parâmetros de operação, assim nascia a simulação de Monte Carlo.

\subsubsection{Parâmetros do sistema e suas propriedades estatísticas}

O sucesso da simulação de Monte Carlo depende significativamente da identificação dos parâmetros críticos do sistema que necessitam ser considerados como variáveis aleatórias e a determinação de suas propriedades estatísticas.

Neste trabalho foram considerados cinco parâmetros do sistema como variáveis aleatórias e conseqüentemente cinco fatores de incerteza foram introduzidos na análise numérica. Os dois primeiros se referem aos fatores de incerteza relativos ao erro potencial dos modelos de previsão da fluência e retração do concreto enquanto que os outros três fatores de incerteza foram atribuídos aos seguintes parâmetros do modelo: resistência do concreto, umidade relativa e temperatura ambiente. Foi considerado ainda que todos os fatores de incerteza assumiam distribuição normal e eram estatisticamente independentes entre si. 


\section{a) Coeficiente de fluência}

O erro na previsão da fluência do concreto é considerado na análise através de um fator de incerteza $\psi_{1}$ de valor médio igual a 1 multiplicando o coeficiente de fluência.

O CEB (1990) apresenta uma avaliação estatística do modelo do CEB-90 (1991) para a previsão da fluência do concreto através da comparação deste modelo com resultados de ensaios de fluência contidos em um banco de dados. Por essa análise, o valor encontrado para o coeficiente de variação é de 20,4\% para a função fluência dada pela seguinte equação.

$$
\Phi\left(\mathrm{t}, \mathrm{t}_{\mathrm{o}}\right)=\frac{1}{\mathrm{E}_{\mathrm{c}}\left(\mathrm{t}_{\mathrm{o}}\right)}+\frac{\psi_{1} \cdot \varphi\left(\mathrm{t}, \mathrm{t}_{\mathrm{o}}\right)}{\mathrm{E}_{\mathrm{c} 28}}
$$

Como o coeficiente de variação é referente à função fluência e não ao coeficiente de fluência, deve-se fazer a conversão com base na análise de propagação de erro [ANG \& TANG (1975)]. Desprezando a parte de variação atribuída ao módulo de elasticidade, tem-se:

$$
\sigma_{\Phi}=\frac{\partial \Phi}{\partial \varphi} \cdot \sigma_{\varphi}
$$

Considerando-se módulo de elasticidade constante e convertendo a equação anterior em termos do coeficiente de variação tem-se, conforme TAKÁCS (2002):

$$
V_{\psi_{1}}=V_{\varphi}=V_{\Phi} \cdot \frac{1+\mu_{\varphi}}{\mu_{\varphi}}
$$

Se o coeficiente de variação para a função fluência é de 20,4\% e estimando um valor médio para o coeficiente de fluência de 2,0, o coeficiente de variação obtido pela equação anterior para o coeficiente de fluência é de 30,6\%. Portanto, será estimado o coeficiente de variação para o coeficiente de fluência em:

$$
V_{\psi_{1}}=30 \%
$$




\section{b) Retração}

O erro na previsão da retração do concreto é considerado através de um fator de incerteza $\psi_{2}$ de valor médio igual a 1 multiplicando o valor da retração.

O CEB (1990) apresenta também uma avaliação estatística do modelo do CEB-90 (1991) para previsão da retração do concreto, obtendo o seguinte valor para o coeficiente de variação:

$$
V_{\psi_{2}}=32,9 \%
$$

\section{c) Resistência do concreto}

BAZANT \& BAWEJA (1995a) sugerem considerar a variabilidade estatística da resistência do concreto com um coeficiente de variação de 15\%, já nos trabalhos de BAZANT \& LIU (1985) e KRISTEK \& BAZANT (1985) o coeficiente de variação utilizado foi de $10 \%$. Na realidade a variabilidade estatística da resistência do concreto vai depender do nível de controle utilizado na confecção do concreto, mas parece razoável considerar o coeficiente de variação para a resistência do concreto entre 10 e $15 \%$. Portanto,

$$
V_{f_{c}}=10-15 \%
$$

\section{d) Umidade relativa e temperatura ambiente}

A umidade relativa e a temperatura ambiente são parâmetros que não variam somente aleatoriamente, mas seguem uma flutuação sazonal e diária. É praticamente impossível considerar essa flutuação na análise estrutural, sendo suficiente considerar a umidade relativa e a temperatura com seus valores médios e atribuir os fatores de incerteza a esses valores. O coeficiente de variação para a umidade relativa sugerido por BAZANT \& BAWEJA (1995a) e utilizado por BAZANT \& LIU (1985) e KRISTEK \& BAZANT (1985) é de 20\%. Assim, os coeficientes de variação para a umidade relativa e temperatura serão estimados em:

$$
\begin{aligned}
& V_{U}=20 \% \\
& V_{T}=20 \%
\end{aligned}
$$




\subsubsection{Amostragem por hipercubo latino}

A amostragem por hipercubo latino foi sugerida por McKAY et al. (1979), sendo um refinamento da amostragem estratificada. A idéia da amostragem por hipercubo latino é dividir o domínio de cada variável aleatória $X_{i}$ em $N$ intervalos $\Delta X_{i}^{k}(k=1,2, \ldots, N)$ de igual probabilidade $1 / N$, como mostrado na figura 4.8. O número de intervalos $N$ na amostragem por hipercubo latino a ser escolhido deve ser igual ao tamanho da amostra desejada, ou seja, igual ao número total de processamentos a ser realizado (simulações). Para cada intervalo, é selecionado apenas um valor, isto é, este valor será usado em uma e apenas uma simulação.

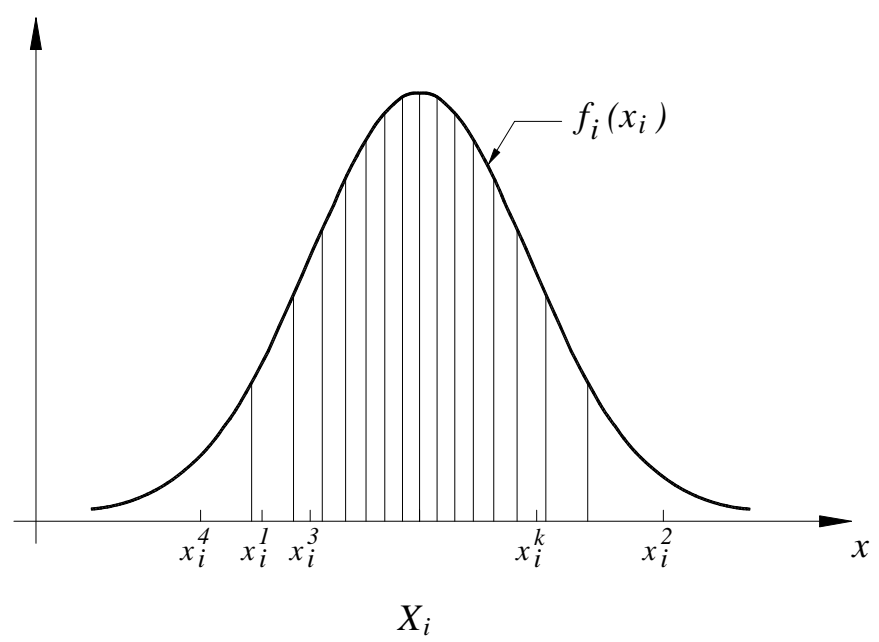

FIGURA 4.8 - Divisão do domínio da variável estatística em intervalos de igual probabilidade

Os valores amostrados $x_{i}^{k}$, para uma seleção aleatória do valor $k$, são obtidos pela resolução da seguinte equação:

$F_{i}\left(x_{i}^{k}\right)=\frac{k-1+R_{k}}{N}$ com $k=1,2, \ldots, N$

onde $R_{k}$ representa uma distribuição aleatória uniforme no intervalo $[0,1]$.

Ou seja, a amostragem é realizada utilizando a transformada inversa da função de distribuição de probabilidade em questão, como mostrada pela expressão: 


$$
x_{i}^{k}=F_{i}^{-1}\left(\frac{k-1+R_{k}}{N}\right) \operatorname{com} k=1,2, \ldots, N
$$

Se o número de intervalos $N$ for grande, BAZANT \& LIU (1985) afirmam que o valor não precisa ser selecionado aleatoriamente (dentro do intervalo), mas pode-se tomar o centróide do intervalo, conforme figura 4.9, resultando na seguinte expressão:

$$
F_{i}\left(x_{i}^{k}\right)=\frac{k-1 / 2}{N} \operatorname{com} k=1,2, \ldots, N
$$

Tal procedimento foi estudado por SALIBY (1989) que o definiu como amostragem descritiva por ser uma seleção determinística dos valores da amostra de entrada, ou seja, enquanto que a amostragem aleatória simples pode ser vista como um processo em que se gera um conjunto de valores e sua seqüência, na amostragem descritiva apenas a seqüência continua sendo gerada aleatoriamente, através de permutações aleatórias; o conjunto, por outro lado, é selecionado de forma determinística e intencional.

A vantagem da amostragem por hipercubo latino em relação a outros métodos de amostragem é que o número de processamentos (simulações) pode ser reduzido consideravelmente para alcançar o mesmo nível de precisão, como observado nas comparações feitas por McKAY et al. (1979), STEIN (1987) e SALIBY \& MOREIRA (2001).

No campo da engenharia estrutural a amostragem por hipercubo latino foi utilizada por BAZANT \& LIU (1985), KRISTEK \& BAZANT (1985), NAVRATIL \& FLORIAN (1993) e OH \& YANG (2000) para a análise dos efeitos da fluência e retração.

BAZANT \& LIU (1985) utilizaram a amostragem por hipercubo latino no estudo dos efeitos da fluência e retração em vigas e demais estruturas de concreto, verificando que se obtém uma precisão aceitável se o número de simulações for igual ao número de variáveis aleatórias, $N=n$. Obtendo-se ainda uma apreciável melhoria na precisão se o número de simulações for igual a duas vezes o número de variáveis aleatórias $N=2 . n$. 


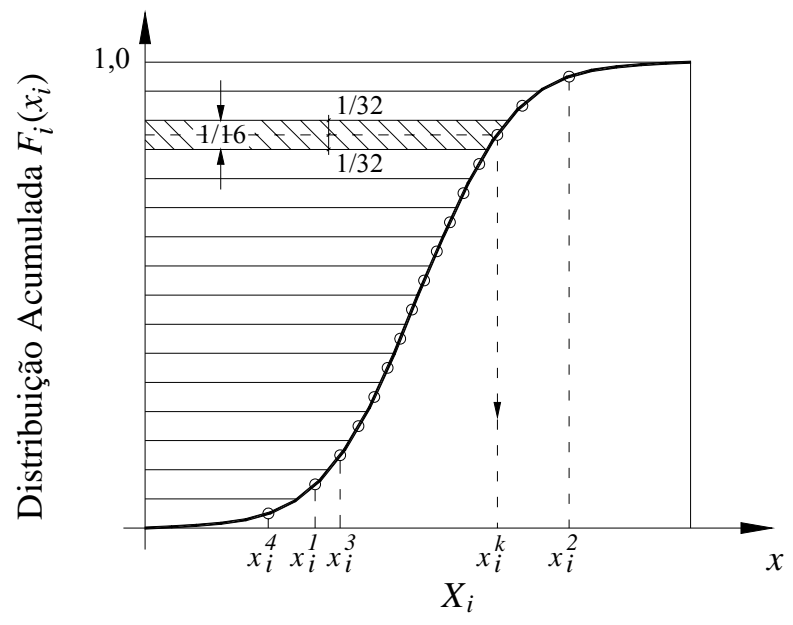

FIGURA 4.9 - Divisão do domínio da variável estatística em 16 intervalos

A seleção aleatória do valor $k$ é realizada mediante a permutação aleatória dos inteiros 1, 2,..., N . Há sub-rotinas para gerar estas permutações aleatórias, sendo que neste trabalho, utilizou-se a sub-rotina baseada no algoritmo apresentado por KNUTH (1969). Este algoritmo define que a partir de um grupo de $t$ números $x_{1}, \ldots, x_{t}$ a ser permutado, faz-se:

P1. [Iniciar] Fixar $j \leftarrow t$.

P2. [Gerar $U]$ Gerar um número aleatório $U$, uniformemente distribuído entre zero e 1.

P3. [Permutar] Fixar $k \leftarrow\lfloor t U\rfloor+1$ ( $k$ será um número aleatório inteiro entre 1 e $j$ ).

Permutar $x_{k} \leftarrow x_{j}$.

P4. [Diminuir $j$ ] Diminuir $j$ de 1 . Se $j>1$, retornar ao passo P2.

A transformada inversa da função de distribuição normal foi obtida a partir da transformada inversa da função de distribuição normal padronizada. Uma distribuição normal $X$ com média $\mu$ e desvio padrão $\sigma$, como indicado por BRATLEY et al. (1987), pode ser gerada a partir da distribuição normal padronizada $Z$ utilizando a seguinte transformação:

$$
X=\mu+\sigma . Z
$$


Para a transformada inversa $Z=F^{-1}(U)$ da distribuição normal padronizada foi empregada a seguinte aproximação numérica apresenta por KENNEDY et al. (1980).

$$
Z=k+\frac{p_{0}+p_{1} \cdot k+p_{2} \cdot k^{2}+p_{3} \cdot k^{3}+p_{4} \cdot k^{4}}{q_{0}+q_{1} \cdot k+q_{2} \cdot k^{2}+q_{3} \cdot k^{3}+q_{4} \cdot k^{4}}
$$

onde

$$
k=\sqrt{-\ln (1-U)^{2}}
$$

e

$$
\begin{array}{ll}
p_{0}=-0,322232431088 & q_{0}=0,0993484626060 \\
p_{1}=-1,0 & q_{1}=0,588581570495 \\
p_{2}=-0,342242088547 & q_{2}=0,531103462366 \\
p_{3}=-0,0204231210245 & q_{3}=0,103537752850 \\
p_{4}=-0,453642210148.10^{-4} & q_{4}=0,38560700634.10^{-2}
\end{array}
$$

Esta aproximação tem uma precisão relativa de aproximadamente seis dígitos e é válida para $0,5<U<1$. A simetria da distribuição normal permite estender tal aproximação para $0<U<1$ pelas transformações $U=1-U$ e $Z=-Z$.

\section{- Estimando a média e a variância}

Após a realização de $N$ simulações, tem-se à disposição um conjunto de dados representando um certo efeito estrutural $Y$ (isto é, deslocamento, reação de apoio, tensão no concreto para um determinado tempo $t$ ). Assim sendo, essa resposta pode ser tratada como uma variável aleatória, cuja média e variância podem ser estimadas por:

$$
\begin{aligned}
& M=\bar{y}=\frac{1}{N} \sum_{i=1}^{N} y_{i} \\
& S^{2}=\frac{1}{N} \sum_{i=1}^{N}\left(y_{i}-\bar{y}\right)^{2}
\end{aligned}
$$

onde $i=1,2, \ldots, N$ representa o número de simulações. 
A variância $S^{2}$ não é um estimador não viciado. De fato, não se conhece o estimador não viciado para o caso da amostragem por Hipercubo Latino, contudo tal estimador está entre os dois valores [McKAY et al. (1979)].

$$
\frac{1}{N} \sum_{i=1}^{N}\left(y_{i}-\bar{y}\right)^{2} \leq E\left(S^{2}\right) \leq \frac{1}{(N-1)} \sum_{i=1}^{N}\left(y_{i}-\bar{y}\right)^{2}
$$

\section{- Estimando o coeficiente de correlação}

Como mencionado anteriormente, a correlação entre duas variáveis $X$ e $Y$ é medida pelo coeficiente de correlação. Baseado em um grupo de valores observados de $X$ e $Y$, o coeficiente de correlação pode ser estimado por:

$$
r=\frac{\sum_{i}\left(x_{i}-\bar{x}\right)\left(y_{i}-\bar{y}\right)}{\sqrt{\sum_{i}\left(x_{i}-\bar{x}\right)^{2}} \sqrt{\sum_{i}\left(y_{i}-\bar{y}\right)^{2}}}
$$

Ou ainda,

$$
r=\frac{N \cdot\left(\sum_{i}\left(x_{i} \cdot y_{i}\right)\right)-\left(\sum_{i}\left(x_{i}\right)\right)\left(\sum_{i}\left(y_{i}\right)\right)}{\sqrt{\left[N \cdot \sum_{i}\left(x_{i}\right)^{2}-\left(\sum_{i}\left(x_{i}\right)\right)^{2}\right]\left[N \cdot \sum_{i}\left(y_{i}\right)^{2}-\left(\sum_{i}\left(y_{i}\right)\right)^{2}\right]}}
$$

\section{- Estimando os limites de confiança}

Os limites de confiança são os valores extremos do intervalo de confiança. Em muitos casos práticos em engenharia é aplicado o intervalo de confiança de 95\%. Isso significa que há probabilidade de 95\% da variável aleatória estar dentro do intervalo de confiança. O intervalo de confiança é denominado bilateral quando for limitado por valores superior e inferior, no entanto, em muitos casos, a natureza do problema exige somente o limite inferior ou o limite superior, e conseqüentemente, o intervalo de confiança é denominado unilateral (o valor característico da resistência do concreto é o limite do intervalo de confiança unilateral inferior). 
Os limites de confiança, denotados por $C$, também podem ser definidos pelo número de desvios padrão acima e abaixo do valor médio. O número de desvios padrão depende do grau de confiança exigido e o tipo de distribuição.

Quando a média e o desvio padrão da resposta forem determinados, os limites de confiança podem ser calculados assumindo que a resposta se aproxima de uma distribuição normal [BAZANT \& BAWEJA (1995a)]. Para o caso de intervalo de confiança bilateral de 95\%, têm-se os seguintes limites de confiança.

$$
C_{0,95}=M \pm 1,960 . S
$$

E para intervalo de confiança unilateral de 95\%, têm-se, respectivamente, os limites de confiança inferior e superior.

$$
\begin{aligned}
& C_{0,95}=M-1,645 . S \\
& C_{0,95}=M+1,645 . S
\end{aligned}
$$

A hipótese de que a resposta se aproxima de uma distribuição normal pode ser verificada pelo gráfico de probabilidade normal. Para desenvolver um gráfico de probabilidade, os dados são ordenados em ordem crescente e a posição no gráfico dos $N$ valores pode ser obtida pela equação de posição de Hazen:

$$
p(i)=\frac{i-0,5}{N} .100
$$

onde $i$ é a posição dos $N$ valores após serem ordenados.

A figura 4.10 mostra os gráficos de probabilidade normal para a flecha aos 40 dias e 103 dias para o exemplo apresentado no item a seguir. 


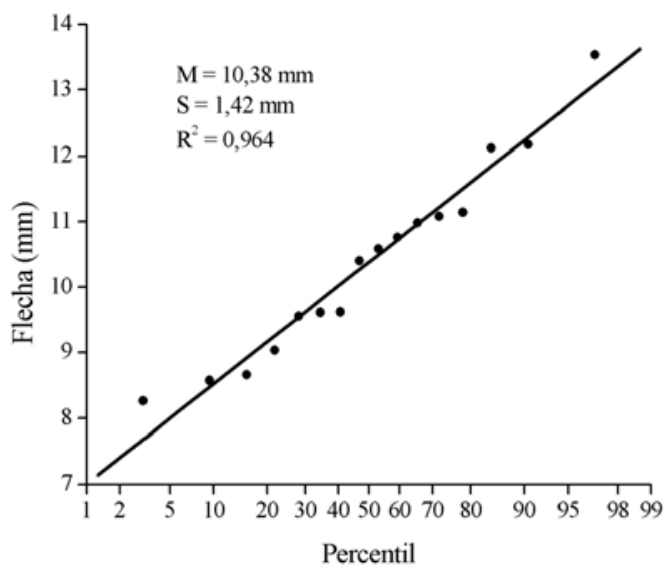

(a) 40 dias

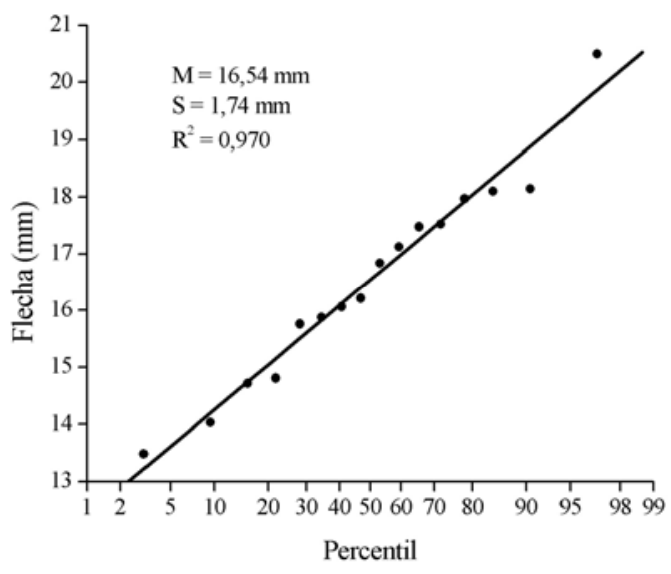

(b) 103 dias

FIGURA 4.10 - Gráficos de probabilidade normal para a flecha

O fato dos valores da resposta se aproximarem da reta no gráfico de probabilidade normal indica que a distribuição de probabilidade da resposta é aproximadamente normal. Pontos distantes da reta indicam que a distribuição normal não é uma boa aproximação.

A validação da distribuição adotada também pode ser feita através do Teste de Kolmogorov-Smirnov ou do Teste $\chi$-quadrado. Neste trabalho será utilizado o Teste de Kolmogorov-Smirnov, pois, como alertado por ANG \& TANG (1975), a vantagem deste teste sobre o $\chi$-quadrado está no fato de não necessitar dividir os dados em intervalos, evitando os problemas associados ao tamanho do intervalo.

O procedimento básico do Teste Kolmogorov-Smirnov envolve a comparação entre a freqüência acumulada obtida e uma função de distribuição teórica. Se a discrepância for grande com relação à esperada para um determinado tamanho de amostra, então o modelo teórico é rejeitado.

Para uma amostra de tamanho $N$, o grupo de dados é rearranjado em ordem crescente. Com os dados ordenados, desenvolve uma função de freqüência acumulada dada por:

$$
S_{N}(x)=\left\{\begin{array}{lc}
0 & x<x_{1} \\
\frac{k}{N} & x_{k} \leq x<x_{k+1} \\
1 & x \geq x_{N}
\end{array}\right.
$$


onde $x_{1}, x_{2}, \ldots, x_{N}$ são os valores dos dados ordenados e $N$ é o tamanho da amostra.

A figura 4.11 mostra um gráfico de $S_{N}(x)$ e também a função de distribuição acumulada teórica proposta $F(x)$. No teste de Kolmogorov-Smirnov, a medida de discrepância entre o modelo teórico e os dados obtidos é a máxima diferença entre $S_{N}(x)$ e $F(x)$ sobre toda a variação de $X$. Esta máxima diferença pode ser denotada por:

$$
D_{N}=\max _{x}\left|F(x)-S_{N}(x)\right|
$$

Teoricamente, $D_{N}$ é uma variável aleatória cuja distribuição depende de $N$. Para um nível de significância $\alpha$ especificado, o Teste de Kolmogorov-Smirnov compara a máxima diferença com o valor crítico $D_{N}^{\alpha}$, que é definido por:

$$
P\left(D_{N} \leq D_{N}^{\alpha}\right)=1-\alpha
$$

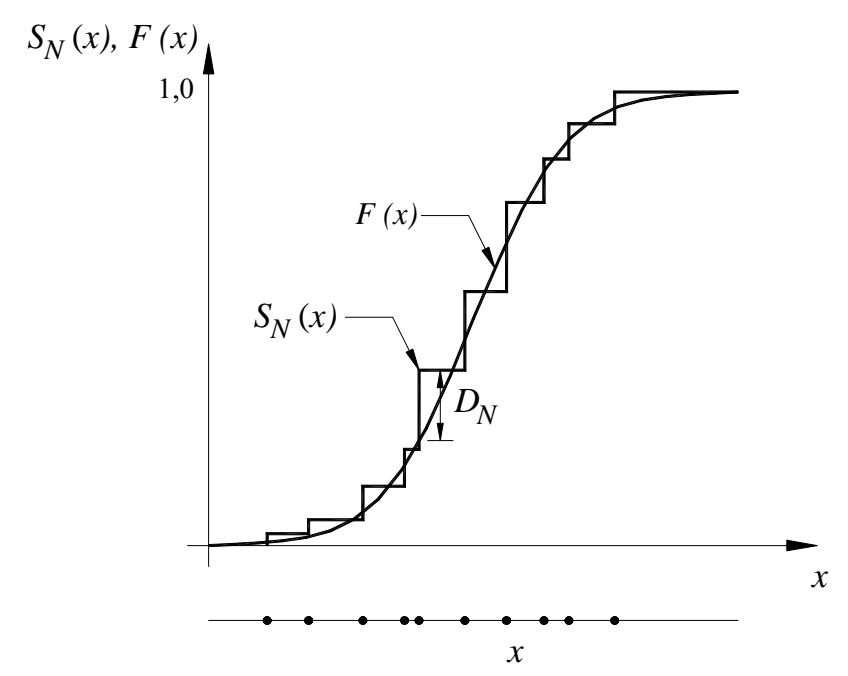

FIGURA 4.11 - Teste de Kolmogorov-Smirnov [adaptado ANG \& TANG (1975)]

Os valores críticos $D_{N}^{\alpha}$ para vários níveis de significância e para vários valores de $N$ estão apresentados na tabela 4.1 [ANG \& TANG (1975)]. Se o valor observado de $D_{N}$ for menor que o valor crítico $D_{N}^{\alpha}$, a distribuição proposta é aceita 
para o nível de significância $\alpha$, caso contrário, a distribuição assumida deverá ser rejeitada.

TABELA 4.1 - Valores críticos $D_{N}^{\alpha}$ no Teste de Kolmogorov-Smirnov [ANG \& TANG (1975)]

\begin{tabular}{|c|c|c|c|c|}
\hline & 0,20 & 0,10 & 0,05 & 0,01 \\
\hline 5 & 0,45 & 0,51 & 0,56 & 0,67 \\
\hline 10 & 0,32 & 0,37 & 0,41 & 0,49 \\
\hline 15 & 0,27 & 0,30 & 0,34 & 0,40 \\
\hline 20 & 0,23 & 0,26 & 0,29 & 0,36 \\
\hline 25 & 0,21 & 0,24 & 0,27 & 0,32 \\
\hline 30 & 0,19 & 0,22 & 0,24 & 0,29 \\
\hline 35 & 0,18 & 0,20 & 0,23 & 0,27 \\
\hline 40 & 0,17 & 0,19 & 0,21 & 0,25 \\
\hline 45 & 0,16 & 0,18 & 0,20 & 0,24 \\
\hline 50 & 0,15 & 0,17 & 0,19 & 0,23 \\
\hline$>50$ & $1,07 / \sqrt{N}$ & $1,22 / \sqrt{N}$ & $1,36 / \sqrt{N}$ & $1,63 / \sqrt{N}$ \\
\hline
\end{tabular}

A função de distribuição normal acumulada $F(x)$ foi obtida a partir da função de distribuição normal padronizada acumulada. Uma forma precisa, eficiente e conveniente de avaliar a função de distribuição normal padronizada acumulada $\Phi(x)$ pode ser feita através da função erro, pois há uma relação matemática exata entre essas funções que é dada por:

$$
\Phi(x)= \begin{cases}\left.\frac{1}{2} \cdot \operatorname{erf}\left(\frac{x}{\sqrt{2}}\right)\right] & x \geq 0 \\ \left.\frac{1}{2} \cdot \operatorname{erfc}\left(\frac{-x}{\sqrt{2}}\right)\right] & x<0\end{cases}
$$

A função erro e seu complemento são definidos por:

$$
\begin{aligned}
& \operatorname{erfc}(x)=\frac{2}{\sqrt{\pi}} \cdot \int_{x}^{\infty} e^{-t^{2}} d t=1-\operatorname{erf}(x) \quad(x>0) \\
& \operatorname{erfc}(x)=\frac{2}{\sqrt{\pi}} \cdot \int_{x}^{\infty} e^{-t^{2}} d t=1-\operatorname{erf}(x) \quad(x>0)
\end{aligned}
$$


KENNEDY et al. (1980) apresentam a seguinte aproximação numérica da função erro:

$$
\begin{array}{lll}
\operatorname{erf}(x) \cong x \cdot R_{1}(x) & 0<x \leq 0,5 & 4.54 \\
\operatorname{erfc}(x) \cong \exp \left(-x^{2}\right) \cdot R_{2}(x) & 0,46875 \leq x \leq 4,0 & 4.55 \\
\operatorname{erfc}(x) \cong\left[\frac{\exp \left(-x^{2}\right)}{x}\right] \cdot\left[\pi^{-1 / 2}+x^{-2} \cdot R_{3}\left(x^{-2}\right)\right] & x \geq 4,0
\end{array}
$$

Quando $x<0,46875, \operatorname{erf}(x)$ pode ser avaliada diretamente pela formulação anterior e $\operatorname{erfc}(x)$ como $1-\operatorname{erf}(x)$. Similarmente, $\operatorname{erfc}(x)$ pode ser avaliada diretamente e $\operatorname{erf}(x)$ como $1-\operatorname{erfc}(x)$ quando $x \geq 0,46875$.

Os valores das frações $R_{1}, R_{2}$ e $R_{3}$ são apresentados a seguir.

$$
\begin{aligned}
& R_{1}=\frac{\sum_{j=0}^{3} p_{j} \cdot x^{2 \cdot j}}{\sum_{j=0}^{3} q_{j} \cdot x^{2 \cdot j}} \quad 0<x \leq 0,5 \\
& \text { e } \\
& p_{0}=2,4266795523053175.10^{2} \quad q_{0}=2,1505887586986120.10^{2} \\
& p_{1}=2,1979261618294152.10^{1} \quad q_{1}=9,1164905404514901.10^{1} \\
& p_{2}=6,9963834886191355 \quad q_{2}=1,5082797630407787.10^{1} \\
& p_{3}=-3,5609843701815385.10^{-2} \quad q_{3}=1,0 \\
& R_{2}=\frac{\sum_{j=0}^{7} p_{j} \cdot x^{j}}{\sum_{j=0}^{7} q_{j} \cdot x^{j}} \quad 0,46875 \leq x \leq 4,0 \\
& \text { e } \\
& p_{0}=3,004592610201616005.10^{2} \quad q_{0}=3,004592609569832933.10^{2} \\
& p_{1}=4,519189537118729422 \cdot 10^{2} \quad q_{1}=7,909509253278980272 \cdot 10^{2} \\
& p_{2}=3,393208167343436870.10^{2} \quad q_{2}=9,313540948506096211.10^{2}
\end{aligned}
$$




$$
\begin{array}{ll}
p_{3}=1,529892850469404039.10^{2} & q_{3}=6,389802644656311665.10^{2} \\
p_{4}=4,316222722205673530.10^{1} & q_{4}=2,775854447439876434.10^{2} \\
p_{5}=7,211758250883093659 & q_{5}=7,700015293522947295.10^{1} \\
p_{6}=5,641955174789739711.10^{-1} & q_{6}=1,278272731962942351.10^{1} \\
p_{7}=-1,368648573827167067.10^{-7} & q_{7}=1,0 \\
R_{3}=\frac{\sum_{j=0}^{4} p_{j} \cdot x^{-2 \cdot j}}{\sum_{j=0}^{4} p_{j} \cdot x^{-2 . j}} & \\
p_{0}=-2,99610707703542174.10^{-3} & q_{0}=1,06209230528467918.10^{-2} \\
p_{1}=-4,94730910623250734.10^{-2} & q_{1}=1,91308926107829841.10^{-1} \\
p_{2}=-2,26956593539686930.10^{-1} & q_{2}=1,05167510706793207 \\
p_{3}=-2,78661308609647788.10^{-1} & q_{3}=1,98733201817135256 \\
p_{4}=-2,23192459734184686.10^{-2} & q_{4}=1,0
\end{array}
$$

\section{- Análise de sensibilidade}

Os resultados das simulações podem ser usados para determinar quais os parâmetros afetam mais significativamente a incerteza da resposta. Para isso, pode-se utilizar o coeficiente de regressão padronizado ou o coeficiente de correlação parcial. A análise de sensibilidade em conjunto com a amostragem está estreitamente relacionada com a construção de modelos de regressão que se aproximam do comportamento obtido pelas simulações. Supondo que um modelo tenha como variáveis de entrada $X_{1}, \ldots, X_{n}$ e resposta $Y$. Depois de $N$ simulações do modelo, as observações multivariadas $\left(X_{i 1}, \ldots, X_{i n}, Y_{i} ; i=1, \ldots, N\right)$ podem ser usadas para construir um modelo de regressão aproximado, dado por:

$$
\hat{Y}=b_{o}+\sum_{j=1}^{n} b_{j} X_{j}
$$


A constante $b_{o}$ e os coeficientes de regressão $b_{j}$ são obtidos por métodos dos mínimos quadrados usuais. Estes coeficientes de regressão são facilmente influenciados pelas unidades em que as variáveis são mediadas. Esse problema pode ser eliminado pela padronização de todas as variáveis usadas no modelo. Assim, o modelo de regressão anterior pode ser reescrito da seguinte forma:

$$
Y^{*}=\sum_{j=1}^{n} b_{j}^{*} X_{j}^{*}
$$

Com,

$$
b_{j}{ }^{*}=\frac{b_{j} s_{X_{j}}}{s_{Y}}
$$

O coeficiente $b_{j}{ }^{*}$ é denominado coeficiente de regressão padronizado. Sendo uma medida adimensional, o coeficiente de regressão padronizado pode ser utilizado para determinar a importância das variáveis de entrada. Quanto maior for o valor absoluto de $b_{j}{ }^{*}$, maior será a influência de $X_{j}$ na resposta $Y$ e valores de $b_{j}{ }^{*}$ próximos de zero indicam pouca importância de $X_{j}$.

Com as $N$ simulações do modelo, pode-se também determinar a matriz de correlação entre as variáveis, podendo ser representada como:

$$
\begin{aligned}
& \mathbf{C}=\left[\begin{array}{cccc:c}
1 & r_{12} & \ldots & r_{1 n} & r_{1 y} \\
r_{21} & 1 & \ldots & r_{2 n} & r_{2 y} \\
\ldots & \ldots & \ldots & \ldots & \ldots \\
r_{n 1} & r_{n 2} & \ldots & 1 & r_{n y} \\
\hdashline r_{y 1} & r_{y 2} & \ldots & r_{y n} & 1
\end{array}\right] \\
& \text { onde } r_{i j} \text { com } i \geq 1 \text { e } j \leq n \text { é o coeficiente de correlação entre as } \\
& \text { variáveis de entrada e } r_{y j} \text { é o coeficiente de correlação entre } Y \text { e } X_{j}, \\
& \text { determinados a partir da equação } 4.42 .
\end{aligned}
$$


A matriz inversa $C^{-1}$ pode ser escrita na forma expandida como:

$$
\boldsymbol{C}^{-1}=\left[\begin{array}{cccc:c}
c_{11} & c_{12} & \ldots & r_{1 n} & c_{1 y} \\
c_{21} & c_{22} & \ldots & r_{2 n} & c_{2 y} \\
\ldots & \ldots & \ldots & \ldots & \ldots \\
c_{n 1} & c_{n 2} & \ldots & c_{n n} & c_{n y} \\
\hdashline c_{y 1} & c_{y 2} & \ldots & c_{y n} & c_{n n}
\end{array}\right]
$$

O coeficiente de correlação parcial de $X_{j}$ e $Y$ é obtido diretamente de $C^{-1}$ como:

$$
P_{X_{j}, Y}=-\frac{c_{j y}}{\sqrt{c_{j j} c_{y y}}}
$$

O coeficiente de regressão padronizado e o coeficiente de correlação parcial medem a associação linear entre as variáveis. Quando envolvem relações não lineares, é mais relevante determinar tais coeficientes com relações aos valores hierarquizados das variáveis que com relação aos seus valores reais.

\subsection{Exemplos}

\subsubsection{Exemplo 1: Viga reforçada à flexão}

Como exemplo de aplicação, será utilizado o ensaio da viga V1 realizado por REIS (2003). As variáveis aleatórias empregadas foram aquelas definidas no item anterior, no entanto, devido à existência de dois tipos de concreto (viga e reforço), as variáveis aleatórias relativas ao concreto (coeficiente de fluência, retração e resistência) estarão duplicadas, totalizando 8 variáveis aleatórias para o caso em questão. As 8 variáveis aleatórias utilizadas estão listadas a seguir. 
$X_{1}$ - coeficiente de fluência do concreto da viga

$X_{2}$ - retração do concreto da viga

$X_{3}$ - resistência do concreto da viga

$X_{4}$ - coeficiente de fluência do concreto do reforço

$X_{5}$ - retração do concreto do reforço

$X_{6}$ - resistência do concreto do reforço

$X_{7}$ - umidade relativa ambiente

$X_{8}$ - temperatura ambiente

Foi realizado o total de simulações recomendado por BAZANT \& LIU (1985) igual a $N=2 . n$, ou seja, 16 simulações.

Na tabela 4.2, apresentam-se as permutações geradas aleatoriamente dos inteiros $1,2, \ldots, N$ para cada variável aleatória $X_{i}$.

TABELA 4.2 - Permutações geradas aleatoriamente dos inteiros 1, 2,..., 16

\begin{tabular}{ccccccccc}
\hline simulação & $X_{1}$ & $X_{2}$ & $X_{3}$ & $X_{4}$ & $X_{5}$ & $X_{6}$ & $X_{7}$ & $X_{8}$ \\
\hline 1 & 4 & 14 & 4 & 4 & 3 & 8 & 9 & 8 \\
2 & 6 & 2 & 2 & 13 & 16 & 6 & 5 & 15 \\
3 & 10 & 1 & 6 & 2 & 5 & 14 & 8 & 6 \\
4 & 14 & 6 & 14 & 1 & 14 & 12 & 1 & 10 \\
5 & 2 & 16 & 9 & 6 & 4 & 13 & 3 & 11 \\
6 & 3 & 5 & 11 & 16 & 13 & 11 & 2 & 12 \\
7 & 13 & 12 & 1 & 11 & 2 & 9 & 15 & 2 \\
8 & 7 & 9 & 13 & 3 & 1 & 3 & 7 & 16 \\
9 & 1 & 11 & 7 & 5 & 7 & 2 & 13 & 3 \\
10 & 8 & 10 & 16 & 12 & 8 & 5 & 4 & 4 \\
11 & 9 & 4 & 10 & 15 & 10 & 16 & 6 & 7 \\
12 & 16 & 13 & 5 & 9 & 6 & 10 & 10 & 13 \\
13 & 5 & 7 & 15 & 10 & 11 & 4 & 16 & 14 \\
14 & 15 & 8 & 8 & 7 & 12 & 1 & 14 & 9 \\
15 & 11 & 15 & 12 & 8 & 9 & 7 & 11 & 5 \\
16 & 12 & 3 & 3 & 14 & 15 & 15 & 12 & 1 \\
\hline
\end{tabular}

A tabela 4.3 mostra os valores dos parâmetros no centróide do intervalo, enquanto a tabela 4.4 mostra o grupo de valores dos parâmetros de entrada para cada simulação. 
TABELA 4.3 - Valores dos parâmetros no centróide dos intervalos

\begin{tabular}{|c|c|c|c|c|c|c|c|c|c|c|}
\hline \multirow{4}{*}{$k$} & \multirow{4}{*}{$F_{i}\left(x_{i}^{k}\right)$} & & $X_{1}$ & $X_{2}$ & $X_{3}$ & $X_{4}$ & $X_{5}$ & $X_{6}$ & $X_{7}$ & $X_{8}$ \\
\hline & & & - & - & (MPa) & - & - & (MPa) & $\%$ & ${ }^{\circ} \mathrm{C}$ \\
\hline & & $\mu$ & 1,0 & 1,0 & 20 & 1,0 & 1,0 & 55 & 50 & 32 \\
\hline & & $V(\%)$ & 30 & 32,9 & 10 & 30 & 32,9 & 10 & 20 & 20 \\
\hline 1 & 0,03125 & & 0,441 & 0,387 & 16,27 & 0,441 & 0,387 & 44,75 & 31,4 & 20,1 \\
\hline 2 & 0,09375 & & 0,605 & 0,566 & 17,36 & 0,605 & 0,566 & 47,75 & 36,8 & 23,6 \\
\hline 3 & 0,15625 & & 0,697 & 0,668 & 17,98 & 0,697 & 0,668 & 49,45 & 39,9 & 25,5 \\
\hline 4 & 0,21875 & & 0,767 & 0,745 & 18,45 & 0,767 & 0,745 & 50,73 & 42,2 & 27,0 \\
\hline 5 & 0,28125 & & 0,826 & 0,809 & 18,84 & 0,826 & 0,809 & 51,81 & 44,2 & 28,3 \\
\hline 6 & 0,34375 & & 0,879 & 0,868 & 19,20 & 0,879 & 0,868 & 52,79 & 46,0 & 29,4 \\
\hline 7 & 0,40625 & & 0,929 & 0,922 & 19,53 & 0,929 & 0,922 & 53,70 & 47,6 & 30,5 \\
\hline 8 & 0,46875 & & 0,976 & 0,974 & 19,84 & 0,976 & 0,974 & 54,57 & 49,2 & 31,5 \\
\hline 9 & 0,53125 & & 1,024 & 1,026 & 20,16 & 1,024 & 1,026 & 55,43 & 50,8 & 32,5 \\
\hline 10 & 0,59375 & & 1,071 & 1,078 & 20,47 & 1,071 & 1,078 & 56,30 & 52,4 & 33,5 \\
\hline 11 & 0,65625 & & 1,121 & 1,132 & 20,80 & 1,121 & 1,132 & 57,21 & 54,0 & 34,6 \\
\hline 12 & 0,71875 & & 1,174 & 1,191 & 21,16 & 1,174 & 1,191 & 58,19 & 55,8 & 35,7 \\
\hline 13 & 0,78125 & & 1,233 & 1,255 & 21,55 & 1,233 & 1,255 & 59,27 & 57,8 & 37,0 \\
\hline 14 & 0,84375 & & 1,303 & 1,332 & 22,02 & 1,303 & 1,332 & 60,55 & 60,1 & 38,5 \\
\hline 15 & 0,90625 & & 1,395 & 1,434 & 22,64 & 1,395 & 1,434 & 62,25 & 63,2 & 40,4 \\
\hline 16 & 0,96875 & & 1,559 & 1,613 & 23,73 & 1,559 & 1,613 & 65,25 & 68,6 & 43,9 \\
\hline
\end{tabular}

TABELA 4.4 - Grupo de valores dos parâmetros de entrada gerados aleatoriamente

\begin{tabular}{ccccccccc}
\hline \multirow{2}{*}{ simulação } & $X_{1}$ & $X_{2}$ & $X_{3}$ & $X_{4}$ & $X_{5}$ & $X_{6}$ & $X_{7}$ & $X_{8}$ \\
\cline { 2 - 8 } & - & - & $(\mathrm{MPa})$ & - & - & $(\mathrm{MPa})$ & $\%$ & ${ }^{\circ} \mathrm{C}$ \\
\hline 1 & 0,767 & 1,332 & 18,45 & 0,767 & 0,668 & 54,57 & 50,8 & 31,5 \\
2 & 0,879 & 0,566 & 17,36 & 1,233 & 1,613 & 52,79 & 44,2 & 40,4 \\
3 & 1,071 & 0,387 & 19,20 & 0,605 & 0,809 & 60,55 & 49,2 & 29,4 \\
4 & 1,303 & 0,868 & 22,02 & 0,441 & 1,332 & 58,19 & 31,4 & 33,5 \\
5 & 0,605 & 1,613 & 20,16 & 0,879 & 0,745 & 59,27 & 39,9 & 34,6 \\
6 & 0,697 & 0,809 & 20,80 & 1,559 & 1,255 & 57,21 & 36,8 & 35,7 \\
7 & 1,233 & 1,191 & 16,27 & 1,121 & 0,566 & 55,43 & 63,2 & 23,6 \\
8 & 0,929 & 1,026 & 21,55 & 0,697 & 0,387 & 49,45 & 47,6 & 43,9 \\
9 & 0,441 & 1,132 & 19,53 & 0,826 & 0,922 & 47,75 & 57,8 & 25,5 \\
10 & 0,976 & 1,078 & 23,73 & 1,174 & 0,974 & 51,81 & 42,2 & 27,0 \\
11 & 1,024 & 0,745 & 20,47 & 1,395 & 1,078 & 65,25 & 46,0 & 30,5 \\
12 & 1,559 & 1,255 & 18,84 & 1,024 & 0,868 & 56,30 & 52,4 & 37,0 \\
13 & 0,826 & 0,922 & 22,64 & 1,071 & 1,132 & 50,73 & 68,6 & 38,5 \\
14 & 1,395 & 0,974 & 19,84 & 0,929 & 1,191 & 44,75 & 60,1 & 32,5 \\
15 & 1,121 & 1,434 & 21,16 & 0,976 & 1,026 & 53,70 & 54,0 & 28,3 \\
16 & 1,174 & 0,668 & 17,98 & 1,303 & 1,434 & 62,25 & 55,8 & 20,1 \\
\hline
\end{tabular}

A validação da distribuição normal proposta para a resposta foi feita através do Teste de Kolmogorov-Smirnov realizado em cada passo de tempo. Como 
observado na tabela 4.1, a distribuição normal será aceita para o nível de significância 0,20 , se o valor observado de $D_{N}$ for menor que o valor crítico $D_{16}^{0,20}=0,27$. Pela figura 4.12, pode-se observar que o valor de $D_{N}$ esteve sempre abaixo do valor crítico, indicando que se pode aceitar a distribuição normal para a resposta.

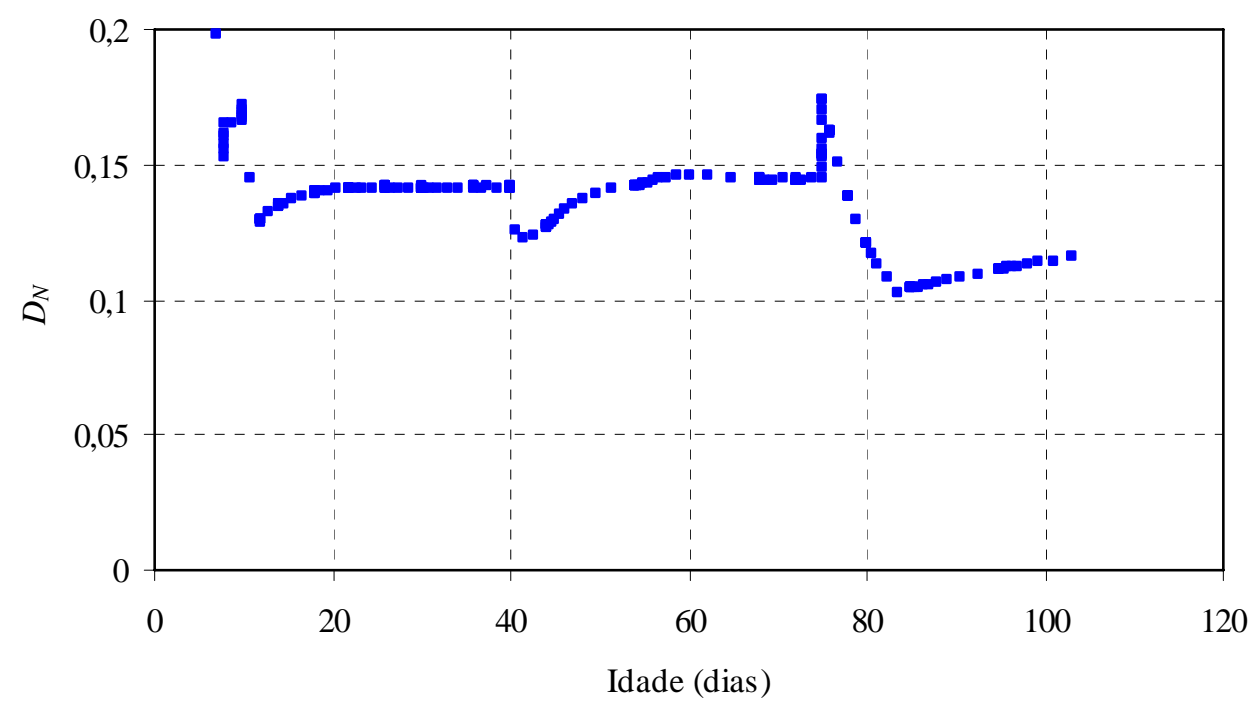

FIGURA 4.12 - Teste de Kolmogorov-Smirnov para a flecha

A figura 4.13 mostra os limites de confiança para o intervalo de confiança bilateral de 95\% para a flecha da viga V1, ou seja, considerando a variabilidade estatística dos parâmetros de entrada, há 95\% de probabilidade da flecha da viga V1 estar entre os limites de confiança. Por exemplo, aos 103 dias existe 95\% de probabilidade da flecha da viga V1 estar entre 13,1 mm e 19,9 mm.

Aparentemente, observando a figura 4.13, parece que o intervalo de confiança possui uma variação grande, no entanto, vale ressaltar que esses limites são válidos para o caso de uma viga real sujeita a variabilidade estatística indicada anteriormente, fato que não ocorre no ensaio, onde os parâmetros já são conhecidos (não há variabilidade). 


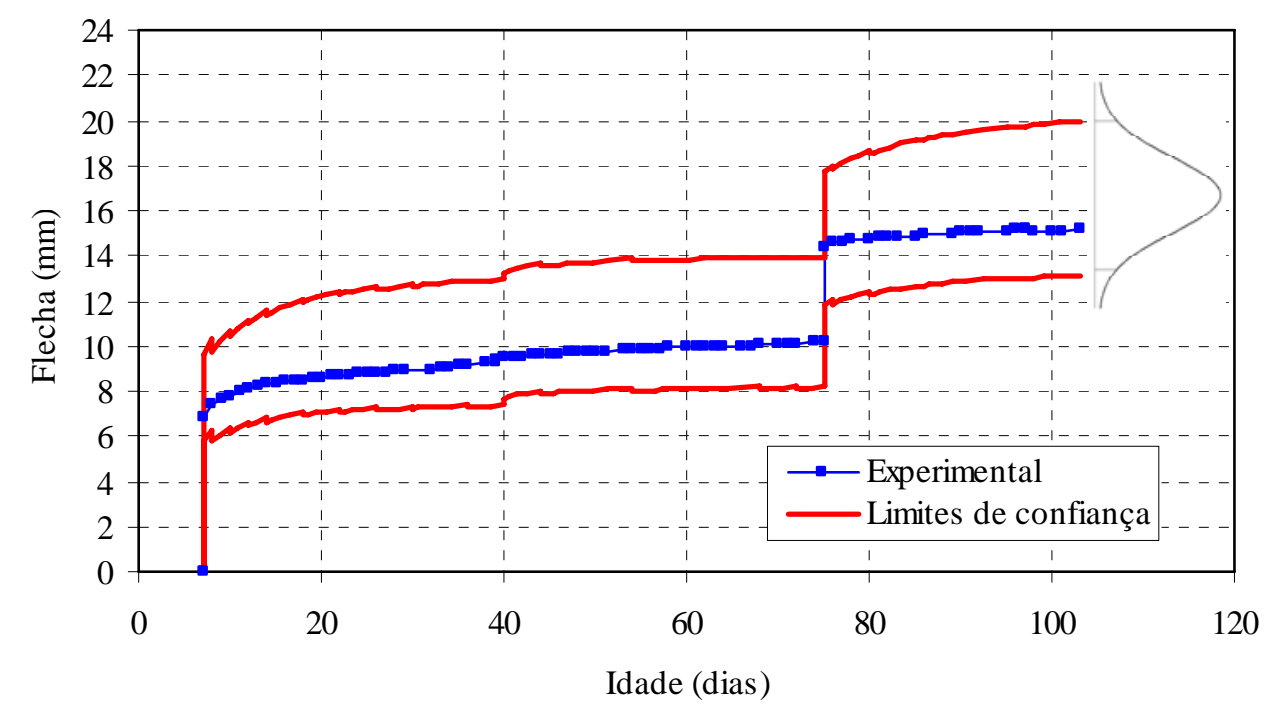

FIGURA 4.13 - Limites de confiança para a flecha

Os resultados das simulações foram usados para determinar quais os parâmetros afetam mais significativamente a incerteza da resposta, no caso a flecha da viga, através do coeficiente de regressão padronizado e do coeficiente de correlação parcial. Apresentam-se nas figuras 4.14 e 4.15, respectivamente, o coeficiente de regressão padronizado e do coeficiente de correlação parcial aos 40 e 103 dias. Pelas figuras, pode-se observar que, para o problema em questão, os parâmetros relacionados com o concreto da viga, ou seja, incertezas nos modelos de fluência e retração e resistência do concreto, assim como os fatores ambientais foram os parâmetros que tiveram maior influência na determinação da flecha da viga.

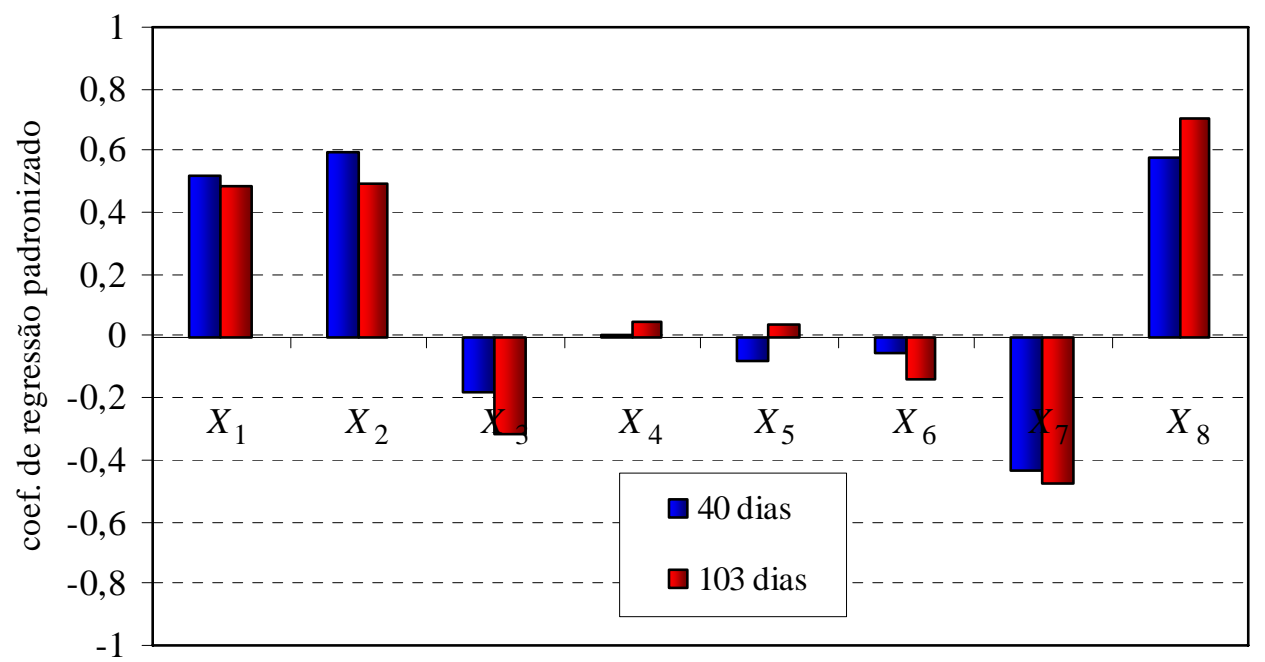

FIGURA 4.14 - Coeficiente de regressão padronizado para a flecha da viga aos 40 e 103 dias 


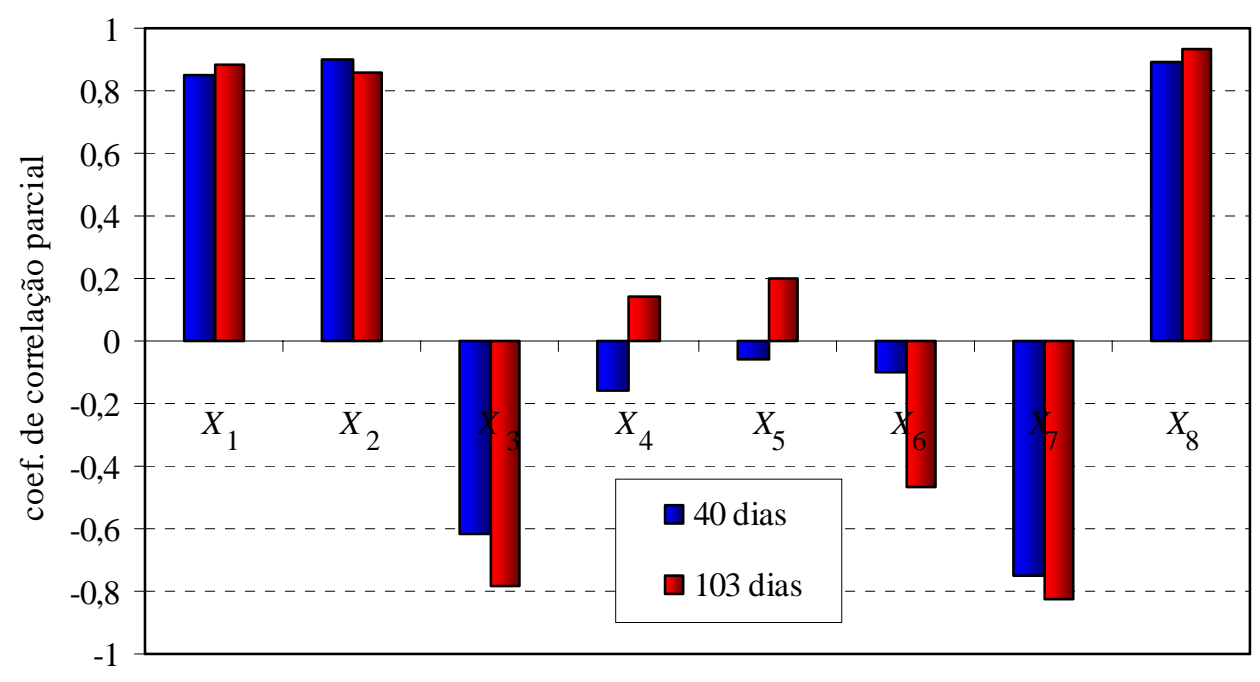

FIGURA 4.15 - Coeficiente de correlação parcial para a flecha da viga aos 40 e 103 dias

\subsubsection{Exemplo 2: Viga reforçada à flexão com continuidade estrutural posterior}

Para este exemplo, será ainda utilizado o ensaio da viga V1 realizado por REIS (2003). No entanto, será considerado o estabelecimento da continuidade estrutural em uma das extremidades da viga após a concretagem do reforço, conforme figura 4.16, com a colocação de 4 barras de $10 \mathrm{~mm}$ para absorver o momento fletor negativo. Por simplificação, será considerada ainda apenas a atuação das forças verticais na viga. As demais considerações e parâmetros são os mesmos utilizados no exemplo anterior.

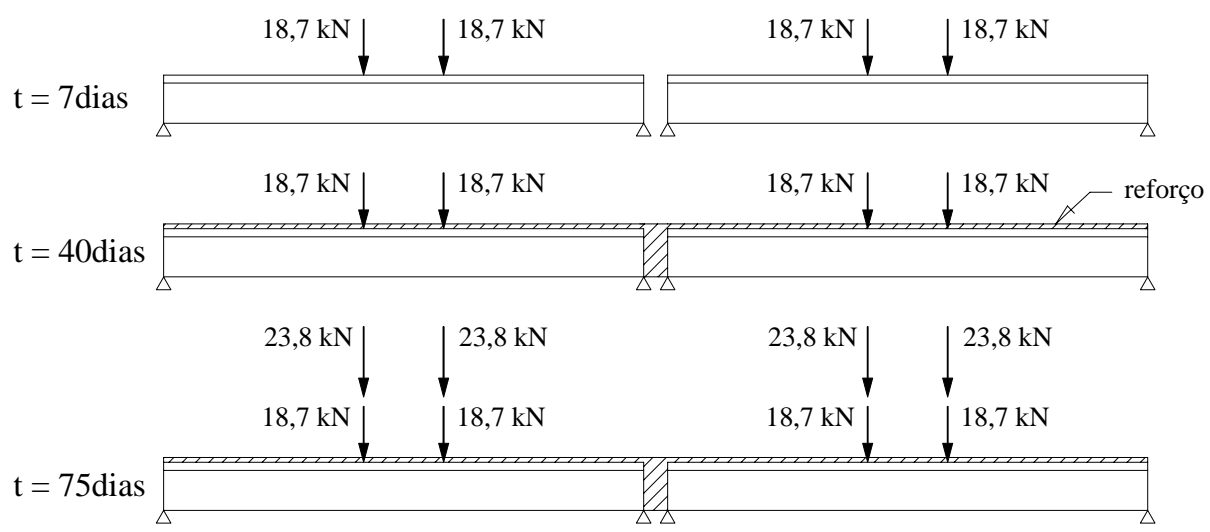

FIGURA 4.16 - Etapas construtivas da viga 
Apresentam-se na tabela 4.5 as permutações geradas aleatoriamente dos inteiros $1,2, \ldots, N$ para cada variável aleatória $X_{i}$ para este exemplo. E a partir dessas permutações geradas aleatoriamente, gerou-se o grupo de valores dos parâmetros de entrada para cada simulação mostrados na tabela 4.6.

TABELA 4.5 - Permutações geradas aleatoriamente dos inteiros 1, 2,.., 16

\begin{tabular}{ccccccccc}
\hline simulação & $X_{1}$ & $X_{2}$ & $X_{3}$ & $X_{4}$ & $X_{5}$ & $X_{6}$ & $X_{7}$ & $X_{8}$ \\
\hline 1 & 4 & 4 & 8 & 10 & 7 & 3 & 4 & 11 \\
2 & 7 & 11 & 14 & 3 & 6 & 9 & 5 & 4 \\
3 & 5 & 7 & 16 & 15 & 16 & 11 & 6 & 9 \\
4 & 15 & 9 & 10 & 8 & 12 & 10 & 15 & 10 \\
5 & 12 & 3 & 9 & 2 & 2 & 1 & 9 & 16 \\
6 & 6 & 2 & 2 & 7 & 3 & 12 & 1 & 7 \\
7 & 8 & 15 & 15 & 14 & 13 & 6 & 7 & 1 \\
8 & 16 & 10 & 3 & 1 & 5 & 7 & 14 & 6 \\
9 & 9 & 14 & 13 & 9 & 10 & 16 & 10 & 2 \\
10 & 13 & 6 & 7 & 12 & 9 & 4 & 13 & 3 \\
11 & 14 & 1 & 4 & 4 & 14 & 2 & 12 & 8 \\
12 & 1 & 13 & 11 & 5 & 11 & 15 & 3 & 15 \\
13 & 2 & 16 & 6 & 13 & 1 & 5 & 11 & 14 \\
14 & 10 & 8 & 1 & 16 & 15 & 14 & 8 & 13 \\
15 & 3 & 12 & 5 & 11 & 8 & 8 & 2 & 5 \\
16 & 11 & 5 & 12 & 6 & 4 & 13 & 16 & 12 \\
\hline
\end{tabular}


TABELA 4.6 - Grupo de valores dos parâmetros de entrada gerados aleatoriamente

\begin{tabular}{ccccccccc}
\hline \multirow{2}{*}{ simulação } & $X_{1}$ & $X_{2}$ & $X_{3}$ & $X_{4}$ & $X_{5}$ & $X_{6}$ & $X_{7}$ & $X_{8}$ \\
\cline { 2 - 8 } & - & - & $(\mathrm{MPa})$ & - & - & $(\mathrm{MPa})$ & $\%$ & ${ }^{\circ} \mathrm{C}$ \\
\hline 1 & 0,767 & 0,745 & 19,84 & 1,071 & 0,922 & 49,45 & 42,2 & 34,6 \\
2 & 0,929 & 1,132 & 22,02 & 0,697 & 0,868 & 55,43 & 44,2 & 27,0 \\
3 & 0,826 & 0,922 & 23,73 & 1,395 & 1,613 & 57,21 & 46,0 & 32,5 \\
4 & 1,395 & 1,026 & 20,47 & 0,976 & 1,191 & 56,30 & 63,2 & 33,5 \\
5 & 1,174 & 0,668 & 20,16 & 0,605 & 0,566 & 44,75 & 50,8 & 43,9 \\
6 & 0,879 & 0,566 & 17,36 & 0,929 & 0,668 & 58,19 & 31,4 & 30,5 \\
7 & 0,976 & 1,434 & 22,64 & 1,303 & 1,255 & 52,79 & 47,6 & 20,1 \\
8 & 1,559 & 1,078 & 17,98 & 0,441 & 0,809 & 53,70 & 60,1 & 29,4 \\
9 & 1,024 & 1,332 & 21,55 & 1,024 & 1,078 & 65,25 & 52,4 & 23,6 \\
10 & 1,233 & 0,868 & 19,53 & 1,174 & 1,026 & 50,73 & 57,8 & 25,5 \\
11 & 1,303 & 0,387 & 18,45 & 0,767 & 1,332 & 47,75 & 55,8 & 31,5 \\
12 & 0,441 & 1,255 & 20,80 & 0,826 & 1,132 & 62,25 & 39,9 & 40,4 \\
13 & 0,605 & 1,613 & 19,20 & 1,233 & 0,387 & 51,81 & 54,0 & 38,5 \\
14 & 1,071 & 0,974 & 16,27 & 1,559 & 1,434 & 60,55 & 49,2 & 37,0 \\
15 & 0,697 & 1,191 & 18,84 & 1,121 & 0,974 & 54,57 & 36,8 & 28,3 \\
16 & 1,121 & 0,809 & 21,16 & 0,879 & 0,745 & 59,27 & 68,6 & 35,7 \\
\hline
\end{tabular}

Após a realização das simulações, a validação da distribuição normal para a flecha da viga foi feita através do Teste de Kolmogorov-Smirnov realizado em cada passo de tempo, como mostrado na figura 4.17. Como se pode observar na figura, o valor observado de $D_{N}$ foi menor que o valor crítico $D_{16}^{0,20}=0,27$, indicando que se pode aceitar a distribuição normal para a flecha da viga. Já a figura 4.18 mostra os limites de confiança para o intervalo de confiança bilateral de 95\% para a flecha da viga. E assim, por exemplo, aos 103 dias existe 95\% de probabilidade da flecha da viga estar entre $8,2 \mathrm{~mm}$ e 12,3 mm. 


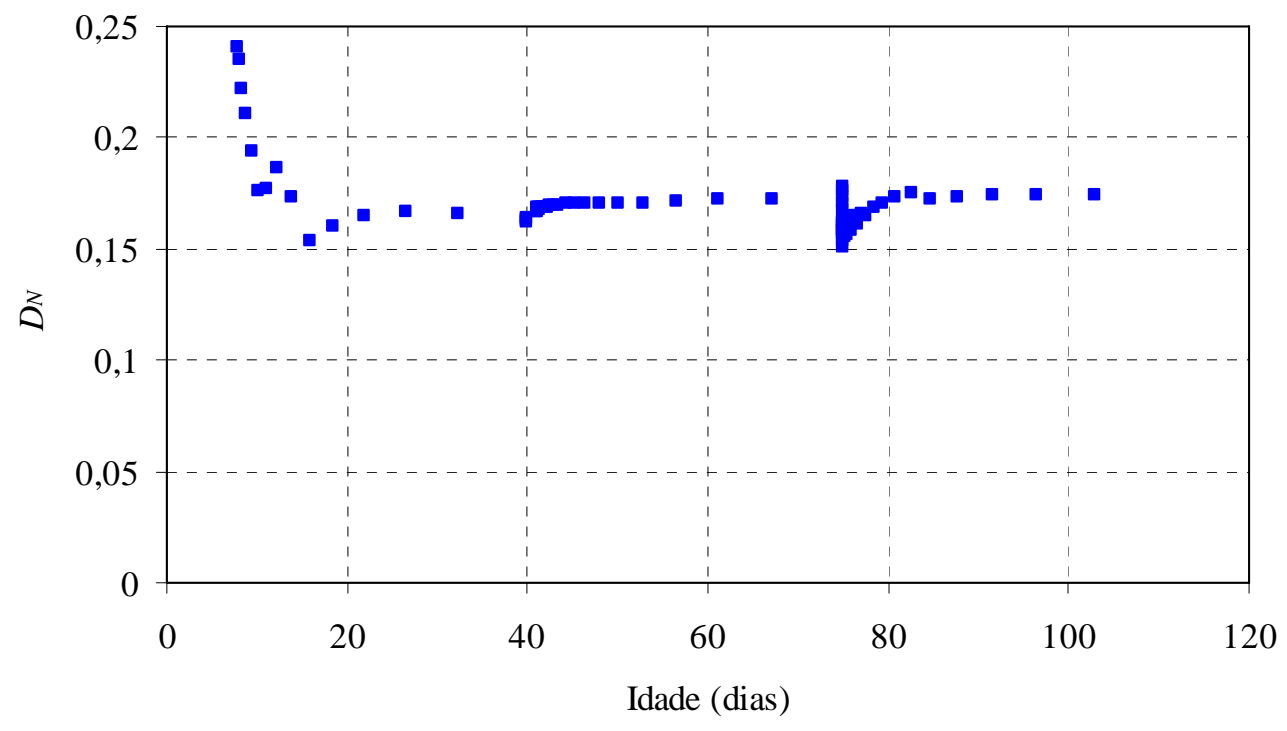

FIGURA 4.17 - Teste de Kolmogorov-Smirnov para a flecha

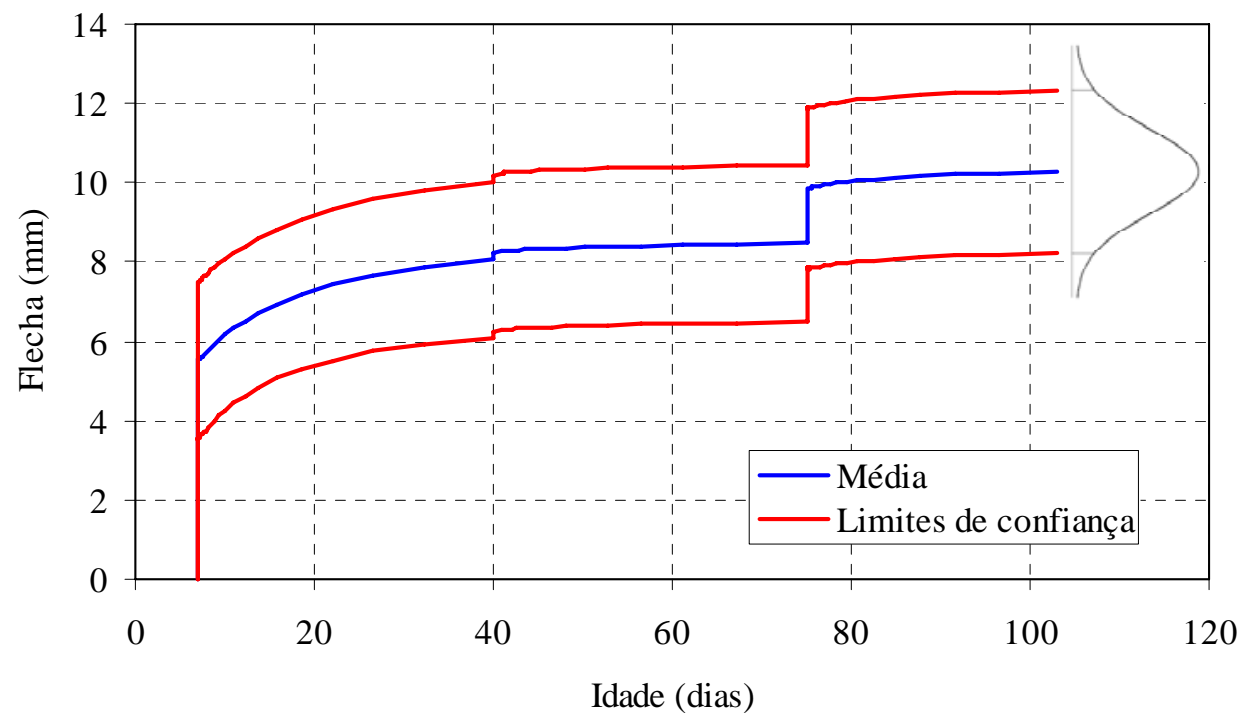

FIGURA 4.18 - Limites de confiança para a flecha

A validação da distribuição normal também foi realizada para o momento fletor no apoio da viga, conforme a figura 4.19. O valor observado de $D_{N}$ foi menor que o valor crítico $D_{16}^{0,20}=0,27$, indicando que se pode aceitar a distribuição normal para o momento fletor no apoio da viga. 


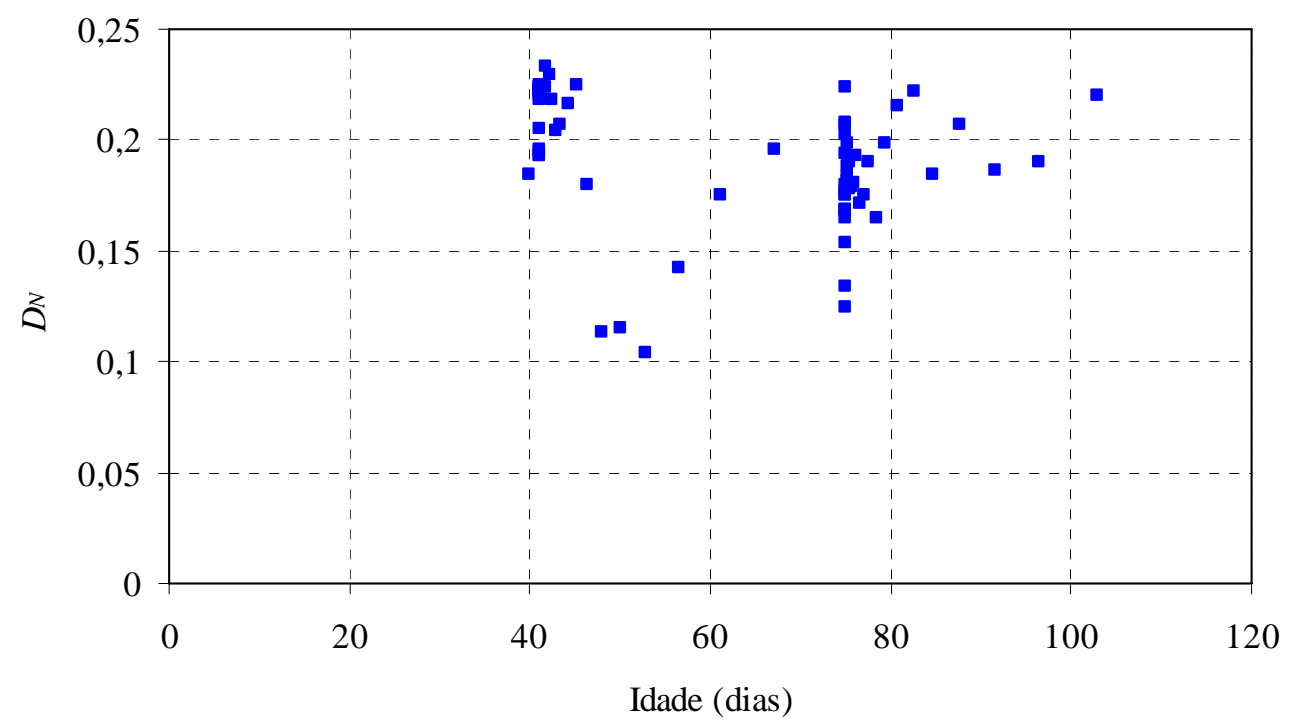

FIGURA 4.19 - Teste de Kolmogorov-Smirnov para o momento fletor no apoio

A figura 4.20 mostra os limites de confiança para o intervalo de confiança bilateral de 95\% para o momento fletor no apoio da viga. E assim, aos 103 dias existe $95 \%$ de probabilidade do momento fletor no apoio estar entre $-25,7 \mathrm{kN}$.m e -27,3 kN.m. Pela figura pode-se perceber ainda que surgem esforços no apoio após o estabelecimento da continuidade em decorrência dos efeitos dependentes do tempo.

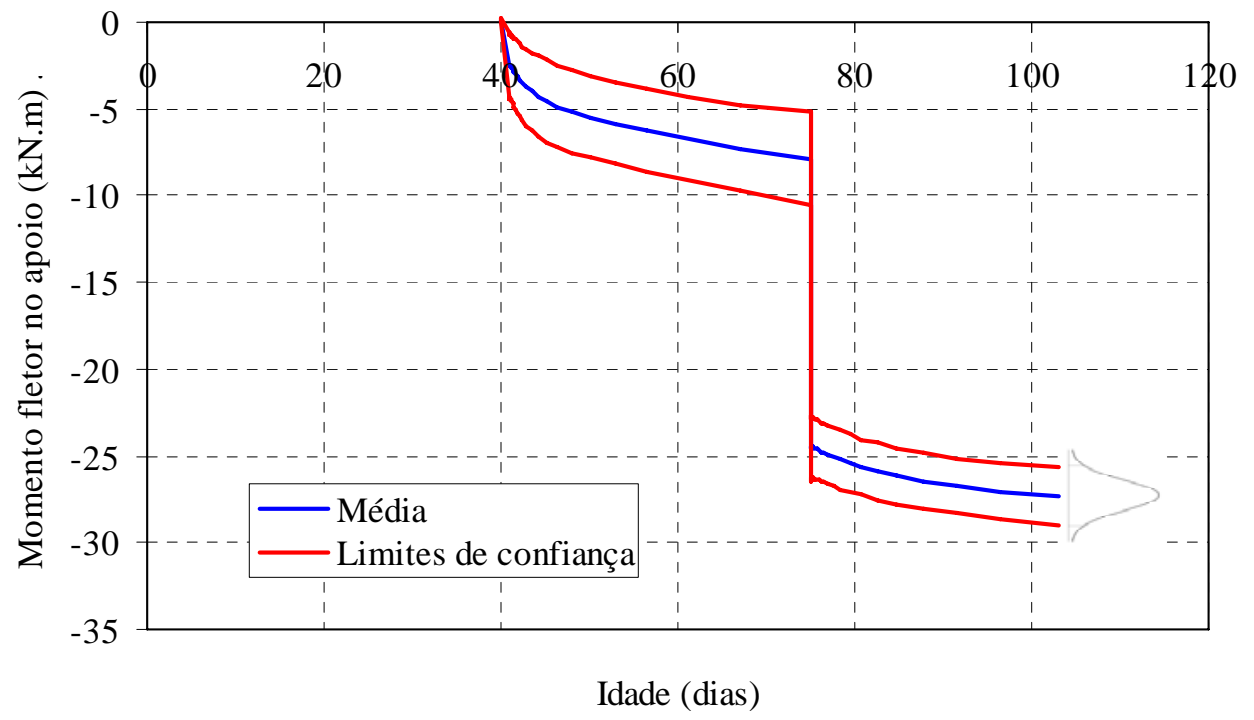

FIGURA 4.20 - Limites de confiança para o momento fletor no apoio

Apresentam-se nas figuras 4.21 e 4.22, respectivamente, o coeficiente de regressão padronizado e do coeficiente de correlação parcial para a flecha da viga na 
idade de 103 dias. Pelas figuras, pode-se observar que, para o exemplo em questão, as incertezas nos modelos de fluência e retração do concreto da viga, assim como os fatores ambientais foram os parâmetros que tiveram maior influência na determinação da flecha da viga. E nas figuras 4.23 e 4.24 são apresentados, respectivamente, o coeficiente de regressão padronizado e do coeficiente de correlação parcial para o momento fletor no apoio da viga aos 103 dias. Pelas figuras, nota-se que as incertezas no modelo de retração do concreto do reforço e a temperatura ambiente influenciaram mais significativamente a determinação do momento fletor no apoio da viga.

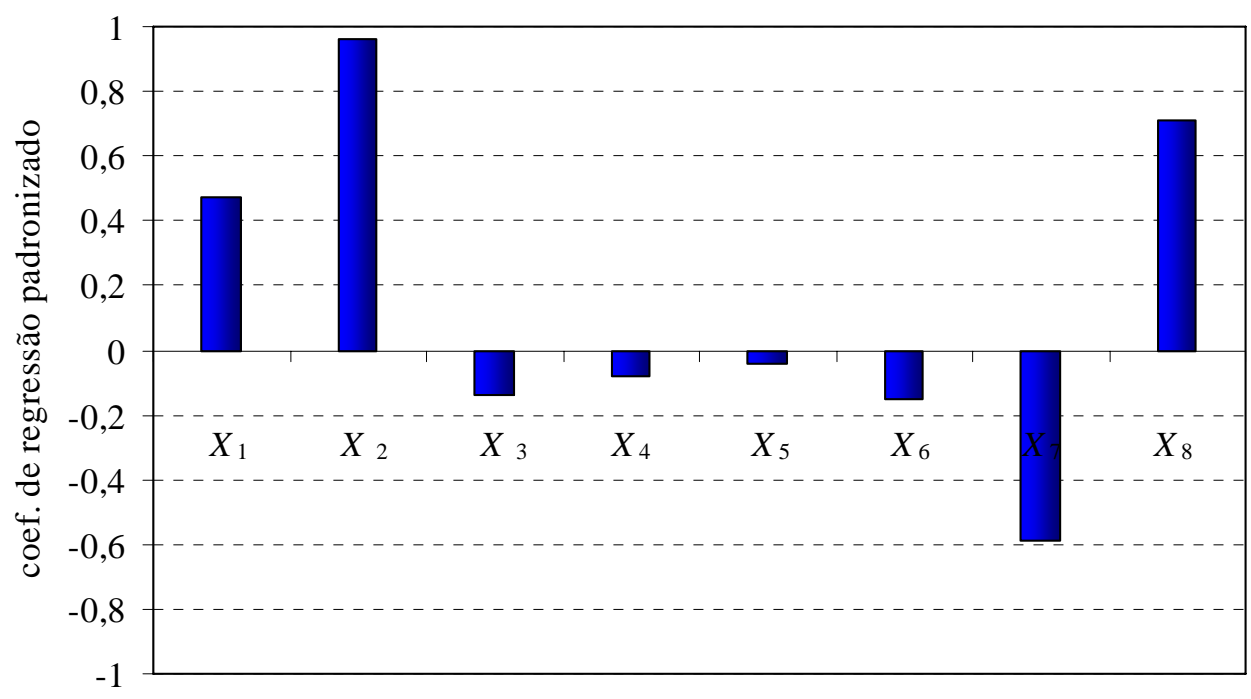

FIGURA 4.21 - Coeficiente de regressão padronizado para a flecha da viga aos 103 dias

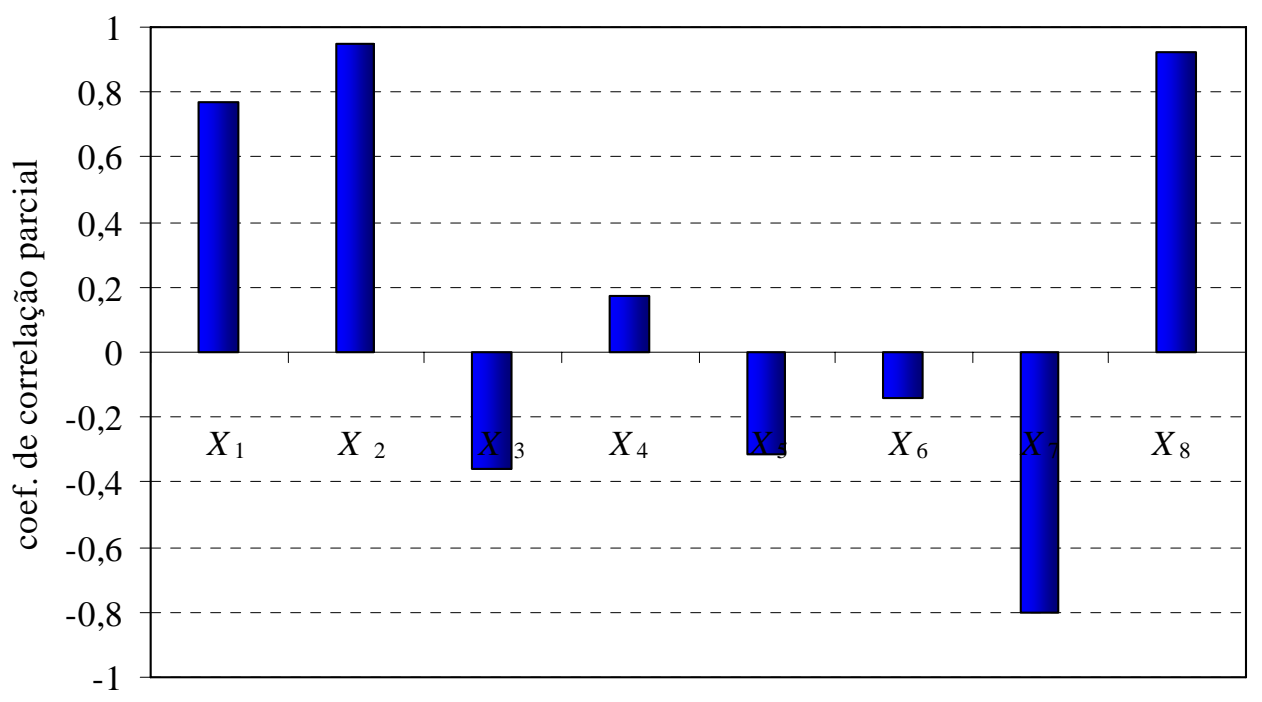

FIGURA 4.22 - Coeficiente de correlação parcial para a flecha da viga aos 103 dias 


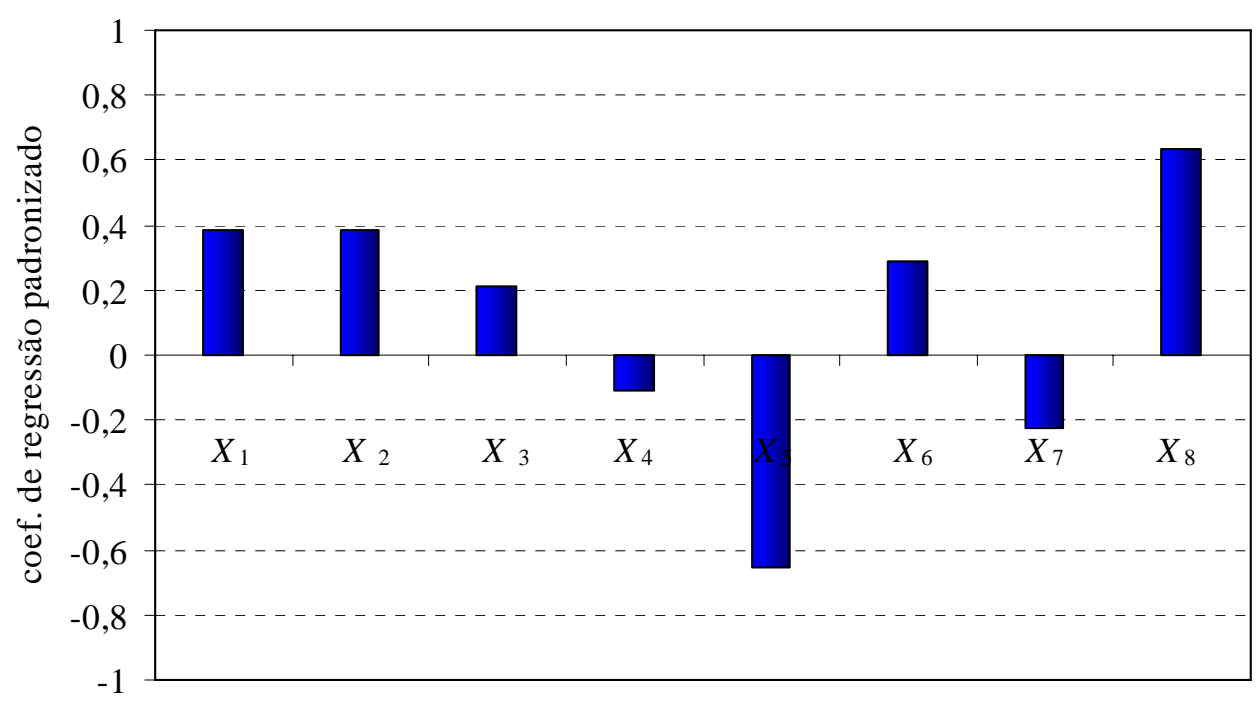

FIGURA 4.23 - Coeficiente de regressão padronizado para o momento fletor no apoio aos 103 dias

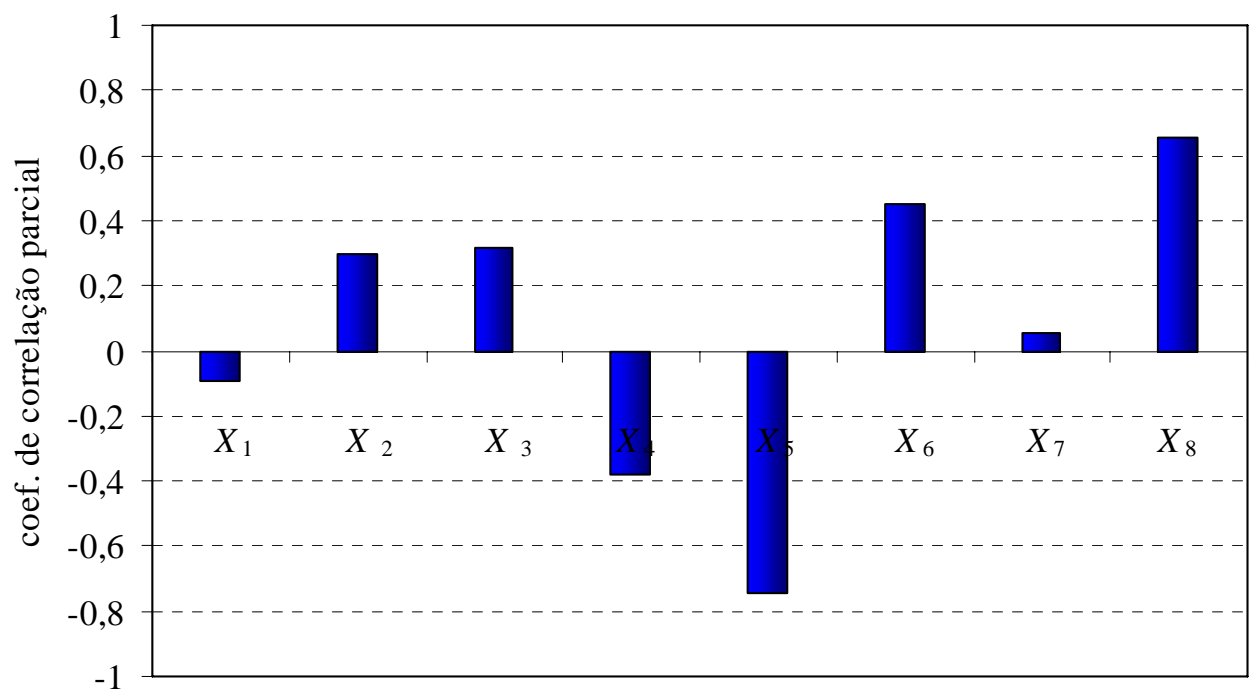

FIGURA 4.24 - Coeficiente de correlação parcial para o momento fletor no apoio aos 103 dias 


\section{ANÁLISE DAS FLECHAS DIFERIDAS EM LAJES PRÉ-MOLDADAS}

\subsection{Considerações iniciais}

As lajes formadas por nervuras pré-moldadas são, conforme ilustradas na figura 5.1, constituídas basicamente de:

a) elementos lineares pré-moldados, que são as nervuras, dispostas espaçadamente em uma direção;

b) elementos de enchimento, intercalados entre os elementos prémoldados;

c) capa de concreto estrutural moldado no local.

Com relação às seções transversais, os elementos pré-moldados também denominados de vigotas podem ser com ou sem armadura saliente, em forma de $\mathrm{T}$ invertido ou I.

Os materiais de enchimento normalmente utilizados são blocos vazados de concreto ou material cerâmico, ou ainda blocos de poliestireno expandido, conhecidos pela sigla EPS. A utilização de elementos de material leve está ligada à idéia de substituir parte do concreto da região tracionada das lajes, bem como servir de sustentação à camada de concreto fresco que é aplicada sobre os painéis das lajes pré-fabricadas. 


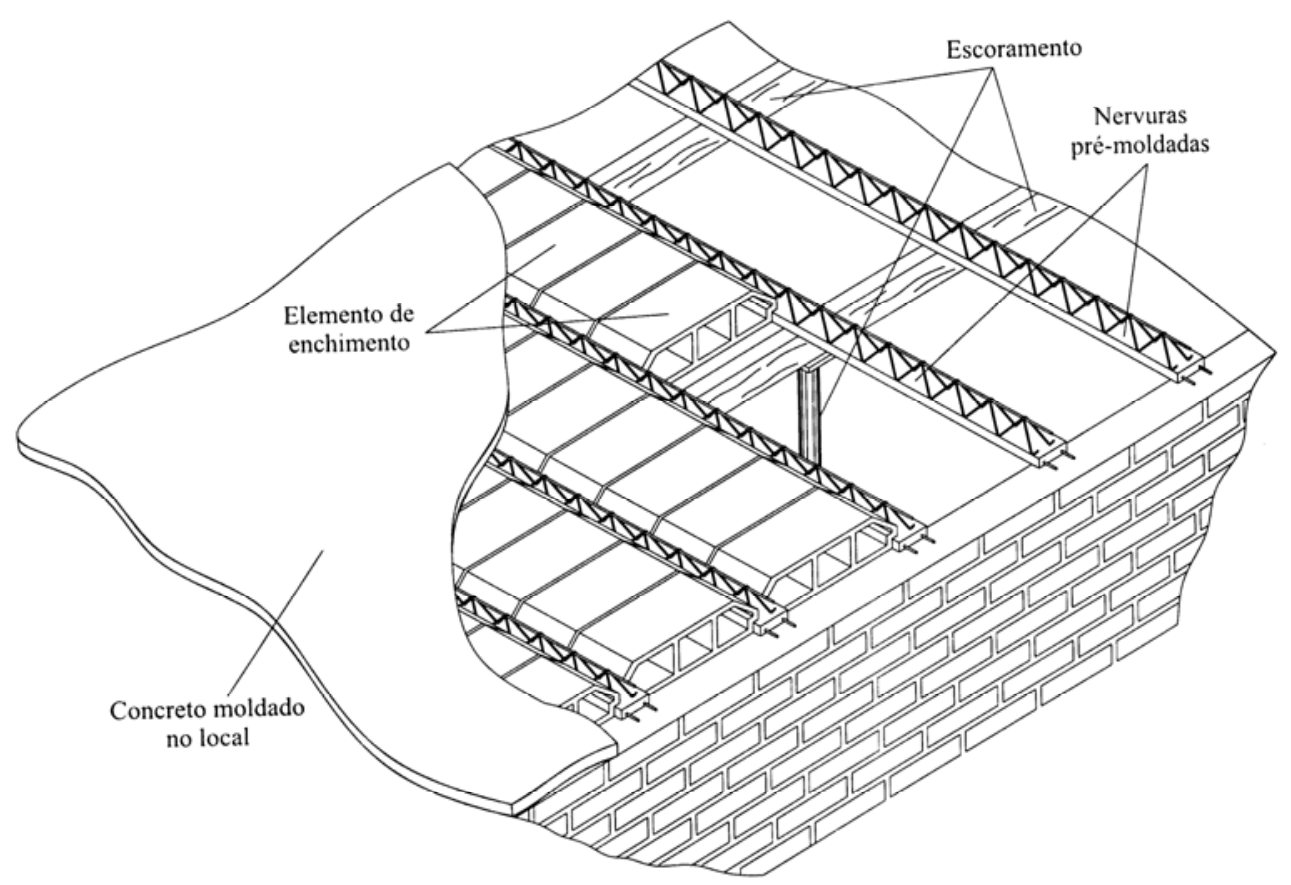

FIGURA 5.1 - Laje formada por nervuras pré-moldadas [EL DEBS (2000)]

Os tipos de vigotas utilizadas atualmente são os seguintes:

a) vigotas de concreto armado comum, não protendido, com seção transversal com a forma aproximada de um $\mathrm{T}$ invertido, com armadura passiva totalmente envolvida pelo concreto;

b) vigotas de concreto protendido, com seção transversal com a forma aproximada de um T invertido, com armadura de protensão prétracionada e totalmente envolvida pelo concreto;

c) vigotas com armação treliçada, formadas por uma armadura treliçada de aço e por uma placa de concreto envolvendo as barras inferiores da treliça que irão compor a armadura da face tracionada da laje.

As vigotas pré-moldadas de concreto armado são executadas em fôrmas metálicas, em pequenas unidades de produção, com instalações físicas simples. As vigotas de concreto protendido são produzidas em pistas de protensão utilizando, geralmente, fôrmas deslizantes. Já a base de concreto das vigotas com armação treliçada é moldada utilizando fôrmas metálicas, em espessuras de 2 a $3 \mathrm{~cm}$. 
As principais vantagens que podem ser apontadas na utilização dos pavimentos formados por vigotas pré-moldadas em relação aos pavimentos tradicionais de lajes maciças de concreto armado são:

a) considerando igualdade de vãos e sobrecargas, possuem menor peso próprio, com conseqüente alívio sobre as fundações;

b) dispensam o uso de fôrmas, pois os elementos pré-moldados e os elementos de enchimento fazem esse papel;

c) proporcionam a diminuição da mão-de-obra de execução.

Enquanto que as principais desvantagens desse sistema, como apontados por DROPPA Jr. (1999), são:

a) em geral, não possui um comportamento monolítico com o restante da estrutura, o que pode ser inconveniente sob o ponto de vista do contraventamento da edificação (exceção feita às vigotas com armação treliçada);

b) as vigotas de concreto armado e as vigotas protendidas são, às vezes, muito pesadas para manuseio, exigindo equipamentos para transporte e montagem no local.

As lajes formadas por vigotas pré-moldadas com armação treliçada têm ganhado destaque na construção civil brasileira nos últimos anos. Como destacado por DROPPA Jr. (1999), as lajes formadas por vigotas treliçadas detinham uma participação no mercado em 1990 de apenas 5\%, em 1998 saltou para 40\%, segundo dados da Abilaje (Associação Brasileira da Indústria de Lajes).

Além da aplicação em obras de pequeno porte, deve-se destacar que recentemente as lajes pré-moldadas com armação treliçada têm avançado rumo aos edifícios com maior número de pavimentos.

A armação treliçada das vigotas é uma estrutura formada por barras de aço eletrosoldadas em alguns pontos de modo a formar uma treliça espacial. Segundo a NBR 14862 (2002), a armação treliçada deve ser classificada a partir da abreviatura de armação treliçada (TR), a altura (em centímetros, sem casas decimais), diâmetros das armaduras do banzo superior, das diagonais (sinusóides) e 
do banzo inferior (diâmetros em milímetros, sem casas decimais). Quando a armadura for de aço CA60, não há nenhuma designação, quando for aço CA50, acrescenta-se a letra “A” em seguida ao número indicativo da bitola correspondente. Por exemplo, uma armação treliçada composta integralmente por aço CA60, com 8,0 cm de altura, banzo superior com 6,0 mm, diagonal com 3,4 mm e banzo inferior com 4,2 mm, será designada TR8634. Já uma armação treliçada composta parcialmente por aço CA50, com 20,0 cm de altura, banzo superior com 10,0 mm em aço CA50, diagonal com 6,0 mm e banzo inferior com 9,5 mm, será designada TR2010A69. Na figura 5.2 estão mostrados os elementos que compõe uma vigota pré-moldada com armação treliçada.
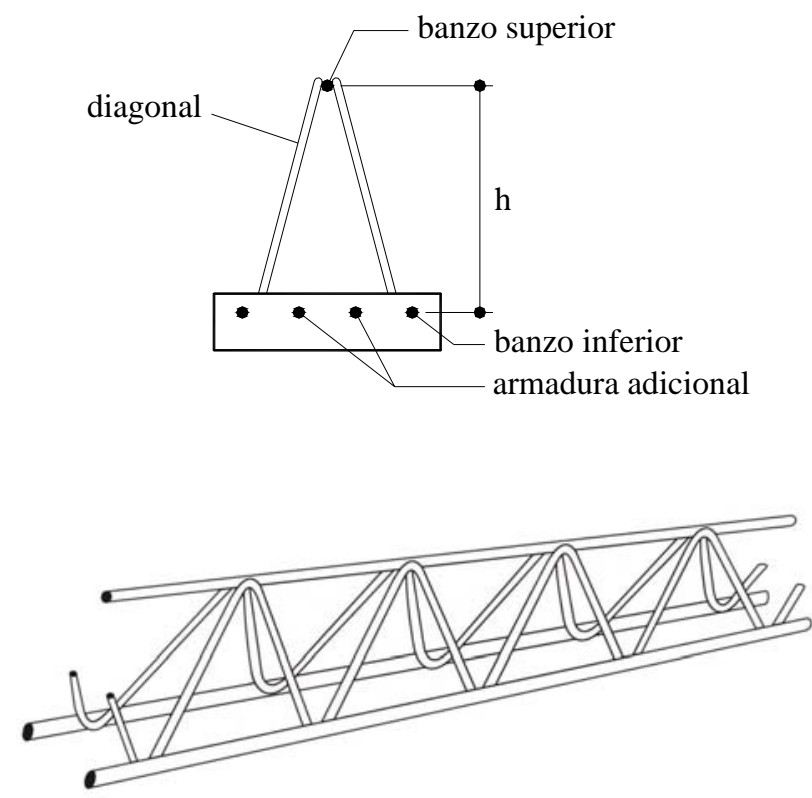

FIGURA 5.2 - Seção transversal da vigota treliçada e perspectiva da armação treliçada

Na utilização das vigotas pré-moldadas com armação treliçada, as seguintes vantagens podem ser destacadas [DROPPA Jr. (1999)]:

a) reduz o aparecimento de fissuras pela condição de aderência entre o concreto do capeamento e o concreto da vigota pré-moldada;

b) facilita a colocação de nervuras moldadas in loco na direção perpendicular às vigotas;

c) pode oferecer maior resistência ao cisalhamento em função da presença das diagonais da treliça. 
Apesar das inúmeras vantagens apresentadas, como em qualquer outro sistema construtivo, alguns cuidados devem ser tomados para que as lajes prémoldadas com armação treliçada apresentem um comportamento adequado. Dentre os cuidados adicionais, MAGALHÃES (2001) destaca:

a) a armadura das diagonais poderá ser considerada colaborante na resistência ao cisalhamento somente se estiver eficazmente ancorada na região comprimida do concreto;

b) em lajes contínuas, deve-se verificar o posicionamento da armadura negativa durante o lançamento e adensamento do concreto, de modo a garantir o valor de altura útil especificado em projeto;

c) sendo estas lajes formadas por elementos esbeltos, em edifícios com maior número de pavimentos deve-se analisar a resistência do plano da laje na transferência de ações horizontais, de modo que as lajes pré-moldadas com armação treliçada apresentem comportamento efetivo de diafragma;

d) por serem formadas por elementos muito esbeltos, deve ser verificado o comportamento para o estado limite de deformações excessivas.

\subsubsection{Cálculo da flecha}

Com relação ao cálculo das flechas imediatas ou diferidas no tempo de lajes formadas por vigotas pré-moldadas, as normas brasileiras NBR 14859-1 (2002) e NBR 14859-2 (2002) sobre lajes pré-fabricadas não apresentam qualquer procedimento de cálculo. E assim, para o cálculo das flechas de lajes formadas por vigotas pré-moldadas unidirecionais, deve remeter-se às indicações contidas na NBR 6118 (2003) relacionadas ao cálculo de flechas em vigas.

A NBR 6118 (2003) avalia a flecha imediata em vigas utilizando a expressão de rigidez equivalente proposto por BRANSON (1968) e a flecha diferida no tempo é avaliada de maneira aproximada pela multiplicação da flecha imediata pelo coeficiente $\alpha_{f}$. A norma espanhola EF-96 (1997), que trata especificamente 
sobre o projeto de lajes formadas por vigotas pré-moldadas, apresenta procedimentos semelhantes aos da NBR 6118 (2003).

\subsubsection{Cálculo da flecha imediata}

O cálculo da flecha imediata ou instantânea para vigas e lajes unidirecionais pode ser efetuado através da expressão padrão de elementos fletidos não fissurados, assumindo o concreto armado como um material de comportamento elástico e linear, dada por:

$\mathrm{a}_{\mathrm{o}}=\beta \cdot \frac{\mathrm{M}_{\max } \cdot \ell^{2}}{\mathrm{E} . \mathrm{I}}$

onde:

$M_{\max }-$ momento fletor máximo no vão $\ell$;

$\ell \quad$ - comprimento do vão;

E - módulo de elasticidade;

I - momento de inércia da seção transversal;

$\beta-$ - coeficiente que depende das condições de apoio e carregamento, conforme figura 5.3.
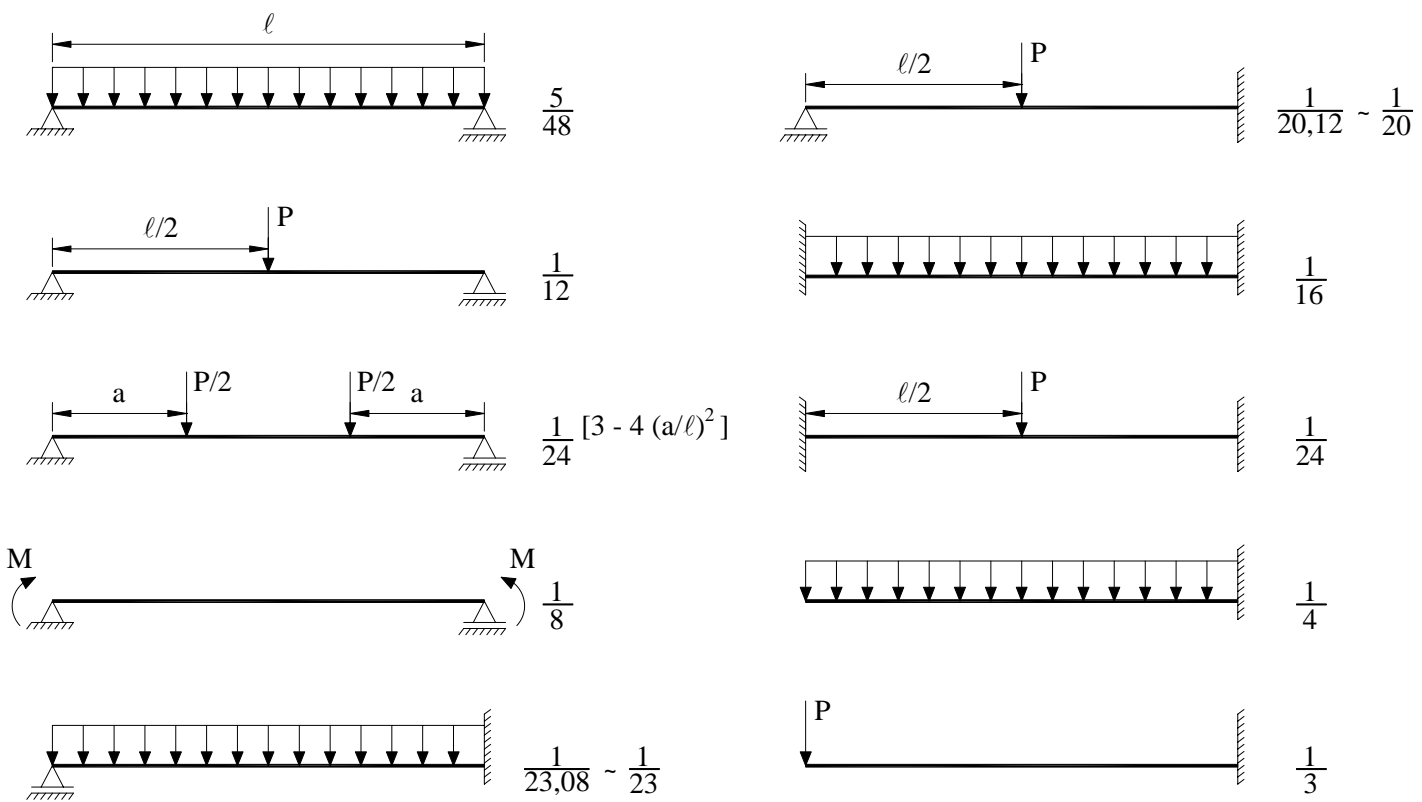

FIGURA 5.3 - Valores do coeficiente $\beta$ 
No entanto, ao longo do vão de um elemento fletido em concreto armado, encontram-se seções fissuradas e não fissuradas, com o concreto íntegro entre as fissuras colaborando para a rigidez da peça. Pode-se concluir, então, que existem seções nas quais o momento de inércia será menor do que o momento de inércia da seção não fissurada, e maior do que o momento de inércia da seção fissurada.

Visando à avaliação da influência da fissuração e da colaboração do concreto tracionado entre as fissuras no momento de inércia da seção transversal, BRANSON (1968) realizou um estudo experimental em vigas retangulares e T, submetidas a carregamentos uniformemente distribuídos e de curta duração.

Baseado nos resultados de seus ensaios e nos de outros pesquisadores, ele sugeriu a utilização de um valor médio de momento de inércia, compreendido entre o momento de inércia da seção não fissurada, $I_{I}$, e o da seção fissurada, $I_{\text {II }}$, chamado de momento de inércia efetivo, dado por:

$$
I_{e}=\left(\frac{M_{r}}{M_{\max }}\right)^{m} \cdot I_{I}+\left[1-\left(\frac{M_{r}}{M_{\max }}\right)^{m}\right] . I_{I I} \leq I_{I}
$$

sendo:

$M_{\mathrm{r}} \quad$ - momento de fissuração;

$\mathrm{M}_{\max }-$ momento fletor máximo atuante no vão;

$\mathrm{I}_{\mathrm{I}} \quad-$ momento de inércia da seção bruta de concreto;

II $\quad-$ momento de inércia da seção de concreto fissurada, no Estádio II;

m - potência que define se o momento de inércia está sendo calculado para seções individuais ou para todo o vão.

Para a determinação do momento de inércia efetivo em seções individuais de um vão qualquer, a potência m da equação anterior deve ser igual a 4 . Já para um valor médio correspondente a todas as seções ao longo do comprimento do vão, a potência m deve ser igual a 3, e a equação anterior passa a ser escrita como:

$$
I_{e}=\left(\frac{M_{r}}{M_{\max }}\right)^{3} \cdot I_{I}+\left[1-\left(\frac{M_{r}}{M_{\text {max }}}\right)^{3}\right] . I_{I I} \leq I_{I}
$$


A equação anterior é a equação apresentada pela NBR 6118 (2003) e pela EF-96 (1997) para o cálculo das flechas imediatas. Esta equação foi inicialmente estabelecida para vigas simplesmente apoiadas sujeitas a um carregamento uniformemente distribuído, NEVILLE et al. (1983) afirma que pequenos erros são introduzidos se a expressão for aplicada para outras configurações de carregamento e condições de apoio. No caso de vigas contínuas, os momentos de inércia efetivos para as regiões de momento fletor positivo e negativo normalmente não têm o mesmo valor. Assim, pode-se obter o valor do momento de inércia efetivo por tramo a partir de uma média simples entre o momento de inércia efetivo da região de momento fletor positivo e o da região de momentos fletores negativos nos apoios, dada por:

$$
\mathrm{I}_{\mathrm{e}}=\frac{\mathrm{I}_{\mathrm{e} 2}+\frac{\left(\mathrm{I}_{\mathrm{e} 1}+\mathrm{I}_{\mathrm{e} 3}\right)}{2}}{2}
$$

sendo:

$\mathrm{I}_{\mathrm{e} 2} \quad-$ momento de inércia efetivo para o meio do vão;

$\mathrm{I}_{\mathrm{e} 1}, \mathrm{I}_{\mathrm{e} 3}$ - momento de inércia efetivo, respectivamente, para o apoio esquerdo e direito.

\subsubsection{Cálculo da flecha diferida no tempo}

A NBR 6118 (2003) prescreve que a flecha adicional diferida, decorrente das cargas de longa duração em função da fluência, pode ser calculada de maneira aproximada pela multiplicação da flecha imediata pelo fator $\alpha_{\mathrm{f}}$ dado pela expressão:

$$
\alpha_{\mathrm{f}}=\frac{\Delta \xi}{1+50 \cdot \rho^{\prime}}
$$

Com

$\rho^{\prime}=\frac{A_{s}^{\prime}}{\text { b.d }}$

onde:
$\mathrm{A}_{\mathrm{S}}{ }^{\prime} \quad$ - área da armadura de compressão;
b - largura da seção transversal;
d - altura útil. 
E ainda

$$
\begin{array}{ll}
\Delta \xi=\xi(\mathrm{t})-\xi\left(\mathrm{t}_{\mathrm{o}}\right) & 5.7 \mathrm{a} \\
\xi(\mathrm{t})=0,68 .\left(0,996^{\mathrm{t}}\right) \mathrm{t}^{0,32} & \text { para } \mathrm{t} \leq 70 \text { meses } \\
\begin{array}{l}
\xi(\mathrm{t})=2 \\
\text { sendo: }
\end{array} & \text { para } \mathrm{t}>70 \text { meses } \\
\mathrm{t} \quad-\text { tempo, em meses, em que o valor do flecha diferida é desejada; } \\
\mathrm{t}_{\mathrm{o}} \quad-\text { idade, em meses, relativa à data de aplicação da carga de longa } \\
\end{array}
$$

No caso de parcelas de carga de longa duração serem aplicadas em idades diferentes, pode-se tomar para $\mathrm{t}_{\mathrm{o}} \mathrm{o}$ valor ponderado por:

$$
\mathrm{t}_{\mathrm{o}}=\frac{\sum \mathrm{P}_{\mathrm{i}} \cdot \mathrm{t}_{\mathrm{oi}}}{\sum \mathrm{P}_{\mathrm{i}}}
$$

onde:

$\mathrm{P}_{\mathrm{i}} \quad$ - representa as parcelas de carga;

$t_{o i} \quad$ - idade em que se aplicou cada parcela $P_{i}$, em meses.

Já a EF-96 (1997) propõe que a flecha diferida de lajes formadas por vigotas pré-moldadas pode ser avaliada utilizando a seguinte expressão:

$$
\mathrm{a}_{\mathrm{d}}=\mathrm{a}_{\mathrm{o}} \cdot \sum \mathrm{k}_{\mathrm{i}} \cdot\left(2-\xi_{\mathrm{i}}\right) \cdot \lambda
$$

sendo:

$\mathrm{a}_{\mathrm{o}} \quad$ - flecha imediata referente à carga total $\mathrm{g}+\mathrm{q}$;

$\mathrm{k}_{\mathrm{i}}$ - relação entre a carga permanente $\mathrm{i}$ (peso próprio da laje, revestimento, etc) e a carga total, $g_{i} / g+q$;

$\xi_{\mathrm{i}} \quad$ - coeficiente dependente do instante de aplicação da carga permanente i, conforme tabela 5.1;

$\lambda$ - coeficiente dependente da taxa geométrica da armadura de compressão nos extremos do tramo e do tipo de tramo, dado por:

$$
\begin{array}{ll}
\lambda=1 & \text { tramo isolado } \\
\lambda=0,85+0,15 /\left(1+50 \cdot \rho_{1}\right) & \text { tramo extremo } \\
\lambda=0,70+0,30 /\left[1+50 \cdot\left(\rho_{1}+\rho_{2}\right)\right] & \text { tramo interno } \\
\lambda=1 /\left(1+50 \cdot \rho_{3}\right) & \text { balanço }
\end{array}
$$


TABELA 5.1 - Coeficiente dependente do instante de aplicação da carga [EF-96 (1997)]

\begin{tabular}{|c|c|}
\hline meses & $\xi_{\mathbf{i}}$ \\
\hline 0,5 & 0,48 \\
\hline 1 & 0,68 \\
\hline 2 & 0,88 \\
\hline 3 & 1,00 \\
\hline 4 & 1,08 \\
\hline 5 & 1,15 \\
\hline 6 & 1,20 \\
\hline 7 & 1,24 \\
\hline 8 & 1,28 \\
\hline 10 & 1,35 \\
\hline 12 & 1,40 \\
\hline 18 & 1,52 \\
\hline 24 & 1,60 \\
\hline 36 & 1,72 \\
\hline 48 & 1,80 \\
\hline 60 & 1,86 \\
\hline 72 & 1,92 \\
\hline 84 & 1,96 \\
\hline 96 & 2,00 \\
\hline
\end{tabular}

\subsubsection{Combinações de ações}

As ações atuantes na construção são classificadas, segundo a NBR 8681 (2003), em permanentes, variáveis e excepcionais.

As ações permanentes são aquelas que ocorrem com valores praticamente constantes durante toda a vida da construção, como por exemplo, o peso próprio da estrutura e dos revestimentos. As ações variáveis são as que apresentam variações significativas durante a vida da construção, como exemplos, têm as cargas acidentais de uso da construção e a ação do vento. Já as ações excepcionais, são as que têm duração extremamente curta e muito baixa probabilidade de ocorrência durante a vida da construção, mas que devem ser consideradas nos projetos de determinadas estruturas, tais como, ações decorrentes de explosões e abalos sísmicos excepcionais.

A NBR 6118 (2003) permite que as ações sejam combinadas em função da probabilidade que têm de atuarem simultaneamente sobre a estrutura, durante um determinado período. Para a verificação dos estados limites de serviço, são definidos três tipos de combinação de ações: quase permanente, freqüente e rara, de acordo com a ordem de grandeza de permanência na estrutura. 
Na combinação quase permanente, utilizada na verificação do estado limite de deformações excessivas, todas as ações variáveis sofrem a mesma redução, sendo consideradas com seus valores quase permanentes $\psi_{2} \cdot \mathrm{F}_{\mathrm{q}, \mathrm{k}}$, conforme a seguinte expressão:

$$
F_{d, s e r}=\sum_{i=1}^{m} F_{g i, k}+\sum_{j=1}^{n} \psi_{2 j} \cdot F_{q j, k}
$$

Na combinação freqüente, utilizada na verificação dos estados limites de formação de fissuras, de abertura de fissuras e de vibrações excessivas, a ação variável principal $\mathrm{F}_{\mathrm{q} 1}$ é considerada com seu valor freqüente $\psi_{1} \cdot \mathrm{F}_{\mathrm{q} 1, \mathrm{k}}$ e todas as demais ações variáveis são tomadas com seus valores quase permanentes $\psi_{2} \cdot \mathrm{F}_{\mathrm{q}, \mathrm{k}}$, conforme a seguinte expressão:

$$
\mathrm{F}_{\mathrm{d}, \mathrm{ser}}=\sum_{\mathrm{i}=1}^{\mathrm{m}} \mathrm{F}_{\mathrm{gi}, \mathrm{k}}+\psi_{1} \cdot \mathrm{F}_{\mathrm{q} 1, \mathrm{k}}+\sum_{\mathrm{j}=1}^{\mathrm{n}} \psi_{2 \mathrm{j}} \cdot \mathrm{F}_{\mathrm{qj}, \mathrm{k}}
$$

Já na combinação rara, utilizada na verificação do estado limite de formação de fissuras, a ação variável principal $\mathrm{F}_{\mathrm{q} 1}$ é considerada com seu valor característico e todas as demais ações variáveis são tomadas com seus valores freqüentes $\psi_{1} \cdot \mathrm{F}_{\mathrm{q}, \mathrm{k}}$, conforme a seguinte expressão:

$$
\mathrm{F}_{\mathrm{d}, \mathrm{ser}}=\sum_{\mathrm{i}=1}^{\mathrm{m}} \mathrm{F}_{\mathrm{gi}, \mathrm{k}}+\mathrm{F}_{\mathrm{q} 1, \mathrm{k}}+\sum_{\mathrm{j}=1}^{\mathrm{n}} \psi_{1 \mathrm{j}} \cdot \mathrm{F}_{\mathrm{qj}, \mathrm{k}}
$$

Nas equações anteriores, $F_{d \text {,ser }}$ representa o valor de cálculo das ações para a combinação considerada e $\psi_{\mathrm{i}}$ é o coeficiente de redução das ações variáveis, conforme tabela 5.2.

Para a verificação dos estados limites de serviço, a EF-96 (1997) adota coeficiente de ponderação igual a zero para as ações variáveis que produzam efeitos favoráveis na estrutura e coeficiente igual a 1,0 para os demais casos. 
TABELA 5.2 - Valores de $\psi_{1}$ e $\psi_{2}$, segundo NBR 6118 (2003)

\begin{tabular}{|c|c|c|c|}
\hline \multicolumn{2}{|r|}{ Ações } & $\psi_{1}$ & $\psi_{2}$ \\
\hline \multirow{3}{*}{$\begin{array}{l}\text { Cargas acidentais } \\
\text { de edifícios }\end{array}$} & $\begin{array}{l}\text { Locais em que não há predominância de pesos de } \\
\text { equipamentos que permanecem fixos por longos } \\
\text { períodos de tempo, nem de elevadas concentrações } \\
\text { de pessoas }\end{array}$ & 0,4 & 0,3 \\
\hline & $\begin{array}{l}\text { Locais em que há predominância de pesos de } \\
\text { equipamentos que permanecem fixos por longos } \\
\text { períodos de tempo, ou de elevadas concentrações de } \\
\text { pessoas }\end{array}$ & 0,6 & 0,4 \\
\hline & Bibliotecas, arquivos, oficinas e garagens & 0,7 & 0,6 \\
\hline Vento & Pressão dinâmica do vento em estruturas em geral & 0,3 & 0 \\
\hline Temperatura & $\begin{array}{l}\text { Variações uniformes de temperatura em relação à } \\
\text { média anual local }\end{array}$ & 0,5 & 0,3 \\
\hline
\end{tabular}

\subsubsection{Deslocamentos limites}

De acordo com a NBR 6118 (2003), deslocamentos limites são valores práticos utilizados para verificação em serviço do estado limite de deformações excessivas da estrutura, sendo classificados nos quatro grupos básicos relacionados a seguir e devem obedecer aos limites estabelecidos na tabela 5.3.

- aceitabilidade sensorial: limite caracterizado por vibrações indesejáveis ou efeito visual desagradável.

- efeitos específicos: os deslocamentos podem impedir a utilização adequada da construção, causando problemas, por exemplo, ao alinhamento de equipamentos sensíveis apoiados nos elementos estruturais, ao desenvolvimento de atividades previstas ou à drenagem de lajes de piso e cobertura.

- efeitos em elementos não estruturais: deslocamentos estruturais podem ocasionar o mau funcionamento de elementos que, apesar de não fazerem parte da estrutura, estão ligados a ela. Os danos em elementos não estruturais podem variar desde fissuras em paredes e forros e problemas de funcionamento de portas e janelas até quebra de elementos de vidro.

- efeitos em elementos estruturais: os deslocamentos podem afetar o comportamento do elemento estrutural, provocando afastamento em relação às hipóteses de cálculo adotadas. Se os deslocamentos forem relevantes para o elemento 
considerado, seus efeitos sobre as tensões ou sobre a estabilidade da estrutura devem ser considerados, incorporando-as ao modelo estrutural adotado.

TABELA 5.3 - Limites para deslocamentos segundo NBR 6118 (2003)

\begin{tabular}{|c|c|c|c|}
\hline $\begin{array}{l}\text { Razão da } \\
\text { limitação }\end{array}$ & Exemplos & $\begin{array}{c}\text { Deslocamento a } \\
\text { considerar }\end{array}$ & $\begin{array}{l}\text { Deslocamento } \\
\text { limite }\end{array}$ \\
\hline \multicolumn{4}{|c|}{ Aceitabilidade sensorial } \\
\hline Visual & $\begin{array}{l}\text { Deslocamentos visíveis } \\
\text { em elementos estruturais }\end{array}$ & Deslocamento total & $\ell / 250$ \\
\hline Outro & $\begin{array}{c}\text { Vibrações sentidas no } \\
\text { piso }\end{array}$ & $\begin{array}{c}\text { Deslocamento devido à } \\
\text { carga acidental }\end{array}$ & $\ell / 350$ \\
\hline \multicolumn{4}{|c|}{ Efeitos estruturais em serviço } \\
\hline $\begin{array}{c}\text { Superfícies que } \\
\text { devem drenar água }\end{array}$ & Coberturas e varandas & Deslocamento total & $\ell / 250^{1)}$ \\
\hline \multirow{2}{*}{$\begin{array}{l}\text { Pavimentos que } \\
\text { devem permanecer } \\
\text { planos }\end{array}$} & \multirow{2}{*}{$\begin{array}{l}\text { Ginásios e pistas de } \\
\text { boliche }\end{array}$} & Deslocamento total & $\begin{array}{c}\ell / 350+ \\
\text { contraflecha }^{2)} \\
\end{array}$ \\
\hline & & $\begin{array}{c}\text { Deslocamento ocorrido } \\
\text { após a construção do piso }\end{array}$ & $\ell / 600$ \\
\hline $\begin{array}{l}\text { Elementos que } \\
\text { suportam } \\
\text { equipamentos } \\
\text { sensíveis }\end{array}$ & Laboratórios & $\begin{array}{l}\text { Deslocamento ocorrido } \\
\text { após nivelamento do } \\
\text { aparelho }\end{array}$ & $\begin{array}{l}\text { De acordo com } \\
\text { recomendações } \\
\text { do fabricante }\end{array}$ \\
\hline \multicolumn{4}{|c|}{ Efeitos em elementos não estruturais } \\
\hline \multirow[b]{2}{*}{ Paredes } & $\begin{array}{c}\text { Alvenaria, caixilhos e } \\
\text { revestimentos }\end{array}$ & $\begin{array}{c}\text { Deslocamento ocorrido } \\
\text { após a construção da parede }\end{array}$ & $\ell / 500^{3)}$ ou $10 \mathrm{~mm}$ \\
\hline & $\begin{array}{l}\text { Divisórias leves e } \\
\text { caixilhos telescópicos }\end{array}$ & $\begin{array}{l}\text { Deslocamento ocorrido } \\
\text { após a instalação da } \\
\text { divisória }\end{array}$ & $\ell / 250^{3)}$ ou $25 \mathrm{~mm}$ \\
\hline \multirow{2}{*}{ Forros } & Revestimentos colados & $\begin{array}{l}\text { Deslocamento ocorrido } \\
\text { após a construção do forro }\end{array}$ & $\ell / 350$ \\
\hline & $\begin{array}{c}\text { Revestimentos } \\
\text { pendurados ou com juntas }\end{array}$ & $\begin{array}{c}\text { Deslocamento ocorrido } \\
\text { após a construção do forro }\end{array}$ & $\ell / 175$ \\
\hline \multicolumn{4}{|c|}{ Efeitos em elementos estruturais } \\
\hline $\begin{array}{l}\text { Afastamento em } \\
\text { relação às hipóteses } \\
\text { de cálculo adotadas }\end{array}$ & \multicolumn{3}{|c|}{$\begin{array}{l}\text { Se os deslocamentos forem relevantes para o elemento considerado, seus } \\
\text { efeitos sobre as tensões ou sobre a estabilidade da estrutura devem ser } \\
\text { considerados, incorporando-os ao modelo estrutural adotado. }\end{array}$} \\
\hline \multirow{2}{*}{\multicolumn{4}{|c|}{$\begin{array}{l}\text { 1) As superfícies devem ser suficientemente inclinadas ou o deslocamento compensado por } \\
\text { contraflechas, de modo a não se ter acúmulo de água. } \\
\text { 2) Os deslocamentos podem ser parcialmente compensados pela especificação de contraflechas. } \\
\text { Entretanto, a situação isolada da contraflecha não pode ocasionar um desvio do plano maior que } \\
\ell / 350 \text {. } \\
\text { 3) O vão } \ell \text { deve ser tomado na direção na qual a parede ou a divisória se desenvolve. }\end{array}$}} \\
\hline & & & \\
\hline \multicolumn{4}{|l|}{ NOTAS: } \\
\hline \multicolumn{4}{|c|}{$\begin{array}{l}\text { 1) Todos os valores limites de deslocamentos supõem elementos de vão } \ell \text { suportados em ambas } \\
\text { as extremidades por apoios que não se movem. Quando se tratar de balanços, o vão } \\
\text { equivalente a ser considerado deve ser o dobro do comprimento do balanço; }\end{array}$} \\
\hline \multicolumn{4}{|c|}{$\begin{array}{l}\text { 2) Para o caso de elementos de superfície, os limites prescritos consideram que o valor de } \ell \text { é o } \\
\text { menor vão, exceto em casos de verificação de paredes e divisórias, onde interessa a direção } \\
\text { na qual a parede ou divisória se desenvolve. }\end{array}$} \\
\hline
\end{tabular}


Já a EF-96 (1997) limita as flechas das lajes nos seguintes valores:

a) a flecha total no tempo infinito não deve exceder o menor dos valores $\ell / 250$ e $\ell / 500+1 \mathrm{~cm}$;

b) para lajes que irão suportar paredes: a flecha ocorrido após a construção da parede não deve exceder o menor dos valores $\ell / 400$ e $\ell / 800+0,6 \mathrm{~cm}$;

c) para lajes que irão suportar paredes muito rígidas: a flecha ocorrido após a construção da parede não deve exceder o menor dos valores $\ell / 500$ e $\ell / 1000+0,5 \mathrm{~cm}$.

Nas expressões anteriores $\ell$ é o valor do vão e, no caso de balanço, 1,6 vezes o valor do balanço.

Nas lajes com vãos menores que 7 metros e sobrecargas não maiores que 4 kN/m², a EF-96 (1997) indica que não é necessário verificar a flecha caso a altura total da laje for maior que:

$\mathrm{h}=\delta_{1} \cdot \delta_{2} \cdot \ell / \mathrm{C}[\mathrm{m}]$

onde:

$\delta_{1} \quad$ - fator que depende da carga total $(\mathrm{p}=\mathrm{g}+\mathrm{q})$, tendo valor igual a $\sqrt{\mathrm{p} / 7}$, com $\mathrm{p}$ em $\mathrm{kN} / \mathrm{m}^{2}$;

$\delta_{2} \quad$ - fator com valor igual a $\sqrt[4]{\ell / 6}$;

$\ell \quad$ - vão de cálculo da laje em metros;

C - coeficiente cujo valor pode ser encontrado na tabela 5.4.

TABELA 5.4 - Valor do coeficiente C definido pela EF-96 (1997)

\begin{tabular}{|c|c|c|c|}
\hline \multirow{2}{*}{} & \multicolumn{3}{|c|}{ tipo de tramo } \\
\cline { 2 - 4 } & isolado & extremo & interior \\
\hline com paredes & 17 & 21 & 24 \\
\hline com divisórias & 18 & 22 & 25 \\
\hline cobertura & 20 & 24 & 27 \\
\hline
\end{tabular}


Como visto acima, as indicações contidas nas normas relativas à avaliação das flechas diferidas no tempo são voltadas para o caso de flechas em vigas, não sendo especificamente para as lajes com vigotas pré-moldadas.

Portanto, o que se pretende neste capítulo é realizar a análise das flechas diferidas de lajes pré-moldadas formadas por vigotas com armação treliçada, visando fornecer indicações de projeto através da proposta de um multiplicador das flechas imediatas para avaliação das flechas diferidas.

Esta análise foi realizada utilizando a metodologia descrita nos capítulos anteriores, ou seja, análise numérica, utilizando o programa computacional CONSNOU, em conjunto com análise probabilística, executada utilizando o método de amostragem por hipercubo latino.

\subsection{Análise preliminar}

Inicialmente foi realizada uma análise preliminar para tentar avaliar quais os parâmetros envolvidos influenciaria mais significativamente o coeficiente multiplicador das flechas imediatas.

\subsubsection{Características das lajes}

Foram analisadas lajes pré-moldadas formadas por vigotas com armação treliçada, compostas ainda por blocos de enchimento de poliestireno expandido (EPS) e uma capa de concreto estrutural moldada no local. Conforme a figura 5.4, as lajes possuíam 49 cm de distância entre nervuras e altura total de 12, 16, 20, 25 e 30 cm, tendo a seguinte denominação, respectivamente, LT12, LT16, LT20, LT25 e LT30. 


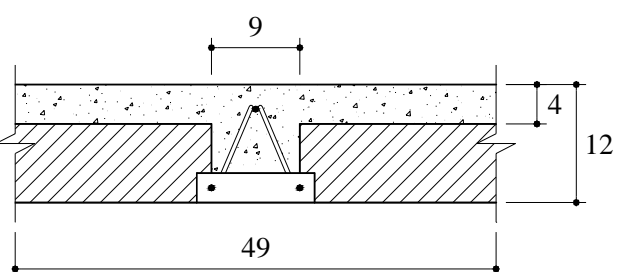

laje LT12

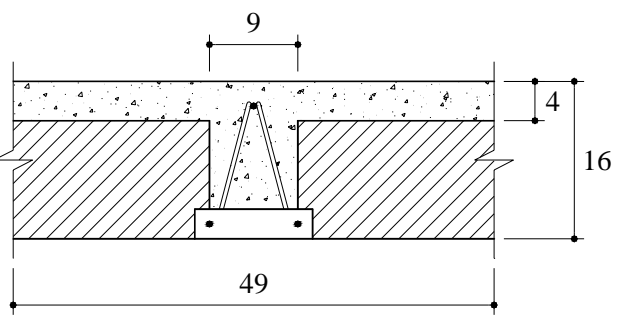

laje LT16

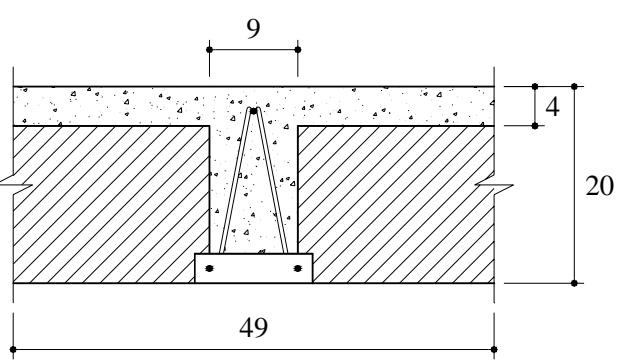

laje LT20

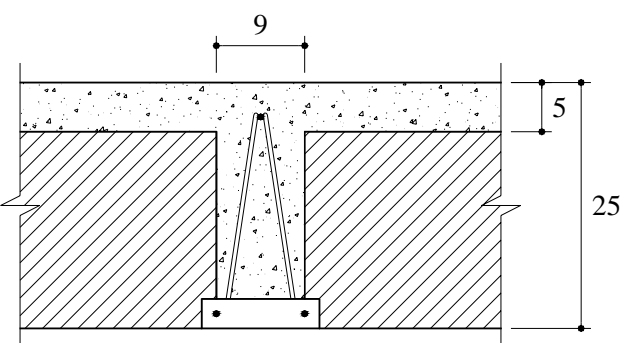

49

laje LT25

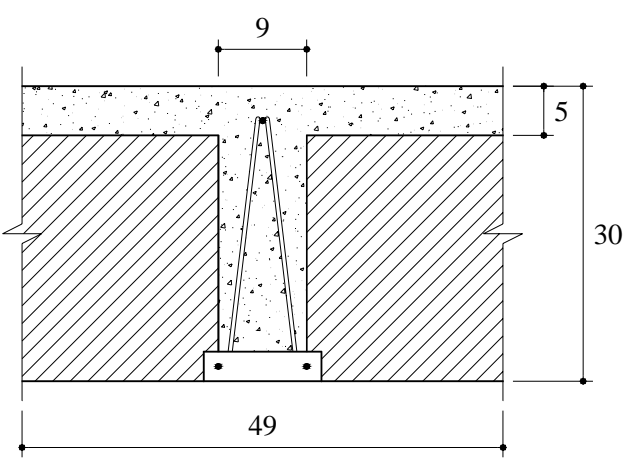

laje LT30

FIGURA 5.4 - Seção transversal das lajes (dimensões em cm)

Para cada tipo de laje, foi empregada uma vigota pré-moldada distinta, sendo que a diferença foi o tipo de treliça eletrosoldada utilizada em cada uma delas. As características geométricas das vigotas estão apresentadas na figura 5.5 e as particularidades das treliças eletrosoldadas utilizadas em cada uma das lajes estão apresentadas na tabela 5.5 .

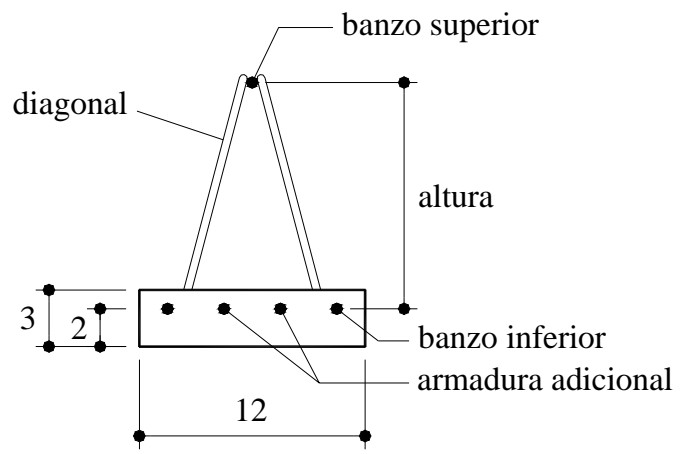

FIGURA 5.5 - Vigota (dimensões em cm) 
TABELA 5.5 - Característica da treliça eletrosoldada (valores em mm)

\begin{tabular}{cccccc}
\hline laje & $\begin{array}{c}\text { altura da } \\
\text { treliça }\end{array}$ & $\begin{array}{c}\text { diâmetro da } \\
\text { armadura do } \\
\text { banzo superior }\end{array}$ & $\begin{array}{c}\text { diâmetro da } \\
\text { armadura } \\
\text { da diagonal }\end{array}$ & $\begin{array}{c}\text { diâmetro da } \\
\text { armadura do } \\
\text { banzo inferior }\end{array}$ & designação \\
\hline LT12 & 8 & 6 & 4,2 & 4,2 & TR08644 \\
LT16 & 12 & 6 & 4,2 & 5 & TR12645 \\
LT20 & 16 & 7 & 4,2 & 5 & TR16745 \\
LT25 & 20 & 7 & 4,2 & 6 & TR20746 \\
LT30 & 25 & 8 & 5 & 6 & TR25856 \\
\hline
\end{tabular}

\subsubsection{Processo construtivo da laje pré-moldada}

Para a construção da laje pré-moldada, as vigotas após terem sido confeccionadas na fábrica são transportadas à obra e posicionadas sobre os apoios, com a presença de apoios provisórios (escoramento). Em seguida, após o posicionamento dos elementos de enchimento é feita a concretagem da capa estrutural. Após o concreto ter resistência suficiente, o escoramento é retirado.

Assim, considerando o processo construtivo da laje pré-moldada, será definido como $t_{1}$ o intervalo de tempo da confecção da vigota até a concretagem da capa estrutural (figura 5.6). Já o intervalo de tempo entre a concretagem da capa e a retirada do escoramento será denominado $t_{2}$. Juntamente com a retirada do escoramento, será considerada a aplicação do carregamento na laje, originando a flecha instantânea $\mathrm{a}_{\text {inst }}$. Mantido o carregamento constante durante todo o intervalo $\mathrm{t}_{3}$, haverá um acréscimo no valor da flecha, resultando na flecha total $\mathrm{a}_{\text {total }}$. 


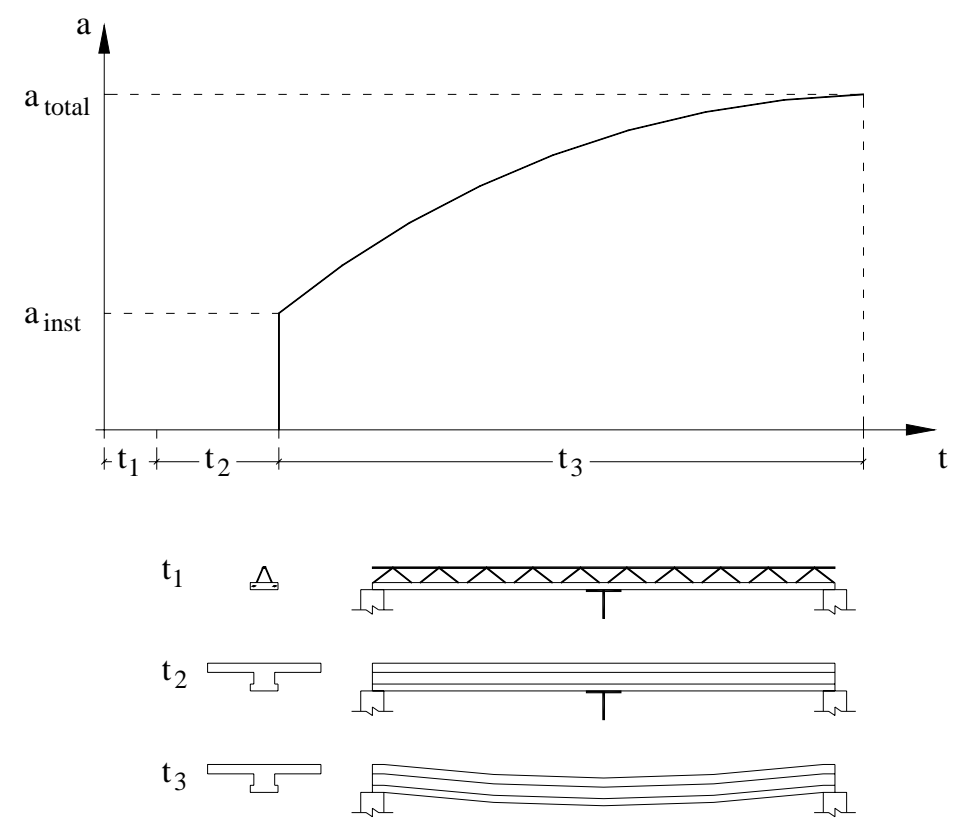

FIGURA 5.6 - Processo construtivo da laje pré-moldada

A flecha diferida pode ser avaliada através de um coeficiente multiplicador da flecha instantânea. Esse coeficiente multiplicador pode ser calculado através da seguinte expressão:

$$
\alpha=\frac{\mathrm{a}_{\text {total }}-\mathrm{a}_{\text {inst }}}{\mathrm{a}_{\text {inst }}}
$$

\subsubsection{Parâmetros adotados}

Para esta análise preliminar, foram consideradas duas situações distintas para cada tipo de laje. A situação 1 correspondendo à atuação de uma carga acidental de $5,0 \mathrm{kN} / \mathrm{m}^{2}$ e a situação 2, com carga acidental de $2,5 \mathrm{kN} / \mathrm{m}^{2}$.

Como mostrados na tabela 5.6, os vãos e armaduras adicionais adotados para cada situação foram compatíveis com a carga acidental empregada, sendo considerada ainda a atuação de uma carga permanente referente ao revestimento de $0,5 \mathrm{kN} / \mathrm{m}^{2}$. A resistência característica à compressão do concreto foi de $20 \mathrm{MPa}$ e a resistência característica à tração do aço foi de $600 \mathrm{MPa}$ para as barras com diâmetro até $6 \mathrm{~mm}$ e $500 \mathrm{MPa}$ para as demais. 
TABELA 5.6 - Situações consideradas para cada tipo de laje

\begin{tabular}{cccc}
\hline laje & $\mathbf{A}_{\text {s,adic }}$ & $\ell_{\mathbf{1}}(\mathbf{m})$ & $\ell_{\mathbf{2}}(\mathbf{m})$ \\
\hline LT12 & $3 \phi 8 \mathrm{~mm}$ & 3,5 & 4,0 \\
LT16 & $3 \phi 10 \mathrm{~mm}$ & 4,5 & 5,5 \\
LT20 & $3 \phi 10 \mathrm{~mm}$ & 5,5 & 6,5 \\
LT25 & $3 \phi 12,5 \mathrm{~mm}$ & 7,0 & 8,5 \\
LT30 & $3 \phi 12,5 \mathrm{~mm}$ & 8,5 & 9,5 \\
\hline$\ell_{1}$ - vão para carga acidental de $5,0 \mathrm{kN} / \mathrm{m}^{2}$ \\
$\ell_{2}$ - vão para carga acidental de $2,5 \mathrm{kN} / \mathrm{m}^{2}$ \\
\hline
\end{tabular}

Para avaliar quais os parâmetros afetam de forma mais relevante o coeficiente multiplicador $\alpha$, foram determinados tais coeficientes a partir de um valor base desses parâmetros e em seguida variando-os um a um. E assim, o parâmetro que gerar maior variação no coeficiente multiplicador $\alpha$, terá maior influência sobre ele. As variações consideradas para a carga acidental (q), resistência

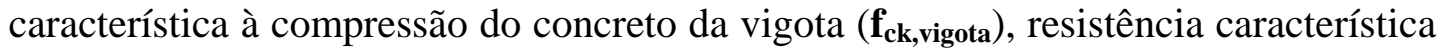
à compressão do concreto da capa ( $\mathbf{f}_{\text {ck,capa }}$ ), idade da concretagem da capa $\left(\mathbf{t}_{1}\right)$, intervalo de tempo entre a concretagem da capa e a retirada do escoramento $\left(\mathbf{t}_{2}\right)$, umidade relativa do ambiente (U) e temperatura ambiente (T) estão apresentados na tabela 5.7. Já as variações consideradas para os vãos das lajes estão mostradas na tabela 5.8.

As flechas foram determinadas a partir da combinação quase-permanente das ações.

$$
\mathrm{F}_{\mathrm{d}, \mathrm{ser}}=\mathrm{F}_{\mathrm{gk}}+0,3 \cdot \mathrm{F}_{\mathrm{qk}}
$$

Foi considerado ainda que o intervalo de tempo que o carregamento atuante permaneceu constante $\left(\mathbf{t}_{3}\right)$ foi de 2200 dias, ou seja, aproximadamente 6 anos.

TABELA 5.7 - Variações consideradas para os parâmetros

\begin{tabular}{|c|c|c|c|c|c|c|c|c|}
\hline & \multicolumn{2}{|c|}{$\underset{\left(k N / m^{2}\right)}{q}$} & \multirow{2}{*}{$\begin{array}{c}\mathbf{f}_{\text {ck,vigota }} \\
\text { (MPa) }\end{array}$} & \multirow{2}{*}{$\begin{array}{l}\mathbf{f}_{\text {ck,capa }} \\
\text { (MPa) }\end{array}$} & \multirow{2}{*}{$\begin{array}{c}\mathbf{t}_{1} \\
\text { (dias) }\end{array}$} & \multirow{2}{*}{$\begin{array}{c}t_{2} \\
\text { (dias) }\end{array}$} & \multirow{2}{*}{$\begin{array}{c}\mathrm{U} \\
(\%)\end{array}$} & \multirow{2}{*}{$\begin{array}{c}\mathrm{T} \\
\left({ }^{\circ} \mathrm{C}\right)\end{array}$} \\
\hline & situação 1 & situação 2 & & & & & & \\
\hline valor base & 5,0 & 2,5 & 20 & 20 & 7 & 14 & 60 & 25 \\
\hline variação & 1,0 & 1,0 & 25 & 25 & 91 & 42 & 80 & 35 \\
\hline
\end{tabular}


TABELA 5.8 - Variações consideradas para os vãos das lajes

\begin{tabular}{ccccc}
\hline \multirow{2}{*}{ laje } & \multicolumn{2}{c}{$\ell_{\mathbf{1}}(\mathbf{m})$} & \multicolumn{2}{c}{$\ell_{\mathbf{2}}(\mathbf{m})$} \\
\cline { 2 - 5 } & valor base & variação & valor base & variação \\
\hline LT12 & 3,5 & 2,0 & 4,0 & 2,5 \\
LT16 & 4,5 & 2,5 & 5,5 & 3,5 \\
LT20 & 5,5 & 3,5 & 6,5 & 3,5 \\
LT25 & 7,0 & 4,0 & 8,5 & 5,5 \\
LT30 & 8,5 & 5,5 & 9,5 & 5,5 \\
\hline$\ell_{1}$ - vão para carga acidental de $5,0 \mathrm{kN} / \mathrm{m}^{2}$ \\
$\ell_{2}$ - vão para carga acidental de $2,5 \mathrm{kN} / \mathrm{m}^{2}$ \\
\hline
\end{tabular}

\subsubsection{Descrição das modelagens numéricas}

A análise numérica foi realizada dividindo a seção transversal das lajes em camadas de $0,5 \mathrm{~cm}$, como pode ser visto na figura 5.7 .

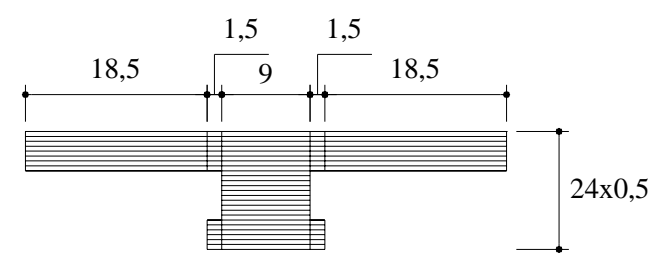

laje LT12

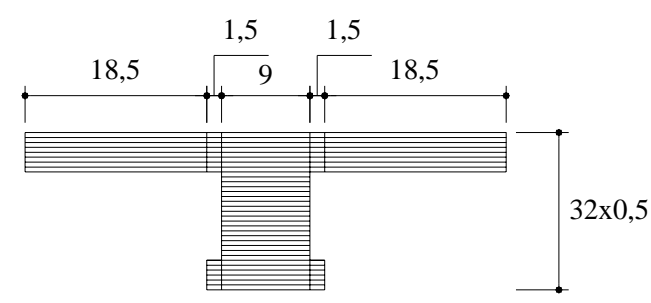

laje LT16

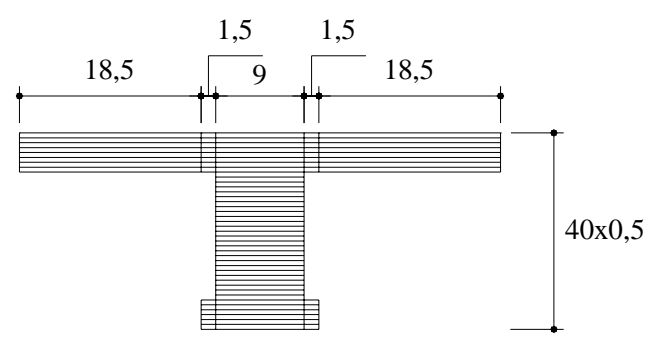

laje LT20

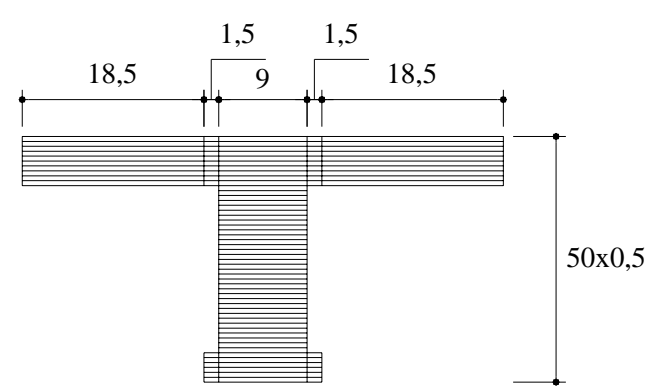

laje LT25

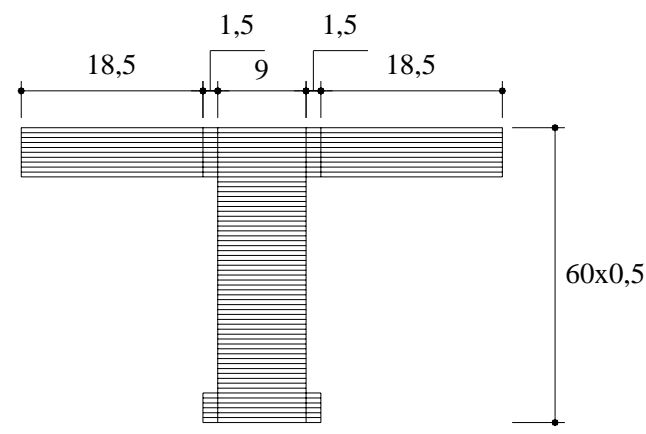

laje LT30

FIGURA 5.7 - Discretização da seção transversal das lajes (dimensões em cm) 
A discretização longitudinal das lajes foi feita adotando elementos com comprimento de $10 \mathrm{~cm}$, como mostrada na figura 5.8 (a) para a laje com $200 \mathrm{~cm}$ de comprimento. No entanto, quando não coincidiu a presença de um nó no meio do vão, este foi introduzido dando origem a dois elementos de $5 \mathrm{~cm}$, como ilustrado na figura 5.8 (b) para a laje com 250 cm. Este nó no meio do vão é utilizado como ponto de escoramento da laje, facilitando na prática a realização de contraflecha. Os outros pontos de escoramento de todas as lajes analisadas, não apenas as lajes desta análise preliminar, estão mostrados na tabela 5.9.

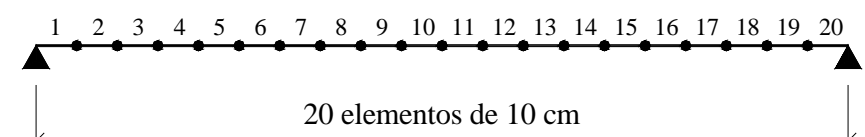

(a) laje de $200 \mathrm{~cm}$

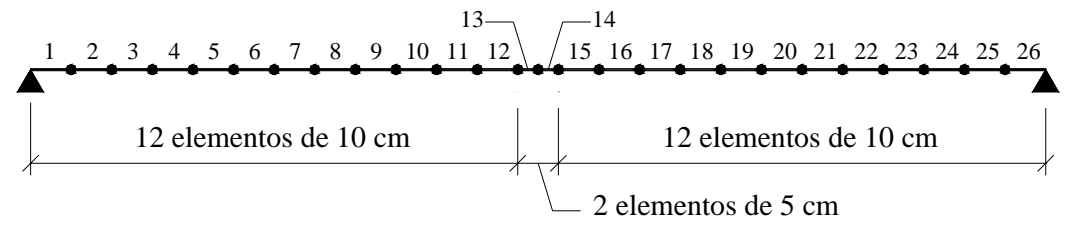

(b) laje de $250 \mathrm{~cm}$

FIGURA 5.8 - Discretização longitudinal das lajes de 200 e $250 \mathrm{~cm}$

TABELA 5.9 - Pontos de escoramento das lajes (dimensões em cm)

\begin{tabular}{|c|c|c|c|}
\hline$\ell(\mathrm{cm})$ & linha de escoras & $\ell(\mathbf{c m})$ & linha de escoras \\
\hline 200 & 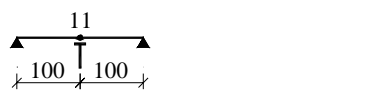 & 600 & 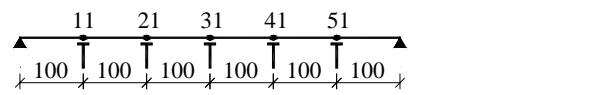 \\
\hline 250 & 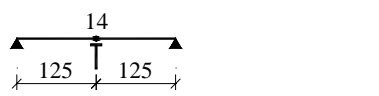 & 650 & 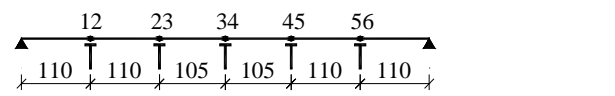 \\
\hline 300 & 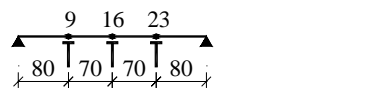 & 700 & 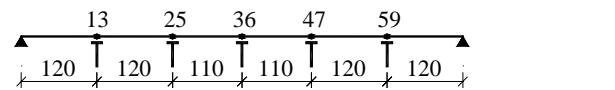 \\
\hline 350 & 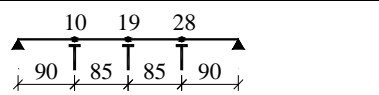 & 750 & 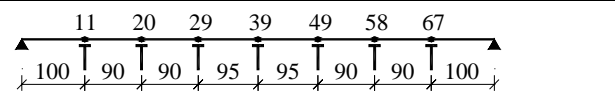 \\
\hline 400 & 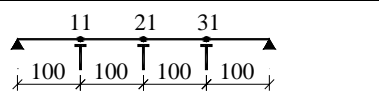 & 800 & 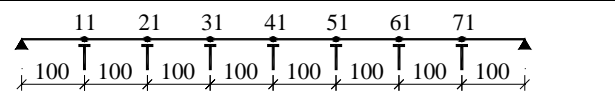 \\
\hline 450 & 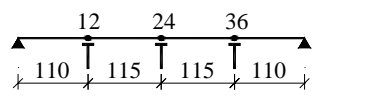 & 850 & 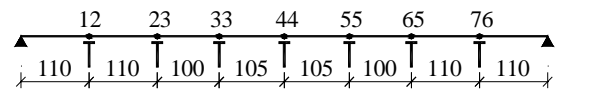 \\
\hline 500 & 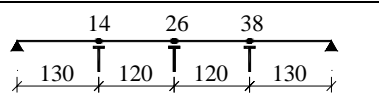 & 900 & 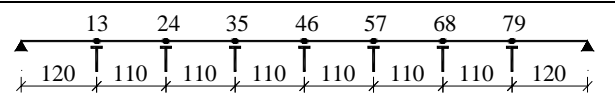 \\
\hline 550 & 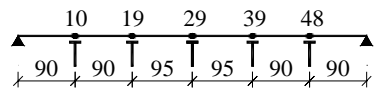 & 950 & 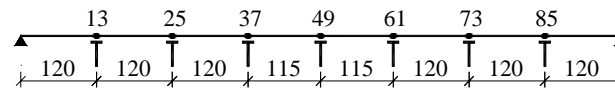 \\
\hline
\end{tabular}




\subsubsection{Resultados obtidos}

Os resultados obtidos para as flechas instantâneas e diferidas das lajes, assim como o coeficiente multiplicador $\alpha$ estão apresentados nas tabelas 5.10 a 5.19.

TABELA 5.10 - Resultados obtidos para a situação 1 da laje LT12

\begin{tabular}{|c|c|c|c|c|c|c|c|c|c|c|}
\hline $\begin{array}{c}\ell \\
(\mathbf{m})\end{array}$ & $\underset{\left(\mathrm{kN} / \mathrm{m}^{2}\right)}{\mathrm{q}}$ & $\begin{array}{l}f_{\text {ck,vigota }} \\
\text { (MPa) }\end{array}$ & $\begin{array}{l}\mathbf{f}_{\text {ck,capa }} \\
\text { (MPa) }\end{array}$ & $\begin{array}{c}t_{1} \\
\text { (dias) }\end{array}$ & $\begin{array}{c}\mathbf{t}_{2} \\
\text { (dias) }\end{array}$ & $\begin{array}{c}U \\
(\%)\end{array}$ & $\begin{array}{c}\mathrm{T} \\
\left({ }^{\circ} \mathrm{C}\right)\end{array}$ & $\begin{array}{c}a_{\text {inst }} \\
(\mathbf{m m})\end{array}$ & $\begin{array}{l}a_{\text {total }} \\
(\mathrm{mm})\end{array}$ & $\alpha$ \\
\hline 3,5 & 5,0 & 20 & 20 & 7 & 14 & 60 & 25 & 10,64 & 22,64 & 1,13 \\
\hline 2,0 & 5,0 & 20 & 20 & 7 & 14 & 60 & 25 & 0,38 & 2,39 & 5,28 \\
\hline 3,5 & 1,0 & 20 & 20 & 7 & 14 & 60 & 25 & 5,31 & 15,21 & 1,87 \\
\hline 3,5 & 5,0 & 25 & 20 & 7 & 14 & 60 & 25 & 10,56 & 22,54 & 1,13 \\
\hline 3,5 & 5,0 & 20 & 25 & 7 & 14 & 60 & 25 & 10,17 & 21,53 & 1,12 \\
\hline 3,5 & 5,0 & 20 & 20 & 91 & 14 & 60 & 25 & 10,63 & 22,77 & 1,14 \\
\hline 3,5 & 5,0 & 20 & 20 & 7 & 42 & 60 & 25 & 9,76 & 20,07 & 1,06 \\
\hline 3,5 & 5,0 & 20 & 20 & 7 & 14 & 80 & 25 & 10,65 & 19,25 & 0,81 \\
\hline 3,5 & 5,0 & 20 & 20 & 7 & 14 & 60 & 35 & 10,64 & 23,22 & 1,18 \\
\hline
\end{tabular}

TABELA 5.11 - Resultados obtidos para a situação 1 da laje LT16

\begin{tabular}{|c|c|c|c|c|c|c|c|c|c|c|}
\hline $\begin{array}{c}\ell \\
\text { (m) }\end{array}$ & $\underset{\left(\mathrm{kN} / \mathrm{m}^{2}\right)}{\mathrm{q}}$ & $\begin{array}{l}\mathbf{f}_{\text {ck,vigota }} \\
\text { (MPa) }\end{array}$ & $\begin{array}{l}\mathbf{f}_{\text {ck,capa }} \\
\text { (MPa) }\end{array}$ & $\begin{array}{c}t_{1} \\
\text { (dias) }\end{array}$ & $\begin{array}{c}\mathbf{t}_{2} \\
\text { (dias) }\end{array}$ & $\begin{array}{c}\mathrm{U} \\
(\%)\end{array}$ & $\begin{array}{c}\mathrm{T} \\
\left({ }^{\circ} \mathrm{C}\right) \\
\end{array}$ & $\begin{array}{c}a_{\text {inst }} \\
(\mathbf{m m})\end{array}$ & $\begin{array}{c}a_{\text {total }} \\
(\mathbf{m m})\end{array}$ & $\alpha$ \\
\hline 4,5 & 5,0 & 20 & 20 & 7 & 14 & 60 & 25 & 9,87 & 22,76 & 1,31 \\
\hline 2,5 & 5,0 & 20 & 20 & 7 & 14 & 60 & 25 & 0,32 & 2,44 & 6,68 \\
\hline 4,5 & 1,0 & 20 & 20 & 7 & 14 & 60 & 25 & 5,13 & 16,30 & 2,18 \\
\hline 4,5 & 5,0 & 25 & 20 & 7 & 14 & 60 & 25 & 9,72 & 22,45 & 1,31 \\
\hline 4,5 & 5,0 & 20 & 25 & 7 & 14 & 60 & 25 & 9,41 & 21,31 & 1,26 \\
\hline 4,5 & 5,0 & 20 & 20 & 91 & 14 & 60 & 25 & 9,82 & 22,76 & 1,32 \\
\hline 4,5 & 5,0 & 20 & 20 & 7 & 42 & 60 & 25 & 9,08 & 19,91 & 1,19 \\
\hline 4,5 & 5,0 & 20 & 20 & 7 & 14 & 80 & 25 & 9,86 & 18,74 & 0,90 \\
\hline 4,5 & 5,0 & 20 & 20 & 7 & 14 & 60 & 35 & 9,90 & 23,63 & 1,39 \\
\hline
\end{tabular}

TABELA 5.12 - Resultados obtidos para a situação 1 da laje LT20

\begin{tabular}{ccccccccccc}
\hline $\begin{array}{c}\ell \\
(\mathbf{m})\end{array}$ & $\begin{array}{c}\mathbf{q} \\
\left(\mathbf{k N} / \mathbf{m}^{2}\right)\end{array}$ & $\begin{array}{c}\mathbf{f}_{\text {ck,vigota }} \\
(\mathbf{M P a})\end{array}$ & $\begin{array}{c}\mathbf{f}_{\text {ck,capa }} \\
(\mathbf{M P a})\end{array}$ & $\begin{array}{c}\mathbf{t}_{\mathbf{1}} \\
(\mathbf{d i a s})\end{array}$ & $\begin{array}{c}\mathbf{t}_{\mathbf{2}} \\
(\mathbf{d i a s})\end{array}$ & $\begin{array}{c}\mathbf{U} \\
(\mathbf{\%})\end{array}$ & $\begin{array}{c}\mathbf{T} \\
\left({ }^{\circ} \mathbf{C}\right)\end{array}$ & $\begin{array}{c}\mathbf{a}_{\text {inst }} \\
(\mathbf{m m})\end{array}$ & $\begin{array}{c}\mathbf{a}_{\text {total }} \\
(\mathbf{m m})\end{array}$ & $\boldsymbol{\alpha}$ \\
\hline 5,5 & 5,0 & 20 & 20 & 7 & 14 & 60 & 25 & 13,44 & 28,67 & 1,13 \\
$\mathbf{3 , 5}$ & 5,0 & 20 & 20 & 7 & 14 & 60 & 25 & 0,93 & 4,84 & 4,20 \\
5,5 & $\mathbf{1 , 0}$ & 20 & 20 & 7 & 14 & 60 & 25 & 6,76 & 19,81 & 1,93 \\
5,5 & 5,0 & $\mathbf{2 5}$ & 20 & 7 & 14 & 60 & 25 & 13,67 & 28,88 & 1,11 \\
5,5 & 5,0 & 20 & $\mathbf{2 5}$ & 7 & 14 & 60 & 25 & 12,65 & 26,85 & 1,12 \\
5,5 & 5,0 & 20 & 20 & $\mathbf{9 1}$ & 14 & 60 & 25 & 13,01 & 28,19 & 1,17 \\
5,5 & 5,0 & 20 & 20 & 7 & $\mathbf{4 2}$ & 60 & 25 & 12,47 & 25,71 & 1,06 \\
5,5 & 5,0 & 20 & 20 & 7 & 14 & $\mathbf{8 0}$ & 25 & 13,38 & 23,99 & 0,79 \\
5,5 & 5,0 & 20 & 20 & 7 & 14 & 60 & $\mathbf{3 5}$ & 13,49 & 29,85 & 1,21 \\
\hline
\end{tabular}


TABELA 5.13 - Resultados obtidos para a situação 1 da laje LT25

\begin{tabular}{|c|c|c|c|c|c|c|c|c|c|c|}
\hline $\begin{array}{c}\ell \\
(\mathbf{m})\end{array}$ & $\underset{\left(k N / m^{2}\right)}{q}$ & $\begin{array}{l}f_{\text {ck,vigota }} \\
\text { (MPa) }\end{array}$ & $\begin{array}{l}\mathbf{f}_{\text {ck,capa }} \\
\text { (MPa) }\end{array}$ & $\begin{array}{c}t_{1} \\
\text { (dias) }\end{array}$ & $\begin{array}{c}\mathbf{t}_{2} \\
\text { (dias) }\end{array}$ & $\begin{array}{c}\mathrm{U} \\
(\%)\end{array}$ & $\begin{array}{c}\mathrm{T} \\
\left({ }^{\circ} \mathrm{C}\right)\end{array}$ & $\begin{array}{c}a_{\text {inst }} \\
(\mathbf{m m})\end{array}$ & $\begin{array}{l}a_{\text {total }} \\
(\mathrm{mm})\end{array}$ & $\alpha$ \\
\hline 7,0 & 5,0 & 20 & 20 & 7 & 14 & 60 & 25 & 16,96 & 36,34 & 1,14 \\
\hline 4,0 & 5,0 & 20 & 20 & 7 & 14 & 60 & 25 & 0,84 & 4,61 & 4,50 \\
\hline 7,0 & 1,0 & 20 & 20 & 7 & 14 & 60 & 25 & 10,41 & 27,60 & 1,65 \\
\hline 7,0 & 5,0 & 25 & 20 & 7 & 14 & 60 & 25 & 16,66 & 35,92 & 1,16 \\
\hline 7,0 & 5,0 & 20 & 25 & 7 & 14 & 60 & 25 & 16,27 & 34,35 & 1,11 \\
\hline 7,0 & 5,0 & 20 & 20 & 91 & 14 & 60 & 25 & 17,02 & 36,46 & 1,14 \\
\hline 7,0 & 5,0 & 20 & 20 & 7 & 42 & 60 & 25 & 15,90 & 32,95 & 1,07 \\
\hline 7,0 & 5,0 & 20 & 20 & 7 & 14 & 80 & 25 & 16,93 & 30,59 & 0,81 \\
\hline 7,0 & 5,0 & 20 & 20 & 7 & 14 & 60 & 35 & 16,98 & 38,51 & 1,27 \\
\hline
\end{tabular}

TABELA 5.14 - Resultados obtidos para a situação 1 da laje LT30

\begin{tabular}{|c|c|c|c|c|c|c|c|c|c|c|}
\hline $\begin{array}{c}\ell \\
\text { (m) }\end{array}$ & $\underset{\left(k N / \mathbf{m}^{2}\right)}{\mathbf{q}}$ & $\begin{array}{l}\mathbf{f}_{\text {ck,vigota }} \\
\text { (MPa) }\end{array}$ & $\begin{array}{l}\mathbf{f}_{\text {ck,capa }} \\
\text { (MPa) }\end{array}$ & $\begin{array}{c}t_{1} \\
\text { (dias) }\end{array}$ & $\begin{array}{c}\mathbf{t}_{2} \\
\text { (dias) }\end{array}$ & $\begin{array}{c}\text { U } \\
(\%)\end{array}$ & $\begin{array}{c}\mathrm{T} \\
\left({ }^{\circ} \mathrm{C}\right)\end{array}$ & $\begin{array}{c}a_{\text {inst }} \\
(\mathbf{m m})\end{array}$ & $\begin{array}{l}a_{\text {total }} \\
(\mathbf{m m})\end{array}$ & $\alpha$ \\
\hline 8,5 & 5,0 & 20 & 20 & 7 & 14 & 60 & 25 & 26,53 & 51,23 & 0,93 \\
\hline 5,5 & 5,0 & 20 & 20 & 7 & 14 & 60 & 25 & 2,21 & 9,00 & 3,07 \\
\hline 8,5 & 1,0 & 20 & 20 & 7 & 14 & 60 & 25 & 17,63 & 39,53 & 1,24 \\
\hline 8,5 & 5,0 & 25 & 20 & 7 & 14 & 60 & 25 & 26,46 & 51,10 & 0,93 \\
\hline 8,5 & 5,0 & 20 & 25 & 7 & 14 & 60 & 25 & 25,69 & 48,63 & 0,89 \\
\hline 8,5 & 5,0 & 20 & 20 & 91 & 14 & 60 & 25 & 27,00 & 51,77 & 0,92 \\
\hline 8,5 & 5,0 & 20 & 20 & 7 & 42 & 60 & 25 & 25,24 & 46,95 & 0,86 \\
\hline 8,5 & 5,0 & 20 & 20 & 7 & 14 & 80 & 25 & 26,52 & 44,13 & 0,66 \\
\hline 8,5 & 5,0 & 20 & 20 & 7 & 14 & 60 & 35 & 26,55 & 54,18 & 1,04 \\
\hline
\end{tabular}

TABELA 5.15 - Resultados obtidos para a situação 2 da laje LT12

\begin{tabular}{|c|c|c|c|c|c|c|c|c|c|c|}
\hline $\begin{array}{c}\ell \\
\text { (m) }\end{array}$ & $\underset{\left(k N / m^{2}\right)}{q}$ & $\begin{array}{l}\mathbf{f}_{\text {ck,vigota }} \\
\text { (MPa) }\end{array}$ & $\begin{array}{l}\mathbf{f}_{\text {ck,capa }} \\
\text { (MPa) }\end{array}$ & $\begin{array}{c}t_{1} \\
\text { (dias) }\end{array}$ & $\begin{array}{c}\mathbf{t}_{2} \\
\text { (dias) }\end{array}$ & $\begin{array}{c}\text { U } \\
(\%)\end{array}$ & $\begin{array}{c}\mathrm{T} \\
\left({ }^{\circ} \mathrm{C}\right)\end{array}$ & $\begin{array}{c}a_{\text {inst }} \\
(\mathbf{m m})\end{array}$ & $\begin{array}{l}a_{\text {total }} \\
(\mathrm{mm})\end{array}$ & $\alpha$ \\
\hline 4,0 & 2,5 & 20 & 20 & 7 & 14 & 60 & 25 & 14,08 & 29,87 & 1,12 \\
\hline 2,5 & 2,5 & 20 & 20 & 7 & 14 & 60 & 25 & 0,64 & 3,89 & 5,06 \\
\hline 4,0 & 1,0 & 20 & 20 & 7 & 14 & 60 & 25 & 10,64 & 25,08 & 1,36 \\
\hline 4,0 & 2,5 & 25 & 20 & 7 & 14 & 60 & 25 & 13,93 & 29,70 & 1,13 \\
\hline 4,0 & 2,5 & 20 & 25 & 7 & 14 & 60 & 25 & 13,45 & 28,37 & 1,11 \\
\hline 4,0 & 2,5 & 20 & 20 & 91 & 14 & 60 & 25 & 14,24 & 30,19 & 1,12 \\
\hline 4,0 & 2,5 & 20 & 20 & 7 & 42 & 60 & 25 & 12,91 & 26,49 & 1,05 \\
\hline 4,0 & 2,5 & 20 & 20 & 7 & 14 & 80 & 25 & 14,08 & 25,41 & 0,81 \\
\hline 4,0 & 2,5 & 20 & 20 & 7 & 14 & 60 & 35 & 14,08 & 30,72 & 1,18 \\
\hline
\end{tabular}


TABELA 5.16 - Resultados obtidos para a situação 2 da laje LT16

\begin{tabular}{ccccccccccc}
\hline $\begin{array}{c}\ell \\
(\mathbf{m})\end{array}$ & $\begin{array}{c}\mathbf{q} \\
\left(\mathbf{k N} / \mathbf{m}^{2}\right)\end{array}$ & $\begin{array}{c}\mathbf{f}_{\text {ck,vigota }} \\
(\mathbf{M P a})\end{array}$ & $\begin{array}{c}\mathbf{f}_{\mathbf{c k}, \text { capa }} \\
(\mathbf{M P a})\end{array}$ & $\begin{array}{c}\mathbf{t}_{\mathbf{1}} \\
(\mathbf{d i a s})\end{array}$ & $\begin{array}{c}\mathbf{t}_{\mathbf{2}} \\
(\mathbf{d i a s})\end{array}$ & $\begin{array}{c}\mathbf{U} \\
(\mathbf{\%})\end{array}$ & $\begin{array}{c}\mathbf{T} \\
\left({ }^{\mathbf{}} \mathbf{C}\right)\end{array}$ & $\begin{array}{c}\mathbf{a}_{\text {inst }} \\
(\mathbf{m m})\end{array}$ & $\begin{array}{c}\mathbf{a}_{\text {total }} \\
(\mathbf{m m})\end{array}$ & $\boldsymbol{\alpha}$ \\
\hline 5,5 & 2,5 & 20 & 20 & 7 & 14 & 60 & 25 & 19,25 & 39,75 & 1,07 \\
$\mathbf{3 , 5}$ & 2,5 & 20 & 20 & 7 & 14 & 60 & 25 & 1,34 & 6,71 & 4,01 \\
5,5 & $\mathbf{1 , 0}$ & 20 & 20 & 7 & 14 & 60 & 25 & 15,51 & 34,83 & 1,25 \\
5,5 & 2,5 & $\mathbf{2 5}$ & 20 & 7 & 14 & 60 & 25 & 19,12 & 39,68 & 1,08 \\
5,5 & 2,5 & 20 & $\mathbf{2 5}$ & 7 & 14 & 60 & 25 & 18,62 & 37,79 & 1,03 \\
5,5 & 2,5 & 20 & 20 & $\mathbf{9 1}$ & 14 & 60 & 25 & 19,17 & 39,92 & 1,08 \\
5,5 & 2,5 & 20 & 20 & 7 & $\mathbf{4 2}$ & 60 & 25 & 18,16 & 35,67 & 0,96 \\
5,5 & 2,5 & 20 & 20 & 7 & 14 & $\mathbf{8 0}$ & 25 & 19,24 & 33,68 & 0,75 \\
5,5 & 2,5 & 20 & 20 & 7 & 14 & 60 & $\mathbf{3 5}$ & 19,26 & 41,15 & 1,14 \\
\hline
\end{tabular}

TABELA 5.17 - Resultados obtidos para a situação 2 da laje LT20

\begin{tabular}{ccccccccccc}
\hline $\begin{array}{c}\ell \\
(\mathbf{m})\end{array}$ & $\begin{array}{c}\mathbf{q} \\
\left(\mathbf{k N} / \mathbf{m}^{2}\right)\end{array}$ & $\begin{array}{c}\mathbf{f}_{\text {ck,vigota }} \\
(\mathbf{M P a})\end{array}$ & $\begin{array}{c}\mathbf{f}_{\text {ck,capa }} \\
(\mathbf{M P a})\end{array}$ & $\begin{array}{c}\mathbf{t}_{\mathbf{1}} \\
(\mathbf{d i a s})\end{array}$ & $\begin{array}{c}\mathbf{t}_{\mathbf{2}} \\
(\mathbf{d i a s})\end{array}$ & $\begin{array}{c}\mathbf{U} \\
\mathbf{( \% )}\end{array}$ & $\begin{array}{c}\mathbf{T} \\
\left({ }^{\mathbf{}} \mathbf{C}\right)\end{array}$ & $\begin{array}{c}\mathbf{a}_{\text {inst }} \\
(\mathbf{m m})\end{array}$ & $\begin{array}{c}\mathbf{a}_{\text {total }} \\
(\mathbf{m m})\end{array}$ & $\boldsymbol{\alpha}$ \\
\hline 6,5 & 2,5 & 20 & 20 & 7 & 14 & 60 & 25 & 22,51 & 44,50 & 0,98 \\
$\mathbf{3 , 5}$ & 2,5 & 20 & 20 & 7 & 14 & 60 & 25 & 0,73 & 4,28 & 4,87 \\
6,5 & $\mathbf{1 , 0}$ & 20 & 20 & 7 & 14 & 60 & 25 & 18,39 & 39,08 & 1,13 \\
6,5 & 2,5 & $\mathbf{2 5}$ & 20 & 7 & 14 & 60 & 25 & 22,56 & 44,59 & 0,98 \\
6,5 & 2,5 & 20 & $\mathbf{2 5}$ & 7 & 14 & 60 & 25 & 21,79 & 42,29 & 0,94 \\
6,5 & 2,5 & 20 & 20 & $\mathbf{9 1}$ & 14 & 60 & 25 & 22,99 & 45,20 & 0,97 \\
6,5 & 2,5 & 20 & 20 & 7 & $\mathbf{4 2}$ & 60 & 25 & 21,38 & 40,30 & 0,89 \\
6,5 & 2,5 & 20 & 20 & 7 & 14 & $\mathbf{8 0}$ & 25 & 22,50 & 38,03 & 0,69 \\
6,5 & 2,5 & 20 & 20 & 7 & 14 & 60 & $\mathbf{3 5}$ & 22,53 & 46,32 & 1,06 \\
\hline
\end{tabular}

TABELA 5.18 - Resultados obtidos para a situação 2 da laje LT25

\begin{tabular}{|c|c|c|c|c|c|c|c|c|c|c|}
\hline $\begin{array}{c}\ell \\
\text { (m) }\end{array}$ & $\underset{\left(k N / m^{2}\right)}{q}$ & $\begin{array}{l}\mathbf{f}_{\text {ck,vigota }} \\
\text { (MPa) }\end{array}$ & $\begin{array}{l}\mathbf{f}_{\text {ck,capa }} \\
\text { (MPa) }\end{array}$ & $\begin{array}{c}\mathbf{t}_{1} \\
\text { (dias) }\end{array}$ & $\begin{array}{c}\mathbf{t}_{2} \\
\text { (dias) }\end{array}$ & $\begin{array}{c}U \\
(\%)\end{array}$ & $\begin{array}{c}\mathbf{T} \\
\left({ }^{\circ} \mathbf{C}\right)\end{array}$ & $\begin{array}{c}a_{\text {inst }} \\
(\mathbf{m m})\end{array}$ & $\begin{array}{l}a_{\text {total }} \\
(\mathrm{mm})\end{array}$ & $\alpha$ \\
\hline 8,5 & 2,5 & 20 & 20 & 7 & 14 & 60 & 25 & 31,82 & 62,74 & 0,97 \\
\hline 5,5 & 2,5 & 20 & 20 & 7 & 14 & 60 & 25 & 2,97 & 11,83 & 2,98 \\
\hline 8,5 & 1,0 & 20 & 20 & 7 & 14 & 60 & 25 & 26,95 & 56,17 & 1,08 \\
\hline 8,5 & 2,5 & 25 & 20 & 7 & 14 & 60 & 25 & 31,94 & 62,93 & 0,97 \\
\hline 8,5 & 2,5 & 20 & 25 & 7 & 14 & 60 & 25 & 30,91 & 59,58 & 0,93 \\
\hline 8,5 & 2,5 & 20 & 20 & 91 & 14 & 60 & 25 & 32,45 & 63,56 & 0,96 \\
\hline 8,5 & 2,5 & 20 & 20 & 7 & 42 & 60 & 25 & 30,40 & 57,23 & 0,88 \\
\hline 8,5 & 2,5 & 20 & 20 & 7 & 14 & 80 & 25 & 31,81 & 53,77 & 0,69 \\
\hline 8,5 & 2,5 & 20 & 20 & 7 & 14 & 60 & 35 & 31,84 & 66,22 & 1,08 \\
\hline
\end{tabular}


TABELA 5.19 - Resultados obtidos para a situação 2 da laje LT30

\begin{tabular}{|c|c|c|c|c|c|c|c|c|c|c|}
\hline $\begin{array}{c}\ell \\
(\mathbf{m})\end{array}$ & $\underset{\left(\mathbf{k N} / \mathbf{m}^{2}\right)}{\mathbf{q}}$ & $\begin{array}{l}\mathbf{f}_{\text {ck,vigota }} \\
\text { (MPa) }\end{array}$ & $\begin{array}{l}\mathbf{f}_{\text {ck,capa }} \\
\text { (MPa) }\end{array}$ & $\begin{array}{c}\mathbf{t}_{1} \\
\text { (dias) }\end{array}$ & $\begin{array}{c}\mathbf{t}_{2} \\
\text { (dias) }\end{array}$ & $\begin{array}{c}\mathrm{U} \\
(\%)\end{array}$ & $\begin{array}{c}\mathrm{T} \\
\left({ }^{\circ} \mathrm{C}\right)\end{array}$ & $\begin{array}{c}\mathbf{a}_{\text {inst }} \\
(\mathbf{m m})\end{array}$ & $\begin{array}{l}a_{\text {total }} \\
(\mathbf{m m})\end{array}$ & $\alpha$ \\
\hline 9,5 & 2,5 & 20 & 20 & 7 & 14 & 60 & 25 & 34,23 & 65,60 & 0,92 \\
\hline 5,5 & 2,5 & 20 & 20 & 7 & 14 & 60 & 25 & 1,70 & 7,85 & 3,62 \\
\hline 9,5 & 1,0 & 20 & 20 & 7 & 14 & 60 & 25 & 29,18 & 58,96 & 1,02 \\
\hline 9,5 & 2,5 & 25 & 20 & 7 & 14 & 60 & 25 & 33,95 & 65,18 & 0,92 \\
\hline 9,5 & 2,5 & 20 & 25 & 7 & 14 & 60 & 25 & 33,16 & 62,27 & 0,88 \\
\hline 9,5 & 2,5 & 20 & 20 & 91 & 14 & 60 & 25 & 34,55 & 65,93 & 0,91 \\
\hline 9,5 & 2,5 & 20 & 20 & 7 & 42 & 60 & 25 & 32,64 & 60,20 & 0,84 \\
\hline 9,5 & 2,5 & 20 & 20 & 7 & 14 & 80 & 25 & 34,19 & 56,55 & 0,65 \\
\hline 9,5 & 2,5 & 20 & 20 & 7 & 14 & 60 & 35 & 34,26 & 69,40 & 1,03 \\
\hline
\end{tabular}

Os resultados obtidos estão apresentados na tabela 5.20 de forma resumida através da variação do coeficiente multiplicador $\alpha$ em porcentagem em função dos parâmetros analisados. Para melhor visualização, os dados desta tabela estão apresentados nas figuras 5.9 e 5.10.

TABELA 5.20 - Variação do coeficiente multiplicador em porcentagem

\begin{tabular}{|c|c|c|c|c|c|c|c|c|c|}
\hline & laje & $\ell$ & $\mathbf{q}$ & $\mathbf{f}_{\text {ck,vigota }}$ & $\mathbf{f}_{\text {ck,capa }}$ & $\mathbf{t}_{1}$ & $\mathbf{t}_{2}$ & $\mathbf{U}$ & $\mathbf{T}$ \\
\hline \multirow{5}{*}{ 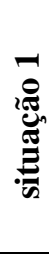 } & LT12 & 368,3 & 65,5 & 0,6 & 1,0 & 1,4 & 6,2 & 28,3 & 4,8 \\
\hline & LT16 & 411,5 & 66,8 & 0,4 & 3,1 & 1,0 & 8,7 & 31,0 & 6,4 \\
\hline & LT20 & 270,6 & 70,5 & 1,8 & 0,9 & 2,9 & 6,3 & 30,0 & 7,1 \\
\hline & LT25 & 294,1 & 44,4 & 1,1 & 2,7 & 0,1 & 6,2 & 29,5 & 10,8 \\
\hline & LT30 & 229,3 & 33,4 & 0,0 & 4,1 & 1,5 & 7,6 & 28,7 & 11,8 \\
\hline \multirow{5}{*}{ 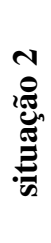 } & LT12 & 351,2 & 20,9 & 0,9 & 1,1 & 0,2 & 6,1 & 28,3 & 5,3 \\
\hline & LT16 & 276,8 & 17,0 & 1,0 & 3,4 & 1,6 & 9,5 & 29,6 & 6,8 \\
\hline & LT20 & 398,6 & 15,3 & 0,1 & 3,7 & 1,0 & 9,4 & 29,3 & 8,1 \\
\hline & LT25 & 206,6 & 11,5 & 0,2 & 4,6 & 1,3 & 9,2 & 28,9 & 11,1 \\
\hline & LT30 & 294,9 & 11,3 & 0,3 & 4,3 & 1,0 & 8,0 & 28,7 & 11,8 \\
\hline
\end{tabular}




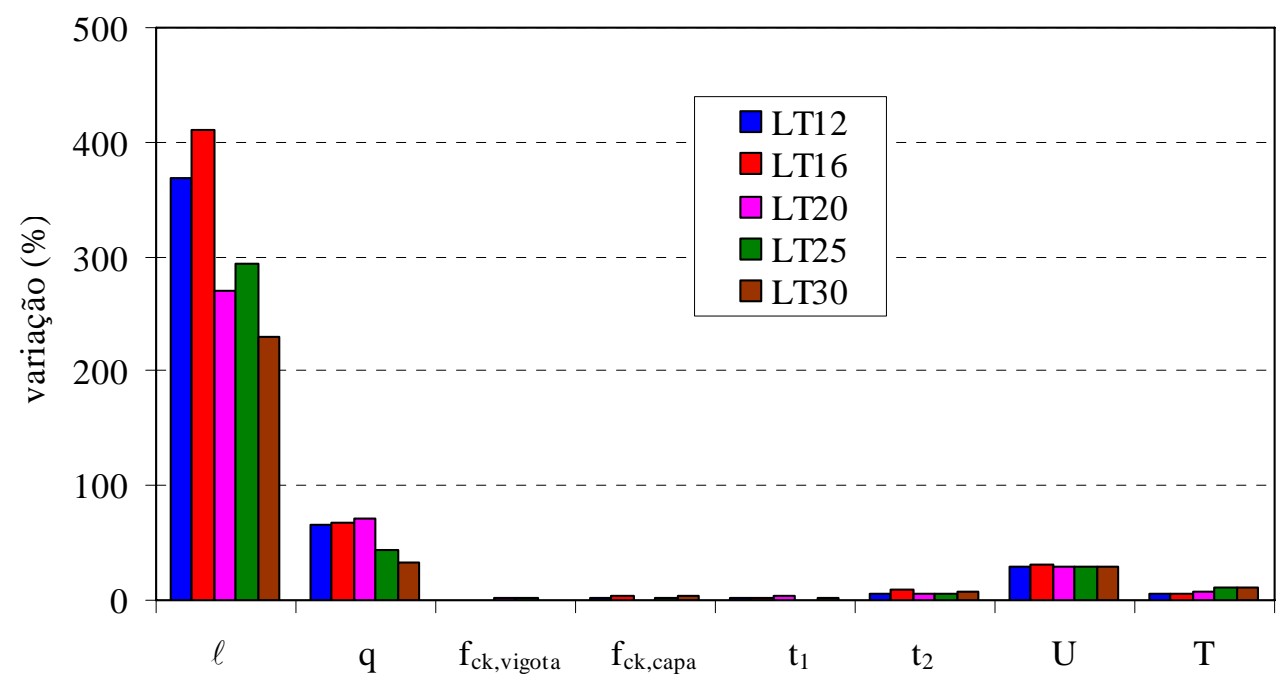

FIGURA 5.9 - Variação do coeficiente multiplicador para a situação 1

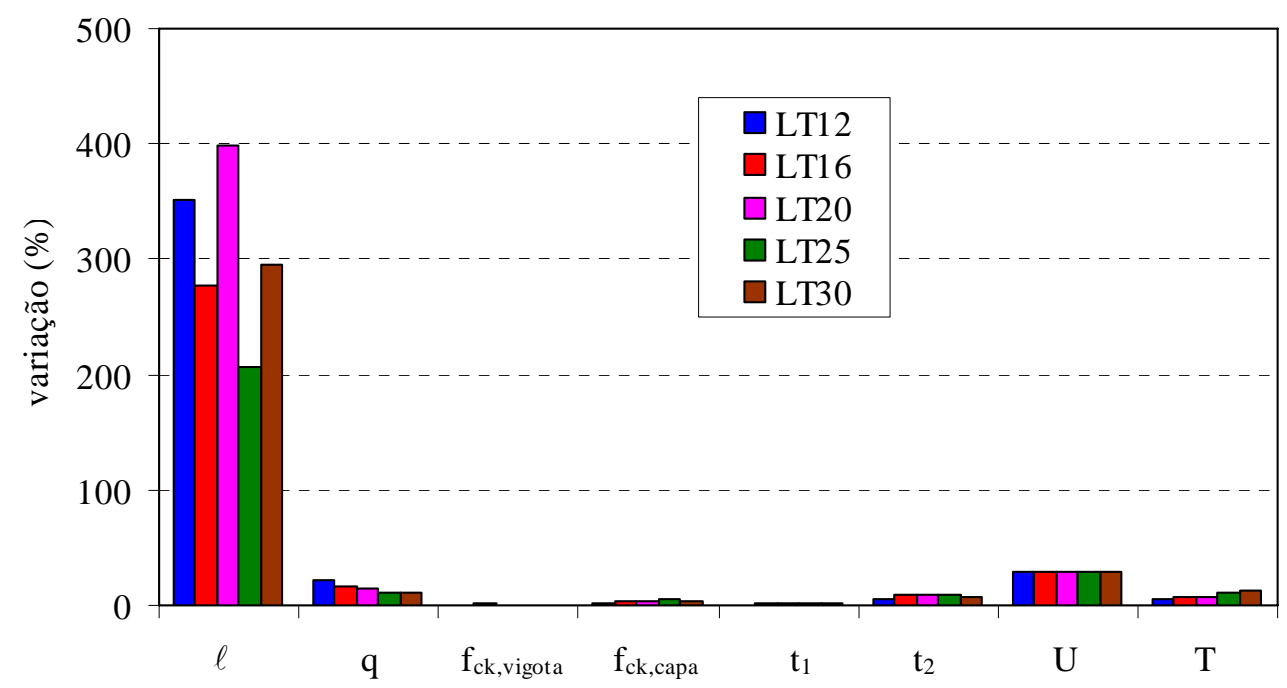

FIGURA 5.10 - Variação do coeficiente multiplicador para a situação 2

Pelas figuras 5.9 e 5.10, pode-se observar que os parâmetros que mais influenciaram o coeficiente multiplicador $\alpha$ foram o vão da laje $(\ell)$ e a carga acidental aplicada (q).

Na realidade, o que se pôde observar, é que tanto o carregamento aplicado quanto a altura e o vão da laje, assim como a armadura utilizada são parâmetros dependentes entre si, ou seja, tem pouco sentido prático considerar uma laje com 5,5 m de vão e sujeita a carga acidental de $2,5 \mathrm{kN} / \mathrm{m}^{2}$ sendo construída com altura de $30 \mathrm{~cm}$ e 3 barras adicionais de 12,5 mm de diâmetro, como foi o caso da situação 2 da laje LT30. E mesmo que isso acontecesse na prática, as flechas obtidas 
seriam muito pequenas. Portanto, o melhor seria desconsiderar esses dois parâmetros e apenas considerar os demais, como apresentados nas figuras 5.11 e 5.12 .

Pelas figuras 5.11 e 5.12, nota-se que a umidade relativa do ambiente (U) influenciou mais significativamente o coeficiente multiplicador $\alpha$, seguido da temperatura ambiente (T) e do tempo em que a laje fica escorada $\left(\mathbf{t}_{2}\right)$. E como a variação no valor da temperatura poderia ter sido ainda maior que aquele considerado $\left(25^{\circ} \mathrm{C}\right.$ a $\left.35^{\circ} \mathrm{C}\right)$, conclui-se que os parâmetros que mais influenciaram o coeficiente multiplicador foram a umidade relativa e a temperatura ambiente.

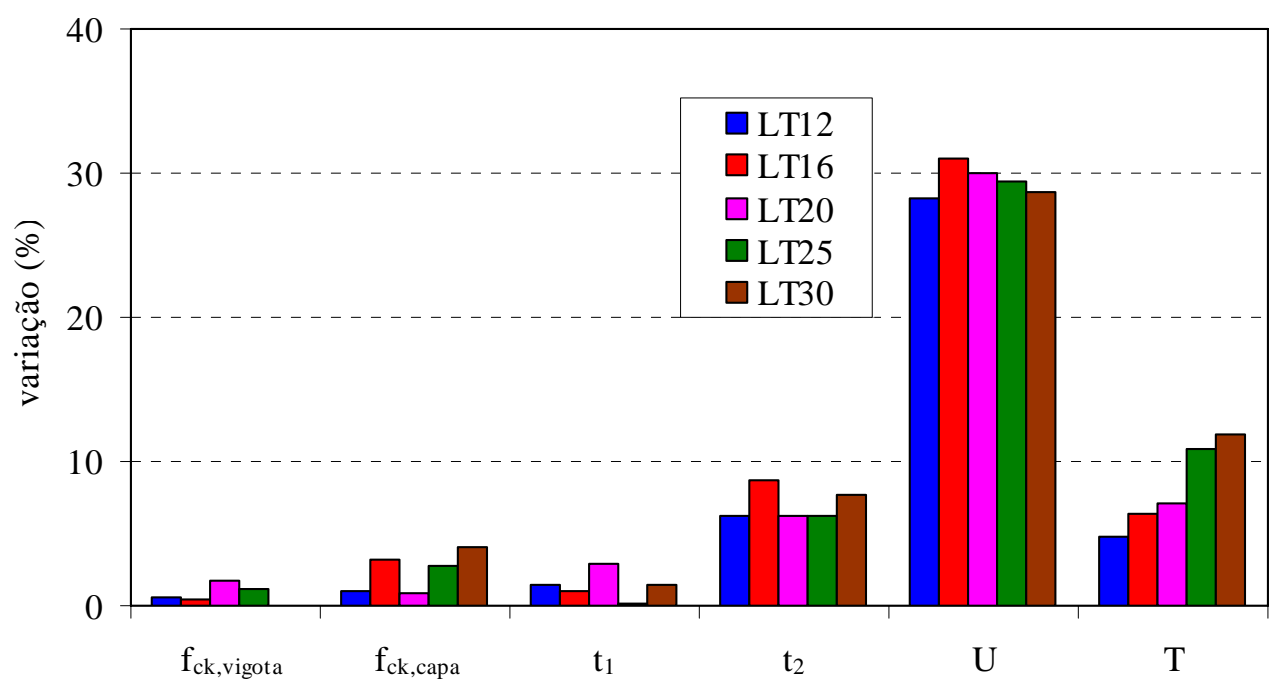

FIGURA 5.11 - Variação do coeficiente multiplicador para a situação 1

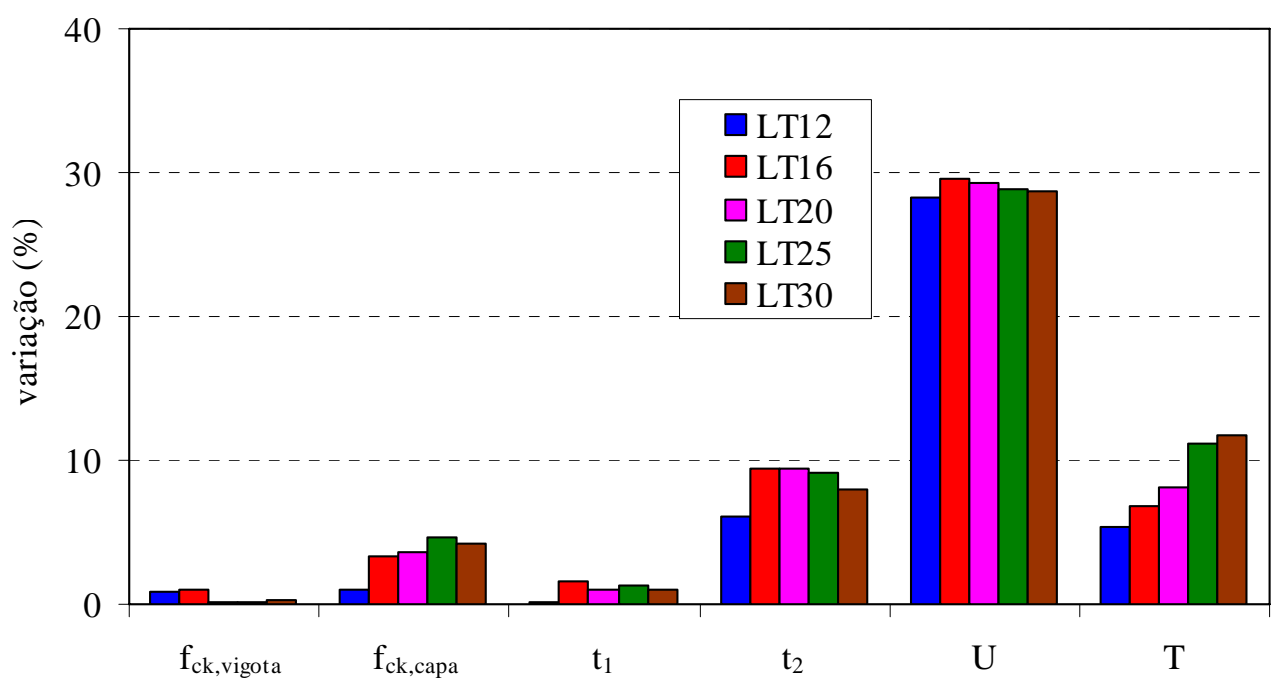

FIGURA 5.12 - Variação do coeficiente multiplicador para a situação 2 


\subsection{Análise determinística}

Como visto no item anterior, os parâmetros que mais influenciaram o coeficiente multiplicador $\alpha$ foram a umidade relativa do ambiente, a temperatura ambiente e o tempo em que a laje fica escorada. No entanto, como também se pôde notar, o vão e altura da laje, assim como o carregamento aplicado e a armadura utilizada, podem influenciar de forma significativa o coeficiente multiplicador, para casos sem sentido prático.

Por isso, foi analisado inicialmente cada tipo de laje variando a carga acidental de $1,0 \mathrm{kN} / \mathrm{m}^{2}$ a $6,0 \mathrm{kN} / \mathrm{m}^{2}$ e considerando-se vãos e armaduras adicionais compatíveis, mantendo-se os demais parâmetros constantes. A partir desta análise, definiu-se um coeficiente multiplicador básico $\alpha_{\text {básico }}$, em seguida foi realizada a análise para considerar a influência da umidade relativa e temperatura ambiente, através do coeficiente $\alpha_{\mathrm{U}, \mathrm{T}}$.

\subsubsection{Coeficiente multiplicador básico}

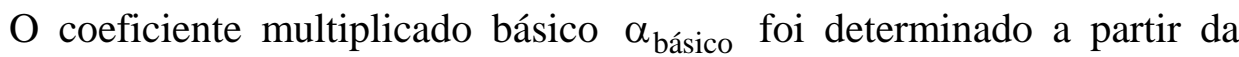
análise de 394 casos, sendo 63 referentes à laje LT12, 79 referentes à laje LT16, 80 referentes à laje LT20, 80 referentes à laje LT25 e 92 referentes à laje LT30, como mostrados respectivamente nas tabelas 5.21, 5.22, 5.23, 5.24 e 5.25. Esta análise foi realizada mantendo-se constante a resistência característica à compressão do concreto da vigota (20 MPa), a resistência característica à compressão do concreto da capa (20 MPa), a idade da concretagem da capa (7 dias), o tempo em que a laje permaneceu escorada (14 dias), a umidade relativa (60\%) e a temperatura ambiente $\left(25^{\circ} \mathrm{C}\right)$.

As demais características e considerações empregadas nesta análise são idênticas às adotadas na análise preliminar desenvolvido anteriormente. 
TABELA 5.21 - Casos analisados para a laje LT12

\begin{tabular}{|c|c|c|c|c|c|c|}
\hline \multirow{3}{*}{$\ell(\mathrm{m})$} & \multicolumn{6}{|c|}{ armadura adicional $A_{\text {s,adic }}\left(\mathrm{cm}^{2}\right)$} \\
\hline & \multicolumn{6}{|c|}{$q\left(\mathrm{kN} / \mathrm{m}^{2}\right)$} \\
\hline & 1,0 & 2,0 & 3,0 & 4,0 & 5,0 & 6,0 \\
\hline \multirow{4}{*}{4,5} & 0,90 & 1,50 & & & & \\
\hline & 1,10 & 1,75 & & & & \\
\hline & 1,30 & 2,10 & & & & \\
\hline & 1,50 & 2,35 & & & & \\
\hline \multirow{4}{*}{4,0} & 0,60 & 0,90 & 1,50 & & & \\
\hline & 0,75 & 1,10 & 1,75 & & & \\
\hline & 0,85 & 1,30 & 2,10 & & & \\
\hline & 1,00 & 1,50 & 2,35 & & & \\
\hline \multirow{4}{*}{3,5} & 0,40 & 0,60 & 1,00 & 1,50 & 1,50 & \\
\hline & 0,45 & 0,75 & 1,15 & 1,75 & 1,75 & \\
\hline & 0,55 & 0,85 & 1,35 & 2,10 & 2,10 & \\
\hline & 0,60 & 1,00 & 1,50 & 2,35 & 2,35 & \\
\hline \multirow{4}{*}{3,0} & \multirow{4}{*}{$\begin{array}{l}0,20 \\
0,25 \\
0,30\end{array}$} & 0,40 & 0,60 & 0,80 & 1,00 & 1,50 \\
\hline & & 0,45 & 0,75 & 0,85 & 1,15 & 1,75 \\
\hline & & 0,55 & 0,85 & 0,95 & 1,35 & 2,10 \\
\hline & & 0,60 & 1,00 & 1,00 & 1,50 & 2,35 \\
\hline
\end{tabular}

TABELA 5.22 - Casos analisados para a laje LT16

\begin{tabular}{|c|c|c|c|c|c|c|}
\hline \multirow{3}{*}{$\ell(\mathbf{m})$} & \multicolumn{6}{|c|}{ armadura adicional $A_{\text {s,adic }}\left(\mathrm{cm}^{2}\right)$} \\
\hline & \multicolumn{6}{|c|}{$q\left(k N / m^{2}\right)$} \\
\hline & 1,0 & 2,0 & 3,0 & 4,0 & 5,0 & 6,0 \\
\hline \multirow{4}{*}{6,0} & 1,20 & 1,50 & & & & \\
\hline & 1,60 & 1,75 & & & & \\
\hline & 1,95 & 2,10 & & & & \\
\hline & 2,35 & 2,35 & & & & \\
\hline \multirow{4}{*}{5,5} & 0,90 & 1,50 & 2,35 & & & \\
\hline & 1,10 & 1,75 & 2,80 & & & \\
\hline & 1,30 & 2,10 & 3,25 & & & \\
\hline & 1,50 & 2,35 & 3,68 & & & \\
\hline \multirow{4}{*}{5,0} & 0,60 & 1,00 & 1,50 & 2,35 & & \\
\hline & 0,75 & 1,15 & 1,75 & 2,80 & & \\
\hline & 0,85 & 1,35 & 2,10 & 3,25 & & \\
\hline & 1,00 & 1,50 & 2,35 & 3,68 & & \\
\hline \multirow{4}{*}{4,5} & 0,40 & 0,80 & 1,20 & 1,50 & 2,35 & \\
\hline & 0,45 & 0,85 & 1,60 & 1,75 & 2,80 & \\
\hline & 0,55 & 0,95 & 1,95 & 2,10 & 3,25 & \\
\hline & 0,60 & 1,00 & 2,35 & 2,35 & 3,68 & \\
\hline \multirow{4}{*}{4,0} & \multirow{4}{*}{$\begin{array}{l}0,20 \\
0,25 \\
0,30\end{array}$} & 0,40 & 0,80 & 1,00 & 1,20 & 1,50 \\
\hline & & 0,45 & 0,85 & 1,15 & 1,60 & 1,75 \\
\hline & & 0,55 & 0,95 & 1,35 & 1,95 & 2,10 \\
\hline & & 0,60 & 1,00 & 1,50 & 2,35 & 2,35 \\
\hline
\end{tabular}


TABELA 5.23 - Casos analisados para a laje LT20

\begin{tabular}{|c|c|c|c|c|c|c|}
\hline \multirow{3}{*}{$\ell(\mathrm{m})$} & \multicolumn{6}{|c|}{ armadura adicional $A_{\text {s,adic }}\left(\mathrm{cm}^{2}\right)$} \\
\hline & \multicolumn{6}{|c|}{$q\left(\mathrm{kN} / \mathrm{m}^{2}\right)$} \\
\hline & 1,0 & 2,0 & 3,0 & 4,0 & 5,0 & 6,0 \\
\hline \multirow{4}{*}{7,0} & 1,50 & 2,35 & & & & \\
\hline & 1,75 & 2,80 & & & & \\
\hline & 2,10 & 3,25 & & & & \\
\hline & 2,35 & 3,68 & & & & \\
\hline \multirow{4}{*}{6,5} & 1,00 & 1,60 & 2,35 & & & \\
\hline & 1,15 & 1,90 & 2,80 & & & \\
\hline & 1,35 & 2,15 & 3,25 & & & \\
\hline & 1,50 & 2,45 & 3,68 & & & \\
\hline \multirow{4}{*}{6,0} & 0,90 & 1,20 & 2,35 & 2,35 & & \\
\hline & 1,10 & 1,60 & 2,80 & 2,80 & & \\
\hline & 1,30 & 1,95 & 3,25 & 3,25 & & \\
\hline & 1,50 & 2,35 & 3,68 & 3,68 & & \\
\hline \multirow{4}{*}{5,5} & 0,60 & 1,00 & 1,50 & 2,35 & 2,35 & \\
\hline & 0,75 & 1,15 & 1,75 & 2,80 & 2,80 & \\
\hline & 0,85 & 1,35 & 2,10 & 3,25 & 3,25 & \\
\hline & 1,00 & 1,50 & 2,35 & 3,68 & 3,68 & \\
\hline \multirow{4}{*}{5,0} & 0,40 & 0,60 & 1,00 & 1,50 & 2,35 & 2,35 \\
\hline & 0,45 & 0,75 & 1,15 & 1,75 & 2,80 & 2,80 \\
\hline & 0,55 & 0,85 & 1,35 & 2,10 & 3,25 & 3,25 \\
\hline & 0,60 & 1,00 & 1,50 & 2,35 & 3,68 & 3,68 \\
\hline
\end{tabular}

TABELA 5.24 - Casos analisados para a laje LT25

\begin{tabular}{|c|c|c|c|c|c|c|}
\hline \multirow{3}{*}{$\ell(\mathbf{m})$} & \multicolumn{6}{|c|}{ armadura adicional $A_{\text {s,adic }}\left(\mathrm{cm}^{2}\right)$} \\
\hline & \multicolumn{6}{|c|}{$q\left(\mathrm{kN} / \mathrm{m}^{2}\right)$} \\
\hline & 1,0 & 2,0 & 3,0 & 4,0 & 5,0 & 6,0 \\
\hline \multirow{4}{*}{8,5} & 1,60 & 2,35 & & & & \\
\hline & 1,90 & 2,80 & & & & \\
\hline & 2,15 & 3,25 & & & & \\
\hline & 2,45 & 3,68 & & & & \\
\hline \multirow{4}{*}{8,0} & 1,50 & 2,35 & 3,68 & & & \\
\hline & 1,75 & 2,80 & 4,00 & & & \\
\hline & 2,10 & 3,25 & 4,50 & & & \\
\hline & 2,35 & 3,68 & 4,90 & & & \\
\hline \multirow{4}{*}{7,5} & 1,20 & 1,60 & 2,35 & 3,68 & & \\
\hline & 1,60 & 1,90 & 2,80 & 4,00 & & \\
\hline & 1,95 & 2,15 & 3,25 & 4,50 & & \\
\hline & 2,35 & 2,45 & 3,68 & 4,90 & & \\
\hline \multirow{4}{*}{7,0} & 1,00 & 1,50 & 2,35 & 2,35 & 3,68 & \\
\hline & 1,15 & 1,75 & 2,80 & 2,80 & 4,00 & \\
\hline & 1,35 & 2,10 & 3,25 & 3,25 & 4,50 & \\
\hline & 1,50 & 2,35 & 3,68 & 3,68 & 4,90 & \\
\hline \multirow{4}{*}{6,5} & 0,80 & 1,00 & 1,50 & 2,35 & 2,35 & 3,68 \\
\hline & 0,85 & 1,15 & 1,75 & 2,80 & 2,80 & 4,00 \\
\hline & 0,95 & 1,35 & 2,10 & 3,25 & 3,25 & 4,50 \\
\hline & 1,00 & 1,50 & 2,35 & 3,68 & 3,68 & 4,90 \\
\hline
\end{tabular}


TABELA 5.25 - Casos analisados para a laje LT30

\begin{tabular}{|c|c|c|c|c|c|c|}
\hline \multirow{3}{*}{$\ell(\mathbf{m})$} & \multicolumn{6}{|c|}{ armadura adicional $A_{s, \text { adic }}\left(\mathrm{cm}^{2}\right)$} \\
\hline & \multicolumn{6}{|c|}{$q\left(\mathbf{k N} / \mathbf{m}^{2}\right)$} \\
\hline & 1,0 & 2,0 & 3,0 & 4,0 & 5,0 & 6,0 \\
\hline \multirow{4}{*}{9,5} & 2,35 & 3,68 & 3,68 & & & \\
\hline & 2,80 & 4,00 & 4,00 & & & \\
\hline & 3,25 & 4,50 & 4,50 & & & \\
\hline & 3,68 & 4,90 & 4,90 & & & \\
\hline \multirow{4}{*}{9,0} & 1,60 & 2,35 & 3,68 & 3,68 & & \\
\hline & 1,90 & 2,80 & 4,00 & 4,00 & & \\
\hline & 2,15 & 3,25 & 4,50 & 4,50 & & \\
\hline & 2,45 & 3,68 & 4,90 & 4,90 & & \\
\hline \multirow{4}{*}{8,5} & 1,50 & 2,35 & 2,35 & 3,68 & 3,68 & \\
\hline & 1,75 & 2,80 & 2,80 & 4,00 & 4,00 & \\
\hline & 2,10 & 3,25 & 3,25 & 4,50 & 4,50 & \\
\hline & 2,35 & 3,68 & 3,68 & 4,90 & 4,90 & \\
\hline \multirow{4}{*}{8,0} & 1,20 & 1,60 & 2,35 & 3,68 & 3,68 & \\
\hline & 1,60 & 1,90 & 2,80 & 4,00 & 4,00 & \\
\hline & 1,95 & 2,15 & 3,25 & 4,50 & 4,50 & \\
\hline & 2,35 & 2,45 & 3,68 & 4,90 & 4,90 & \\
\hline \multirow{4}{*}{7,5} & 0,90 & 1,50 & 2,35 & 2,35 & 3,68 & 3,68 \\
\hline & 1,10 & 1,75 & 2,80 & 2,80 & 4,00 & 4,00 \\
\hline & 1,30 & 2,10 & 3,25 & 3,25 & 4,50 & 4,50 \\
\hline & 1,50 & 2,35 & 3,68 & 3,68 & 4,90 & 4,90 \\
\hline
\end{tabular}

Para desenvolver um coeficiente multiplicador básico que levasse em consideração a variação do vão e altura da laje, o carregamento aplicado e a armadura utilizada, foi criado um coeficiente denominado de $\kappa$ que englobou esses quatro parâmetros. A preocupação com a criação do coeficiente $\kappa$ foi conseguir agrupar os valores dos coeficientes multiplicadores, diminuindo, assim, a sua dispersão, para poder realizar uma regressão dos valores com maior correlação possível. Isso foi realizado partindo-se da multiplicação do índice de esbeltez do elemento $\mathrm{h} / \ell$ e do coeficiente de dimensionamento $\mathrm{k}_{\mathrm{s}}$ dado por:

$$
\mathrm{k}_{\mathrm{s}}=\frac{\mathrm{A}_{\mathrm{s}} \cdot \mathrm{d}}{\mathrm{M}_{\mathrm{d}}}=8 \cdot \frac{\mathrm{A}_{\mathrm{s}} \cdot \mathrm{d}}{\mathrm{p} \cdot \ell^{2}}
$$

A partir disso, por tentativas, chegou-se no seguinte coeficiente $\kappa$ :

$$
\kappa=\frac{\mathrm{A}_{\mathrm{S}} \cdot \mathrm{h}^{2,05}}{\mathrm{p}^{1,5} \cdot \ell^{3}} \cdot 10^{3}
$$


onde:

$\mathrm{A}_{\mathrm{s}} \quad$ - armadura $\left[\mathrm{cm}^{2}\right]$;

h $\quad$ - altura da laje [m];

p - carregamento aplicado $[\mathrm{kN} / \mathrm{m}]$;

$\ell \quad$ - vão da laje [m].

Os resultados obtidos desta análise estão apresentados no Apêndice A, mas podem ser vistos na figura 5.13. Apresenta-se nesta figura o coeficiente multiplicador $\alpha$, encontrado para cada caso, em função do coeficiente $\kappa$.

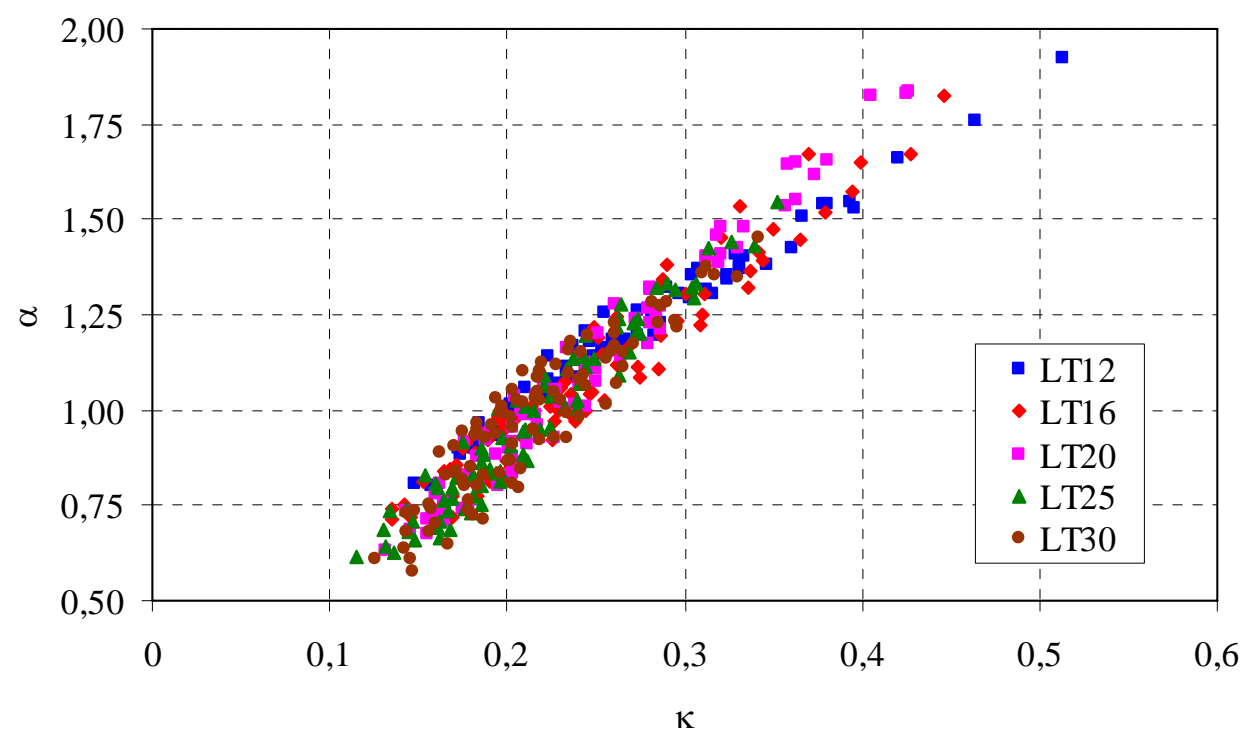

FIGURA 5.13 - Coeficiente multiplicador

E assim, como mostrado na figura 5.14, obteve-se a seguinte expressão para o coeficiente multiplicador básico, através de regressão linear dos resultados obtidos.

$$
\begin{aligned}
& \alpha_{\text {básico }}=3,73 . \kappa+0,18 \\
& \text { com }
\end{aligned}
$$

$$
\mathrm{R}^{2}=0,93
$$

A expressão desenvolvida para o coeficiente multiplicador básico $\alpha_{\text {básico }}$ se aplica às lajes comumente utilizadas na construção civil, como mostradas nas 
tabelas 5.21, 5.22, 5.23, 5.24 e 5.25. Isso equivale a lajes com valores do coeficiente $\kappa$ variando entre 0,10 e 0,55 .

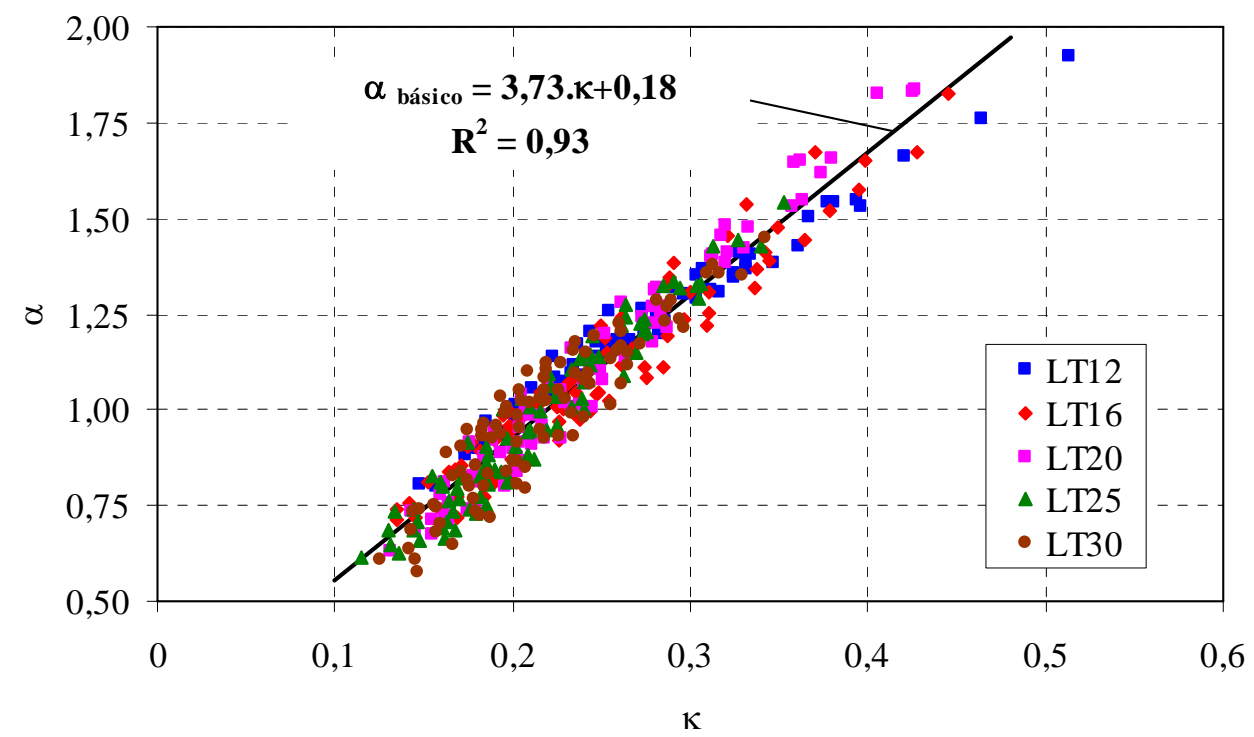

FIGURA 5.14 - Regressão linear dos resultados

Por definição, resíduo da regressão é a diferença entre os valores observados e os valores estimados. Para a análise em questão, o resíduo da regressão em função do coeficiente $\kappa$ está apresentado na figura 5.15. Por essa figura, pode-se notar que o resíduo variou entre $-0,17$ e $+0,14$ e não houve tendência no espalhamento.

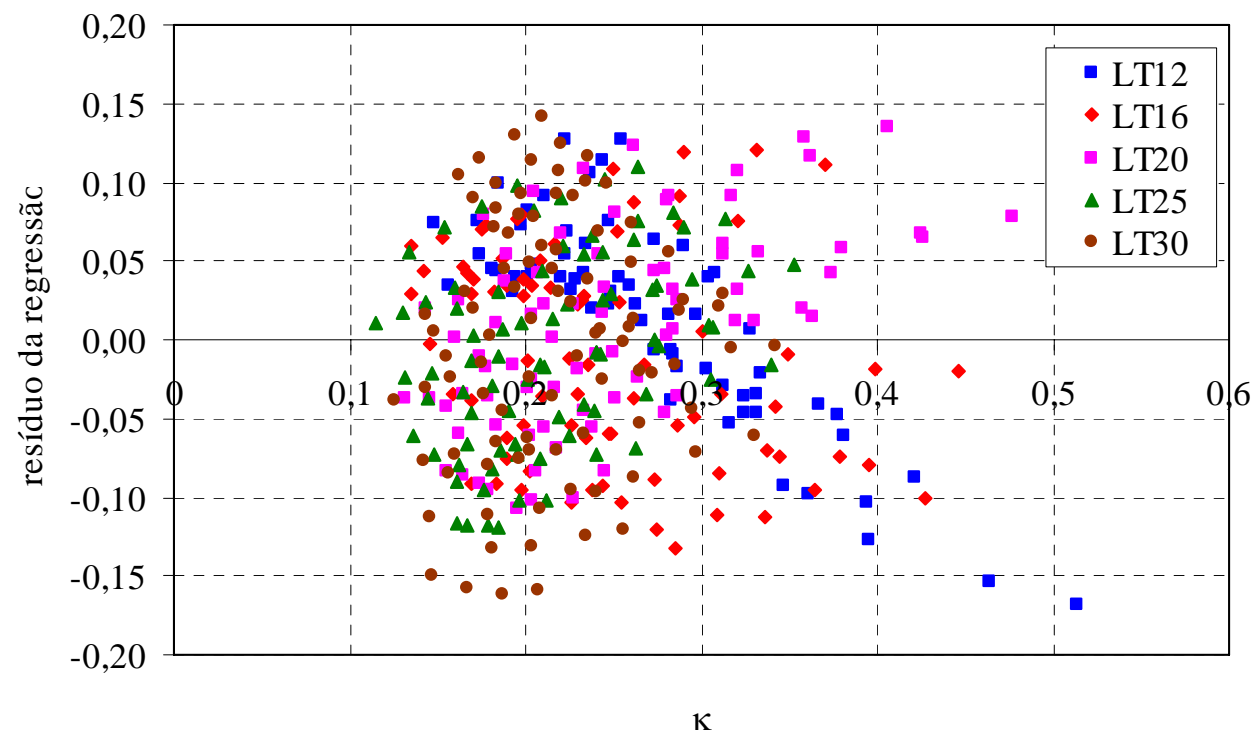

FIGURA 5.15 - Resíduo da regressão 
Nas figuras 5.16, 5.17, 5.18, 5.19 e 5.20 estão apresentados os coeficientes multiplicadores $\alpha$ em função do coeficiente $\kappa$, respectivamente, para as lajes LT12, LT16, LT20, LT25 e LT30. Apresenta-se também nas figuras o resíduo máximo obtido com a regressão. Por essas figuras, pode-se notar que o resíduo obtido com a regressão não foi função do tipo nem do vão da laje.

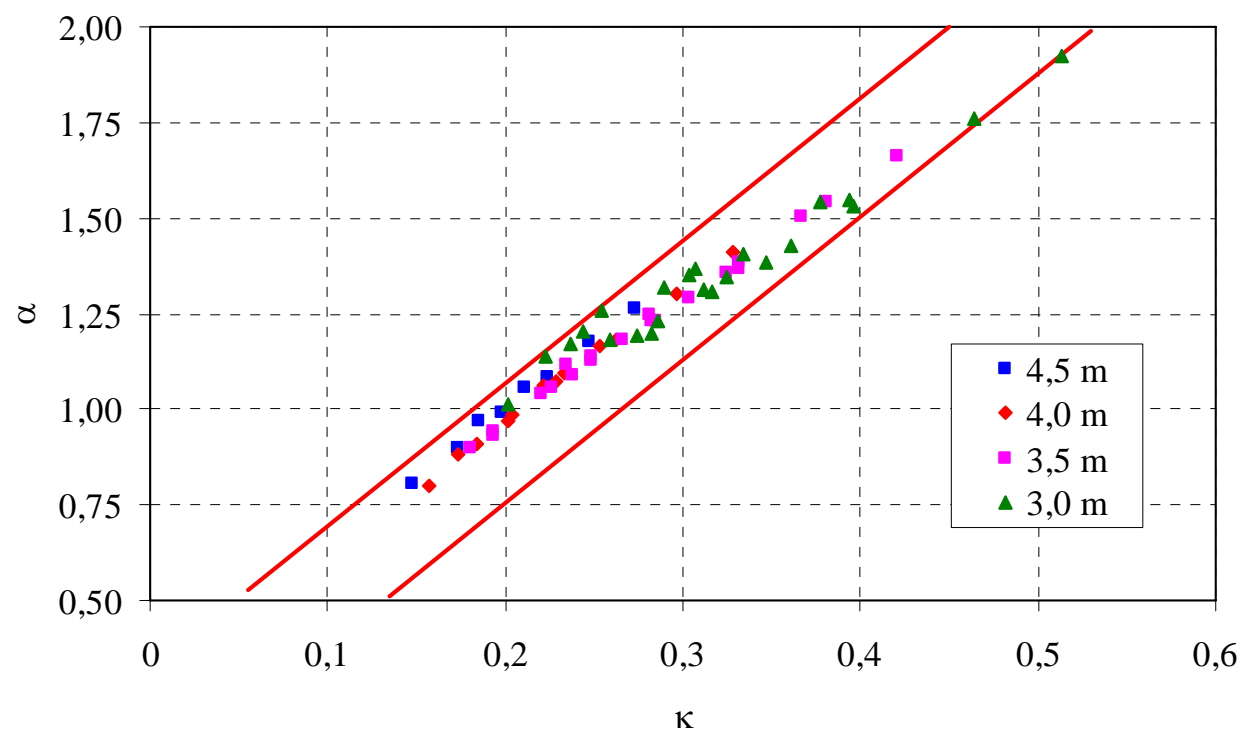

FIGURA 5.16 - Coeficiente multiplicador para a laje LT12

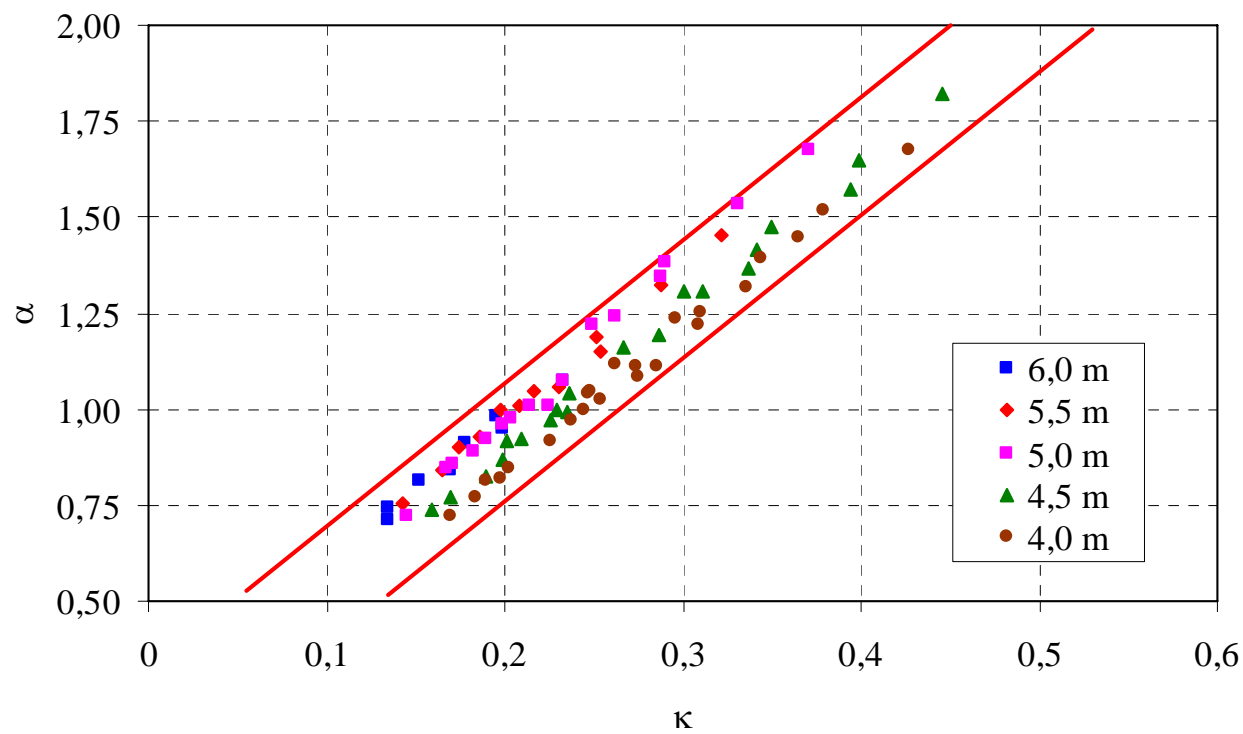

FIGURA 5.17 - Coeficiente multiplicador para a laje LT16 


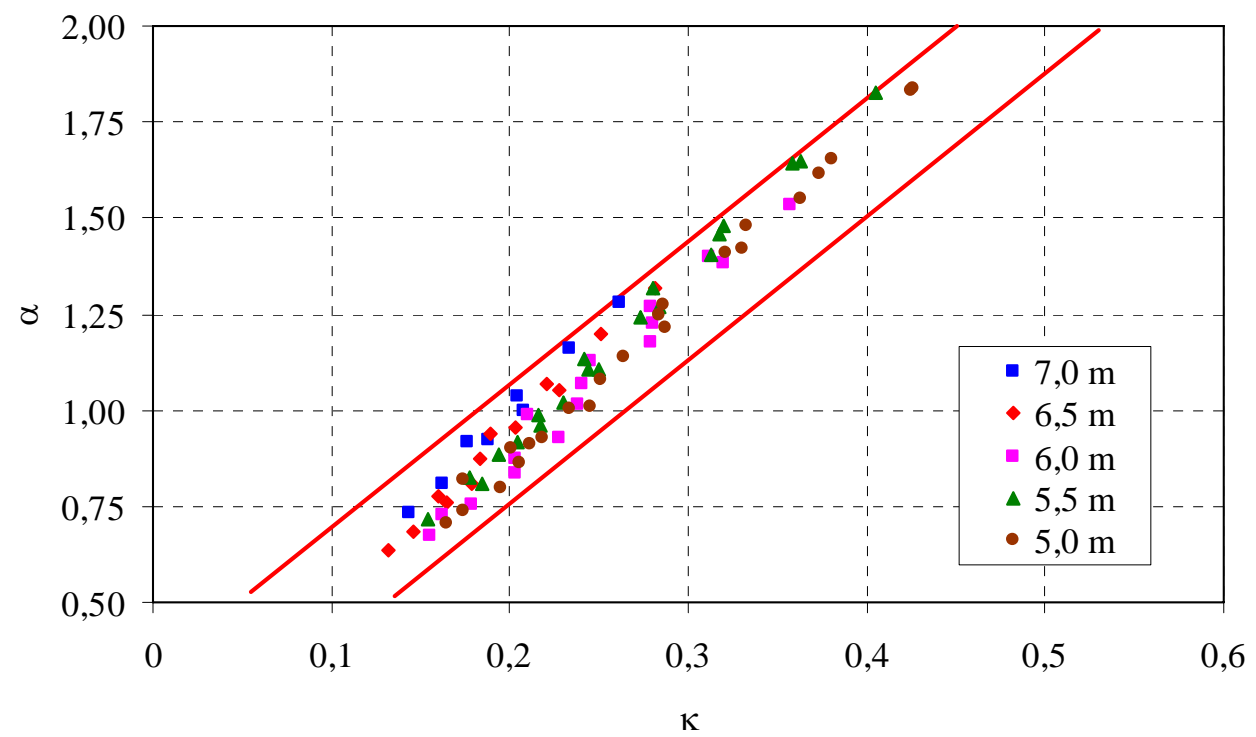

FIGURA 5.18 - Coeficiente multiplicador para a laje LT20

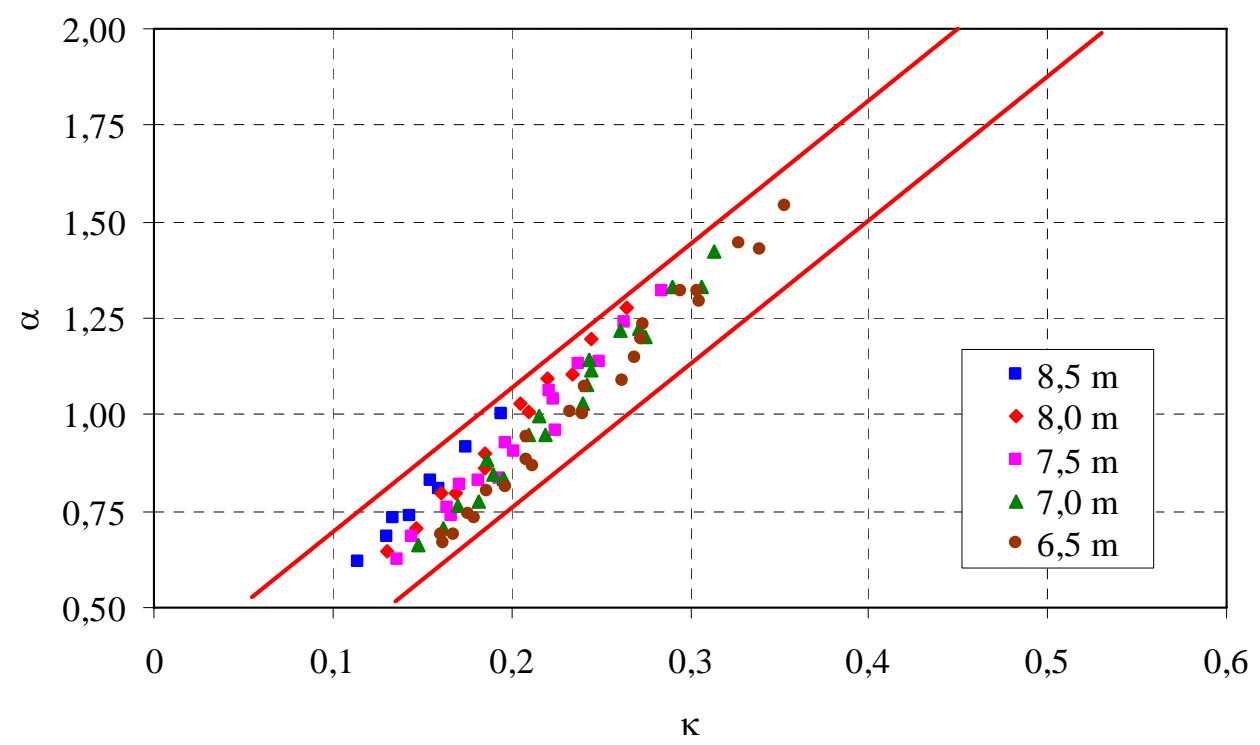

FIGURA 5.19 - Coeficiente multiplicador para a laje LT25 


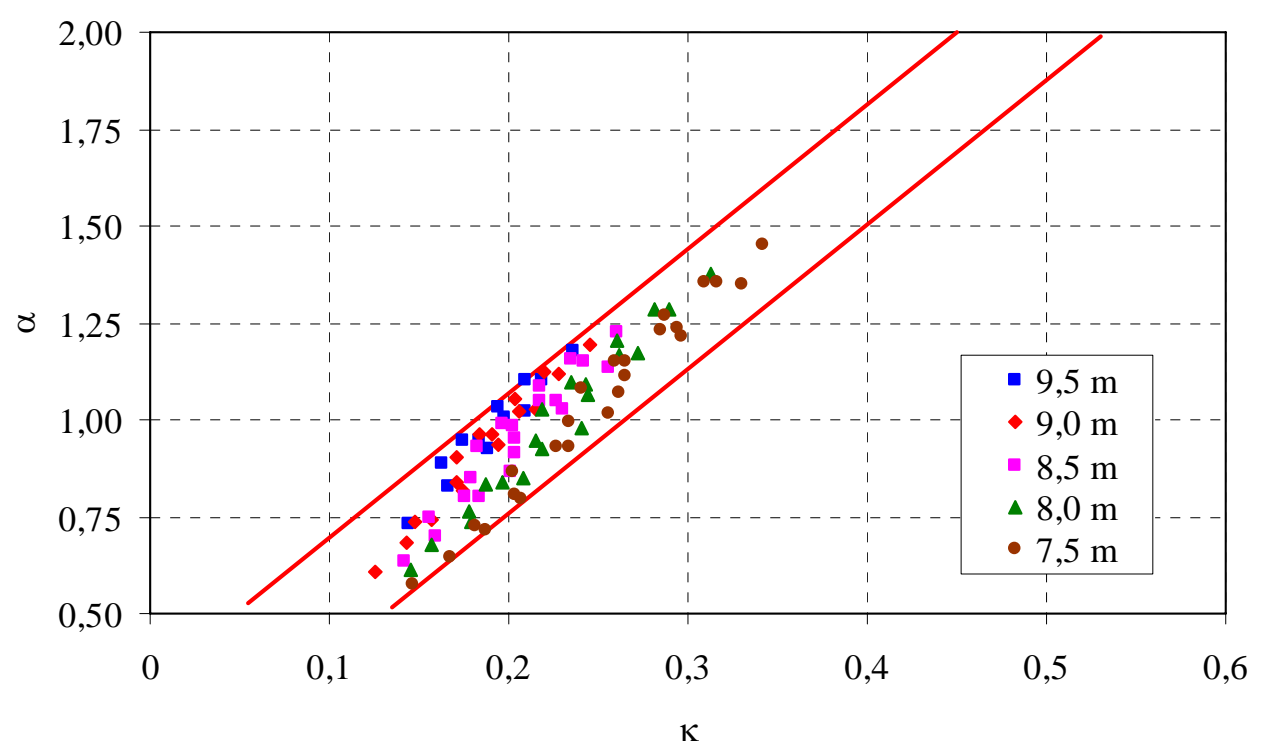

FIGURA 5.20 - Coeficiente multiplicador para a laje LT30

\subsubsection{Influência da umidade relativa e temperatura no coeficiente multiplicador}

Para averiguar a influência da umidade relativa e temperatura ambiente no coeficiente multiplicador foram analisados 31 casos, como mostrados na tabela 5.26. Esta análise foi realizada variando a umidade relativa em $40 \%, 60 \%$, $80 \%$ e a temperatura ambiente em $15^{\circ} \mathrm{C}, 25^{\circ} \mathrm{C}, 35^{\circ} \mathrm{C}$, totalizando, portanto, 279 casos.

Os demais parâmetros e considerações empregadas nesta análise foram os mesmos adotados no item anterior.

A influência da umidade relativa e temperatura ambiente foram consideradas através do coeficiente $\alpha_{\mathrm{U}, \mathrm{T}}$. Este coeficiente foi determinado dividindo o coeficiente multiplicador obtido em cada caso pelo resultado obtido para o caso com as mesmas características, mas com umidade relativa de 60\% e temperatura ambiente de $25^{\circ} \mathrm{C}$. 
TABELA 5.26 - Casos analisados para a determinação de $\alpha_{U, T}$

\begin{tabular}{|c|c|c|c|c|}
\hline \multirow{3}{*}{ laje } & \multirow{3}{*}{$\ell(\mathbf{m})$} & \multirow{2}{*}{\multicolumn{3}{|c|}{$\begin{array}{c}\text { armadura adicional } A_{s, \text { adic }}\left(\mathrm{cm}^{2}\right) \\
q\left(\mathrm{kN} / \mathrm{m}^{2}\right) \\
\end{array}$}} \\
\hline & & & & \\
\hline & & 2,0 & 4,0 & 6,0 \\
\hline \multirow{4}{*}{ LT12 } & 4,5 & 1,50 & & \\
\hline & 4,0 & 0,90 & & \\
\hline & 3,5 & 0,60 & 1,50 & \\
\hline & 3,0 & 0,40 & 0,80 & 1,50 \\
\hline \multirow{3}{*}{ LT16 } & 6,0 & 1,50 & & \\
\hline & 5,0 & 1,00 & 2,35 & \\
\hline & 4,0 & 0,40 & 1,00 & 1,50 \\
\hline \multirow{3}{*}{ LT20 } & 7,0 & 2,35 & & \\
\hline & 6,0 & 1,20 & 2,35 & \\
\hline & 5,0 & 0,60 & 1,50 & 2,35 \\
\hline \multirow{3}{*}{ LT25 } & 8,5 & 2,35 & & \\
\hline & 7,5 & 1,60 & 3,68 & \\
\hline & 6,5 & 1,00 & 2,35 & 3,68 \\
\hline \multirow{3}{*}{ LT30 } & 9,5 & 3,68 & & \\
\hline & 8,5 & 2,35 & 3,68 & \\
\hline & 7,5 & 1,50 & 2,35 & 3,68 \\
\hline
\end{tabular}

Os resultados obtidos estão apresentados no Apêndice B, mas podem ser vistos na figura 5.21, que mostra o coeficiente $\alpha_{U, T}$, encontrado para cada caso, em função da umidade relativa e temperatura ambiente.

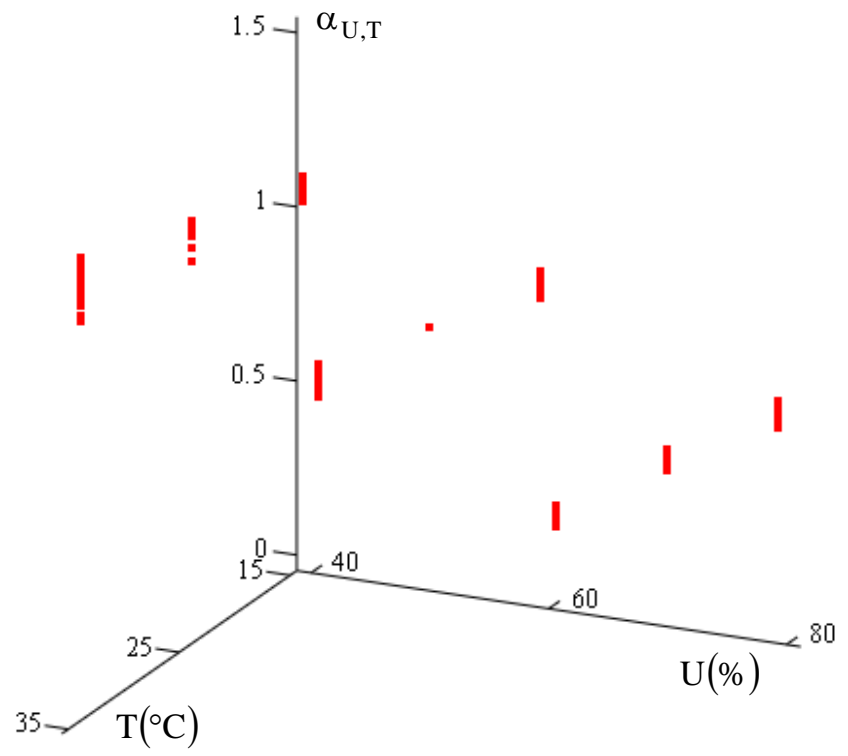

FIGURA 5.21 - Coeficiente $\alpha_{U, T}$ 
Através de regressão não-linear dos valores obtidos, como mostrado na figura 5.22, obteve-se a seguinte expressão para o coeficiente $\alpha_{\mathrm{U}, \mathrm{T}}$.

$$
\begin{aligned}
& \alpha_{\mathrm{U}, \mathrm{T}}=0,016 \cdot \mathrm{T}+4,9 \cdot 10^{-3} \cdot \mathrm{U}-2,7 \cdot 10^{-5} \cdot \mathrm{T} . \mathrm{U}- \\
& -1,03 \cdot 10^{-4} \cdot \mathrm{T}^{2}-1,32 \cdot 10^{-4} \cdot \mathrm{U}^{2}+0,90 \\
& \text { com } \\
& \mathrm{R}^{2}=0,99
\end{aligned}
$$

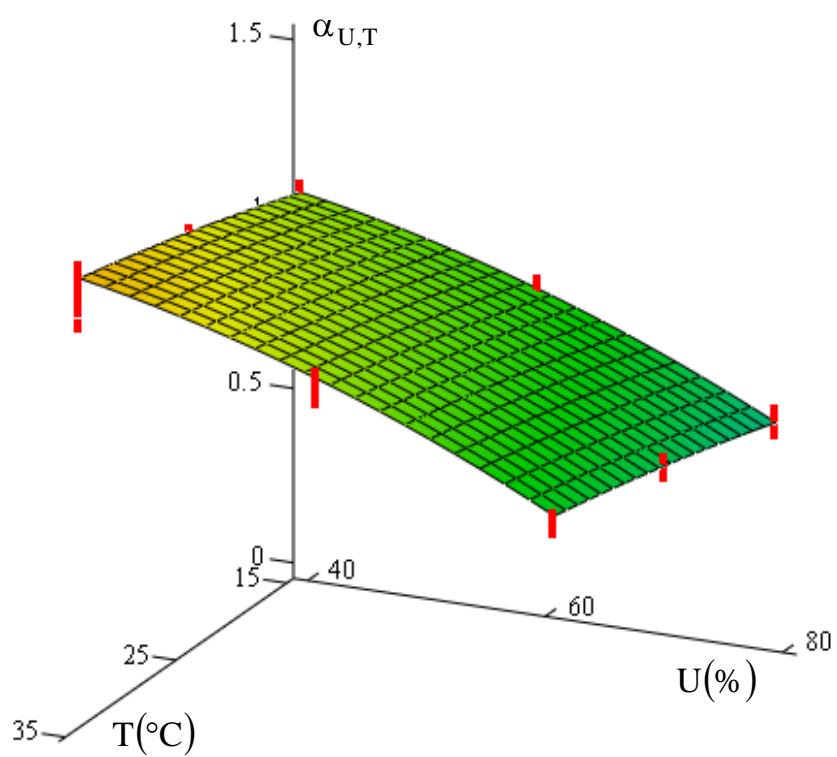

FIGURA 5.22 - Regressão não-linear do coeficiente $\alpha_{U, T}$

E, como mostrado na figura 5.23, obteve-se a seguinte expressão para o coeficiente $\alpha_{\mathrm{U}, \mathrm{T}}$, através de regressão linear dos resultados obtidos.

$\alpha_{\mathrm{U}, \mathrm{T}}=8,8 \cdot 10^{-3} . \mathrm{T}-0,012 . \mathrm{U}+1,43$

com

$\mathrm{R}^{2}=0,97$ 


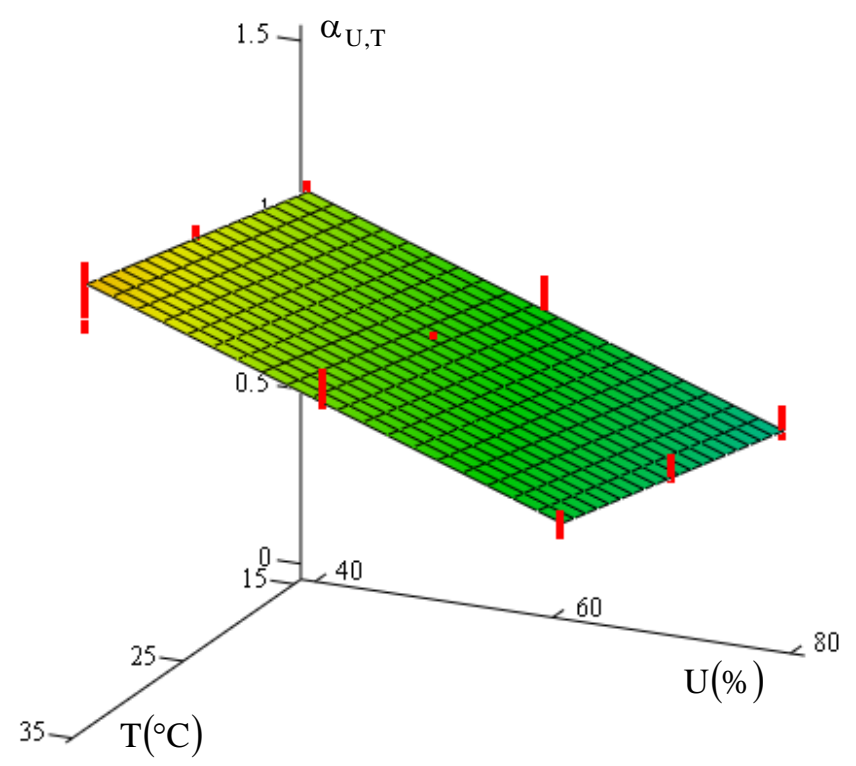

FIGURA 5.23 - Regressão linear do coeficiente $\alpha_{\mathrm{U}, \mathrm{T}}$

E assim, o coeficiente multiplicador $\alpha$ da flecha instantânea para avaliação da flecha diferida de lajes pré-moldadas formadas por vigotas com armação treliçada é determinado a partir do coeficiente multiplicador básico $\alpha_{\text {básico }}$ e do coeficiente $\alpha_{U, T}$, que considera a influência da umidade relativa e temperatura ambiente.

Ou seja,

$$
\alpha=\alpha_{\text {básico }} \cdot \alpha_{\mathrm{U}, \mathrm{T}}
$$

\section{Com}

$\alpha_{\text {básico }}=3,73 . \kappa+0,18$

sendo

$\kappa=\frac{A_{s} \cdot h^{2,05}}{p^{1,5} \cdot \ell^{3}} \cdot 10^{3}$

onde:
$\mathrm{A}_{\mathrm{S}}$ - armadura $\left[\mathrm{cm}^{2}\right]$;
h - altura da laje [m];
p - carregamento aplicado [kN/m];
$\ell \quad$ - vão da laje [m]. 
E ainda,

$$
\begin{aligned}
& \alpha_{\mathrm{U}, \mathrm{T}}=0,016 \cdot \mathrm{T}+4,9 \cdot 10^{-3} \cdot \mathrm{U}-2,7 \cdot 10^{-5} . \mathrm{T} . \mathrm{U}- \\
& -1,03 \cdot 10^{-4} \cdot T^{2}-1,32 \cdot 10^{-4} \cdot U^{2}+0,90 \\
& \text { ou } \\
& \alpha_{\mathrm{U}, \mathrm{T}}=8,8 \cdot 10^{-3} . \mathrm{T}-0,012 . \mathrm{U}+1,43 \\
& \text { onde: } \\
& \text { U - umidade relativa do ambiente [\%]; } \\
& \mathrm{T} \text { - temperatura do ambiente }\left[{ }^{\circ} \mathrm{C}\right] \text {. }
\end{aligned}
$$

\subsection{Análise probabilística}

Para determinar o coeficiente multiplicador $\alpha$, levando-se em conta a

\begin{tabular}{|c|c|c|c|c|c|c|}
\hline casos & laje & $\ell(\mathbf{m})$ & $q\left(\mathbf{k N} / \mathbf{m}^{2}\right)$ & $A_{s, \text { adic }}\left(\mathrm{cm}^{2}\right)$ & U (\%) & $\mathrm{T}\left({ }^{\circ} \mathrm{C}\right)$ \\
\hline caso 1 & LT30 & 8,5 & 4,0 & 3,68 & 40 & 35 \\
\hline caso 2 & LT20 & 5,0 & 4,0 & 1,50 & 40 & 25 \\
\hline caso 3 & LT12 & 3,5 & 4,0 & 1,50 & 40 & 15 \\
\hline caso 4 & LT30 & 8,5 & 4,0 & 3,68 & 60 & 35 \\
\hline caso 5 & LT12 & 3,5 & 2,0 & 0,60 & 60 & 15 \\
\hline caso 6 & LT30 & 9,5 & 2,0 & 3,68 & 80 & 35 \\
\hline caso 7 & LT12 & 3,0 & 2,0 & 0,40 & 80 & 25 \\
\hline caso 8 & LT12 & 3,0 & 2,0 & 0,40 & 80 & 15 \\
\hline
\end{tabular}
variabilidade estatística dos principais parâmetros, selecionou-se os casos analisados anteriormente que resultaram os maiores valores no coeficiente $\alpha_{U, T}$, comparando casos com mesma umidade relativa e temperatura ambiente. Desta seleção resultaram 8 casos, que estão apresentados na tabela 5.27. E para esses casos foi realizada a análise probabilística utilizando o método de amostragem por hipercubo latino, conforme descrito no capítulo 4. 
Os parâmetros que foram considerados como variáveis aleatórias estão listadas a seguir, totalizando 8 variáveis aleatórias para cada caso. Foi considerado ainda que essas variáveis aleatórias eram estatisticamente independentes entre si e seguiam uma distribuição normal.

$$
\begin{aligned}
& \Psi_{1, c 1} \text { - coeficiente de fluência do concreto da vigota } \\
& \Psi_{2, c 1} \text { - retração do concreto da vigota } \\
& f_{c 1} \text { - resistência do concreto da vigota } \\
& \Psi_{1, c 2} \text { - coeficiente de fluência do concreto da capa estrutural } \\
& \Psi_{2, c 2} \text { - retração do concreto da capa estrutural } \\
& f_{c 2} \text { - resistência do concreto da capa estrutural } \\
& U \text { - umidade relativa } \\
& T \text { - temperatura ambiente }
\end{aligned}
$$

As propriedades estatísticas das variáveis aleatórias, ou seja, a média $(\mu)$ e o coeficiente de variação $(V)$ estão apresentados na tabela 5.28.

TABELA 5.28 - Propriedades estatísticas das variáveis aleatórias

\begin{tabular}{ccccccccc}
\hline & $\Psi_{1, c 1}$ & $\Psi_{2, c 1}$ & $f_{c 1}$ & $\Psi_{1, c 2}$ & $\Psi_{2, c 2}$ & $f_{c 2}$ & $U$ & $T$ \\
\hline$\mu$ & - & - & $(\mathrm{MPa})$ & - & - & $(\mathrm{MPa})$ & $\%$ & ${ }^{\circ} \mathrm{C}$ \\
\hline$(\%)$ & 1,0 & 1,0 & 20 & 1,0 & 1,0 & 20 & $\begin{array}{c}\text { conforme } \\
\text { tabela 5.27 }\end{array}$ & $\begin{array}{c}\text { conforme } \\
\text { tabela 5.27 }\end{array}$ \\
\hline
\end{tabular}

O total de simulações realizadas para cada caso foi igual a 100. Preferiuse aumentar o número de simulações para melhorar a precisão da resposta. Para ilustrar a diferença que pode ocorrer com o aumento do número de simulações, apresenta-se na figura 5.24 a distribuição uniforme no quadrado unitário dos pares utilizados para calcular os valores das resistências mostradas na figura 5.25. Por essas figuras, pode-se perceber que, com o aumento do número de pares, será mais difícil ocorrer regiões com acúmulo de pontos ou com vazios. 


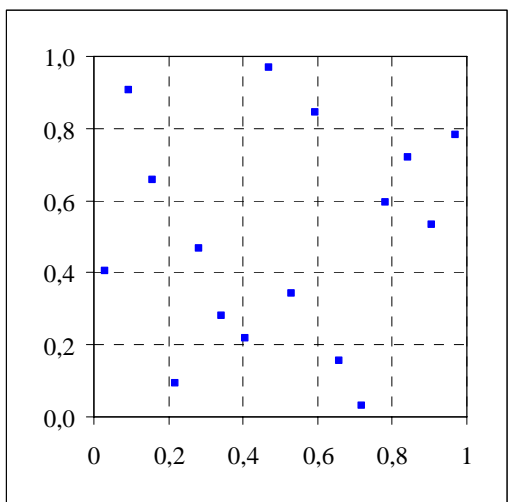

(a) 16 pares

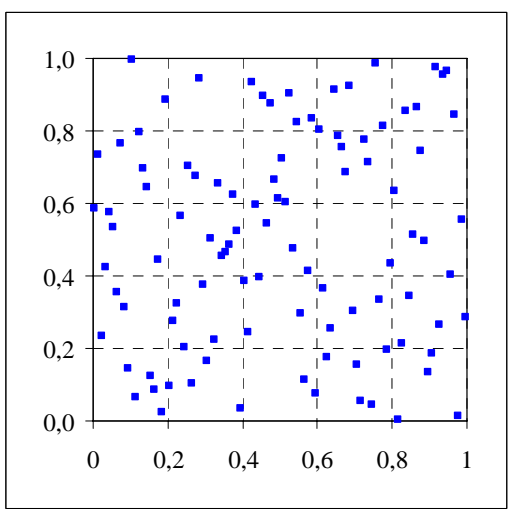

(b) 100 pares

FIGURA 5.24 - Distribuição uniforme no quadrado unitário

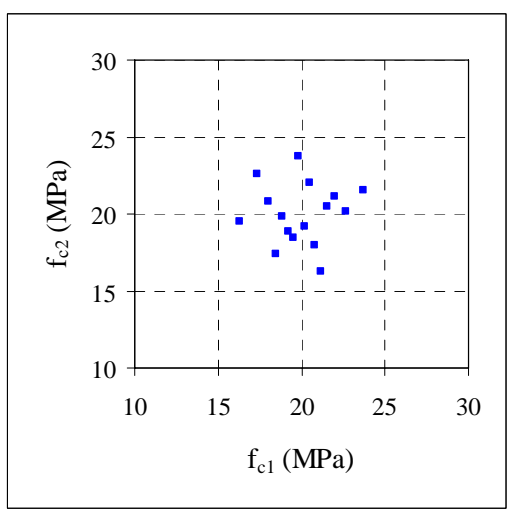

$\begin{array}{ll}\text { (a) } 16 \text { pares } & \text { (b) } 100 \text { pares }\end{array}$

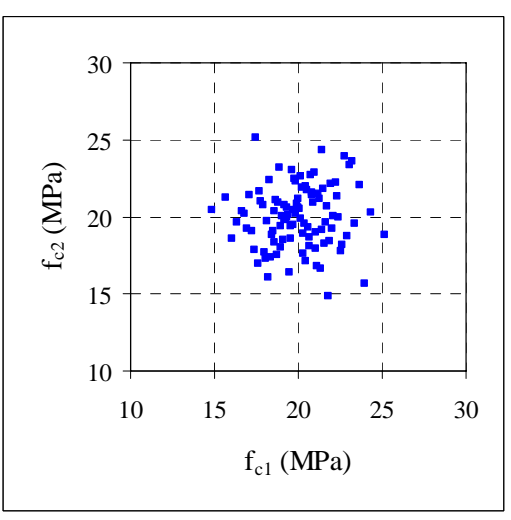

(b) 100 pares

A partir dos resultados das simulações, pôde-se verificar quais os parâmetros afetam mais significativamente o valor do coeficiente multiplicador através do coeficiente de regressão padronizado e coeficiente de correlação parcial, como mostrados nas figuras 5.26 e 5.27. Pelas figuras, pode-se notar que as incertezas nos modelos da fluência e retração do concreto da capa estrutural e, como já era esperado, os fatores ambientais (umidade relativa e temperatura ambiente) foram os parâmetros que tiveram maior influência no coeficiente multiplicador $\alpha$. 


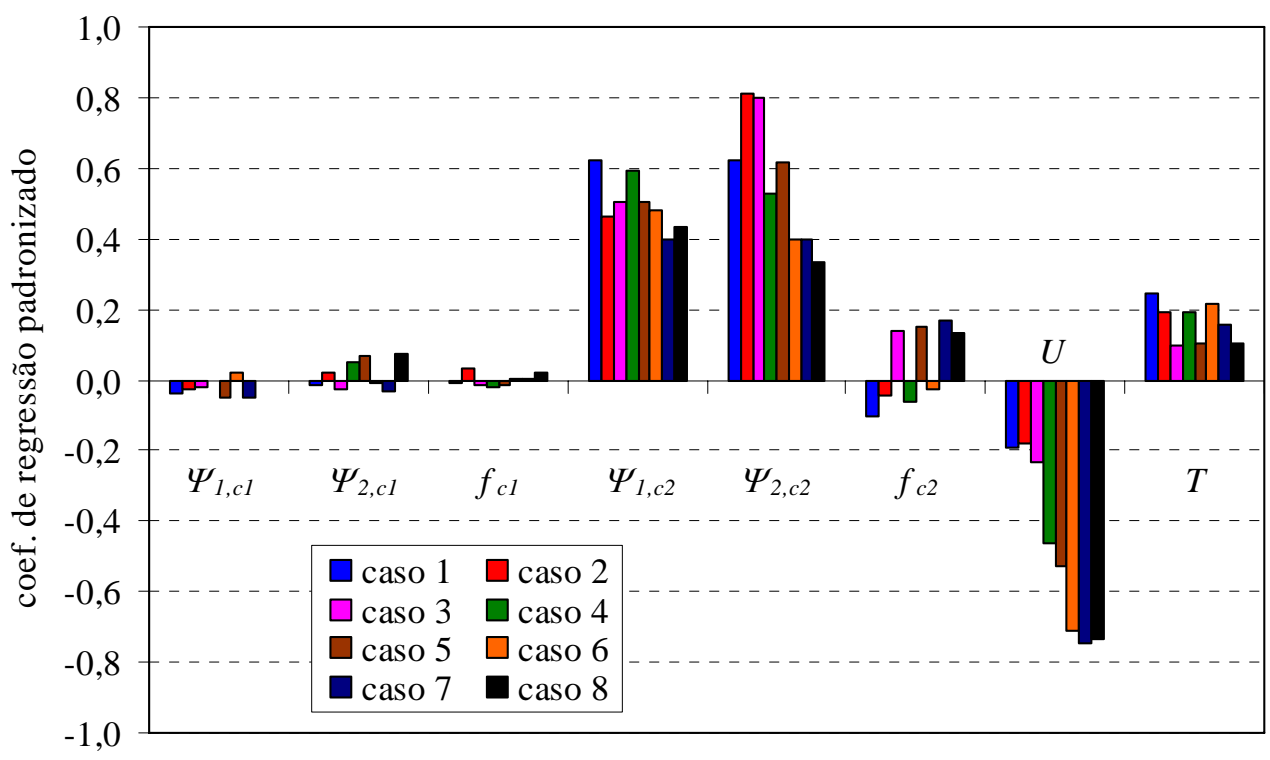

FIGURA 5.26 - Coeficiente de regressão padronizado para o coeficiente multiplicador $\alpha$

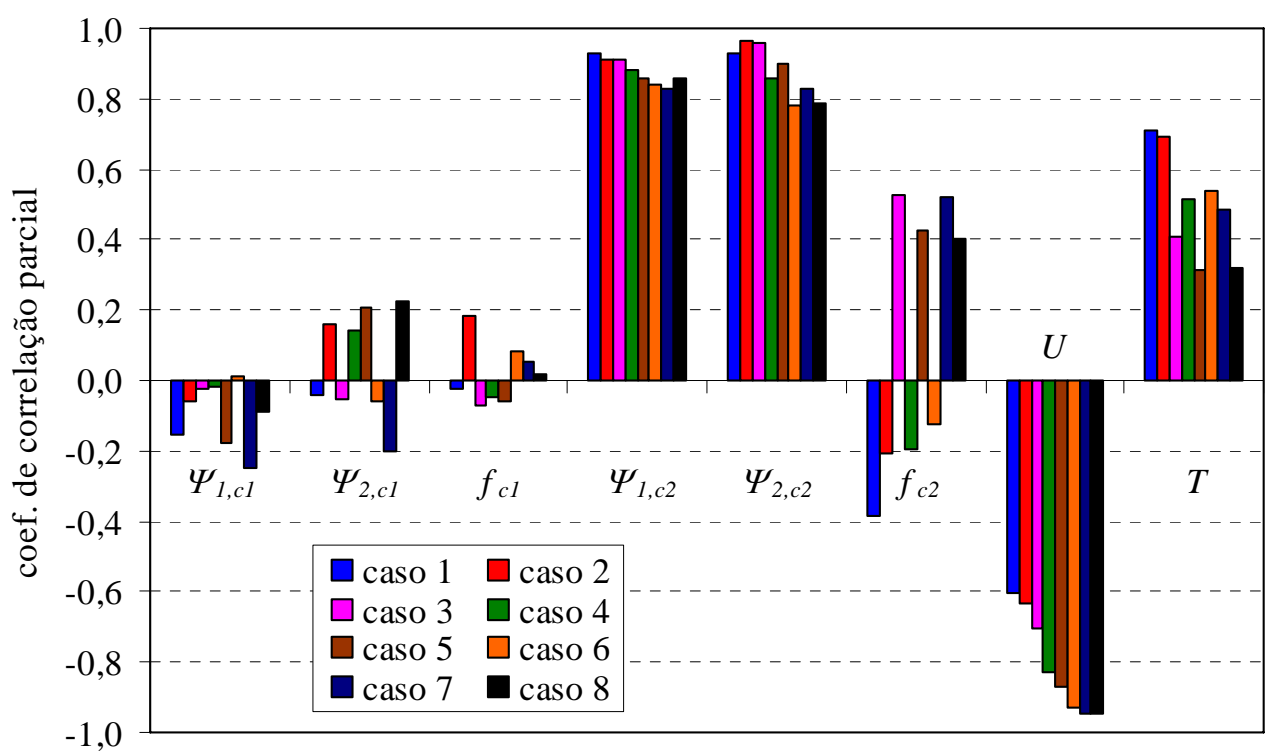

FIGURA 5.27 - Coeficiente de correlação parcial para o coeficiente multiplicador $\alpha$

Para verificar se o coeficiente multiplicador $\alpha$ se aproxima de uma distribuição normal, construiu o gráfico de probabilidade normal do coeficiente multiplicador obtido para cada caso, conforme figura 5.28. Por essa figura, nota-se que os valores ficaram próximos da reta, indicando que a distribuição normal é uma boa aproximação. 
(a) caso 1

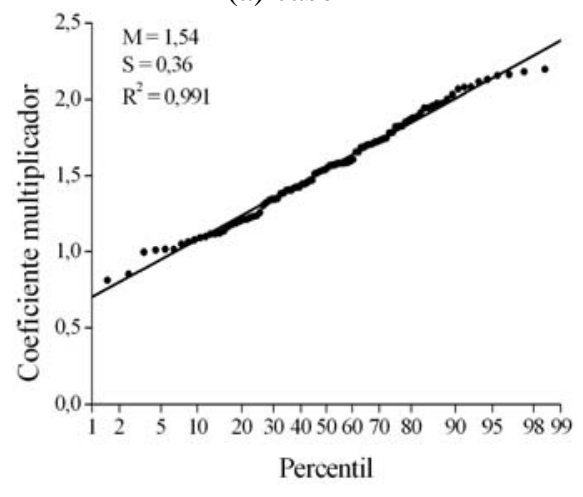

(c) caso 3

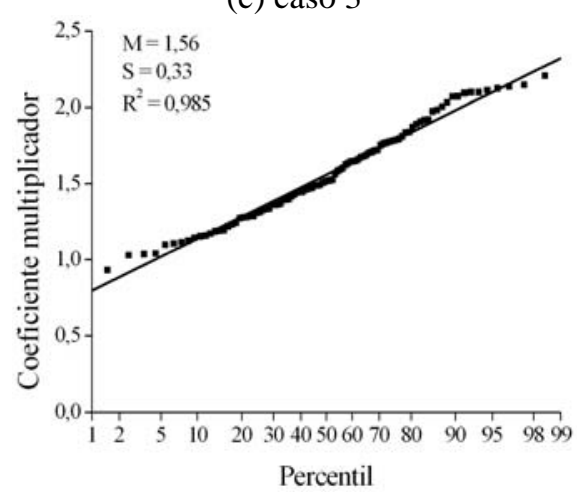

(e) caso 5

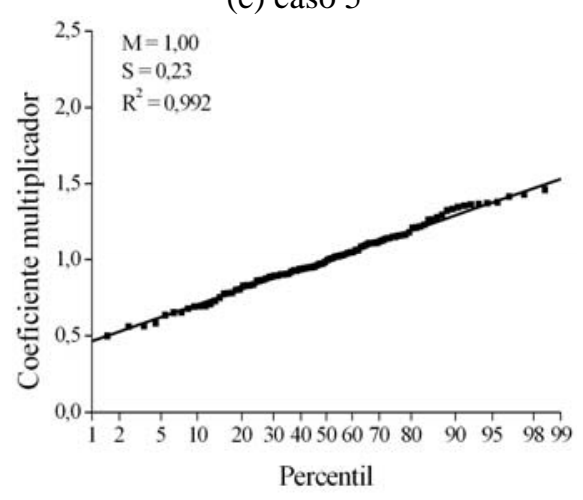

(g) caso 7

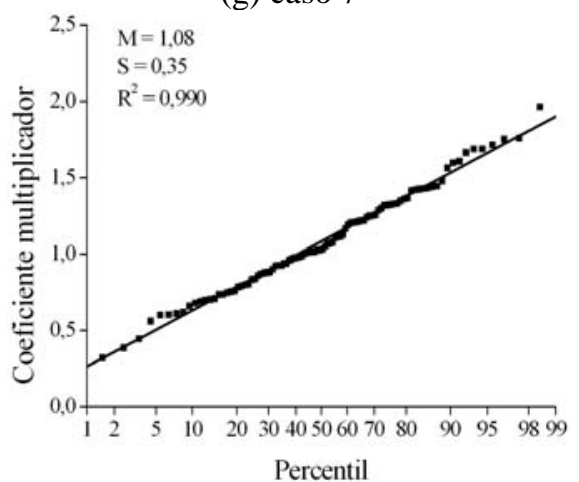

(b) caso 2

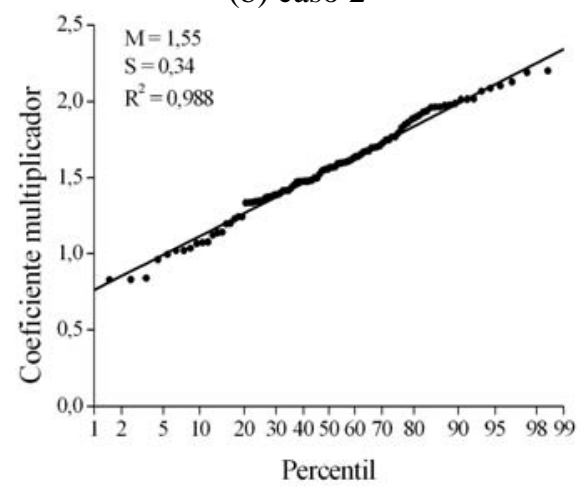

(d) caso 4

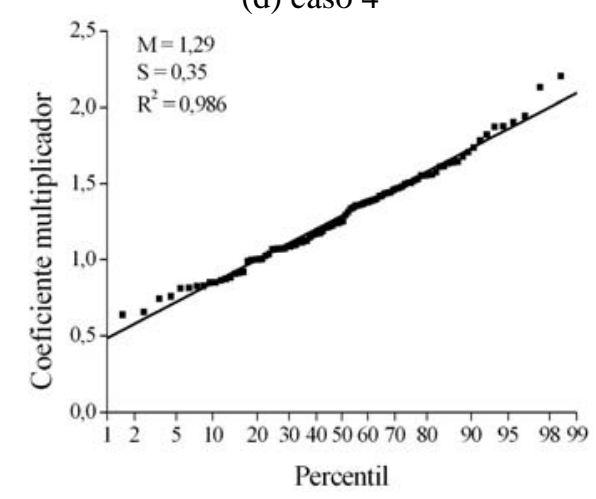

(f) caso 6

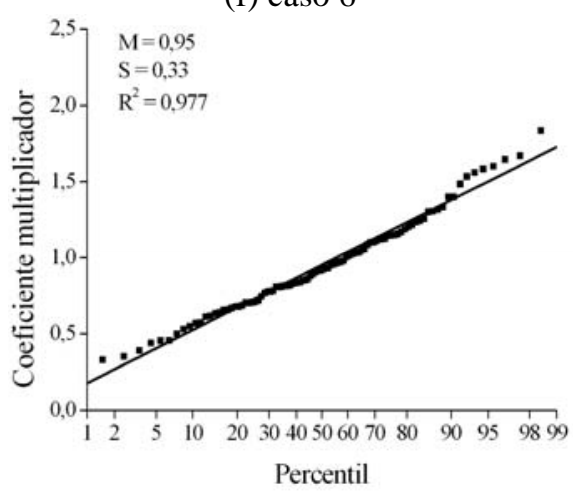

(h) caso 8

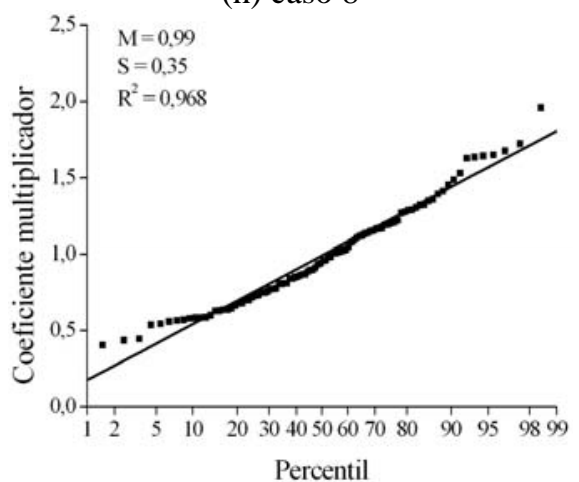

FIGURA 5.28 - Gráficos de probabilidade normal para o coeficiente multiplicador 
Com os valores obtidos para o coeficiente multiplicador $\alpha$ para os 8 casos analisados, determinou-se o coeficiente $\alpha_{\mathrm{U}, \mathrm{T}}$, como definido anteriormente. Foram determinados para cada par de valores de umidade relativa e temperatura, os coeficientes $\alpha_{\mathrm{U}, \mathrm{T}}$ com 5\%, 10\% e 15\% de probabilidade de serem ultrapassados, ou seja, 95\%, 90\% e $85 \%$ de probabilidade dos coeficientes $\alpha_{U, T}$ estarem abaixo do valor determinado.

A partir da regressão desses valores, obteve-se as seguintes expressões para o coeficiente $\alpha_{U, T}$, como mostrados nas figuras 5.29, 5.30 e 5.31, respectivamente para 95\%, 90\% e 85\% de probabilidade.

- $95 \%$ de probabilidade:

$$
\begin{aligned}
\alpha_{\mathrm{U}, \mathrm{T}}= & 0,029 \cdot \mathrm{T}-0,011 \cdot \mathrm{U}-2,83 \cdot 10^{-4} \cdot \mathrm{T} \cdot \mathrm{U}+ \\
& +1,31 \cdot 10^{-4} \cdot \mathrm{T}^{2}+4,93 \cdot 10^{-5} \cdot \mathrm{U}^{2}+1,78
\end{aligned}
$$

ou

$$
\alpha_{\mathrm{U}, \mathrm{T}}=0,019 . \mathrm{T}-0,012 . \mathrm{U}+1,97
$$

- $90 \%$ de probabilidade:

$$
\begin{aligned}
\alpha_{\mathrm{U}, \mathrm{T}}= & 0,029 \cdot \mathrm{T}-9,17 \cdot 10^{-3} \cdot \mathrm{U}-2,61 \cdot 10^{-4} \cdot \mathrm{T} \cdot \mathrm{U}+ \\
& +7,86 \cdot 10^{-5} \cdot \mathrm{T}^{2}+2,76 \cdot 10^{-5} \cdot \mathrm{U}^{2}+1,64 \\
\text { ou } & \\
\alpha_{\mathrm{U}, \mathrm{T}}= & 0,017 \cdot \mathrm{T}-0,012 \cdot \mathrm{U}+1,89
\end{aligned}
$$

- $85 \%$ de probabilidade:

$$
\begin{aligned}
\alpha_{\mathrm{U}, \mathrm{T}}= & 0,029 \cdot \mathrm{T}-7,82 \cdot 10^{-3} \cdot \mathrm{U}-2,45 \cdot 10^{-4} \cdot \mathrm{T} \cdot \mathrm{U}+ \\
& +4,29 \cdot 10^{-5} \cdot \mathrm{T}^{2}+1,30 \cdot 10^{-5} \cdot \mathrm{U}^{2}+1,54 \\
\text { ou } & \\
\alpha_{\mathrm{U}, \mathrm{T}}= & 0,016 \cdot \mathrm{T}-0,012 \cdot \mathrm{U}+1,84
\end{aligned}
$$




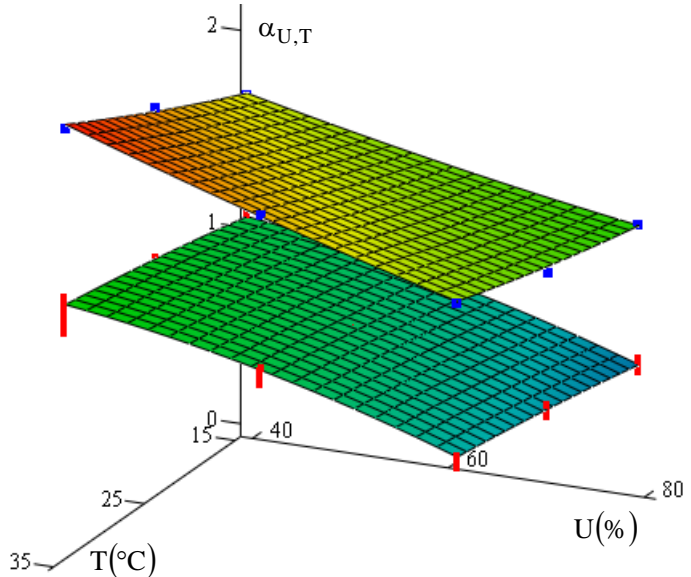

(a) não-linear

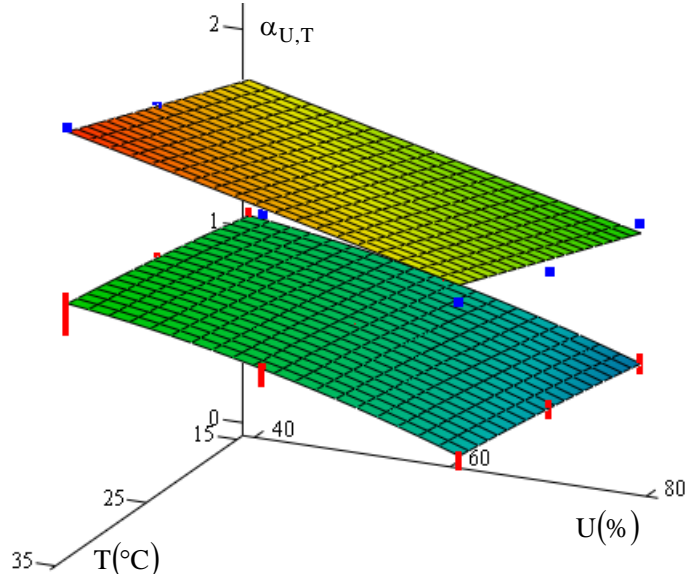

(b) linear

FIGURA 5.29 - Regressão do coeficiente $\alpha_{\mathrm{U,T}}$ com 95\% probabilidade

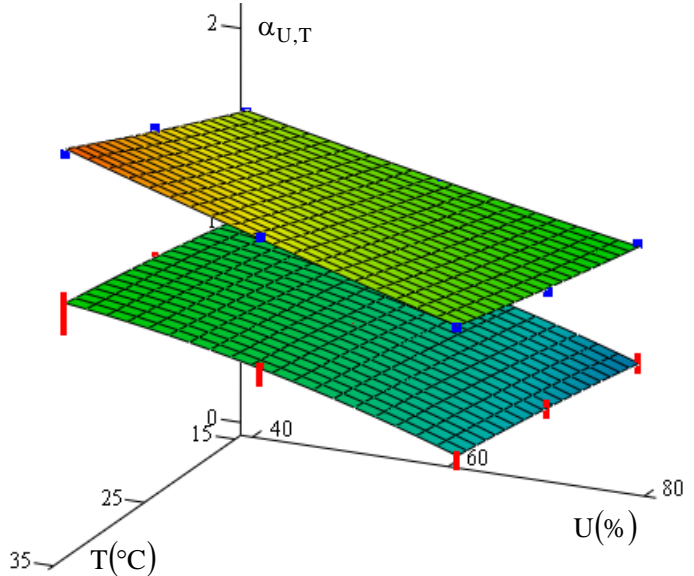

(a) não-linear

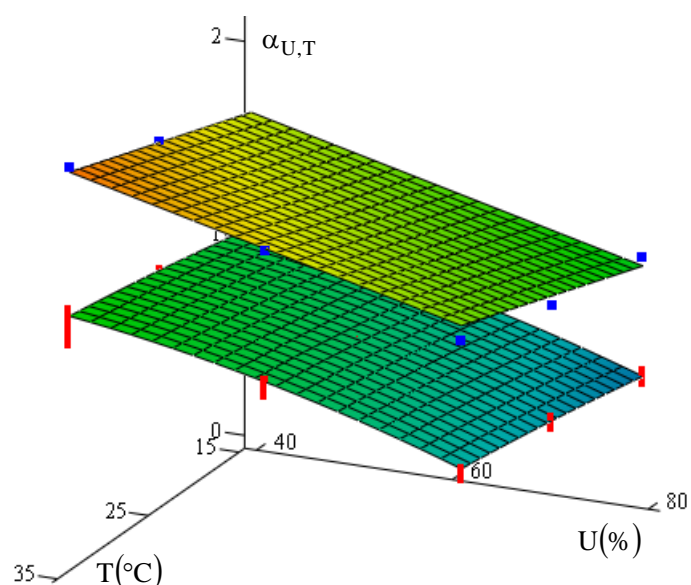

(b) linear

FIGURA 5.30 - Regressão do coeficiente $\alpha_{\mathrm{U}, \mathrm{T}}$ com 90\% probabilidade

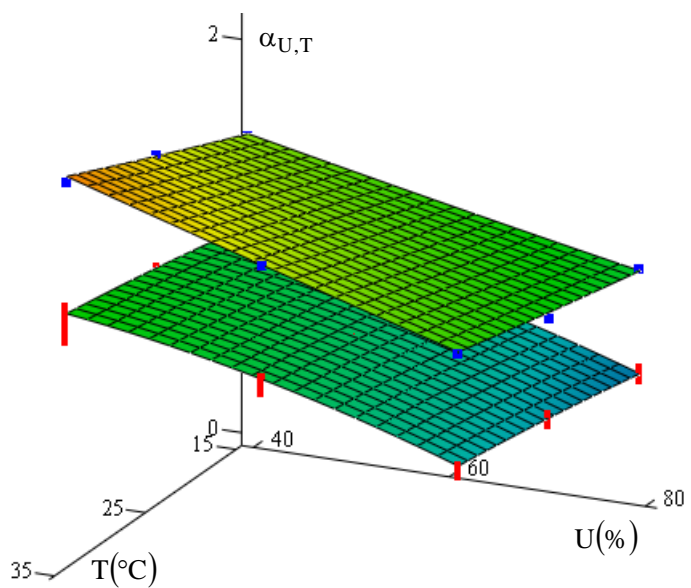

(a) não-linear

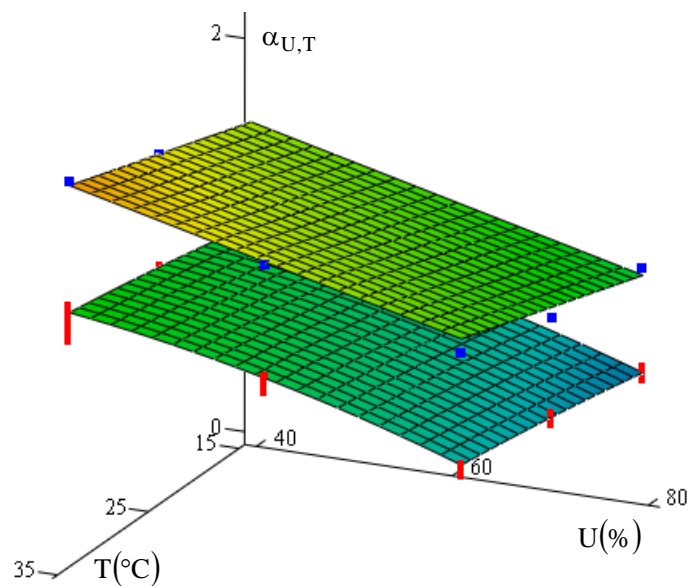

(b) linear

FIGURA 5.31 - Regressão do coeficiente $\alpha_{\mathrm{U}, \mathrm{T}}$ com 85\% probabilidade 
Portanto, o coeficiente multiplicador $\alpha$ da flecha instantânea para avaliação da flecha diferida de lajes pré-moldadas formadas por vigotas com armação treliçada será:

$$
\alpha=\alpha_{\text {básico }} \cdot \alpha_{\mathrm{U}, \mathrm{T}}
$$

Com

$\alpha_{\text {básico }}=3,73 . \kappa+0,18$

sendo

$\kappa=\frac{A_{s} \cdot h^{2,05}}{p^{1,5} \cdot \ell^{3}} \cdot 10^{3}$

onde:

$$
\begin{array}{ll}
A_{\mathrm{s}} & \text { - armadura }\left[\mathrm{cm}^{2}\right] ; \\
\mathrm{h} & \text { - altura da laje }[\mathrm{m}] ; \\
\mathrm{p} & \text { - carregamento aplicado }[\mathrm{kN} / \mathrm{m}] ; \\
\ell & \text { - vão da laje }[\mathrm{m}] .
\end{array}
$$

E o coeficiente $\alpha_{U, T}$, que considera a influência da umidade relativa e temperatura ambiente, com 85\% de probabilidade é dado por:

$$
\begin{aligned}
\alpha_{\mathrm{U}, \mathrm{T}}= & 0,029 \cdot \mathrm{T}-7,82 \cdot 10^{-3} \cdot \mathrm{U}-2,45 \cdot 10^{-4} \cdot \mathrm{T} \cdot \mathrm{U}+ \\
& +4,29 \cdot 10^{-5} \cdot \mathrm{T}^{2}+1,30 \cdot 10^{-5} \cdot \mathrm{U}^{2}+1,54
\end{aligned}
$$

ou

$\alpha_{\mathrm{U}, \mathrm{T}}=0,016 . \mathrm{T}-0,012 . \mathrm{U}+1,84$

onde:

U - umidade relativa média do ambiente [\%];

$\mathrm{T}$ - temperatura média do ambiente $\left[{ }^{\circ} \mathrm{C}\right]$.

O coeficiente $\alpha_{U, T}$ foi determinado considerando 95\%, $90 \%$ e $85 \%$ de probabilidade. No entanto, na falta de indicações sobre o assunto e considerando que o coeficiente $\alpha_{\mathrm{U}, \mathrm{T}}$ com $95 \%$ de probabilidade parece ser muito restritivo, está se adotando aqui o coeficiente $\alpha_{\mathrm{U}, \mathrm{T}}$ com $85 \%$ de probabilidade. 


\section{$5.5 \quad$ Laje contínua}

O coeficiente multiplicador da flecha imediata foi desenvolvido considerando a situação de lajes pré-moldadas biapoiadas. E assim, procurou-se verificar a possibilidade de extrapolar as expressões para o caso de lajes contínuas. Para isso, realizou-se a análise das lajes LT12, LT16, LT20 e LT25 utilizadas para a determinação do coeficiente $\alpha_{\mathrm{U}, \mathrm{T}}$, totalizando 25 casos, conforme apresentadas na tabela 5.29. No entanto, essas lajes foram analisadas como lajes contínuas formadas por dois tramos de mesmo comprimento.

As lajes contínuas foram analisadas mantendo as características e considerações feitas anteriormente para o caso biapoiado. A única distinção foi a consideração de uma armadura de continuidade composta por $4 \phi 5 \mathrm{~mm}, 4 \phi 6 \mathrm{~mm}$, $5 \phi 6 \mathrm{~mm}$ e $6 \phi 6 \mathrm{~mm}$, respectivamente, para as lajes LT12, LT16, LT20 e LT25. Essa armadura de continuidade adotada corresponde a uma armadura mínima de flexão para controle de fissuração no apoio intermediário.

TABELA 5.29 - Casos analisados para o caso de lajes contínuas

\begin{tabular}{|c|c|c|c|c|}
\hline \multirow{3}{*}{ laje } & \multirow{3}{*}{$\ell(\mathbf{m})$} & \multirow{2}{*}{\multicolumn{3}{|c|}{$\begin{array}{c}\text { armadura adicional } A_{\text {s,adic }}\left(\mathrm{cm}^{2}\right) \\
q\left(\mathrm{kN} / \mathrm{m}^{2}\right)\end{array}$}} \\
\hline & & & & \\
\hline & & 2,0 & 4,0 & 6,0 \\
\hline \multirow{4}{*}{ LT12 } & 4,5 & 1,50 & & \\
\hline & 4,0 & 0,90 & & \\
\hline & 3,5 & 0,60 & 1,50 & \\
\hline & 3,0 & 0,40 & 0,80 & 1,50 \\
\hline \multirow{3}{*}{ LT16 } & 6,0 & 1,50 & & \\
\hline & 5,0 & 1,00 & 2,35 & \\
\hline & 4,0 & 0,40 & 1,00 & 1,50 \\
\hline \multirow{3}{*}{ LT20 } & 7,0 & 2,35 & & \\
\hline & 6,0 & 1,20 & 2,35 & \\
\hline & 5,0 & 0,60 & 1,50 & 2,35 \\
\hline \multirow{3}{*}{ LT25 } & 8,5 & 2,35 & & \\
\hline & 7,5 & 1,60 & 3,68 & \\
\hline & 6,5 & 1,00 & 2,35 & 3,68 \\
\hline
\end{tabular}

Apresentam-se na figura 5.32 as relações entre os coeficientes multiplicadores para as lajes continua e biapoiada obtidas para os casos analisados. 
Pela figura pode-se notar que ocorreu uma diferença elevada entre os coeficientes, sendo que o coeficiente multiplicador para a laje contínua chegou a ser mais que três vezes o valor do coeficiente para a laje biapoiada correspondente.

A explicação para essa diferença se deve ao fato de que o carregamento atuante nas lajes, que foi obtido considerado a combinação quase permanente das ações, leva as lajes biapoiadas a um nível de fissuração diferente das lajes contínuas.

Isso pôde ser comprovado quando as lajes contínuas foram submetidas a um carregamento considerando a combinação rara de ações. Para essa nova situação o nível de fissuração das lajes contínuas foi maior e as relações entre os coeficientes mudaram drasticamente comparadas com a situação anterior, como pode ser visto na figura 5.33. Por essa figura pode-se notar que os coeficientes multiplicadores para a laje contínua ficaram em torno de $80 \%$ dos valores dos coeficientes para a laje biapoiada correspondente.

Os casos foram ainda analisados aplicando-se um carregamento correspondente à combinação rara de ações e em seguida retirando-o até atingir a combinação quase permanente. Os resultados desta análise estão apresentados na figura 5.34, e como se pode verificar, os resultados foram diferentes, mas próximos dos resultados obtidos considerando combinação rara de ações.

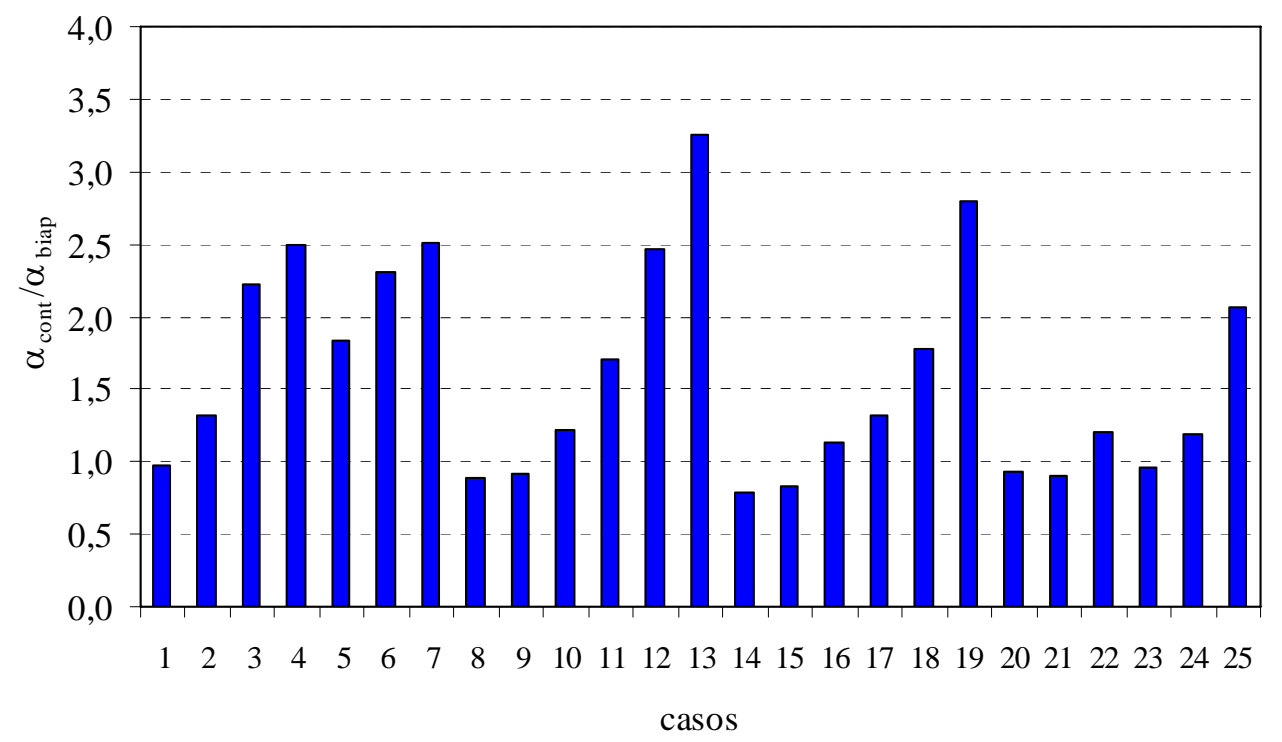

FIGURA 5.32 - Relação entre os coeficientes multiplicadores (contínua e biapoiada) - condição 1 


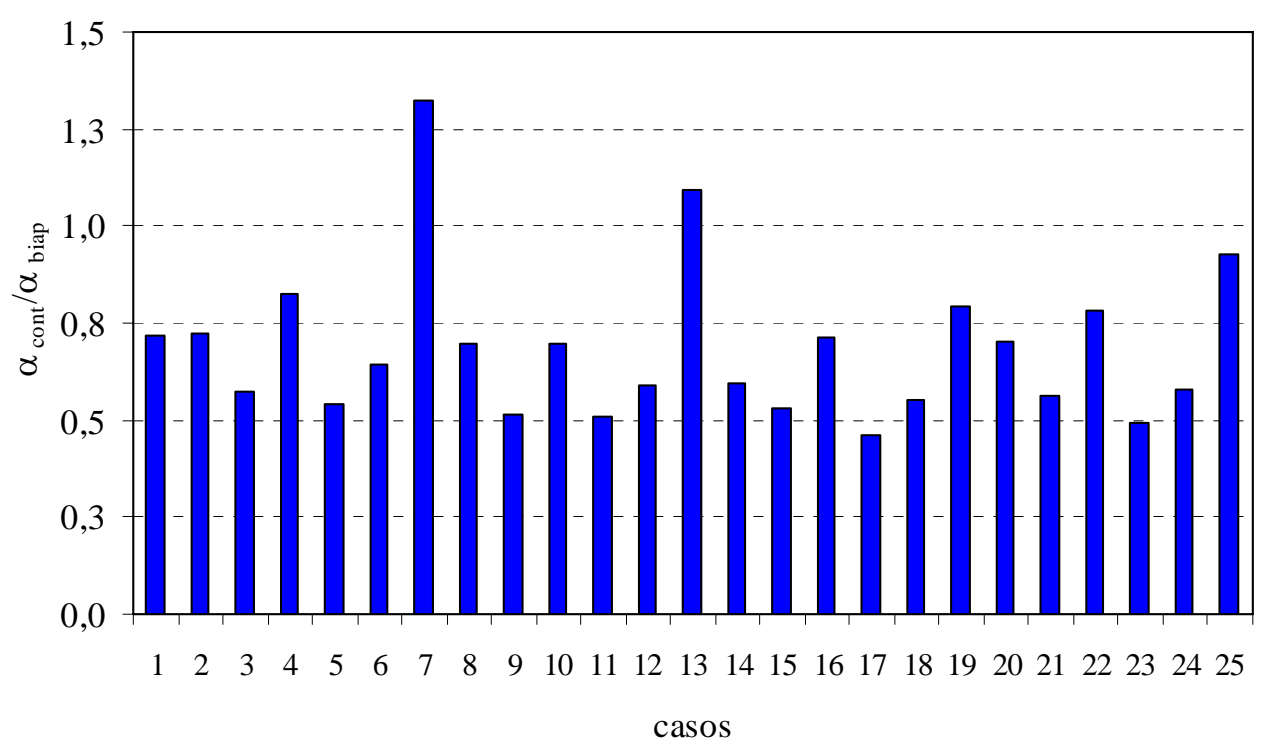

FIGURA 5.33 - Relação entre os coeficientes multiplicadores (contínua e biapoiada) - condição 2

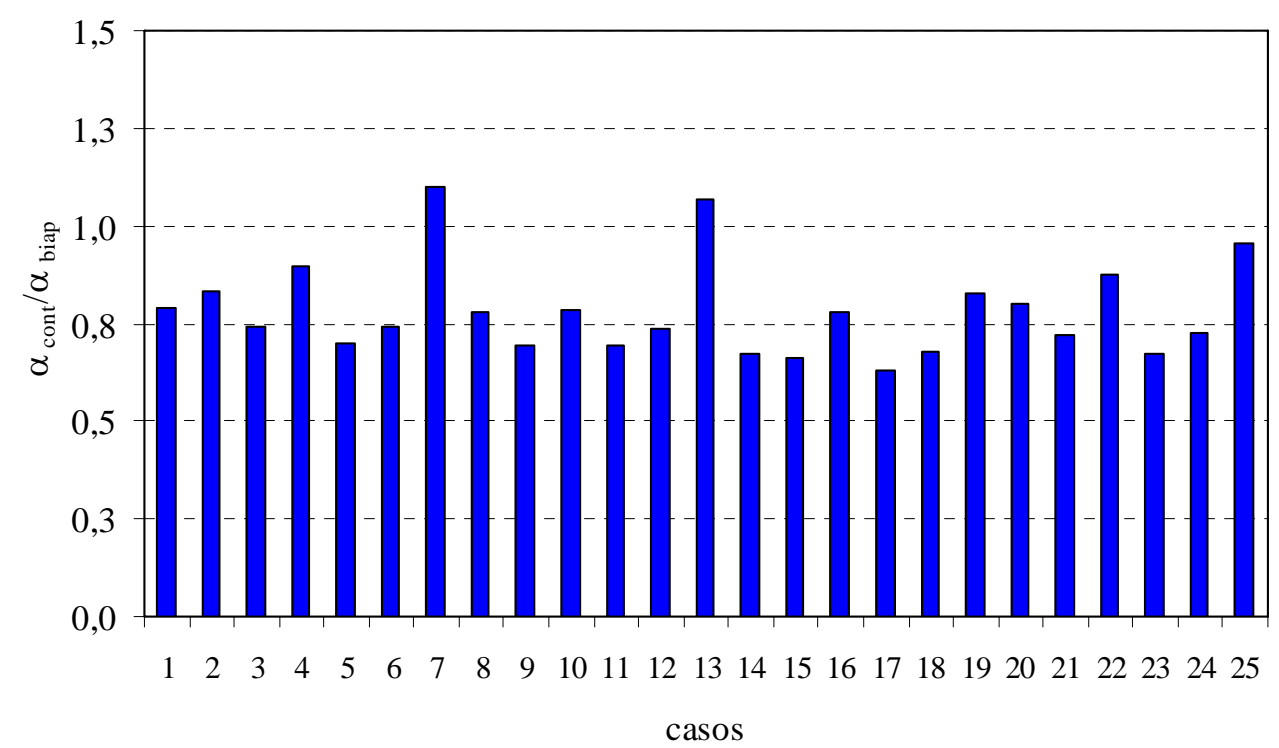

FIGURA 5.34 - Relação entre os coeficientes multiplicadores (contínua e biapoiada) - condição 3

Portanto, o que se pode concluir é que as expressões obtidas para as lajes biapoiadas podem ser utilizadas para as lajes contínuas desde que estas apresentem um estado de fissuração compatível com o ocorrido com as lajes biapoiadas. 


\subsection{Exemplos de cálculo}

A seguir, são apresentados exemplos de determinação do coeficiente multiplicador da flecha imediata de lajes pré-moldadas formadas por vigotas com armação treliçada, utilizando as expressões propostas nos itens anteriores.

Os cálculos do coeficiente multiplicador foram realizados considerando três casos de lajes com dimensões do vão de 3,2 m (vão pequeno), 4,4 m (vão médio) e 6,6 m (vão grande).

\subsubsection{Laje com vão pequeno}

Para este caso foi considerada laje de 3,2 m de vão com altura total de $12 \mathrm{~cm}$ e $49 \mathrm{~cm}$ de distância entre nervuras, conforme figura 5.35.

Para a determinação do peso próprio da laje foi considerado concreto com massa específica igual a $2500 \mathrm{~kg} / \mathrm{m}^{3}$ e material de enchimento composto por blocos de poliestireno expandido (EPS) com massa específica igual a $15 \mathrm{~kg} / \mathrm{m}^{3}$, resultado em peso próprio da laje de $0,697 \mathrm{kN} / \mathrm{m}$.

Além da atuação de uma carga permanente referente ao revestimento de $0,5 \mathrm{kN} / \mathrm{m}^{2}$, foi considerada ainda três valores de carga de utilização de $2,0 \mathrm{kN} / \mathrm{m}^{2}$, $3,5 \mathrm{kN} / \mathrm{m}^{2}$ e $5,0 \mathrm{kN} / \mathrm{m}^{2}$, necessitando a utilização de uma armadura adicional composta, respectivamente, por 2 barras de $5 \mathrm{~mm}$ de diâmetro, 3 barras de 6,3 mm de diâmetro e 3 barras de 8 mm de diâmetro.

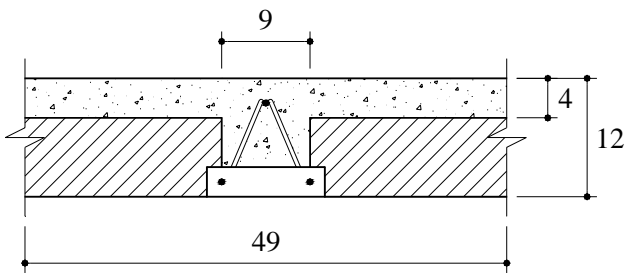

(a) laje

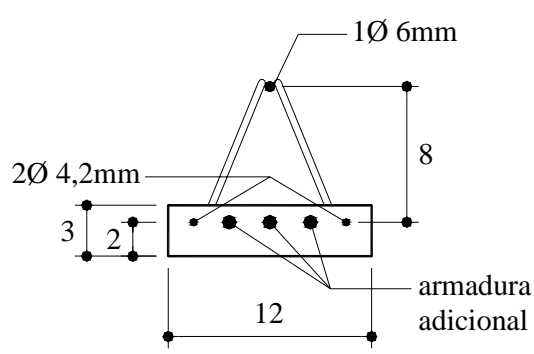

(b) vigota

FIGURA 5.35 - Seção transversal da laje com vão pequeno (dimensões em cm)

Foi considerada ainda umidade relativa média de 60\% e temperatura média de $30^{\circ} \mathrm{C}$. 
Utilizando combinação quase permanente das ações, o carregamento atuante na laje, assim como os demais parâmetros considerados para o cálculo dos coeficientes multiplicadores estão apresentados na tabela 5.30 .

TABELA 5.30 - Parâmetros considerados para a laje com vão pequeno

\begin{tabular}{ccccccc}
\hline $\mathbf{q}$ & $\mathbf{A}_{\mathbf{s}}$ & $\mathbf{h}$ & $\mathbf{p}$ & $\boldsymbol{\ell}$ & $\mathbf{U}$ & $\mathbf{T}$ \\
$\mathbf{( k N / \mathbf { m } ^ { 2 } )}$ & $\mathbf{( \mathbf { c m } ^ { 2 } )}$ & $\mathbf{( m )}$ & $\mathbf{( k N / m )}$ & $\mathbf{( m )}$ & $\mathbf{( \% )}$ & $\left({ }^{\circ} \mathbf{C}\right)$ \\
\hline 2,0 & 0,675 & 0,12 & 1,236 & 3,2 & 60 & 30 \\
3,5 & 1,21 & 0,12 & 1,457 & 3,2 & 60 & 30 \\
5,0 & 1,775 & 0,12 & 1,677 & 3,2 & 60 & 30 \\
\hline
\end{tabular}

\section{- Cálculo determinístico}

Para a determinação do coeficiente multiplicador, calcula-se inicialmente o coeficiente $\kappa$, através da expressão:

$$
\kappa=\frac{A_{s} \cdot h^{2,05}}{p^{1,5} \cdot \ell^{3}} \cdot 10^{3}
$$

E a partir de $\kappa$, tem-se:

$$
\alpha_{\text {básico }}=3,73 . \kappa+0,18
$$

O valor do coeficiente $\alpha_{U, T}$ é dado por:

$$
\begin{aligned}
\alpha_{\mathrm{U}, \mathrm{T}}= & 0,016 \cdot \mathrm{T}+4,9 \cdot 10^{-3} \cdot \mathrm{U}-2,7 \cdot 10^{-5} \cdot \mathrm{T} \cdot \mathrm{U}- \\
& -1,03 \cdot 10^{-4} \cdot \mathrm{T}^{2}-1,32 \cdot 10^{-4} \cdot \mathrm{U}^{2}+0,90
\end{aligned}
$$

E, portanto, o coeficiente multiplicador $\alpha$ é determinado por:

$$
\alpha=\alpha_{\text {básico }} \cdot \alpha_{\mathrm{U}, \mathrm{T}}
$$

Os coeficientes multiplicadores obtidos com as expressões mostradas acima estão apresentados na tabela 5.31 . 
TABELA 5.31 - Resultados obtidos para a laje com vão pequeno (análise determinística)

\begin{tabular}{ccccc}
\hline $\mathbf{q}$ & $\boldsymbol{\kappa}$ & $\boldsymbol{\alpha}_{\text {básico }}$ & $\boldsymbol{\alpha}_{\mathbf{U , T}}$ & $\boldsymbol{\alpha}$ \\
\hline $\left.\mathbf{k N} / \mathbf{m}^{2}\right)$ & 0,194 & 0,90 & 1,06 & 0,95 \\
3,0 & 0,272 & 1,19 & 1,06 & 1,26 \\
5,0 & 0,323 & 1,38 & 1,06 & 1,46 \\
\hline
\end{tabular}

\section{- Cálculo probabilístico}

O valor do coeficiente $\alpha_{U, T}$ considerando $85 \%$ de probabilidade é determinado através da seguinte expressão:

$$
\begin{aligned}
\alpha_{\mathrm{U}, \mathrm{T}}= & 0,029 \cdot \mathrm{T}-7,82 \cdot 10^{-3} \cdot \mathrm{U}-2,45 \cdot 10^{-4} \cdot \mathrm{T} \cdot \mathrm{U}+ \\
& +4,29 \cdot 10^{-5} \cdot \mathrm{T}^{2}+1,30 \cdot 10^{-5} \cdot \mathrm{U}^{2}+1,54
\end{aligned}
$$

Portanto, o coeficiente multiplicador $\alpha$ é dado por:

$\alpha=\alpha_{\text {básico }} \cdot \alpha_{\mathrm{U}, \mathrm{T}}$

E assim, os coeficientes multiplicadores determinados através das expressões anteriores estão mostrados na tabela 5.32 .

TABELA 5.32 - Resultados obtidos para a laje com vão pequeno (análise probabilística)

\begin{tabular}{ccccc}
\hline $\begin{array}{c}\mathbf{q} \\
\left(\mathbf{k N} / \mathbf{m}^{2}\right)\end{array}$ & $\boldsymbol{\kappa}$ & $\boldsymbol{\alpha}_{\text {básico }}$ & $\boldsymbol{\alpha}_{\mathbf{U , T}}$ & $\boldsymbol{\alpha}$ \\
\hline 2,0 & 0,194 & 0,90 & 1,59 & 1,43 \\
3,5 & 0,272 & 1,19 & 1,59 & 1,89 \\
5,0 & 0,323 & 1,38 & 1,59 & 2,19 \\
\hline
\end{tabular}

\subsubsection{Laje com vão médio}

Para este caso foi considerada laje de 4,4 m de vão com altura total de 16 cm e 49 cm de distância entre nervuras, conforme figura 5.36.

O peso próprio da laje foi de $0,790 \mathrm{kN} / \mathrm{m}$, com a consideração de concreto com massa específica igual a $2500 \mathrm{~kg} / \mathrm{m}^{3}$ e material de enchimento composto por blocos de EPS com massa específica igual a $15 \mathrm{~kg} / \mathrm{m}^{3}$. 
Além da atuação de uma carga permanente referente ao revestimento de $0,5 \mathrm{kN} / \mathrm{m}^{2}$, foi considerada ainda três valores de carga de utilização de $2,0 \mathrm{kN} / \mathrm{m}^{2}$, $3,5 \mathrm{kN} / \mathrm{m}^{2}$ e $5,0 \mathrm{kN} / \mathrm{m}^{2}$, necessitando a utilização de uma armadura adicional composta, respectivamente, por 2 barras de $6 \mathrm{~mm}$ de diâmetro, 3 barras de $8 \mathrm{~mm}$ de diâmetro e 3 barras de 10 mm de diâmetro.

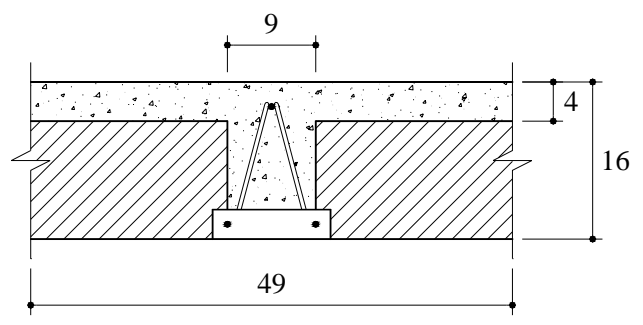

(a) laje

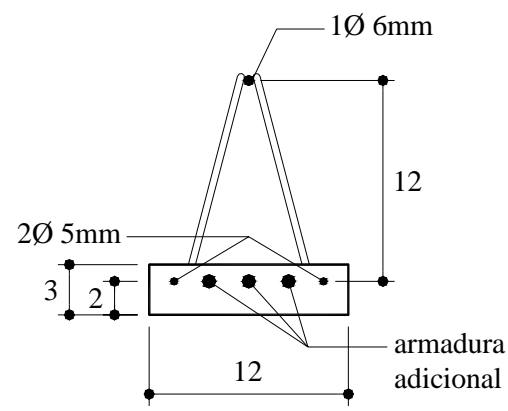

(b) vigota

FIGURA 5.36 - Seção transversal da laje com vão médio (dimensões em cm)

Foi considerada ainda umidade relativa média de 50\% e temperatura média de $25^{\circ} \mathrm{C}$.

E assim, os parâmetros considerados no cálculo do coeficiente multiplicador estão apresentados na tabela 5.33. O carregamento atuante na laje foi determinado considerando combinação quase permanente das ações.

TABELA 5.33 - Parâmetros considerados para a laje com vão médio

\begin{tabular}{|c|c|c|c|c|c|c|}
\hline$\underset{\left(k N / m^{2}\right)}{q}$ & $\begin{array}{c}A_{s} \\
\left(\mathrm{~cm}^{2}\right)\end{array}$ & $\begin{array}{c}\text { h } \\
(\mathbf{m})\end{array}$ & $\underset{(k N / m)}{p}$ & $\begin{array}{c}\ell \\
(\mathbf{m})\end{array}$ & $\begin{array}{c}\mathrm{U} \\
(\%)\end{array}$ & $\begin{array}{c}\mathbf{T} \\
\left({ }^{\circ} \mathrm{C}\right)\end{array}$ \\
\hline 2,0 & 0,955 & 0,16 & 1,329 & 4,4 & 50 & 25 \\
\hline 3,5 & 1,89 & 0,16 & 1,550 & 4,4 & 50 & 25 \\
\hline 5,0 & 2,74 & 0,16 & 1,770 & 4,4 & 50 & 25 \\
\hline
\end{tabular}

\section{- Cálculo determinístico}

Os coeficientes multiplicadores determinados através das expressões obtidas da análise determinística estão apresentados na tabela 5.34. 
TABELA 5.34 - Resultados obtidos para a laje com vão médio (análise determinística)

\begin{tabular}{ccccc}
\hline $\begin{array}{c}\mathbf{q} \\
\left(\mathbf{k N} / \mathbf{m}^{2}\right)\end{array}$ & $\boldsymbol{\kappa}$ & $\boldsymbol{\alpha}_{\text {básico }}$ & $\boldsymbol{\alpha}_{\mathbf{U , T}}$ & $\boldsymbol{\alpha}$ \\
\hline 2,0 & 0,171 & 0,82 & 1,12 & 0,92 \\
3,5 & 0,269 & 1,18 & 1,12 & 1,32 \\
5,0 & 0,319 & 1,37 & 1,12 & 1,53 \\
\hline
\end{tabular}

\section{- Cálculo probabilístico}

Os coeficientes multiplicadores determinados através das expressões obtidas da análise probabilística estão apresentados na tabela 5.35.

TABELA 5.35 - Resultados obtidos para a laje com vão médio (análise probabilística)

\begin{tabular}{ccccc}
\hline $\begin{array}{c}\mathbf{q} \\
\left(\mathbf{k N} / \mathbf{m}^{2}\right)\end{array}$ & $\boldsymbol{\kappa}$ & $\boldsymbol{\alpha}_{\text {básico }}$ & $\boldsymbol{\alpha}_{\mathbf{U , T}}$ & $\boldsymbol{\alpha}$ \\
\hline 2,0 & 0,171 & 0,82 & 1,63 & 1,34 \\
3,5 & 0,269 & 1,18 & 1,63 & 1,92 \\
5,0 & 0,319 & 1,37 & 1,63 & 2,23 \\
\hline
\end{tabular}

\subsubsection{Laje com vão grande}

Para este caso foi considerada laje de 6,6 m de vão com altura total de 20 cm e 49 cm de distância entre nervuras, conforme figura 5.37.

Para a determinação do peso próprio da laje foi considerado concreto com massa específica igual a $2500 \mathrm{~kg} / \mathrm{m}^{3}$ e material de enchimento composto por blocos de poliestireno expandido (EPS) com massa específica igual a $15 \mathrm{~kg} / \mathrm{m}^{3}$, resultado em peso próprio da laje de $0,882 \mathrm{kN} / \mathrm{m}$.

Além da atuação de uma carga permanente referente ao revestimento de $0,5 \mathrm{kN} / \mathrm{m}^{2}$, foi considerada ainda carga de utilização de $2,0 \mathrm{kN} / \mathrm{m}^{2}$, necessitando a utilização de uma armadura adicional composta por 3 barras de $10 \mathrm{~mm}$ de diâmetro. O coeficiente multiplicador não foi determinado considerando valores de carga de utilização maiores, como realizado nos exemplos anteriores, pois esta laje não possui capacidade para suportar cargas maiores para o vão em questão.

Foi considerada ainda umidade relativa média de $70 \%$ e temperatura média de $20^{\circ} \mathrm{C}$. 


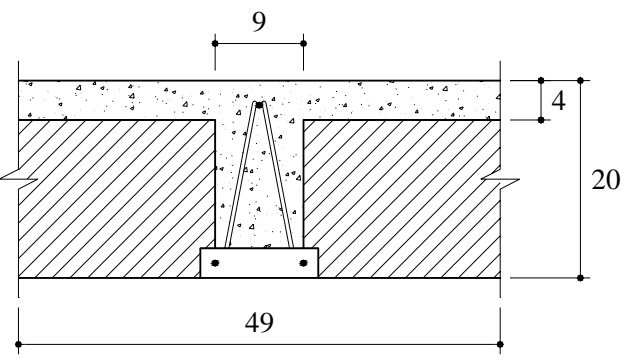

(a) laje

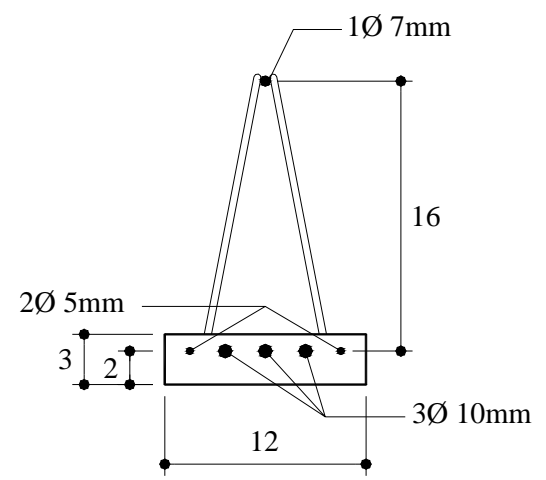

(b) vigota

FIGURA 5.37 - Seção transversal da laje com vão grande (dimensões em cm)

Utilizando combinação quase permanente das ações, o carregamento atuante na laje considerado será:

$$
p=g+0,3 . q \Rightarrow p=(0,882+0,245)+0,3 \cdot 0,98 \Rightarrow p=1,421 k N / m
$$

E assim, têm-se:

$$
\begin{aligned}
& \mathrm{A}_{\mathrm{s}}=2,74 \mathrm{~cm}^{2} \\
& \mathrm{~h}=0,20 \mathrm{~m} \\
& \mathrm{p}=1,421 \mathrm{kN} / \mathrm{m} \\
& \ell=6,6 \mathrm{~m} \\
& \mathrm{U}=70 \% \\
& \mathrm{~T}=20{ }^{\circ} \mathrm{C}
\end{aligned}
$$

\section{- Cálculo determinístico}

Para a determinação do coeficiente multiplicador, calcula-se inicialmente o coeficiente $\kappa$, através da expressão:

$$
\kappa=\frac{A_{s} \cdot h^{2,05}}{p^{1,5} \cdot \ell^{3}} \cdot 10^{3} \Rightarrow \kappa=0,208
$$

Com isso, tem-se:

$$
\alpha_{\text {básico }}=3,73 . \kappa+0,18 \Rightarrow \alpha_{\text {básico }}=0,96
$$


O valor do coeficiente $\alpha_{U, T}$ é dado por:

$$
\begin{aligned}
\alpha_{\mathrm{U}, \mathrm{T}}= & 0,016 \cdot \mathrm{T}+4,9 \cdot 10^{-3} \cdot \mathrm{U}-2,7 \cdot 10^{-5} \cdot \mathrm{T} \cdot \mathrm{U}- \\
& -1,03 \cdot 10^{-4} \cdot \mathrm{T}^{2}-1,32 \cdot 10^{-4} \cdot \mathrm{U}^{2}+0,90 \Rightarrow \alpha_{\mathrm{U}, \mathrm{T}}=0,84
\end{aligned}
$$

E, portanto, o coeficiente multiplicador $\alpha$ é determinado por:

$\alpha=\alpha_{\text {básico }} \cdot \alpha_{U, T} \Rightarrow \alpha=0,81$

- Cálculo probabilístico

O valor do coeficiente $\alpha_{U, T}$ considerando $85 \%$ de probabilidade é determinado através da seguinte expressão:

$$
\begin{aligned}
\alpha_{\mathrm{U}, \mathrm{T}}= & 0,029 \cdot \mathrm{T}-7,82 \cdot 10^{-3} \cdot \mathrm{U}-2,45 \cdot 10^{-4} \cdot \mathrm{T} \cdot \mathrm{U}+ \\
& +4,29 \cdot 10^{-5} \cdot \mathrm{T}^{2}+1,30 \cdot 10^{-5} \cdot \mathrm{U}^{2}+1,54 \Rightarrow \alpha_{\mathrm{U}, \mathrm{T}}=1,31
\end{aligned}
$$

Portanto, o coeficiente multiplicador $\alpha$ é dado por:

$$
\alpha=\alpha_{\text {básico }} \cdot \alpha_{\mathrm{U}, \mathrm{T}} \Rightarrow \alpha=1,26
$$

\subsection{Análise dos resultados e comentários}

Procurou-se com este capítulo realizar a análise probabilística das flechas diferidas de lajes pré-moldadas formadas por vigotas com armação treliçada, visando fornecer indicações de projeto através da proposta de um coeficiente multiplicador das flechas imediatas para avaliação das flechas diferidas. Esta análise foi realizada utilizando o programa computacional CONSNOU, em conjunto com análise probabilística, através do método de amostragem por hipercubo latino.

Inicialmente foi realizada uma análise preliminar para avaliar quais os parâmetros envolvidos influenciaria mais significativamente o coeficiente multiplicador das flechas imediatas. Por essa análise preliminar, pôde-se verificar que tanto o carregamento aplicado quanto a altura e o vão da laje, assim como a 
armadura utilizada são parâmetros dependentes entre si, ou seja, tais parâmetros não podem ser analisados isoladamente, caso contrário, pode originar casos com coeficientes multiplicadores elevados, mas de pouco sentido prático. E assim, levando isso em consideração, pôde-se concluir que os parâmetros que mais influenciam o coeficiente multiplicador das flechas imediatas são a umidade relativa e a temperatura ambiente.

Em seguida, foi determinado o coeficiente multiplicador $\alpha$ através do produto de um coeficiente multiplicador básico $\alpha_{\text {básico }}$ e do coeficiente $\alpha_{U, T}$, que considera a influência da umidade relativa e temperatura ambiente. O coeficiente $\alpha_{U, T}$ foi determinado através de uma análise determinística e outra probabilística.

O coeficiente multiplicador básico $\alpha_{\text {básico }}$ é determinado a partir de um coeficiente denominado $\kappa$ que é função da armadura utilizada, do carregamento aplicado e da altura e do vão da laje. O coeficiente $\kappa$ mostra que o coeficiente multiplicador aumenta com o aumento da taxa de armadura e da altura da laje e diminui com o aumento do carregamento aplicado e do vão da laje.

A partir dos resultados da análise probabilística, pôde-se verificar ainda quais os parâmetros afetam mais significativamente o valor do coeficiente multiplicador através do coeficiente de regressão padronizado e coeficiente de correlação parcial. Através desses coeficientes, pôde-se verificar que as incertezas nos modelos da fluência e retração do concreto da capa estrutural e, como já era esperado, os fatores ambientais (umidade relativa e temperatura ambiente) foram os parâmetros que tiveram maior influência no coeficiente multiplicador $\alpha$.

Como o coeficiente multiplicador da flecha imediata foi desenvolvido considerando a situação de lajes pré-moldadas biapoiadas. Procurou-se verificar a possibilidade de extrapolar as expressões para o caso de lajes contínuas. E através da análise de vários casos de lajes, pôde-se concluir que as expressões obtidas para as lajes biapoiadas podem ser utilizadas para as lajes contínuas desde que estas apresentem um nível de fissuração compatível com o ocorrido com as lajes biapoiadas, ou seja, além da fissuração no apoio deve haver a fissuração no vão compatível com a laje biapoiada correspondente. 
Foram realizados exemplos de determinação do coeficiente multiplicador da flecha imediata de lajes pré-moldadas formadas por vigotas com armação treliçada. Nos exemplos, foram consideradas lajes com $12 \mathrm{~cm}, 16 \mathrm{~cm}$ e $20 \mathrm{~cm}$ de altura, obtendo-se para o coeficiente multiplicador os valores apresentados na tabela 5.36. Nessa tabela, apresenta-se também o fator $\alpha_{f}$ e o coeficiente de fluência $\alpha$ recomendados pela NBR 6118 (2003), considerando idade de aplicação da carga de 21 dias.

O aumento entre os valores determinístico e probabilístico do coeficiente multiplicador variou entre 45,5\% para a laje LT16 com carga de utilização de 3,5 $\mathrm{kN} / \mathrm{m}^{2}$ e 55,6\% para a laje LT20, mostrando a importância da realização da análise probabilística. Quando comparado com o fator $\alpha_{\mathrm{f}}$, o coeficiente multiplicador da análise probabilística aumentou em até 59,3\%. Na realidade, se for considerado, por exemplo, umidade relativa de $50 \%$ e temperatura ambiente de $30^{\circ} \mathrm{C}$, o coeficiente $\alpha_{\mathrm{U}, \mathrm{T}}$ com $85 \%$ de probabilidade é de 1,72. E como o maior coeficiente

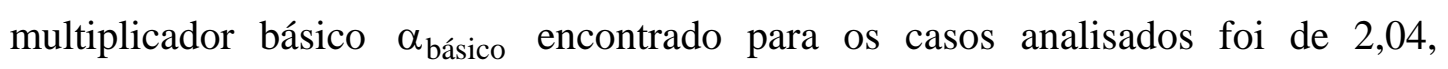
significa que o coeficiente multiplicador seria 3,51. Portanto, o valor do coeficiente multiplicador da flecha imediata de lajes pré-moldadas considerando análise probabilística com $85 \%$ de probabilidade pode alcançar valores muito além do fator $\alpha_{\mathrm{f}}$ recomendado pela NBR 6118 (2003) para o caso de vigas de concreto armado. Já o coeficiente de fluência $\alpha$ foi maior que o coeficiente multiplicador da análise probabilística para todos os exemplos, chegando a uma diferença de até 162,7\%.

TABELA 5.36 - Coeficientes obtidos para os exemplos realizados

\begin{tabular}{cccccc}
\hline \multirow{2}{*}{ laje } & $\begin{array}{c}\mathbf{q} \\
\left(\mathbf{k N} / \mathbf{m}^{2}\right)\end{array}$ & $\begin{array}{c}\boldsymbol{\alpha} \\
\text { análise } \\
\text { determinística }\end{array}$ & $\begin{array}{c}\boldsymbol{\alpha} \\
\text { análise } \\
\text { probabilística }\end{array}$ & $\begin{array}{c}\boldsymbol{\alpha}_{\mathbf{f}} \\
\text { (NBR 6118) }\end{array}$ & $\begin{array}{c}\boldsymbol{\varphi} \\
\text { (NBR 6118) }\end{array}$ \\
\hline \multirow{2}{*}{ LT12 } & 2,0 & 0,95 & 1,43 & 1,40 & 3,05 \\
\cline { 2 - 6 } & 3,5 & 1,26 & 1,89 & 1,40 & 3,05 \\
\cline { 2 - 6 } & 5,0 & 1,46 & 2,19 & 1,40 & 3,05 \\
\hline \multirow{2}{*}{ LT16 } & 2,0 & 0,92 & 1,34 & 1,40 & 3,52 \\
\cline { 2 - 6 } & 3,5 & 1,32 & 1,92 & 1,40 & 3,52 \\
\hline LT20 & 5,0 & 1,53 & 2,23 & 1,40 & 3,52 \\
\hline
\end{tabular}




\section{ANÁLISE DAS FLECHAS DIFERIDAS EM LAJES PRÉ-MOLDADAS}

\subsection{Considerações iniciais}

As lajes formadas por nervuras pré-moldadas são, conforme ilustradas na figura 5.1, constituídas basicamente de:

a) elementos lineares pré-moldados, que são as nervuras, dispostas espaçadamente em uma direção;

b) elementos de enchimento, intercalados entre os elementos prémoldados;

c) capa de concreto estrutural moldado no local.

Com relação às seções transversais, os elementos pré-moldados também denominados de vigotas podem ser com ou sem armadura saliente, em forma de $\mathrm{T}$ invertido ou I.

Os materiais de enchimento normalmente utilizados são blocos vazados de concreto ou material cerâmico, ou ainda blocos de poliestireno expandido, conhecidos pela sigla EPS. A utilização de elementos de material leve está ligada à idéia de substituir parte do concreto da região tracionada das lajes, bem como servir de sustentação à camada de concreto fresco que é aplicada sobre os painéis das lajes pré-fabricadas. 


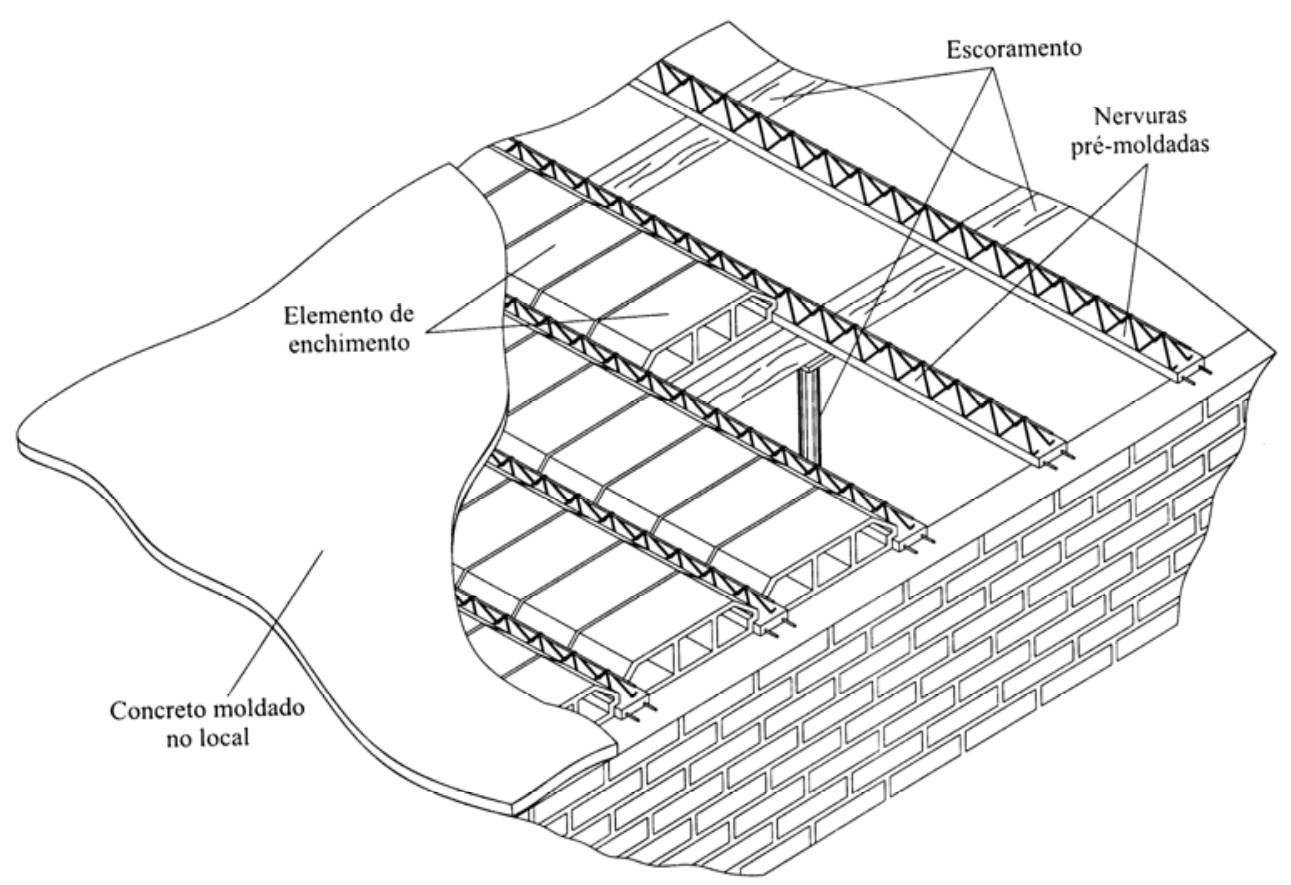

FIGURA 5.1 - Laje formada por nervuras pré-moldadas [EL DEBS (2000)]

Os tipos de vigotas utilizadas atualmente são os seguintes:

a) vigotas de concreto armado comum, não protendido, com seção transversal com a forma aproximada de um $\mathrm{T}$ invertido, com armadura passiva totalmente envolvida pelo concreto;

b) vigotas de concreto protendido, com seção transversal com a forma aproximada de um T invertido, com armadura de protensão prétracionada e totalmente envolvida pelo concreto;

c) vigotas com armação treliçada, formadas por uma armadura treliçada de aço e por uma placa de concreto envolvendo as barras inferiores da treliça que irão compor a armadura da face tracionada da laje.

As vigotas pré-moldadas de concreto armado são executadas em fôrmas metálicas, em pequenas unidades de produção, com instalações físicas simples. As vigotas de concreto protendido são produzidas em pistas de protensão utilizando, geralmente, fôrmas deslizantes. Já a base de concreto das vigotas com armação treliçada é moldada utilizando fôrmas metálicas, em espessuras de 2 a $3 \mathrm{~cm}$. 
As principais vantagens que podem ser apontadas na utilização dos pavimentos formados por vigotas pré-moldadas em relação aos pavimentos tradicionais de lajes maciças de concreto armado são:

a) considerando igualdade de vãos e sobrecargas, possuem menor peso próprio, com conseqüente alívio sobre as fundações;

b) dispensam o uso de fôrmas, pois os elementos pré-moldados e os elementos de enchimento fazem esse papel;

c) proporcionam a diminuição da mão-de-obra de execução.

Enquanto que as principais desvantagens desse sistema, como apontados por DROPPA Jr. (1999), são:

a) em geral, não possui um comportamento monolítico com o restante da estrutura, o que pode ser inconveniente sob o ponto de vista do contraventamento da edificação (exceção feita às vigotas com armação treliçada);

b) as vigotas de concreto armado e as vigotas protendidas são, às vezes, muito pesadas para manuseio, exigindo equipamentos para transporte e montagem no local.

As lajes formadas por vigotas pré-moldadas com armação treliçada têm ganhado destaque na construção civil brasileira nos últimos anos. Como destacado por DROPPA Jr. (1999), as lajes formadas por vigotas treliçadas detinham uma participação no mercado em 1990 de apenas 5\%, em 1998 saltou para 40\%, segundo dados da Abilaje (Associação Brasileira da Indústria de Lajes).

Além da aplicação em obras de pequeno porte, deve-se destacar que recentemente as lajes pré-moldadas com armação treliçada têm avançado rumo aos edifícios com maior número de pavimentos.

A armação treliçada das vigotas é uma estrutura formada por barras de aço eletrosoldadas em alguns pontos de modo a formar uma treliça espacial. Segundo a NBR 14862 (2002), a armação treliçada deve ser classificada a partir da abreviatura de armação treliçada (TR), a altura (em centímetros, sem casas decimais), diâmetros das armaduras do banzo superior, das diagonais (sinusóides) e 
do banzo inferior (diâmetros em milímetros, sem casas decimais). Quando a armadura for de aço CA60, não há nenhuma designação, quando for aço CA50, acrescenta-se a letra “A” em seguida ao número indicativo da bitola correspondente. Por exemplo, uma armação treliçada composta integralmente por aço CA60, com 8,0 cm de altura, banzo superior com 6,0 mm, diagonal com 3,4 mm e banzo inferior com 4,2 mm, será designada TR8634. Já uma armação treliçada composta parcialmente por aço CA50, com 20,0 cm de altura, banzo superior com 10,0 mm em aço CA50, diagonal com 6,0 mm e banzo inferior com 9,5 mm, será designada TR2010A69. Na figura 5.2 estão mostrados os elementos que compõe uma vigota pré-moldada com armação treliçada.
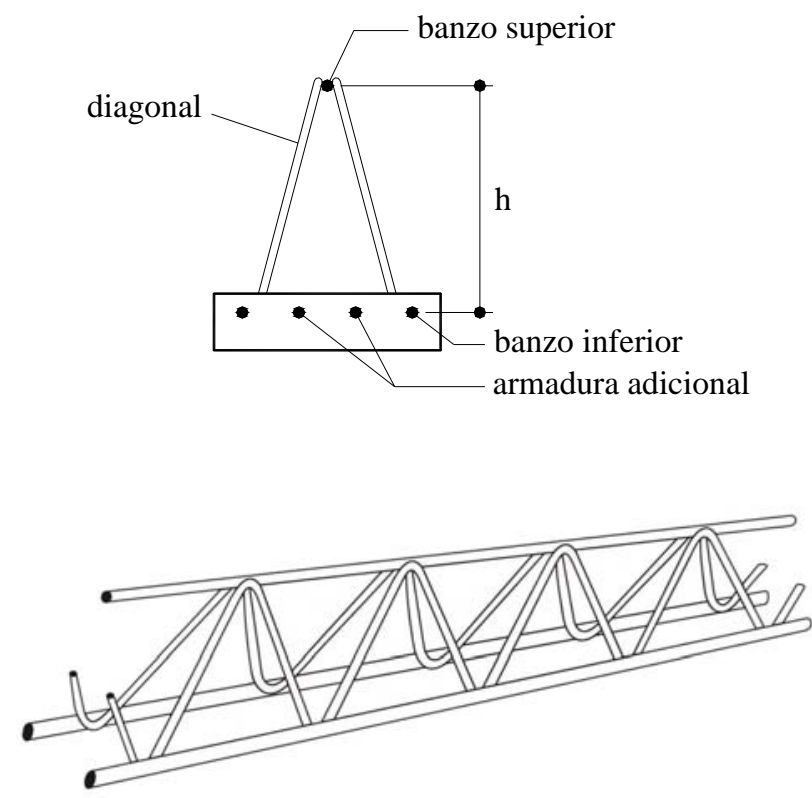

FIGURA 5.2 - Seção transversal da vigota treliçada e perspectiva da armação treliçada

Na utilização das vigotas pré-moldadas com armação treliçada, as seguintes vantagens podem ser destacadas [DROPPA Jr. (1999)]:

a) reduz o aparecimento de fissuras pela condição de aderência entre o concreto do capeamento e o concreto da vigota pré-moldada;

b) facilita a colocação de nervuras moldadas in loco na direção perpendicular às vigotas;

c) pode oferecer maior resistência ao cisalhamento em função da presença das diagonais da treliça. 
Apesar das inúmeras vantagens apresentadas, como em qualquer outro sistema construtivo, alguns cuidados devem ser tomados para que as lajes prémoldadas com armação treliçada apresentem um comportamento adequado. Dentre os cuidados adicionais, MAGALHÃES (2001) destaca:

a) a armadura das diagonais poderá ser considerada colaborante na resistência ao cisalhamento somente se estiver eficazmente ancorada na região comprimida do concreto;

b) em lajes contínuas, deve-se verificar o posicionamento da armadura negativa durante o lançamento e adensamento do concreto, de modo a garantir o valor de altura útil especificado em projeto;

c) sendo estas lajes formadas por elementos esbeltos, em edifícios com maior número de pavimentos deve-se analisar a resistência do plano da laje na transferência de ações horizontais, de modo que as lajes pré-moldadas com armação treliçada apresentem comportamento efetivo de diafragma;

d) por serem formadas por elementos muito esbeltos, deve ser verificado o comportamento para o estado limite de deformações excessivas.

\subsubsection{Cálculo da flecha}

Com relação ao cálculo das flechas imediatas ou diferidas no tempo de lajes formadas por vigotas pré-moldadas, as normas brasileiras NBR 14859-1 (2002) e NBR 14859-2 (2002) sobre lajes pré-fabricadas não apresentam qualquer procedimento de cálculo. E assim, para o cálculo das flechas de lajes formadas por vigotas pré-moldadas unidirecionais, deve remeter-se às indicações contidas na NBR 6118 (2003) relacionadas ao cálculo de flechas em vigas.

A NBR 6118 (2003) avalia a flecha imediata em vigas utilizando a expressão de rigidez equivalente proposto por BRANSON (1968) e a flecha diferida no tempo é avaliada de maneira aproximada pela multiplicação da flecha imediata pelo coeficiente $\alpha_{f}$. A norma espanhola EF-96 (1997), que trata especificamente 
sobre o projeto de lajes formadas por vigotas pré-moldadas, apresenta procedimentos semelhantes aos da NBR 6118 (2003).

\subsubsection{Cálculo da flecha imediata}

O cálculo da flecha imediata ou instantânea para vigas e lajes unidirecionais pode ser efetuado através da expressão padrão de elementos fletidos não fissurados, assumindo o concreto armado como um material de comportamento elástico e linear, dada por:

$\mathrm{a}_{\mathrm{o}}=\beta \cdot \frac{\mathrm{M}_{\max } \cdot \ell^{2}}{\mathrm{E} . \mathrm{I}}$

onde:

$M_{\max }-$ momento fletor máximo no vão $\ell$;

$\ell \quad$ - comprimento do vão;

E - módulo de elasticidade;

I - momento de inércia da seção transversal;

$\beta-$ - coeficiente que depende das condições de apoio e carregamento, conforme figura 5.3.
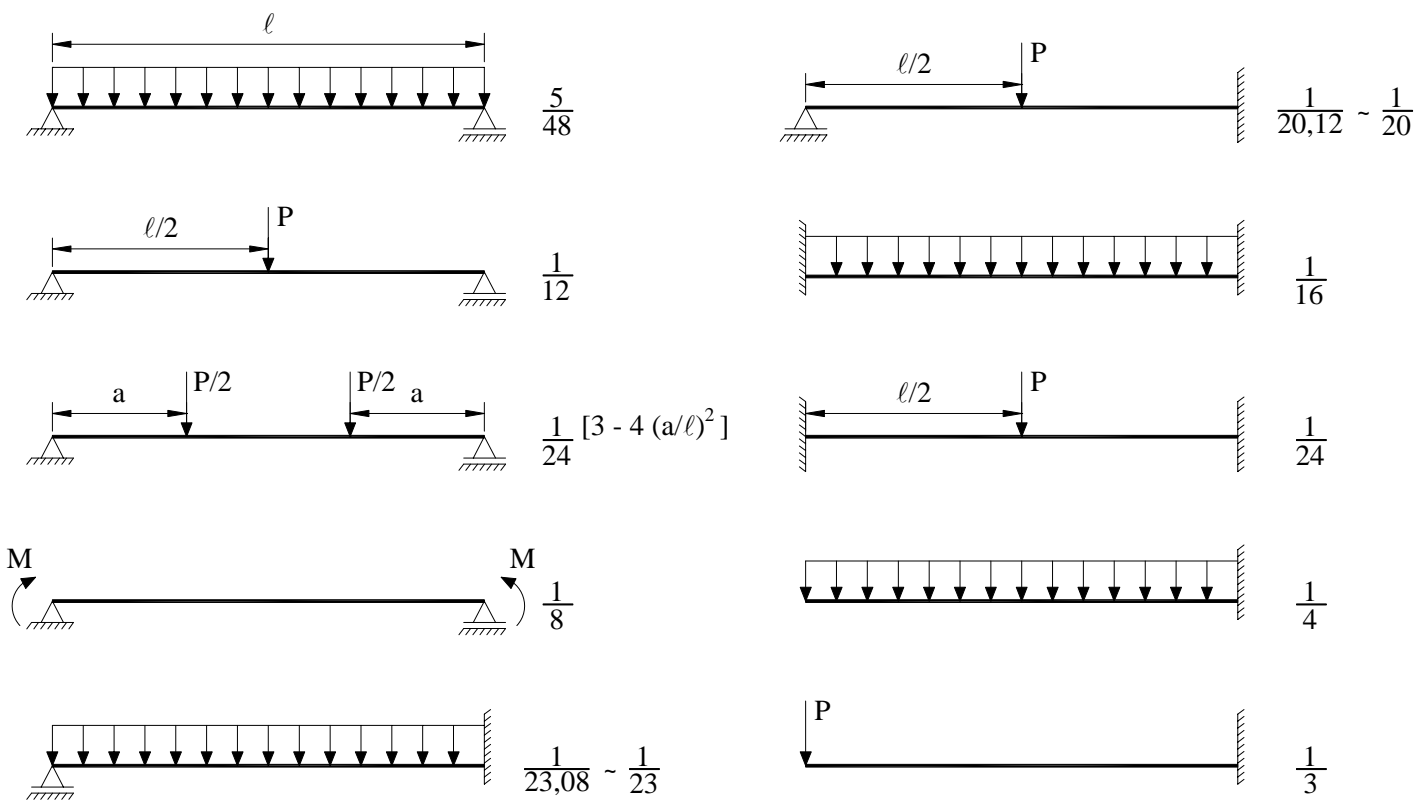

FIGURA 5.3 - Valores do coeficiente $\beta$ 
No entanto, ao longo do vão de um elemento fletido em concreto armado, encontram-se seções fissuradas e não fissuradas, com o concreto íntegro entre as fissuras colaborando para a rigidez da peça. Pode-se concluir, então, que existem seções nas quais o momento de inércia será menor do que o momento de inércia da seção não fissurada, e maior do que o momento de inércia da seção fissurada.

Visando à avaliação da influência da fissuração e da colaboração do concreto tracionado entre as fissuras no momento de inércia da seção transversal, BRANSON (1968) realizou um estudo experimental em vigas retangulares e T, submetidas a carregamentos uniformemente distribuídos e de curta duração.

Baseado nos resultados de seus ensaios e nos de outros pesquisadores, ele sugeriu a utilização de um valor médio de momento de inércia, compreendido entre o momento de inércia da seção não fissurada, $I_{I}$, e o da seção fissurada, $I_{\text {II }}$, chamado de momento de inércia efetivo, dado por:

$$
I_{e}=\left(\frac{M_{r}}{M_{\max }}\right)^{m} \cdot I_{I}+\left[1-\left(\frac{M_{r}}{M_{\max }}\right)^{m}\right] . I_{I I} \leq I_{I}
$$

sendo:

$M_{\mathrm{r}} \quad$ - momento de fissuração;

$\mathrm{M}_{\max }-$ momento fletor máximo atuante no vão;

$\mathrm{I}_{\mathrm{I}} \quad-$ momento de inércia da seção bruta de concreto;

II $\quad-$ momento de inércia da seção de concreto fissurada, no Estádio II;

m - potência que define se o momento de inércia está sendo calculado para seções individuais ou para todo o vão.

Para a determinação do momento de inércia efetivo em seções individuais de um vão qualquer, a potência m da equação anterior deve ser igual a 4 . Já para um valor médio correspondente a todas as seções ao longo do comprimento do vão, a potência m deve ser igual a 3, e a equação anterior passa a ser escrita como:

$$
I_{e}=\left(\frac{M_{r}}{M_{\max }}\right)^{3} \cdot I_{I}+\left[1-\left(\frac{M_{r}}{M_{\text {max }}}\right)^{3}\right] . I_{I I} \leq I_{I}
$$


A equação anterior é a equação apresentada pela NBR 6118 (2003) e pela EF-96 (1997) para o cálculo das flechas imediatas. Esta equação foi inicialmente estabelecida para vigas simplesmente apoiadas sujeitas a um carregamento uniformemente distribuído, NEVILLE et al. (1983) afirma que pequenos erros são introduzidos se a expressão for aplicada para outras configurações de carregamento e condições de apoio. No caso de vigas contínuas, os momentos de inércia efetivos para as regiões de momento fletor positivo e negativo normalmente não têm o mesmo valor. Assim, pode-se obter o valor do momento de inércia efetivo por tramo a partir de uma média simples entre o momento de inércia efetivo da região de momento fletor positivo e o da região de momentos fletores negativos nos apoios, dada por:

$$
\mathrm{I}_{\mathrm{e}}=\frac{\mathrm{I}_{\mathrm{e} 2}+\frac{\left(\mathrm{I}_{\mathrm{e} 1}+\mathrm{I}_{\mathrm{e} 3}\right)}{2}}{2}
$$

sendo:

$\mathrm{I}_{\mathrm{e} 2} \quad-$ momento de inércia efetivo para o meio do vão;

$\mathrm{I}_{\mathrm{e} 1}, \mathrm{I}_{\mathrm{e} 3}$ - momento de inércia efetivo, respectivamente, para o apoio esquerdo e direito.

\subsubsection{Cálculo da flecha diferida no tempo}

A NBR 6118 (2003) prescreve que a flecha adicional diferida, decorrente das cargas de longa duração em função da fluência, pode ser calculada de maneira aproximada pela multiplicação da flecha imediata pelo fator $\alpha_{\mathrm{f}}$ dado pela expressão:

$$
\alpha_{\mathrm{f}}=\frac{\Delta \xi}{1+50 \cdot \rho^{\prime}}
$$

Com

$\rho^{\prime}=\frac{A_{s}^{\prime}}{\text { b.d }}$

onde:
$\mathrm{A}_{\mathrm{S}}{ }^{\prime} \quad$ - área da armadura de compressão;
b - largura da seção transversal;
d - altura útil. 
E ainda

$$
\begin{array}{ll}
\Delta \xi=\xi(\mathrm{t})-\xi\left(\mathrm{t}_{\mathrm{o}}\right) & 5.7 \mathrm{a} \\
\xi(\mathrm{t})=0,68 .\left(0,996^{\mathrm{t}}\right) \mathrm{t}^{0,32} & \text { para } \mathrm{t} \leq 70 \text { meses } \\
\begin{array}{l}
\xi(\mathrm{t})=2 \\
\text { sendo: }
\end{array} & \text { para } \mathrm{t}>70 \text { meses } \\
\mathrm{t} \quad-\text { tempo, em meses, em que o valor do flecha diferida é desejada; } \\
\mathrm{t}_{\mathrm{o}} \quad-\text { idade, em meses, relativa à data de aplicação da carga de longa } \\
\end{array}
$$

No caso de parcelas de carga de longa duração serem aplicadas em idades diferentes, pode-se tomar para $\mathrm{t}_{\mathrm{o}} \mathrm{o}$ valor ponderado por:

$$
\mathrm{t}_{\mathrm{o}}=\frac{\sum \mathrm{P}_{\mathrm{i}} \cdot \mathrm{t}_{\mathrm{oi}}}{\sum \mathrm{P}_{\mathrm{i}}}
$$

onde:

$\mathrm{P}_{\mathrm{i}} \quad$ - representa as parcelas de carga;

$t_{o i} \quad$ - idade em que se aplicou cada parcela $P_{i}$, em meses.

Já a EF-96 (1997) propõe que a flecha diferida de lajes formadas por vigotas pré-moldadas pode ser avaliada utilizando a seguinte expressão:

$$
\mathrm{a}_{\mathrm{d}}=\mathrm{a}_{\mathrm{o}} \cdot \sum \mathrm{k}_{\mathrm{i}} \cdot\left(2-\xi_{\mathrm{i}}\right) \cdot \lambda
$$

sendo:

$\mathrm{a}_{\mathrm{o}} \quad$ - flecha imediata referente à carga total $\mathrm{g}+\mathrm{q}$;

$\mathrm{k}_{\mathrm{i}}$ - relação entre a carga permanente $\mathrm{i}$ (peso próprio da laje, revestimento, etc) e a carga total, $g_{i} / g+q$;

$\xi_{\mathrm{i}} \quad$ - coeficiente dependente do instante de aplicação da carga permanente i, conforme tabela 5.1;

$\lambda$ - coeficiente dependente da taxa geométrica da armadura de compressão nos extremos do tramo e do tipo de tramo, dado por:

$$
\begin{array}{ll}
\lambda=1 & \text { tramo isolado } \\
\lambda=0,85+0,15 /\left(1+50 \cdot \rho_{1}\right) & \text { tramo extremo } \\
\lambda=0,70+0,30 /\left[1+50 \cdot\left(\rho_{1}+\rho_{2}\right)\right] & \text { tramo interno } \\
\lambda=1 /\left(1+50 \cdot \rho_{3}\right) & \text { balanço }
\end{array}
$$


TABELA 5.1 - Coeficiente dependente do instante de aplicação da carga [EF-96 (1997)]

\begin{tabular}{|c|c|}
\hline meses & $\xi_{\mathbf{i}}$ \\
\hline 0,5 & 0,48 \\
\hline 1 & 0,68 \\
\hline 2 & 0,88 \\
\hline 3 & 1,00 \\
\hline 4 & 1,08 \\
\hline 5 & 1,15 \\
\hline 6 & 1,20 \\
\hline 7 & 1,24 \\
\hline 8 & 1,28 \\
\hline 10 & 1,35 \\
\hline 12 & 1,40 \\
\hline 18 & 1,52 \\
\hline 24 & 1,60 \\
\hline 36 & 1,72 \\
\hline 48 & 1,80 \\
\hline 60 & 1,86 \\
\hline 72 & 1,92 \\
\hline 84 & 1,96 \\
\hline 96 & 2,00 \\
\hline
\end{tabular}

\subsubsection{Combinações de ações}

As ações atuantes na construção são classificadas, segundo a NBR 8681 (2003), em permanentes, variáveis e excepcionais.

As ações permanentes são aquelas que ocorrem com valores praticamente constantes durante toda a vida da construção, como por exemplo, o peso próprio da estrutura e dos revestimentos. As ações variáveis são as que apresentam variações significativas durante a vida da construção, como exemplos, têm as cargas acidentais de uso da construção e a ação do vento. Já as ações excepcionais, são as que têm duração extremamente curta e muito baixa probabilidade de ocorrência durante a vida da construção, mas que devem ser consideradas nos projetos de determinadas estruturas, tais como, ações decorrentes de explosões e abalos sísmicos excepcionais.

A NBR 6118 (2003) permite que as ações sejam combinadas em função da probabilidade que têm de atuarem simultaneamente sobre a estrutura, durante um determinado período. Para a verificação dos estados limites de serviço, são definidos três tipos de combinação de ações: quase permanente, freqüente e rara, de acordo com a ordem de grandeza de permanência na estrutura. 
Na combinação quase permanente, utilizada na verificação do estado limite de deformações excessivas, todas as ações variáveis sofrem a mesma redução, sendo consideradas com seus valores quase permanentes $\psi_{2} \cdot \mathrm{F}_{\mathrm{q}, \mathrm{k}}$, conforme a seguinte expressão:

$$
F_{d, s e r}=\sum_{i=1}^{m} F_{g i, k}+\sum_{j=1}^{n} \psi_{2 j} \cdot F_{q j, k}
$$

Na combinação freqüente, utilizada na verificação dos estados limites de formação de fissuras, de abertura de fissuras e de vibrações excessivas, a ação variável principal $\mathrm{F}_{\mathrm{q} 1}$ é considerada com seu valor freqüente $\psi_{1} \cdot \mathrm{F}_{\mathrm{q} 1, \mathrm{k}}$ e todas as demais ações variáveis são tomadas com seus valores quase permanentes $\psi_{2} \cdot \mathrm{F}_{\mathrm{q}, \mathrm{k}}$, conforme a seguinte expressão:

$$
\mathrm{F}_{\mathrm{d}, \mathrm{ser}}=\sum_{\mathrm{i}=1}^{\mathrm{m}} \mathrm{F}_{\mathrm{gi}, \mathrm{k}}+\psi_{1} \cdot \mathrm{F}_{\mathrm{q} 1, \mathrm{k}}+\sum_{\mathrm{j}=1}^{\mathrm{n}} \psi_{2 \mathrm{j}} \cdot \mathrm{F}_{\mathrm{qj}, \mathrm{k}}
$$

Já na combinação rara, utilizada na verificação do estado limite de formação de fissuras, a ação variável principal $\mathrm{F}_{\mathrm{q} 1}$ é considerada com seu valor característico e todas as demais ações variáveis são tomadas com seus valores freqüentes $\psi_{1} \cdot \mathrm{F}_{\mathrm{q}, \mathrm{k}}$, conforme a seguinte expressão:

$$
\mathrm{F}_{\mathrm{d}, \mathrm{ser}}=\sum_{\mathrm{i}=1}^{\mathrm{m}} \mathrm{F}_{\mathrm{gi}, \mathrm{k}}+\mathrm{F}_{\mathrm{q} 1, \mathrm{k}}+\sum_{\mathrm{j}=1}^{\mathrm{n}} \psi_{1 \mathrm{j}} \cdot \mathrm{F}_{\mathrm{qj}, \mathrm{k}}
$$

Nas equações anteriores, $F_{d \text {,ser }}$ representa o valor de cálculo das ações para a combinação considerada e $\psi_{\mathrm{i}}$ é o coeficiente de redução das ações variáveis, conforme tabela 5.2.

Para a verificação dos estados limites de serviço, a EF-96 (1997) adota coeficiente de ponderação igual a zero para as ações variáveis que produzam efeitos favoráveis na estrutura e coeficiente igual a 1,0 para os demais casos. 
TABELA 5.2 - Valores de $\psi_{1}$ e $\psi_{2}$, segundo NBR 6118 (2003)

\begin{tabular}{|c|c|c|c|}
\hline \multicolumn{2}{|r|}{ Ações } & $\psi_{1}$ & $\psi_{2}$ \\
\hline \multirow{3}{*}{$\begin{array}{l}\text { Cargas acidentais } \\
\text { de edifícios }\end{array}$} & $\begin{array}{l}\text { Locais em que não há predominância de pesos de } \\
\text { equipamentos que permanecem fixos por longos } \\
\text { períodos de tempo, nem de elevadas concentrações } \\
\text { de pessoas }\end{array}$ & 0,4 & 0,3 \\
\hline & $\begin{array}{l}\text { Locais em que há predominância de pesos de } \\
\text { equipamentos que permanecem fixos por longos } \\
\text { períodos de tempo, ou de elevadas concentrações de } \\
\text { pessoas }\end{array}$ & 0,6 & 0,4 \\
\hline & Bibliotecas, arquivos, oficinas e garagens & 0,7 & 0,6 \\
\hline Vento & Pressão dinâmica do vento em estruturas em geral & 0,3 & 0 \\
\hline Temperatura & $\begin{array}{l}\text { Variações uniformes de temperatura em relação à } \\
\text { média anual local }\end{array}$ & 0,5 & 0,3 \\
\hline
\end{tabular}

\subsubsection{Deslocamentos limites}

De acordo com a NBR 6118 (2003), deslocamentos limites são valores práticos utilizados para verificação em serviço do estado limite de deformações excessivas da estrutura, sendo classificados nos quatro grupos básicos relacionados a seguir e devem obedecer aos limites estabelecidos na tabela 5.3.

- aceitabilidade sensorial: limite caracterizado por vibrações indesejáveis ou efeito visual desagradável.

- efeitos específicos: os deslocamentos podem impedir a utilização adequada da construção, causando problemas, por exemplo, ao alinhamento de equipamentos sensíveis apoiados nos elementos estruturais, ao desenvolvimento de atividades previstas ou à drenagem de lajes de piso e cobertura.

- efeitos em elementos não estruturais: deslocamentos estruturais podem ocasionar o mau funcionamento de elementos que, apesar de não fazerem parte da estrutura, estão ligados a ela. Os danos em elementos não estruturais podem variar desde fissuras em paredes e forros e problemas de funcionamento de portas e janelas até quebra de elementos de vidro.

- efeitos em elementos estruturais: os deslocamentos podem afetar o comportamento do elemento estrutural, provocando afastamento em relação às hipóteses de cálculo adotadas. Se os deslocamentos forem relevantes para o elemento 
considerado, seus efeitos sobre as tensões ou sobre a estabilidade da estrutura devem ser considerados, incorporando-as ao modelo estrutural adotado.

TABELA 5.3 - Limites para deslocamentos segundo NBR 6118 (2003)

\begin{tabular}{|c|c|c|c|}
\hline $\begin{array}{l}\text { Razão da } \\
\text { limitação }\end{array}$ & Exemplos & $\begin{array}{c}\text { Deslocamento a } \\
\text { considerar }\end{array}$ & $\begin{array}{l}\text { Deslocamento } \\
\text { limite }\end{array}$ \\
\hline \multicolumn{4}{|c|}{ Aceitabilidade sensorial } \\
\hline Visual & $\begin{array}{l}\text { Deslocamentos visíveis } \\
\text { em elementos estruturais }\end{array}$ & Deslocamento total & $\ell / 250$ \\
\hline Outro & $\begin{array}{c}\text { Vibrações sentidas no } \\
\text { piso }\end{array}$ & $\begin{array}{c}\text { Deslocamento devido à } \\
\text { carga acidental }\end{array}$ & $\ell / 350$ \\
\hline \multicolumn{4}{|c|}{ Efeitos estruturais em serviço } \\
\hline $\begin{array}{c}\text { Superfícies que } \\
\text { devem drenar água }\end{array}$ & Coberturas e varandas & Deslocamento total & $\ell / 250^{1)}$ \\
\hline \multirow{2}{*}{$\begin{array}{l}\text { Pavimentos que } \\
\text { devem permanecer } \\
\text { planos }\end{array}$} & \multirow{2}{*}{$\begin{array}{l}\text { Ginásios e pistas de } \\
\text { boliche }\end{array}$} & Deslocamento total & $\begin{array}{c}\ell / 350+ \\
\text { contraflecha }^{2)} \\
\end{array}$ \\
\hline & & $\begin{array}{c}\text { Deslocamento ocorrido } \\
\text { após a construção do piso }\end{array}$ & $\ell / 600$ \\
\hline $\begin{array}{l}\text { Elementos que } \\
\text { suportam } \\
\text { equipamentos } \\
\text { sensíveis }\end{array}$ & Laboratórios & $\begin{array}{l}\text { Deslocamento ocorrido } \\
\text { após nivelamento do } \\
\text { aparelho }\end{array}$ & $\begin{array}{l}\text { De acordo com } \\
\text { recomendações } \\
\text { do fabricante }\end{array}$ \\
\hline \multicolumn{4}{|c|}{ Efeitos em elementos não estruturais } \\
\hline \multirow[b]{2}{*}{ Paredes } & $\begin{array}{c}\text { Alvenaria, caixilhos e } \\
\text { revestimentos }\end{array}$ & $\begin{array}{c}\text { Deslocamento ocorrido } \\
\text { após a construção da parede }\end{array}$ & $\ell / 500^{3)}$ ou $10 \mathrm{~mm}$ \\
\hline & $\begin{array}{l}\text { Divisórias leves e } \\
\text { caixilhos telescópicos }\end{array}$ & $\begin{array}{l}\text { Deslocamento ocorrido } \\
\text { após a instalação da } \\
\text { divisória }\end{array}$ & $\ell / 250^{3)}$ ou $25 \mathrm{~mm}$ \\
\hline \multirow{2}{*}{ Forros } & Revestimentos colados & $\begin{array}{l}\text { Deslocamento ocorrido } \\
\text { após a construção do forro }\end{array}$ & $\ell / 350$ \\
\hline & $\begin{array}{c}\text { Revestimentos } \\
\text { pendurados ou com juntas }\end{array}$ & $\begin{array}{c}\text { Deslocamento ocorrido } \\
\text { após a construção do forro }\end{array}$ & $\ell / 175$ \\
\hline \multicolumn{4}{|c|}{ Efeitos em elementos estruturais } \\
\hline $\begin{array}{l}\text { Afastamento em } \\
\text { relação às hipóteses } \\
\text { de cálculo adotadas }\end{array}$ & \multicolumn{3}{|c|}{$\begin{array}{l}\text { Se os deslocamentos forem relevantes para o elemento considerado, seus } \\
\text { efeitos sobre as tensões ou sobre a estabilidade da estrutura devem ser } \\
\text { considerados, incorporando-os ao modelo estrutural adotado. }\end{array}$} \\
\hline \multirow{2}{*}{\multicolumn{4}{|c|}{$\begin{array}{l}\text { 1) As superfícies devem ser suficientemente inclinadas ou o deslocamento compensado por } \\
\text { contraflechas, de modo a não se ter acúmulo de água. } \\
\text { 2) Os deslocamentos podem ser parcialmente compensados pela especificação de contraflechas. } \\
\text { Entretanto, a situação isolada da contraflecha não pode ocasionar um desvio do plano maior que } \\
\ell / 350 \text {. } \\
\text { 3) O vão } \ell \text { deve ser tomado na direção na qual a parede ou a divisória se desenvolve. }\end{array}$}} \\
\hline & & & \\
\hline \multicolumn{4}{|l|}{ NOTAS: } \\
\hline \multicolumn{4}{|c|}{$\begin{array}{l}\text { 1) Todos os valores limites de deslocamentos supõem elementos de vão } \ell \text { suportados em ambas } \\
\text { as extremidades por apoios que não se movem. Quando se tratar de balanços, o vão } \\
\text { equivalente a ser considerado deve ser o dobro do comprimento do balanço; }\end{array}$} \\
\hline \multicolumn{4}{|c|}{$\begin{array}{l}\text { 2) Para o caso de elementos de superfície, os limites prescritos consideram que o valor de } \ell \text { é o } \\
\text { menor vão, exceto em casos de verificação de paredes e divisórias, onde interessa a direção } \\
\text { na qual a parede ou divisória se desenvolve. }\end{array}$} \\
\hline
\end{tabular}


Já a EF-96 (1997) limita as flechas das lajes nos seguintes valores:

a) a flecha total no tempo infinito não deve exceder o menor dos valores $\ell / 250$ e $\ell / 500+1 \mathrm{~cm}$;

b) para lajes que irão suportar paredes: a flecha ocorrido após a construção da parede não deve exceder o menor dos valores $\ell / 400$ e $\ell / 800+0,6 \mathrm{~cm}$;

c) para lajes que irão suportar paredes muito rígidas: a flecha ocorrido após a construção da parede não deve exceder o menor dos valores $\ell / 500$ e $\ell / 1000+0,5 \mathrm{~cm}$.

Nas expressões anteriores $\ell$ é o valor do vão e, no caso de balanço, 1,6 vezes o valor do balanço.

Nas lajes com vãos menores que 7 metros e sobrecargas não maiores que 4 kN/m², a EF-96 (1997) indica que não é necessário verificar a flecha caso a altura total da laje for maior que:

$\mathrm{h}=\delta_{1} \cdot \delta_{2} \cdot \ell / \mathrm{C}[\mathrm{m}]$

onde:

$\delta_{1} \quad$ - fator que depende da carga total $(\mathrm{p}=\mathrm{g}+\mathrm{q})$, tendo valor igual a $\sqrt{\mathrm{p} / 7}$, com $\mathrm{p}$ em $\mathrm{kN} / \mathrm{m}^{2}$;

$\delta_{2} \quad$ - fator com valor igual a $\sqrt[4]{\ell / 6}$;

$\ell \quad$ - vão de cálculo da laje em metros;

C - coeficiente cujo valor pode ser encontrado na tabela 5.4.

TABELA 5.4 - Valor do coeficiente C definido pela EF-96 (1997)

\begin{tabular}{|c|c|c|c|}
\hline \multirow{2}{*}{} & \multicolumn{3}{|c|}{ tipo de tramo } \\
\cline { 2 - 4 } & isolado & extremo & interior \\
\hline com paredes & 17 & 21 & 24 \\
\hline com divisórias & 18 & 22 & 25 \\
\hline cobertura & 20 & 24 & 27 \\
\hline
\end{tabular}


Como visto acima, as indicações contidas nas normas relativas à avaliação das flechas diferidas no tempo são voltadas para o caso de flechas em vigas, não sendo especificamente para as lajes com vigotas pré-moldadas.

Portanto, o que se pretende neste capítulo é realizar a análise das flechas diferidas de lajes pré-moldadas formadas por vigotas com armação treliçada, visando fornecer indicações de projeto através da proposta de um multiplicador das flechas imediatas para avaliação das flechas diferidas.

Esta análise foi realizada utilizando a metodologia descrita nos capítulos anteriores, ou seja, análise numérica, utilizando o programa computacional CONSNOU, em conjunto com análise probabilística, executada utilizando o método de amostragem por hipercubo latino.

\subsection{Análise preliminar}

Inicialmente foi realizada uma análise preliminar para tentar avaliar quais os parâmetros envolvidos influenciaria mais significativamente o coeficiente multiplicador das flechas imediatas.

\subsubsection{Características das lajes}

Foram analisadas lajes pré-moldadas formadas por vigotas com armação treliçada, compostas ainda por blocos de enchimento de poliestireno expandido (EPS) e uma capa de concreto estrutural moldada no local. Conforme a figura 5.4, as lajes possuíam 49 cm de distância entre nervuras e altura total de 12, 16, 20, 25 e 30 cm, tendo a seguinte denominação, respectivamente, LT12, LT16, LT20, LT25 e LT30. 


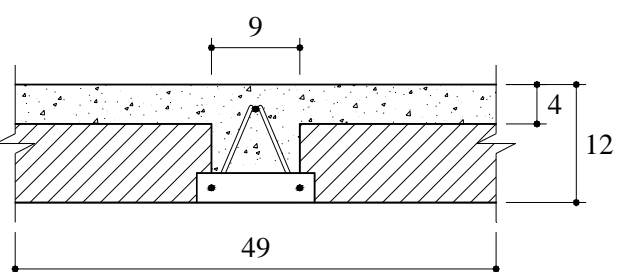

laje LT12

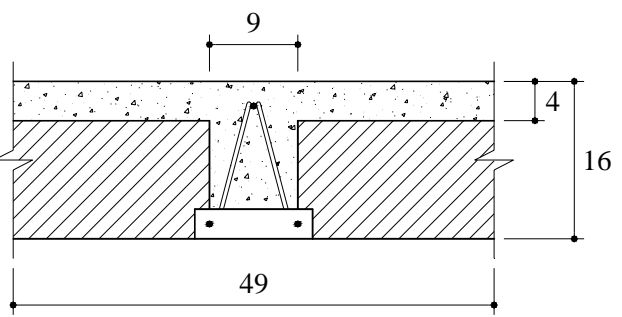

laje LT16

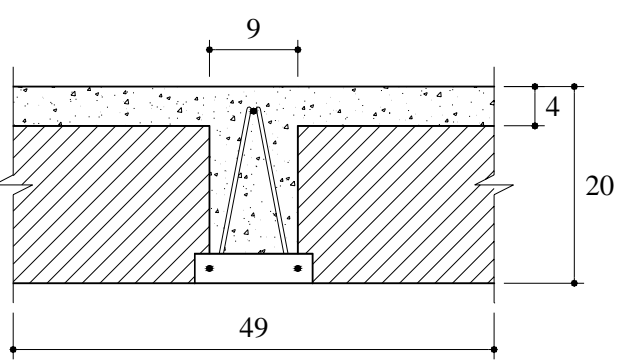

laje LT20

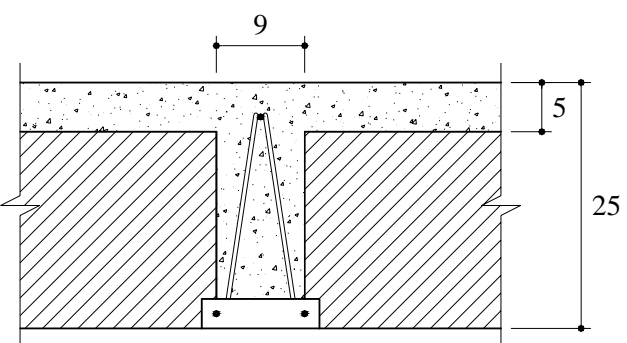

49

laje LT25

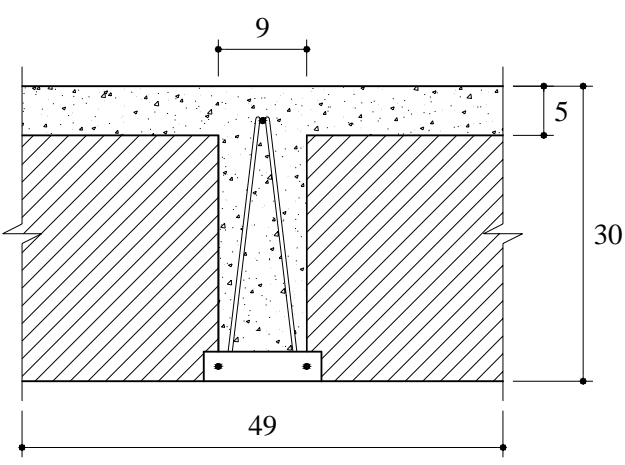

laje LT30

FIGURA 5.4 - Seção transversal das lajes (dimensões em cm)

Para cada tipo de laje, foi empregada uma vigota pré-moldada distinta, sendo que a diferença foi o tipo de treliça eletrosoldada utilizada em cada uma delas. As características geométricas das vigotas estão apresentadas na figura 5.5 e as particularidades das treliças eletrosoldadas utilizadas em cada uma das lajes estão apresentadas na tabela 5.5 .

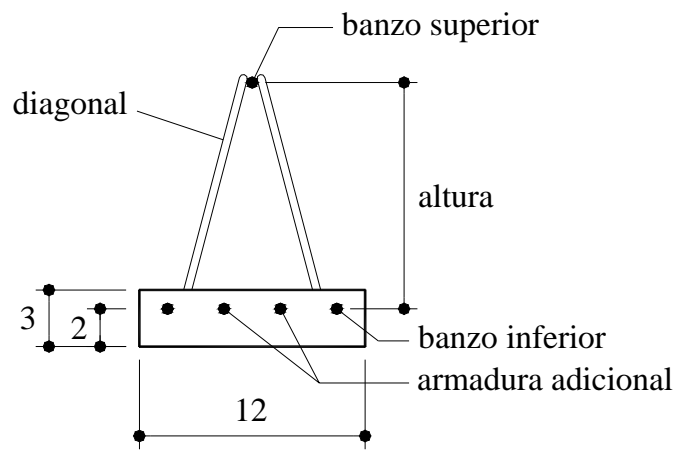

FIGURA 5.5 - Vigota (dimensões em cm) 
TABELA 5.5 - Característica da treliça eletrosoldada (valores em mm)

\begin{tabular}{cccccc}
\hline laje & $\begin{array}{c}\text { altura da } \\
\text { treliça }\end{array}$ & $\begin{array}{c}\text { diâmetro da } \\
\text { armadura do } \\
\text { banzo superior }\end{array}$ & $\begin{array}{c}\text { diâmetro da } \\
\text { armadura } \\
\text { da diagonal }\end{array}$ & $\begin{array}{c}\text { diâmetro da } \\
\text { armadura do } \\
\text { banzo inferior }\end{array}$ & designação \\
\hline LT12 & 8 & 6 & 4,2 & 4,2 & TR08644 \\
LT16 & 12 & 6 & 4,2 & 5 & TR12645 \\
LT20 & 16 & 7 & 4,2 & 5 & TR16745 \\
LT25 & 20 & 7 & 4,2 & 6 & TR20746 \\
LT30 & 25 & 8 & 5 & 6 & TR25856 \\
\hline
\end{tabular}

\subsubsection{Processo construtivo da laje pré-moldada}

Para a construção da laje pré-moldada, as vigotas após terem sido confeccionadas na fábrica são transportadas à obra e posicionadas sobre os apoios, com a presença de apoios provisórios (escoramento). Em seguida, após o posicionamento dos elementos de enchimento é feita a concretagem da capa estrutural. Após o concreto ter resistência suficiente, o escoramento é retirado.

Assim, considerando o processo construtivo da laje pré-moldada, será definido como $t_{1}$ o intervalo de tempo da confecção da vigota até a concretagem da capa estrutural (figura 5.6). Já o intervalo de tempo entre a concretagem da capa e a retirada do escoramento será denominado $t_{2}$. Juntamente com a retirada do escoramento, será considerada a aplicação do carregamento na laje, originando a flecha instantânea $\mathrm{a}_{\text {inst }}$. Mantido o carregamento constante durante todo o intervalo $\mathrm{t}_{3}$, haverá um acréscimo no valor da flecha, resultando na flecha total $\mathrm{a}_{\text {total }}$. 


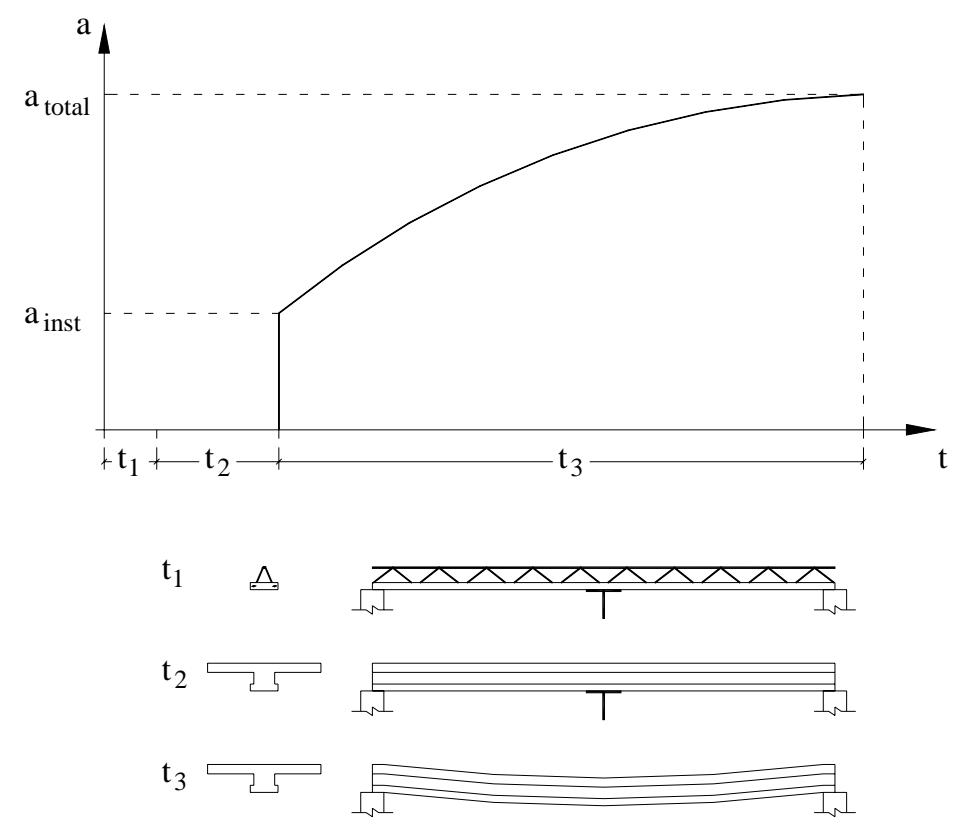

FIGURA 5.6 - Processo construtivo da laje pré-moldada

A flecha diferida pode ser avaliada através de um coeficiente multiplicador da flecha instantânea. Esse coeficiente multiplicador pode ser calculado através da seguinte expressão:

$$
\alpha=\frac{\mathrm{a}_{\text {total }}-\mathrm{a}_{\text {inst }}}{\mathrm{a}_{\text {inst }}}
$$

\subsubsection{Parâmetros adotados}

Para esta análise preliminar, foram consideradas duas situações distintas para cada tipo de laje. A situação 1 correspondendo à atuação de uma carga acidental de $5,0 \mathrm{kN} / \mathrm{m}^{2}$ e a situação 2, com carga acidental de $2,5 \mathrm{kN} / \mathrm{m}^{2}$.

Como mostrados na tabela 5.6, os vãos e armaduras adicionais adotados para cada situação foram compatíveis com a carga acidental empregada, sendo considerada ainda a atuação de uma carga permanente referente ao revestimento de $0,5 \mathrm{kN} / \mathrm{m}^{2}$. A resistência característica à compressão do concreto foi de $20 \mathrm{MPa}$ e a resistência característica à tração do aço foi de $600 \mathrm{MPa}$ para as barras com diâmetro até $6 \mathrm{~mm}$ e $500 \mathrm{MPa}$ para as demais. 
TABELA 5.6 - Situações consideradas para cada tipo de laje

\begin{tabular}{cccc}
\hline laje & $\mathbf{A}_{\text {s,adic }}$ & $\ell_{\mathbf{1}}(\mathbf{m})$ & $\ell_{\mathbf{2}}(\mathbf{m})$ \\
\hline LT12 & $3 \phi 8 \mathrm{~mm}$ & 3,5 & 4,0 \\
LT16 & $3 \phi 10 \mathrm{~mm}$ & 4,5 & 5,5 \\
LT20 & $3 \phi 10 \mathrm{~mm}$ & 5,5 & 6,5 \\
LT25 & $3 \phi 12,5 \mathrm{~mm}$ & 7,0 & 8,5 \\
LT30 & $3 \phi 12,5 \mathrm{~mm}$ & 8,5 & 9,5 \\
\hline$\ell_{1}$ - vão para carga acidental de $5,0 \mathrm{kN} / \mathrm{m}^{2}$ \\
$\ell_{2}$ - vão para carga acidental de $2,5 \mathrm{kN} / \mathrm{m}^{2}$ \\
\hline
\end{tabular}

Para avaliar quais os parâmetros afetam de forma mais relevante o coeficiente multiplicador $\alpha$, foram determinados tais coeficientes a partir de um valor base desses parâmetros e em seguida variando-os um a um. E assim, o parâmetro que gerar maior variação no coeficiente multiplicador $\alpha$, terá maior influência sobre ele. As variações consideradas para a carga acidental (q), resistência

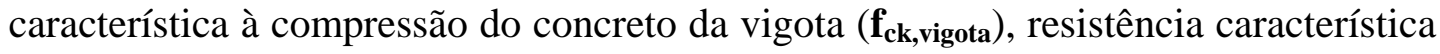
à compressão do concreto da capa ( $\mathbf{f}_{\text {ck,capa }}$ ), idade da concretagem da capa $\left(\mathbf{t}_{1}\right)$, intervalo de tempo entre a concretagem da capa e a retirada do escoramento $\left(\mathbf{t}_{2}\right)$, umidade relativa do ambiente (U) e temperatura ambiente (T) estão apresentados na tabela 5.7. Já as variações consideradas para os vãos das lajes estão mostradas na tabela 5.8.

As flechas foram determinadas a partir da combinação quase-permanente das ações.

$$
\mathrm{F}_{\mathrm{d}, \mathrm{ser}}=\mathrm{F}_{\mathrm{gk}}+0,3 \cdot \mathrm{F}_{\mathrm{qk}}
$$

Foi considerado ainda que o intervalo de tempo que o carregamento atuante permaneceu constante $\left(\mathbf{t}_{3}\right)$ foi de 2200 dias, ou seja, aproximadamente 6 anos.

TABELA 5.7 - Variações consideradas para os parâmetros

\begin{tabular}{|c|c|c|c|c|c|c|c|c|}
\hline & \multicolumn{2}{|c|}{$\underset{\left(k N / m^{2}\right)}{q}$} & \multirow{2}{*}{$\begin{array}{c}\mathbf{f}_{\text {ck,vigota }} \\
\text { (MPa) }\end{array}$} & \multirow{2}{*}{$\begin{array}{l}\mathbf{f}_{\text {ck,capa }} \\
\text { (MPa) }\end{array}$} & \multirow{2}{*}{$\begin{array}{c}\mathbf{t}_{1} \\
\text { (dias) }\end{array}$} & \multirow{2}{*}{$\begin{array}{c}t_{2} \\
\text { (dias) }\end{array}$} & \multirow{2}{*}{$\begin{array}{c}\mathrm{U} \\
(\%)\end{array}$} & \multirow{2}{*}{$\begin{array}{c}\mathrm{T} \\
\left({ }^{\circ} \mathrm{C}\right)\end{array}$} \\
\hline & situação 1 & situação 2 & & & & & & \\
\hline valor base & 5,0 & 2,5 & 20 & 20 & 7 & 14 & 60 & 25 \\
\hline variação & 1,0 & 1,0 & 25 & 25 & 91 & 42 & 80 & 35 \\
\hline
\end{tabular}


TABELA 5.8 - Variações consideradas para os vãos das lajes

\begin{tabular}{ccccc}
\hline \multirow{2}{*}{ laje } & \multicolumn{2}{c}{$\ell_{\mathbf{1}}(\mathbf{m})$} & \multicolumn{2}{c}{$\ell_{\mathbf{2}}(\mathbf{m})$} \\
\cline { 2 - 5 } & valor base & variação & valor base & variação \\
\hline LT12 & 3,5 & 2,0 & 4,0 & 2,5 \\
LT16 & 4,5 & 2,5 & 5,5 & 3,5 \\
LT20 & 5,5 & 3,5 & 6,5 & 3,5 \\
LT25 & 7,0 & 4,0 & 8,5 & 5,5 \\
LT30 & 8,5 & 5,5 & 9,5 & 5,5 \\
\hline$\ell_{1}$ - vão para carga acidental de $5,0 \mathrm{kN} / \mathrm{m}^{2}$ \\
$\ell_{2}$ - vão para carga acidental de $2,5 \mathrm{kN} / \mathrm{m}^{2}$ \\
\hline
\end{tabular}

\subsubsection{Descrição das modelagens numéricas}

A análise numérica foi realizada dividindo a seção transversal das lajes em camadas de $0,5 \mathrm{~cm}$, como pode ser visto na figura 5.7 .

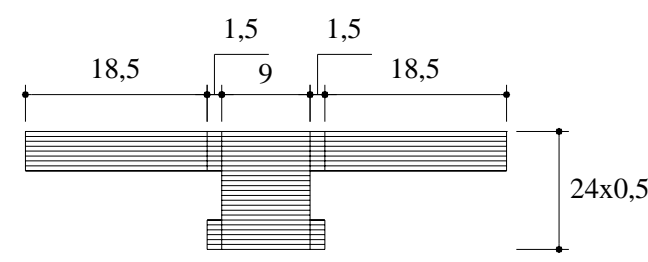

laje LT12

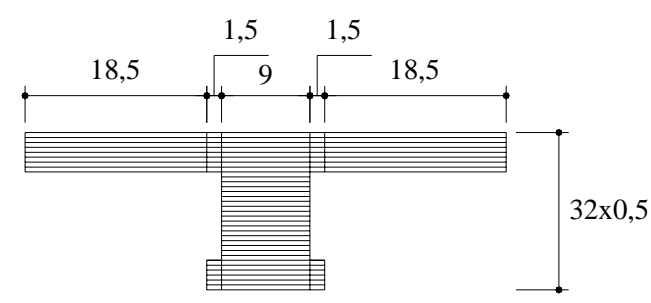

laje LT16

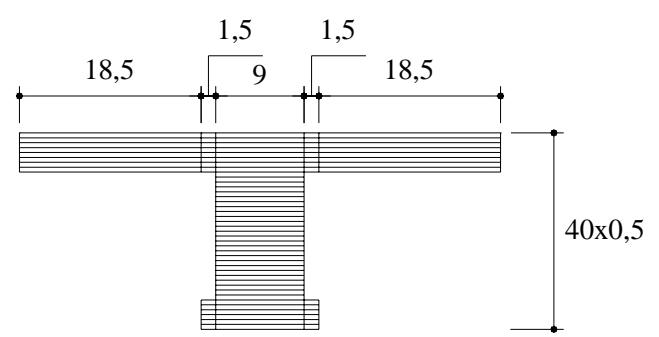

laje LT20

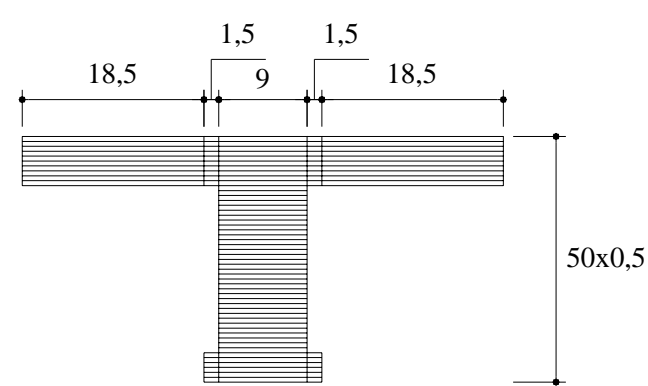

laje LT25

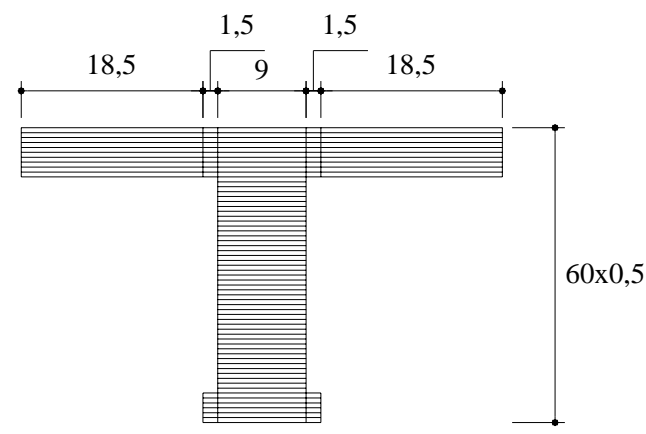

laje LT30

FIGURA 5.7 - Discretização da seção transversal das lajes (dimensões em cm) 
A discretização longitudinal das lajes foi feita adotando elementos com comprimento de $10 \mathrm{~cm}$, como mostrada na figura 5.8 (a) para a laje com $200 \mathrm{~cm}$ de comprimento. No entanto, quando não coincidiu a presença de um nó no meio do vão, este foi introduzido dando origem a dois elementos de $5 \mathrm{~cm}$, como ilustrado na figura 5.8 (b) para a laje com 250 cm. Este nó no meio do vão é utilizado como ponto de escoramento da laje, facilitando na prática a realização de contraflecha. Os outros pontos de escoramento de todas as lajes analisadas, não apenas as lajes desta análise preliminar, estão mostrados na tabela 5.9.

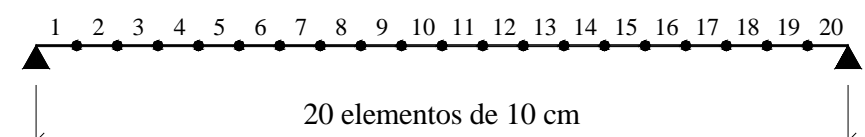

(a) laje de $200 \mathrm{~cm}$

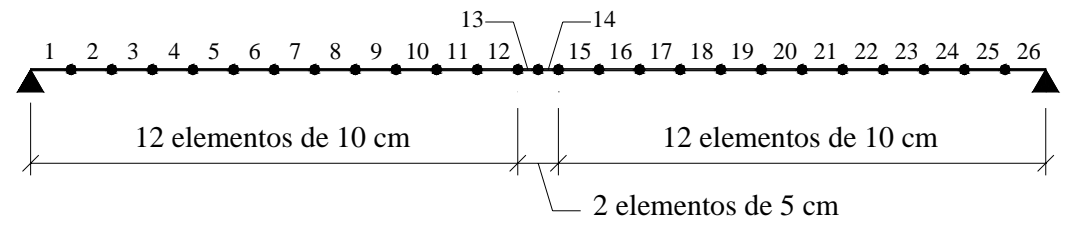

(b) laje de $250 \mathrm{~cm}$

FIGURA 5.8 - Discretização longitudinal das lajes de 200 e $250 \mathrm{~cm}$

TABELA 5.9 - Pontos de escoramento das lajes (dimensões em cm)

\begin{tabular}{|c|c|c|c|}
\hline$\ell(\mathrm{cm})$ & linha de escoras & $\ell(\mathbf{c m})$ & linha de escoras \\
\hline 200 & 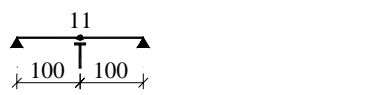 & 600 & 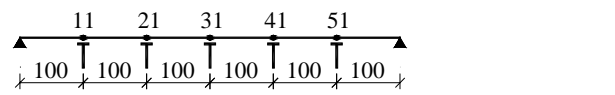 \\
\hline 250 & 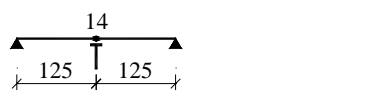 & 650 & 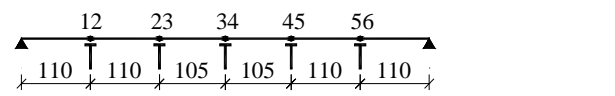 \\
\hline 300 & 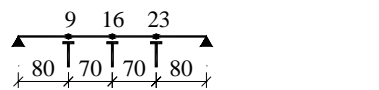 & 700 & 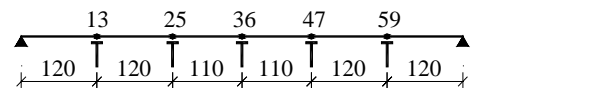 \\
\hline 350 & 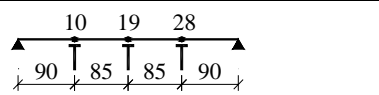 & 750 & 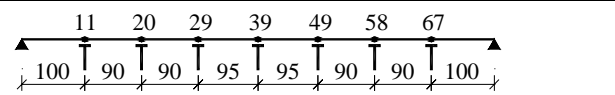 \\
\hline 400 & 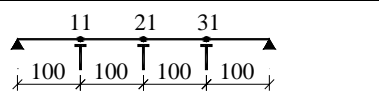 & 800 & 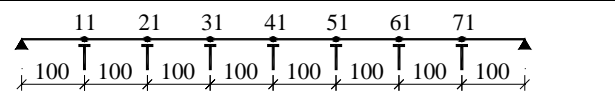 \\
\hline 450 & 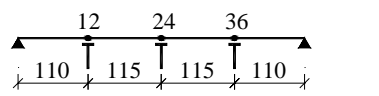 & 850 & 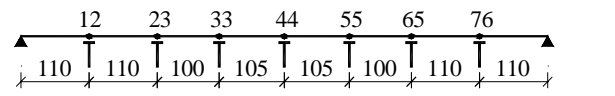 \\
\hline 500 & 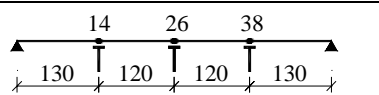 & 900 & 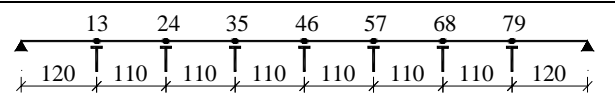 \\
\hline 550 & 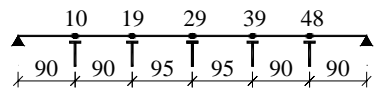 & 950 & 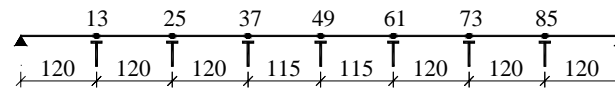 \\
\hline
\end{tabular}




\subsubsection{Resultados obtidos}

Os resultados obtidos para as flechas instantâneas e diferidas das lajes, assim como o coeficiente multiplicador $\alpha$ estão apresentados nas tabelas 5.10 a 5.19.

TABELA 5.10 - Resultados obtidos para a situação 1 da laje LT12

\begin{tabular}{|c|c|c|c|c|c|c|c|c|c|c|}
\hline $\begin{array}{c}\ell \\
(\mathbf{m})\end{array}$ & $\underset{\left(\mathrm{kN} / \mathrm{m}^{2}\right)}{\mathrm{q}}$ & $\begin{array}{l}f_{\text {ck,vigota }} \\
\text { (MPa) }\end{array}$ & $\begin{array}{l}\mathbf{f}_{\text {ck,capa }} \\
\text { (MPa) }\end{array}$ & $\begin{array}{c}t_{1} \\
\text { (dias) }\end{array}$ & $\begin{array}{c}\mathbf{t}_{2} \\
\text { (dias) }\end{array}$ & $\begin{array}{c}U \\
(\%)\end{array}$ & $\begin{array}{c}\mathrm{T} \\
\left({ }^{\circ} \mathrm{C}\right)\end{array}$ & $\begin{array}{c}a_{\text {inst }} \\
(\mathbf{m m})\end{array}$ & $\begin{array}{l}a_{\text {total }} \\
(\mathrm{mm})\end{array}$ & $\alpha$ \\
\hline 3,5 & 5,0 & 20 & 20 & 7 & 14 & 60 & 25 & 10,64 & 22,64 & 1,13 \\
\hline 2,0 & 5,0 & 20 & 20 & 7 & 14 & 60 & 25 & 0,38 & 2,39 & 5,28 \\
\hline 3,5 & 1,0 & 20 & 20 & 7 & 14 & 60 & 25 & 5,31 & 15,21 & 1,87 \\
\hline 3,5 & 5,0 & 25 & 20 & 7 & 14 & 60 & 25 & 10,56 & 22,54 & 1,13 \\
\hline 3,5 & 5,0 & 20 & 25 & 7 & 14 & 60 & 25 & 10,17 & 21,53 & 1,12 \\
\hline 3,5 & 5,0 & 20 & 20 & 91 & 14 & 60 & 25 & 10,63 & 22,77 & 1,14 \\
\hline 3,5 & 5,0 & 20 & 20 & 7 & 42 & 60 & 25 & 9,76 & 20,07 & 1,06 \\
\hline 3,5 & 5,0 & 20 & 20 & 7 & 14 & 80 & 25 & 10,65 & 19,25 & 0,81 \\
\hline 3,5 & 5,0 & 20 & 20 & 7 & 14 & 60 & 35 & 10,64 & 23,22 & 1,18 \\
\hline
\end{tabular}

TABELA 5.11 - Resultados obtidos para a situação 1 da laje LT16

\begin{tabular}{|c|c|c|c|c|c|c|c|c|c|c|}
\hline $\begin{array}{c}\ell \\
\text { (m) }\end{array}$ & $\underset{\left(\mathrm{kN} / \mathrm{m}^{2}\right)}{\mathrm{q}}$ & $\begin{array}{l}\mathbf{f}_{\text {ck,vigota }} \\
\text { (MPa) }\end{array}$ & $\begin{array}{l}\mathbf{f}_{\text {ck,capa }} \\
\text { (MPa) }\end{array}$ & $\begin{array}{c}t_{1} \\
\text { (dias) }\end{array}$ & $\begin{array}{c}\mathbf{t}_{2} \\
\text { (dias) }\end{array}$ & $\begin{array}{c}\mathrm{U} \\
(\%)\end{array}$ & $\begin{array}{c}\mathrm{T} \\
\left({ }^{\circ} \mathrm{C}\right) \\
\end{array}$ & $\begin{array}{c}a_{\text {inst }} \\
(\mathbf{m m})\end{array}$ & $\begin{array}{c}a_{\text {total }} \\
(\mathbf{m m})\end{array}$ & $\alpha$ \\
\hline 4,5 & 5,0 & 20 & 20 & 7 & 14 & 60 & 25 & 9,87 & 22,76 & 1,31 \\
\hline 2,5 & 5,0 & 20 & 20 & 7 & 14 & 60 & 25 & 0,32 & 2,44 & 6,68 \\
\hline 4,5 & 1,0 & 20 & 20 & 7 & 14 & 60 & 25 & 5,13 & 16,30 & 2,18 \\
\hline 4,5 & 5,0 & 25 & 20 & 7 & 14 & 60 & 25 & 9,72 & 22,45 & 1,31 \\
\hline 4,5 & 5,0 & 20 & 25 & 7 & 14 & 60 & 25 & 9,41 & 21,31 & 1,26 \\
\hline 4,5 & 5,0 & 20 & 20 & 91 & 14 & 60 & 25 & 9,82 & 22,76 & 1,32 \\
\hline 4,5 & 5,0 & 20 & 20 & 7 & 42 & 60 & 25 & 9,08 & 19,91 & 1,19 \\
\hline 4,5 & 5,0 & 20 & 20 & 7 & 14 & 80 & 25 & 9,86 & 18,74 & 0,90 \\
\hline 4,5 & 5,0 & 20 & 20 & 7 & 14 & 60 & 35 & 9,90 & 23,63 & 1,39 \\
\hline
\end{tabular}

TABELA 5.12 - Resultados obtidos para a situação 1 da laje LT20

\begin{tabular}{ccccccccccc}
\hline $\begin{array}{c}\ell \\
(\mathbf{m})\end{array}$ & $\begin{array}{c}\mathbf{q} \\
\left(\mathbf{k N} / \mathbf{m}^{2}\right)\end{array}$ & $\begin{array}{c}\mathbf{f}_{\text {ck,vigota }} \\
(\mathbf{M P a})\end{array}$ & $\begin{array}{c}\mathbf{f}_{\text {ck,capa }} \\
(\mathbf{M P a})\end{array}$ & $\begin{array}{c}\mathbf{t}_{\mathbf{1}} \\
(\mathbf{d i a s})\end{array}$ & $\begin{array}{c}\mathbf{t}_{\mathbf{2}} \\
(\mathbf{d i a s})\end{array}$ & $\begin{array}{c}\mathbf{U} \\
(\mathbf{\%})\end{array}$ & $\begin{array}{c}\mathbf{T} \\
\left({ }^{\circ} \mathbf{C}\right)\end{array}$ & $\begin{array}{c}\mathbf{a}_{\text {inst }} \\
(\mathbf{m m})\end{array}$ & $\begin{array}{c}\mathbf{a}_{\text {total }} \\
(\mathbf{m m})\end{array}$ & $\boldsymbol{\alpha}$ \\
\hline 5,5 & 5,0 & 20 & 20 & 7 & 14 & 60 & 25 & 13,44 & 28,67 & 1,13 \\
$\mathbf{3 , 5}$ & 5,0 & 20 & 20 & 7 & 14 & 60 & 25 & 0,93 & 4,84 & 4,20 \\
5,5 & $\mathbf{1 , 0}$ & 20 & 20 & 7 & 14 & 60 & 25 & 6,76 & 19,81 & 1,93 \\
5,5 & 5,0 & $\mathbf{2 5}$ & 20 & 7 & 14 & 60 & 25 & 13,67 & 28,88 & 1,11 \\
5,5 & 5,0 & 20 & $\mathbf{2 5}$ & 7 & 14 & 60 & 25 & 12,65 & 26,85 & 1,12 \\
5,5 & 5,0 & 20 & 20 & $\mathbf{9 1}$ & 14 & 60 & 25 & 13,01 & 28,19 & 1,17 \\
5,5 & 5,0 & 20 & 20 & 7 & $\mathbf{4 2}$ & 60 & 25 & 12,47 & 25,71 & 1,06 \\
5,5 & 5,0 & 20 & 20 & 7 & 14 & $\mathbf{8 0}$ & 25 & 13,38 & 23,99 & 0,79 \\
5,5 & 5,0 & 20 & 20 & 7 & 14 & 60 & $\mathbf{3 5}$ & 13,49 & 29,85 & 1,21 \\
\hline
\end{tabular}


TABELA 5.13 - Resultados obtidos para a situação 1 da laje LT25

\begin{tabular}{|c|c|c|c|c|c|c|c|c|c|c|}
\hline $\begin{array}{c}\ell \\
(\mathbf{m})\end{array}$ & $\underset{\left(k N / m^{2}\right)}{q}$ & $\begin{array}{l}f_{\text {ck,vigota }} \\
\text { (MPa) }\end{array}$ & $\begin{array}{l}\mathbf{f}_{\text {ck,capa }} \\
\text { (MPa) }\end{array}$ & $\begin{array}{c}t_{1} \\
\text { (dias) }\end{array}$ & $\begin{array}{c}\mathbf{t}_{2} \\
\text { (dias) }\end{array}$ & $\begin{array}{c}\mathrm{U} \\
(\%)\end{array}$ & $\begin{array}{c}\mathrm{T} \\
\left({ }^{\circ} \mathrm{C}\right)\end{array}$ & $\begin{array}{c}a_{\text {inst }} \\
(\mathbf{m m})\end{array}$ & $\begin{array}{l}a_{\text {total }} \\
(\mathrm{mm})\end{array}$ & $\alpha$ \\
\hline 7,0 & 5,0 & 20 & 20 & 7 & 14 & 60 & 25 & 16,96 & 36,34 & 1,14 \\
\hline 4,0 & 5,0 & 20 & 20 & 7 & 14 & 60 & 25 & 0,84 & 4,61 & 4,50 \\
\hline 7,0 & 1,0 & 20 & 20 & 7 & 14 & 60 & 25 & 10,41 & 27,60 & 1,65 \\
\hline 7,0 & 5,0 & 25 & 20 & 7 & 14 & 60 & 25 & 16,66 & 35,92 & 1,16 \\
\hline 7,0 & 5,0 & 20 & 25 & 7 & 14 & 60 & 25 & 16,27 & 34,35 & 1,11 \\
\hline 7,0 & 5,0 & 20 & 20 & 91 & 14 & 60 & 25 & 17,02 & 36,46 & 1,14 \\
\hline 7,0 & 5,0 & 20 & 20 & 7 & 42 & 60 & 25 & 15,90 & 32,95 & 1,07 \\
\hline 7,0 & 5,0 & 20 & 20 & 7 & 14 & 80 & 25 & 16,93 & 30,59 & 0,81 \\
\hline 7,0 & 5,0 & 20 & 20 & 7 & 14 & 60 & 35 & 16,98 & 38,51 & 1,27 \\
\hline
\end{tabular}

TABELA 5.14 - Resultados obtidos para a situação 1 da laje LT30

\begin{tabular}{|c|c|c|c|c|c|c|c|c|c|c|}
\hline $\begin{array}{c}\ell \\
\text { (m) }\end{array}$ & $\underset{\left(k N / \mathbf{m}^{2}\right)}{\mathbf{q}}$ & $\begin{array}{l}\mathbf{f}_{\text {ck,vigota }} \\
\text { (MPa) }\end{array}$ & $\begin{array}{l}\mathbf{f}_{\text {ck,capa }} \\
\text { (MPa) }\end{array}$ & $\begin{array}{c}t_{1} \\
\text { (dias) }\end{array}$ & $\begin{array}{c}\mathbf{t}_{2} \\
\text { (dias) }\end{array}$ & $\begin{array}{c}\text { U } \\
(\%)\end{array}$ & $\begin{array}{c}\mathrm{T} \\
\left({ }^{\circ} \mathrm{C}\right)\end{array}$ & $\begin{array}{c}a_{\text {inst }} \\
(\mathbf{m m})\end{array}$ & $\begin{array}{l}a_{\text {total }} \\
(\mathbf{m m})\end{array}$ & $\alpha$ \\
\hline 8,5 & 5,0 & 20 & 20 & 7 & 14 & 60 & 25 & 26,53 & 51,23 & 0,93 \\
\hline 5,5 & 5,0 & 20 & 20 & 7 & 14 & 60 & 25 & 2,21 & 9,00 & 3,07 \\
\hline 8,5 & 1,0 & 20 & 20 & 7 & 14 & 60 & 25 & 17,63 & 39,53 & 1,24 \\
\hline 8,5 & 5,0 & 25 & 20 & 7 & 14 & 60 & 25 & 26,46 & 51,10 & 0,93 \\
\hline 8,5 & 5,0 & 20 & 25 & 7 & 14 & 60 & 25 & 25,69 & 48,63 & 0,89 \\
\hline 8,5 & 5,0 & 20 & 20 & 91 & 14 & 60 & 25 & 27,00 & 51,77 & 0,92 \\
\hline 8,5 & 5,0 & 20 & 20 & 7 & 42 & 60 & 25 & 25,24 & 46,95 & 0,86 \\
\hline 8,5 & 5,0 & 20 & 20 & 7 & 14 & 80 & 25 & 26,52 & 44,13 & 0,66 \\
\hline 8,5 & 5,0 & 20 & 20 & 7 & 14 & 60 & 35 & 26,55 & 54,18 & 1,04 \\
\hline
\end{tabular}

TABELA 5.15 - Resultados obtidos para a situação 2 da laje LT12

\begin{tabular}{|c|c|c|c|c|c|c|c|c|c|c|}
\hline $\begin{array}{c}\ell \\
\text { (m) }\end{array}$ & $\underset{\left(k N / m^{2}\right)}{q}$ & $\begin{array}{l}\mathbf{f}_{\text {ck,vigota }} \\
\text { (MPa) }\end{array}$ & $\begin{array}{l}\mathbf{f}_{\text {ck,capa }} \\
\text { (MPa) }\end{array}$ & $\begin{array}{c}t_{1} \\
\text { (dias) }\end{array}$ & $\begin{array}{c}\mathbf{t}_{2} \\
\text { (dias) }\end{array}$ & $\begin{array}{c}\text { U } \\
(\%)\end{array}$ & $\begin{array}{c}\mathrm{T} \\
\left({ }^{\circ} \mathrm{C}\right)\end{array}$ & $\begin{array}{c}a_{\text {inst }} \\
(\mathbf{m m})\end{array}$ & $\begin{array}{l}a_{\text {total }} \\
(\mathrm{mm})\end{array}$ & $\alpha$ \\
\hline 4,0 & 2,5 & 20 & 20 & 7 & 14 & 60 & 25 & 14,08 & 29,87 & 1,12 \\
\hline 2,5 & 2,5 & 20 & 20 & 7 & 14 & 60 & 25 & 0,64 & 3,89 & 5,06 \\
\hline 4,0 & 1,0 & 20 & 20 & 7 & 14 & 60 & 25 & 10,64 & 25,08 & 1,36 \\
\hline 4,0 & 2,5 & 25 & 20 & 7 & 14 & 60 & 25 & 13,93 & 29,70 & 1,13 \\
\hline 4,0 & 2,5 & 20 & 25 & 7 & 14 & 60 & 25 & 13,45 & 28,37 & 1,11 \\
\hline 4,0 & 2,5 & 20 & 20 & 91 & 14 & 60 & 25 & 14,24 & 30,19 & 1,12 \\
\hline 4,0 & 2,5 & 20 & 20 & 7 & 42 & 60 & 25 & 12,91 & 26,49 & 1,05 \\
\hline 4,0 & 2,5 & 20 & 20 & 7 & 14 & 80 & 25 & 14,08 & 25,41 & 0,81 \\
\hline 4,0 & 2,5 & 20 & 20 & 7 & 14 & 60 & 35 & 14,08 & 30,72 & 1,18 \\
\hline
\end{tabular}


TABELA 5.16 - Resultados obtidos para a situação 2 da laje LT16

\begin{tabular}{ccccccccccc}
\hline $\begin{array}{c}\ell \\
(\mathbf{m})\end{array}$ & $\begin{array}{c}\mathbf{q} \\
\left(\mathbf{k N} / \mathbf{m}^{2}\right)\end{array}$ & $\begin{array}{c}\mathbf{f}_{\text {ck,vigota }} \\
(\mathbf{M P a})\end{array}$ & $\begin{array}{c}\mathbf{f}_{\mathbf{c k}, \text { capa }} \\
(\mathbf{M P a})\end{array}$ & $\begin{array}{c}\mathbf{t}_{\mathbf{1}} \\
(\mathbf{d i a s})\end{array}$ & $\begin{array}{c}\mathbf{t}_{\mathbf{2}} \\
(\mathbf{d i a s})\end{array}$ & $\begin{array}{c}\mathbf{U} \\
(\mathbf{\%})\end{array}$ & $\begin{array}{c}\mathbf{T} \\
\left({ }^{\mathbf{}} \mathbf{C}\right)\end{array}$ & $\begin{array}{c}\mathbf{a}_{\text {inst }} \\
(\mathbf{m m})\end{array}$ & $\begin{array}{c}\mathbf{a}_{\text {total }} \\
(\mathbf{m m})\end{array}$ & $\boldsymbol{\alpha}$ \\
\hline 5,5 & 2,5 & 20 & 20 & 7 & 14 & 60 & 25 & 19,25 & 39,75 & 1,07 \\
$\mathbf{3 , 5}$ & 2,5 & 20 & 20 & 7 & 14 & 60 & 25 & 1,34 & 6,71 & 4,01 \\
5,5 & $\mathbf{1 , 0}$ & 20 & 20 & 7 & 14 & 60 & 25 & 15,51 & 34,83 & 1,25 \\
5,5 & 2,5 & $\mathbf{2 5}$ & 20 & 7 & 14 & 60 & 25 & 19,12 & 39,68 & 1,08 \\
5,5 & 2,5 & 20 & $\mathbf{2 5}$ & 7 & 14 & 60 & 25 & 18,62 & 37,79 & 1,03 \\
5,5 & 2,5 & 20 & 20 & $\mathbf{9 1}$ & 14 & 60 & 25 & 19,17 & 39,92 & 1,08 \\
5,5 & 2,5 & 20 & 20 & 7 & $\mathbf{4 2}$ & 60 & 25 & 18,16 & 35,67 & 0,96 \\
5,5 & 2,5 & 20 & 20 & 7 & 14 & $\mathbf{8 0}$ & 25 & 19,24 & 33,68 & 0,75 \\
5,5 & 2,5 & 20 & 20 & 7 & 14 & 60 & $\mathbf{3 5}$ & 19,26 & 41,15 & 1,14 \\
\hline
\end{tabular}

TABELA 5.17 - Resultados obtidos para a situação 2 da laje LT20

\begin{tabular}{ccccccccccc}
\hline $\begin{array}{c}\ell \\
(\mathbf{m})\end{array}$ & $\begin{array}{c}\mathbf{q} \\
\left(\mathbf{k N} / \mathbf{m}^{2}\right)\end{array}$ & $\begin{array}{c}\mathbf{f}_{\text {ck,vigota }} \\
(\mathbf{M P a})\end{array}$ & $\begin{array}{c}\mathbf{f}_{\text {ck,capa }} \\
(\mathbf{M P a})\end{array}$ & $\begin{array}{c}\mathbf{t}_{\mathbf{1}} \\
(\mathbf{d i a s})\end{array}$ & $\begin{array}{c}\mathbf{t}_{\mathbf{2}} \\
(\mathbf{d i a s})\end{array}$ & $\begin{array}{c}\mathbf{U} \\
\mathbf{( \% )}\end{array}$ & $\begin{array}{c}\mathbf{T} \\
\left({ }^{\mathbf{}} \mathbf{C}\right)\end{array}$ & $\begin{array}{c}\mathbf{a}_{\text {inst }} \\
(\mathbf{m m})\end{array}$ & $\begin{array}{c}\mathbf{a}_{\text {total }} \\
(\mathbf{m m})\end{array}$ & $\boldsymbol{\alpha}$ \\
\hline 6,5 & 2,5 & 20 & 20 & 7 & 14 & 60 & 25 & 22,51 & 44,50 & 0,98 \\
$\mathbf{3 , 5}$ & 2,5 & 20 & 20 & 7 & 14 & 60 & 25 & 0,73 & 4,28 & 4,87 \\
6,5 & $\mathbf{1 , 0}$ & 20 & 20 & 7 & 14 & 60 & 25 & 18,39 & 39,08 & 1,13 \\
6,5 & 2,5 & $\mathbf{2 5}$ & 20 & 7 & 14 & 60 & 25 & 22,56 & 44,59 & 0,98 \\
6,5 & 2,5 & 20 & $\mathbf{2 5}$ & 7 & 14 & 60 & 25 & 21,79 & 42,29 & 0,94 \\
6,5 & 2,5 & 20 & 20 & $\mathbf{9 1}$ & 14 & 60 & 25 & 22,99 & 45,20 & 0,97 \\
6,5 & 2,5 & 20 & 20 & 7 & $\mathbf{4 2}$ & 60 & 25 & 21,38 & 40,30 & 0,89 \\
6,5 & 2,5 & 20 & 20 & 7 & 14 & $\mathbf{8 0}$ & 25 & 22,50 & 38,03 & 0,69 \\
6,5 & 2,5 & 20 & 20 & 7 & 14 & 60 & $\mathbf{3 5}$ & 22,53 & 46,32 & 1,06 \\
\hline
\end{tabular}

TABELA 5.18 - Resultados obtidos para a situação 2 da laje LT25

\begin{tabular}{|c|c|c|c|c|c|c|c|c|c|c|}
\hline $\begin{array}{c}\ell \\
\text { (m) }\end{array}$ & $\underset{\left(k N / m^{2}\right)}{q}$ & $\begin{array}{l}\mathbf{f}_{\text {ck,vigota }} \\
\text { (MPa) }\end{array}$ & $\begin{array}{l}\mathbf{f}_{\text {ck,capa }} \\
\text { (MPa) }\end{array}$ & $\begin{array}{c}\mathbf{t}_{1} \\
\text { (dias) }\end{array}$ & $\begin{array}{c}\mathbf{t}_{2} \\
\text { (dias) }\end{array}$ & $\begin{array}{c}U \\
(\%)\end{array}$ & $\begin{array}{c}\mathbf{T} \\
\left({ }^{\circ} \mathbf{C}\right)\end{array}$ & $\begin{array}{c}a_{\text {inst }} \\
(\mathbf{m m})\end{array}$ & $\begin{array}{l}a_{\text {total }} \\
(\mathrm{mm})\end{array}$ & $\alpha$ \\
\hline 8,5 & 2,5 & 20 & 20 & 7 & 14 & 60 & 25 & 31,82 & 62,74 & 0,97 \\
\hline 5,5 & 2,5 & 20 & 20 & 7 & 14 & 60 & 25 & 2,97 & 11,83 & 2,98 \\
\hline 8,5 & 1,0 & 20 & 20 & 7 & 14 & 60 & 25 & 26,95 & 56,17 & 1,08 \\
\hline 8,5 & 2,5 & 25 & 20 & 7 & 14 & 60 & 25 & 31,94 & 62,93 & 0,97 \\
\hline 8,5 & 2,5 & 20 & 25 & 7 & 14 & 60 & 25 & 30,91 & 59,58 & 0,93 \\
\hline 8,5 & 2,5 & 20 & 20 & 91 & 14 & 60 & 25 & 32,45 & 63,56 & 0,96 \\
\hline 8,5 & 2,5 & 20 & 20 & 7 & 42 & 60 & 25 & 30,40 & 57,23 & 0,88 \\
\hline 8,5 & 2,5 & 20 & 20 & 7 & 14 & 80 & 25 & 31,81 & 53,77 & 0,69 \\
\hline 8,5 & 2,5 & 20 & 20 & 7 & 14 & 60 & 35 & 31,84 & 66,22 & 1,08 \\
\hline
\end{tabular}


TABELA 5.19 - Resultados obtidos para a situação 2 da laje LT30

\begin{tabular}{|c|c|c|c|c|c|c|c|c|c|c|}
\hline $\begin{array}{c}\ell \\
(\mathbf{m})\end{array}$ & $\underset{\left(\mathbf{k N} / \mathbf{m}^{2}\right)}{\mathbf{q}}$ & $\begin{array}{l}\mathbf{f}_{\text {ck,vigota }} \\
\text { (MPa) }\end{array}$ & $\begin{array}{l}\mathbf{f}_{\text {ck,capa }} \\
\text { (MPa) }\end{array}$ & $\begin{array}{c}\mathbf{t}_{1} \\
\text { (dias) }\end{array}$ & $\begin{array}{c}\mathbf{t}_{2} \\
\text { (dias) }\end{array}$ & $\begin{array}{c}\mathrm{U} \\
(\%)\end{array}$ & $\begin{array}{c}\mathrm{T} \\
\left({ }^{\circ} \mathrm{C}\right)\end{array}$ & $\begin{array}{c}\mathbf{a}_{\text {inst }} \\
(\mathbf{m m})\end{array}$ & $\begin{array}{l}a_{\text {total }} \\
(\mathbf{m m})\end{array}$ & $\alpha$ \\
\hline 9,5 & 2,5 & 20 & 20 & 7 & 14 & 60 & 25 & 34,23 & 65,60 & 0,92 \\
\hline 5,5 & 2,5 & 20 & 20 & 7 & 14 & 60 & 25 & 1,70 & 7,85 & 3,62 \\
\hline 9,5 & 1,0 & 20 & 20 & 7 & 14 & 60 & 25 & 29,18 & 58,96 & 1,02 \\
\hline 9,5 & 2,5 & 25 & 20 & 7 & 14 & 60 & 25 & 33,95 & 65,18 & 0,92 \\
\hline 9,5 & 2,5 & 20 & 25 & 7 & 14 & 60 & 25 & 33,16 & 62,27 & 0,88 \\
\hline 9,5 & 2,5 & 20 & 20 & 91 & 14 & 60 & 25 & 34,55 & 65,93 & 0,91 \\
\hline 9,5 & 2,5 & 20 & 20 & 7 & 42 & 60 & 25 & 32,64 & 60,20 & 0,84 \\
\hline 9,5 & 2,5 & 20 & 20 & 7 & 14 & 80 & 25 & 34,19 & 56,55 & 0,65 \\
\hline 9,5 & 2,5 & 20 & 20 & 7 & 14 & 60 & 35 & 34,26 & 69,40 & 1,03 \\
\hline
\end{tabular}

Os resultados obtidos estão apresentados na tabela 5.20 de forma resumida através da variação do coeficiente multiplicador $\alpha$ em porcentagem em função dos parâmetros analisados. Para melhor visualização, os dados desta tabela estão apresentados nas figuras 5.9 e 5.10.

TABELA 5.20 - Variação do coeficiente multiplicador em porcentagem

\begin{tabular}{|c|c|c|c|c|c|c|c|c|c|}
\hline & laje & $\ell$ & $\mathbf{q}$ & $\mathbf{f}_{\text {ck,vigota }}$ & $\mathbf{f}_{\text {ck,capa }}$ & $\mathbf{t}_{1}$ & $\mathbf{t}_{2}$ & $\mathbf{U}$ & $\mathbf{T}$ \\
\hline \multirow{5}{*}{ 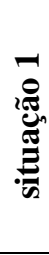 } & LT12 & 368,3 & 65,5 & 0,6 & 1,0 & 1,4 & 6,2 & 28,3 & 4,8 \\
\hline & LT16 & 411,5 & 66,8 & 0,4 & 3,1 & 1,0 & 8,7 & 31,0 & 6,4 \\
\hline & LT20 & 270,6 & 70,5 & 1,8 & 0,9 & 2,9 & 6,3 & 30,0 & 7,1 \\
\hline & LT25 & 294,1 & 44,4 & 1,1 & 2,7 & 0,1 & 6,2 & 29,5 & 10,8 \\
\hline & LT30 & 229,3 & 33,4 & 0,0 & 4,1 & 1,5 & 7,6 & 28,7 & 11,8 \\
\hline \multirow{5}{*}{ 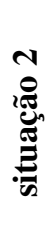 } & LT12 & 351,2 & 20,9 & 0,9 & 1,1 & 0,2 & 6,1 & 28,3 & 5,3 \\
\hline & LT16 & 276,8 & 17,0 & 1,0 & 3,4 & 1,6 & 9,5 & 29,6 & 6,8 \\
\hline & LT20 & 398,6 & 15,3 & 0,1 & 3,7 & 1,0 & 9,4 & 29,3 & 8,1 \\
\hline & LT25 & 206,6 & 11,5 & 0,2 & 4,6 & 1,3 & 9,2 & 28,9 & 11,1 \\
\hline & LT30 & 294,9 & 11,3 & 0,3 & 4,3 & 1,0 & 8,0 & 28,7 & 11,8 \\
\hline
\end{tabular}




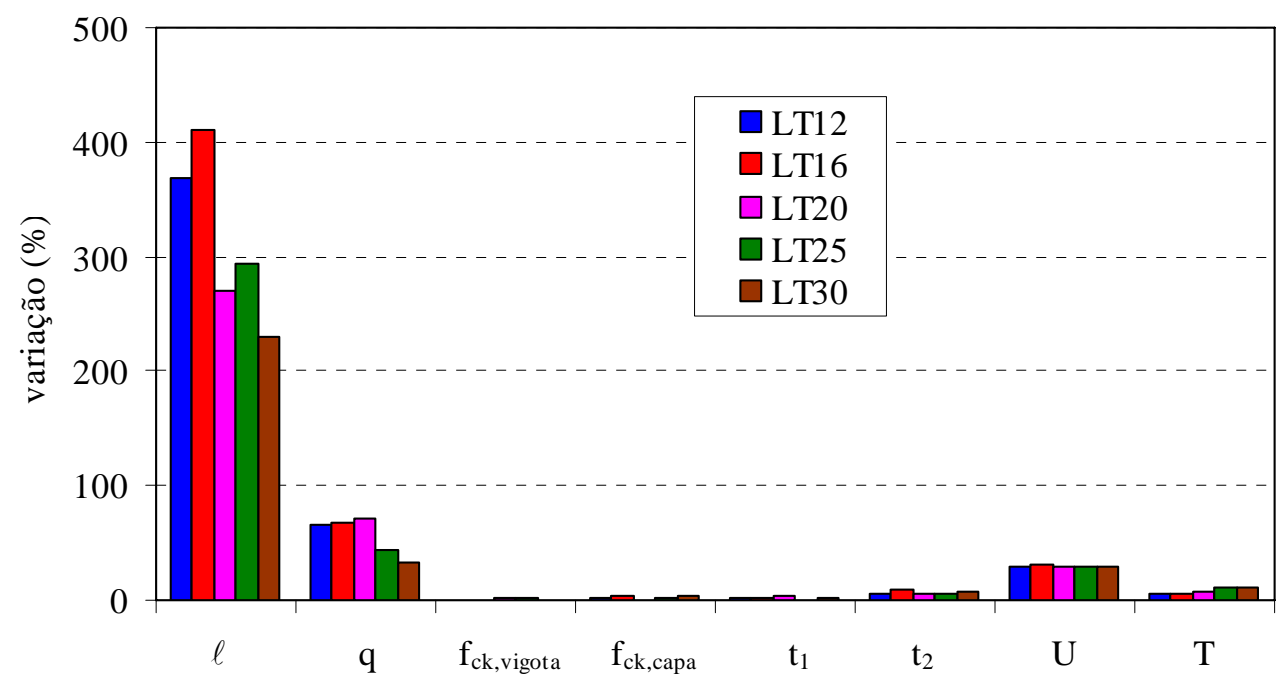

FIGURA 5.9 - Variação do coeficiente multiplicador para a situação 1

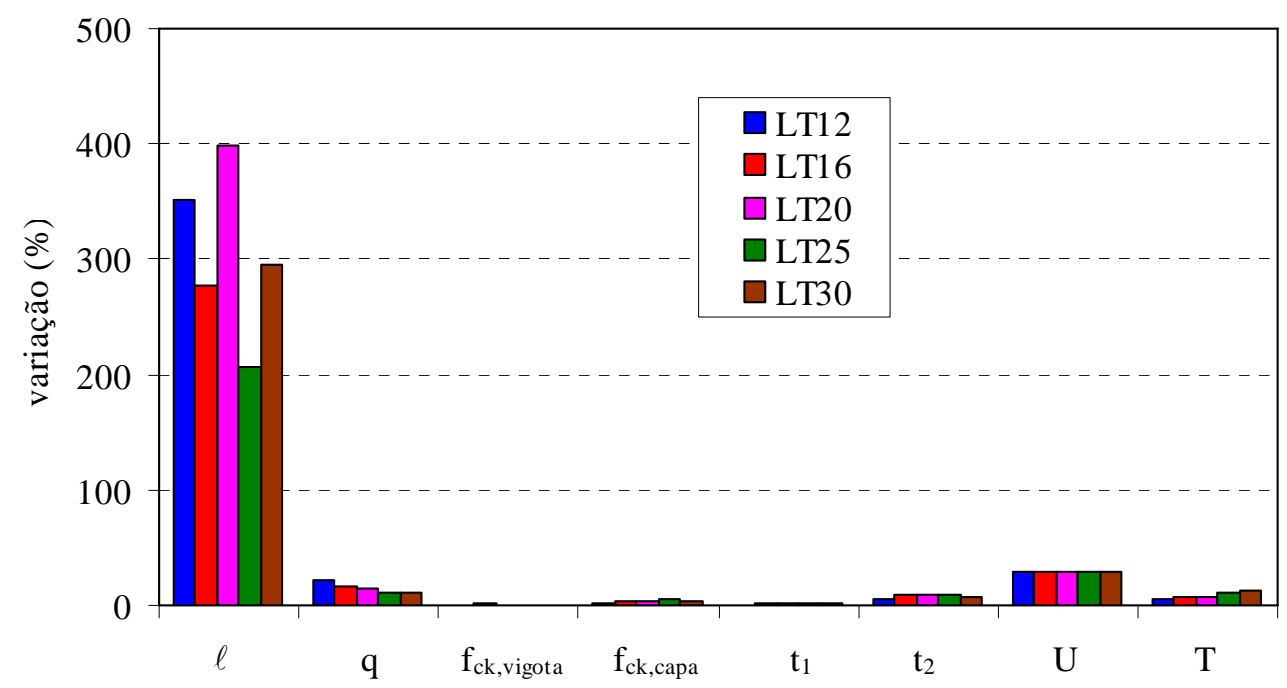

FIGURA 5.10 - Variação do coeficiente multiplicador para a situação 2

Pelas figuras 5.9 e 5.10, pode-se observar que os parâmetros que mais influenciaram o coeficiente multiplicador $\alpha$ foram o vão da laje $(\ell)$ e a carga acidental aplicada (q).

Na realidade, o que se pôde observar, é que tanto o carregamento aplicado quanto a altura e o vão da laje, assim como a armadura utilizada são parâmetros dependentes entre si, ou seja, tem pouco sentido prático considerar uma laje com 5,5 m de vão e sujeita a carga acidental de $2,5 \mathrm{kN} / \mathrm{m}^{2}$ sendo construída com altura de $30 \mathrm{~cm}$ e 3 barras adicionais de 12,5 mm de diâmetro, como foi o caso da situação 2 da laje LT30. E mesmo que isso acontecesse na prática, as flechas obtidas 
seriam muito pequenas. Portanto, o melhor seria desconsiderar esses dois parâmetros e apenas considerar os demais, como apresentados nas figuras 5.11 e 5.12 .

Pelas figuras 5.11 e 5.12, nota-se que a umidade relativa do ambiente (U) influenciou mais significativamente o coeficiente multiplicador $\alpha$, seguido da temperatura ambiente (T) e do tempo em que a laje fica escorada $\left(\mathbf{t}_{2}\right)$. E como a variação no valor da temperatura poderia ter sido ainda maior que aquele considerado $\left(25^{\circ} \mathrm{C}\right.$ a $\left.35^{\circ} \mathrm{C}\right)$, conclui-se que os parâmetros que mais influenciaram o coeficiente multiplicador foram a umidade relativa e a temperatura ambiente.

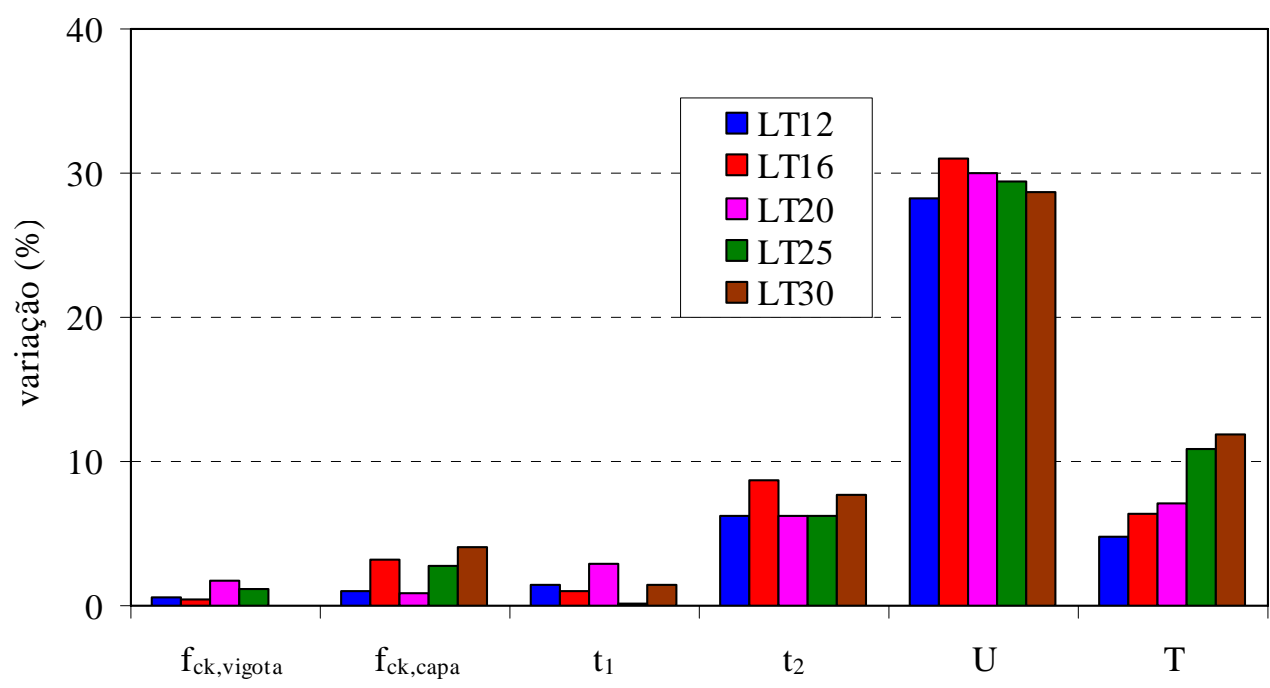

FIGURA 5.11 - Variação do coeficiente multiplicador para a situação 1

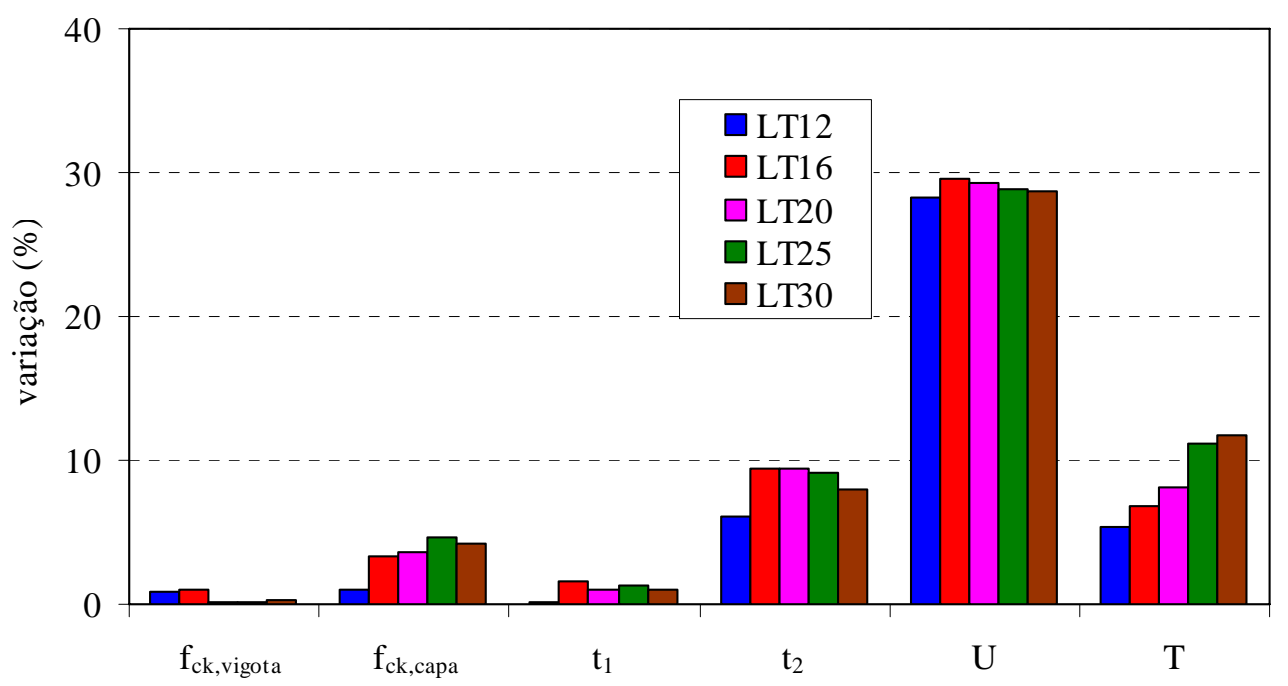

FIGURA 5.12 - Variação do coeficiente multiplicador para a situação 2 


\subsection{Análise determinística}

Como visto no item anterior, os parâmetros que mais influenciaram o coeficiente multiplicador $\alpha$ foram a umidade relativa do ambiente, a temperatura ambiente e o tempo em que a laje fica escorada. No entanto, como também se pôde notar, o vão e altura da laje, assim como o carregamento aplicado e a armadura utilizada, podem influenciar de forma significativa o coeficiente multiplicador, para casos sem sentido prático.

Por isso, foi analisado inicialmente cada tipo de laje variando a carga acidental de $1,0 \mathrm{kN} / \mathrm{m}^{2}$ a $6,0 \mathrm{kN} / \mathrm{m}^{2}$ e considerando-se vãos e armaduras adicionais compatíveis, mantendo-se os demais parâmetros constantes. A partir desta análise, definiu-se um coeficiente multiplicador básico $\alpha_{\text {básico }}$, em seguida foi realizada a análise para considerar a influência da umidade relativa e temperatura ambiente, através do coeficiente $\alpha_{\mathrm{U}, \mathrm{T}}$.

\subsubsection{Coeficiente multiplicador básico}

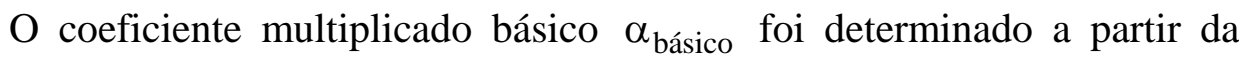
análise de 394 casos, sendo 63 referentes à laje LT12, 79 referentes à laje LT16, 80 referentes à laje LT20, 80 referentes à laje LT25 e 92 referentes à laje LT30, como mostrados respectivamente nas tabelas 5.21, 5.22, 5.23, 5.24 e 5.25. Esta análise foi realizada mantendo-se constante a resistência característica à compressão do concreto da vigota (20 MPa), a resistência característica à compressão do concreto da capa (20 MPa), a idade da concretagem da capa (7 dias), o tempo em que a laje permaneceu escorada (14 dias), a umidade relativa (60\%) e a temperatura ambiente $\left(25^{\circ} \mathrm{C}\right)$.

As demais características e considerações empregadas nesta análise são idênticas às adotadas na análise preliminar desenvolvido anteriormente. 
TABELA 5.21 - Casos analisados para a laje LT12

\begin{tabular}{|c|c|c|c|c|c|c|}
\hline \multirow{3}{*}{$\ell(\mathrm{m})$} & \multicolumn{6}{|c|}{ armadura adicional $A_{\text {s,adic }}\left(\mathrm{cm}^{2}\right)$} \\
\hline & \multicolumn{6}{|c|}{$q\left(\mathrm{kN} / \mathrm{m}^{2}\right)$} \\
\hline & 1,0 & 2,0 & 3,0 & 4,0 & 5,0 & 6,0 \\
\hline \multirow{4}{*}{4,5} & 0,90 & 1,50 & & & & \\
\hline & 1,10 & 1,75 & & & & \\
\hline & 1,30 & 2,10 & & & & \\
\hline & 1,50 & 2,35 & & & & \\
\hline \multirow{4}{*}{4,0} & 0,60 & 0,90 & 1,50 & & & \\
\hline & 0,75 & 1,10 & 1,75 & & & \\
\hline & 0,85 & 1,30 & 2,10 & & & \\
\hline & 1,00 & 1,50 & 2,35 & & & \\
\hline \multirow{4}{*}{3,5} & 0,40 & 0,60 & 1,00 & 1,50 & 1,50 & \\
\hline & 0,45 & 0,75 & 1,15 & 1,75 & 1,75 & \\
\hline & 0,55 & 0,85 & 1,35 & 2,10 & 2,10 & \\
\hline & 0,60 & 1,00 & 1,50 & 2,35 & 2,35 & \\
\hline \multirow{4}{*}{3,0} & \multirow{4}{*}{$\begin{array}{l}0,20 \\
0,25 \\
0,30\end{array}$} & 0,40 & 0,60 & 0,80 & 1,00 & 1,50 \\
\hline & & 0,45 & 0,75 & 0,85 & 1,15 & 1,75 \\
\hline & & 0,55 & 0,85 & 0,95 & 1,35 & 2,10 \\
\hline & & 0,60 & 1,00 & 1,00 & 1,50 & 2,35 \\
\hline
\end{tabular}

TABELA 5.22 - Casos analisados para a laje LT16

\begin{tabular}{|c|c|c|c|c|c|c|}
\hline \multirow{3}{*}{$\ell(\mathbf{m})$} & \multicolumn{6}{|c|}{ armadura adicional $A_{\text {s,adic }}\left(\mathrm{cm}^{2}\right)$} \\
\hline & \multicolumn{6}{|c|}{$q\left(k N / m^{2}\right)$} \\
\hline & 1,0 & 2,0 & 3,0 & 4,0 & 5,0 & 6,0 \\
\hline \multirow{4}{*}{6,0} & 1,20 & 1,50 & & & & \\
\hline & 1,60 & 1,75 & & & & \\
\hline & 1,95 & 2,10 & & & & \\
\hline & 2,35 & 2,35 & & & & \\
\hline \multirow{4}{*}{5,5} & 0,90 & 1,50 & 2,35 & & & \\
\hline & 1,10 & 1,75 & 2,80 & & & \\
\hline & 1,30 & 2,10 & 3,25 & & & \\
\hline & 1,50 & 2,35 & 3,68 & & & \\
\hline \multirow{4}{*}{5,0} & 0,60 & 1,00 & 1,50 & 2,35 & & \\
\hline & 0,75 & 1,15 & 1,75 & 2,80 & & \\
\hline & 0,85 & 1,35 & 2,10 & 3,25 & & \\
\hline & 1,00 & 1,50 & 2,35 & 3,68 & & \\
\hline \multirow{4}{*}{4,5} & 0,40 & 0,80 & 1,20 & 1,50 & 2,35 & \\
\hline & 0,45 & 0,85 & 1,60 & 1,75 & 2,80 & \\
\hline & 0,55 & 0,95 & 1,95 & 2,10 & 3,25 & \\
\hline & 0,60 & 1,00 & 2,35 & 2,35 & 3,68 & \\
\hline \multirow{4}{*}{4,0} & \multirow{4}{*}{$\begin{array}{l}0,20 \\
0,25 \\
0,30\end{array}$} & 0,40 & 0,80 & 1,00 & 1,20 & 1,50 \\
\hline & & 0,45 & 0,85 & 1,15 & 1,60 & 1,75 \\
\hline & & 0,55 & 0,95 & 1,35 & 1,95 & 2,10 \\
\hline & & 0,60 & 1,00 & 1,50 & 2,35 & 2,35 \\
\hline
\end{tabular}


TABELA 5.23 - Casos analisados para a laje LT20

\begin{tabular}{|c|c|c|c|c|c|c|}
\hline \multirow{3}{*}{$\ell(\mathrm{m})$} & \multicolumn{6}{|c|}{ armadura adicional $A_{\text {s,adic }}\left(\mathrm{cm}^{2}\right)$} \\
\hline & \multicolumn{6}{|c|}{$q\left(\mathrm{kN} / \mathrm{m}^{2}\right)$} \\
\hline & 1,0 & 2,0 & 3,0 & 4,0 & 5,0 & 6,0 \\
\hline \multirow{4}{*}{7,0} & 1,50 & 2,35 & & & & \\
\hline & 1,75 & 2,80 & & & & \\
\hline & 2,10 & 3,25 & & & & \\
\hline & 2,35 & 3,68 & & & & \\
\hline \multirow{4}{*}{6,5} & 1,00 & 1,60 & 2,35 & & & \\
\hline & 1,15 & 1,90 & 2,80 & & & \\
\hline & 1,35 & 2,15 & 3,25 & & & \\
\hline & 1,50 & 2,45 & 3,68 & & & \\
\hline \multirow{4}{*}{6,0} & 0,90 & 1,20 & 2,35 & 2,35 & & \\
\hline & 1,10 & 1,60 & 2,80 & 2,80 & & \\
\hline & 1,30 & 1,95 & 3,25 & 3,25 & & \\
\hline & 1,50 & 2,35 & 3,68 & 3,68 & & \\
\hline \multirow{4}{*}{5,5} & 0,60 & 1,00 & 1,50 & 2,35 & 2,35 & \\
\hline & 0,75 & 1,15 & 1,75 & 2,80 & 2,80 & \\
\hline & 0,85 & 1,35 & 2,10 & 3,25 & 3,25 & \\
\hline & 1,00 & 1,50 & 2,35 & 3,68 & 3,68 & \\
\hline \multirow{4}{*}{5,0} & 0,40 & 0,60 & 1,00 & 1,50 & 2,35 & 2,35 \\
\hline & 0,45 & 0,75 & 1,15 & 1,75 & 2,80 & 2,80 \\
\hline & 0,55 & 0,85 & 1,35 & 2,10 & 3,25 & 3,25 \\
\hline & 0,60 & 1,00 & 1,50 & 2,35 & 3,68 & 3,68 \\
\hline
\end{tabular}

TABELA 5.24 - Casos analisados para a laje LT25

\begin{tabular}{|c|c|c|c|c|c|c|}
\hline \multirow{3}{*}{$\ell(\mathbf{m})$} & \multicolumn{6}{|c|}{ armadura adicional $A_{\text {s,adic }}\left(\mathrm{cm}^{2}\right)$} \\
\hline & \multicolumn{6}{|c|}{$q\left(\mathrm{kN} / \mathrm{m}^{2}\right)$} \\
\hline & 1,0 & 2,0 & 3,0 & 4,0 & 5,0 & 6,0 \\
\hline \multirow{4}{*}{8,5} & 1,60 & 2,35 & & & & \\
\hline & 1,90 & 2,80 & & & & \\
\hline & 2,15 & 3,25 & & & & \\
\hline & 2,45 & 3,68 & & & & \\
\hline \multirow{4}{*}{8,0} & 1,50 & 2,35 & 3,68 & & & \\
\hline & 1,75 & 2,80 & 4,00 & & & \\
\hline & 2,10 & 3,25 & 4,50 & & & \\
\hline & 2,35 & 3,68 & 4,90 & & & \\
\hline \multirow{4}{*}{7,5} & 1,20 & 1,60 & 2,35 & 3,68 & & \\
\hline & 1,60 & 1,90 & 2,80 & 4,00 & & \\
\hline & 1,95 & 2,15 & 3,25 & 4,50 & & \\
\hline & 2,35 & 2,45 & 3,68 & 4,90 & & \\
\hline \multirow{4}{*}{7,0} & 1,00 & 1,50 & 2,35 & 2,35 & 3,68 & \\
\hline & 1,15 & 1,75 & 2,80 & 2,80 & 4,00 & \\
\hline & 1,35 & 2,10 & 3,25 & 3,25 & 4,50 & \\
\hline & 1,50 & 2,35 & 3,68 & 3,68 & 4,90 & \\
\hline \multirow{4}{*}{6,5} & 0,80 & 1,00 & 1,50 & 2,35 & 2,35 & 3,68 \\
\hline & 0,85 & 1,15 & 1,75 & 2,80 & 2,80 & 4,00 \\
\hline & 0,95 & 1,35 & 2,10 & 3,25 & 3,25 & 4,50 \\
\hline & 1,00 & 1,50 & 2,35 & 3,68 & 3,68 & 4,90 \\
\hline
\end{tabular}


TABELA 5.25 - Casos analisados para a laje LT30

\begin{tabular}{|c|c|c|c|c|c|c|}
\hline \multirow{3}{*}{$\ell(\mathbf{m})$} & \multicolumn{6}{|c|}{ armadura adicional $A_{s, \text { adic }}\left(\mathrm{cm}^{2}\right)$} \\
\hline & \multicolumn{6}{|c|}{$q\left(\mathbf{k N} / \mathbf{m}^{2}\right)$} \\
\hline & 1,0 & 2,0 & 3,0 & 4,0 & 5,0 & 6,0 \\
\hline \multirow{4}{*}{9,5} & 2,35 & 3,68 & 3,68 & & & \\
\hline & 2,80 & 4,00 & 4,00 & & & \\
\hline & 3,25 & 4,50 & 4,50 & & & \\
\hline & 3,68 & 4,90 & 4,90 & & & \\
\hline \multirow{4}{*}{9,0} & 1,60 & 2,35 & 3,68 & 3,68 & & \\
\hline & 1,90 & 2,80 & 4,00 & 4,00 & & \\
\hline & 2,15 & 3,25 & 4,50 & 4,50 & & \\
\hline & 2,45 & 3,68 & 4,90 & 4,90 & & \\
\hline \multirow{4}{*}{8,5} & 1,50 & 2,35 & 2,35 & 3,68 & 3,68 & \\
\hline & 1,75 & 2,80 & 2,80 & 4,00 & 4,00 & \\
\hline & 2,10 & 3,25 & 3,25 & 4,50 & 4,50 & \\
\hline & 2,35 & 3,68 & 3,68 & 4,90 & 4,90 & \\
\hline \multirow{4}{*}{8,0} & 1,20 & 1,60 & 2,35 & 3,68 & 3,68 & \\
\hline & 1,60 & 1,90 & 2,80 & 4,00 & 4,00 & \\
\hline & 1,95 & 2,15 & 3,25 & 4,50 & 4,50 & \\
\hline & 2,35 & 2,45 & 3,68 & 4,90 & 4,90 & \\
\hline \multirow{4}{*}{7,5} & 0,90 & 1,50 & 2,35 & 2,35 & 3,68 & 3,68 \\
\hline & 1,10 & 1,75 & 2,80 & 2,80 & 4,00 & 4,00 \\
\hline & 1,30 & 2,10 & 3,25 & 3,25 & 4,50 & 4,50 \\
\hline & 1,50 & 2,35 & 3,68 & 3,68 & 4,90 & 4,90 \\
\hline
\end{tabular}

Para desenvolver um coeficiente multiplicador básico que levasse em consideração a variação do vão e altura da laje, o carregamento aplicado e a armadura utilizada, foi criado um coeficiente denominado de $\kappa$ que englobou esses quatro parâmetros. A preocupação com a criação do coeficiente $\kappa$ foi conseguir agrupar os valores dos coeficientes multiplicadores, diminuindo, assim, a sua dispersão, para poder realizar uma regressão dos valores com maior correlação possível. Isso foi realizado partindo-se da multiplicação do índice de esbeltez do elemento $\mathrm{h} / \ell$ e do coeficiente de dimensionamento $\mathrm{k}_{\mathrm{s}}$ dado por:

$$
\mathrm{k}_{\mathrm{s}}=\frac{\mathrm{A}_{\mathrm{s}} \cdot \mathrm{d}}{\mathrm{M}_{\mathrm{d}}}=8 \cdot \frac{\mathrm{A}_{\mathrm{s}} \cdot \mathrm{d}}{\mathrm{p} \cdot \ell^{2}}
$$

A partir disso, por tentativas, chegou-se no seguinte coeficiente $\kappa$ :

$$
\kappa=\frac{\mathrm{A}_{\mathrm{S}} \cdot \mathrm{h}^{2,05}}{\mathrm{p}^{1,5} \cdot \ell^{3}} \cdot 10^{3}
$$


onde:

$\mathrm{A}_{\mathrm{s}} \quad$ - armadura $\left[\mathrm{cm}^{2}\right]$;

h $\quad$ - altura da laje [m];

p - carregamento aplicado $[\mathrm{kN} / \mathrm{m}]$;

$\ell \quad$ - vão da laje [m].

Os resultados obtidos desta análise estão apresentados no Apêndice A, mas podem ser vistos na figura 5.13. Apresenta-se nesta figura o coeficiente multiplicador $\alpha$, encontrado para cada caso, em função do coeficiente $\kappa$.

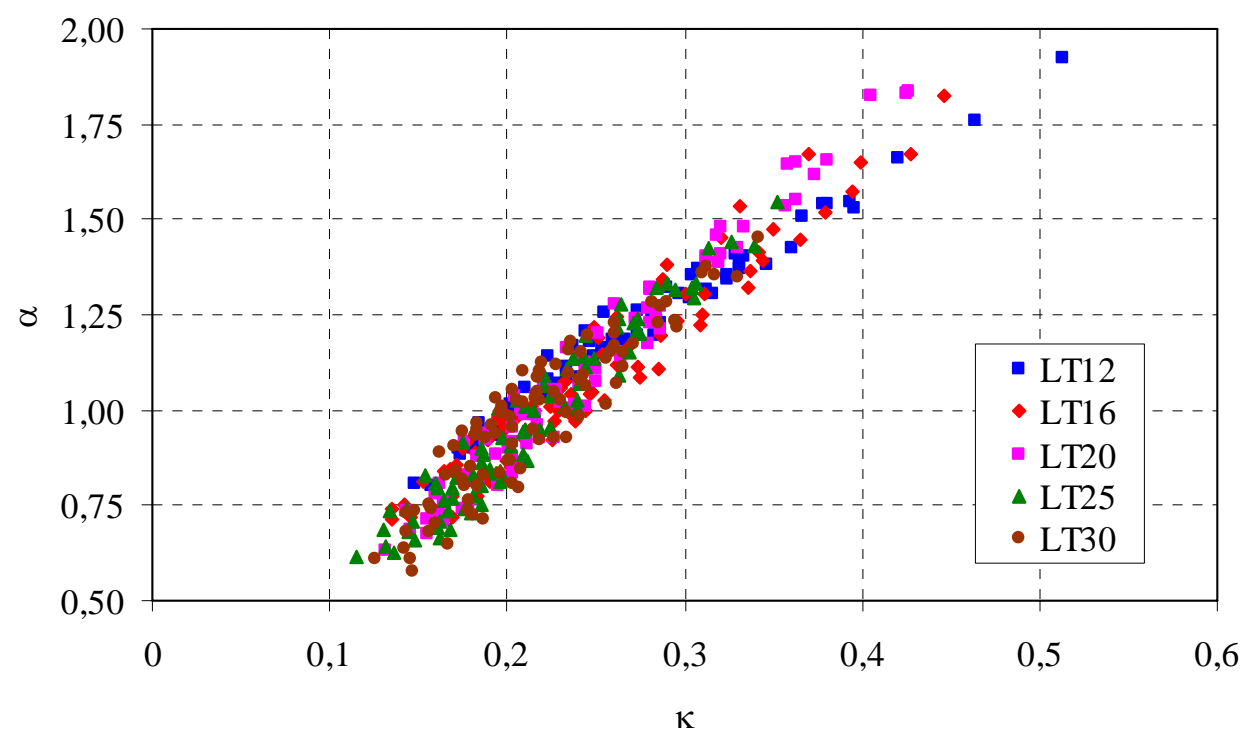

FIGURA 5.13 - Coeficiente multiplicador

E assim, como mostrado na figura 5.14, obteve-se a seguinte expressão para o coeficiente multiplicador básico, através de regressão linear dos resultados obtidos.

$$
\begin{aligned}
& \alpha_{\text {básico }}=3,73 . \kappa+0,18 \\
& \text { com }
\end{aligned}
$$

$$
\mathrm{R}^{2}=0,93
$$

A expressão desenvolvida para o coeficiente multiplicador básico $\alpha_{\text {básico }}$ se aplica às lajes comumente utilizadas na construção civil, como mostradas nas 
tabelas 5.21, 5.22, 5.23, 5.24 e 5.25. Isso equivale a lajes com valores do coeficiente $\kappa$ variando entre 0,10 e 0,55 .

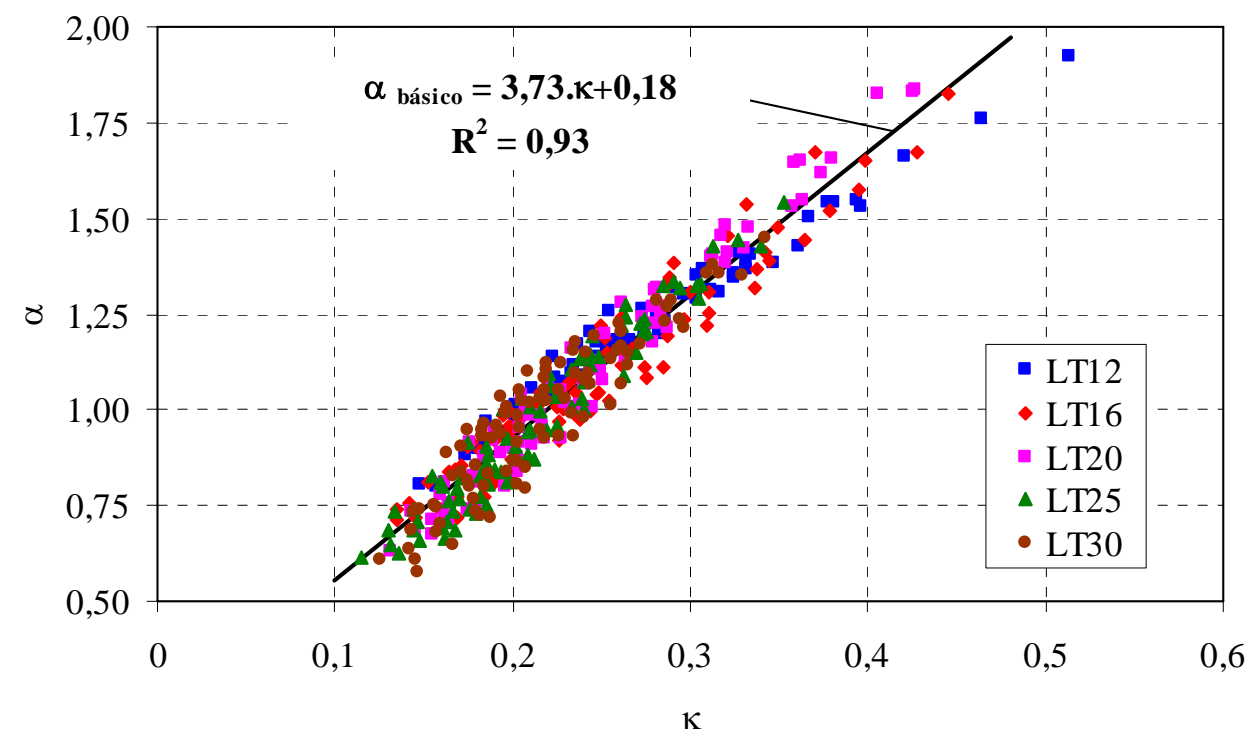

FIGURA 5.14 - Regressão linear dos resultados

Por definição, resíduo da regressão é a diferença entre os valores observados e os valores estimados. Para a análise em questão, o resíduo da regressão em função do coeficiente $\kappa$ está apresentado na figura 5.15. Por essa figura, pode-se notar que o resíduo variou entre $-0,17$ e $+0,14$ e não houve tendência no espalhamento.

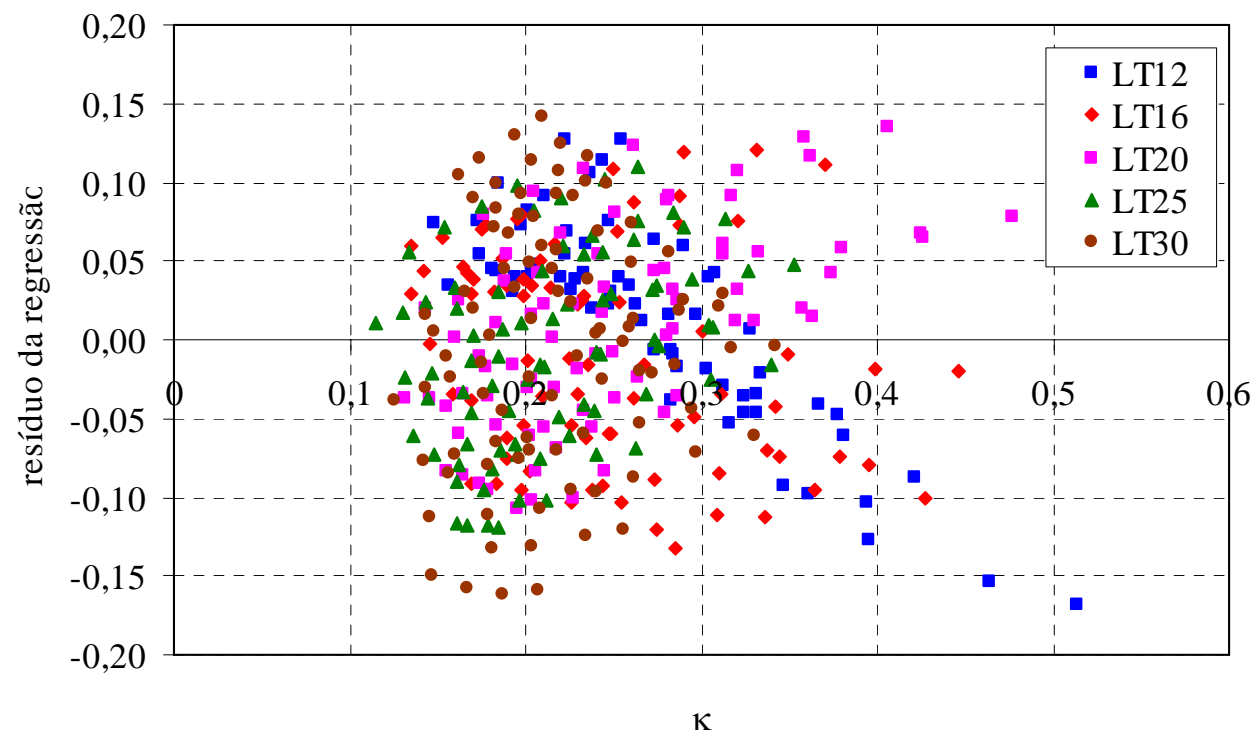

FIGURA 5.15 - Resíduo da regressão 
Nas figuras 5.16, 5.17, 5.18, 5.19 e 5.20 estão apresentados os coeficientes multiplicadores $\alpha$ em função do coeficiente $\kappa$, respectivamente, para as lajes LT12, LT16, LT20, LT25 e LT30. Apresenta-se também nas figuras o resíduo máximo obtido com a regressão. Por essas figuras, pode-se notar que o resíduo obtido com a regressão não foi função do tipo nem do vão da laje.

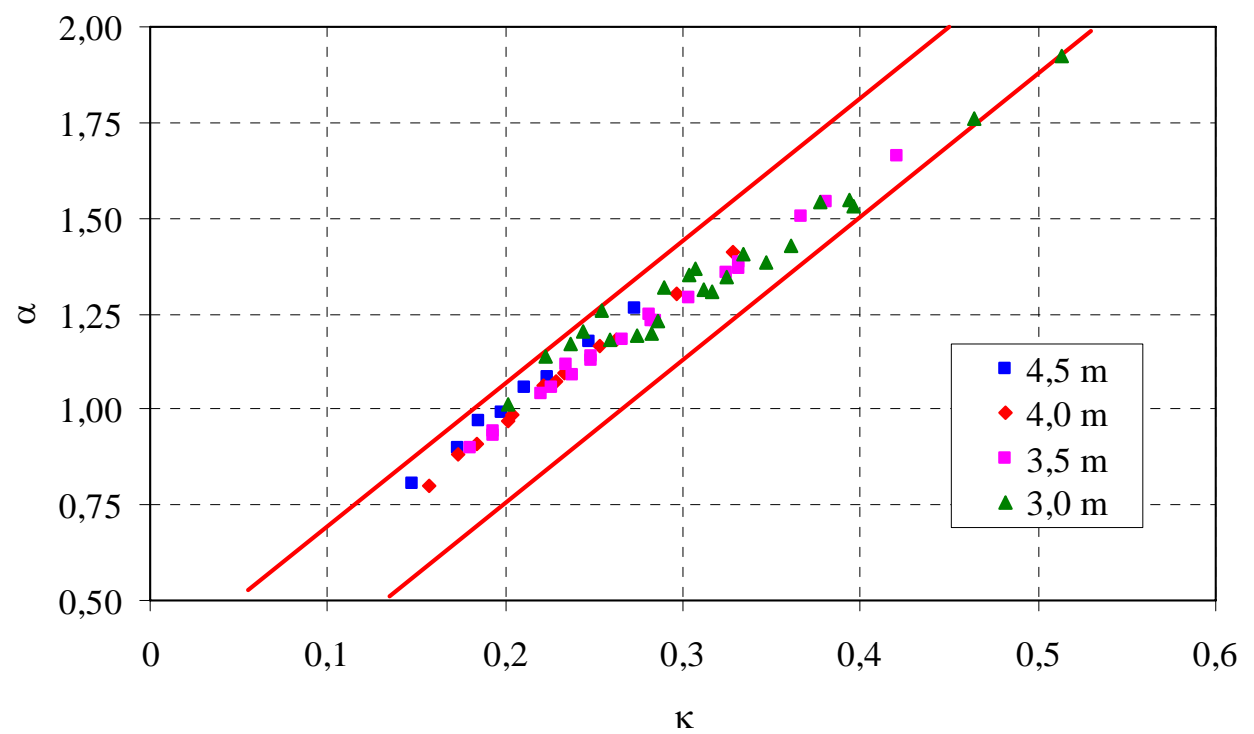

FIGURA 5.16 - Coeficiente multiplicador para a laje LT12

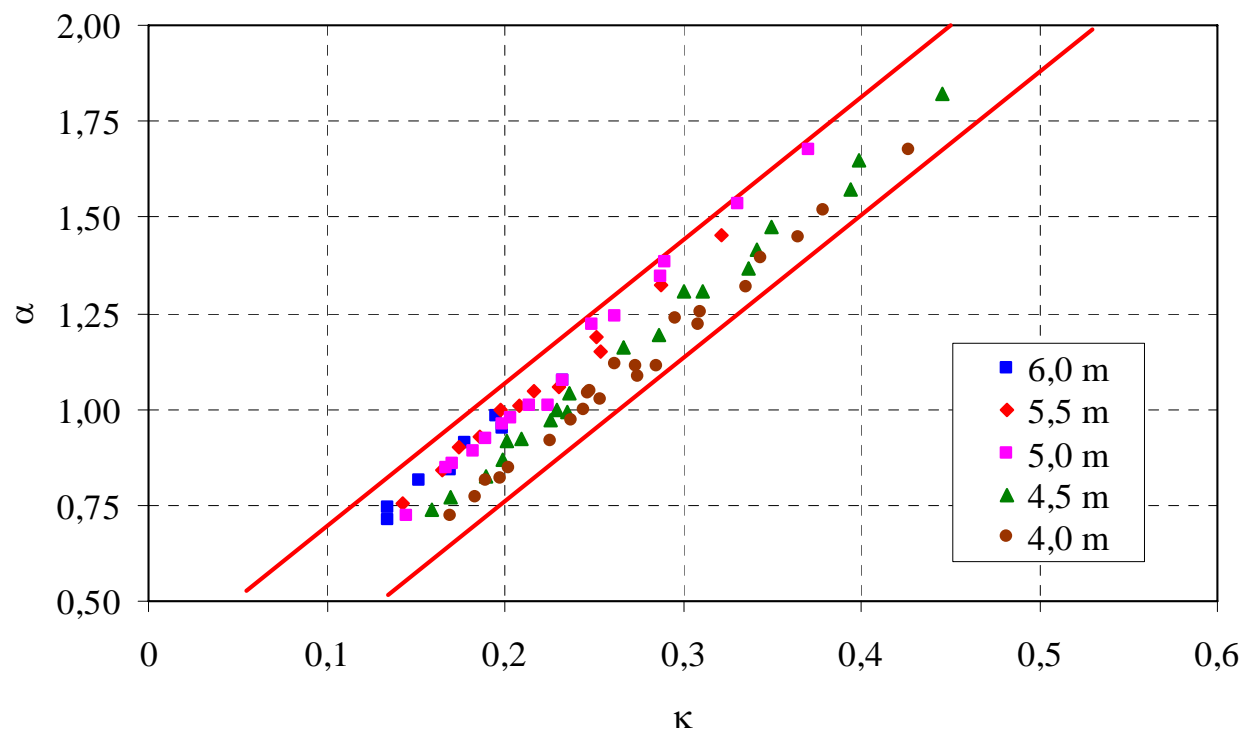

FIGURA 5.17 - Coeficiente multiplicador para a laje LT16 


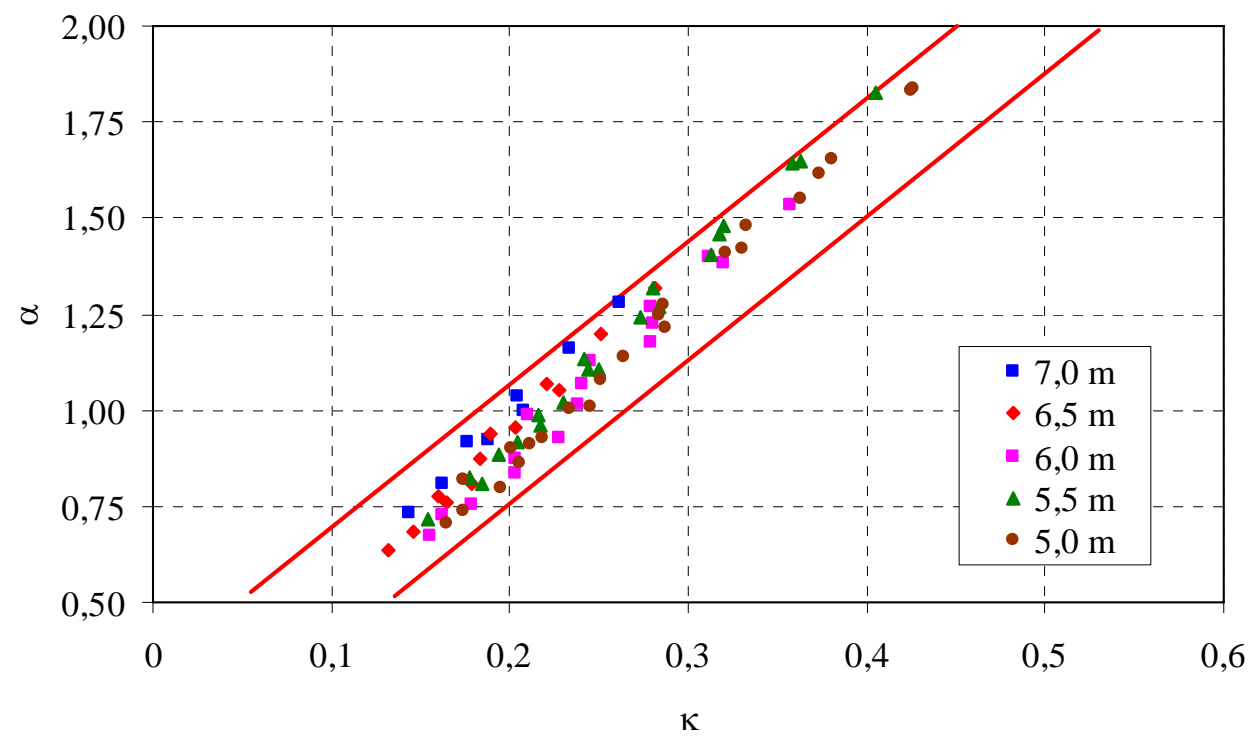

FIGURA 5.18 - Coeficiente multiplicador para a laje LT20

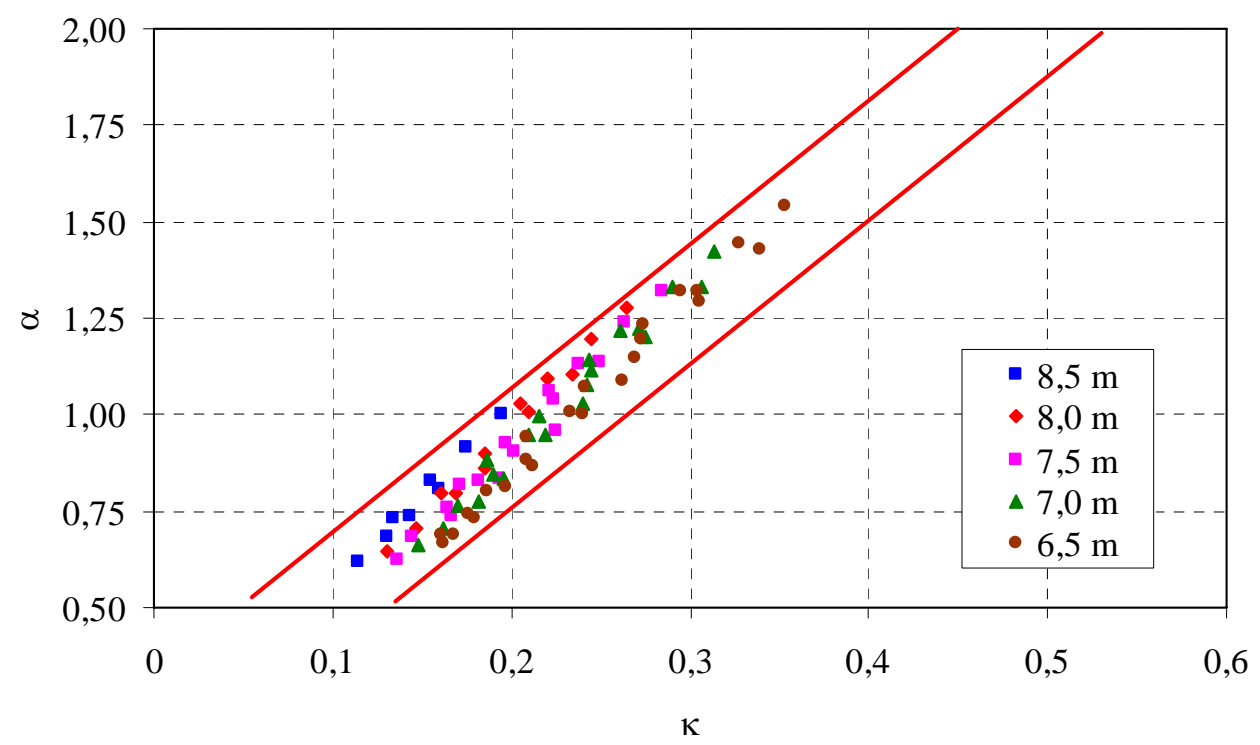

FIGURA 5.19 - Coeficiente multiplicador para a laje LT25 


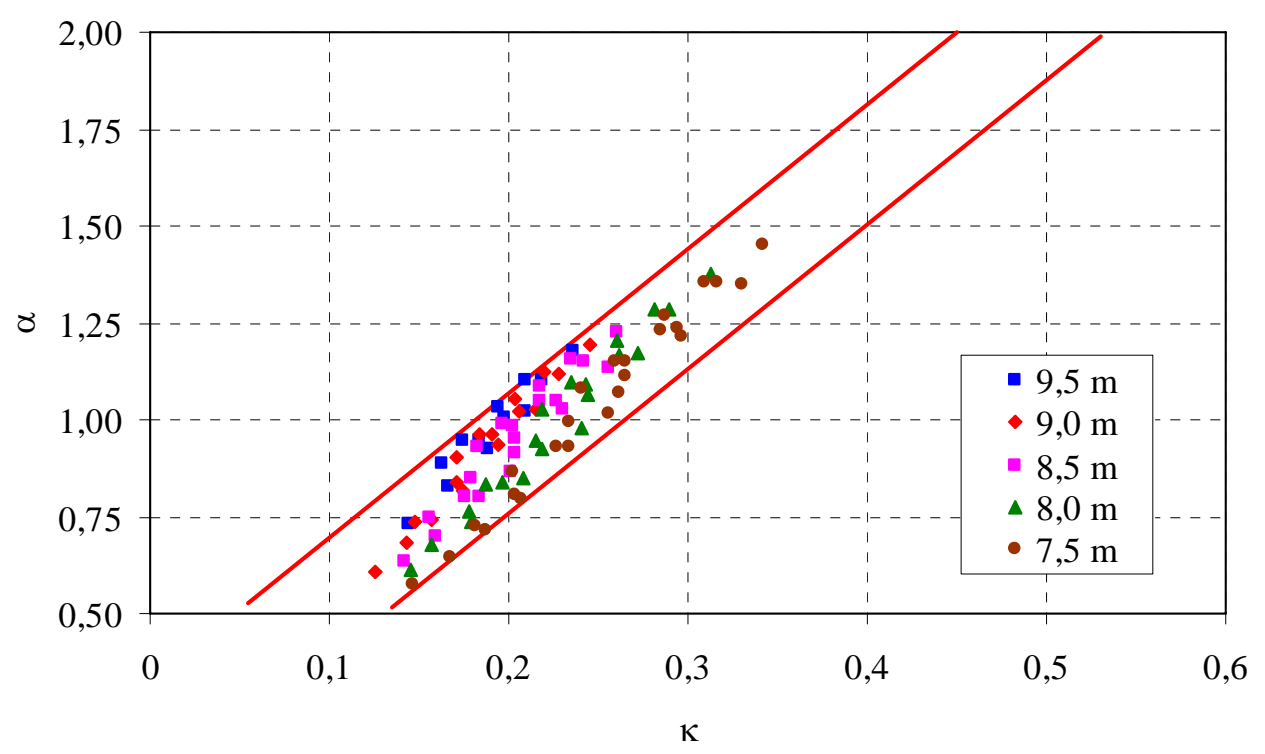

FIGURA 5.20 - Coeficiente multiplicador para a laje LT30

\subsubsection{Influência da umidade relativa e temperatura no coeficiente multiplicador}

Para averiguar a influência da umidade relativa e temperatura ambiente no coeficiente multiplicador foram analisados 31 casos, como mostrados na tabela 5.26. Esta análise foi realizada variando a umidade relativa em $40 \%, 60 \%$, $80 \%$ e a temperatura ambiente em $15^{\circ} \mathrm{C}, 25^{\circ} \mathrm{C}, 35^{\circ} \mathrm{C}$, totalizando, portanto, 279 casos.

Os demais parâmetros e considerações empregadas nesta análise foram os mesmos adotados no item anterior.

A influência da umidade relativa e temperatura ambiente foram consideradas através do coeficiente $\alpha_{\mathrm{U}, \mathrm{T}}$. Este coeficiente foi determinado dividindo o coeficiente multiplicador obtido em cada caso pelo resultado obtido para o caso com as mesmas características, mas com umidade relativa de 60\% e temperatura ambiente de $25^{\circ} \mathrm{C}$. 
TABELA 5.26 - Casos analisados para a determinação de $\alpha_{U, T}$

\begin{tabular}{|c|c|c|c|c|}
\hline \multirow{3}{*}{ laje } & \multirow{3}{*}{$\ell(\mathbf{m})$} & \multirow{2}{*}{\multicolumn{3}{|c|}{$\begin{array}{c}\text { armadura adicional } A_{s, \text { adic }}\left(\mathrm{cm}^{2}\right) \\
q\left(\mathrm{kN} / \mathrm{m}^{2}\right) \\
\end{array}$}} \\
\hline & & & & \\
\hline & & 2,0 & 4,0 & 6,0 \\
\hline \multirow{4}{*}{ LT12 } & 4,5 & 1,50 & & \\
\hline & 4,0 & 0,90 & & \\
\hline & 3,5 & 0,60 & 1,50 & \\
\hline & 3,0 & 0,40 & 0,80 & 1,50 \\
\hline \multirow{3}{*}{ LT16 } & 6,0 & 1,50 & & \\
\hline & 5,0 & 1,00 & 2,35 & \\
\hline & 4,0 & 0,40 & 1,00 & 1,50 \\
\hline \multirow{3}{*}{ LT20 } & 7,0 & 2,35 & & \\
\hline & 6,0 & 1,20 & 2,35 & \\
\hline & 5,0 & 0,60 & 1,50 & 2,35 \\
\hline \multirow{3}{*}{ LT25 } & 8,5 & 2,35 & & \\
\hline & 7,5 & 1,60 & 3,68 & \\
\hline & 6,5 & 1,00 & 2,35 & 3,68 \\
\hline \multirow{3}{*}{ LT30 } & 9,5 & 3,68 & & \\
\hline & 8,5 & 2,35 & 3,68 & \\
\hline & 7,5 & 1,50 & 2,35 & 3,68 \\
\hline
\end{tabular}

Os resultados obtidos estão apresentados no Apêndice B, mas podem ser vistos na figura 5.21, que mostra o coeficiente $\alpha_{U, T}$, encontrado para cada caso, em função da umidade relativa e temperatura ambiente.

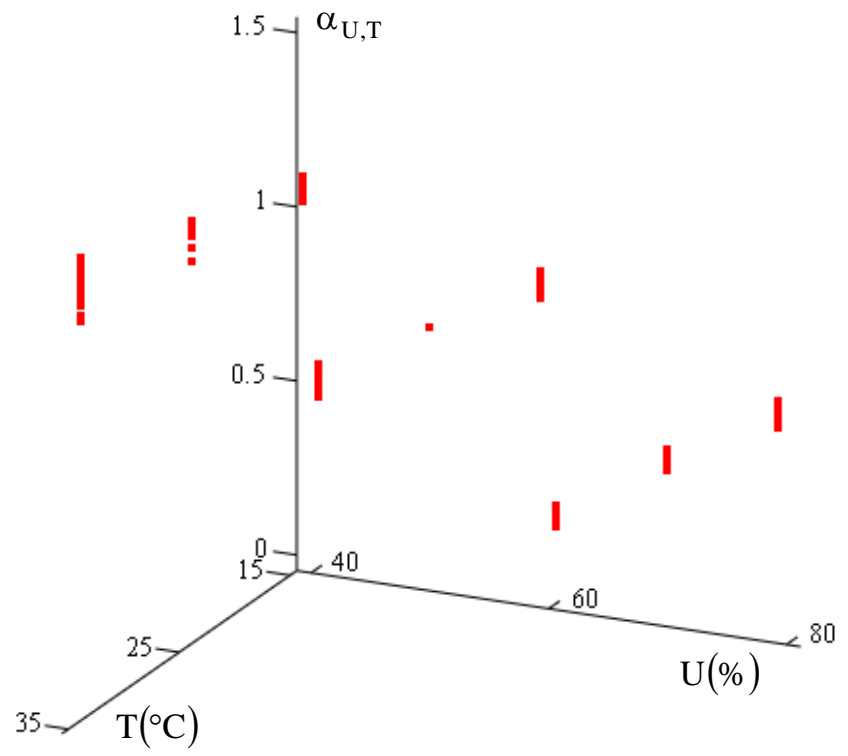

FIGURA 5.21 - Coeficiente $\alpha_{U, T}$ 
Através de regressão não-linear dos valores obtidos, como mostrado na figura 5.22, obteve-se a seguinte expressão para o coeficiente $\alpha_{\mathrm{U}, \mathrm{T}}$.

$$
\begin{aligned}
& \alpha_{\mathrm{U}, \mathrm{T}}=0,016 \cdot \mathrm{T}+4,9 \cdot 10^{-3} \cdot \mathrm{U}-2,7 \cdot 10^{-5} \cdot \mathrm{T} . \mathrm{U}- \\
& -1,03 \cdot 10^{-4} \cdot \mathrm{T}^{2}-1,32 \cdot 10^{-4} \cdot \mathrm{U}^{2}+0,90 \\
& \text { com } \\
& \mathrm{R}^{2}=0,99
\end{aligned}
$$

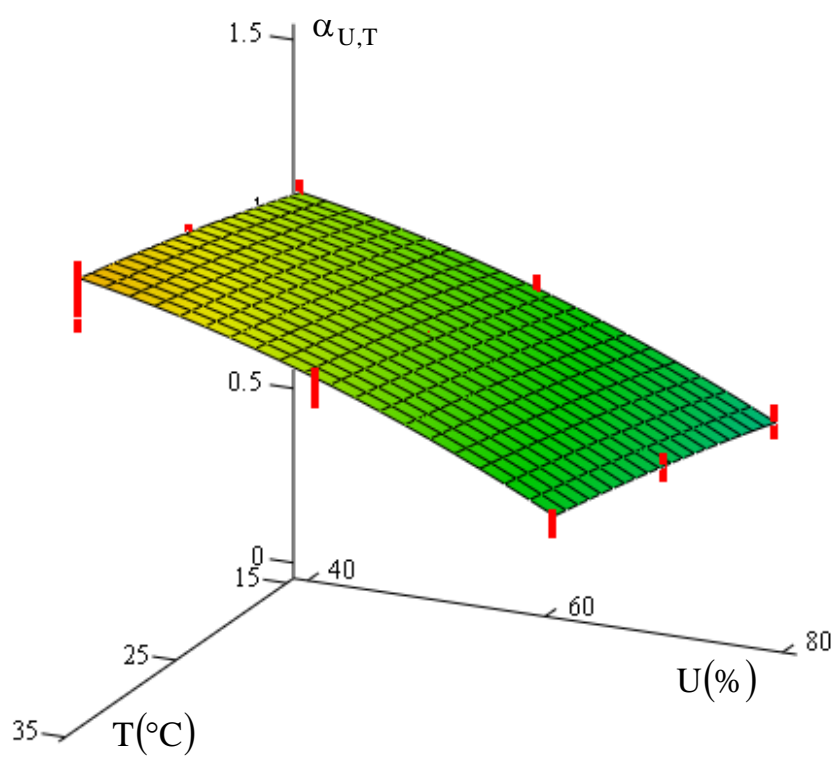

FIGURA 5.22 - Regressão não-linear do coeficiente $\alpha_{U, T}$

E, como mostrado na figura 5.23, obteve-se a seguinte expressão para o coeficiente $\alpha_{\mathrm{U}, \mathrm{T}}$, através de regressão linear dos resultados obtidos.

$\alpha_{\mathrm{U}, \mathrm{T}}=8,8 \cdot 10^{-3} . \mathrm{T}-0,012 . \mathrm{U}+1,43$

com

$\mathrm{R}^{2}=0,97$ 


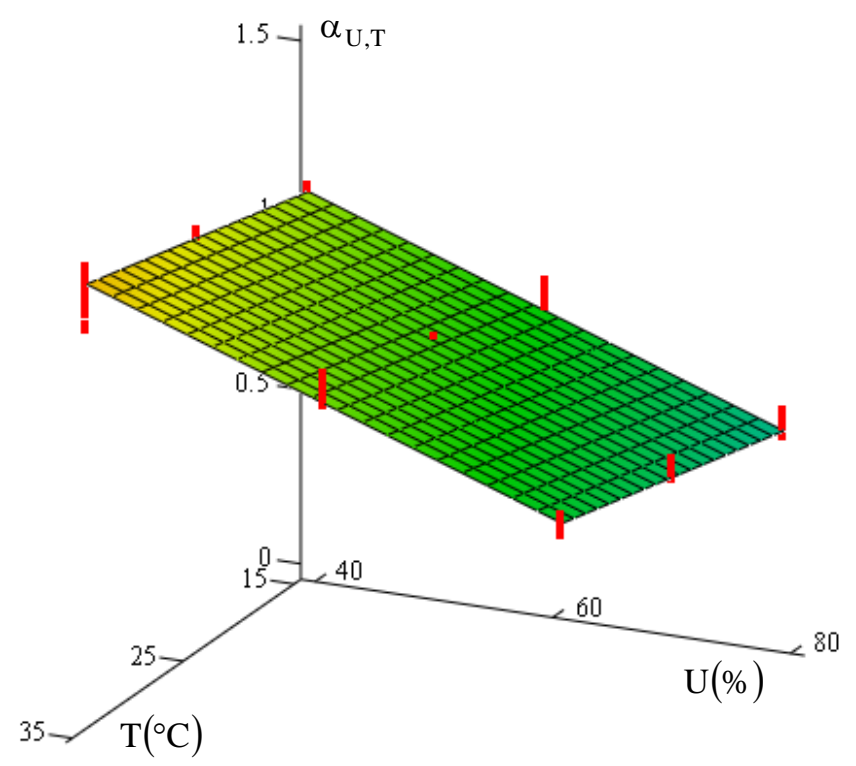

FIGURA 5.23 - Regressão linear do coeficiente $\alpha_{\mathrm{U}, \mathrm{T}}$

E assim, o coeficiente multiplicador $\alpha$ da flecha instantânea para avaliação da flecha diferida de lajes pré-moldadas formadas por vigotas com armação treliçada é determinado a partir do coeficiente multiplicador básico $\alpha_{\text {básico }}$ e do coeficiente $\alpha_{U, T}$, que considera a influência da umidade relativa e temperatura ambiente.

Ou seja,

$$
\alpha=\alpha_{\text {básico }} \cdot \alpha_{\mathrm{U}, \mathrm{T}}
$$

\section{Com}

$\alpha_{\text {básico }}=3,73 . \kappa+0,18$

sendo

$\kappa=\frac{A_{s} \cdot h^{2,05}}{p^{1,5} \cdot \ell^{3}} \cdot 10^{3}$

onde:
$\mathrm{A}_{\mathrm{S}}$ - armadura $\left[\mathrm{cm}^{2}\right]$;
h - altura da laje [m];
p - carregamento aplicado [kN/m];
$\ell \quad$ - vão da laje [m]. 
E ainda,

$$
\begin{aligned}
& \alpha_{\mathrm{U}, \mathrm{T}}=0,016 \cdot \mathrm{T}+4,9 \cdot 10^{-3} \cdot \mathrm{U}-2,7 \cdot 10^{-5} . \mathrm{T} . \mathrm{U}- \\
& -1,03 \cdot 10^{-4} \cdot T^{2}-1,32 \cdot 10^{-4} \cdot U^{2}+0,90 \\
& \text { ou } \\
& \alpha_{\mathrm{U}, \mathrm{T}}=8,8 \cdot 10^{-3} . \mathrm{T}-0,012 . \mathrm{U}+1,43 \\
& \text { onde: } \\
& \text { U - umidade relativa do ambiente [\%]; } \\
& \mathrm{T} \text { - temperatura do ambiente }\left[{ }^{\circ} \mathrm{C}\right] \text {. }
\end{aligned}
$$

\subsection{Análise probabilística}

Para determinar o coeficiente multiplicador $\alpha$, levando-se em conta a

\begin{tabular}{|c|c|c|c|c|c|c|}
\hline casos & laje & $\ell(\mathbf{m})$ & $q\left(\mathbf{k N} / \mathbf{m}^{2}\right)$ & $A_{s, \text { adic }}\left(\mathrm{cm}^{2}\right)$ & U (\%) & $\mathrm{T}\left({ }^{\circ} \mathrm{C}\right)$ \\
\hline caso 1 & LT30 & 8,5 & 4,0 & 3,68 & 40 & 35 \\
\hline caso 2 & LT20 & 5,0 & 4,0 & 1,50 & 40 & 25 \\
\hline caso 3 & LT12 & 3,5 & 4,0 & 1,50 & 40 & 15 \\
\hline caso 4 & LT30 & 8,5 & 4,0 & 3,68 & 60 & 35 \\
\hline caso 5 & LT12 & 3,5 & 2,0 & 0,60 & 60 & 15 \\
\hline caso 6 & LT30 & 9,5 & 2,0 & 3,68 & 80 & 35 \\
\hline caso 7 & LT12 & 3,0 & 2,0 & 0,40 & 80 & 25 \\
\hline caso 8 & LT12 & 3,0 & 2,0 & 0,40 & 80 & 15 \\
\hline
\end{tabular}
variabilidade estatística dos principais parâmetros, selecionou-se os casos analisados anteriormente que resultaram os maiores valores no coeficiente $\alpha_{U, T}$, comparando casos com mesma umidade relativa e temperatura ambiente. Desta seleção resultaram 8 casos, que estão apresentados na tabela 5.27. E para esses casos foi realizada a análise probabilística utilizando o método de amostragem por hipercubo latino, conforme descrito no capítulo 4. 
Os parâmetros que foram considerados como variáveis aleatórias estão listadas a seguir, totalizando 8 variáveis aleatórias para cada caso. Foi considerado ainda que essas variáveis aleatórias eram estatisticamente independentes entre si e seguiam uma distribuição normal.

$$
\begin{aligned}
& \Psi_{1, c 1} \text { - coeficiente de fluência do concreto da vigota } \\
& \Psi_{2, c 1} \text { - retração do concreto da vigota } \\
& f_{c 1} \text { - resistência do concreto da vigota } \\
& \Psi_{1, c 2} \text { - coeficiente de fluência do concreto da capa estrutural } \\
& \Psi_{2, c 2} \text { - retração do concreto da capa estrutural } \\
& f_{c 2} \text { - resistência do concreto da capa estrutural } \\
& U \text { - umidade relativa } \\
& T \text { - temperatura ambiente }
\end{aligned}
$$

As propriedades estatísticas das variáveis aleatórias, ou seja, a média $(\mu)$ e o coeficiente de variação $(V)$ estão apresentados na tabela 5.28.

TABELA 5.28 - Propriedades estatísticas das variáveis aleatórias

\begin{tabular}{ccccccccc}
\hline & $\Psi_{1, c 1}$ & $\Psi_{2, c 1}$ & $f_{c 1}$ & $\Psi_{1, c 2}$ & $\Psi_{2, c 2}$ & $f_{c 2}$ & $U$ & $T$ \\
\hline$\mu$ & - & - & $(\mathrm{MPa})$ & - & - & $(\mathrm{MPa})$ & $\%$ & ${ }^{\circ} \mathrm{C}$ \\
\hline$(\%)$ & 1,0 & 1,0 & 20 & 1,0 & 1,0 & 20 & $\begin{array}{c}\text { conforme } \\
\text { tabela 5.27 }\end{array}$ & $\begin{array}{c}\text { conforme } \\
\text { tabela 5.27 }\end{array}$ \\
\hline
\end{tabular}

O total de simulações realizadas para cada caso foi igual a 100. Preferiuse aumentar o número de simulações para melhorar a precisão da resposta. Para ilustrar a diferença que pode ocorrer com o aumento do número de simulações, apresenta-se na figura 5.24 a distribuição uniforme no quadrado unitário dos pares utilizados para calcular os valores das resistências mostradas na figura 5.25. Por essas figuras, pode-se perceber que, com o aumento do número de pares, será mais difícil ocorrer regiões com acúmulo de pontos ou com vazios. 


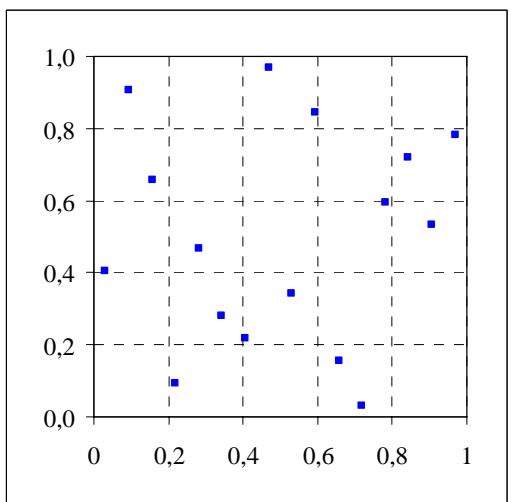

(a) 16 pares

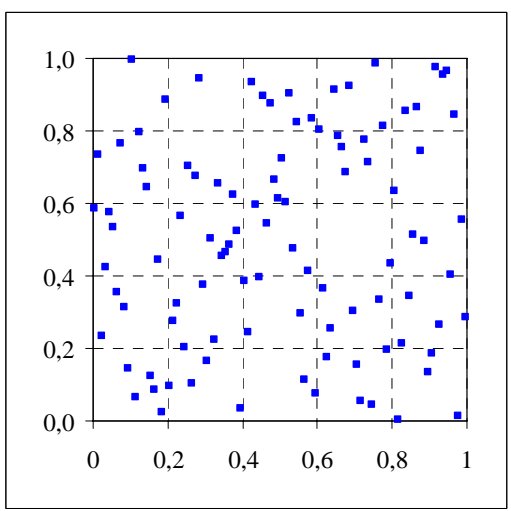

(b) 100 pares

FIGURA 5.24 - Distribuição uniforme no quadrado unitário

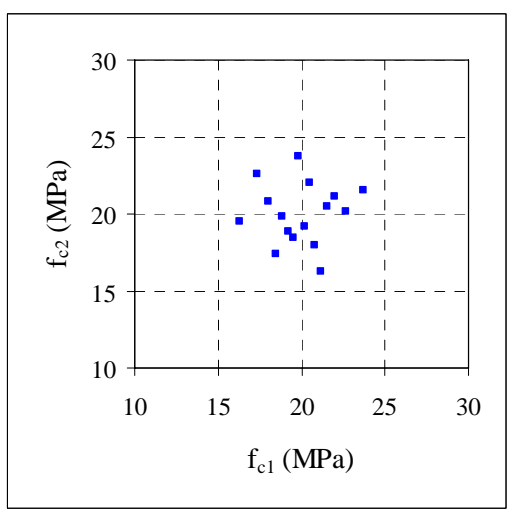

$\begin{array}{ll}\text { (a) } 16 \text { pares } & \text { (b) } 100 \text { pares }\end{array}$

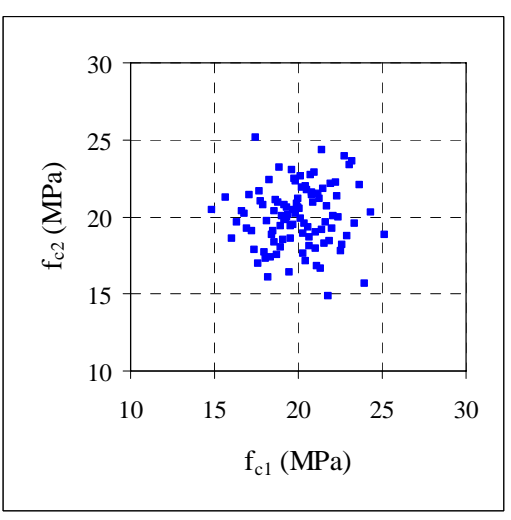

(b) 100 pares

A partir dos resultados das simulações, pôde-se verificar quais os parâmetros afetam mais significativamente o valor do coeficiente multiplicador através do coeficiente de regressão padronizado e coeficiente de correlação parcial, como mostrados nas figuras 5.26 e 5.27. Pelas figuras, pode-se notar que as incertezas nos modelos da fluência e retração do concreto da capa estrutural e, como já era esperado, os fatores ambientais (umidade relativa e temperatura ambiente) foram os parâmetros que tiveram maior influência no coeficiente multiplicador $\alpha$. 


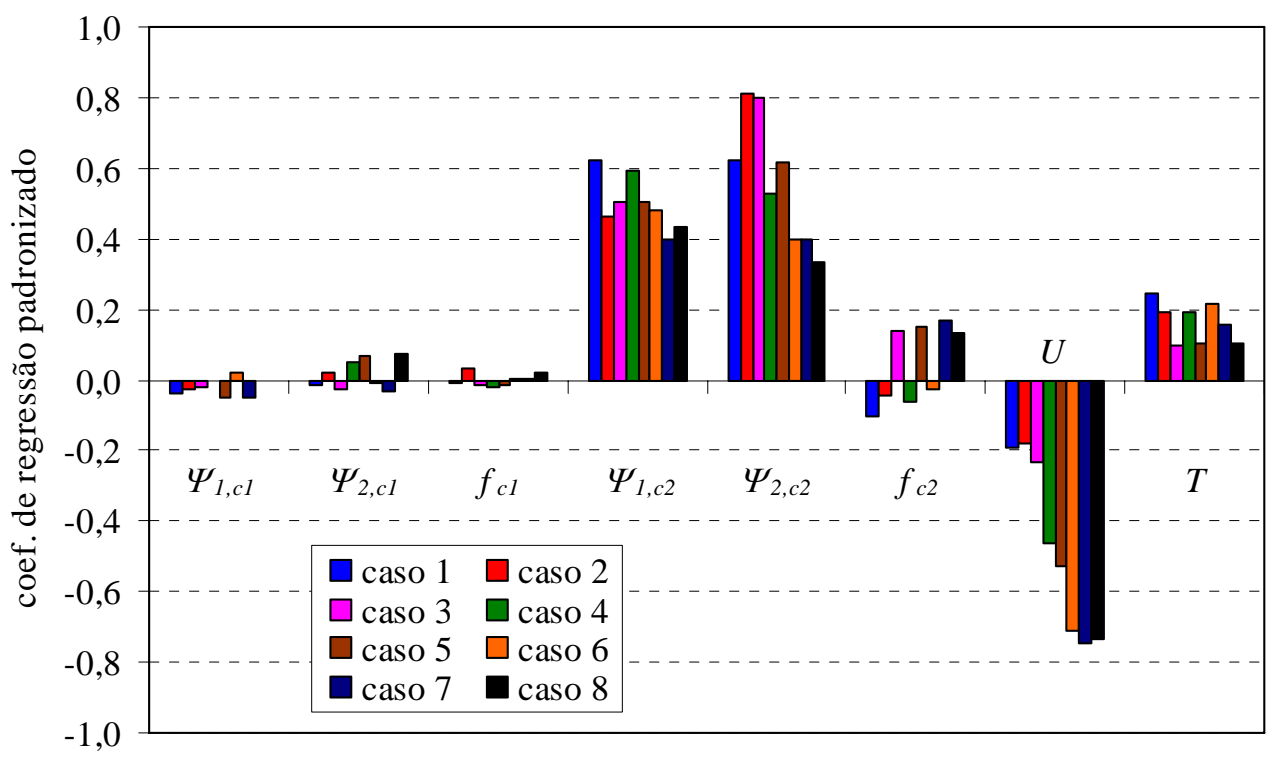

FIGURA 5.26 - Coeficiente de regressão padronizado para o coeficiente multiplicador $\alpha$

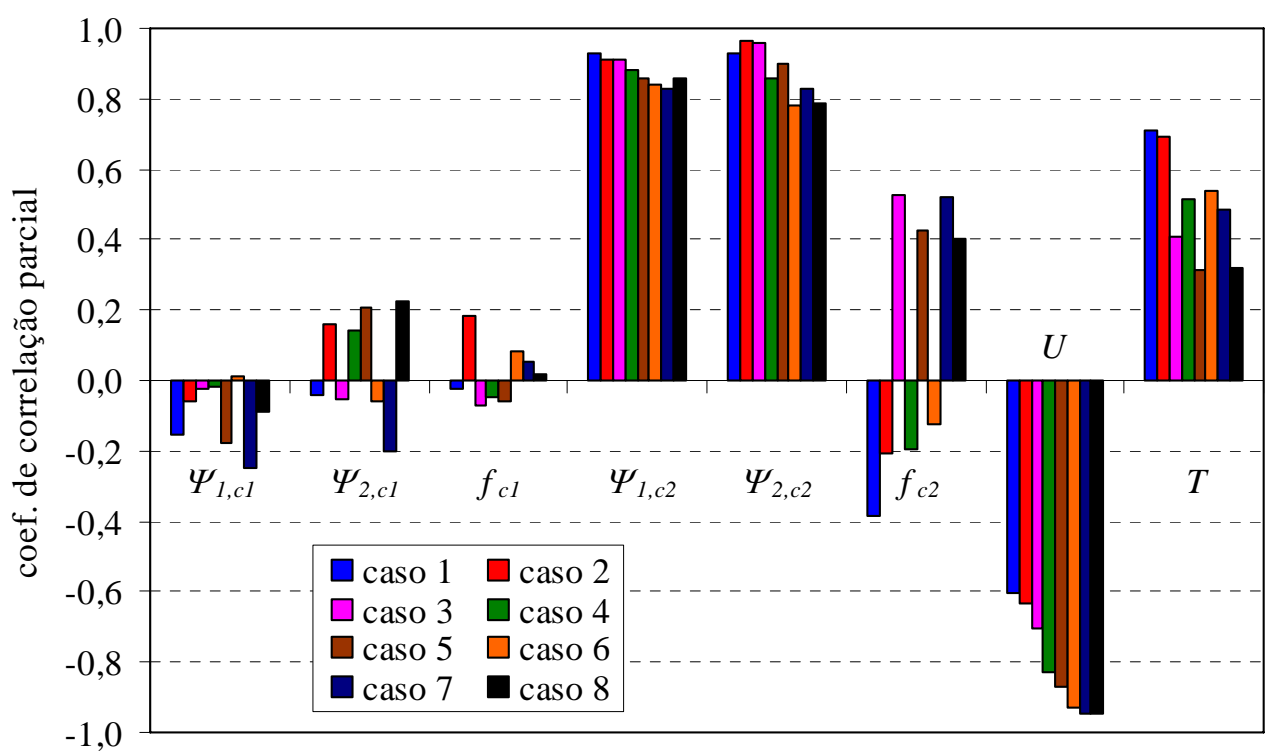

FIGURA 5.27 - Coeficiente de correlação parcial para o coeficiente multiplicador $\alpha$

Para verificar se o coeficiente multiplicador $\alpha$ se aproxima de uma distribuição normal, construiu o gráfico de probabilidade normal do coeficiente multiplicador obtido para cada caso, conforme figura 5.28. Por essa figura, nota-se que os valores ficaram próximos da reta, indicando que a distribuição normal é uma boa aproximação. 
(a) caso 1

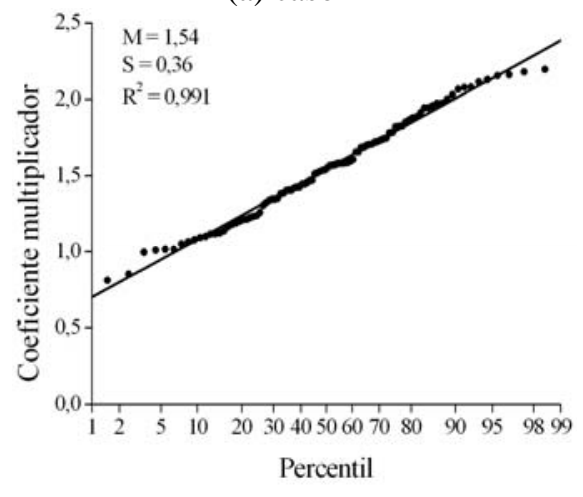

(c) caso 3

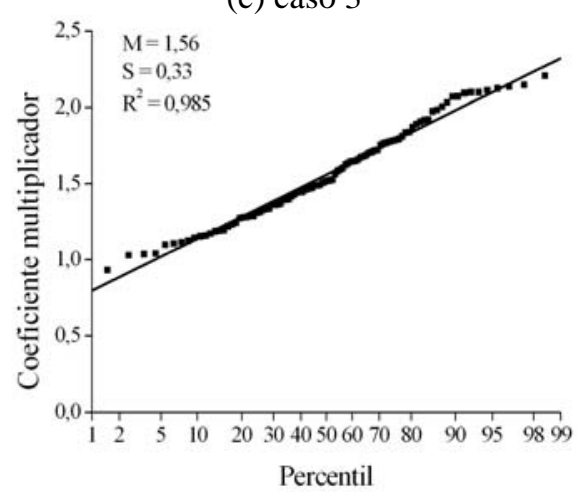

(e) caso 5

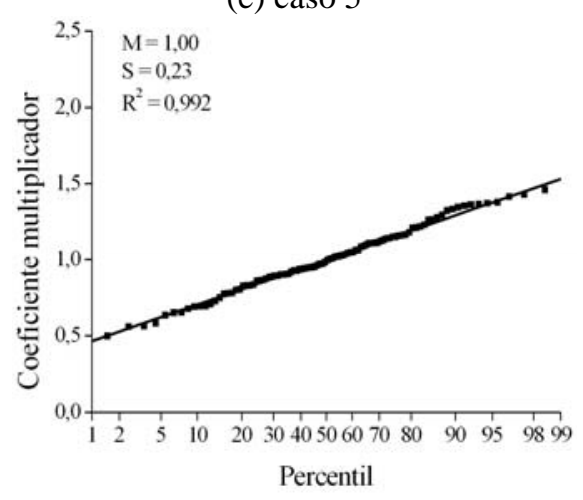

(g) caso 7

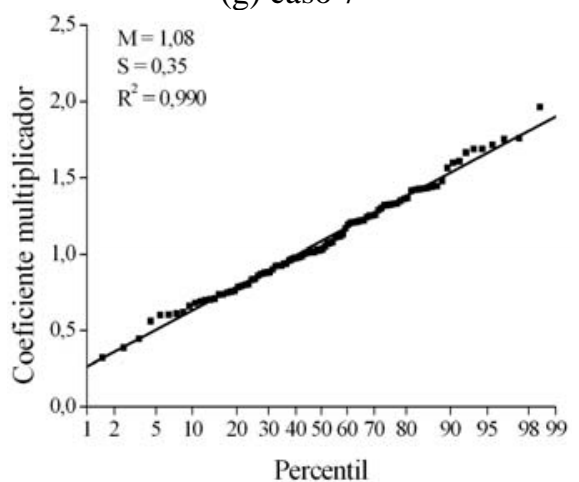

(b) caso 2

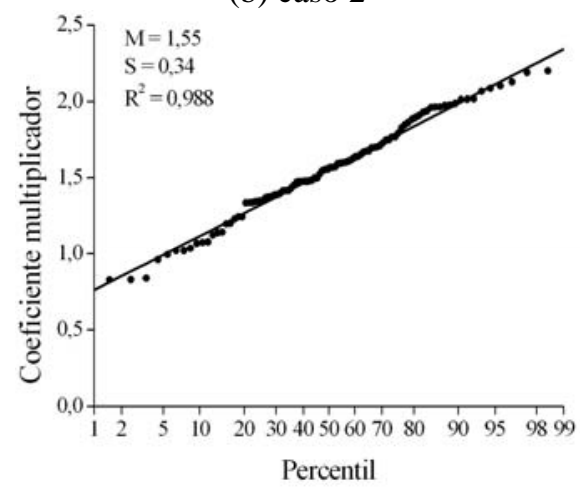

(d) caso 4

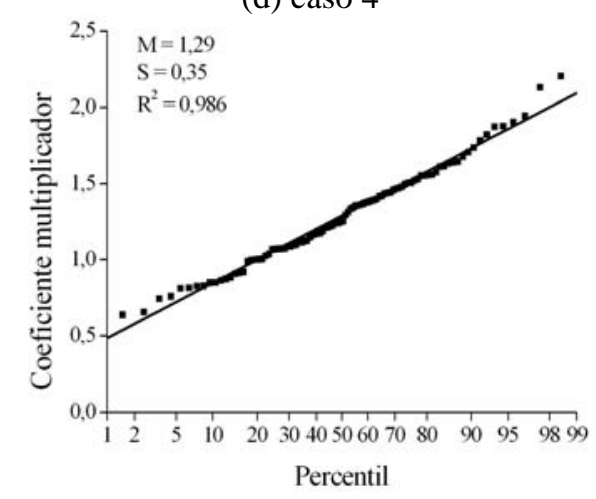

(f) caso 6

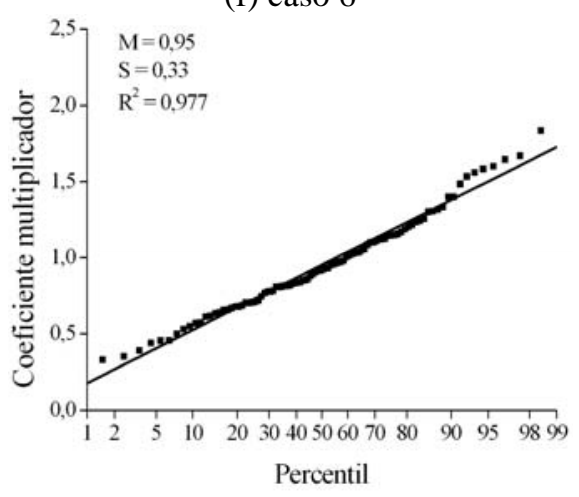

(h) caso 8

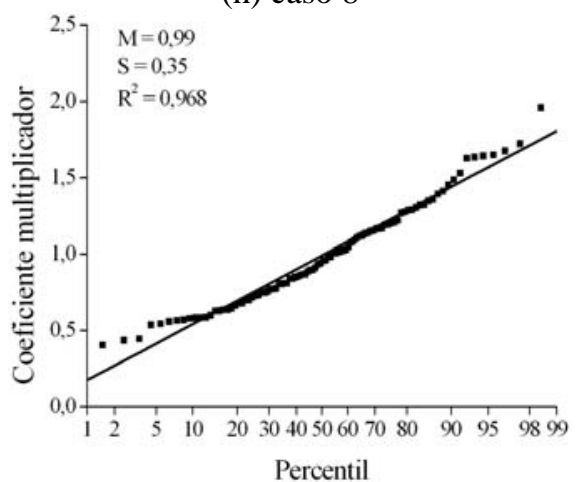

FIGURA 5.28 - Gráficos de probabilidade normal para o coeficiente multiplicador 
Com os valores obtidos para o coeficiente multiplicador $\alpha$ para os 8 casos analisados, determinou-se o coeficiente $\alpha_{\mathrm{U}, \mathrm{T}}$, como definido anteriormente. Foram determinados para cada par de valores de umidade relativa e temperatura, os coeficientes $\alpha_{\mathrm{U}, \mathrm{T}}$ com 5\%, 10\% e 15\% de probabilidade de serem ultrapassados, ou seja, 95\%, 90\% e $85 \%$ de probabilidade dos coeficientes $\alpha_{U, T}$ estarem abaixo do valor determinado.

A partir da regressão desses valores, obteve-se as seguintes expressões para o coeficiente $\alpha_{U, T}$, como mostrados nas figuras 5.29, 5.30 e 5.31, respectivamente para 95\%, 90\% e 85\% de probabilidade.

- $95 \%$ de probabilidade:

$$
\begin{aligned}
\alpha_{\mathrm{U}, \mathrm{T}}= & 0,029 \cdot \mathrm{T}-0,011 \cdot \mathrm{U}-2,83 \cdot 10^{-4} \cdot \mathrm{T} \cdot \mathrm{U}+ \\
& +1,31 \cdot 10^{-4} \cdot \mathrm{T}^{2}+4,93 \cdot 10^{-5} \cdot \mathrm{U}^{2}+1,78
\end{aligned}
$$

ou

$$
\alpha_{\mathrm{U}, \mathrm{T}}=0,019 . \mathrm{T}-0,012 . \mathrm{U}+1,97
$$

- $90 \%$ de probabilidade:

$$
\begin{aligned}
\alpha_{\mathrm{U}, \mathrm{T}}= & 0,029 \cdot \mathrm{T}-9,17 \cdot 10^{-3} \cdot \mathrm{U}-2,61 \cdot 10^{-4} \cdot \mathrm{T} \cdot \mathrm{U}+ \\
& +7,86 \cdot 10^{-5} \cdot \mathrm{T}^{2}+2,76 \cdot 10^{-5} \cdot \mathrm{U}^{2}+1,64 \\
\text { ou } & \\
\alpha_{\mathrm{U}, \mathrm{T}}= & 0,017 \cdot \mathrm{T}-0,012 \cdot \mathrm{U}+1,89
\end{aligned}
$$

- $85 \%$ de probabilidade:

$$
\begin{aligned}
\alpha_{\mathrm{U}, \mathrm{T}}= & 0,029 \cdot \mathrm{T}-7,82 \cdot 10^{-3} \cdot \mathrm{U}-2,45 \cdot 10^{-4} \cdot \mathrm{T} \cdot \mathrm{U}+ \\
& +4,29 \cdot 10^{-5} \cdot \mathrm{T}^{2}+1,30 \cdot 10^{-5} \cdot \mathrm{U}^{2}+1,54 \\
\text { ou } & \\
\alpha_{\mathrm{U}, \mathrm{T}}= & 0,016 \cdot \mathrm{T}-0,012 \cdot \mathrm{U}+1,84
\end{aligned}
$$




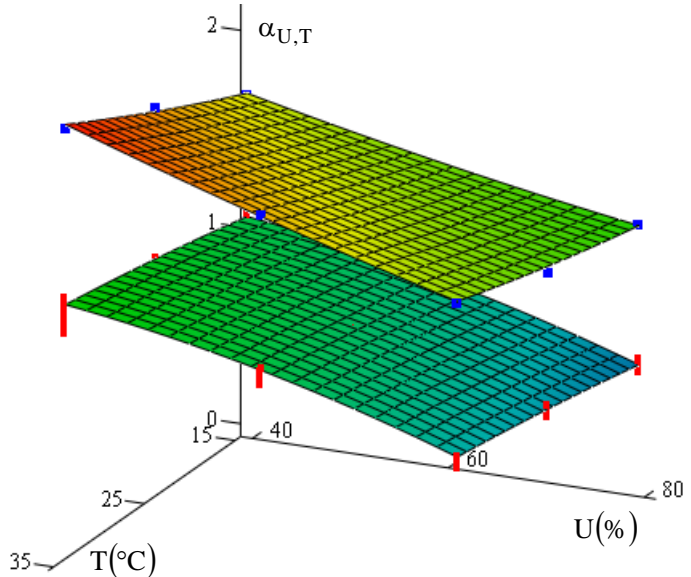

(a) não-linear

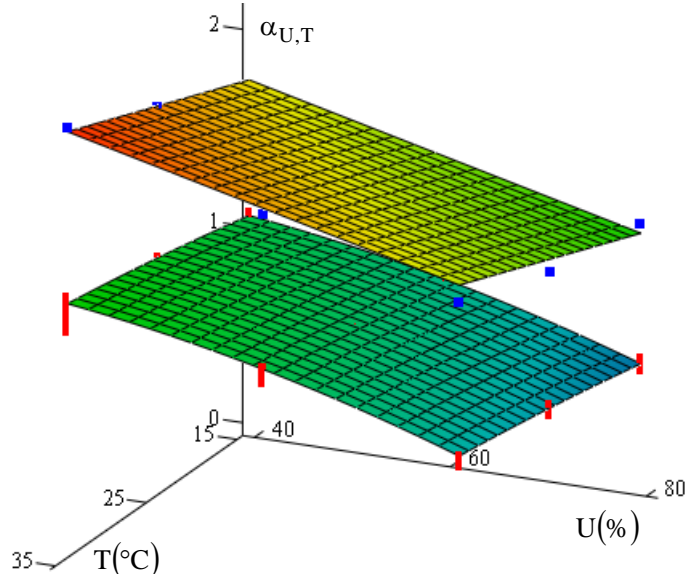

(b) linear

FIGURA 5.29 - Regressão do coeficiente $\alpha_{\mathrm{U,T}}$ com 95\% probabilidade

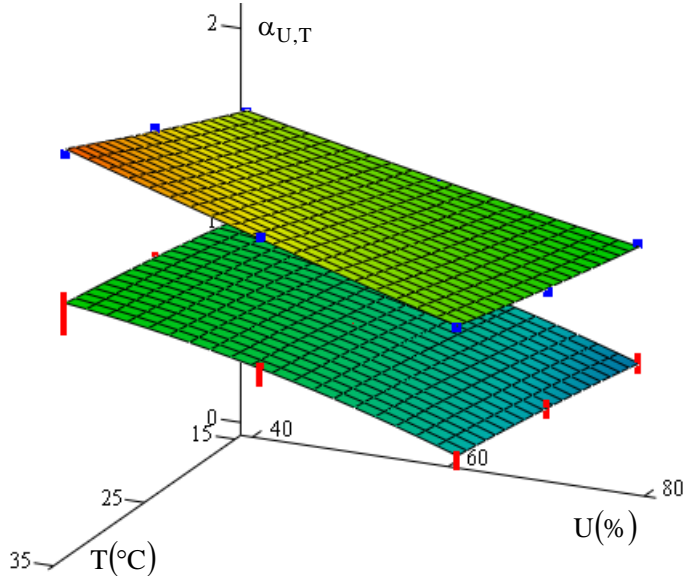

(a) não-linear

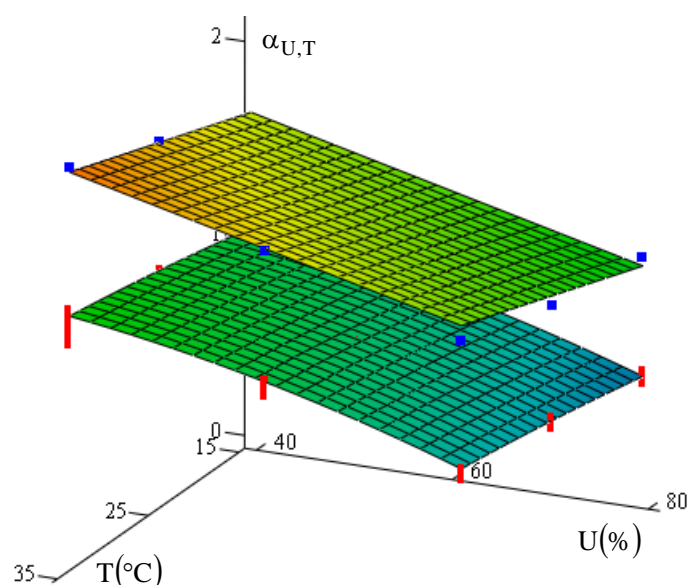

(b) linear

FIGURA 5.30 - Regressão do coeficiente $\alpha_{\mathrm{U}, \mathrm{T}}$ com 90\% probabilidade

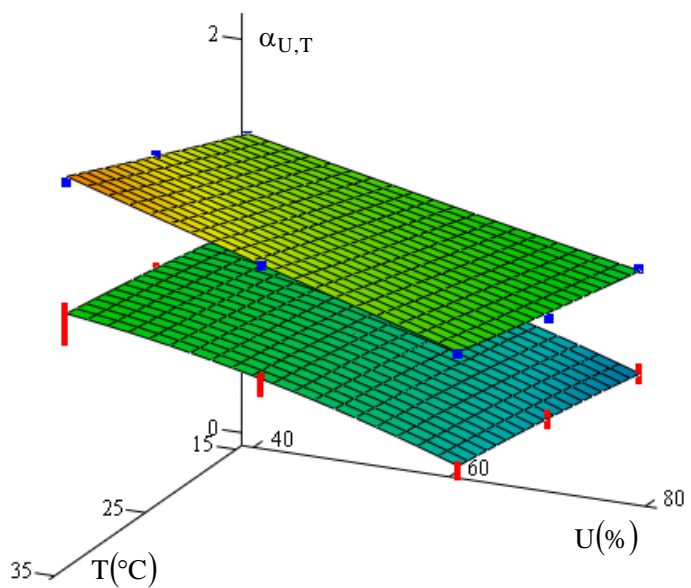

(a) não-linear

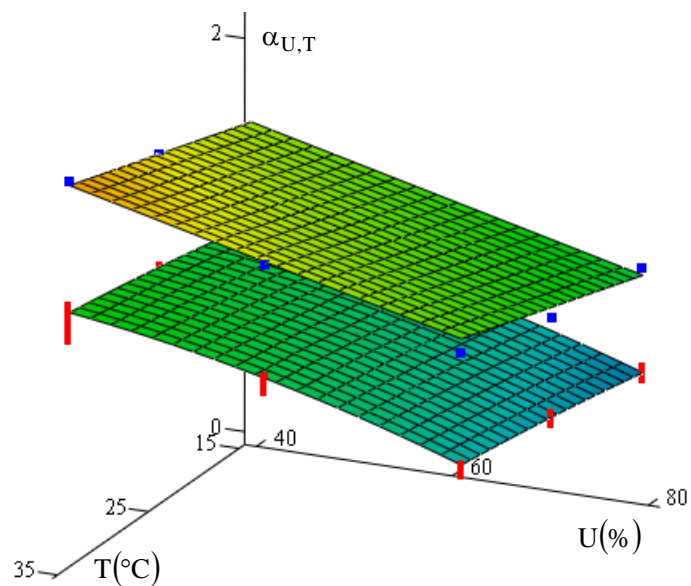

(b) linear

FIGURA 5.31 - Regressão do coeficiente $\alpha_{\mathrm{U}, \mathrm{T}}$ com 85\% probabilidade 
Portanto, o coeficiente multiplicador $\alpha$ da flecha instantânea para avaliação da flecha diferida de lajes pré-moldadas formadas por vigotas com armação treliçada será:

$$
\alpha=\alpha_{\text {básico }} \cdot \alpha_{\mathrm{U}, \mathrm{T}}
$$

Com

$\alpha_{\text {básico }}=3,73 . \kappa+0,18$

sendo

$\kappa=\frac{A_{s} \cdot h^{2,05}}{p^{1,5} \cdot \ell^{3}} \cdot 10^{3}$

onde:

$$
\begin{array}{ll}
A_{\mathrm{s}} & \text { - armadura }\left[\mathrm{cm}^{2}\right] ; \\
\mathrm{h} & \text { - altura da laje }[\mathrm{m}] ; \\
\mathrm{p} & \text { - carregamento aplicado }[\mathrm{kN} / \mathrm{m}] ; \\
\ell & \text { - vão da laje }[\mathrm{m}] .
\end{array}
$$

E o coeficiente $\alpha_{U, T}$, que considera a influência da umidade relativa e temperatura ambiente, com 85\% de probabilidade é dado por:

$$
\begin{aligned}
\alpha_{\mathrm{U}, \mathrm{T}}= & 0,029 \cdot \mathrm{T}-7,82 \cdot 10^{-3} \cdot \mathrm{U}-2,45 \cdot 10^{-4} \cdot \mathrm{T} \cdot \mathrm{U}+ \\
& +4,29 \cdot 10^{-5} \cdot \mathrm{T}^{2}+1,30 \cdot 10^{-5} \cdot \mathrm{U}^{2}+1,54
\end{aligned}
$$

ou

$\alpha_{\mathrm{U}, \mathrm{T}}=0,016 . \mathrm{T}-0,012 . \mathrm{U}+1,84$

onde:

U - umidade relativa média do ambiente [\%];

$\mathrm{T}$ - temperatura média do ambiente $\left[{ }^{\circ} \mathrm{C}\right]$.

O coeficiente $\alpha_{U, T}$ foi determinado considerando 95\%, $90 \%$ e $85 \%$ de probabilidade. No entanto, na falta de indicações sobre o assunto e considerando que o coeficiente $\alpha_{\mathrm{U}, \mathrm{T}}$ com $95 \%$ de probabilidade parece ser muito restritivo, está se adotando aqui o coeficiente $\alpha_{\mathrm{U}, \mathrm{T}}$ com $85 \%$ de probabilidade. 


\section{$5.5 \quad$ Laje contínua}

O coeficiente multiplicador da flecha imediata foi desenvolvido considerando a situação de lajes pré-moldadas biapoiadas. E assim, procurou-se verificar a possibilidade de extrapolar as expressões para o caso de lajes contínuas. Para isso, realizou-se a análise das lajes LT12, LT16, LT20 e LT25 utilizadas para a determinação do coeficiente $\alpha_{\mathrm{U}, \mathrm{T}}$, totalizando 25 casos, conforme apresentadas na tabela 5.29. No entanto, essas lajes foram analisadas como lajes contínuas formadas por dois tramos de mesmo comprimento.

As lajes contínuas foram analisadas mantendo as características e considerações feitas anteriormente para o caso biapoiado. A única distinção foi a consideração de uma armadura de continuidade composta por $4 \phi 5 \mathrm{~mm}, 4 \phi 6 \mathrm{~mm}$, $5 \phi 6 \mathrm{~mm}$ e $6 \phi 6 \mathrm{~mm}$, respectivamente, para as lajes LT12, LT16, LT20 e LT25. Essa armadura de continuidade adotada corresponde a uma armadura mínima de flexão para controle de fissuração no apoio intermediário.

TABELA 5.29 - Casos analisados para o caso de lajes contínuas

\begin{tabular}{|c|c|c|c|c|}
\hline \multirow{3}{*}{ laje } & \multirow{3}{*}{$\ell(\mathbf{m})$} & \multirow{2}{*}{\multicolumn{3}{|c|}{$\begin{array}{c}\text { armadura adicional } A_{\text {s,adic }}\left(\mathrm{cm}^{2}\right) \\
q\left(\mathrm{kN} / \mathrm{m}^{2}\right)\end{array}$}} \\
\hline & & & & \\
\hline & & 2,0 & 4,0 & 6,0 \\
\hline \multirow{4}{*}{ LT12 } & 4,5 & 1,50 & & \\
\hline & 4,0 & 0,90 & & \\
\hline & 3,5 & 0,60 & 1,50 & \\
\hline & 3,0 & 0,40 & 0,80 & 1,50 \\
\hline \multirow{3}{*}{ LT16 } & 6,0 & 1,50 & & \\
\hline & 5,0 & 1,00 & 2,35 & \\
\hline & 4,0 & 0,40 & 1,00 & 1,50 \\
\hline \multirow{3}{*}{ LT20 } & 7,0 & 2,35 & & \\
\hline & 6,0 & 1,20 & 2,35 & \\
\hline & 5,0 & 0,60 & 1,50 & 2,35 \\
\hline \multirow{3}{*}{ LT25 } & 8,5 & 2,35 & & \\
\hline & 7,5 & 1,60 & 3,68 & \\
\hline & 6,5 & 1,00 & 2,35 & 3,68 \\
\hline
\end{tabular}

Apresentam-se na figura 5.32 as relações entre os coeficientes multiplicadores para as lajes continua e biapoiada obtidas para os casos analisados. 
Pela figura pode-se notar que ocorreu uma diferença elevada entre os coeficientes, sendo que o coeficiente multiplicador para a laje contínua chegou a ser mais que três vezes o valor do coeficiente para a laje biapoiada correspondente.

A explicação para essa diferença se deve ao fato de que o carregamento atuante nas lajes, que foi obtido considerado a combinação quase permanente das ações, leva as lajes biapoiadas a um nível de fissuração diferente das lajes contínuas.

Isso pôde ser comprovado quando as lajes contínuas foram submetidas a um carregamento considerando a combinação rara de ações. Para essa nova situação o nível de fissuração das lajes contínuas foi maior e as relações entre os coeficientes mudaram drasticamente comparadas com a situação anterior, como pode ser visto na figura 5.33. Por essa figura pode-se notar que os coeficientes multiplicadores para a laje contínua ficaram em torno de $80 \%$ dos valores dos coeficientes para a laje biapoiada correspondente.

Os casos foram ainda analisados aplicando-se um carregamento correspondente à combinação rara de ações e em seguida retirando-o até atingir a combinação quase permanente. Os resultados desta análise estão apresentados na figura 5.34, e como se pode verificar, os resultados foram diferentes, mas próximos dos resultados obtidos considerando combinação rara de ações.

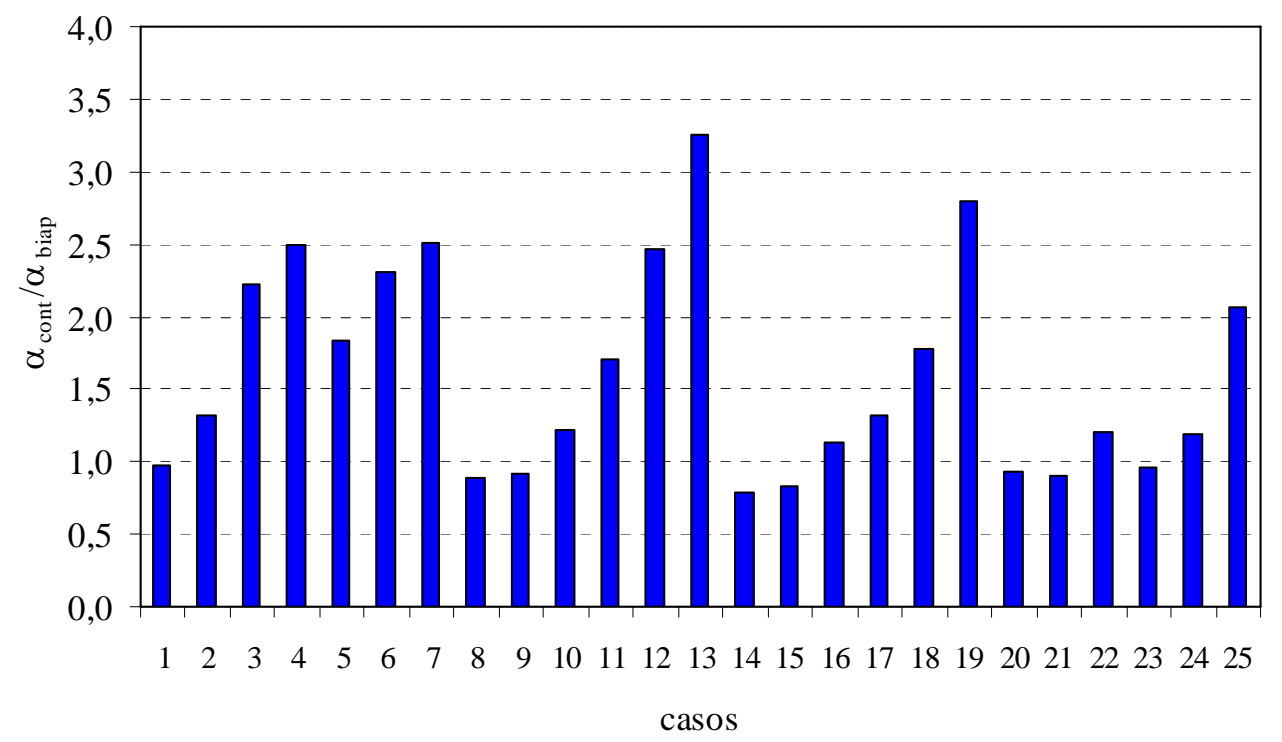

FIGURA 5.32 - Relação entre os coeficientes multiplicadores (contínua e biapoiada) - condição 1 


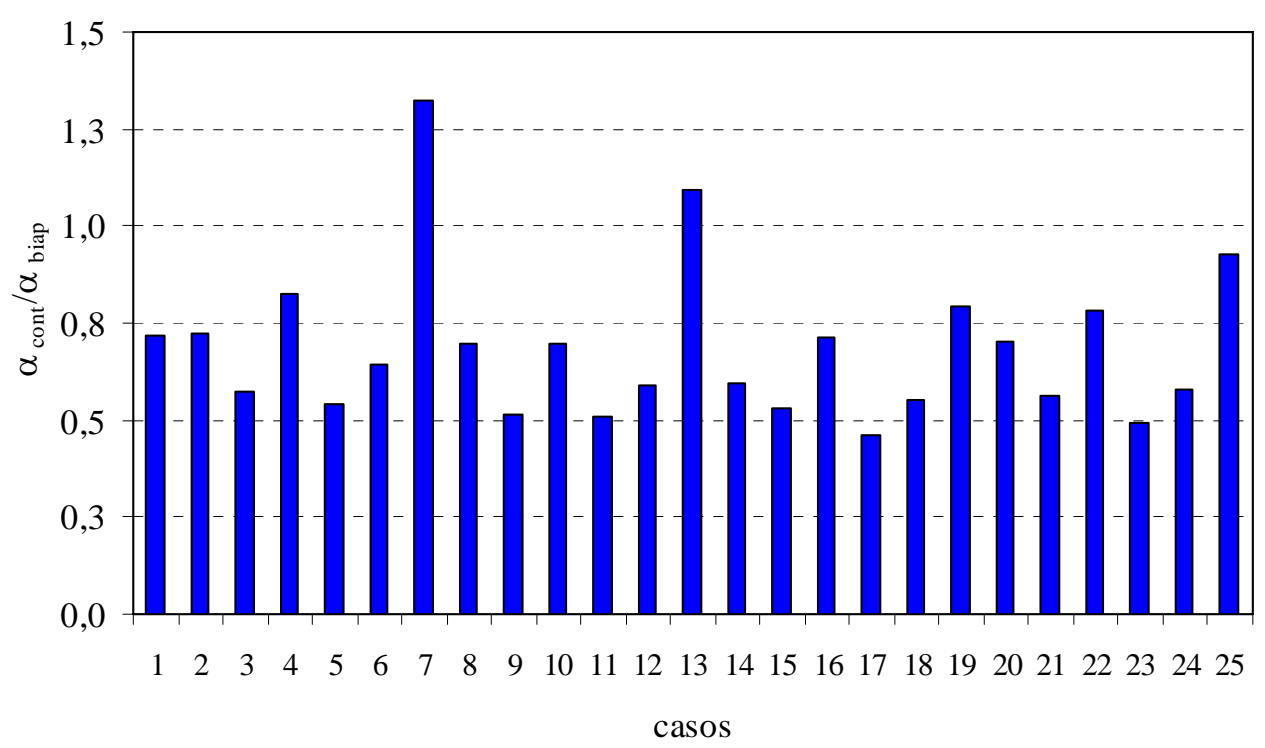

FIGURA 5.33 - Relação entre os coeficientes multiplicadores (contínua e biapoiada) - condição 2

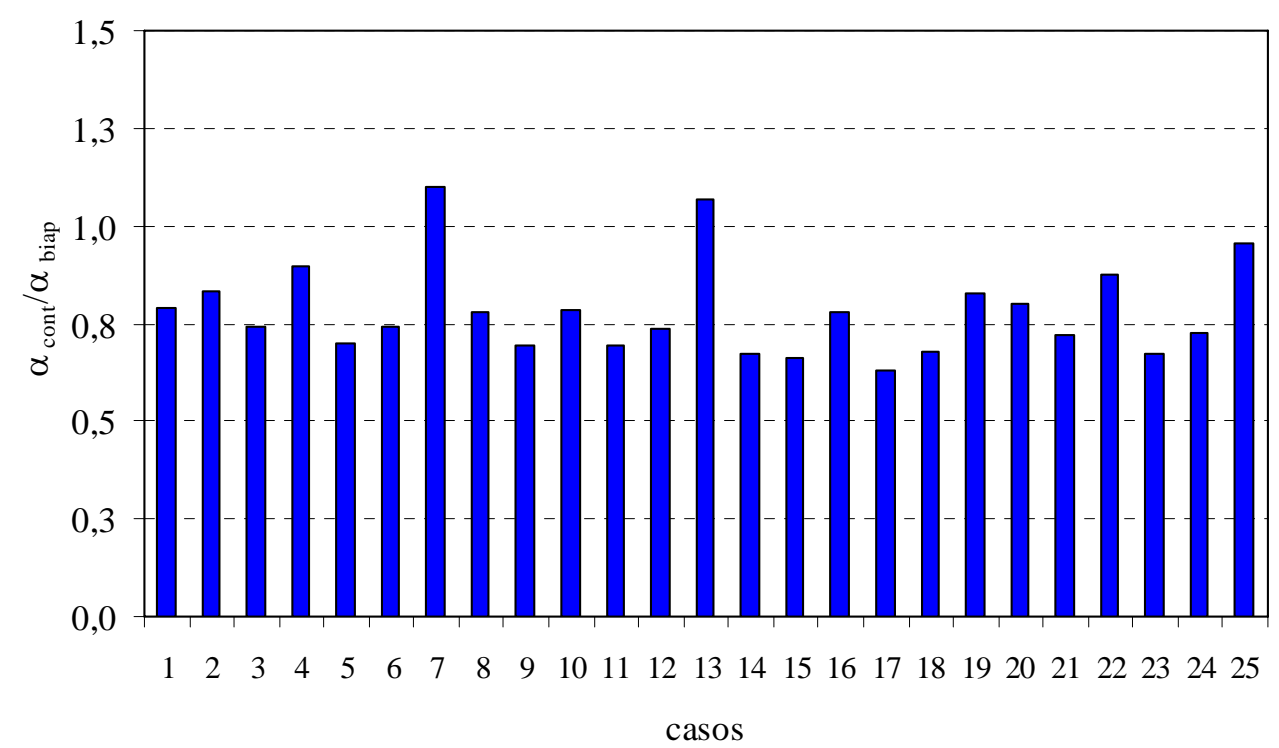

FIGURA 5.34 - Relação entre os coeficientes multiplicadores (contínua e biapoiada) - condição 3

Portanto, o que se pode concluir é que as expressões obtidas para as lajes biapoiadas podem ser utilizadas para as lajes contínuas desde que estas apresentem um estado de fissuração compatível com o ocorrido com as lajes biapoiadas. 


\subsection{Exemplos de cálculo}

A seguir, são apresentados exemplos de determinação do coeficiente multiplicador da flecha imediata de lajes pré-moldadas formadas por vigotas com armação treliçada, utilizando as expressões propostas nos itens anteriores.

Os cálculos do coeficiente multiplicador foram realizados considerando três casos de lajes com dimensões do vão de 3,2 m (vão pequeno), 4,4 m (vão médio) e 6,6 m (vão grande).

\subsubsection{Laje com vão pequeno}

Para este caso foi considerada laje de 3,2 m de vão com altura total de $12 \mathrm{~cm}$ e $49 \mathrm{~cm}$ de distância entre nervuras, conforme figura 5.35.

Para a determinação do peso próprio da laje foi considerado concreto com massa específica igual a $2500 \mathrm{~kg} / \mathrm{m}^{3}$ e material de enchimento composto por blocos de poliestireno expandido (EPS) com massa específica igual a $15 \mathrm{~kg} / \mathrm{m}^{3}$, resultado em peso próprio da laje de $0,697 \mathrm{kN} / \mathrm{m}$.

Além da atuação de uma carga permanente referente ao revestimento de $0,5 \mathrm{kN} / \mathrm{m}^{2}$, foi considerada ainda três valores de carga de utilização de $2,0 \mathrm{kN} / \mathrm{m}^{2}$, $3,5 \mathrm{kN} / \mathrm{m}^{2}$ e $5,0 \mathrm{kN} / \mathrm{m}^{2}$, necessitando a utilização de uma armadura adicional composta, respectivamente, por 2 barras de $5 \mathrm{~mm}$ de diâmetro, 3 barras de 6,3 mm de diâmetro e 3 barras de 8 mm de diâmetro.

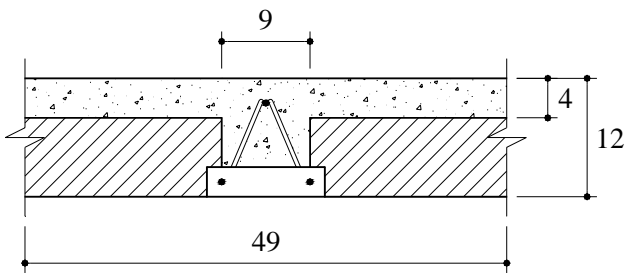

(a) laje

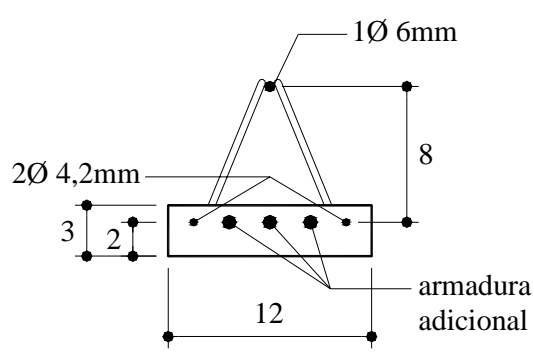

(b) vigota

FIGURA 5.35 - Seção transversal da laje com vão pequeno (dimensões em cm)

Foi considerada ainda umidade relativa média de 60\% e temperatura média de $30^{\circ} \mathrm{C}$. 
Utilizando combinação quase permanente das ações, o carregamento atuante na laje, assim como os demais parâmetros considerados para o cálculo dos coeficientes multiplicadores estão apresentados na tabela 5.30 .

TABELA 5.30 - Parâmetros considerados para a laje com vão pequeno

\begin{tabular}{ccccccc}
\hline $\mathbf{q}$ & $\mathbf{A}_{\mathbf{s}}$ & $\mathbf{h}$ & $\mathbf{p}$ & $\boldsymbol{\ell}$ & $\mathbf{U}$ & $\mathbf{T}$ \\
$\mathbf{( k N / \mathbf { m } ^ { 2 } )}$ & $\mathbf{( \mathbf { c m } ^ { 2 } )}$ & $\mathbf{( m )}$ & $\mathbf{( k N / m )}$ & $\mathbf{( m )}$ & $\mathbf{( \% )}$ & $\left({ }^{\circ} \mathbf{C}\right)$ \\
\hline 2,0 & 0,675 & 0,12 & 1,236 & 3,2 & 60 & 30 \\
3,5 & 1,21 & 0,12 & 1,457 & 3,2 & 60 & 30 \\
5,0 & 1,775 & 0,12 & 1,677 & 3,2 & 60 & 30 \\
\hline
\end{tabular}

\section{- Cálculo determinístico}

Para a determinação do coeficiente multiplicador, calcula-se inicialmente o coeficiente $\kappa$, através da expressão:

$$
\kappa=\frac{A_{s} \cdot h^{2,05}}{p^{1,5} \cdot \ell^{3}} \cdot 10^{3}
$$

E a partir de $\kappa$, tem-se:

$$
\alpha_{\text {básico }}=3,73 . \kappa+0,18
$$

O valor do coeficiente $\alpha_{U, T}$ é dado por:

$$
\begin{aligned}
\alpha_{\mathrm{U}, \mathrm{T}}= & 0,016 \cdot \mathrm{T}+4,9 \cdot 10^{-3} \cdot \mathrm{U}-2,7 \cdot 10^{-5} \cdot \mathrm{T} \cdot \mathrm{U}- \\
& -1,03 \cdot 10^{-4} \cdot \mathrm{T}^{2}-1,32 \cdot 10^{-4} \cdot \mathrm{U}^{2}+0,90
\end{aligned}
$$

E, portanto, o coeficiente multiplicador $\alpha$ é determinado por:

$$
\alpha=\alpha_{\text {básico }} \cdot \alpha_{\mathrm{U}, \mathrm{T}}
$$

Os coeficientes multiplicadores obtidos com as expressões mostradas acima estão apresentados na tabela 5.31 . 
TABELA 5.31 - Resultados obtidos para a laje com vão pequeno (análise determinística)

\begin{tabular}{ccccc}
\hline $\mathbf{q}$ & $\boldsymbol{\kappa}$ & $\boldsymbol{\alpha}_{\text {básico }}$ & $\boldsymbol{\alpha}_{\mathbf{U , T}}$ & $\boldsymbol{\alpha}$ \\
\hline $\left.\mathbf{k N} / \mathbf{m}^{2}\right)$ & 0,194 & 0,90 & 1,06 & 0,95 \\
3,0 & 0,272 & 1,19 & 1,06 & 1,26 \\
5,0 & 0,323 & 1,38 & 1,06 & 1,46 \\
\hline
\end{tabular}

\section{- Cálculo probabilístico}

O valor do coeficiente $\alpha_{U, T}$ considerando $85 \%$ de probabilidade é determinado através da seguinte expressão:

$$
\begin{aligned}
\alpha_{\mathrm{U}, \mathrm{T}}= & 0,029 \cdot \mathrm{T}-7,82 \cdot 10^{-3} \cdot \mathrm{U}-2,45 \cdot 10^{-4} \cdot \mathrm{T} \cdot \mathrm{U}+ \\
& +4,29 \cdot 10^{-5} \cdot \mathrm{T}^{2}+1,30 \cdot 10^{-5} \cdot \mathrm{U}^{2}+1,54
\end{aligned}
$$

Portanto, o coeficiente multiplicador $\alpha$ é dado por:

$\alpha=\alpha_{\text {básico }} \cdot \alpha_{\mathrm{U}, \mathrm{T}}$

E assim, os coeficientes multiplicadores determinados através das expressões anteriores estão mostrados na tabela 5.32 .

TABELA 5.32 - Resultados obtidos para a laje com vão pequeno (análise probabilística)

\begin{tabular}{ccccc}
\hline $\begin{array}{c}\mathbf{q} \\
\left(\mathbf{k N} / \mathbf{m}^{2}\right)\end{array}$ & $\boldsymbol{\kappa}$ & $\boldsymbol{\alpha}_{\text {básico }}$ & $\boldsymbol{\alpha}_{\mathbf{U , T}}$ & $\boldsymbol{\alpha}$ \\
\hline 2,0 & 0,194 & 0,90 & 1,59 & 1,43 \\
3,5 & 0,272 & 1,19 & 1,59 & 1,89 \\
5,0 & 0,323 & 1,38 & 1,59 & 2,19 \\
\hline
\end{tabular}

\subsubsection{Laje com vão médio}

Para este caso foi considerada laje de 4,4 m de vão com altura total de 16 cm e 49 cm de distância entre nervuras, conforme figura 5.36.

O peso próprio da laje foi de $0,790 \mathrm{kN} / \mathrm{m}$, com a consideração de concreto com massa específica igual a $2500 \mathrm{~kg} / \mathrm{m}^{3}$ e material de enchimento composto por blocos de EPS com massa específica igual a $15 \mathrm{~kg} / \mathrm{m}^{3}$. 
Além da atuação de uma carga permanente referente ao revestimento de $0,5 \mathrm{kN} / \mathrm{m}^{2}$, foi considerada ainda três valores de carga de utilização de $2,0 \mathrm{kN} / \mathrm{m}^{2}$, $3,5 \mathrm{kN} / \mathrm{m}^{2}$ e $5,0 \mathrm{kN} / \mathrm{m}^{2}$, necessitando a utilização de uma armadura adicional composta, respectivamente, por 2 barras de $6 \mathrm{~mm}$ de diâmetro, 3 barras de $8 \mathrm{~mm}$ de diâmetro e 3 barras de 10 mm de diâmetro.

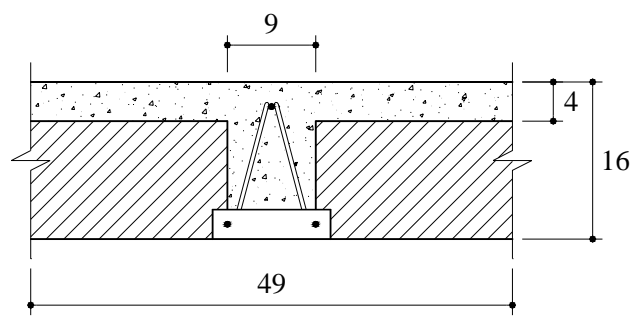

(a) laje

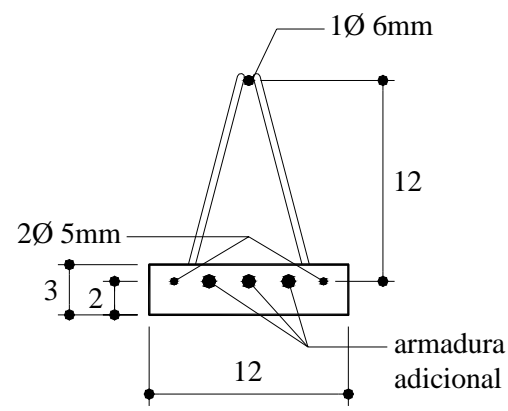

(b) vigota

FIGURA 5.36 - Seção transversal da laje com vão médio (dimensões em cm)

Foi considerada ainda umidade relativa média de 50\% e temperatura média de $25^{\circ} \mathrm{C}$.

E assim, os parâmetros considerados no cálculo do coeficiente multiplicador estão apresentados na tabela 5.33. O carregamento atuante na laje foi determinado considerando combinação quase permanente das ações.

TABELA 5.33 - Parâmetros considerados para a laje com vão médio

\begin{tabular}{|c|c|c|c|c|c|c|}
\hline$\underset{\left(k N / m^{2}\right)}{q}$ & $\begin{array}{c}A_{s} \\
\left(\mathrm{~cm}^{2}\right)\end{array}$ & $\begin{array}{c}\text { h } \\
(\mathbf{m})\end{array}$ & $\underset{(k N / m)}{p}$ & $\begin{array}{c}\ell \\
(\mathbf{m})\end{array}$ & $\begin{array}{c}\mathrm{U} \\
(\%)\end{array}$ & $\begin{array}{c}\mathbf{T} \\
\left({ }^{\circ} \mathrm{C}\right)\end{array}$ \\
\hline 2,0 & 0,955 & 0,16 & 1,329 & 4,4 & 50 & 25 \\
\hline 3,5 & 1,89 & 0,16 & 1,550 & 4,4 & 50 & 25 \\
\hline 5,0 & 2,74 & 0,16 & 1,770 & 4,4 & 50 & 25 \\
\hline
\end{tabular}

\section{- Cálculo determinístico}

Os coeficientes multiplicadores determinados através das expressões obtidas da análise determinística estão apresentados na tabela 5.34. 
TABELA 5.34 - Resultados obtidos para a laje com vão médio (análise determinística)

\begin{tabular}{ccccc}
\hline $\begin{array}{c}\mathbf{q} \\
\left(\mathbf{k N} / \mathbf{m}^{2}\right)\end{array}$ & $\boldsymbol{\kappa}$ & $\boldsymbol{\alpha}_{\text {básico }}$ & $\boldsymbol{\alpha}_{\mathbf{U , T}}$ & $\boldsymbol{\alpha}$ \\
\hline 2,0 & 0,171 & 0,82 & 1,12 & 0,92 \\
3,5 & 0,269 & 1,18 & 1,12 & 1,32 \\
5,0 & 0,319 & 1,37 & 1,12 & 1,53 \\
\hline
\end{tabular}

\section{- Cálculo probabilístico}

Os coeficientes multiplicadores determinados através das expressões obtidas da análise probabilística estão apresentados na tabela 5.35.

TABELA 5.35 - Resultados obtidos para a laje com vão médio (análise probabilística)

\begin{tabular}{ccccc}
\hline $\begin{array}{c}\mathbf{q} \\
\left(\mathbf{k N} / \mathbf{m}^{2}\right)\end{array}$ & $\boldsymbol{\kappa}$ & $\boldsymbol{\alpha}_{\text {básico }}$ & $\boldsymbol{\alpha}_{\mathbf{U , T}}$ & $\boldsymbol{\alpha}$ \\
\hline 2,0 & 0,171 & 0,82 & 1,63 & 1,34 \\
3,5 & 0,269 & 1,18 & 1,63 & 1,92 \\
5,0 & 0,319 & 1,37 & 1,63 & 2,23 \\
\hline
\end{tabular}

\subsubsection{Laje com vão grande}

Para este caso foi considerada laje de 6,6 m de vão com altura total de 20 cm e 49 cm de distância entre nervuras, conforme figura 5.37.

Para a determinação do peso próprio da laje foi considerado concreto com massa específica igual a $2500 \mathrm{~kg} / \mathrm{m}^{3}$ e material de enchimento composto por blocos de poliestireno expandido (EPS) com massa específica igual a $15 \mathrm{~kg} / \mathrm{m}^{3}$, resultado em peso próprio da laje de $0,882 \mathrm{kN} / \mathrm{m}$.

Além da atuação de uma carga permanente referente ao revestimento de $0,5 \mathrm{kN} / \mathrm{m}^{2}$, foi considerada ainda carga de utilização de $2,0 \mathrm{kN} / \mathrm{m}^{2}$, necessitando a utilização de uma armadura adicional composta por 3 barras de $10 \mathrm{~mm}$ de diâmetro. O coeficiente multiplicador não foi determinado considerando valores de carga de utilização maiores, como realizado nos exemplos anteriores, pois esta laje não possui capacidade para suportar cargas maiores para o vão em questão.

Foi considerada ainda umidade relativa média de $70 \%$ e temperatura média de $20^{\circ} \mathrm{C}$. 


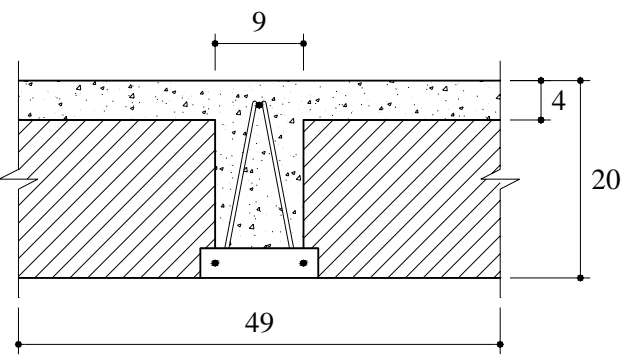

(a) laje

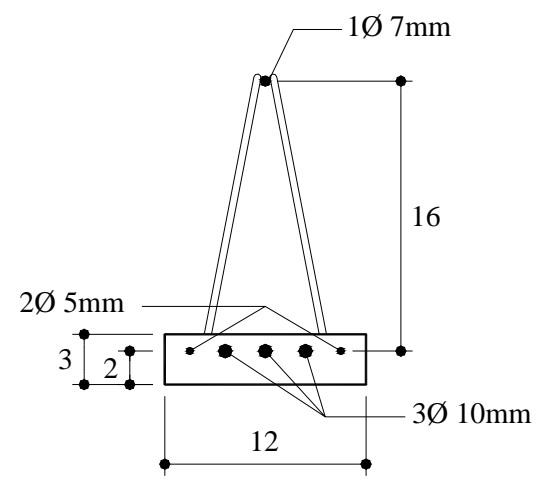

(b) vigota

FIGURA 5.37 - Seção transversal da laje com vão grande (dimensões em cm)

Utilizando combinação quase permanente das ações, o carregamento atuante na laje considerado será:

$$
p=g+0,3 . q \Rightarrow p=(0,882+0,245)+0,3 \cdot 0,98 \Rightarrow p=1,421 k N / m
$$

E assim, têm-se:

$$
\begin{aligned}
& \mathrm{A}_{\mathrm{s}}=2,74 \mathrm{~cm}^{2} \\
& \mathrm{~h}=0,20 \mathrm{~m} \\
& \mathrm{p}=1,421 \mathrm{kN} / \mathrm{m} \\
& \ell=6,6 \mathrm{~m} \\
& \mathrm{U}=70 \% \\
& \mathrm{~T}=20{ }^{\circ} \mathrm{C}
\end{aligned}
$$

\section{- Cálculo determinístico}

Para a determinação do coeficiente multiplicador, calcula-se inicialmente o coeficiente $\kappa$, através da expressão:

$$
\kappa=\frac{A_{s} \cdot h^{2,05}}{p^{1,5} \cdot \ell^{3}} \cdot 10^{3} \Rightarrow \kappa=0,208
$$

Com isso, tem-se:

$$
\alpha_{\text {básico }}=3,73 . \kappa+0,18 \Rightarrow \alpha_{\text {básico }}=0,96
$$


O valor do coeficiente $\alpha_{U, T}$ é dado por:

$$
\begin{aligned}
\alpha_{\mathrm{U}, \mathrm{T}}= & 0,016 \cdot \mathrm{T}+4,9 \cdot 10^{-3} \cdot \mathrm{U}-2,7 \cdot 10^{-5} \cdot \mathrm{T} \cdot \mathrm{U}- \\
& -1,03 \cdot 10^{-4} \cdot \mathrm{T}^{2}-1,32 \cdot 10^{-4} \cdot \mathrm{U}^{2}+0,90 \Rightarrow \alpha_{\mathrm{U}, \mathrm{T}}=0,84
\end{aligned}
$$

E, portanto, o coeficiente multiplicador $\alpha$ é determinado por:

$\alpha=\alpha_{\text {básico }} \cdot \alpha_{U, T} \Rightarrow \alpha=0,81$

- Cálculo probabilístico

O valor do coeficiente $\alpha_{U, T}$ considerando $85 \%$ de probabilidade é determinado através da seguinte expressão:

$$
\begin{aligned}
\alpha_{\mathrm{U}, \mathrm{T}}= & 0,029 \cdot \mathrm{T}-7,82 \cdot 10^{-3} \cdot \mathrm{U}-2,45 \cdot 10^{-4} \cdot \mathrm{T} \cdot \mathrm{U}+ \\
& +4,29 \cdot 10^{-5} \cdot \mathrm{T}^{2}+1,30 \cdot 10^{-5} \cdot \mathrm{U}^{2}+1,54 \Rightarrow \alpha_{\mathrm{U}, \mathrm{T}}=1,31
\end{aligned}
$$

Portanto, o coeficiente multiplicador $\alpha$ é dado por:

$$
\alpha=\alpha_{\text {básico }} \cdot \alpha_{\mathrm{U}, \mathrm{T}} \Rightarrow \alpha=1,26
$$

\subsection{Análise dos resultados e comentários}

Procurou-se com este capítulo realizar a análise probabilística das flechas diferidas de lajes pré-moldadas formadas por vigotas com armação treliçada, visando fornecer indicações de projeto através da proposta de um coeficiente multiplicador das flechas imediatas para avaliação das flechas diferidas. Esta análise foi realizada utilizando o programa computacional CONSNOU, em conjunto com análise probabilística, através do método de amostragem por hipercubo latino.

Inicialmente foi realizada uma análise preliminar para avaliar quais os parâmetros envolvidos influenciaria mais significativamente o coeficiente multiplicador das flechas imediatas. Por essa análise preliminar, pôde-se verificar que tanto o carregamento aplicado quanto a altura e o vão da laje, assim como a 
armadura utilizada são parâmetros dependentes entre si, ou seja, tais parâmetros não podem ser analisados isoladamente, caso contrário, pode originar casos com coeficientes multiplicadores elevados, mas de pouco sentido prático. E assim, levando isso em consideração, pôde-se concluir que os parâmetros que mais influenciam o coeficiente multiplicador das flechas imediatas são a umidade relativa e a temperatura ambiente.

Em seguida, foi determinado o coeficiente multiplicador $\alpha$ através do produto de um coeficiente multiplicador básico $\alpha_{\text {básico }}$ e do coeficiente $\alpha_{U, T}$, que considera a influência da umidade relativa e temperatura ambiente. O coeficiente $\alpha_{U, T}$ foi determinado através de uma análise determinística e outra probabilística.

O coeficiente multiplicador básico $\alpha_{\text {básico }}$ é determinado a partir de um coeficiente denominado $\kappa$ que é função da armadura utilizada, do carregamento aplicado e da altura e do vão da laje. O coeficiente $\kappa$ mostra que o coeficiente multiplicador aumenta com o aumento da taxa de armadura e da altura da laje e diminui com o aumento do carregamento aplicado e do vão da laje.

A partir dos resultados da análise probabilística, pôde-se verificar ainda quais os parâmetros afetam mais significativamente o valor do coeficiente multiplicador através do coeficiente de regressão padronizado e coeficiente de correlação parcial. Através desses coeficientes, pôde-se verificar que as incertezas nos modelos da fluência e retração do concreto da capa estrutural e, como já era esperado, os fatores ambientais (umidade relativa e temperatura ambiente) foram os parâmetros que tiveram maior influência no coeficiente multiplicador $\alpha$.

Como o coeficiente multiplicador da flecha imediata foi desenvolvido considerando a situação de lajes pré-moldadas biapoiadas. Procurou-se verificar a possibilidade de extrapolar as expressões para o caso de lajes contínuas. E através da análise de vários casos de lajes, pôde-se concluir que as expressões obtidas para as lajes biapoiadas podem ser utilizadas para as lajes contínuas desde que estas apresentem um nível de fissuração compatível com o ocorrido com as lajes biapoiadas, ou seja, além da fissuração no apoio deve haver a fissuração no vão compatível com a laje biapoiada correspondente. 
Foram realizados exemplos de determinação do coeficiente multiplicador da flecha imediata de lajes pré-moldadas formadas por vigotas com armação treliçada. Nos exemplos, foram consideradas lajes com $12 \mathrm{~cm}, 16 \mathrm{~cm}$ e $20 \mathrm{~cm}$ de altura, obtendo-se para o coeficiente multiplicador os valores apresentados na tabela 5.36. Nessa tabela, apresenta-se também o fator $\alpha_{f}$ e o coeficiente de fluência $\alpha$ recomendados pela NBR 6118 (2003), considerando idade de aplicação da carga de 21 dias.

O aumento entre os valores determinístico e probabilístico do coeficiente multiplicador variou entre 45,5\% para a laje LT16 com carga de utilização de 3,5 $\mathrm{kN} / \mathrm{m}^{2}$ e 55,6\% para a laje LT20, mostrando a importância da realização da análise probabilística. Quando comparado com o fator $\alpha_{\mathrm{f}}$, o coeficiente multiplicador da análise probabilística aumentou em até 59,3\%. Na realidade, se for considerado, por exemplo, umidade relativa de $50 \%$ e temperatura ambiente de $30^{\circ} \mathrm{C}$, o coeficiente $\alpha_{\mathrm{U}, \mathrm{T}}$ com $85 \%$ de probabilidade é de 1,72. E como o maior coeficiente

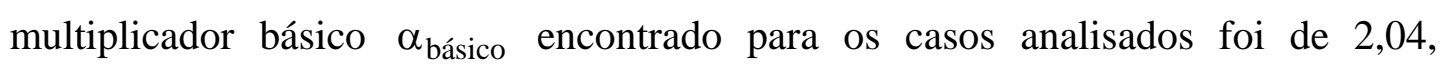
significa que o coeficiente multiplicador seria 3,51. Portanto, o valor do coeficiente multiplicador da flecha imediata de lajes pré-moldadas considerando análise probabilística com $85 \%$ de probabilidade pode alcançar valores muito além do fator $\alpha_{\mathrm{f}}$ recomendado pela NBR 6118 (2003) para o caso de vigas de concreto armado. Já o coeficiente de fluência $\alpha$ foi maior que o coeficiente multiplicador da análise probabilística para todos os exemplos, chegando a uma diferença de até 162,7\%.

TABELA 5.36 - Coeficientes obtidos para os exemplos realizados

\begin{tabular}{cccccc}
\hline \multirow{2}{*}{ laje } & $\begin{array}{c}\mathbf{q} \\
\left(\mathbf{k N} / \mathbf{m}^{2}\right)\end{array}$ & $\begin{array}{c}\boldsymbol{\alpha} \\
\text { análise } \\
\text { determinística }\end{array}$ & $\begin{array}{c}\boldsymbol{\alpha} \\
\text { análise } \\
\text { probabilística }\end{array}$ & $\begin{array}{c}\boldsymbol{\alpha}_{\mathbf{f}} \\
\text { (NBR 6118) }\end{array}$ & $\begin{array}{c}\boldsymbol{\varphi} \\
\text { (NBR 6118) }\end{array}$ \\
\hline \multirow{2}{*}{ LT12 } & 2,0 & 0,95 & 1,43 & 1,40 & 3,05 \\
\cline { 2 - 6 } & 3,5 & 1,26 & 1,89 & 1,40 & 3,05 \\
\cline { 2 - 6 } & 5,0 & 1,46 & 2,19 & 1,40 & 3,05 \\
\hline \multirow{2}{*}{ LT16 } & 2,0 & 0,92 & 1,34 & 1,40 & 3,52 \\
\cline { 2 - 6 } & 3,5 & 1,32 & 1,92 & 1,40 & 3,52 \\
\hline LT20 & 5,0 & 1,53 & 2,23 & 1,40 & 3,52 \\
\hline
\end{tabular}




\section{CONSIDERAÇÕES FINAIS E CONCLUSÕES}

O avanço computacional ocorrido nas últimas décadas permitiu realizar, de forma eficiente, a análise dos mais complexos problemas de engenharia. Cada vez mais é comum a utilização de modelos que consideram a não linearidade física dos materiais, fissuração, fluência e retração do concreto, comportamento elasto-plástico da armadura, relaxação da armadura de protensão, além da influência do processo construtivo no comportamento da estrutura, tais como, a mudança das características resistentes da seção, incorporação de novas partes à estrutura, ou ainda, variação nas condições de contorno devido, por exemplo, aos processos de cimbramento e descimbramento.

Apesar de todo esse avanço, a análise estrutural normalmente é realizada considerando os parâmetros do problema com base em valores determinísticos, não considerando as incertezas causadas pela variabilidade estatística dos parâmetros, ou através de métodos semi-probabilísticos, considerando valores para determinados parâmetros com pequena probabilidade de serem ultrapassados (valores característicos). No entanto, tais incertezas deveriam ser consideradas a fim de minimizar o risco de ocorrência de efeitos significativos para a segurança estrutural, ou seja, a análise estrutural deveria ser realizada considerando os parâmetros como variáveis aleatórias que possuem um determinado valor médio, uma certa medida de dispersão (desvio padrão) e uma distribuição de probabilidade. E assim, a resposta da estrutura (deslocamento, reação de apoio, tensão no concreto, por exemplo) também seria uma variável aleatória, que pode ser caracterizada por um valor esperado, desvio padrão e uma distribuição de probabilidade. E a partir da análise da distribuição de probabilidade da resposta, as estruturas seriam projetadas para que 
certos efeitos extremos, tal como deslocamento máximo ou tensão máxima, tivessem pequena probabilidade especificada de serem ultrapassados.

Neste contexto, o objetivo principal deste trabalho foi apresentar um modelo para análise probabilística do comportamento de estruturas de concreto sujeitas aos fenômenos de fluência e retração do concreto. Para isso, a análise probabilística foi realizada em conjunto com análise numérica.

Na análise numérica foi utilizado o programa computacional denominado CONSNOU desenvolvido em linguagem FORTRAN pelo Professor Antonio R. Marí da Universidade Politécnica da Catalunha. Este programa computacional, baseado no método dos elementos finitos, divide a seção transversal dos elementos em número discreto de filamentos de concreto e aço e a integração das áreas dos filamentos é feita considerando o comportamento não-linear e dependente do tempo dos materiais, assim como o processo evolutivo da construção. O programa computacional foi avaliado através da comparação com resultados de ensaios de curta duração de lajes contínuas, ensaios de longa duração de lajes formadas por vigotas pré-moldadas com armação treliçada e ensaios de longa duração de vigas reforçadas à flexão no bordo comprimido. Os resultados obtidos da análise numérica tiveram boa concordância com os resultados experimentais.

Para determinar o efeito das incertezas dos parâmetros foi realizada uma análise probabilística, através do método de simulações de Monte Carlo. Inicialmente, gera-se um grupo de valores (amostragem) das variáveis aleatórias de acordo com suas correspondentes distribuição de probabilidade, utilizando o método de amostragem por hipercubo latino. Então, aplica-se a análise numérica para cada uma das amostras geradas. Cada análise, feita desta forma, chama-se de uma simulação. Após a realização de $N$ simulações, tem-se à disposição um conjunto de dados representando uma resposta da estrutura (deslocamento, reação de apoio, tensão no concreto), que também pode ser tratado como uma variável aleatória, da qual se conhece uma amostra de $N$ componentes. Mediante uma análise estatística desta amostra, torna-se possível caracterizar os principais momentos e o tipo de distribuição de probabilidade desta variável aleatória.

O modelo apresentado pode ser aplicado para a análise probabilística do comportamento ao longo do tempo das estruturas de concreto em geral, no entanto, 
foi aplicado neste trabalho para a análise das flechas diferidas de lajes pré-moldadas formadas por vigotas com armação treliçada. Com esta análise, pôde-se propor um coeficiente multiplicador das flechas imediatas para a avaliação das flechas diferidas no tempo.

Inicialmente foi realizada uma análise preliminar para avaliar quais os parâmetros envolvidos influenciaria mais significativamente o coeficiente multiplicador das flechas imediatas. Por essa análise preliminar, pôde-se verificar que tanto o carregamento aplicado quanto a altura e o vão da laje, assim como a armadura utilizada são parâmetros dependentes entre si, ou seja, tais parâmetros não podem ser analisados isoladamente, caso contrário, pode originar casos com coeficientes multiplicadores elevados, mas de pouco sentido prático. E assim, levando isso em consideração, concluiu-se que os parâmetros que mais influenciaram o coeficiente multiplicador das flechas imediatas foram a umidade relativa e a temperatura ambiente.

Em seguida, o coeficiente multiplicador foi determinado através do produto de um coeficiente multiplicador básico $\alpha_{\text {básico }}$ e do coeficiente $\alpha_{U, T}$, que considera a influência da umidade relativa e temperatura ambiente.

$$
\alpha=\alpha_{\text {básico }} \cdot \alpha_{\mathrm{U}, \mathrm{T}}
$$

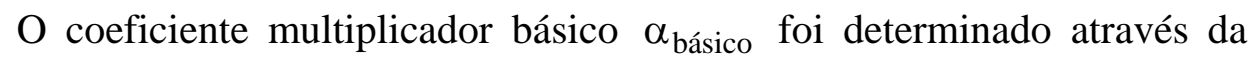
análise de lajes pré-moldadas com $12 \mathrm{~cm}, 16 \mathrm{~cm}, 20 \mathrm{~cm}, 25 \mathrm{~cm}$ e $30 \mathrm{~cm}$ de altura, variando a carga acidental e considerando-se vãos e armaduras adicionais compatíveis. Os demais parâmetros foram mantidos constantes, inclusive a umidade relativa $(60 \%)$ e a temperatura ambiente $\left(25^{\circ} \mathrm{C}\right)$. Com isso, obteve-se o coeficiente multiplicador básico $\alpha_{\text {básico }}$ através da seguinte expressão:

$$
\alpha_{\text {básico }}=3,73 . \kappa+0,18
$$

Com

$$
\kappa=\frac{\mathrm{A}_{\mathrm{S}} \cdot \mathrm{h}^{2,05}}{\mathrm{p}^{1,5} \cdot \ell^{3}} \cdot 10^{3}
$$


onde:

$$
\begin{array}{ll}
A_{\mathrm{s}} & \text { - armadura }\left[\mathrm{cm}^{2}\right] ; \\
\mathrm{h} & \text { - altura da laje }[\mathrm{m}] ; \\
\mathrm{p} & \text { - carregamento aplicado }[\mathrm{kN} / \mathrm{m}] ; \\
\ell & \text { - vão da laje }[\mathrm{m}] .
\end{array}
$$

Pelo coeficiente $\kappa$ pode-se concluir que o coeficiente multiplicador aumenta com o aumento da taxa de armadura e da altura da laje e diminui com o aumento do carregamento aplicado e do vão da laje.

As expressões desenvolvidas se aplicam às lajes formadas por vigotas com armação treliçada comumente utilizadas na construção civil. Isso equivale a lajes com valores do coeficiente $\kappa$ variando entre 0,10 e 0,55.

Para averiguar a influência da umidade relativa e temperatura ambiente no coeficiente multiplicador foram analisados alguns casos variando a umidade relativa em $40 \%, 60 \%, 80 \%$ e a temperatura ambiente em $15^{\circ} \mathrm{C}, 25^{\circ} \mathrm{C}, 35^{\circ} \mathrm{C}$. E a influência desses parâmetros foi considerada através do coeficiente $\alpha_{U, T}$. Este coeficiente foi determinado dividindo o coeficiente multiplicador obtido em cada caso pelo resultado obtido para o caso com as mesmas características, mas com umidade relativa de $60 \%$ e temperatura ambiente de $25^{\circ} \mathrm{C}$. O coeficiente $\alpha_{U, T}$ foi determinado através de uma análise determinística e outra probabilística.

\section{- análise determinística:}

O valor do coeficiente $\alpha_{U, T}$ obtido da análise determinística é dado por:

$$
\begin{aligned}
\alpha_{\mathrm{U}, \mathrm{T}}= & 0,016 \cdot \mathrm{T}+4,9 \cdot 10^{-3} \cdot \mathrm{U}-2,7 \cdot 10^{-5} \cdot \mathrm{T} \cdot \mathrm{U}- \\
& -1,03 \cdot 10^{-4} \cdot \mathrm{T}^{2}-1,32 \cdot 10^{-4} \cdot \mathrm{U}^{2}+0,90
\end{aligned}
$$

ou

$\alpha_{\mathrm{U}, \mathrm{T}}=8,8 \cdot 10^{-3} \cdot \mathrm{T}-0,012 \cdot \mathrm{U}+1,43$

onde:

U - umidade relativa do ambiente [\%];

$\mathrm{T}$ - temperatura do ambiente $\left[{ }^{\circ} \mathrm{C}\right]$. 


\section{- análise probabilística:}

E o coeficiente $\alpha_{U, T}$ obtido da análise probabilística, com $85 \%$ de probabilidade é dado por:

$$
\begin{aligned}
& \alpha_{\mathrm{U}, \mathrm{T}}=0,029 \cdot \mathrm{T}-7,82 \cdot 10^{-3} . \mathrm{U}-2,45 \cdot 10^{-4} . \mathrm{T} . \mathrm{U}+ \\
& +4,29 \cdot 10^{-5} \cdot \mathrm{T}^{2}+1,30 \cdot 10^{-5} \cdot \mathrm{U}^{2}+1,54
\end{aligned}
$$

O coeficiente $\alpha_{\mathrm{U}, \mathrm{T}}$ foi determinado considerando $95 \%$, $90 \%$ e $85 \%$ de probabilidade. No entanto, na falta de indicações sobre o assunto e considerando que o coeficiente $\alpha_{U, T}$ com $95 \%$ de probabilidade parece ser muito restritivo, foi adotado aqui o coeficiente $\alpha_{\mathrm{U}, \mathrm{T}}$ com $85 \%$ de probabilidade. No entanto, recomenda-se a realização de um estudo mais aprofundado para averiguar qual seria o coeficiente $\alpha_{U, T}$ mais satisfatório.

Sugere-se ainda para a realização de pesquisas futuras a aplicação do modelo apresentado na análise probabilística do comportamento dos mais diversos tipos de estruturas de concreto, como por exemplo, a análise ao longo do tempo dos deslocamentos e redistribuição de momentos fletores de elementos pré-moldados em que a continuidade estrutural é estabelecida no local. 


\section{REFERÊNCIAS BIBLIOGRÁFICAS}

ALWIS, W.A.M.; OLORUNNIWO, A.; ANG, K.K. (1994). Long-term deflection of RC beams. Journal of Structural Engineering, v.120, n.7, p.2220-6.

AMERICAN CONCRETE INSTITUTE (1992), ACI Committee 209, Subcommittee II. Prediction of Creep, Shrinkage and Temperature Effects in Concrete Structures. Detroit. (Report ACI 209R-92).

ANG, A.H-S; TANG, W.H. (1975). Probability concepts in engineering planning and design. Volume I: basic principles. New York, John Wiley \& Sons.

ASSOCIAÇÃO BRASILEIRA DE NORMAS TÉCNICAS. (2002). NBR 14859-1 Laje pré-fabricada - Requisitos - Parte 1: Lajes unidirecionais. Rio de Janeiro.

ASSOCIAÇÃO BRASILEIRA DE NORMAS TÉCNICAS. (2002). NBR 14859-2 Laje pré-fabricada - Requisitos - Parte 1: Lajes bidirecionais. Rio de Janeiro. ASSOCIAÇÃO BRASILEIRA DE NORMAS TÉCNICAS. (2002). NBR 14862 Armações treliçadas eletrossoldadas - Requisitos. Rio de Janeiro.

ASSOCIAÇÃO BRASILEIRA DE NORMAS TÉCNICAS. (2003). NBR 6118 Projeto e execução de obras de concreto armado. Rio de Janeiro.

ASSOCIAÇÃO BRASILEIRA DE NORMAS TÉCNICAS. (2003). NBR 8681 Ações e segurança nas estruturas - Procedimentos. Rio de Janeiro.

AUGUSTI, G.; BARATTA, P.; CASCIATI, F. (1984). Probabilistic methods in structural engineering. London, Chapman and Hall.

BAZANT, Z.P. (1972). Prediction of concrete creep effects using age-ajusted effective modulus method. Journal of American Concrete Institute, v.69, n.4, p.212-7. 
BAZANT, Z.P. (1988). Mathematical modeling of creep and shrinkage of concrete. New York, John Wiley \& Sons.

BAZANT, Z.P.; BAWEJA, S. (1995a). Creep and shrinkage prediction model for analysis and design of concrete structures - model B3. Materials and Structures, v.28, n.180, p.357-65.

BAZANT, Z.P.; BAWEJA, S. (1995b). Justification and refinements of Model B3 for concrete creep and shrinkage 1.Statistics and sensitivity. Materials and Structures, v.28, n.181, p.415-430.

BAZANT, Z.P.; CHERN, J.C. (1982). Comment on the use of ross'hyperbola and recent comparisons of various practical creep prediction models. Cement and Concrete Research, v.12, n.4, p.527-32.

BAZANT, Z.P.; LIU, K.L. (1985). Random creep and shrinkage in structures: sampling. Journal of Structural Engineering, v.111, n.5, p.1113-34.

BAZANT, Z.P.; OH, B.H. (1984). Deformation of progressively cracking reinforced concrete beams. Journal of American Concrete Institute, v.81, n.3, p.268-78.

BAZANT, Z.P.; PANULA, L. (1980). Creep and shrinkage characterization fore characterization for prestressed concrete structures. Journal of the Prestressed Concrete Institute, v.25, n.3, p.86-122.

BAZANT, Z.P. (1982). Mathematical models for creep and shrinkage of concrete. In: BAZANT, Z.P.; WITTMANN, F.H., eds. Creep and shrinkage in concrete structures. New York, John Wiley \& Sons. Cap. 7, p.163-256.

BAZANT, Z.P.; WU, S.T. (1973). Dirichlet series creep function for aging concrete. Journal of Engineering Mechanics Division, v.99, n.2, p.367-87.

BRADFORD, M.A.; GILBERT, R.I. (1992). Composite beams with partial interaction under sustained loads. Journal of Structural Engineering, v.118, n.7, p.1871-83.

BRANSON, D.E. (1968). Design procedures for computing deflections. Journal of American Concrete Institute, v.65, n.9, p.730-42.

BRATLEY, P.; FOX, B.L.; SCHRAGE, L.E. (1987). Guide to simulation. New York, Springer-Verlag. 
CAROL, I.; MURCIA, J. (1989). Nonlinear time-dependent analysis of planar frames using an “exact”formulation: I - theory , II - computer implementation for RC structures and examples. Computers and Structures, v.33, n.1, p.79-102.

CARREIRA, D.J.; CHU, K.H. (1986). Stress-strain relationship of reinforced concrete in tension. Journal of American Concrete Institute, v.83, n.1, p.21-8.

CERVENKA, V. (1985). Constitutive model for cracked reinforced concrete. Journal of American Concrete Institute, v.82, n.6, p.877-82.

COMITE EURO-INTERNACIONAL DU BETON (1984). Structural effects of time-dependent behaviour of concrete. Bulletin d'Information, n. 142/142 Bis.

COMITE EURO-INTERNACIONAL DU BETON (1991). CEB-FIP model code 1990. Bulletin d'Information, n. 203.

COMITE EURO-INTERNACIONAL DU BETON (1990). Evaluation of the time dependent behavior of concrete. Bulletin d'Information, n. 199.

CRUZ, P.J.S.; MARÍ, A.R.; ROCA, P. (1998). Nonlinear time-dependent analysis of segmentally constructed structures. Journal of Structural Engineering, v.124, n.3, p.278-87.

DEZI, L.; TARANTINO, A.M. (1991). Time-dependent analysis of concrete structures with a variable structural system. ACI Materials Journal, v.88, n.3, p.320-4.

DEZI, L.; TARANTINO, A. M. (1993). Creep in composite continuous beams. I: theoretical treatment. Journal of Structural Engineering, v.119, n.7, p.2095-111.

DILGER, W.H. (1982a). Creep analysis of prestressed concrete member using creeptransformed section properties. Journal of prestressed concrete institute, v.27, n.1, p.98-117.

DILGER, W.H. (1982b). Methods of structural creep analysis. In: BAZANT, Z.P.; WITTMANN, F.H., eds. Creep and shrinkage in concrete structures. New York, John Wiley \& Sons. Cap. 9, p.305-340.

DROPPA Jr., A. (1999). Análise estrutural de lajes formadas por elementos prémoldados tipo vigota com armação treliçada. 177p. + apêndice. Dissertação (Mestrado) - Escola de Engenharia de São Carlos, Universidade de São Paulo.

EL DEBS, M.K. (2000). Concreto pré-moldado: fundamentos e Aplicações. São Carlos. Projeto REENGE. EESC - USP. 
ESPANHA. Ministério de Fomento (1997). EF-96 - Instruccion para el proyecto y la ejecucion de forjados unidireccionales de hormigon armado o pretensado.

ESPION, B.; HALLEUX, P. (1990). Long-term deflections of reinforced concrete beams: reconsideration of their variability. ACI Structural Journal, v.87, n.2, p.232-6.

GARDNER, W. (1986). Introduction to random processes. New York, McGrawHill, Inc.

GHALI, A.; ELBADRY, M. (1989). Serviceability design of continuous prestressed concrete structures. PCI Journal, v.34, n.1, p.54-91.

GHALI, A.; FAVRE, R. (1986). Concrete structures. Stresses and Deformations. London, Chapman and Hall.

GILBERT, R.I. (1989). Time-dependent analysis of composite steel-concrete sections. Journal of Structural Engineering, v.115, n.11, p.2687-705.

GILBERT, R.I.; BRADFORD, M.A. (1995). Time-dependent behavior of continuous composite beams at service loads. Journal of Structural Engineering, v.121, n.2, p.319-27.

HASPARYK, N.P.; LOPES, A.N.M.; ANDRADE, M.A.S.; SANTOS, S.B. (2005). Deformação por retração e fluência. In: ISAIA, G.C., ed. Concreto: ensino, pesquisa e realizações. São Paulo, IBRACON. Cap. 22, p.655-685.

HERKENHOFF, L. (1994). Análisis y criterios para proyecto de puentes continuos construidos a partir de elementos prefabricados de hormigón armado y pretensado. Barcelona. 208p + anexo. Tese (Doutorado) - Universidade Politécnica da Catalunha.

HSU, T.T.C.; ZHANG, L.X. (1996). Tension-stiffening in reinforced concrete membrane elements. ACI Structural Journal, v.93, n.1, p.108-15.

HU, H.T.; SCHNOBRICH, W.C. (1990). Nonlinear analysis of cracked reinforced concrete. ACI Structural Journal, v.87, n.2, p.199-207.

JENDELE, L.; PHILLIPS, D.V. (1992). Finite element software for creep and shrinkage in concrete. Computers and Structures, v.45, n.1, p.113-26.

JURKIEWIEZ, B.; DESTREBECQ, J.F.; VERGNE, A. (1999). Incremental analysis of time-dependent effects in composite structures. Computers and Structures, v.73, n.1-5, p.425-35. 
KANG, Y.J.; SCORDELIS, A.C. (1980). Nonlinear analysis of prestressed concrete frames. Journal of Structural Division, v.106, n.2, p.445-62.

KENNEDY, W.J.; GENTLE, J.E (1980). Statistical computing. New York, Marcel Dekker, INC.

KNUTH, D.E. (1969). Seminumerical algorithms. Vol. 2. London, Addison-Wesley Pub. Co.

KRISTEK, V.; BAZANT, Z.P. (1985). Shear lag effect and uncertainty in concrete box girder creep. Journal of Structural Engineering, v.113, n.3, p.557-74.

KWAK, H.G.; SEO, Y.J. (2000). Long-term behavior of composite girder bridges. Computers and Structures, v.74, n.5, p.583-99.

LEIBENGOOD, L.D.; DARWIN, D.; DODDS, R.H. (1986). Parameters affecting FE analysis of concrete structures. Journal of Structural Engineering, v.112, n.2, p.326-41.

LEONHARDT, F.; MÖNNING, E. (1978). Construções de concreto: princípios básicos do dimensionamento de estruturas de concreto armado. Rio de Janeiro, Interciência. V.1.

MAGALHÃES, F.L. (2001). Estudo dos momentos fletores negativos nos apoios de lajes formadas por elementos pré-moldados tipo nervuras com armação treliçada. São Carlos. 135p. + apêndice. Dissertação (Mestrado) - Escola de Engenharia de São Carlos, Universidade de São Paulo.

MAGURA, D.D.; SOZEN, M.A.; SIESS, C.P. (1964). A study of stress relaxation in prestressing reinforcement. PCI Journal, v.9, n.2, p.185-92.

MARÍ, A.R. (2000). Numerical simulation of segmental construction of three dimensional concrete frames. Journal of Engineering Structures, v.22, n.6, p.58596.

MASSICOTTE, B.; ELWI, A.E.; McGREGOR, J.G. (1990). Tension-stiffening model of planar of reinforced concrete members. Journal of Structural Engineering, v.116, n.11, p.3039-58.

McKAY, M.D.; BERCKMAN, R.J.; CONOVER, W.H. (1979). A comparison of three methods for selecting values of input variables in the analysis of output from a computer code. Technometrics, v.21, n.2, p.239-45. 
MEHTA, P.K.; MONTEIRO, P.J.M. (1994). Concreto: estrutura, propriedades e materiais. São Paulo, Pini.

NAVRATIL, J.; FLORIAN, A. (1993). Time-dependent analysis of a cable stayed bridge with uncertainties in input parameters. In: INTERNATIONAL RILEM SYMPOSIUM ON CREEP AND SHRINKAGE OF CONCRETE, 5., Barcelona, 1993. Proceedings. London, E\&FN Spon, p.623-8.

NEVILLE, A.M. (1997). Propriedades do concreto. São Paulo, Pini.

NEVILLE, A.M.; DILGER, W.H.; BROOKS, J.J. (1983). Creep of plain and structural concrete. London, Construction Press-Longman.

OH, B.H.; YANG, I.H. (2000). Sensitivity analysis of time-dependent behavior in PSC box girder bridges. Journal of Structural Engineering, v.126, n.2, p.171-9.

OWEN, D.R.J.; FIGUEIRAS, J.A.; DAMJANIC, F. (1983). Finite element analysis of reinforced and prestressed concrete structures including thernal loading. Computer Methods in Applied Mechanics and Engineering, v.41, n.3, p.323-66.

RAJASHEKHAR, M.R.; ELLINGWOOD, B.R. (1995). Reliability of reinforced concrete cylindrical shells. Journal of Structural Engineering, v.121, n.2, p.33647.

RAO, P.; JAYARAMAN, R.; VILAMANANDAM, V.; BABU, S.S. (1994). Predicting creep and shrinkage effects in cracked concrete elements. Journal of Structural Engineering, v.120, n.9, p.2784-92.

REAL, M.V. (2000). Análise probabilística de estruturas de concreto armado, sob estado plano de tensão, através do método dos elementos finitos. Porto Alegre. 224p. (Tese de Doutorado) - PPGEC - UFRGS.

REIS, A.P.A. (2003). Reforço de vigas de concreto armado submetidas à précarregamento e ações de longa duração com aplicação de concretos de alta resistência e concretos com fibras de aço. São Carlos. 285p + apêndice. Tese (Doutorado) - Escola de Engenharia de São Carlos, Universidade de São Paulo.

ROGGE, A.C. (2001). Estudo experimental da deformação ao longo do tempo de lajes com nervuras pré-moldadas. São Carlos. Relatório de iniciação científica Universidade Federal de São Carlos. 
RUSSEL, H.G.; MEYERS, B.L.; DAYE, M.A. (1982). Observations on structures. In: BAZANT, Z.P.; WITTMANN, F.H., eds. Creep and shrinkage in concrete structures. New York, John Wiley \& Sons. Cap. 10, p.341-358.

SALIBY, E. (1989). Repensando a simulação: a amostragem descritiva. São Paulo, Atlas.

SALIBY, E.; MOREIRA, F.F.P. (2001). Análise da eficiência dos métodos QuasiMonte Carlo, Amostragem Descritiva, Hipercubo Latino e Monte Carlo em aplicações de simulação. In: SIMPÓSIO BRASILEIRO DE PESQUISA OPERACIONAL, 33., Campos do Jordão, 2001. Anais. Campos do Jordão, p.58586.

SATHURAPPAN, G.; RAJAGOPALAN, N.; KRISHNAMOORTHY, S. (1992). Nonlinear finite element analysis of reinforced and prestressed concrete slabs with reinforcement modelled as discrete integral components. Computers and Structures, v.44, n.3, p.575-84.

SHUSHKEWICH, K.W. (1986). Time-dependent analysis of segmental bridges. Computers and Structures, v.23, n.1, p.95-118.

SMERDA, Z.; KRISTEK, V. (1988). Creep and shrinkage of concrete elements and structures. Elsevier, Amsterdam.

STEIN, M. (1987). Large sample properties of simulations using latin hypercube sampling. Technometrics, v.29, n.2, p.143-51.

SUN, C.H.; BRADFORD, M.A.; GILBERT, R.I. (1993). Nonlinear analysis for concrete frame structures using the element finite method. Computers and Structures, v.48, n.1, p.73-9.

TAKÁCS, P.F. (2002). Deformations in concrete cantilever bridges: observations and theoretical modelling. Trondheim. 177p + apêndice. Tese (Doutorado) Universidade Norueguesa de Ciência e Tecnologia.

TORRES, Ll. (2001). Modelo numérico y verificación experimental del comportamiento em servicio de estructuras de hormigón. Barcelona. 212p + apêndice. Tese (Doutorado) - Universidade Politécnica da Catalunha.

TRADOS, M.K.; GHALI, A.; DILGER, W.H. (1979). Long-term stresses and deformation of segmental bridges. PCI Journal, v.24, n.4, p.66-87. 
TSUBAKI, T. (1993). Uncertainty of prediction. In: INTERNATIONAL RILEM SYMPOSIUM ON CREEP AND SHRINKAGE OF CONCRETE, 5., Barcelona, 1993. Proceedings. London, E\&FN Spon, p.831-47.

VAN ZYL, S.F.; SCORDELIS, A.C. (1979). Analysis of curved prestressed segmental bridges. Journal of the Structural Division, v.105, n.11, p.2399-417. 


\section{APÊNDICE A - Resultados obtidos para a determinação do coeficiente multiplicador básico}

No Apêndice A são apresentados os resultados obtidos da análise das lajes pré-moldadas formadas por vigotas com armação treliçada para a determinação do coeficiente multiplicador básico.

Essa análise foi realizada mantendo-se constante a umidade relativa (60\%) e a temperatura ambiente $\left(25^{\circ} \mathrm{C}\right)$. Com isso, pôde-se determinar para cada caso o coeficiente multiplicador $\alpha$ através da seguinte expressão:

$\alpha=\frac{\mathrm{a}_{\text {total }}-\mathrm{a}_{\text {inst }}}{\mathrm{a}_{\text {inst }}}$

onde:

$\mathrm{a}_{\text {inst }} \quad$ - flecha instantânea da laje;

$\mathrm{a}_{\text {total }} \quad$ - flecha total da laje (instantânea e diferida).

E o coeficiente $\kappa$ :

$\kappa=\frac{A_{s} \cdot h^{2,05}}{p^{1,5} \cdot \ell^{3}} \cdot 10^{3}$

onde:

$$
\begin{array}{ll}
A_{\mathrm{s}} & \text { - armadura }\left[\mathrm{cm}^{2}\right] ; \\
\mathrm{h} & \text { - altura da laje }[\mathrm{m}] ; \\
\mathrm{p} & \text { - carregamento aplicado }[\mathrm{kN} / \mathrm{m}] ; \\
\ell & \text { - vão da laje }[\mathrm{m}] .
\end{array}
$$

A seguir são apresentados os resultados do coeficiente multiplicador $\alpha$ e do coeficiente $\kappa$ obtidos em cada caso. 
$\checkmark$ 占

$\because$ :

ด. \& $\infty$

o $\rightarrow$ -

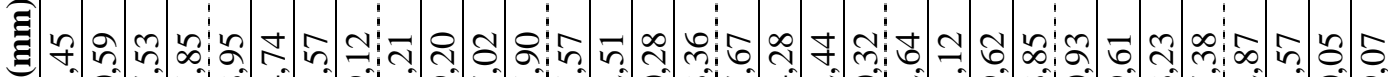

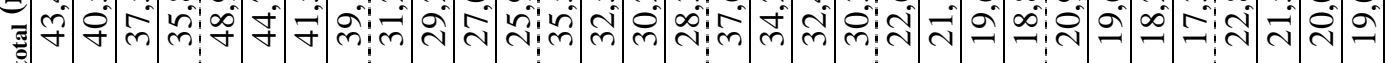

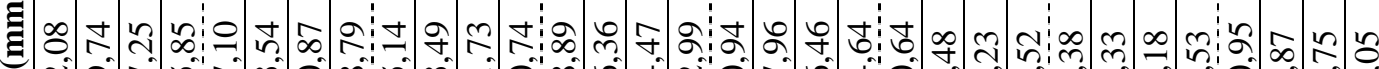

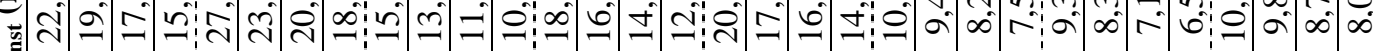

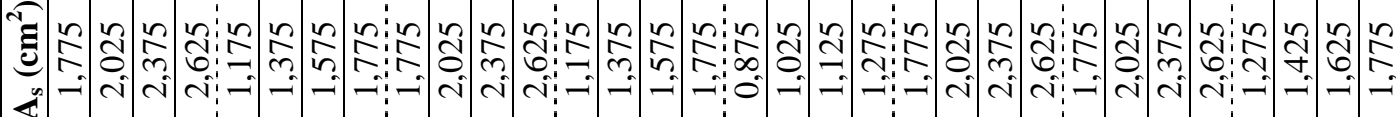

(ี)

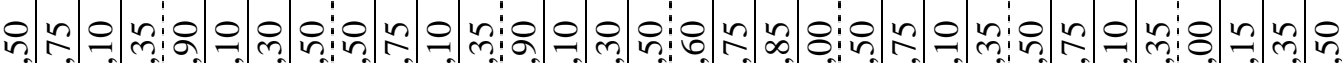

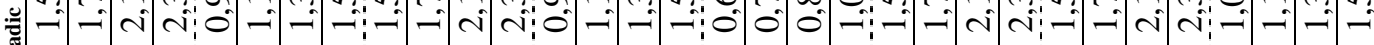

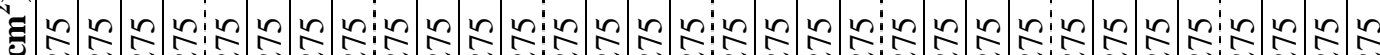

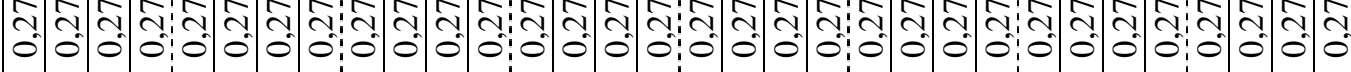

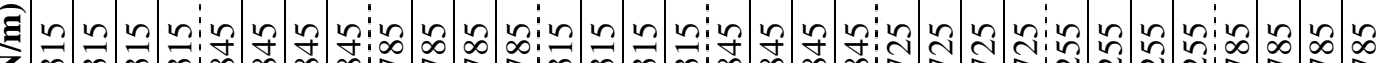

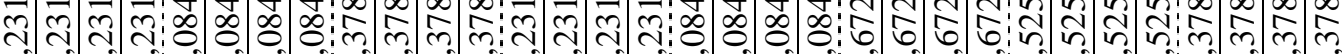

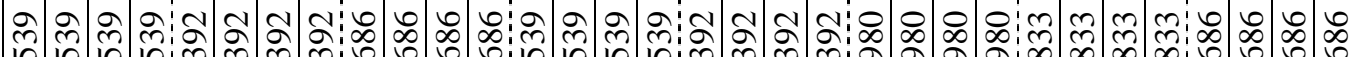

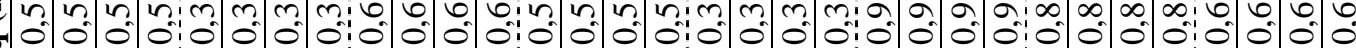
空

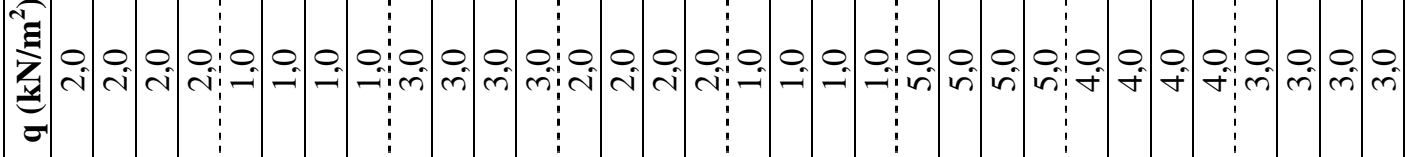

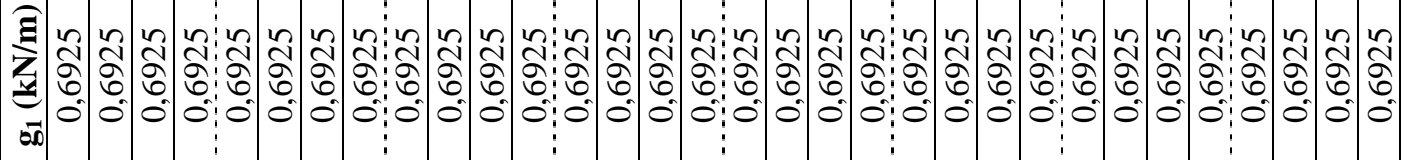

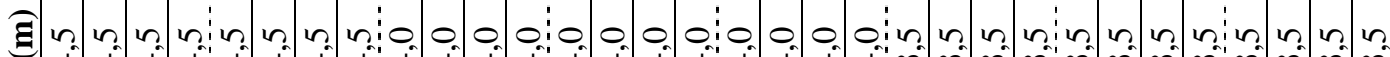
బ

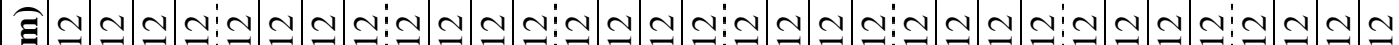

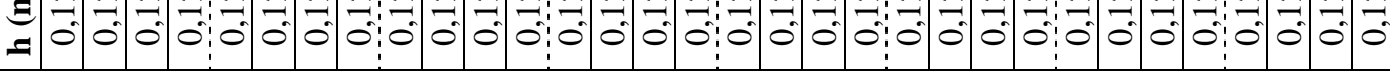
: 


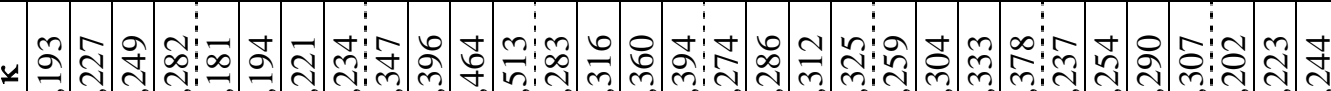
萑 ૪

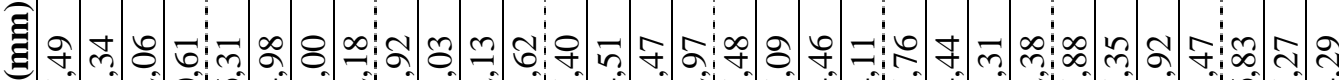

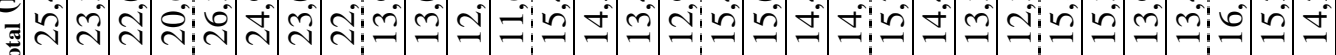
זั0

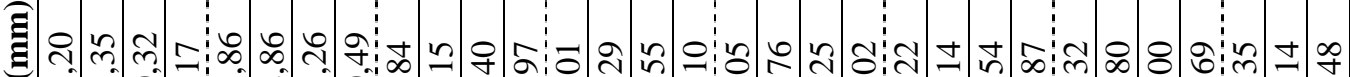
药 बें

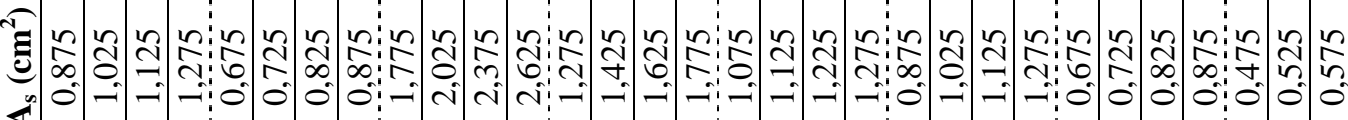

五

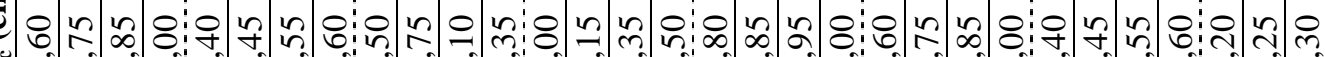
: 0 0

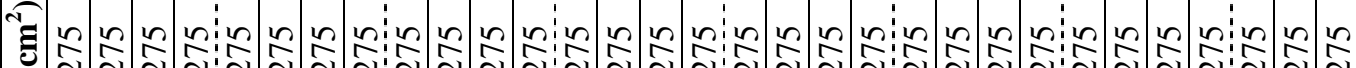
:

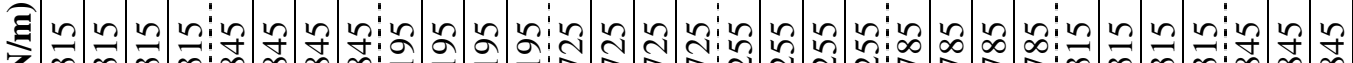
సิ సิ సิ సี: .

E

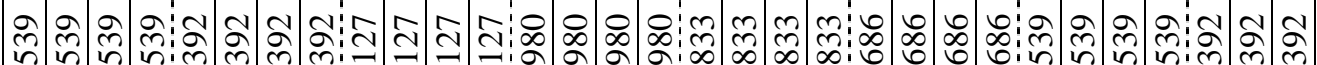
б 0. $\dot{\mathbf{v}}$

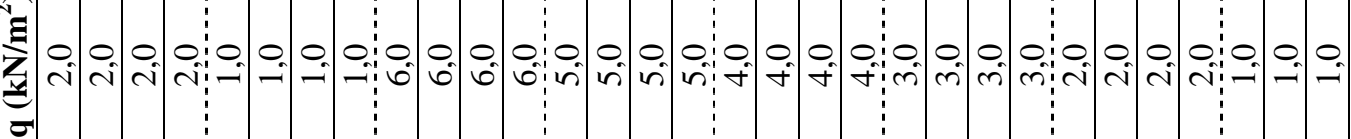

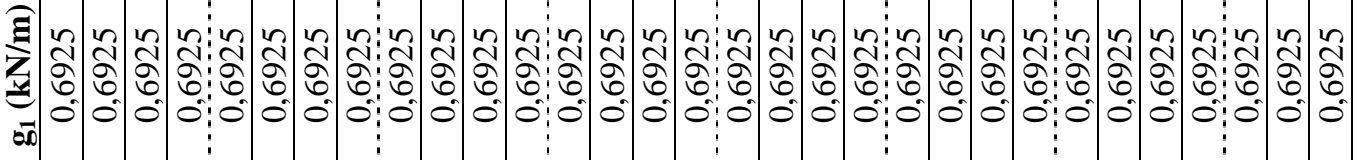

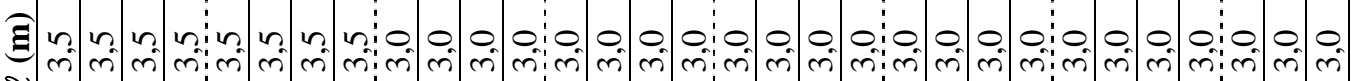

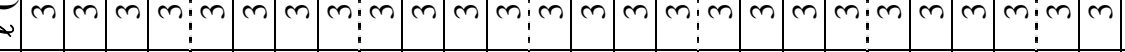

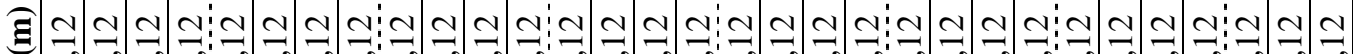
= : 
$\checkmark$ م

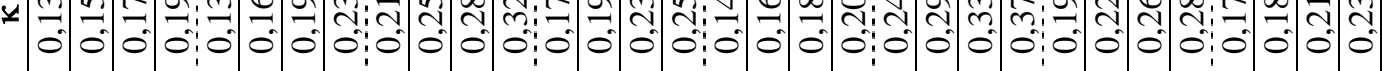

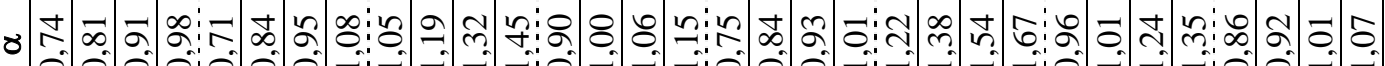

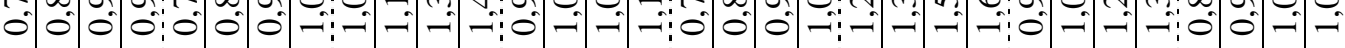

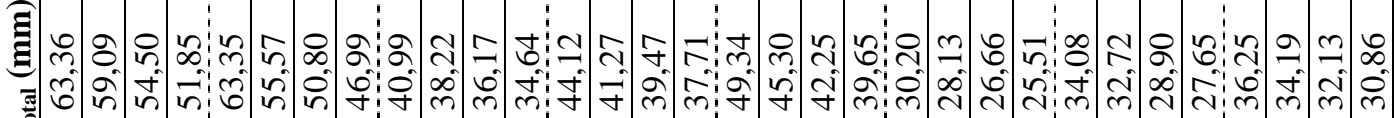

苞

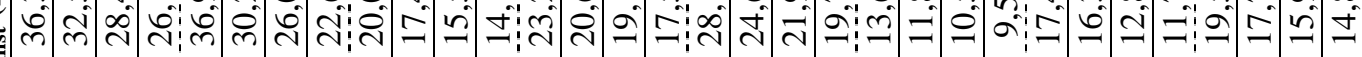

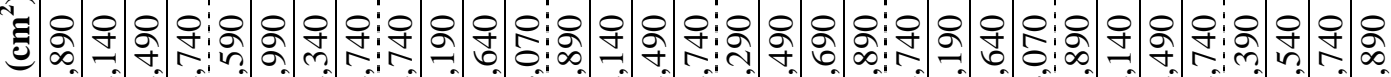

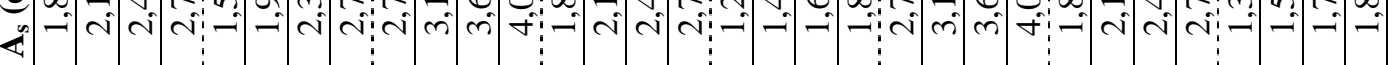

(ี

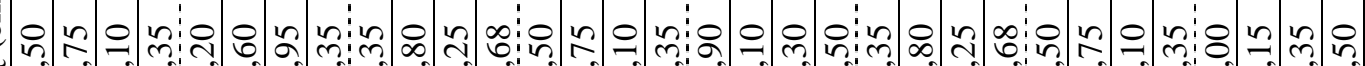

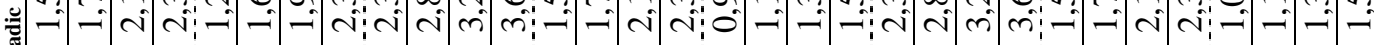

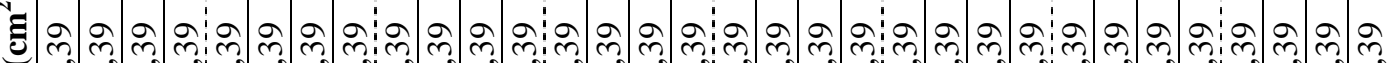
l.

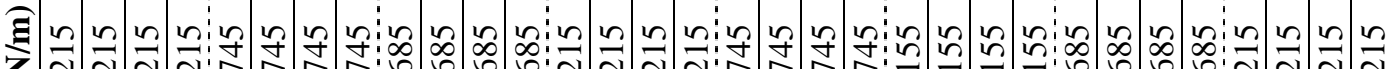

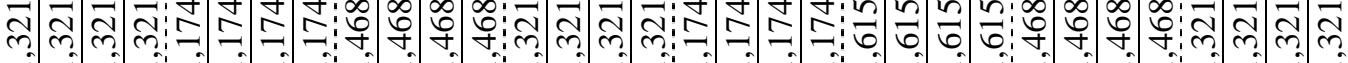

จ จ จ

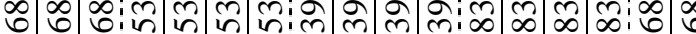

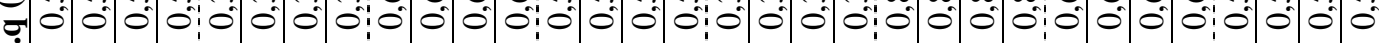

年

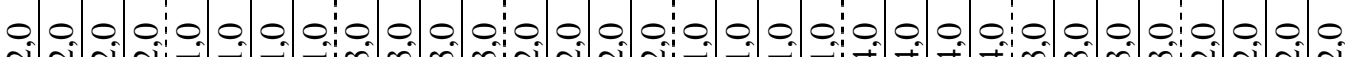
री $\hat{n}$ री

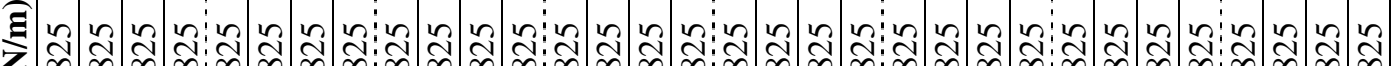

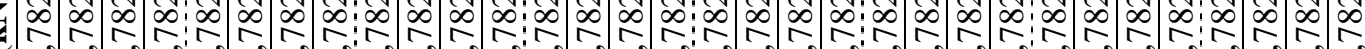

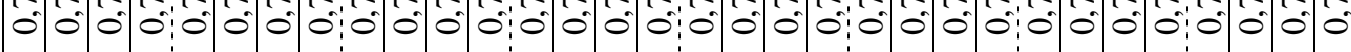

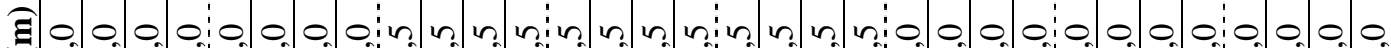

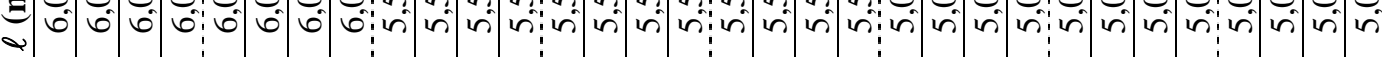

§ิ

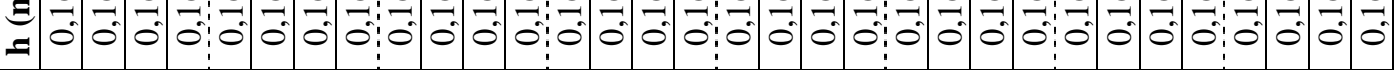
苛坣 


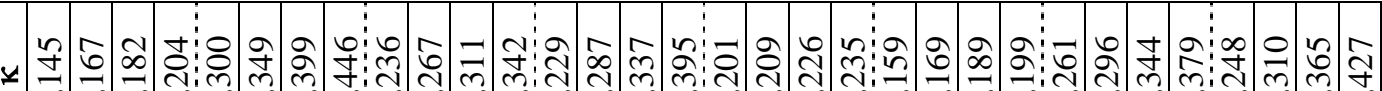

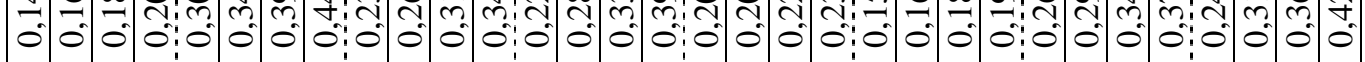
스요요

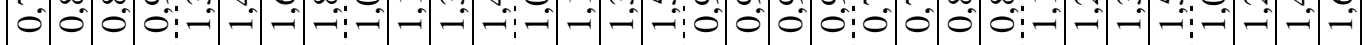

苞

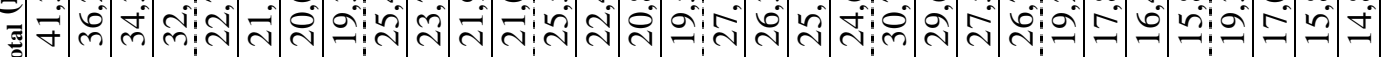
(艹)

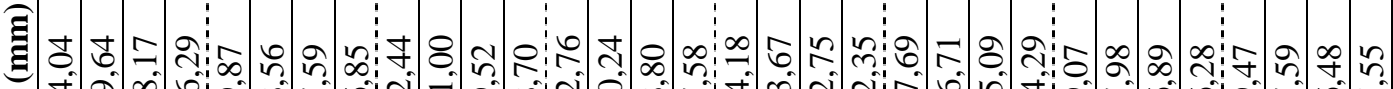
ธิ (َ)

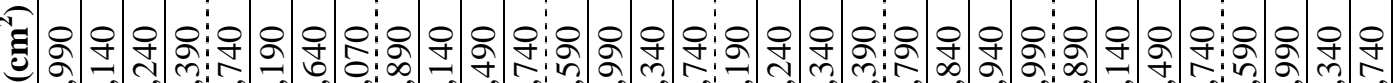

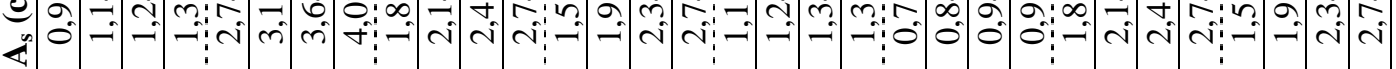

กี

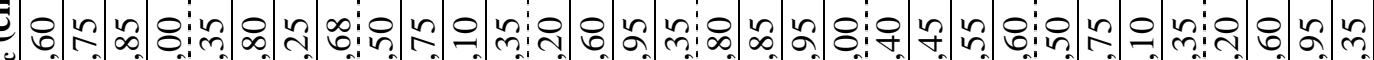

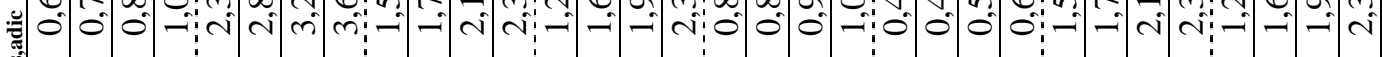

స్ర ભి य.

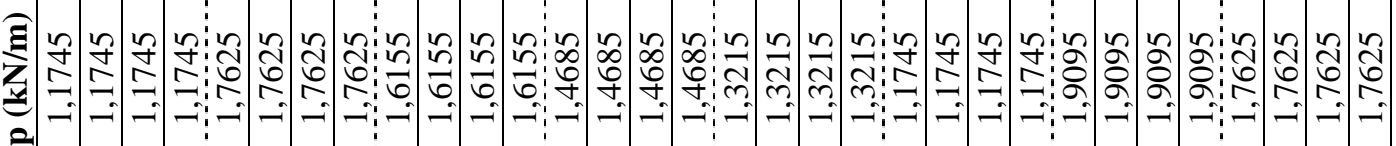

$\widehat{\mathbf{E}}$

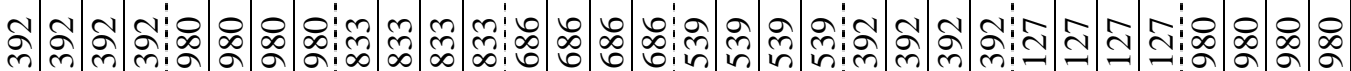

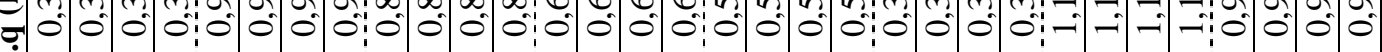
$\dot{\dot{\sim}}$

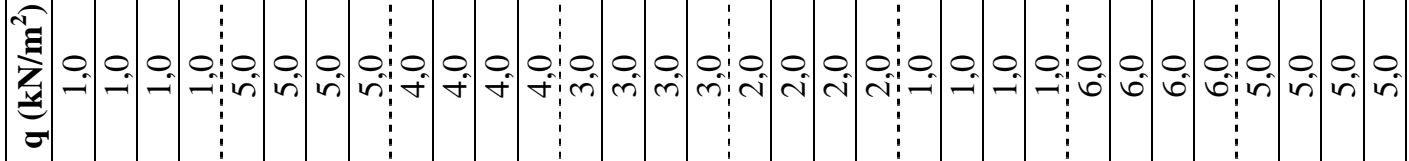

ำㄴำㄴำ

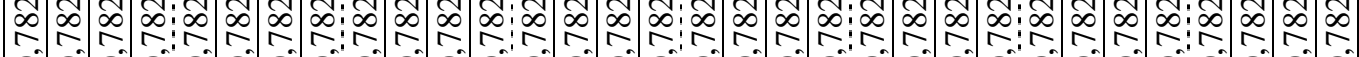

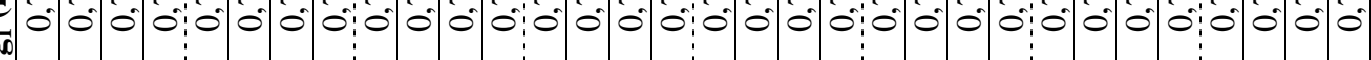

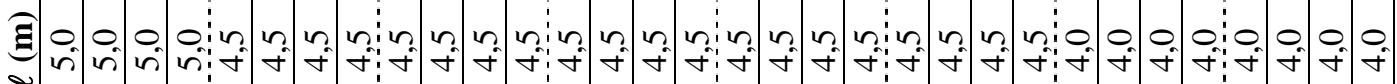
司

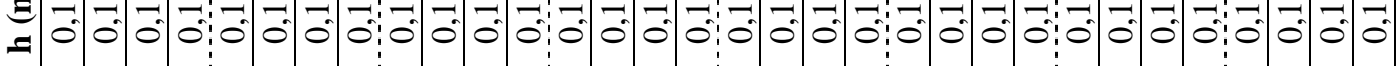
$\therefore 0$ 3.tat 


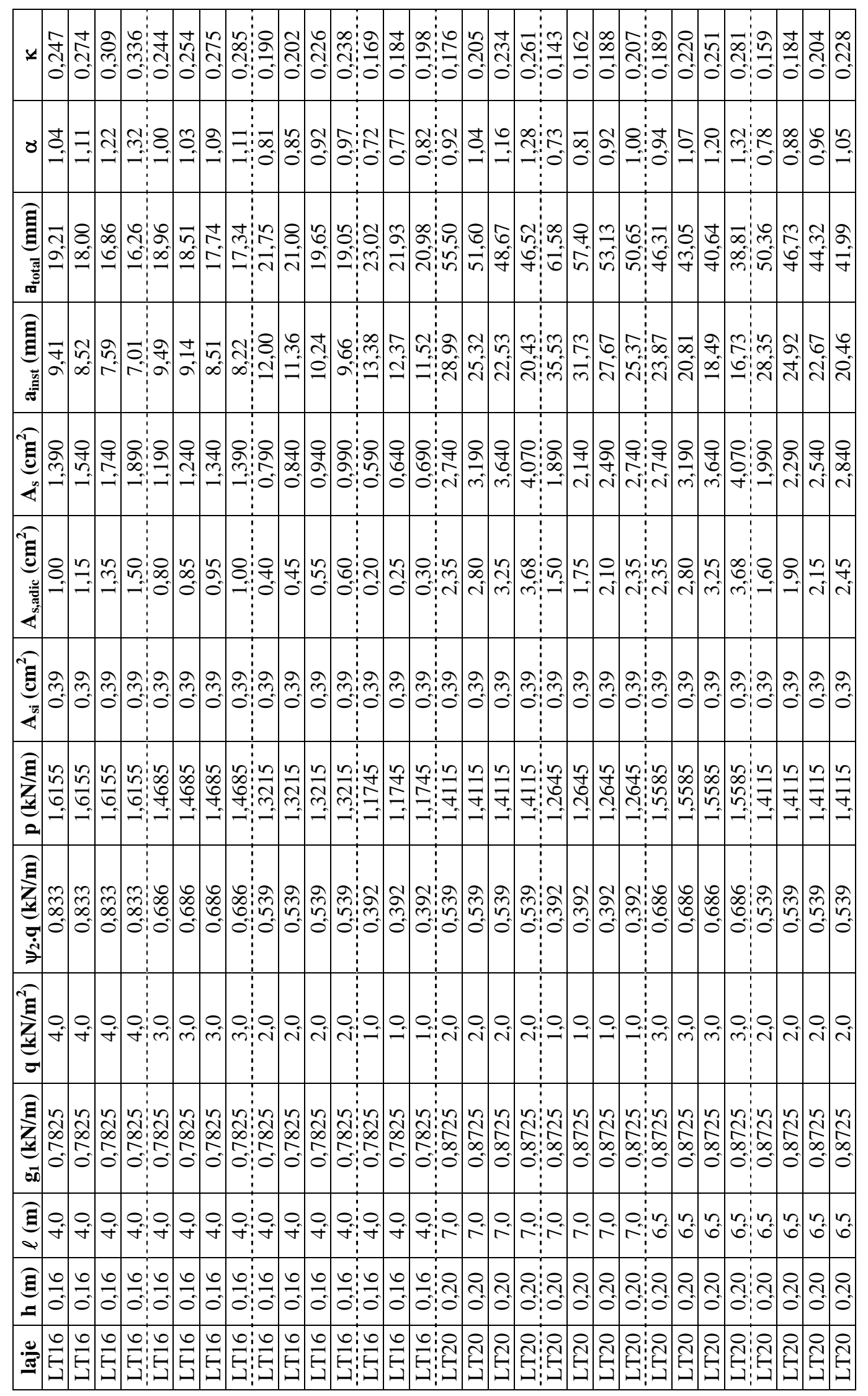




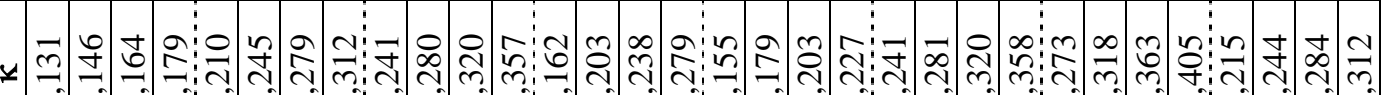

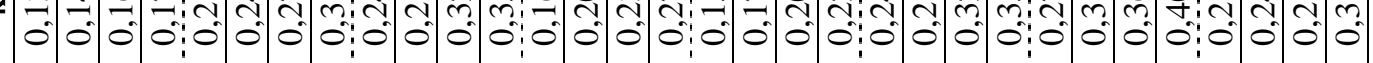
ช ชิ

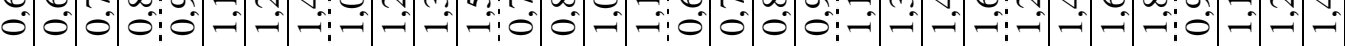

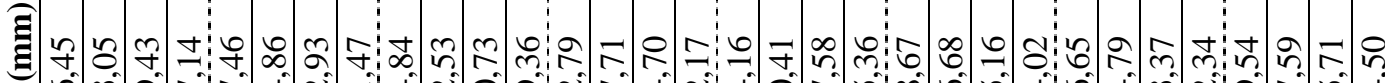
ज़ी ผึं के m.

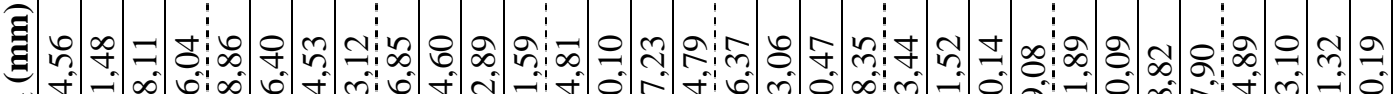
जे ¿

ت

กี

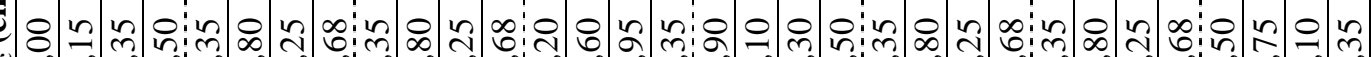

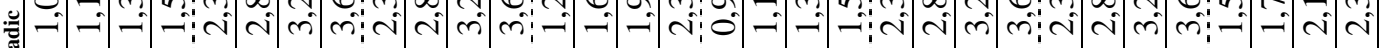

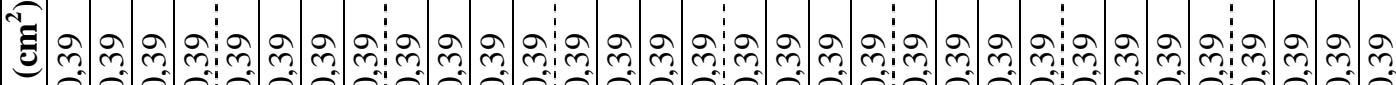

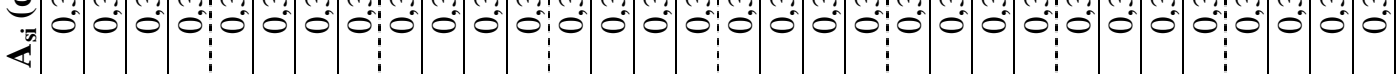

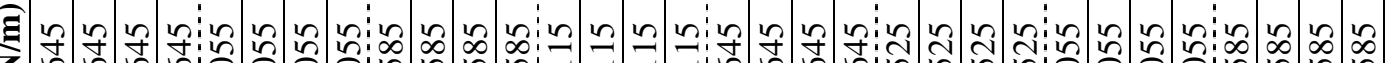

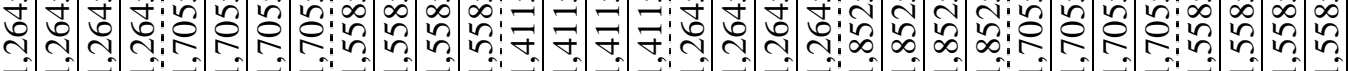

$\widehat{\mathbf{g}}$

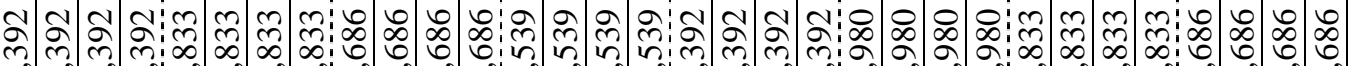

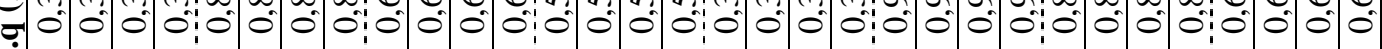
$\dot{\mathbf{N}}$

ש

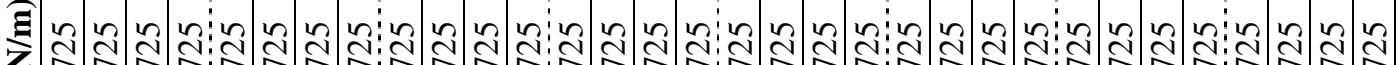

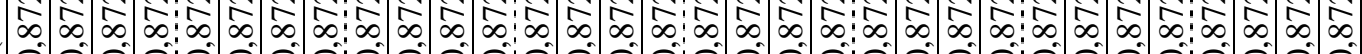

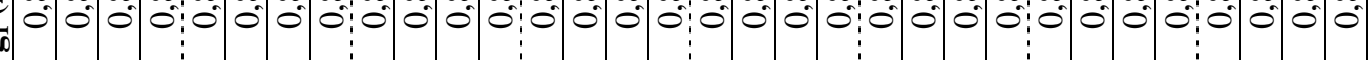

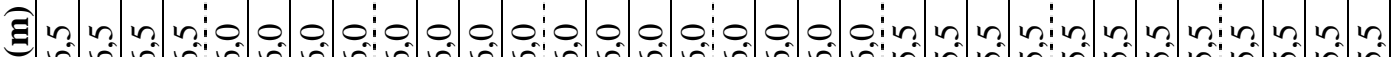

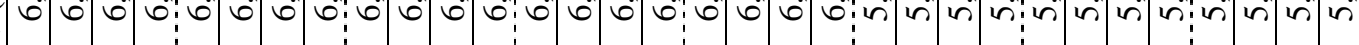

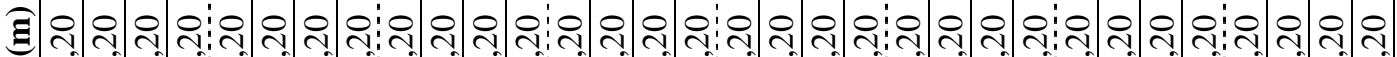

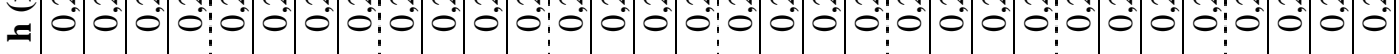

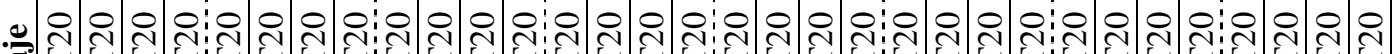
无兒兒兒: 


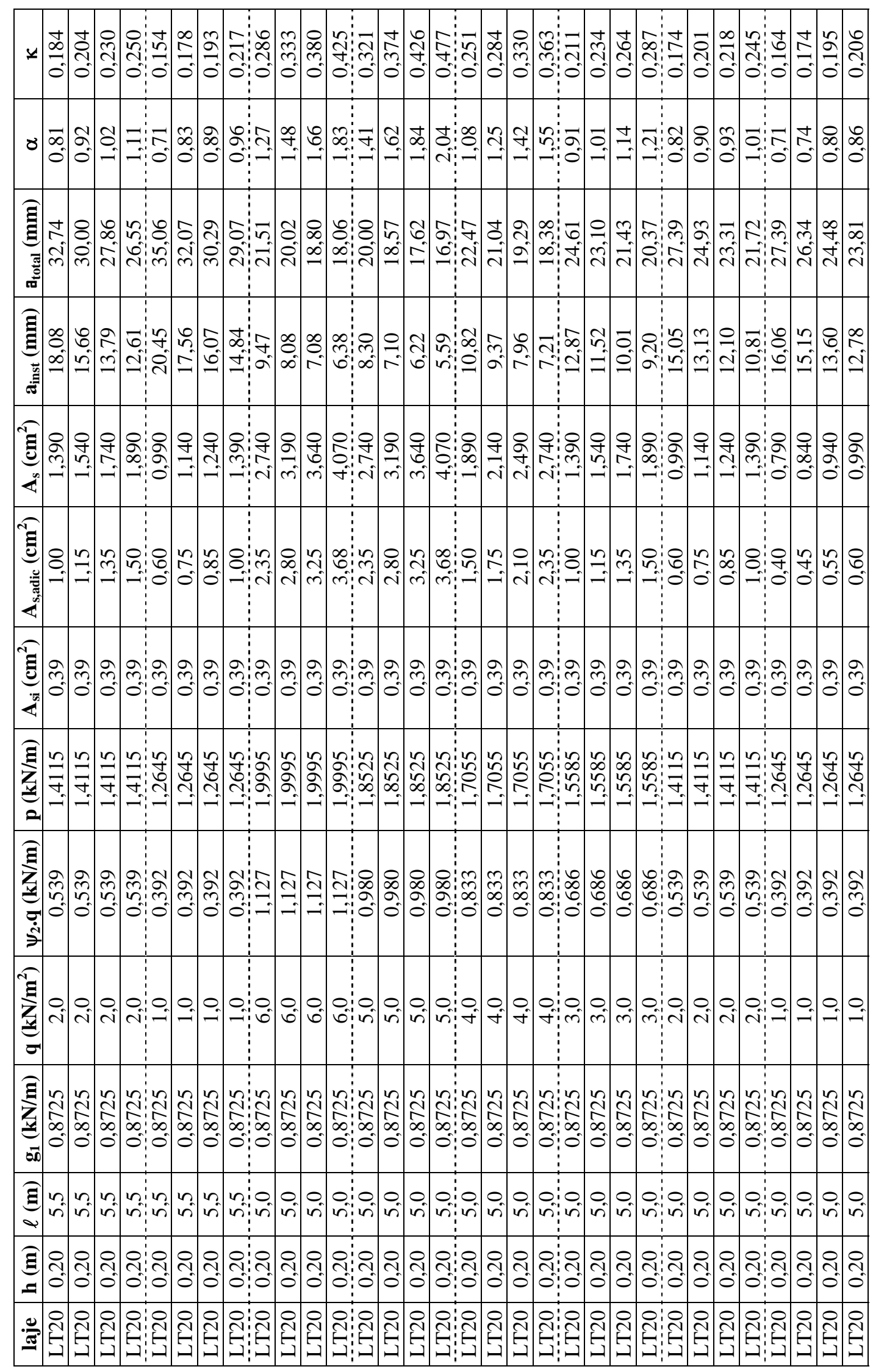


mิ

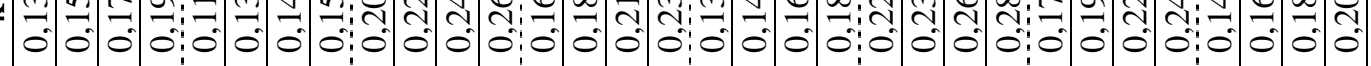
○ ำ 0 0.

코ำ

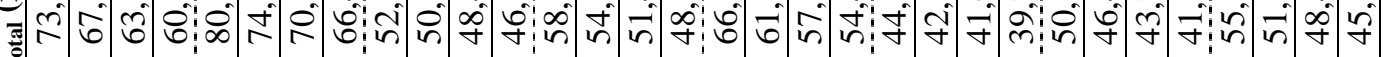
זั.

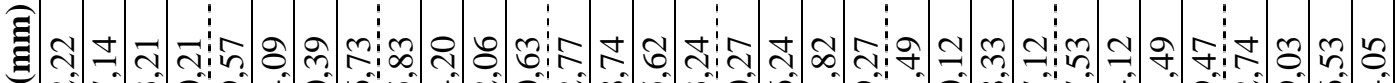
ज̂. i

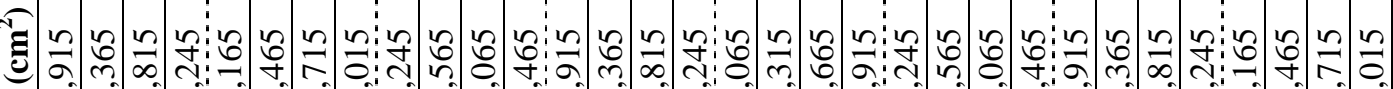

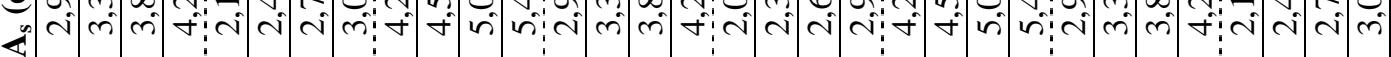

嗮

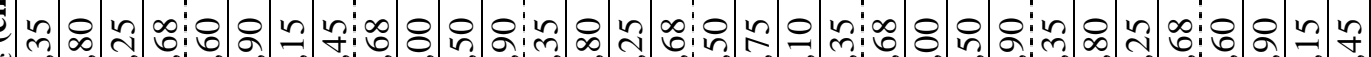
जी

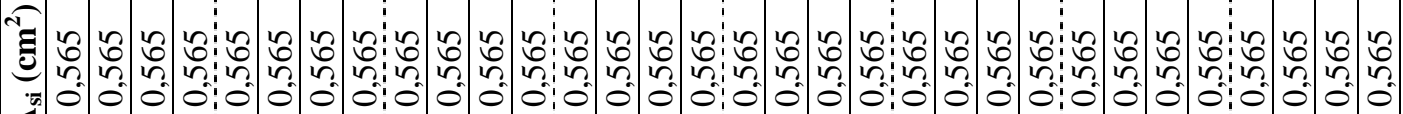

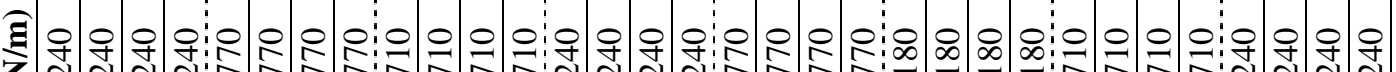

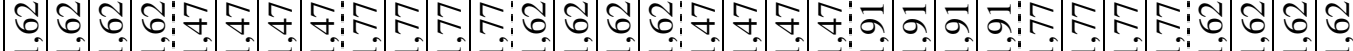
$\underset{2}{2}$

疋

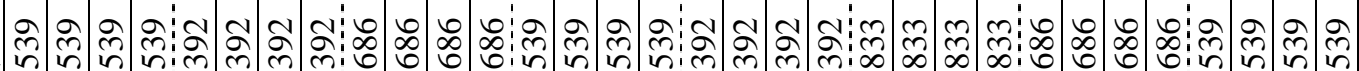

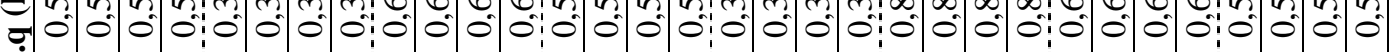
$\dot{\dot{\nu}}$

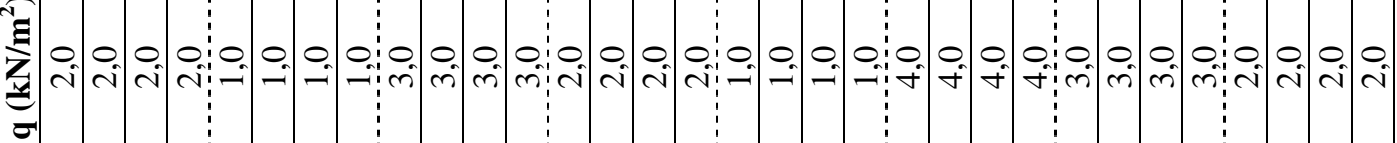

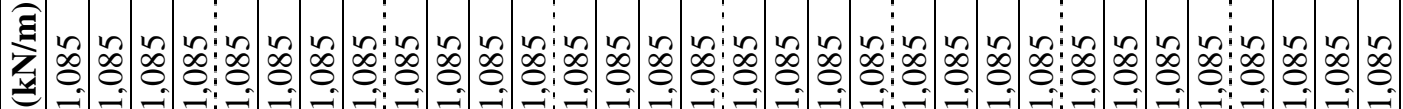
की

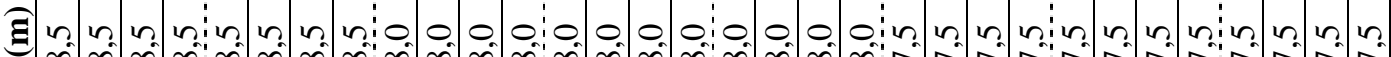

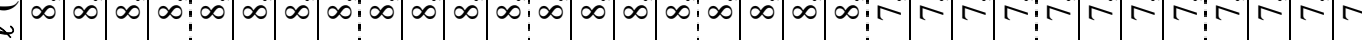

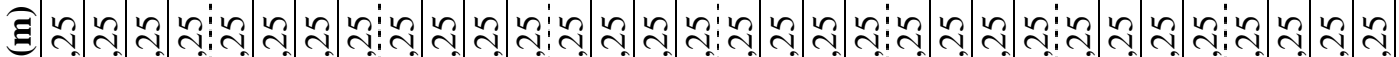

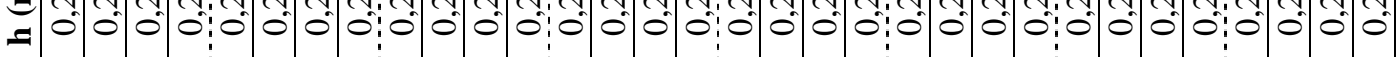

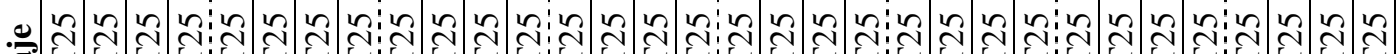

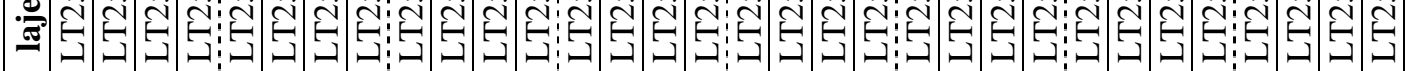




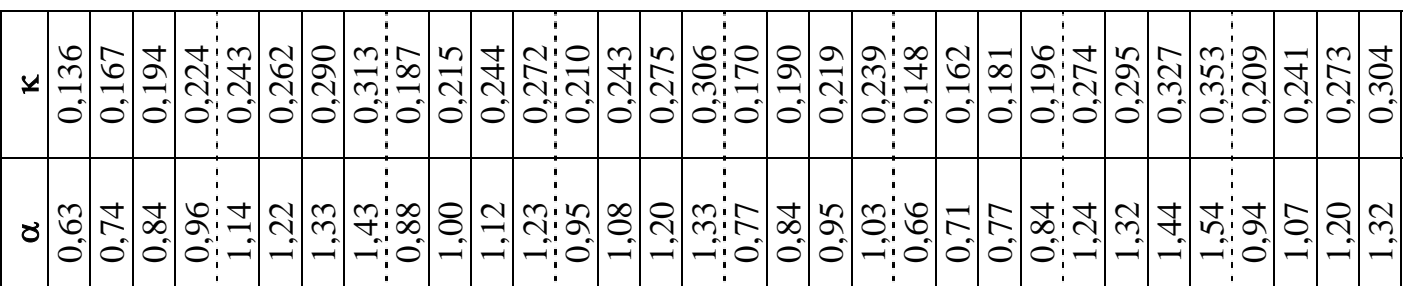

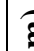

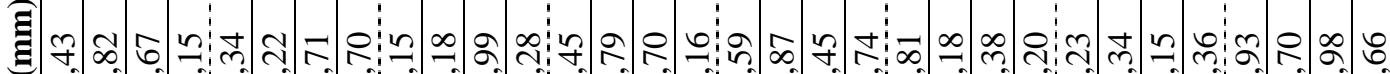

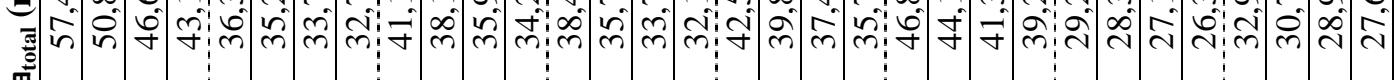
(10

ஸి స๐

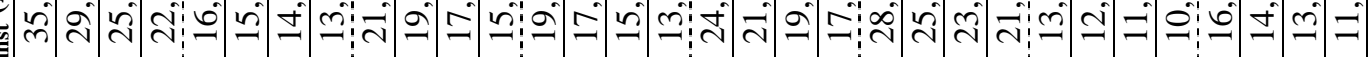

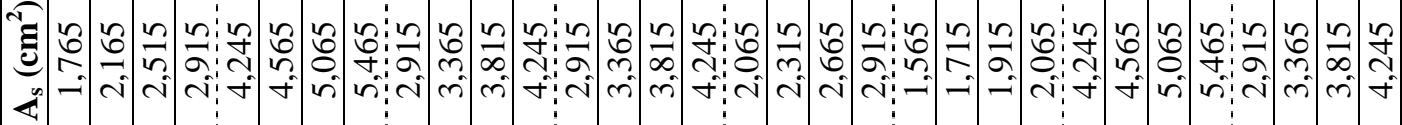

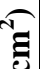

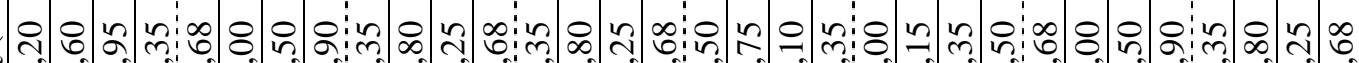

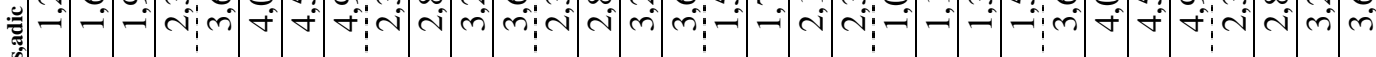

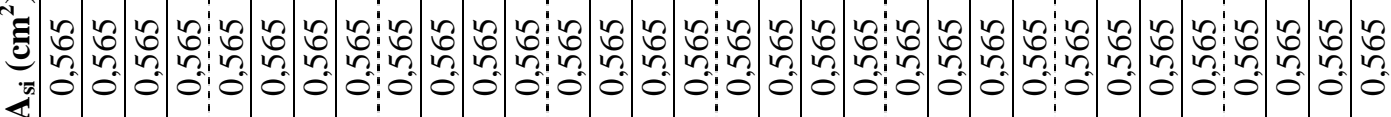

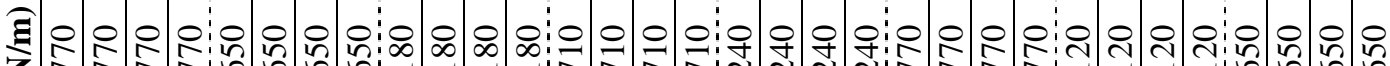

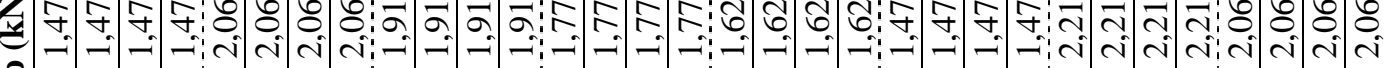

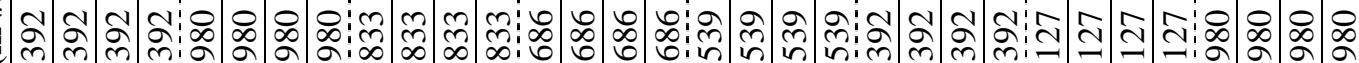

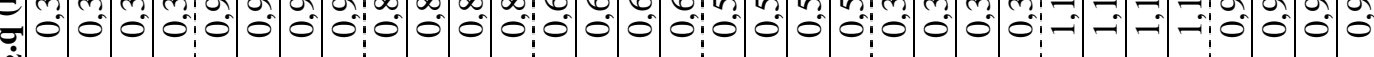

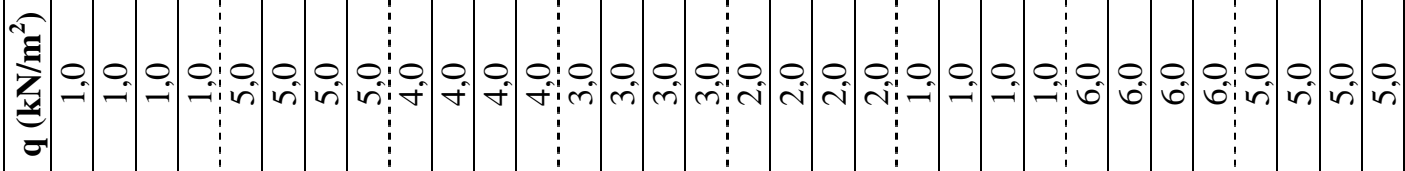

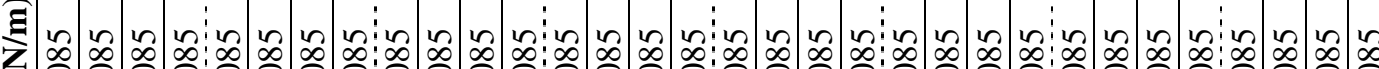

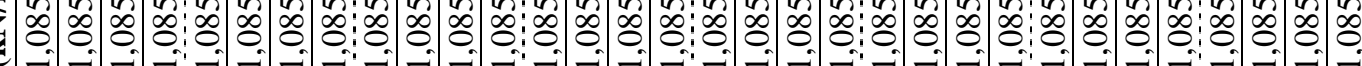

की

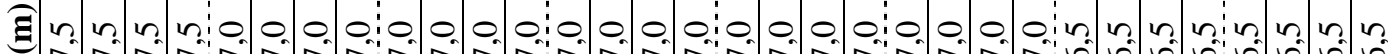

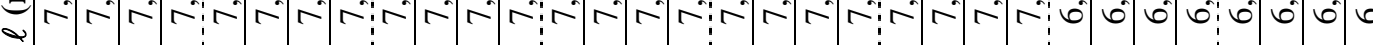

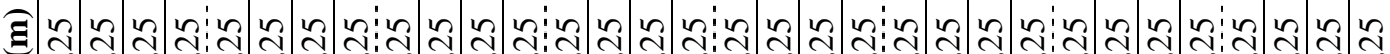

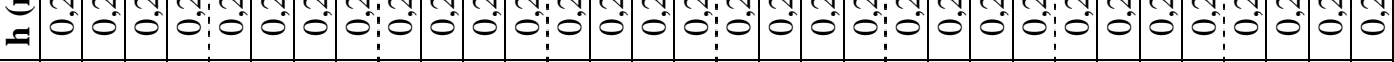
岢 
× N.

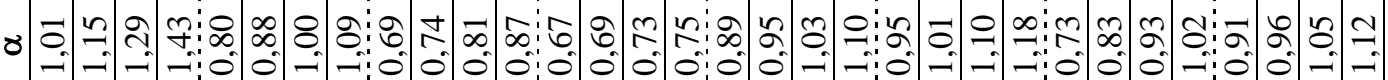

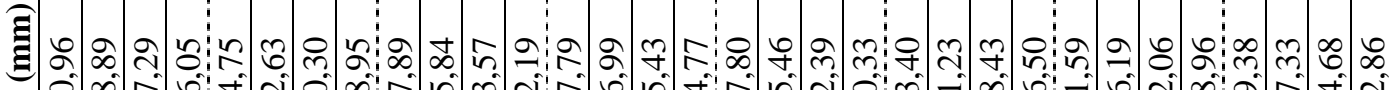

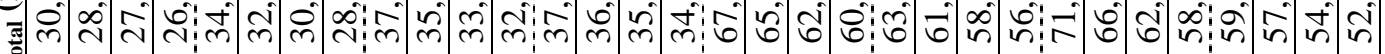
(1)

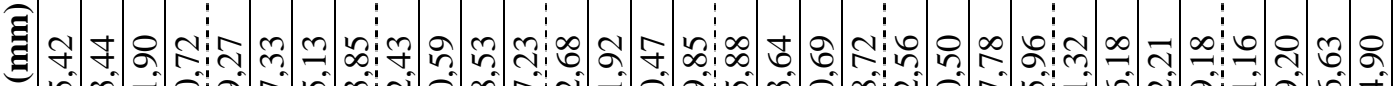
เी (艹)

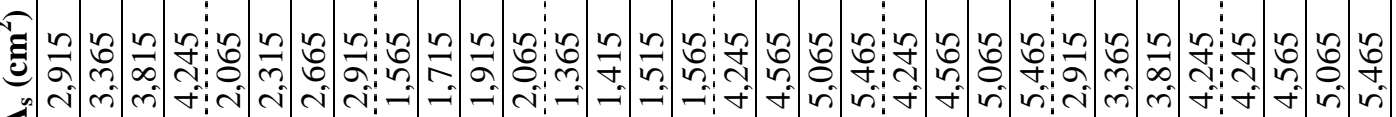

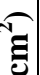

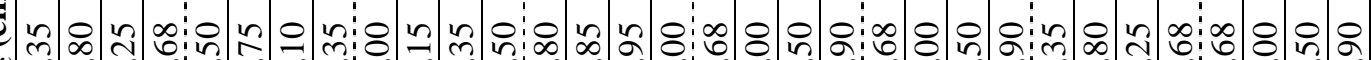

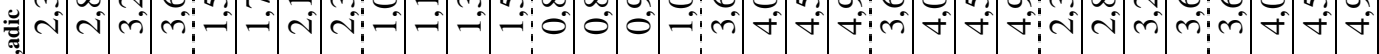

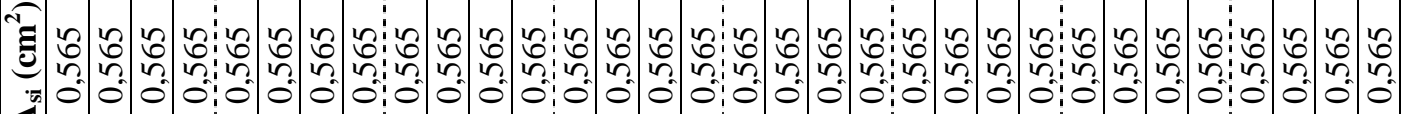

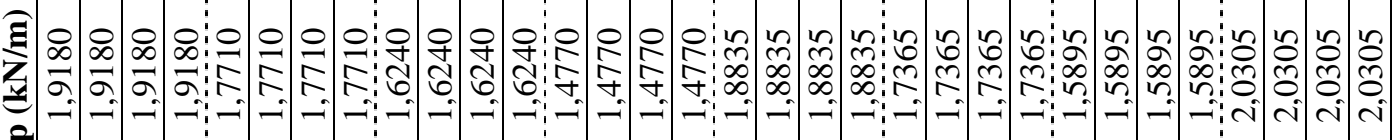

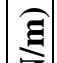

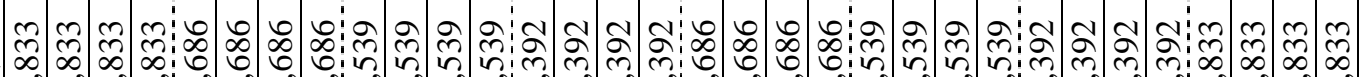

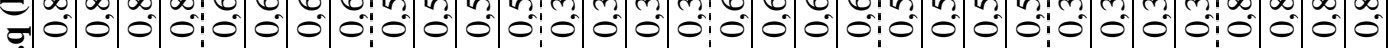
$\dot{\text { ஸे }}$

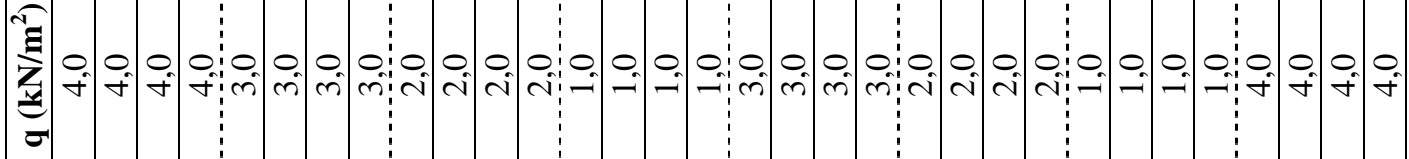

§

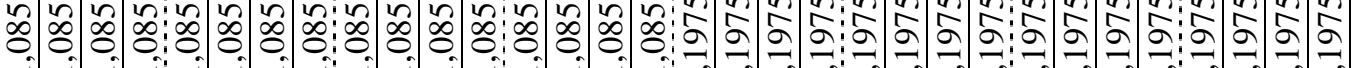
อี

Е

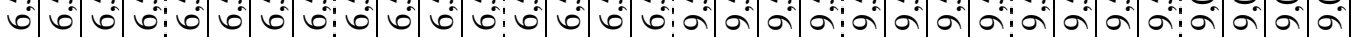

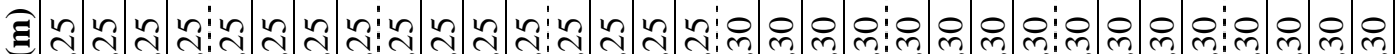

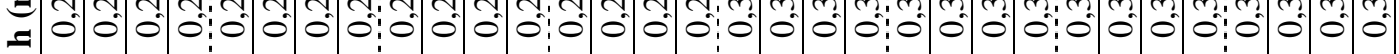

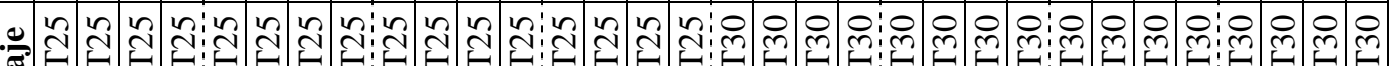
急 


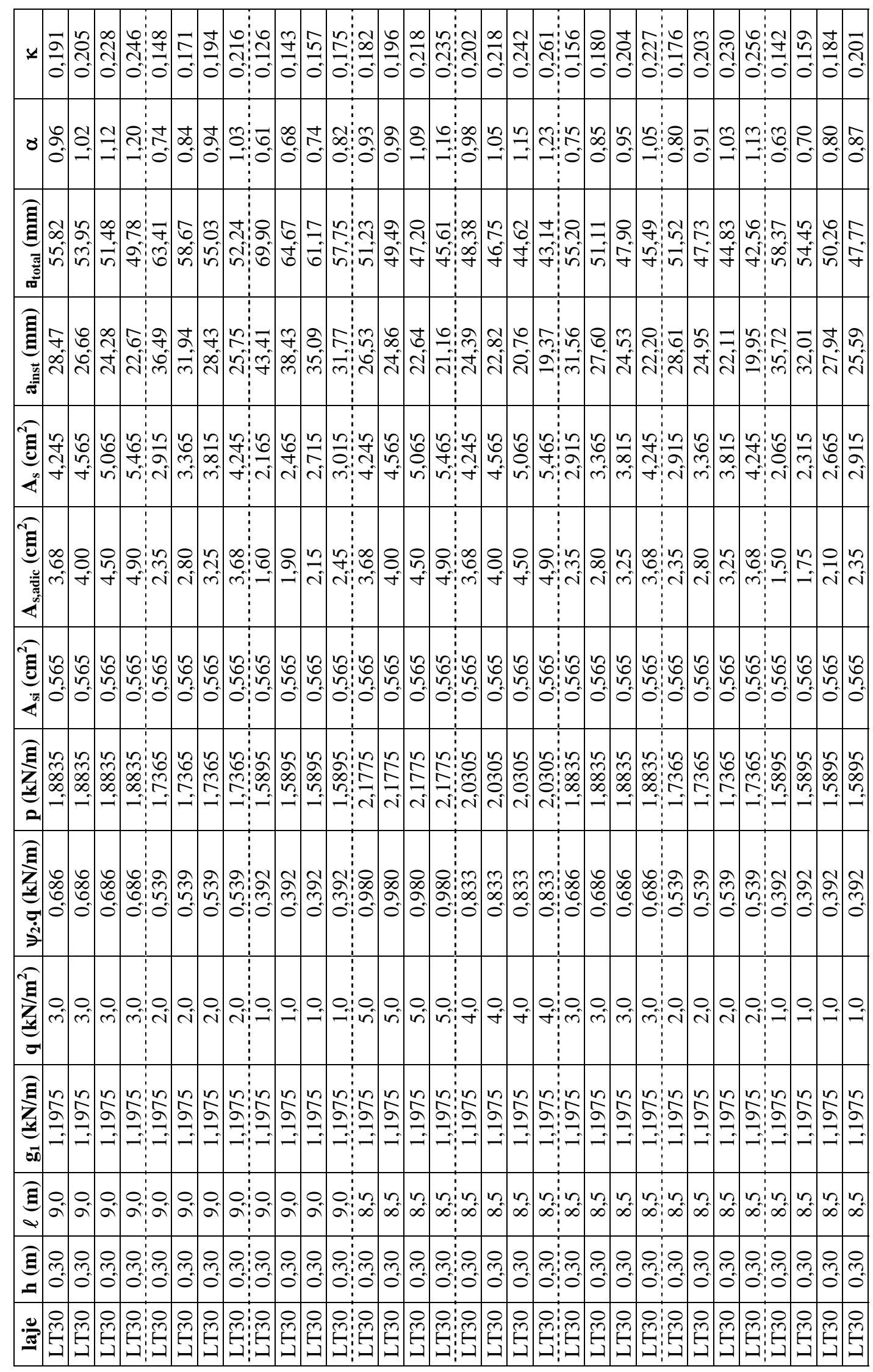




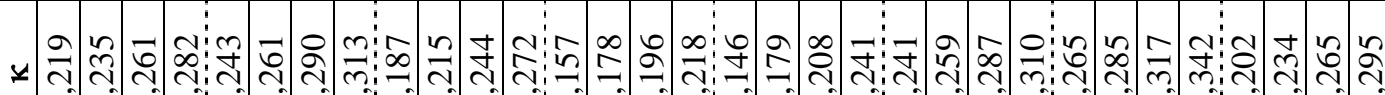
స̂. ช

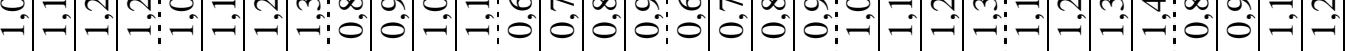

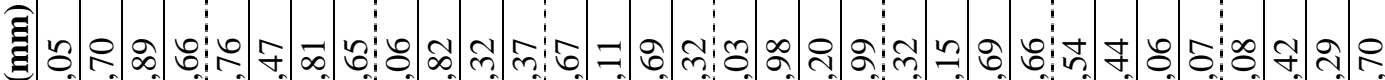

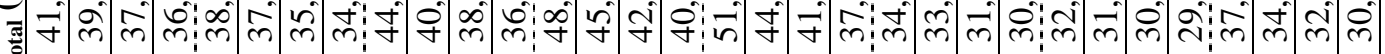
(ז)

สำำ ปิ

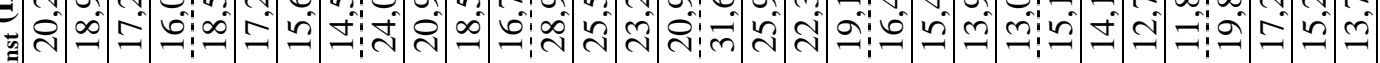
(َ)

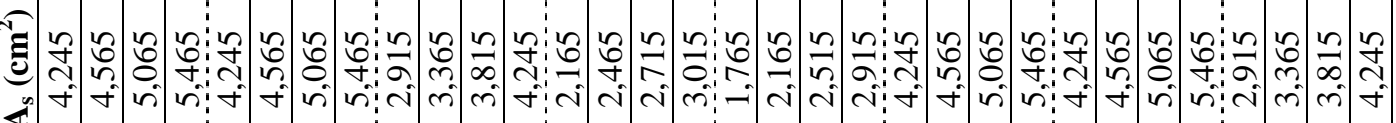

ह

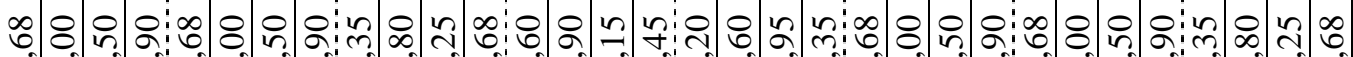

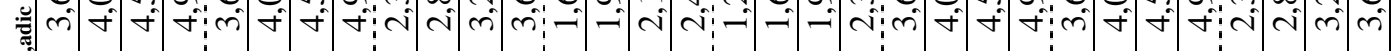

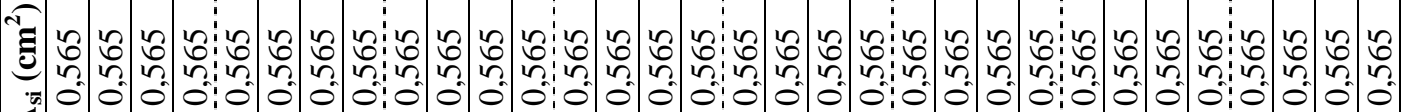

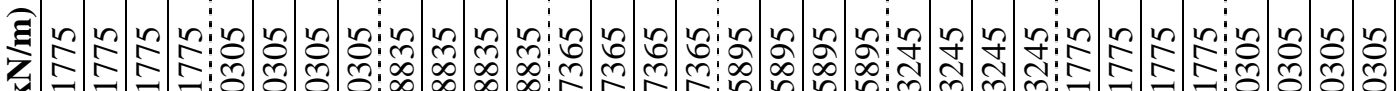

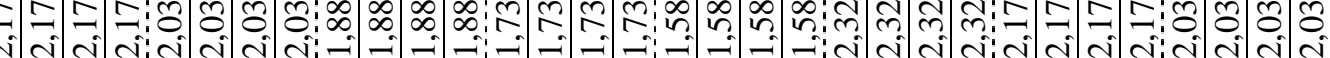

$\widehat{\mathbf{g}}$

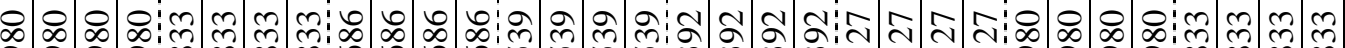

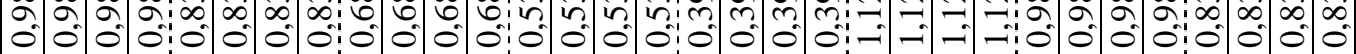
$\dot{\dot{v}}$

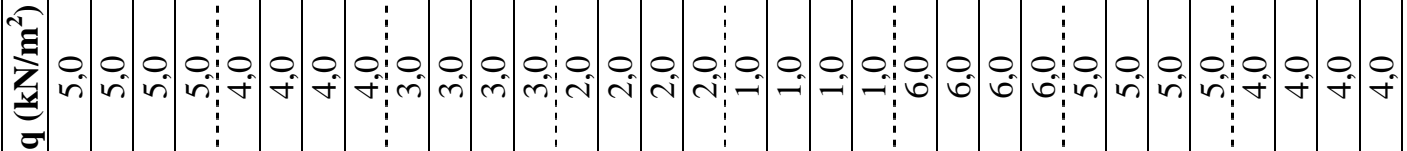

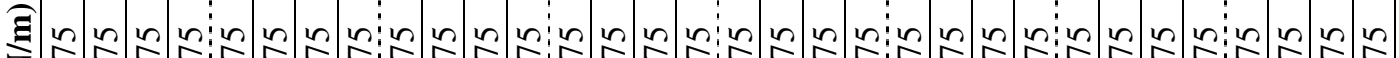

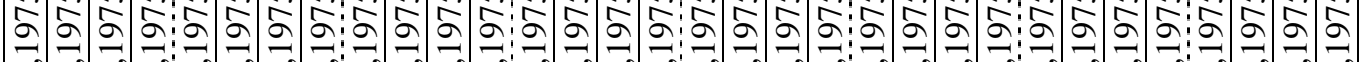
का

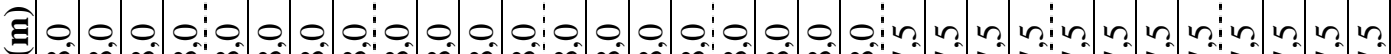

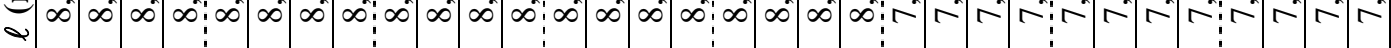

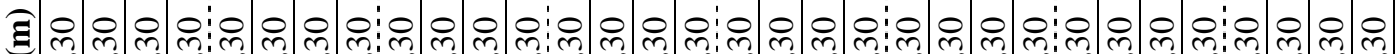

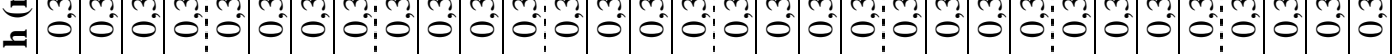

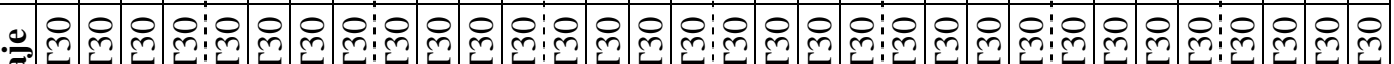

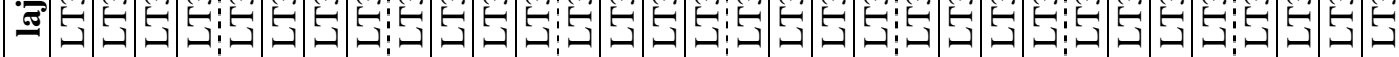




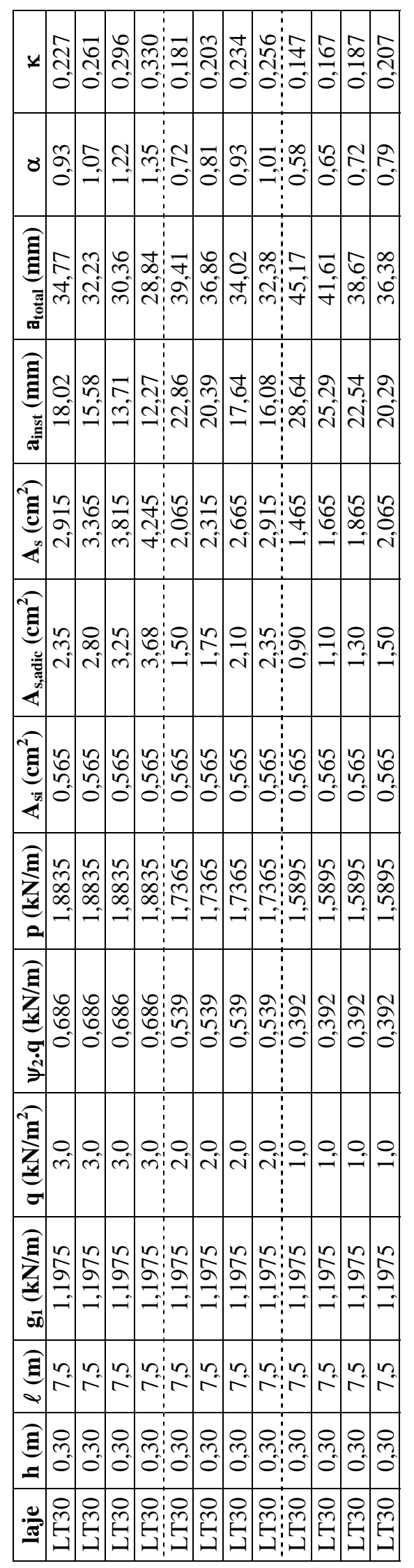




\section{APÊNDICE B - Resultados obtidos para a determinação do coeficiente $\alpha_{U, T}$}

No Apêndice B são apresentados os resultados obtidos da análise das lajes pré-moldadas formadas por vigotas com armação treliçada para a determinação do coeficiente $\alpha_{U, T}$ que considera a influência da umidade relativa e temperatura ambiente no coeficiente multiplicador $\alpha$.

Com os resultados da análise das lajes foi determinado o coeficiente multiplicador $\alpha$ para cada caso através da seguinte expressão:

$$
\alpha=\frac{\mathrm{a}_{\text {total }}-\mathrm{a}_{\text {inst }}}{\mathrm{a}_{\text {inst }}}
$$

onde:

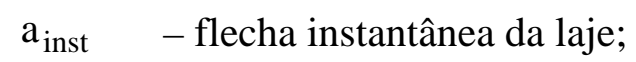

$\mathrm{a}_{\text {total }} \quad$ - flecha total da laje (instantânea e diferida).

Já o coeficiente $\alpha_{U, T}$ foi determinado dividindo o coeficiente multiplicador $\alpha$ obtido em cada caso pelo resultado obtido para o caso com as mesmas características, mas com umidade relativa de 60\% e temperatura ambiente de $25^{\circ} \mathrm{C}$.

A seguir são apresentados os resultados do coeficiente multiplicador $\alpha$ e do coeficiente $\alpha_{U, T}$ obtidos em cada caso. 


\begin{tabular}{|c|c|c|c|c|c|c|c|c|c|c|c|c|c|c|c|c|c|c|c|c|c|c|c|c|c|c|}
\hline 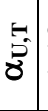 & $\Leftrightarrow$ & $\begin{array}{llll} & 0 \\
& 0 \\
\end{array}$ & & : & & 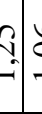 & & \begin{tabular}{l}
0 \\
\hdashline$:=$ \\
\hdashline
\end{tabular} & $\begin{array}{l}\text { के } \\
\sigma \\
0\end{array}$ & & & & & ثิ) & & & $\begin{array}{l}\text { gి } \\
2 \\
0\end{array}$ & : & $=8$ & $\begin{array}{l}N \\
N \\
0\end{array}$ & \begin{tabular}{ll}
0 & \multicolumn{2}{c}{} \\
- & $=$
\end{tabular} & : & बे & & & \\
\hline ૪ & \begin{tabular}{lll}
1 & 0 \\
\hdashline & 0 \\
$c$ & 0
\end{tabular} & \begin{tabular}{lll}
0 & 0 \\
0 & 0 \\
\hdashline & 0 \\
0
\end{tabular} & 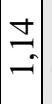 & 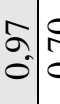 & 8 & $\checkmark \mid$ & & $\begin{array}{l}\hat{y} \\
0 \\
0\end{array}$ & $\mid$ & . & : & $\begin{array}{ll}\infty \\
\infty \\
0 \\
0\end{array}$ & t) & $=0$ & & $\hat{m}$ & $\stackrel{2}{=}$ & . & $f \underset{\sim}{f}$ & $\begin{array}{l}\infty \\
\infty \\
\infty \\
0 \\
0 \\
0\end{array}$ & $\stackrel{F}{\because} \underset{\sim}{\sim}$ & $\begin{array}{l:c}\sigma & 0 \\
0 & 0\end{array}$ & $\mid$ & $\approx$ & & 0 \\
\hline 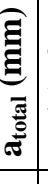 & 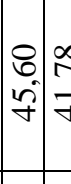 & & & 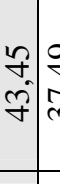 & & & & 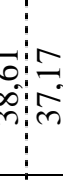 & $\left|\begin{array}{c}m \\
m \\
\hat{m}\end{array}\right|$ & & & & & 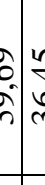 & & N & $\begin{array}{l}0 \\
-1 \\
0 \\
-1\end{array}$ & & & 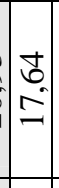 & 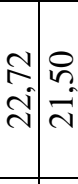 & 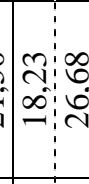 & & & & \\
\hline & 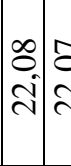 & & $\mid$ & 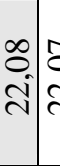 & & & & $\begin{array}{l}\infty \\
\infty \\
\infty \\
\infty\end{array}$ & $\left|\begin{array}{l}\infty \\
\infty \\
\infty \\
-1\end{array}\right|$ & & ". & 象 & 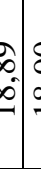 & $=0$ & & $\begin{array}{l}\infty \\
m \\
\sigma^{2}\end{array}$ & $\begin{array}{l}\hat{m} \\
\sigma^{2}\end{array}$ & & & $\mid \begin{array}{l}\infty \\
\infty \\
m \\
\sigma \\
\sigma^{2}\end{array}$ & \begin{tabular}{c|c}
$\infty$ & $\infty$ \\
$m$ & $m$ \\
$\sigma^{2}$ & $\sigma^{2}$
\end{tabular} & $\left\{\begin{array}{l:l}\infty & 0 \\
m & n \\
\sigma^{2} & n\end{array}\right.$ & & 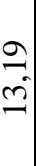 & & \\
\hline & P & ৪) & q & 88 & & $\vec{f} \mid \delta$ & & $\infty: 8$ & 8 & $\infty$ & $\vec{f}$ & $b \mid$ & $p$ & 8 & & :워 & 8 & $\infty$ & 88 & $\varnothing$ & ஒ & 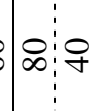 & 8 & $\infty$ & & 8 \\
\hline & 늠ㄴㄷㅁ & 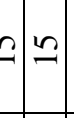 & $\stackrel{\llcorner}{\sim}$ & 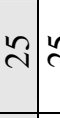 & & 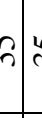 & & $\stackrel{\sim}{\sim}$ & $\stackrel{\sim}{\sim}$ & เص & f̂l & ? 2 & مै & مُ & & : & 递 & 는 & $\stackrel{2}{\sim} \stackrel{\llcorner}{N}$ & $\stackrel{\infty}{N}$ & $\stackrel{M}{M} \stackrel{m}{m}$ & م: & $\stackrel{2}{\sim}$ & & & 느 \\
\hline 至 & 5 & & 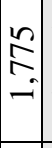 & 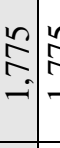 & & & & & 足 & 宸 & 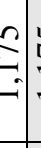 & & & $=$ & & & & & & $\mid \begin{array}{l}n \\
\stackrel{2}{1} \\
-7\end{array}$ & & 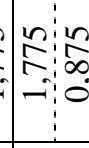 & & $\infty$ & & $\begin{array}{l}n \\
0 \\
0 \\
0 \\
0\end{array}$ \\
\hline 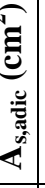 & เి & مُ & $\mid$ & 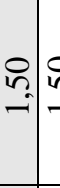 & & & & : & ' & o & S & & se & s.t. & & $\stackrel{\text { n̊ }}{\sim}$ & in & & เి & 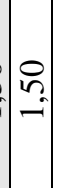 & 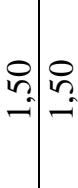 & \begin{tabular}{lll}
0 & 0 \\
\hdashline & 0
\end{tabular} & & & & $\begin{array}{l}0 \\
0 . \\
0^{-1}\end{array}$ \\
\hline 1 & 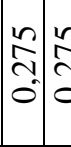 & & & & & 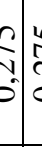 & $0^{\circ}$ & & & $\begin{array}{l}3 \\
\text { a } \\
0\end{array}$ & 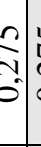 & & م & 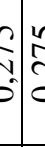 & & $0^{\circ}$ & הู & $0^{\circ}$ & & $\mid \begin{array}{l}n \\
\stackrel{n}{2} \\
0\end{array}$ & & 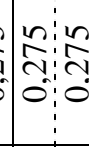 & 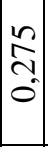 & & & $\begin{array}{l}\text { na } \\
\text { Na } \\
0\end{array}$ \\
\hline $\begin{array}{l}\mathbf{y} \\
2 \\
0\end{array}$ & 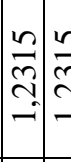 & s. & $\left|\begin{array}{l}n \\
\vec{N} \\
\\
-1\end{array}\right|$ & 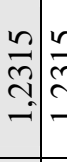 & & 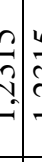 & & & 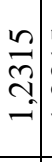 & $\underset{-1}{-1}$ & . & . & $\begin{array}{cc}3 \\
2 \\
2\end{array}$ & 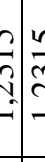 & & 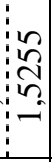 & 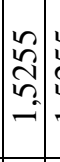 & $\begin{array}{l}\mathrm{L} \\
\mathrm{L} \\
\mathrm{L} \\
- \\
-\end{array}$ & 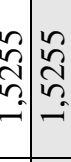 & 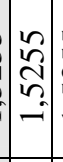 & 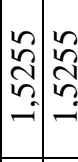 & 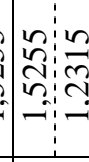 & $\mid$ & - & & 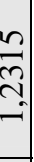 \\
\hline | & 总 & & $\begin{array}{l}0 \\
\tilde{\omega} \\
0 \\
0\end{array}$ & 宽 & & 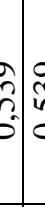 & & 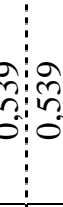 & $\left|\begin{array}{l}0 \\
\tilde{\omega} \\
0 \\
0\end{array}\right|$ & م్ & ?. & 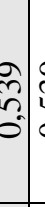 & 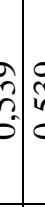 & 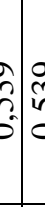 & & $\begin{array}{l}m \\
0 \\
0 \\
0\end{array}$ & $\begin{array}{l}m \\
m \\
\infty \\
0\end{array}$ & $\begin{array}{c}\mathbb{N} \\
\infty \\
0 \\
0\end{array}$ & & $\begin{array}{l}\infty \\
\infty \\
0 \\
0 \\
0\end{array}$ & $\begin{array}{ll}m & m \\
\infty & 0 \\
0 & 0 \\
0 & 0\end{array}$ & 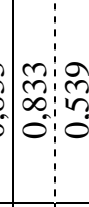 & & & & $\begin{array}{l}9 \\
\text { से } \\
\text { مी } \\
0\end{array}$ \\
\hline 童 & s & & 0 & & & & & 0 & $\stackrel{\circ}{\circ}$ & & & & & & & $\begin{array}{l}0 \\
+\end{array}$ & $\stackrel{0}{*}$ & & & $\stackrel{\circ}{f}$ & \begin{tabular}{c|c}
0 & 0 \\
$\dot{f}$ & $f$
\end{tabular} & $=\left[\begin{array}{l:l}0 & 0 \\
\hdashline & 0\end{array}\right.$ & c & & & i. \\
\hline $\begin{array}{l}\vec{y} \\
\overrightarrow{0}\end{array}$ & 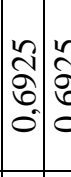 & 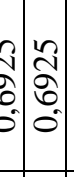 & $\mid$ & 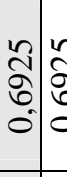 & bे & $\begin{array}{l}\text { S. } \\
\text { bे } \\
\text { - }\end{array}$ & है & 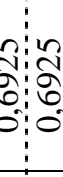 & 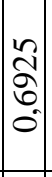 & $\begin{array}{l}\text { בे } \\
6 \\
0 \\
0\end{array}$ & 家 & $\begin{array}{l}\text { W } \\
\text { bे } \\
0^{\circ}\end{array}$ & D & 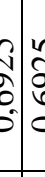 & & $\begin{array}{l}0 \\
0 \\
0 \\
0\end{array}$ & $\begin{array}{l}\text { L్ } \\
\text { Dे } \\
0 \\
0\end{array}$ & 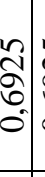 & 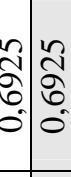 & 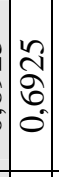 & 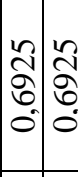 & 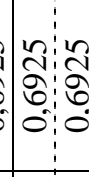 & $\begin{array}{l}\text { 岗 } \\
\hat{D} \\
0 \\
0\end{array}$ & & & 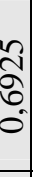 \\
\hline 2 & $\stackrel{\llcorner}{\sim}$ & 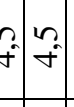 & $\stackrel{4}{\rightarrow}$ & $\stackrel{L}{\rightarrow}$ & & & & \begin{tabular}{l:l}
0 \\
\hdashline \\
\hdashline
\end{tabular} & $\stackrel{0}{\circ}$ & & & & & & & $\stackrel{n}{m}$ & $\stackrel{L}{m}$ & $\stackrel{\sim}{\infty}$ & 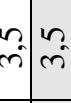 & $\stackrel{n}{m}$ & $\stackrel{L}{\sim}$ & 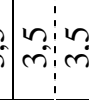 & เم & & & $m$ \\
\hline$=1$ & $\stackrel{7}{0}$ & $\begin{array}{llll}\because & 7 \\
0 & \ddots\end{array}$ & & $\begin{array}{ll}\approx & \\
0 & \end{array}$ & & $\begin{array}{l}7 \\
5\end{array}$ & 5 & \begin{tabular}{c}
7 \\
\hdashline \\
0
\end{tabular} & 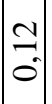 & & 7 & $\begin{array}{c}7 \\
0\end{array}$ & $\begin{array}{l}y \\
0\end{array}$ & $=\AA$ & & $\begin{array}{l}7 \\
0\end{array}$ & $\because$ & $\frac{7}{7}$ & $\begin{array}{l}\approx \\
0 \\
0\end{array}$ & $\because$ & $\because \frac{7}{7}$ & \begin{tabular}{lll}
\hdashline & 7 \\
\hdashline & 0
\end{tabular} & ב & & & $\begin{array}{l}\approx \\
0\end{array}$ \\
\hline 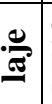 & $\stackrel{\Xi}{\exists} \underset{\exists}{\exists}$ & & & 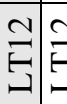 & & 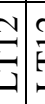 & & $\underset{Z}{Z}$ & $\begin{array}{c} \\
\\
\exists \\
\end{array}$ & & 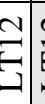 & & 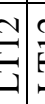 & & & & 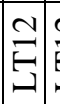 & & $\underset{\exists}{\exists} \underset{\exists}{\stackrel{\exists}{\exists}}$ & 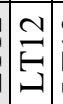 & $\stackrel{\Xi}{\exists} \underset{G}{ت}$ & 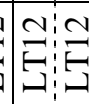 & $\vec{\Xi}$ & & ב⿱彐士心 & \\
\hline
\end{tabular}




\begin{tabular}{|c|c|c|c|c|c|c|c|c|c|c|c|c|c|c|c|c|c|c|c|c|c|c|c|c|c|c|c|}
\hline$\xi$ & $\begin{array}{l}1 \\
\hat{0} \\
0\end{array}$ & $\vec{\sim}$ & D. & $\begin{array}{lll}0 \\
0 \\
0\end{array}$ & & 4 & $=$ & $\stackrel{8}{-1}$ & $\sigma_{0}$ & $\begin{array}{l}\mathbb{N} \\
-\end{array}$ & !no & $\begin{array}{l}0 \\
2 \\
0 \\
0\end{array}$ & Oू & $\begin{array}{l}\mathscr{b} \\
0 \\
0\end{array}$ & $\stackrel{\infty}{=}$ & 용 & $\begin{array}{l}\Omega \\
\\
0 \\
0\end{array}$ & 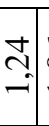 & & $\begin{array}{c}0 \\
0 \\
0 \\
0\end{array}$ & & & & $\rightarrow-$ & & & 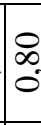 \\
\hline & $\begin{array}{l}R \\
0 \\
0\end{array}$ & $\Rightarrow$ & ". & \begin{aligned} 0 \\
\hdashline \\
\hdashline\end{aligned} & 文 & $\mid \begin{array}{c}\infty \\
\infty \\
0\end{array}$ & - & $\stackrel{m}{-1}$ & o. & $\begin{array}{l}0 \\
-1 \\
-1\end{array}$ & \begin{tabular}{l}
\multirow{J}{*}{} \\
- \\
$-i$
\end{tabular} & \begin{tabular}{l}
$\Delta$ \\
\hdashline
\end{tabular} & $\Rightarrow$ & \begin{tabular}{l}
$\infty$ \\
\multirow{2}{0}{} \\
0
\end{tabular} & & $\begin{array}{l}\stackrel{2}{2} \\
-\rightarrow\end{array}$ & | & 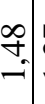 & & 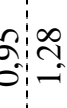 & $\mid \begin{array}{l}\infty \\
0 \\
-1\end{array}$ & $\begin{array}{l}2 \\
x^{2} \\
0\end{array}$ & & $=\infty$ & & & \\
\hline 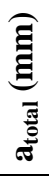 & 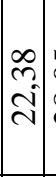 & 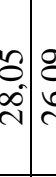 & & 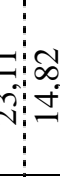 & & & & $\begin{array}{l}\text { పे } \\
\text { ले }\end{array}$ & & & $\begin{array}{l}\stackrel{2}{2} \\
\pm \\
-\end{array}$ & 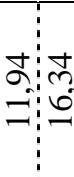 & $\vec{\sigma}$ & 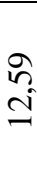 & & 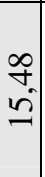 & $\begin{array}{l}0 \\
\vec{m} \\
\vec{n}\end{array}$ & 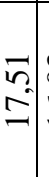 & $\begin{array}{l}0 \\
0 \\
0 \\
0\end{array}$ & 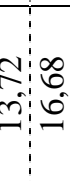 & & & & 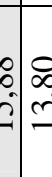 & & & \\
\hline & $\stackrel{-1}{\rightarrow}$ & r & & 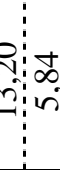 & & $\mid \begin{array}{l}0 \\
\infty \\
10 \\
10\end{array}$ & & $\begin{array}{l}\text { के } \\
\text { மी }\end{array}$ & & & | & 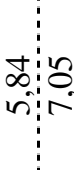 & 뇽 & 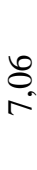 & $\begin{array}{l}\mathscr{8} \\
\wedge\end{array}$ & \begin{tabular}{l}
2 \\
\hdashline \\
0
\end{tabular} & 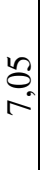 & $\begin{array}{l}8 \\
\therefore \\
\wedge\end{array}$ & $\stackrel{8}{2}$ & 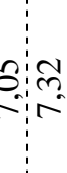 & & $\begin{array}{c}\text { mat } \\
\end{array}$ & & $\stackrel{m}{n}$ & & & \\
\hline & 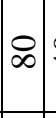 & f) & & D: & 8 & $\infty$ & o & 8 & $\infty$ & \& & 8 & $\infty: 8$ & 8 & 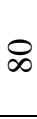 & ㅇ & 8 & $\triangleright$ & f & 8 & D: & $8 \delta$ & $\infty$ & q & $b \propto$ & $b$ & & 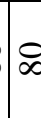 \\
\hline & $\mathcal{N}$ & மூ & & מิ:L & $\stackrel{10}{\sim}$ & $\stackrel{20}{-1}$ & 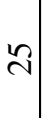 & $\stackrel{2}{\sim}$ & $\stackrel{\sim}{\sim}$ & 邑 & ले & مِ: & $\stackrel{2}{\sim}$ & $\stackrel{2}{\sim}$ & & $\stackrel{ㄴ}{\mathrm{~N}}$ & $\stackrel{\llcorner}{N}$ & $\stackrel{m}{m}$ & ח & min: & 늠는 & 는ㄷㄴ & & แூ & & $\dot{p}$ & 5 \\
\hline$=$ & 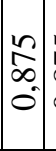 & & & $\begin{array}{l}0 \\
0 \\
0 \\
0\end{array}$ & & 迟 & 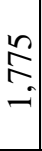 & 今- & 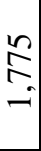 & 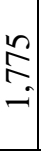 & 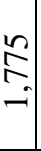 & & 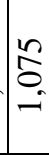 & $\begin{array}{l}\hat{N} \\
\stackrel{0}{\circ} \\
-i\end{array}$ & 赑 & 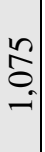 & 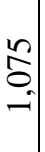 & & & & $\mid \begin{array}{l}n \\
\hat{n} \\
0 \\
0 \\
0\end{array}$ & 年 & & $\begin{array}{c}0 \\
0 \\
0 \\
0 \\
0\end{array}$ & & & \\
\hline 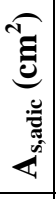 & $\begin{array}{l}0 \\
0 \\
0\end{array}$ & & & $\begin{array}{c}0 \\
b \\
0\end{array}$ & & & & เำ & & & & 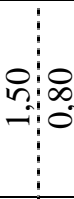 & $\begin{array}{l}\infty \\
\infty \\
\infty \\
\infty\end{array}$ & $\begin{array}{l}\infty \\
0 \\
0\end{array}$ & & $\begin{array}{l}\circ \\
\infty \\
0\end{array}$ & $\begin{array}{l}\circ \\
\infty \\
0\end{array}$ & $\begin{array}{c}8 \\
\infty \\
0\end{array}$ & & $\begin{array}{c}0 \\
0 \\
0\end{array}$ & & & & $\stackrel{f}{+}$ & & & \\
\hline$\sum$ & 0 & & & 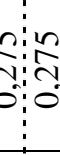 & $\begin{array}{l}\text { L } \\
\text { ה } \\
0 \\
0\end{array}$ & ה & $\begin{array}{l}\text { त̂. } \\
\text { - }\end{array}$ & ลู & הู & 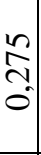 & $\begin{array}{l}n \\
\\
\\
0 \\
0\end{array}$ & 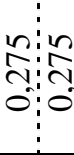 & $\left|\begin{array}{l}n \\
\hat{N} \\
0 \\
0\end{array}\right|$ & 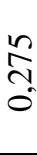 & $\begin{array}{l}\frac{1}{2} \\
\text { ה } \\
\text { o. }\end{array}$ & 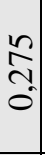 & $\begin{array}{l}n \\
\\
\\
0 \\
0\end{array}$ & 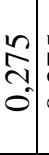 & है & \begin{tabular}{l}
0 \\
\hdashline \\
0
\end{tabular} & $\begin{array}{ll} & \\
\\
0 \\
0\end{array}$ & $\begin{array}{c}\hat{N} \\
0 \\
0\end{array}$ & & 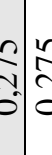 & & & \\
\hline 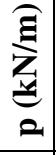 & 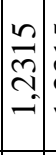 & & & 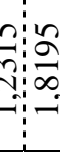 & $\begin{array}{l}\mathscr{2} \\
\stackrel{2}{\sigma} \\
\infty \\
-\end{array}$ & 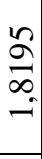 & 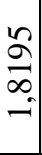 & | & \begin{tabular}{l}
2 \\
\multicolumn{2}{c}{} \\
$\infty$ \\
-1 \\
-1
\end{tabular} & \begin{tabular}{l}
2 \\
\multicolumn{2}{c}{} \\
$\infty$ \\
-1 \\
-1
\end{tabular} & $\begin{array}{l}\text { 2. } \\
- \\
0 \\
-1 \\
-1\end{array}$ & 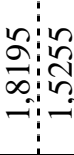 & 岇 & 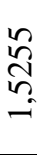 & 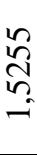 & 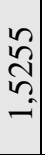 & 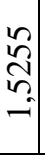 & 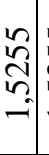 & 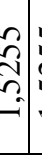 & & $\mid$\begin{tabular}{l}
$n$ \\
$\vec{N}$ \\
\\
$-\rightarrow$ \\
\hdashline
\end{tabular} & ר్ & & 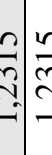 & & & \\
\hline 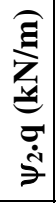 & ב̂ & & & 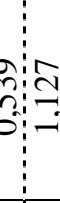 & & $\begin{array}{l}\hat{\Xi} \\
\stackrel{-}{-}\end{array}$ & & & & & & 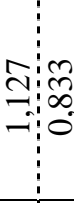 & $\begin{array}{l}m \\
\infty \\
\infty \\
0 \\
0\end{array}$ & 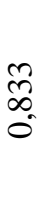 & & $\begin{array}{l}m \\
m \\
\infty \\
0 \\
0\end{array}$ & $\begin{array}{c}M \\
0 \\
0 \\
0 \\
0\end{array}$ & $\begin{array}{c}m \\
\infty \\
\infty \\
0 \\
0\end{array}$ & $\begin{array}{c}m \\
0 \\
0 \\
0 \\
0\end{array}$ & 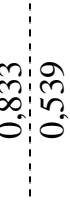 & $\mid \begin{array}{l}0 \\
0 \\
0 \\
0 \\
0\end{array}$ & & & & & & 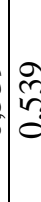 \\
\hline$\underbrace{z}_{\sigma}$ & $v$ & & & ': & 0 & 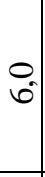 & 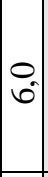 & 0 & $\sigma^{\circ}$ & $6^{\circ}$ & $\begin{array}{l}0 \\
6 \\
0\end{array}$ & $\begin{array}{ll}0 \\
0 \\
0\end{array}$ & $\stackrel{\circ}{\circ}$ & $\stackrel{\circ}{+}$ & & $\stackrel{0}{\circ}$ & 으. & 0 & & e & 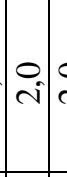 & 어 & & & & & \\
\hline 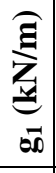 & $\begin{array}{c}2 \\
0 \\
0 \\
0 \\
\end{array}$ & $\begin{array}{c}0 \\
b \\
0 \\
0\end{array}$ & 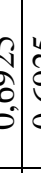 & 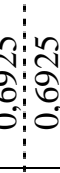 & D. & Oे & $\begin{array}{l}n \\
0 \\
0 \\
0 \\
0\end{array}$ & $\begin{array}{l}\text { 周 } \\
\hat{\delta} \\
0 \\
0\end{array}$ & $\begin{array}{l}\text { న్ } \\
\text { వ్ } \\
0 \\
0\end{array}$ & 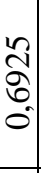 & 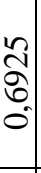 & 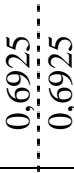 & $\begin{array}{l}2 \\
0 \\
0 \\
0\end{array}$ & லิ & 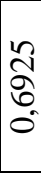 & 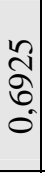 & 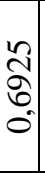 & 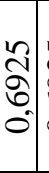 & 8 & $\begin{array}{c:c}1 \\
0 \\
0\end{array}$ & 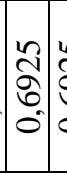 & 政 & ?. & ôd & & & 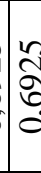 \\
\hline$\underset{\mathbf{\Xi}}{\widehat{\Xi}}$ & & & & ":o & & $\left|\begin{array}{c}0 \\
\dot{m}\end{array}\right|$ & $\begin{array}{c}0 \\
\dot{m}\end{array} \mid$ & $\stackrel{0}{\dot{m}}$ & & $\begin{array}{l}\text { Oे } \\
\text { m. }\end{array}$ & & $\begin{array}{c:c}0 \\
m \\
m\end{array}$ & $\stackrel{0}{0}$ & $\stackrel{\circ}{m}$ & & ले & $\begin{array}{l}0 \\
\dot{m}\end{array}$ & $\stackrel{0}{m}$ & & $\begin{array}{c:c}0 \\
0 \\
m\end{array}$ & & & & & & & \\
\hline $\begin{array}{l}\boldsymbol{\Xi} \\
\mathbf{z}\end{array}$ & $\stackrel{7}{0}$ & 0 & 5 & \begin{tabular}{c:c}
7 \\
\hdashline
\end{tabular} & $\cong$ & $\approx$ & च & శ్ & 0 & 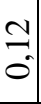 & ㄱ. & $\begin{array}{c:c}7 \\
7 \\
0\end{array}$ & $\approx$ & नै & $\approx$ & בै & $\begin{array}{l}\approx \\
0 \\
0\end{array}$ & 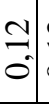 & $0^{\circ}$ & $\begin{array}{c:c}7 & 7 \\
0 & 0\end{array}$ & $\because$ & 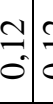 & & 7 & & & \\
\hline 孛 & & & & 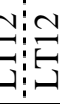 & & & & & & & & & & & & -1 & & & & & & & & & & & \\
\hline
\end{tabular}




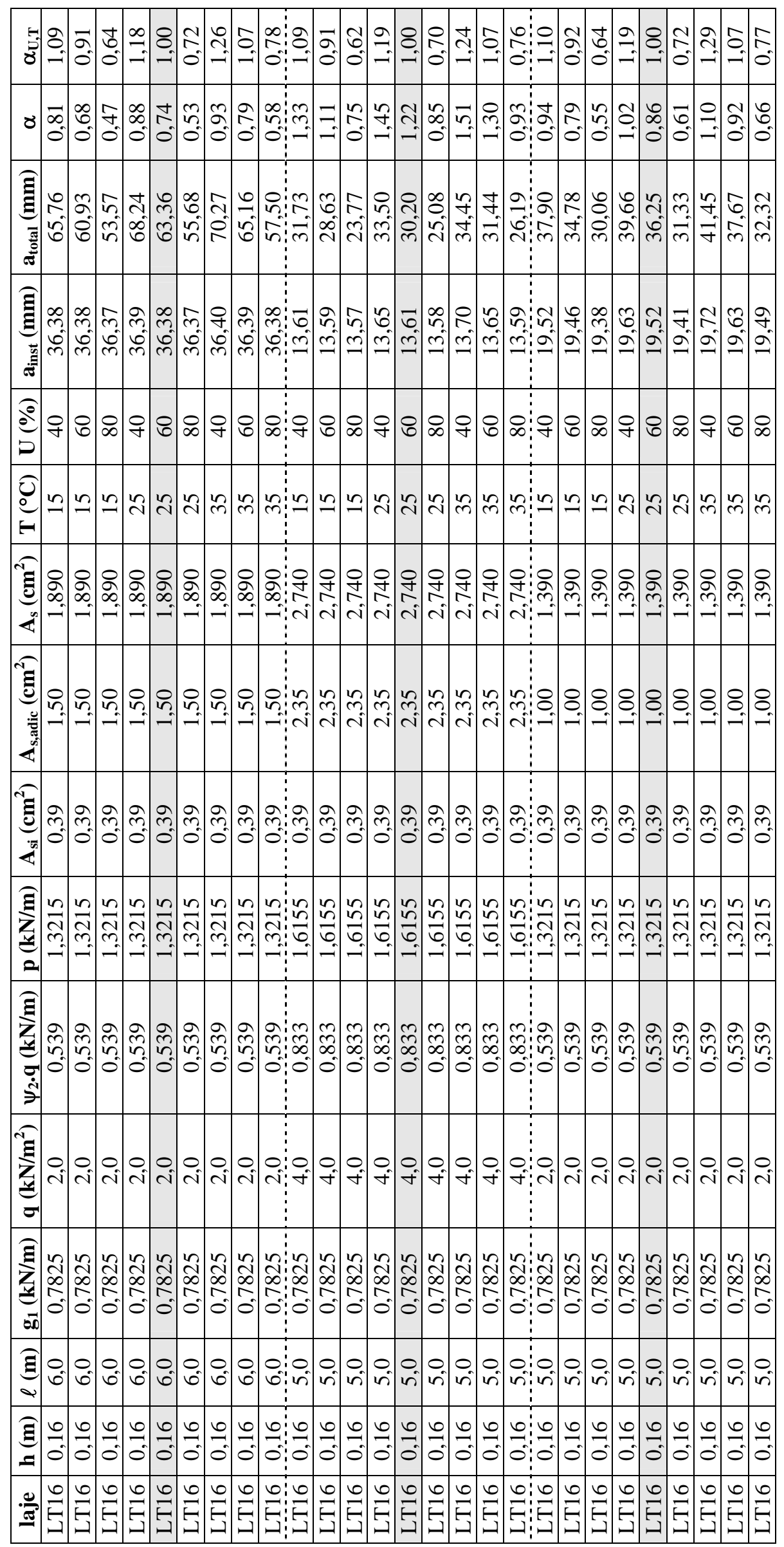




\begin{tabular}{|c|c|c|c|c|c|c|c|c|c|c|c|c|c|c|c|c|c|c|c|c|c|c|}
\hline 8 & S. & $\left|\begin{array}{l}0 \\
0 \\
0\end{array}\right|$ & & & & & & & & $c$ & & & & & & {$\left[\begin{array}{c}\infty \\
0 \\
-1 \\
-\infty\end{array}\right.$} & $\begin{array}{l}\sigma \\
\sigma \\
0\end{array}$ & $\begin{array}{ll}0 \\
0 \\
0\end{array}$ & & & & \\
\hline & $\therefore$ & 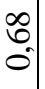 & $\stackrel{m}{\rightarrow}$ & $\begin{array}{l}\approx \\
\Rightarrow\end{array}$ & & $\stackrel{m}{\rightarrow}$ & $=$ & & $-i c$ & $c$ & & & & & & & $\left|\begin{array}{c}\overrightarrow{1} \\
\hat{0} \\
0\end{array}\right|$ & & & & & 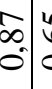 \\
\hline 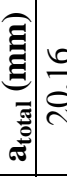 & & {$\left[\begin{array}{l}2 \\
\omega \\
\omega\end{array}\right.$} & & & & & & & & 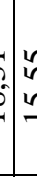 & & & & & & & & & & & $\mid \begin{array}{c}0 \\
2 \\
\stackrel{2}{d}\end{array}$ & \\
\hline 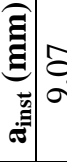 & & $\mid \begin{array}{l}0 \\
0 \\
\sigma^{2}\end{array}$ & & & $\begin{array}{l}\mathbf{J} \\
\sigma^{2}\end{array}$ & & & & & $\begin{array}{l}n \\
f \\
n\end{array}$ & 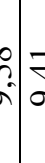 & & & & & 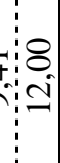 & {$\left[\begin{array}{l}0 \\
\hat{i} \\
-1\end{array}\right]$} & & & 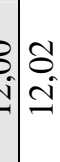 & $\left|\begin{array}{l}\infty \\
\stackrel{\infty}{a} \\
=\end{array}\right|$ & \\
\hline & ర్ & $\infty$ & f & 8 & $\infty$ & f & 8 & & 9 & $b$ & $8 \mid \subsetneq$ & & 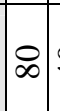 & q & $8 \propto$ & bi:아 & (8) & $\infty$ & & 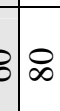 & P & 이 \\
\hline & & $\stackrel{0}{-1}$ & เั & $\stackrel{2}{\sim}$ & $\stackrel{\sim}{\sim}$ & & లి & $m$ & & $\stackrel{4}{7}$ & $\theta$ & & $\stackrel{\llcorner}{N}$ & เి & & حـ: & 늠 & مِ & & $\checkmark \stackrel{\sim}{N}$ & 놈 & $\stackrel{\mathrm{m}}{\mathrm{m}}$ \\
\hline 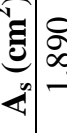 & $\begin{array}{c}8 \\
\\
-\infty\end{array}$ & $\mid \begin{array}{l}\mathscr{8} \\
\infty \\
-i\end{array}$ & $\begin{array}{l}8 \\
\infty \\
- \\
-1\end{array}$ & $\begin{array}{c}\text { هి } \\
\infty \\
- \\
-1\end{array}$ & $\begin{array}{c}8 \\
\infty \\
-1 \\
-1\end{array}$ & $\begin{array}{c}8 \\
\infty \\
- \\
-1\end{array}$ & $\begin{array}{l}0 \\
0 \\
\infty \\
-1 \\
-1\end{array}$ & 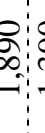 & 鸽 & ฮิ & $=\mid \begin{array}{llll}0 \\
\end{array}$ & & & $\begin{array}{l}\text { बे } \\
\text { m }\end{array}$ & & & $\left|\begin{array}{l}\diamond \\
\widehat{a} \\
0\end{array}\right|$ & & & م: & $\begin{array}{l}8 \\
\stackrel{2}{\widehat{N}} \\
0\end{array}$ & $\begin{array}{l}8 \\
\text { } \\
0^{\prime} \\
\end{array}$ \\
\hline 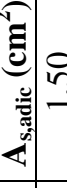 & & 옥 & ئ & & & & & & & & ș & & 8 & ৪) & & 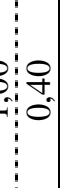 & 吕 & $\begin{array}{l}q \\
+ \\
0\end{array}$ & & 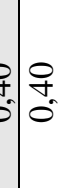 & fo & \\
\hline$\underbrace{\Xi}_{\overline{4}}$ & & $\begin{array}{c}\text { mे } \\
\text { m. }\end{array}$ & $\begin{array}{c}\text { m. } \\
\text { ald }\end{array}$ & $\begin{array}{c}9 \\
\text { m. } \\
\text { che }\end{array}$ & $\begin{array}{l}\stackrel{8}{m} \\
0 \\
0\end{array}$ & 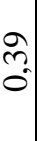 & के & $\begin{array}{l}m_{0} \\
\mathrm{~m}^{2}\end{array}$ & $\begin{array}{c}\text { ma } \\
\text { a }\end{array}$ & di & $c^{n}$ & & 足 & $\begin{array}{c}9 \\
\text { m. } \\
\text { | }\end{array}$ & & $\begin{array}{l}n \\
0 \\
0 \\
0\end{array}$ & $\mid$ & & & ch & $\mid \begin{array}{c}2 \\
\tilde{m} \\
0\end{array}$ & \\
\hline \begin{tabular}{l}
$z$ \\
$z$ \\
$z$ \\
\hdashline
\end{tabular} & 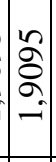 & 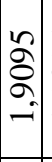 & 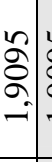 & 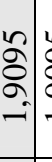 & 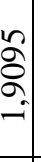 & 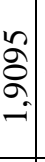 & 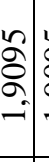 & 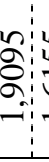 & 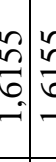 & $=$ & $=0$ & & $\mid \begin{array}{l}2 \\
0 \\
6 \\
-7\end{array}$ & 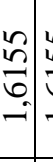 & & 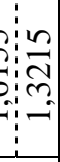 & 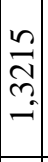 & 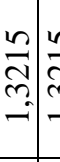 & 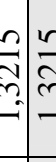 & 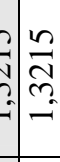 & $\begin{array}{l}0 \\
\sim \\
\sim \\
\sim\end{array} \mid$ & 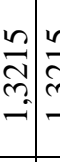 \\
\hline 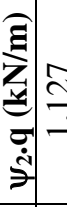 & & 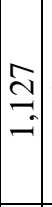 & $\begin{array}{l}\hat{\Xi} \\
\approx \\
\approx\end{array}$ & & $\begin{array}{l}\widehat{y} \\
\stackrel{-}{-}\end{array}$ & & & & 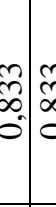 & & $\hat{a}$ & & $\mid \begin{array}{c}0 \\
\infty \\
\infty \\
0\end{array}$ & $\begin{array}{l}m \\
0 \\
0 \\
0 \\
0\end{array}$ & & 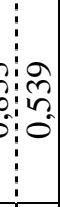 & \begin{tabular}{|}
9 \\
$\hat{W}$ \\
0 \\
0 \\
0
\end{tabular} & & & & $\begin{array}{l}0 \\
\tilde{\omega} \\
\text { L్ } \\
0\end{array}$ & \\
\hline \begin{tabular}{l}
0 \\
\hdashline \\
\hdashline
\end{tabular} & & 6" & $\begin{array}{l}0 \\
\sigma^{\prime}\end{array}$ & & $\begin{array}{l}0 \\
0^{-1}\end{array}$ & $\begin{array}{l}\circ \\
0 \\
0\end{array}$ & $\begin{array}{l}0 \\
0^{\circ}\end{array}$ & & & & & & $\begin{array}{l}0 \\
\stackrel{f}{+} .\end{array}$ & & & $\begin{array}{c}0 \\
f:\end{array}$ & 0 & & & & & $\begin{array}{l}0 \\
\text { i|l }\end{array}$ \\
\hline 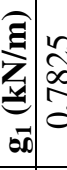 & 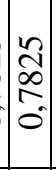 & 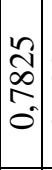 & 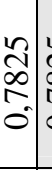 & $\begin{array}{c}2 \\
0 \\
0 \\
0 \\
0 \\
0\end{array}$ & $\begin{array}{l}0 \\
0 \\
0 \\
0 \\
0\end{array}$ & $\begin{array}{l}0 \\
0 \\
0 \\
0\end{array}$ & $\begin{array}{c}2 \\
0 \\
0 \\
0 \\
0 \\
0\end{array}$ & $\begin{array}{l}\text { D. } \\
\text { d. } \\
\text {. } \\
\end{array}$ & 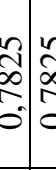 & ڤૂ & 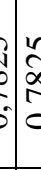 & & $\begin{array}{l}2 \\
2 \\
0 \\
2 \\
0 \\
0\end{array}$ & $\begin{array}{l}\text { L్ } \\
\text { o } \\
\text { o } \\
0\end{array}$ & & $\begin{array}{c}1: 2 \\
0 \\
0 \\
0 \\
0 \\
0 \\
0\end{array}$ & {$\left[\begin{array}{l}2 \\
0 \\
0 \\
0 \\
0 \\
0\end{array}\right]$} & 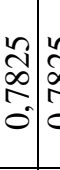 & 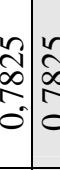 & 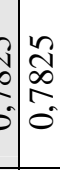 & $\begin{array}{c}2 \\
0 \\
\infty \\
2 \\
0\end{array}$ & 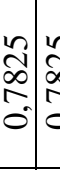 \\
\hline$\stackrel{\circ}{7}$ & & & 0.1 & & 0 & & 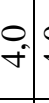 & & & & & & $\begin{array}{l}0 \\
\nabla\end{array}$ & $\nabla$ & & \begin{tabular}{l}
0 \\
\hdashline \\
\hdashline
\end{tabular} & & $\stackrel{\circ}{\rightarrow}$ & & $\begin{array}{l}f_{f} \\
\end{array}$ & $\stackrel{0}{\nabla}$ & \\
\hline$\underset{\mathbf{E}}{\mathbf{E}} \stackrel{0}{0}$ & & & $\frac{0}{0}$ & & $\begin{array}{l}0 \\
-1 \\
0 \\
0\end{array}$ & & & 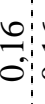 & $\frac{0}{0}$ & & & & 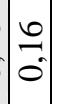 & $\begin{array}{l}0 \\
0 \\
0\end{array}$ & & \begin{tabular}{c:c}
0 \\
\hdashline \\
0 & 0
\end{tabular} & & $\begin{array}{ll}0 \\
0 \\
0\end{array}$ & 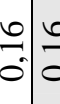 & $=0$ & $\stackrel{0}{0}$ & 00 \\
\hline 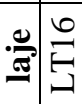 & 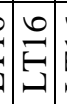 & & & & & & & & $\underline{F}$ & & & & 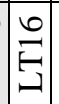 & $\begin{array}{l}0 \\
\\
\end{array}$ & 60 & $\begin{array}{c:c}0 \\
\end{array}$ & ㄱ. & $\begin{array}{c}0 \\
G\end{array}$ & 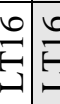 & 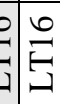 & 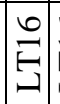 & 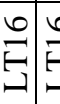 \\
\hline
\end{tabular}




\begin{tabular}{|c|c|c|c|c|c|c|c|c|c|c|c|c|c|c|c|c|c|c|c|c|c|c|c|c|}
\hline - & & $\begin{array}{l}8 \\
\text { a }\end{array}$ & & & 8 & & & & ? & ब, & $\mid \begin{array}{l}\mathbb{S} \\
0 \\
0\end{array}$ & $\stackrel{\Omega}{\Rightarrow}=$ & 8 & $\begin{array}{l}R \\
0 \\
0\end{array}$ & $\vec{m}$ & & $\begin{array}{l}\infty \\
0^{\infty}\end{array}$ & $\begin{array}{l}8 \\
0\end{array}$ & $\begin{array}{l}\mathscr{\theta} \\
0 \\
0\end{array}$ & $\stackrel{\Omega}{=}$ & $\stackrel{8}{8}$ & $\begin{array}{l}-1 \\
0^{\circ}\end{array}$ & & 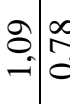 \\
\hline & $\begin{array}{l}8 \\
2 \\
0\end{array}$ & $\begin{array}{c}N \\
\infty \\
0 \\
0\end{array}$ & & & & 8 & & & $\begin{array}{lll}0 \\
-10\end{array}$ & क् & $\begin{array}{l}\vec{b} \\
0\end{array}$ & 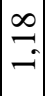 & ब & $\begin{array}{l}8 \\
0 \\
0\end{array}$ & $\begin{array}{l}\stackrel{2}{N} \\
-i\end{array}$ & & \begin{tabular}{c:c}
$\hat{N}$ & $\infty$ \\
\hdashline 0 & 0
\end{tabular} & $\begin{array}{l}0 \\
0 \\
0 \\
0\end{array}$ & $\left.\mid \begin{array}{l}0 \\
0 \\
0 \\
0\end{array}\right]$ & $\begin{array}{l}\infty \\
0 \\
0\end{array}$ & $\begin{array}{l}m \\
\hat{0} \\
0\end{array}$ & & & 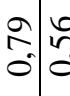 \\
\hline 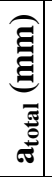 & & กิ & $\begin{array}{l}\overrightarrow{7} \\
\vec{v} \\
\end{array}$ & & & 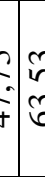 & 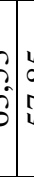 & & $\begin{array}{l}0: 8 \\
0 \\
f: \\
0\end{array}$ & 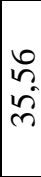 & & $\begin{array}{l}\text { 영 } \\
\vec{\gamma}\end{array}$ & & $\begin{array}{l}\tilde{\sigma} \\
\vec{m}\end{array}$ & 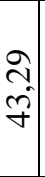 & & $\begin{array}{l}f_{1} \\
m^{n} \\
m\end{array}$ & $\mid \begin{array}{l}2 \\
0 \\
-7\end{array}$ & $\left|\begin{array}{l}8 \\
0 \\
0 \\
ల\end{array}\right|$ & $\left|\begin{array}{l}\hat{y} \\
0 \\
0 \\
0\end{array}\right|$ & 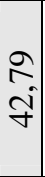 & $\begin{array}{l}0 \\
\text { m) }\end{array}$ & & \\
\hline 节 & & क & & ลे & & & 3 & & 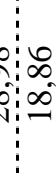 & $\mid \begin{array}{l}0 \\
\infty \\
\infty \\
\infty \\
\rightarrow \\
\rightarrow\end{array}$ & $\left|\begin{array}{l}\infty \\
\infty \\
0 \\
0 \\
-1\end{array}\right|$ & $\left.\mid \begin{array}{c}\infty \\
\infty \\
\infty \\
-1\end{array}\right]$ & $\left|\begin{array}{l}\infty \\
\infty \\
\infty \\
-1 \\
-1\end{array}\right|$ & $\begin{array}{l}0 \\
\infty \\
\infty \\
\infty \\
-1\end{array}$ & $\begin{array}{l}9 \\
\infty \\
\infty \\
0 \\
-1\end{array}$ & & \begin{tabular}{lll}
$\infty$ \\
$\infty$ \\
\hdashline
\end{tabular} & 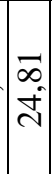 & 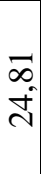 & 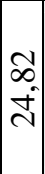 & $\begin{array}{l}\infty \\
\dot{\mathbb{N}} \\
\vec{N}\end{array}$ & 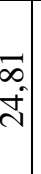 & & \\
\hline & & 8 & $\infty$ & of & 88 & 8 & S & & $b:$ & 8 & $\infty$ & 워 & 8 & $\infty$ & f & 8 & $\infty: 8$ & 8 & $\infty$ & f & 8 & ৯ & & $8 \propto$ \\
\hline & & : & صـ & & 몬 & v & & & صـا:م' & $\stackrel{\sim}{\sim}$ & $\stackrel{2}{\rightarrow}$ & $\stackrel{\llcorner}{N}$ & $\stackrel{\llcorner}{N}$ & $\stackrel{\sim}{\sim}$ & 늘 & m & ๓⿴囗十 & $\stackrel{2}{\sim}$ & $\stackrel{1 ㅇ}{\rightarrow}$ & $\stackrel{\llcorner}{\Upsilon}$ & 느 & 느 & & 냈냈 \\
\hline 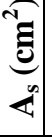 & & & & & & 7 & is & & 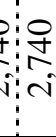 & 寽 & $\mid \begin{array}{c}q \\
\hat{A} \\
\hat{i}\end{array}$ & $\begin{array}{c}q \\
\stackrel{1}{A} \\
i\end{array}$ & 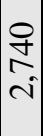 & 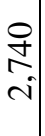 & 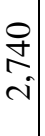 & $\begin{array}{l}\stackrel{9}{5} \\
\text { iv }\end{array}$ & \begin{tabular}{c:c}
$\mathcal{O}$ & 8 \\
\hdashline & $\delta$ \\
\hdashline & 0
\end{tabular} & 号 & 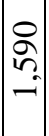 & $\begin{array}{l}\text { 足 } \\
\\
-1\end{array}$ & & | & & \\
\hline 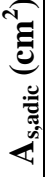 & & & & & & $\hat{n}$ & & & 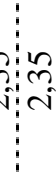 & $\left|\begin{array}{l}n \\
\\
\end{array}\right|$ & m. & & & & & 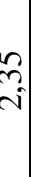 & 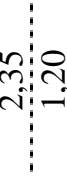 & & & & & సి & & \\
\hline$\sqrt{-\bar{n}}$ & & $\begin{array}{c}9 \\
m \\
0\end{array}$ & ल. & 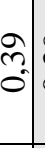 & & 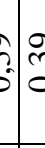 & & & $\begin{array}{c}n: 0 \\
0 \\
0\end{array}$ & ले & $\begin{array}{c}\bar{m} \\
\tilde{m} \\
0\end{array}$ & $\begin{array}{c}9 \\
m \\
0\end{array}$ & $\begin{array}{c}9 \\
m \\
0\end{array}$ & $\begin{array}{l}9 \\
\text { m. } \\
0\end{array}$ & $\begin{array}{c}9 \\
\text { m. } \\
0 \\
0\end{array}$ & $\begin{array}{c}2 \\
\text { c. } \\
0\end{array}$ & 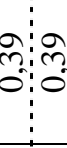 & $\begin{array}{c}2 \\
m \\
0\end{array}$ & ले & $\begin{array}{c}9 \\
m \\
0 \\
0\end{array}$ & $\begin{array}{c}9 \\
m \\
0 \\
0\end{array}$ & $\begin{array}{c}9 \\
\text { m. } \\
0 \\
0\end{array}$ & & 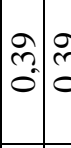 \\
\hline 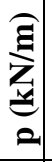 & $\begin{array}{l}\stackrel{0}{7} \\
\overrightarrow{7} \\
- \\
-\end{array}$ & 过: & . & 告 & 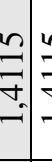 & & 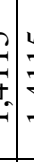 & & 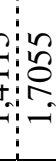 & 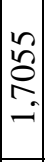 & 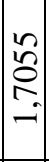 & $\begin{array}{l}1 \\
0 \\
0 \\
0 \\
\\
-7 \\
\end{array}$ & 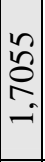 & $\begin{array}{l}\stackrel{2}{2} \\
\stackrel{0}{2} \\
-1 \\
-1\end{array}$ & 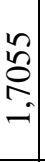 & है & \begin{tabular}{l}
10 \\
\hdashline \\
\hdashline
\end{tabular} & 送 & 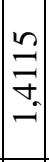 & 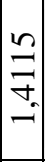 & 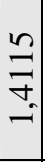 & 告 & & 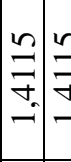 \\
\hline 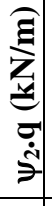 & & 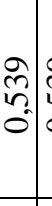 & $\begin{array}{l}\text { के } \\
\text { ch } \\
\text { o. }\end{array}$ & $\begin{array}{l}\text { D. } \\
\text { ch } \\
0 \\
0\end{array}$ & 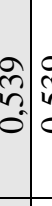 & & & & 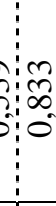 & $\begin{array}{l}\text { M } \\
\infty \\
0 \\
0\end{array}$ & $\mid \begin{array}{c}m \\
\infty \\
0 \\
0\end{array}$ & $\begin{array}{l}M \\
m \\
0 \\
0\end{array}$ & $\mid \begin{array}{c}m \\
m \\
\infty \\
\tilde{c}\end{array}$ & $\begin{array}{l}\mathscr{M} \\
\infty \\
0 \\
0\end{array}$ & $\begin{array}{c}M \\
0 \\
0 \\
0 \\
0\end{array}$ & & 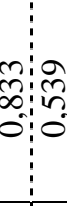 & 拨 & $\mid \begin{array}{l}9 \\
\tilde{m} \\
\hat{n} \\
0\end{array}$ & $\begin{array}{l}9 \\
\tilde{D} \\
\\
0\end{array}$ & & 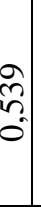 & & \\
\hline | & & & & & 0 & & & & $\begin{array}{ll}0 \\
\forall\end{array}$ & $\stackrel{\circ}{*}$ & $1=$ & $\begin{array}{l}0 \\
f\end{array}$ & 0 & $\stackrel{\circ}{\circ}$ & & $\forall$ & \begin{tabular}{l}
$0: 0$ \\
\multirow{7}{*}{$:$}
\end{tabular} & $\begin{array}{l}0 \\
\text { i }\end{array}$ & $\stackrel{0}{i}$ & $\stackrel{0}{i}$ & & & & \\
\hline 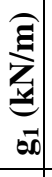 & $\begin{array}{l}\hat{N} \\
0 \\
0 \\
0\end{array}$ & $\begin{array}{c}\text { N } \\
\text { on } \\
0\end{array}$ & 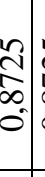 & 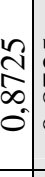 & 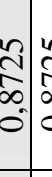 & $\begin{array}{l}\hat{N} \\
0 \\
0 \\
0 \\
0\end{array}$ & & & 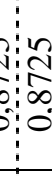 & $\mid \begin{array}{l}\mathbb{N} \\
\mathbb{N} \\
0 \\
0 \\
0\end{array}$ & $\mid$ & $\begin{array}{c}\infty \\
0 \\
0\end{array}$ & $\left|\begin{array}{c}\mathbb{N} \\
\infty \\
0 \\
0\end{array}\right|$ & $\begin{array}{l}1 \\
\infty \\
0 \\
0\end{array}$ & $\begin{array}{c}\hat{N} \\
\text { on } \\
0 \\
0\end{array}$ & $\begin{array}{l}\infty \\
\infty \\
0 \\
0\end{array}$ & 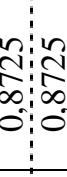 & $\mid \begin{array}{l}\stackrel{2}{\mathbb{N}} \\
\infty \\
0 \\
0 \\
0\end{array}$ & $\left|\begin{array}{c}\mathbb{N} \\
\mathbb{N} \\
0 \\
0 \\
0\end{array}\right|$ & $\mid \begin{array}{l}n \\
\hat{N} \\
0 \\
0 \\
0\end{array}$ & & . & & 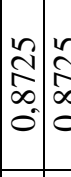 \\
\hline 氕 & & $\stackrel{\circ}{\wedge}$ & & & & & & & $\begin{array}{c}0 \\
0 \\
0\end{array}$ & 0 & $0^{\circ}$ & $\begin{array}{l}0 \\
0 \\
0\end{array}$ & $\begin{array}{l}0 \\
0\end{array}$ & $\begin{array}{l}0 \\
0\end{array}$ & $\begin{array}{l}0 \\
0\end{array}$ & 6 & \begin{tabular}{c:c}
0 \\
0 \\
\hdashline & 0
\end{tabular} & 0. & 0 & $\begin{array}{l}0 \\
0 \\
0\end{array}$ & & 0 & & $\begin{array}{cc}0 & 0 \\
0 & 0\end{array}$ \\
\hline$=$ & & & 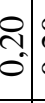 & & 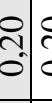 & & & & a & & & & & & 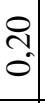 & & 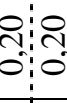 & & & & & & & 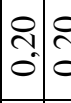 \\
\hline$\therefore$ & $£$ & 0 & $\stackrel{\overbrace{}}{\overparen{G}}$ & શ્⿹ & & & & & $\stackrel{\Xi}{ت}$ & શ્ & 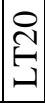 & : & : & 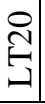 & 0 & & בֶ: & $\stackrel{2}{\stackrel{N}{ت}}$ & શ્ & 密 & 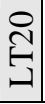 & & & શิ \\
\hline
\end{tabular}




\begin{tabular}{|c|c|c|c|c|c|c|c|c|c|c|c|c|c|c|c|c|c|c|c|c|c|c|}
\hline : & $=$ & $\left\{\begin{array}{l}0 \\
0 \\
0\end{array}\right.$ & సิ & 8 & & $\oint$ & & $\begin{array}{l}0 \\
0 \\
0\end{array}$ & & $\begin{array}{l}8 \\
0 \\
0\end{array}$ & & 8 & $\bar{ָ}$ & $\int_{-1}^{\infty}$ & $\begin{array}{l}0 \\
2 \\
0 \\
0\end{array}$ & $=$ & ర్ & $=$ & $\hat{\widehat{\lambda}}$ & $=$ & & \\
\hline & 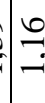 & 会 & 5 & הิ & . & (6. & & $\begin{array}{l}\infty \\
0 \\
0\end{array}$ & ब्. & $\begin{array}{l}0 \\
0 \\
0 \\
0 \\
0\end{array}$ & શి & & $=$ & 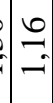 & $\begin{array}{lll}\infty & 0 \\
0 & 0 \\
0 & 0\end{array}$ & $\mid \begin{array}{l}2 \\
0 \\
0\end{array}$ & & S: & & 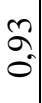 & & \\
\hline 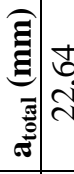 & $\hat{\overbrace{}}$ & & & & & & & 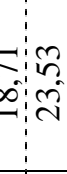 & & & & & & $\begin{array}{l}\text { f } \\
\tilde{\text { N }}\end{array}$ & $\begin{array}{l}R: \infty \\
\sigma^{2}: \infty\end{array}$ & $\begin{array}{l}m \\
0 \\
0 \\
0 \\
0\end{array}$ & & 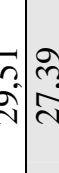 & స̃ & $\begin{array}{l}\Omega \\
0 \\
2\end{array}$ & & \\
\hline 氝 & & $\begin{array}{l}m \\
m \\
\sigma^{2}\end{array}$ & & & & & & 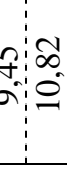 & $\begin{array}{l}\Omega \\
\hat{0} \\
-1\end{array}$ & 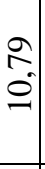 & $\begin{array}{l}\infty \\
\infty \\
0 \\
-1\end{array}$ & & : & $\mid \begin{array}{l}\infty \\
\infty \\
0 \\
0\end{array}$ & $\begin{array}{ll}-\infty \\
0 \\
0\end{array}$ & 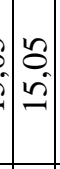 & & 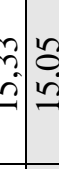 & $\mid \begin{array}{l}2 \\
0 \\
\text { 엄 }\end{array}$ & 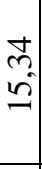 & 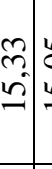 & \\
\hline ? & 8 & $\infty$ & P & & $\infty$ & of & & $\infty$ \&:아 & 8 & $\bowtie$ & 아 & 8 & b) & 8 & $\infty: ণ$ & 8 & $\infty$ & 8 & $\infty$ & P & 이 & 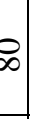 \\
\hline$\stackrel{ㄴ ㅡ}{-}$ & - & $\stackrel{2}{-1}$ & $\stackrel{2}{2}$ & & $\stackrel{2}{\sim}$ & ñ & & & $\stackrel{12}{-1}$ & $\stackrel{\Omega}{\sim}$ & $\stackrel{\sim}{\sim}$ & ᄂ & val & 虫 & 닌:는 & 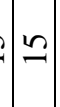 & $\stackrel{2}{\sim})^{2}$ & స̂ㄴํㅠ & $\stackrel{\llcorner}{N}$ & 另 & mat' & m \\
\hline 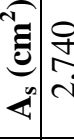 & & is & 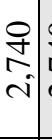 & & & & & 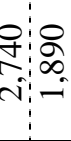 & & $\begin{array}{l}8 \\
8 \\
\infty \\
-1\end{array}$ & $\begin{array}{l}\text { \&. } \\
\infty \\
-1 \\
-1\end{array}$ & $\begin{array}{c}\mathbf{8} \\
\infty \\
- \\
-1\end{array}$ & 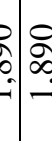 & 冓 & $\begin{array}{c}8: 0 \\
\infty \\
\infty \\
-10\end{array}$ & : & $\begin{array}{l}8 \\
\mathscr{2} \\
0\end{array}$ & $\begin{array}{l}\text { S: } \\
\text { s. }\end{array}$ & 8. & $\begin{array}{l}\text { \&ి } \\
\text {. }\end{array}$ & & \\
\hline 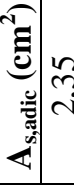 & wi & $\mid \begin{array}{l}n \\
\\
\end{array}$ & & & 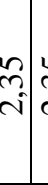 & ली & & 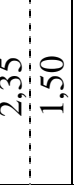 & 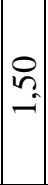 & 员 & $\begin{array}{l}\text { 에 } \\
-1 \\
-1\end{array}$ & & & & $\begin{array}{lll}0 & 0 \\
& 0 \\
-\rightarrow & 0\end{array}$ & $\begin{array}{l}8 \\
0 \\
0\end{array}$ & $\begin{array}{l}8 \\
0 \\
0\end{array}$ & $\begin{array}{lll}8 \\
0 \\
0\end{array}$ & $\begin{array}{l}8 \\
0 \\
0\end{array}$ & $\begin{array}{l}8 \\
0 \\
0\end{array}$ & & \\
\hline 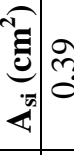 & & $\mid \begin{array}{l}9 \\
m \\
0\end{array}$ & & & $\begin{array}{c}\text { ले } \\
\text { o. }\end{array}$ & $\begin{array}{c}9 \\
m \\
0 \\
0\end{array}$ & & $\begin{array}{c}2: 0 \\
m: \\
0\end{array}$ & $\begin{array}{c}9 \\
\tilde{m} \\
0\end{array}$ & $\begin{array}{c}9 \\
\text { m. } \\
0\end{array}$ & $\begin{array}{l}9 \\
\text { m. } \\
0\end{array}$ & & $\begin{array}{c}m \\
m \\
0\end{array}$ & a & 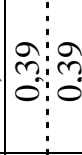 & 足 & & $\begin{array}{l}m \\
m^{\prime}\end{array}$ & 孚 & $\begin{array}{l}\sigma \\
m \\
c\end{array}$ & $\begin{array}{c}9 \\
\text { mె } \\
0\end{array}$ & \\
\hline : & 岁 & 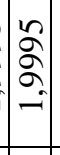 & बి & - & - & S. & Sু & 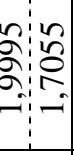 & 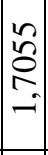 & 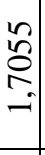 & & & 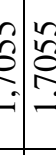 & 贺 & 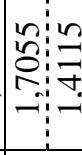 & 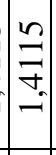 & 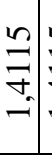 & \begin{tabular}{l}
$f$ \\
\hdashline
\end{tabular} & 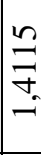 & $\begin{array}{l}\stackrel{0}{=} \\
\stackrel{\vec{v}}{\vec{v}} \\
\stackrel{-}{-1}\end{array}$ & 足| & \\
\hline 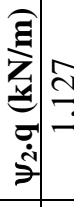 & & & & & & & & \begin{tabular}{cc} 
& $m$ \\
\hdashline & 0 \\
-1 & 0
\end{tabular} & $\begin{array}{l}m \\
0 \\
\infty \\
0\end{array}$ & $\begin{array}{c}\mathscr{M} \\
\infty \\
0 \\
0\end{array}$ & $\begin{array}{l}m \\
0 \\
0 \\
0 \\
0\end{array}$ & $\begin{array}{c}\mid \\
\mathbb{m} \\
0 \\
0 \\
0\end{array}$ & 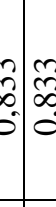 & $\begin{array}{l}\text { m } \\
\infty \\
0 \\
0\end{array}$ & $\begin{array}{ll}\text { Dr: } \\
\infty \\
0 \\
0\end{array}$ & 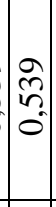 & $\begin{array}{l}\text { ले } \\
\text { מू. } \\
\text { ô }\end{array}$ & 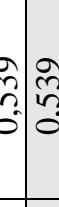 & 令 & $\mid \begin{array}{l}9 \\
\tilde{D} \\
0 \\
0\end{array}$ & & \\
\hline \begin{tabular}{l}
0 \\
\hdashline \\
\hdashline \\
\hdashline
\end{tabular} & 0 & $\mid \begin{array}{l}0 \\
0^{\circ}\end{array}$ & $\stackrel{0}{6}$ & $\begin{array}{l}0 \\
6 \\
0^{\circ}\end{array}$ & $\begin{array}{l}0 \\
0^{\circ}\end{array}$ & 6 & 6 & $\begin{array}{l}0 \\
\sigma^{\prime}\end{array}$ & 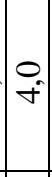 & 영 & o & : & $\begin{array}{l}0 \\
\forall \\
\forall\end{array}$ & $=\frac{0}{+}$ & $\begin{array}{lll}0 & 0 \\
\rightarrow & 0\end{array}$ & $\stackrel{0}{i}$ & & $\dot{v} \mid \stackrel{i}{i}$ & a & & 8 & \\
\hline 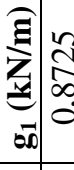 & & $\mid \begin{array}{l}n \\
\stackrel{n}{N} \\
0 \\
0 \\
0\end{array}$ & $\begin{array}{c}\mathbb{N} \\
\infty \\
0 \\
0\end{array}$ & \begin{tabular}{c|c}
$N$ & \\
$\infty$ & \\
0 & 0 \\
0 & 0 \\
0
\end{tabular} & 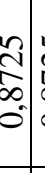 & $\begin{array}{ccc} & \\
c & \\
0 \\
0 \\
0\end{array}$ & 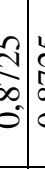 & 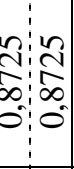 & 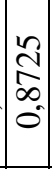 & $\begin{array}{c}\stackrel{2}{\mathbb{N}} \\
\infty \\
0 \\
0\end{array}$ & 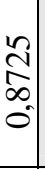 & 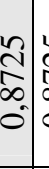 & 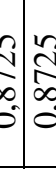 & $\mid \begin{array}{l}\text { W } \\
\mathbb{N} \\
\infty \\
0 \\
0\end{array}$ & 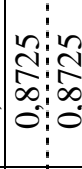 & $\mid \begin{array}{l}2 \\
\mathbb{N} \\
0 \\
0 \\
0 \\
0\end{array}$ & 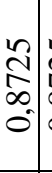 & 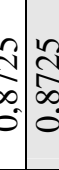 & 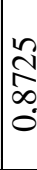 & $\begin{array}{c}2 \\
\mathbb{N} \\
0 \\
0 \\
0 \\
0\end{array}$ & 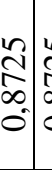 & \\
\hline 焉 & t & $\begin{array}{l}0 \\
10\end{array}$ & $\begin{array}{c}0 \\
\text { L }^{n}\end{array}$ & 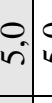 & i & 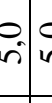 & 0 & $\begin{array}{c}0: 0 \\
n^{n} \\
\vdots\end{array}$ & $\begin{array}{c}0 \\
10 \\
10\end{array}$ & id & & 에 & ० & is & $\begin{array}{c}0: 0 \\
n^{\prime}: \text { in } \\
\vdots\end{array}$ & $\mid \begin{array}{l}0 \\
10\end{array}$ & & 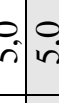 & is & $\begin{array}{c}0 \\
\omega^{\circ}\end{array}$ & & 5 \\
\hline 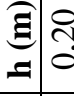 & & 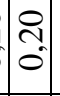 & 0 & o.|c & 0 & है? & $\begin{array}{c}2 \\
\text { D. } \\
\end{array}$ & 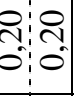 & 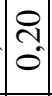 & $0^{\circ}$ & $0^{\circ}$ & 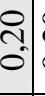 & こี & \begin{tabular}{l}
2 \\
\multirow{N}{*}{} \\
0
\end{tabular} & $\begin{array}{l}0 \\
2 \\
0 \\
0\end{array}$ & \begin{tabular}{l}
2 \\
\multirow{2}{*}{} \\
0
\end{tabular} & & 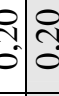 & 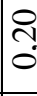 & 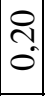 & & \\
\hline 坣芯 & & & & & & & & 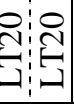 & & & & & & & & & & $\begin{array}{l}\vec{y} \\
\vec{y}\end{array}$ & $\overline{\tilde{E}}$ & 1 & $\underset{G}{-1}$ & \\
\hline
\end{tabular}




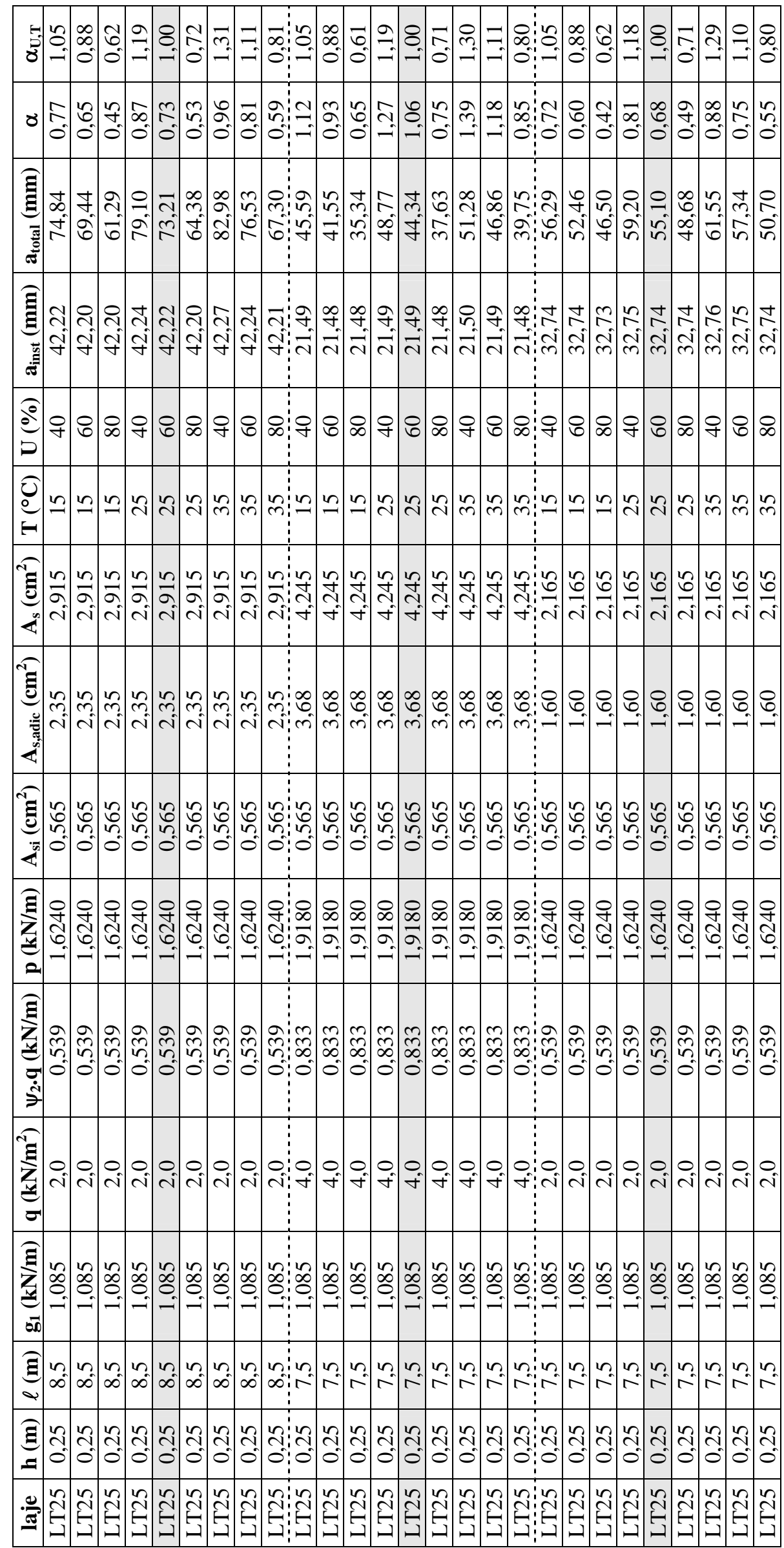




\begin{tabular}{|c|c|c|c|c|c|c|c|c|c|c|c|c|c|c|c|c|c|c|c|c|c|c|c|}
\hline 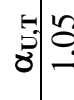 & $=$ & $\begin{array}{l}8 \\
\vdots \\
0\end{array}$ & & & & & & 0 & $\begin{array}{l}\infty \\
0^{0}\end{array}$ & 尊 & & : & & & & 0 & & $\begin{array}{l}\text { b. } \\
0 \\
0\end{array}$ & & & $\stackrel{\mathrm{L}}{\stackrel{N}{-}}$ & & $\begin{array}{l}\text { \&. } \\
0 \\
0\end{array}$ \\
\hline & 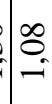 & $\begin{array}{l}\hat{t} \\
0^{\prime}\end{array}$ & 冓 & - & & & 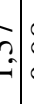 & & $\begin{array}{l}\infty \\
\infty \\
0 \\
0\end{array}$ & ? & $\begin{array}{l}\stackrel{2}{-1} \\
-\rightarrow\end{array}$ & $\stackrel{0}{-0}$ & & & & & $\begin{array}{l}-0 \\
0 \\
0\end{array}$ & & & & $\begin{array}{l}\mathscr{0} \\
0 \\
0\end{array}$ & & $\mid$ \\
\hline 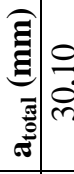 & & $\hat{\mathrm{N}}$ & 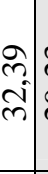 & & & $\begin{array}{l}v \\
f \\
f\end{array}$ & & & $\begin{array}{l}\mathscr{8} \\
\text { Dे }\end{array}$ & $\begin{array}{l}\stackrel{0}{2} \\
\dot{\mathbb{N}}\end{array}$ & & & & 0 & & $\begin{array}{l}\overline{1} \\
\infty \\
m\end{array}$ & & & & 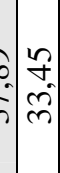 & & $\begin{array}{l}\tilde{y} \\
\tilde{m} \\
\tilde{m}\end{array} \mid$ & \\
\hline 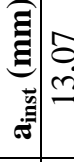 & & $\begin{array}{l}0 \\
\vec{\sim} \\
\vec{\sim}\end{array}$ & 象 & & & 0 & & & t) & $\begin{array}{l}\text { I } \\
\stackrel{2}{2}\end{array}$ & & & & & & & & & & & & 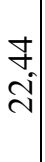 & \\
\hline$\left.b^{0}\right)$ & 6 & $\infty$ & P & 8 & & $f$ & & ㅇํㅇㅇ & 8 & $\infty$ & ㅇ & 8 & 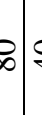 & P & & f & 8 & $\infty$ & & 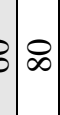 & f & 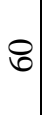 & $\infty$ \\
\hline 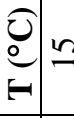 & & 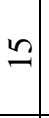 & ลิ & $\stackrel{\sim}{\sim}$ & & & & hi: & $\stackrel{2}{-1}$ & $\stackrel{2}{\sim}$ & 느 & $\stackrel{\sim}{\sim}$ & $\hat{\mathcal{N}}$ & $n$ & & $\stackrel{1}{\sim}$ & 늠 & $\stackrel{\sim \Omega}{\sim}$ & 소는 & 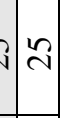 & $\stackrel{m}{m}$ & 남 & m \\
\hline 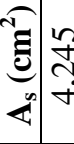 & & 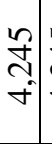 & 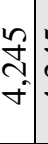 & & & 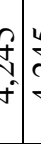 & 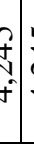 & & 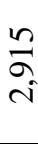 & $\stackrel{n}{\sigma}$ & & & s) & & & & 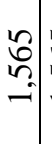 & & & 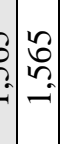 & 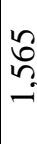 & $\mid$ & 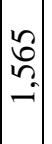 \\
\hline 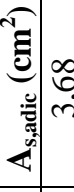 & & $\begin{array}{c}\infty \\
\Theta^{n} \\
m^{2}\end{array}$ & $\begin{array}{c}0 \\
0 \\
m^{-}\end{array}$ & & & $\begin{array}{l}0 \\
0 \\
n\end{array}$ & & & $\begin{array}{l}\stackrel{m}{m} \\
\text { Ni }\end{array}$ & $\stackrel{m}{m}$ & 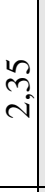 & & $\begin{array}{l}\hat{n} \\
\text { v. }\end{array}$ & ר. & & 8 & $\underset{-1}{8}$ & & & & 8 & & 8 \\
\hline$\underbrace{0}_{4}$ & & $\begin{array}{l}\text { Un } \\
0 \\
0 \\
0 \\
0\end{array}$ & 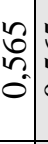 & 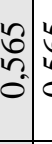 & & مُ & & 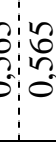 & $\begin{array}{l}0^{2} \\
1 \\
0 \\
0\end{array}$ & 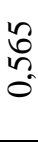 & 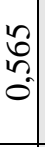 & & ?" & & & ما & 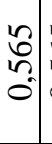 & 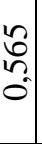 & & $\begin{array}{c}b \\
b \\
0\end{array}$ & $\begin{array}{l}\text { Lी } \\
\text { th } \\
0 \\
0\end{array}$ & & $\mid$ \\
\hline $\begin{array}{l}n \\
z \\
z \\
z\end{array}$ & & 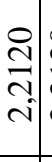 & $\begin{array}{l}\stackrel{2}{\mathrm{a}} \\
\mathrm{a} \\
\mathrm{N}\end{array}$ & 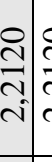 & & & $\begin{array}{c}\vec{y} \\
\mathbf{v} \\
\mathrm{v}\end{array}$ & 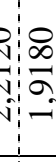 & 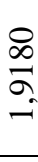 & $\begin{array}{l}\infty \\
\vec{\sigma} \\
\rightarrow\end{array}$ & $\begin{array}{l}0 \\
\infty \\
-5 \\
-1\end{array}$ & $\begin{array}{l}\infty \\
\infty \\
\vec{\sigma} \\
-1 \\
-1\end{array}$ & D. & 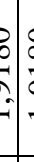 & & 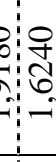 & 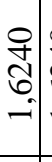 & 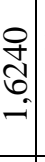 & 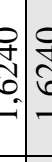 & 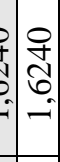 & 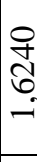 & 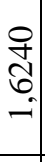 & 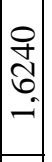 \\
\hline 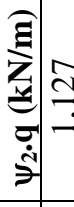 & & $\begin{array}{l}\simeq \\
\cong\end{array}$ & $\begin{array}{l}\text { a } \\
-1\end{array}$ & & & & & $\begin{array}{rl} & m \\
- & 0 \\
-1 & 0\end{array}$ & & $\begin{array}{l}M \\
m \\
\infty \\
0 \\
0\end{array}$ & $\begin{array}{c}m \\
0 \\
0 \\
0 \\
0\end{array}$ & $\begin{array}{c}2 \\
\text { ch } \\
\infty \\
0 \\
0\end{array}$ & $\begin{array}{l}n \\
\text { D. } \\
0 \\
0\end{array}$ & & & 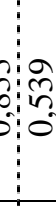 & $\begin{array}{l}\text { Dे } \\
\bigsqcup \\
0 \\
0\end{array}$ & 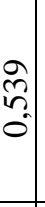 & & 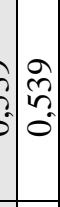 & 令 & & $\begin{array}{l}9 \\
\hat{0} \\
0 \\
0 \\
0\end{array}$ \\
\hline $\begin{array}{l}\sum_{0}^{n} \\
0 \\
0 \\
0\end{array}$ & & $\begin{array}{l}0 \\
0 \\
0\end{array}$ & $\begin{array}{c}0 \\
\hat{n}^{-}\end{array}$ & $\begin{array}{lll}0 & \\
0 & 4\end{array}$ & & & & $\stackrel{\circ}{\rightarrow}$ & & & & & & & & & $\circ$ & & & $\vec{j} \mid \stackrel{i}{i}$ & $\stackrel{\circ}{i}$ & & \\
\hline 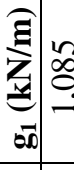 & & $\begin{array}{l}\infty \\
0 \\
-i\end{array}$ & ב & 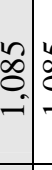 & & & & $\stackrel{\infty}{\stackrel{0}{-1}}$ & -1 & $\infty$ & $\begin{array}{l}0 \\
0 \\
-1 \\
-1\end{array}$ & 然 & & & & 7 & \begin{tabular}{lll}
0 \\
\hdashline \\
- & 0
\end{tabular} & & & $=$ & 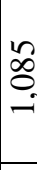 & & \\
\hline 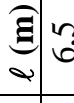 & & 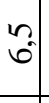 & 6) & $0^{0}$ & & & & $\begin{array}{l}0^{\circ} \\
\end{array}$ & & & $0^{\circ}$ & $\sigma^{\prime \prime}$ & & & & & 6 & ". & 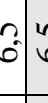 & \begin{tabular}{l|l}
$0^{\prime}$ \\
$0^{\prime}$
\end{tabular} & ڤึ. & $\mid$ & 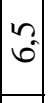 \\
\hline 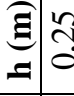 & $\begin{array}{c}\sim \\
0\end{array}$ & $\begin{array}{l}\text { Na} \\
0\end{array}$ & $\begin{array}{l}\text { N్ } \\
\text { ○ी }\end{array}$ & $\begin{array}{l}\stackrel{2}{2} \\
0 \\
0\end{array}$ & & & & 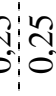 & & & $\begin{array}{l}2 \\
0\end{array}$ & $\begin{array}{c}2 \\
0 \\
0\end{array}$ & & & & ': & 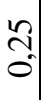 & 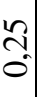 & $b^{\circ} c$ & : & $\begin{array}{l}\text { Na } \\
0 \\
0\end{array}$ & & $0^{\circ}$ \\
\hline 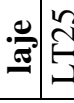 & & & & 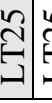 & & & & & & & & $\stackrel{5}{-}$ & & & & & & & & 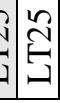 & $\mathscr{F}$ & $1-1$ & \\
\hline
\end{tabular}




\begin{tabular}{|c|c|c|c|c|c|c|c|c|c|c|c|c|c|c|c|c|c|c|c|c|c|c|}
\hline 8 & 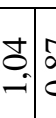 & \begin{tabular}{c|c}
$\infty$ & -1 \\
0 & 0 \\
0 & 0
\end{tabular} & 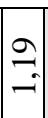 & -1 & & $\stackrel{m}{\rightarrow}$ & $\cong$ & 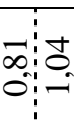 & $\mid \begin{array}{l}0 \\
0 \\
0 \\
0\end{array}$ & $\begin{array}{l}8 \\
0 \\
0\end{array}$ & $\begin{array}{l}\Omega \\
-\end{array}$ & 8 & $\begin{array}{c}\hat{n} \\
\text { O. }\end{array}$ & $\stackrel{m}{\rightarrow}$ & 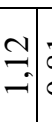 & 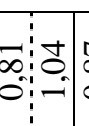 & की & $\begin{array}{l}8 \\
0 \\
0\end{array}$ & & sit & ని & \begin{tabular}{l}
$\simeq$ \\
$\approx$ \\
\hdashline \\
0
\end{tabular} \\
\hline & 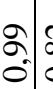 & \begin{tabular}{c|c}
1 & $\infty$ \\
$\infty$ & 0 \\
0 & 1 \\
0 & 0
\end{tabular} & 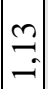 & & & $\stackrel{-1}{-}$ & - & & $\begin{array}{l}0 \\
0 \\
0\end{array}$ & 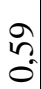 & 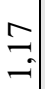 & . & $\begin{array}{l}\text { R. } \\
0^{\circ}\end{array}$ & लि & $=$ & $\begin{array}{c:c}\infty & 0 \\
\infty & 0 \\
0 & 0\end{array}$ & $\begin{array}{c}R \\
0 \\
0\end{array}$ & o & & & $\mid$ & 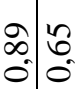 \\
\hline$\xi$ & $\begin{array}{lll} & 0 \\
0 & 0\end{array}$ & 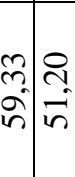 & 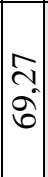 & है & $\begin{array}{l}\text { f } \\
\dot{f}\end{array}$ & & $\begin{array}{l}8 \\
0 \\
6\end{array}$ & $\begin{array}{l}8: q \\
b \text { : } \\
\text { Ln: }\end{array}$ & 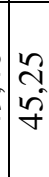 & & & $\left|\begin{array}{c}\infty \\
m \\
0 \\
o \\
\sigma\end{array}\right|$ & $\begin{array}{l}\vec{f} \\
\vec{\nabla}\end{array}$ & $\begin{array}{l}7 \\
6 \\
6 \\
10\end{array}$ & 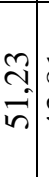 & & $\begin{array}{l}0 \\
0 \\
\infty \\
\infty\end{array}$ & & & & $\left|\begin{array}{c}n \\
\infty \\
\infty \\
n\end{array}\right|$ & 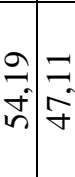 \\
\hline 可 & & 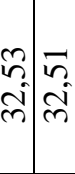 & $\mid$ & $\begin{array}{l}\text { Lึ } \\
\tilde{n}\end{array}$ & 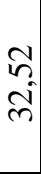 & & 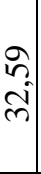 & 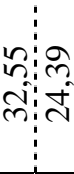 & 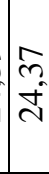 & 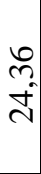 & $\begin{array}{l}\text { oे } \\
\dot{\sim}\end{array}$ & 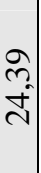 & 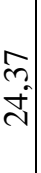 & 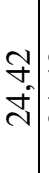 & 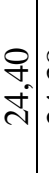 & & & & & $\begin{array}{ccc}6 & 8 \\
0 \\
D^{0}\end{array}$ & $\mid$\begin{tabular}{l}
0 \\
0 \\
0 \\
0 \\
\hdashline
\end{tabular} & 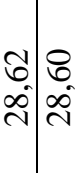 \\
\hline & $f$ & $8 \infty$ & |워 & 8 & $\infty$ & 아 & 8 & œ:아 & 8 & $\infty$ & 우 & 8 & $\triangleright$ & ๆ & 8 & $\infty: 8$ & 8 & $\infty$ & of & $8 \infty$ & 우 앙 & 8 \\
\hline & -1 & $\stackrel{2}{\sim}$ & $\stackrel{\llcorner}{\sim}$ & N & $\stackrel{\llcorner}{N}$ & ณn & ले & min: & 는 & $\stackrel{20}{-1}$ & $\stackrel{2}{\sim}$ & $\stackrel{\sim}{\sim}$ & 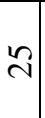 & $\stackrel{m}{m}$ & 넹 & 냉 & 늠 & 는 & & $\stackrel{N}{N} \stackrel{\llcorner}{N}$ & $\stackrel{n}{m}$ & 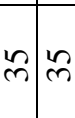 \\
\hline (3) & 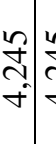 & 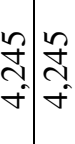 & 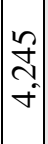 & 岁 & 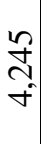 & 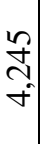 & 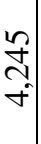 & 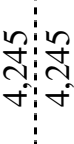 & $\mid \begin{array}{l}5 \\
\mathbf{7} \\
7 \\
7\end{array}$ & 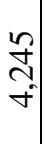 & 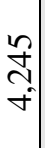 & \begin{tabular}{l} 
年 \\
\multirow{\sim}{*}{} \\
$\forall$
\end{tabular} & 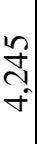 & 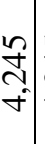 & 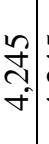 & 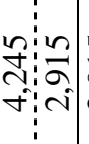 & & & & 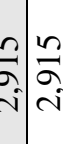 & 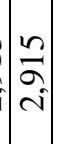 & 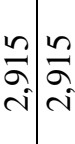 \\
\hline 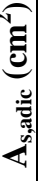 & & 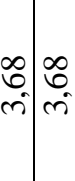 & $\left|\begin{array}{l}\infty \\
0 \\
m\end{array}\right|$ & & & & $\begin{array}{l}0 \\
0 \\
m \\
m\end{array}$ & 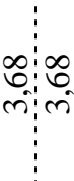 & $\mid \begin{array}{l}\infty \\
0 \\
0 \\
0\end{array}$ & $\begin{array}{c}\infty \\
\vdots \\
\tilde{m}\end{array}$ & $\mid$ & 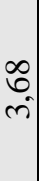 & $\begin{array}{c}0 \\
\vdots \\
\tilde{m}\end{array}$ & 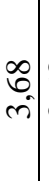 & 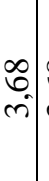 & & & & & & $\begin{array}{l}n \\
m \\
n \\
n\end{array}$ & 足 \\
\hline 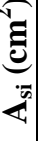 & & 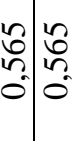 & $\mid$ & {$\left[\begin{array}{c}1 \\
120 \\
0 \\
0\end{array}\right]$} & $\begin{array}{l}0 \\
\text { L̊n } \\
0\end{array}$ & 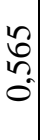 & 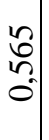 & 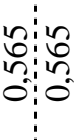 & $\begin{array}{l}2 \\
0 \\
0 \\
0 \\
0 \\
0\end{array}$ & $\begin{array}{l}0 \\
0 \\
1 \\
0 \\
0\end{array}$ & $\mid$ & 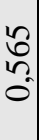 & 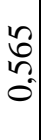 & $\begin{array}{l}\text { 足 } \\
\text { Lnم } \\
0 \\
0\end{array}$ & 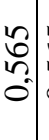 & & $\begin{array}{l}0 \\
0 \\
0 \\
0\end{array}$ & 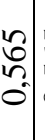 & 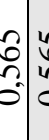 & & $\begin{array}{l}2 \\
0 \\
0 \\
0 \\
0 \\
0 \\
0\end{array}$ & 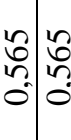 \\
\hline בِي & 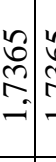 & 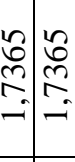 & 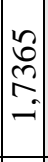 & $\begin{array}{l}0 \\
0 \\
\\
-1 \\
-1\end{array}$ & 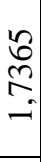 & - & $\begin{array}{l}n \\
0 \\
0 \\
\\
-i\end{array}$ & 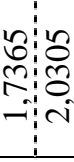 & 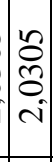 & 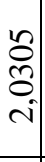 & 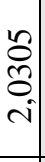 & 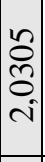 & 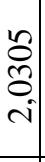 & $\begin{array}{l}n \\
\tilde{c} \\
\tilde{c} \\
i\end{array}$ & 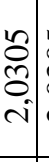 & 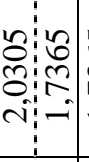 & $\begin{array}{l}\qquad 0 \\
\mathscr{D} \\
\\
--\end{array}$ & 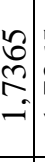 & 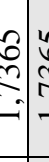 & 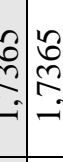 & 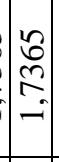 & 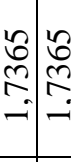 \\
\hline 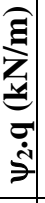 & 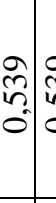 & 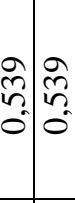 & \begin{tabular}{|c|}
9 \\
$\tilde{\omega}$ \\
0 \\
0
\end{tabular} & 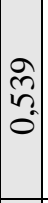 & $\begin{array}{l}\text { Dे } \\
\text { Dू. } \\
0\end{array}$ & लె & $\mid$ & 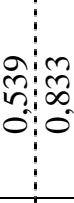 & $\begin{array}{l}m \\
\infty \\
0 \\
0 \\
0\end{array}$ & $\begin{array}{l}m \\
\infty \\
0 \\
0\end{array}$ & $\mid \begin{array}{c}m \\
0 \\
\infty \\
0 \\
0\end{array}$ & $\left|\begin{array}{c}m \\
m \\
\infty \\
0 \\
0\end{array}\right|$ & $\begin{array}{l}m \\
m \\
\infty \\
0 \\
0\end{array}$ & $\begin{array}{c}m \\
\infty \\
\infty \\
0 \\
0\end{array}$ & $\begin{array}{c}m \\
\text { s. } \\
0 \\
0\end{array}$ & $\begin{array}{c:c}m & 0 \\
\infty & \bar{m} \\
\infty^{\circ} & 1 \\
0\end{array}$ & $\begin{array}{c}0 \\
0 \\
102 \\
0\end{array}$ & & 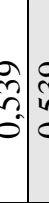 & & $\begin{array}{l}2 \\
0 \\
n \\
0 \\
0 \\
0\end{array}$ & 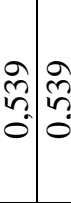 \\
\hline 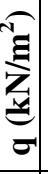 & & in & & & ㅇ. & & i. & $\begin{array}{l}0 \\
\text { in: }\end{array}$ & $\stackrel{\circ}{\rightarrow}$ & $\forall$ & 0 & $\left|\begin{array}{l}0 \\
-\end{array}\right|$ & ㅇ. & $\stackrel{\circ}{f}$ & $\begin{array}{l}0 \\
f^{\circ}\end{array}$ & & 0 & & & & $\left|\begin{array}{l}0 \\
\text { in }\end{array}\right|$ & 시 \\
\hline | & 至 & $\Rightarrow$ & $=$ & $\Rightarrow$ & $\stackrel{\text { बे }}{=}$ & $=$ & $\begin{array}{l}\text { a } \\
\stackrel{2}{-}\end{array}$ & 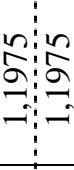 & $\begin{array}{l}\text { â } \\
-\approx\end{array}$ & $\approx$ & $\Rightarrow$ & $\begin{array}{l}\hat{\sigma} \\
-\end{array}$ & $\begin{array}{l}\text { â } \\
- \\
-\end{array}$ & बิ & 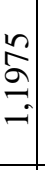 & 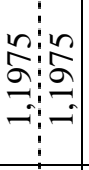 & - & . & $\begin{array}{ll}5 \\
6 \\
2\end{array}$ & 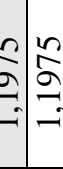 & $\begin{array}{l}0 \\
0 \\
0 \\
-7 \\
-1\end{array}$ & 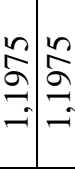 \\
\hline 5 & & 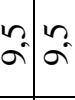 & 1 & & $\begin{array}{l}\llcorner 0 \\
\sigma\end{array}$ & & $\stackrel{2}{\sigma}$ & 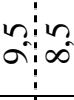 & {$\left[\begin{array}{l}1 \\
\infty \\
\infty\end{array}\right.$} & $\begin{array}{l}10 \\
\infty\end{array}$ & $\begin{array}{l}10 \\
\infty \\
\infty\end{array}$ & $\mid \begin{array}{l}0 \\
\infty \\
\infty\end{array}$ & 1 & ?. & 冓 & 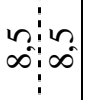 & $\begin{array}{l}\llcorner \\
\infty \\
\infty\end{array}$ & $\begin{array}{l}\sim^{\circ} \\
\infty\end{array}$ & & م & $\mid \begin{array}{l}\infty \\
\infty \\
\infty\end{array}$ & 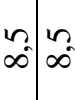 \\
\hline$=$ & & \begin{tabular}{l|l} 
mે & mి \\
0 & 0
\end{tabular} & $\begin{array}{l}0 \\
m \\
0\end{array}$ & & $\begin{array}{l}\text { ले } \\
0\end{array}$ & 0 & $\begin{array}{l}m \\
0 \\
0\end{array}$ & $\begin{array}{c:c} & 0 \\
\text { m} & \text { m. } \\
0 & 0\end{array}$ & $0^{2}$ & $0^{\circ}$ & $0^{2}$ & $0^{\circ}$ & $0^{3}$ & - & $\begin{array}{l}0 \\
\text { m. } \\
0 \\
0\end{array}$ & $\begin{array}{c:c}0 & 0 \\
m & m \\
0 & 0\end{array}$ & 今ે & $0^{\circ}$ & & $\begin{array}{cc}\text { ले } & \text { లి } \\
0 & 0 \\
0\end{array}$ & $\mid \begin{array}{l}0 \\
\tilde{n} \\
0 \\
0\end{array}$ & \begin{tabular}{c|c} 
ले & లి \\
0 & 0
\end{tabular} \\
\hline 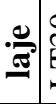 & & 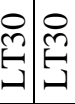 & & & & & & & 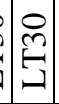 & & & & & & & 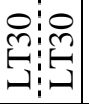 & & & & के & 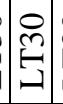 & 角 \\
\hline
\end{tabular}




\begin{tabular}{|c|c|c|c|c|c|c|c|c|c|c|c|c|c|c|c|c|c|c|c|c|c|c|c|}
\hline 8 & $\begin{array}{c}t \\
-1 \\
0 \\
0 \\
0\end{array}$ & $\begin{array}{lll}0 \\
0 \\
0\end{array}$ & $\Rightarrow$ & & & : & & & $\begin{array}{l}\infty \\
\infty \\
0\end{array}$ & $\sigma_{0}^{\circ}$ & & & & & & 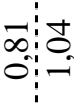 & $\left|\begin{array}{c}0 \\
0 \\
0\end{array}\right|$ & $\begin{array}{l}8 \\
8 \\
0\end{array}$ & & & & & \\
\hline & $\Rightarrow c$ & $\begin{array}{l}\text { S. } \\
\end{array}$ & 2 & 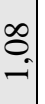 & $\begin{array}{l}0 \\
\begin{array}{l}0 \\
0^{\circ}\end{array}\end{array}$ & -7 & $\underset{-1}{-1}$ & & o & 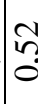 & $=$ & & & & & & $\left|\begin{array}{l}0 \\
0 \\
0\end{array}\right|$ & & $\begin{array}{l}0 \\
\infty \\
0 \\
0\end{array}$ & & J & & \\
\hline 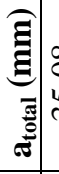 & & 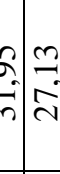 & $\hat{N}$ & & & & & & & $\stackrel{0}{0}$ & $\begin{array}{l}\text { Na } \\
\text { ô }\end{array}$ & & $\begin{array}{l}\text { ब. } \\
\bar{m}\end{array}$ & Ұ & Dr & & & & & & $\begin{array}{l}\stackrel{J}{\sim} \\
\vec{f}\end{array}$ & & \\
\hline 苞 & & 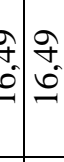 & $\begin{array}{l}0 \\
10 \\
0 \\
0 \\
-1\end{array}$ & $\begin{array}{l}\stackrel{9}{+} \\
6 \\
-1\end{array}$ & $\begin{array}{c}9 \\
+ \\
6 \\
-1 \\
-10\end{array}$ & $\begin{array}{c}n \\
6 \\
6 \\
-6\end{array}$ & : & & $\begin{array}{l}2 \\
\infty \\
0 \\
\end{array}$ & $\mid \begin{array}{l}\infty \\
\infty \\
0\end{array}$ & $\begin{array}{l}\infty \\
\infty \\
-\end{array}$ & & $\begin{array}{l}\mathscr{D} \\
\text { త్ }\end{array}$ & & a & & 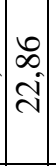 & & & 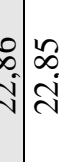 & 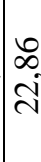 & & \\
\hline 5 & & ০) & q & & $\infty$ & $q$ & 8 & 5 & 8 & $\infty$ & 워 & 8 & $\infty$ & 암 & 8 & $\infty: \bigcirc$ & 8 & $\infty$ & 아 & b) & ㅇ & 8 & $\infty$ \\
\hline-1 & & $=0$ & $\stackrel{\sim}{N}$ & $\stackrel{\sim}{\sim}$ & & rn & ma & 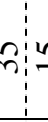 & $\stackrel{4}{12}$ & 느 & $\stackrel{2}{\sim}$ & & $\stackrel{2}{\sim}$ & m. & $m$ & & $\stackrel{ㄴ}{\sim}$ & $\stackrel{2}{\sim}$ & ㄴํำ & $\stackrel{2}{\sim} \stackrel{2}{\sim}$ & $\stackrel{m}{m}$ & & $\stackrel{m}{m}$ \\
\hline$\underset{\&}{\mathbb{E}}$ & & & & & & & $\begin{array}{l}f \\
\text { and } \\
f^{2}\end{array}$ & 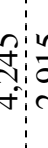 & $\frac{\mathrm{L}}{\sigma}$ & 夏 & 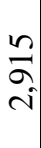 & & & 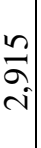 & 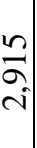 & & $\left|\begin{array}{l}0 \\
0 \\
0 \\
i\end{array}\right|$ & & & 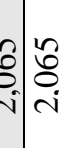 & $\begin{array}{l}\text { 농 } \\
0 \\
i\end{array}$ & & \\
\hline 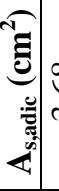 & & & & & & 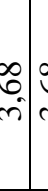 & |ct & & 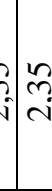 & $\begin{array}{l}L \\
m \\
\end{array}$ & $\mid \begin{array}{l}n \\
m \\
\cdots \\
v\end{array}$ & & 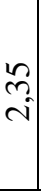 & . & 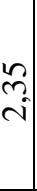 & & $\mid \begin{array}{c}0 \\
\text { เి } \\
-1\end{array}$ & & & & เి & & \\
\hline $\begin{array}{l}5 \\
0 \\
4\end{array}$ & & & 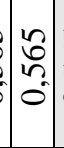 & $\begin{array}{l}\text { 足 } \\
\text { Lh? } \\
0\end{array}$ & & 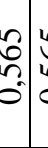 & $\begin{array}{lll} \\
: \\
0\end{array}$ & $\begin{array}{l}0 \\
0 \\
0 \\
0 \\
0 \\
0\end{array}$ & 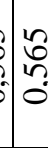 & $\begin{array}{l}\text { 定 } \\
\text { Ln } \\
0\end{array}$ & $\begin{array}{l}20 \\
0 \\
10 \\
0 \\
0\end{array}$ & $\begin{array}{l}\text { Lึ } \\
\text { เू }\end{array}$ & 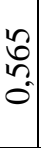 & $\begin{array}{l}\text { Lొ } \\
\text { on. } \\
0\end{array}$ & | & & 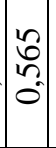 & $\begin{array}{l}\text { 足 } \\
\text { Ln. } \\
0^{\circ}\end{array}$ & & 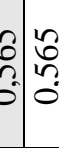 & $\begin{array}{l}\text { Ln } \\
\text { Ln } \\
0 \\
0\end{array}$ & & \\
\hline 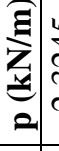 & & & 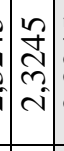 & 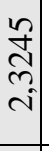 & & & 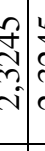 & 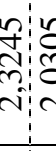 & $\begin{array}{ll}b \\
b \\
b \\
b\end{array}$ & $\begin{array}{l}\text { L } \\
\text { Oे } \\
0 \\
\text { iv }\end{array}$ & $\begin{array}{l}2 \\
0 \\
0 \\
0 \\
0\end{array}$ & $\begin{array}{l}\text { ôे } \\
\text { ర్ }\end{array}$ & 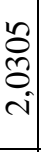 & $\begin{array}{l}0 \\
\tilde{c} \\
0 \\
\end{array}$ & 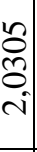 & & 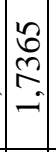 & $\begin{array}{l}n \\
\stackrel{0}{0} \\
\\
-1\end{array}$ & 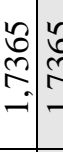 & 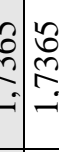 & 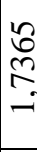 & & \\
\hline 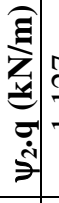 & & & & & & & $=$ & & & $\begin{array}{l}\tilde{m} \\
\infty \\
0 \\
0\end{array}$ & $\mid \begin{array}{l}m \\
m \\
\infty \\
0 \\
0\end{array}$ & & & - & m) & & $\mid \begin{array}{c}9 \\
\tilde{1} \\
0 \\
0\end{array}$ & 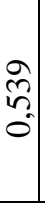 & 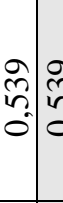 & 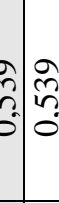 & 令 & & 赑 \\
\hline 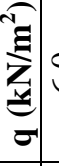 & & & & & $\begin{array}{l}0 \\
0 \\
0\end{array}$ & \begin{tabular}{c|c}
0 \\
$0^{-1}$ &
\end{tabular} & ह & & & $\underset{f}{0}$ & & & & & & & i & & & $\begin{array}{ccc}. \\
v\end{array}$ & $\stackrel{\circ}{i}$ & & 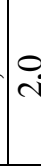 \\
\hline 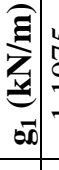 & & $=$ & $\Rightarrow$ & 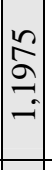 & & $=$ & & $\sigma_{-}$ & 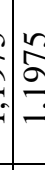 & 능 & $\Rightarrow$ & & & & 7 & $\begin{array}{l}0 \\
0 \\
0\end{array}$ & $\begin{array}{l}\mathrm{u} \\
\widehat{\sigma} \\
-1 \\
-1\end{array}$ & $\Rightarrow$ & 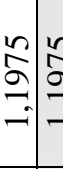 & 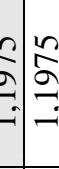 & I & & $\begin{array}{l}\frac{1}{2} \\
\text { - } \\
\end{array}$ \\
\hline 焉 & & & & & & & & & $\stackrel{\sim}{\sim}$ & 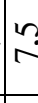 & 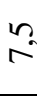 & & & & & תמ: & 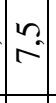 & & & תִ & $\stackrel{2}{N}$ & & \\
\hline 馬 & & $\begin{array}{l}\text { mे } \\
0 \\
0\end{array}$ & {$\left[\begin{array}{l}0 \\
\text { s. } \\
0\end{array}\right.$} & $\begin{array}{c}0 \\
\text { ले } \\
0\end{array}$ & & $\begin{array}{c}\text { ले } \\
\text { ली }\end{array}$ & के & $\begin{array}{l}\text { ma } \\
\text { on }\end{array}$ & $\begin{array}{l}0 \\
\text { mे } \\
0\end{array}$ & 0 & & & & & & 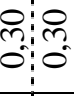 & 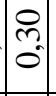 & $0^{\circ}$ & 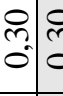 & $\begin{array}{c}n \\
m \\
0 \\
0\end{array}$ & ग. & $0^{\circ}$ & \\
\hline 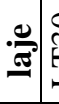 & & 官 & 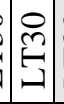 & 今ి & & 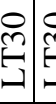 & & 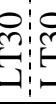 & & & & & & & & & & & 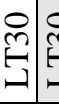 & 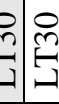 & 1 & 1 & \\
\hline
\end{tabular}


